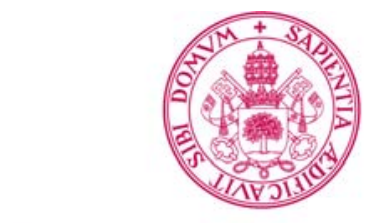

Universidad deValladolid

PROGRAMA DE DOCTORADO EN CIENCIAS DE LA

SALUD

TESIS DOCTORAL:

\title{
MARCO JURÍDICO DE LAS AGRESIONES \\ AL PERSONAL SANITARIO Y \\ VALORACIÓN POR LOS PROFESIONALES \\ DE LA SALUD DE LAS MEDIDAS \\ ADOPTADAS
}

Presentada por MARÍA DEL CARMEN SÁNCHEZ

BENITO

para optar al grado de

Doctora por la Universidad de Valladolid

Dirigida por:

Dra. MERCEDES MARTÍNEZ LEÓN.

Dr. DANIEL QUEIPO BURÓN. 
Daría todo lo que sé por la mitad de lo que ignoro.

René Descartes.

On doit exiger de moi que je cherche la vérité, non que je la trouve.

Diderot.

Cuando creíamos que teníamos todas las respuestas, de pronto, cambiaron todas las preguntas.

Mario Benedetti. 
A mis padres, in memoriam.

A Ana Isabel, mi esposa. 


\section{Agradecimientos}

Al Ilustre Colegio de Abogados de Valladolid, por facilitar la consulta y el acceso a sus fondos bibliográficos y jurisprudenciales.

A D. Pedro López de Gea, letrado de los causahabientes de la Dra. Eugenia Moreno, por la información ofrecida sobre el caso del asesinato de Moratalla y también a la familia de la víctima, por acceder a compartir varios materiales jurídicos pertinentes para su análisis.

A mis amigos, los abogados palentinos D. Luis Antonio Calvo Alonso y D $\mathrm{D}^{\mathrm{a}}$ Margarita Calle Monge, cuyo Bufete contribuyó a solucionar dudas procesales como sólo pueden hacerlo profesionales con su experiencia.

A los Profs. D ${ }^{a}$ Mercedes Martínez León y D. Daniel Queipo Burón, por aceptarme para realizar esta Tesis Doctoral bajo su dirección y por sus orientaciones.

Al Tutor de la Tesis Doctoral, el Prof. D. Antonio Dueñas Laita, por su apoyo absoluto e inestimable, sus ideas inspiradoras y tantos momentos en que me animó a continuar.

Al Profesor D. Ángel Sanz Morán por su colaboración, buenos consejos, enseñanzas y, por supuesto, por brindarme su amistad.

Al Profesor D. Jesús Bustamante Bustamante, por sus valiosos consejos, sus aportaciones siempre acertadas y toda la ayuda que me ha prestado a lo largo de este proceso tan laborioso.

A los Profesores D. Antonio Jimeno Carruez y D. Alberto Miranda Romero, por su ayuda, su ánimo en todos los numerosos instantes en que creí abandonar la batalla y, por encima de todo, por su amistad.

A mi amiga Eva, por impulsarme, y por compartir conmigo sus conocimientos médicos, atesorados a lo largo de tantos años de ejercicio profesional.

A todas aquellas personas e instituciones que colaboraron desinteresadamente en la difusión del cuestionario de encuesta, muy especialmente a las Profesoras $\mathrm{D}^{\mathrm{a}}$ Verónica Casado Vicente, $D^{a}$ Nieves López Fernández y D ${ }^{a}$ Natividad García Atarés, así como al Colegio de Médicos de Valladolid y a los Colegios de Psicólogos, de Odontólogos, de Logopedas y de Fisioterapeutas de Castilla y León. En esta misma tarea, debo agradecer su inestimable ayuda a los sindicatos CCOO, CGT, CSIF, SATSE, SAE y UGT.

A quienes participaron en la encuesta y en su prueba piloto, a los que también quiero agradecer sus sugerencias y, sobre todo, la propia participación, porque sin ella, un trabajo como este no puede llegar a realizarse.

A Ana Isabel, por su ayuda constante y tenaz, por su apoyo inquebrantable y por la ilusión con que me ha acompañado en este proyecto.

A todos, muchas gracias. Porque sin vosotros este barco nunca hubiera llegado a buen puerto. 


\section{ÍNDICE DE SIGLAS Y ABREVIATURAS}

AP: Audiencia Provincial.

AAP: Auto de Audiencia Provincial.

AGE: Administración General del Estado.

ATS: Ayudante Técnico Sanitario.

AuTS: Auto del Tribunal Supremo.

BOAR: Boletín Oficial de Aragón.

BOCYL: Boletín Oficial de Castilla y León.

BOE: Boletín Oficial del Estado.

CC: Código Civil.

CCAA: Comunidades Autónomas.

CCOO: Comisiones Obreras.

CDC: Centros para la prevención y control de las enfermedades.

CE: Constitución Española.

CECA: Comunidad Europea del Carbón y del Acero.

CEE: Comunidad Económica Europea.

CEMSATSE: Unión del Sindicato Médico con el SATSE.

CIE: Consejo Internacional de Enfermería.

COM: Colegio Oficial de Médicos.

COMB: Colegio Oficial de Médicos de Barcelona.

CP: Código Penal.

CRTS: Centro Regional de Transfusión Sanguínea.

CSIF: Central Sindical Independiente de Funcionarios.

DOCLM: Diario Oficial de Castilla-La Mancha.

DOUE: Diario Oficial de la Unión Europea.

DRAE: Diccionario de la Real Academia Española de la Lengua.

DUE: Diplomado Universitario en Enfermería.

EBEP: Estatuto Básico del Empleado Público.

ET: Estatuto de los Trabajadores.

EVI: Equipo de Valoración de Incapacidades.

GRUE: Graduado Universitario en Enfermería.

INE: Instituto Nacional de Estadística.

INSHT: Instituto Nacional de Seguridad e Higiene.

INSS: Instituto Nacional de la Seguridad Social.

ISP: Internacional de Servicios Públicos. 
IT: Incapacidad Temporal.

ITSS: Inspección de Trabajo y Seguridad Social.

LEC: Ley de Enjuiciamiento Civil.

LECrim: Ley de Enjuiciamiento Criminal.

LEVD: Ley de Estatuto de la Víctima del Delito.

LGSS: Ley General de Seguridad Social.

LISOS: Ley de Infracciones y Sanciones en el Orden Social.

LPAC: Ley de Procedimiento Administrativo Común.

LOPD: Ley Orgánica de Protección de Datos.

LPRL: Ley de Prevención de Riesgos laborales.

LRJPAC: Ley de Régimen Jurídico de las Administraciones Públicas y Procedimiento Administrativo Común.

LRJSP: Ley de Régimen Jurídico del Sector Público.

MSSSI: Ministerio de Sanidad, Servicios Sociales e Igualdad.

OECT: Observatorio Estatal de Condiciones de Trabajo.

OIT: Organización Internacional del Trabajo.

OMC: Organización Médica Colegial.

OMS: Organización Mundial de la Salud.

PAC: Puntos de Atención Continuada.

PPRL: Plan de Prevención de Riesgos Laborales.

PRL: Prevención de Riesgos Laborales.

RD: Real Decreto.

RDL: Real Decreto Legislativo.

RpRpS: Reglamento del procedimiento para el ejercicio de la potestad sancionadora, aprobado por Real Decreto 1398/1993, de 4 de agosto.

SAN: Sentencia de la Audiencia Nacional.

SAP: Sentencia de Audiencia Provincial.

SAS: Servicio Andaluz de Salud.

SACYL: Servicio de Salud de Castilla y León.

SATSE: Sindicato de Enfermería y Sanidad.

SCS: Servicio Cántabro de Salud.

SDP: Síndrome de Desgaste Profesional.

SERGAS: Servicio Gallego de Salud.

SERIS: Servicio Riojano de Salud.

SERMAS: Servicio Madrileño de Salud.

SJUE: Sentencia del Tribunal de Justicia de la Unión Europea.

SMS: Servicio Murciano de Salud. 
SNS: Sistema Nacional de Salud.

SNS-O: Servicio Navarro de Salud-Osasunbidea.

SPRL: Servicio de Prevención de Riesgos Laborales.

SSPA: Sistema Sanitario Público de Andalucía.

STC: Sentencia del Tribunal Constitucional.

STS: Sentencia del Tribunal Supremo.

STSJ: Sentencia de Tribunal Superior de Justicia.

SUAP: Servicios de Urgencia en Atención Primaria.

TC: Tribunal Constitucional.

TCAE: Técnico en Cuidados Auxiliares de Enfermería.

TDH: Tribunal de Derechos Humanos.

TJUE: Tribunal de Justicia de la Unión Europea.

TRLGSS: Texto Refundido de la Ley General de Seguridad Social.

TS: Tribunal Supremo.

TSJ: Tribunal Superior de Justicia.

TUE: Tratado de la Unión Europea hecho en Maastricht el 7 de febrero de 1992, en la versión resultante del Tratado de Lisboa, que entró en vigor en diciembre de 2009.

UCI: Unidad de Cuidados Intensivos.

UE: Unión Europea.

UGT: Unión General de Trabajadores.

ZBS: Zonas Básicas de Salud. 


\section{ÍNDICE DE CONTENIDOS}

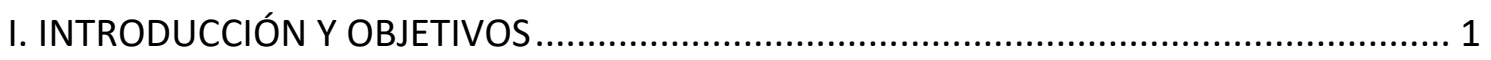

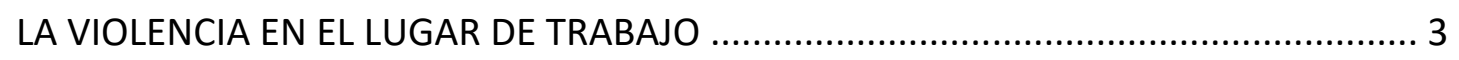

LA VIOLENCIA EN EL SECTOR SANITARIO ...................................................... 5

EL CAMBIO DE PARADIGMA EN LA VIOLENCIA CONTRA EL PERSONAL SANITARIO.

EL INCREMENTO DE LAS AGRESIONES Y LA TOMA DE CONCIENCIA POR PARTE DE

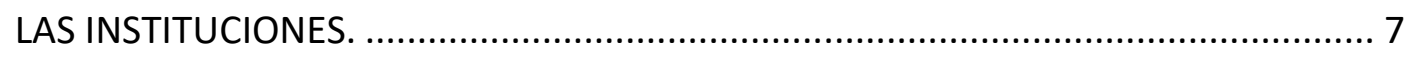

CONSECUENCIAS DE LA VIOLENCIA EN EL ENTORNO SANITARIO........................... 13

EL PROBLEMA DE LA «INFRANOTIFICACIÓN», «INFRAREGISTRO»O «INFRADENUNCIA». EL INSUFICIENTE CONOCIMIENTO DE LA INCIDENCIA DEL

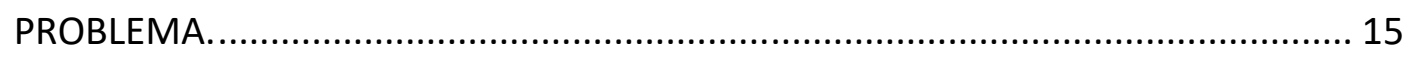

LA INVESTIGACIÓN SOBRE LAS AGRESIONES CONTRA EL PERSONAL SANITARIO EN

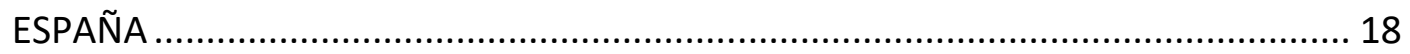

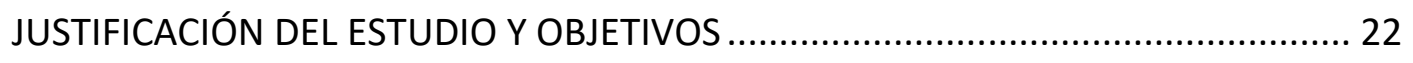

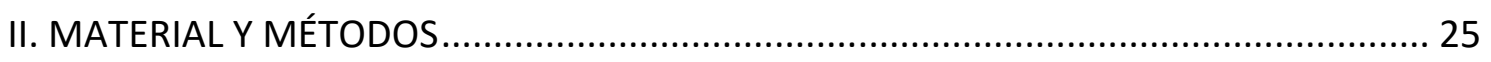

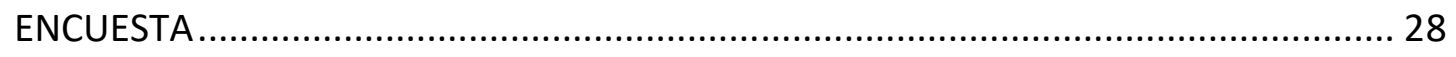

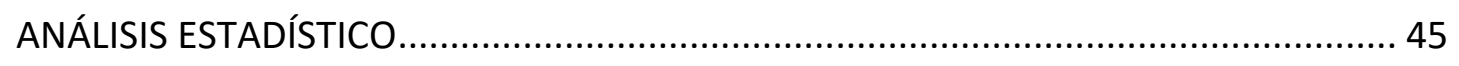

III. EL DERECHO DEL TRABAJO ANTE LAS AGRESIONES AL PERSONAL SANITARIO ......... 47

LA NORMATIVA SOBRE SALUD Y SEGURIDAD EN EL TRABAJO .............................. 49

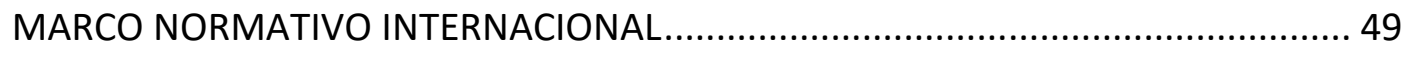

NORMATIVA COMUNITARIA EUROPEA ...................................................... 50

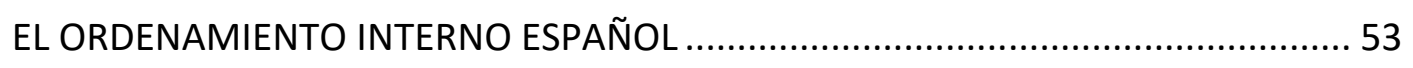

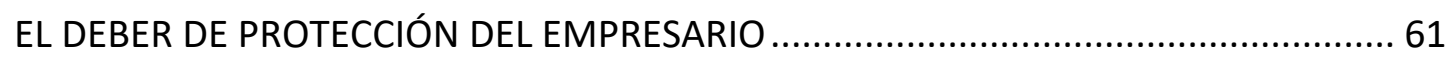

LOS PLANES DE PREVENCIÓN DE AGRESIONES A LOS PROFESIONALES SANITARIOS.67 EL ACCIDENTE DE TRABAJO Y LA VIOLENCIA CONTRA LOS PROFESIONALES DE LA

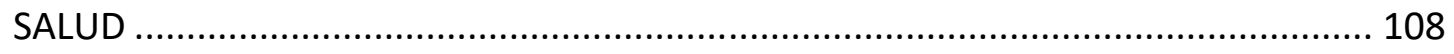

CONCEPTO, ELEMENTOS Y TIPOS DE ACCIDENTE DE TRABAJO. EXCLUSIONES... 108 EL ACCIDENTE DE TRABAJO EN LAS AGRESIONES A LOS PROFESIONALES DE LA

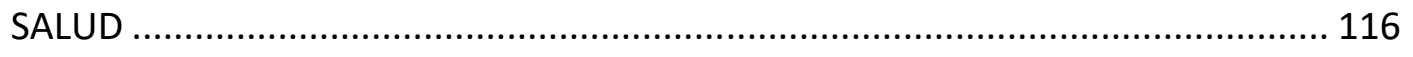

LA RESPONSABILIDAD EN MATERIA DE PREVENCIÓN DE RIESGOS LABORALES. LOS

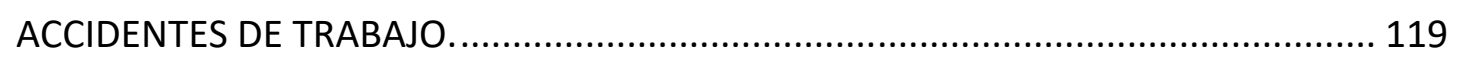

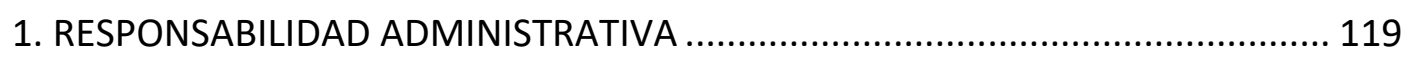

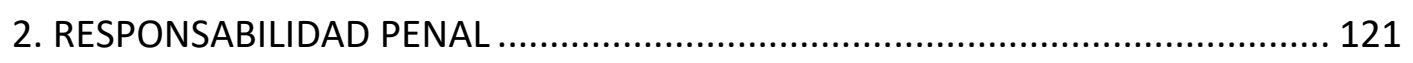

3. RESPONSABILIDADES EN MATERIA DE SEGURIDAD SOCIAL .......................... 124

4. RESPONSABILIDAD CIVIL O PATRIMONIAL ............................................... 127

5. ESPECIALIDADES EN RESPONSABILIDAD DERIVADA DE PRL: EL CASO DE LAS

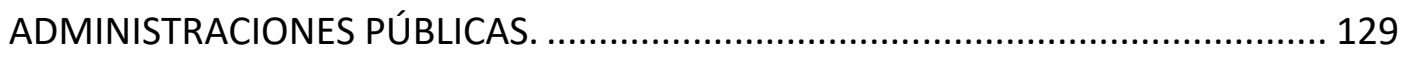


LA NORMATIVA SOBRE DERECHOS Y DEBERES DE LOS PACIENTES Y USUARIOS DE LA SANIDAD

LA REGULACIÓN DE LOS DERECHOS DE LOS PACIENTES

EL BINOMIO DERECHO-DEBER EN LAS RELACIONES ENTRE LOS PACIENTES Y LOS PROFESIONALES SANITARIOS. NATURALEZA JURÍDICA DE LA RELACIÓN CLÍNICA.

LOS DEBERES DE LOS PACIENTES Y USUARIOS DE LA SANIDAD 136 NORMATIVA DICTADA POR LAS COMUNIDADES AUTÓNOMAS EN MATERIA DE DEBERES DE LOS PACIENTES Y USUARIOS 145

EL RÉGIMEN SANCIONADOR ADMINISTRATIVO. 154

LA POTESTAD SANCIONADORA DE LA ADMINISTRACIÓN. 155

PRINCIPIOS DEL DERECHO SANCIONADOR ADMINISTRATIVO 156

RÉGIMEN SANCIONADOR ADMINISTRATIVO DE LAS AGRESIONES DESARROLLADO POR LAS CCAA. 165

LAS LEYES DE AUTORIDAD 177

MARCO NORMATIVO DE AGRESIONES AL PERSONAL SANITARIO EN LA COMUNIDAD AUTÓNOMA DE CASTILLA Y LEÓN 187

LA RESPONSABILIDAD PATRIMONIAL DE LAS ADMINISTRACIONES PÚBLICAS........ 215

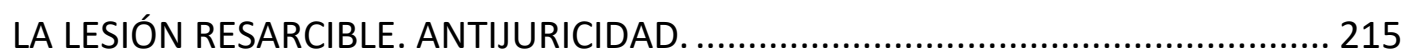

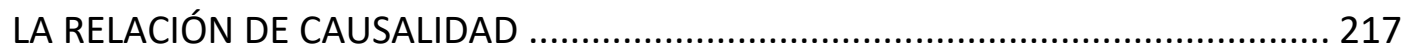

LA REPARACIÓN DE LA LESIÓN RESARCIBLE ................................................. 217

ACCIÓN DE RESARCIMIENTO CONTRA LA ADMINISTRACIÓN PÚBLICA ................ 218 RESPONSABILIDAD PATRIMONIAL DE LA ADMINISTRACIÓN PÚBLICA EN LAS AGRESIONES A SUS EMPLEADOS ............................................................... 220

LOS PROCEDIMIENTOS SEGUIDOS EN EL CASO DEL ASESINATO DE MORATALLA

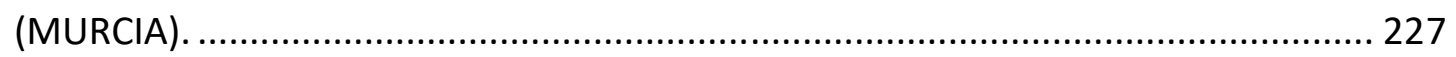

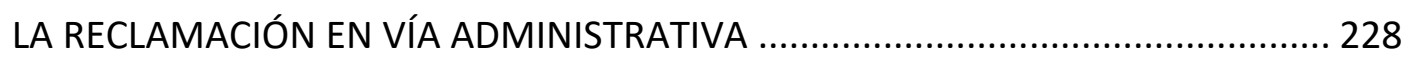

EL DICTAMEN 87/14 DEL CONSEJO JURÍDICO DE LA REGIÓN DE MURCIA .......... 235

LA STSJ DE MURCIA 790/2016, DE 18 DE NOVIEMBRE................................... 243

V. EL DERECHO PENAL Y SU TRATAMIENTO DE LAS AGRESIONES A LOS PROFESIONALES SANITARIOS

EL DERECHO PENAL ANTES Y DESPUÉS DE LA REFORMA DEL CP DE 2015 EN RELACIÓN CON LAS AGRESIONES AL PERSONAL SANITARIO 249

1.- Estado de la cuestión en la legislación penal anterior a la reforma de 2015.. 249

2.- El planteamiento a partir de la reforma del ordenamiento Penal en 2015.... 251

3.- Conclusiones. 255 
LA JURISPRUDENCIA PENAL SOBRE AGRESIONES AL PERSONAL SANITARIO TRAS LA REFORMA DEL CP DE 2015

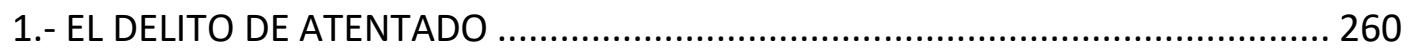

2.- LA APLICACIÓN RETROACTIVA DE LA REFORMA .......................................... 284

3.- RESOLUCIONES EN RELACIÓN CON LA CONDICIÓN DE AUTORIDAD ............... 296

4.- SENTENCIAS CON TERMINOLOGÍA O CONCEPTOS DISCUTIBLES ..................... 300

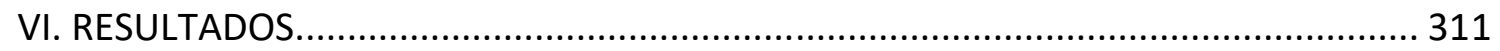

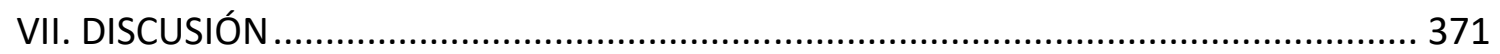

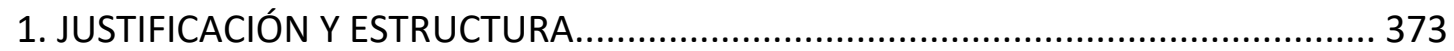

2. LAS AGRESIONES EN LOS DISTINTOS ORDENAMIENTOS................................... 377 CONSIDERACIONES SOBRE EL DERECHO LABORAL ANTE LAS AGRESIONES AL PERSONAL SANITARIO.

CONSIDERACIONES SOBRE EL TRATAMIENTO DEL DERECHO ADMINISTRATIVO DE LAS AGRESIONES A LOS PROFESIONALES DE LA SALUD .................................... 403

CONSIDERACIONES SOBRE LA ACTUACIÓN DEL DERECHO PENAL ANTE LAS AGRESIONES AL PERSONAL SANITARIO.

3. EXPERIENCIA ANTE LAS AGRESIONES Y VALORACIÓN POR LOS PROFESIONALES DE LAS MEDIDAS TOMADAS

CONSIDERACIONES SOBRE LAS AGRESIONES A PARTIR DE LA EXPERIENCIA DE LOS PROFESIONALES ENCUESTADOS.

LA VALORACIÓN DE LOS ENCUESTADOS SOBRE LAS MEDIDAS ADOPTADAS CONTRA LAS AGRESIONES EN LOS DIFERENTES ORDENAMIENTOS JURÍDICOS .. 441

4. UN CASO PRÁCTICO: EL ASESINATO DE MORATALLA. .469

A) NARRACIÓN FÁCTICA Y ACTUACIONES PENALES 469

B) ACTUACIONES EN VÍA ADMINISTRATIVA PREVIAS AL DICTAMEN DEL CONSEJO JURÍDICO DE LA REGIÓN DE MURCIA

C) EL DICTAMEN DEL CONSEJO JURÍDICO DE LA REGIÓN DE MURCIA (Dictamen 87/2014 de 31 de marzo).

D) LA SENTENCIA 790/2016, DE 18 DE NOVIEMBRE, DEL TRIBUNAL SUPERIOR DE JUSTICIA DE MURCIA Y ACTUACIONES POSTERIORES. 477

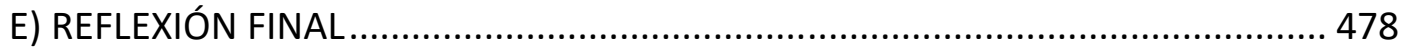

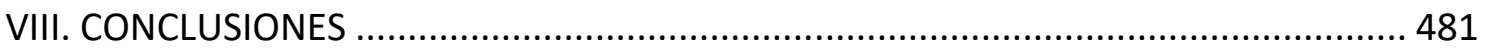

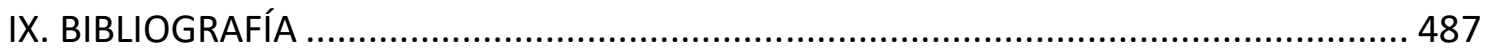

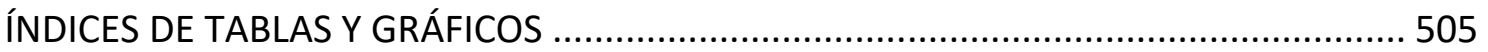

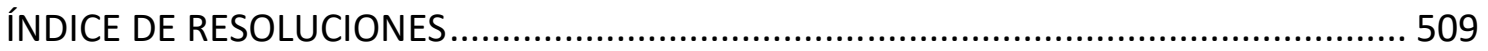

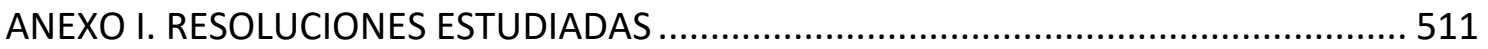

ANEXO II. PROPUESTAS DE LOS ENCUESTADOS: RESPUESTAS A LA PREGUNTA № 30 DEL CUESTIONARIO 
I. INTRODUCCIÓN Y OBJETIVOS 


\section{LA VIOLENCIA EN EL LUGAR DE TRABAJO}

La violencia en el trabajo viene siendo en los últimos tiempos un fenómeno de importante magnitud, que afecta a la mayoría de contextos laborales y que provoca consecuencias indeseables tanto en el entorno de trabajo, como en el propio trabajador y, por extensión, en las distintas organizaciones y empresas.

La clasificación de la violencia en el trabajo generalmente más aceptada es la elaborada en el seno de la OMS (Cooper \& Swanson, 2000):

1. Violencia «externa»: contra trabajadores por parte de personas ajenas a la organización.

2. Violencia por «clientes»: hacia los trabajadores, desde los usuarios de la organización (en el caso sanitario: pacientes y acompañantes o familiares).

3. Violencia «interna»: la que se perpetra por parte de trabajadores y directivos contra trabajadores (horizontal y vertical).

Otra clasificación es la diseñada por la OSHA, que establece cuatro tipos de violencia en el trabajo.

Tabla 1. Tipos de violencia en el trabajo (OSHA, 2004)

\begin{tabular}{|c|l|}
\hline $\begin{array}{l}\text { Tipo de } \\
\text { violencia }\end{array}$ & Definición \\
\hline Tipo I & Sin relación con el trabajo. Delincuencia. \\
\hline Tipo II & $\begin{array}{l}\text { Ejercida por: clientes, usuarios, pacientes, alumnos, } \\
\text { etc. }\end{array}$ \\
\hline Tipo III & $\begin{array}{l}\text { Ejercida por miembros de la plantilla: jefes, } \\
\text { compañeros, subordinados. }\end{array}$ \\
\hline Tipo IV & $\begin{array}{l}\text { Violencia doméstica o problemas personales sin } \\
\text { relación con el trabajo. }\end{array}$ \\
\hline
\end{tabular}

(O.S.H.A. Occupational Safety and Health Administration., 2004).

También se hace constar un cuarto tipo de violencia laboral, causada por presiones económicosociales, que provocan inseguridad en el trabajo, ansiedad, intolerancia y sobrecarga laboral (por ejemplo, una intensificación de la presión en el trabajo por no cubrir bajas, plantillas insuficientes de personal para atender la demanda de los usuarios, etc.) (Mayorca Yancán, Lucena García, Cortés Martínez, \& Lucerna Méndez, 2013).

Aunque su única repercusión fuera la esfera propia del individuo trabajador, ya merecería el interés y la actuación, tanto de las instituciones públicas como de la propia sociedad, pues afecta 
a su dignidad, provocando desigualdades, estigmatización y pérdida de salud, en cuanto que disminuye la autoestima.

Los efectos de la violencia laboral pueden ser, como veremos más adelante, no sólo de gran importancia, sino incluso letales, siendo por tanto obligada la adopción de medidas inmediatas y de actuaciones eficaces contra el problema.

Pero, además, sus consecuencias no afectan únicamente al trabajador, sino también a las empresas y Administraciones Públicas, lo que hace que en realidad involucre a todo el sistema social.

La violencia laboral es una amenaza grave, fuente de perturbaciones tanto a corto como a largo plazo, que puede comprometer la efectividad de las organizaciones (Burgos \& Paravic, 2003). Mayorca et al. (2013) la califican como una «cuestión olvidada» que ha ido adquiriendo importancia en los últimos años y ha llegado a convertirse en una cuestión prioritaria. La OIT manifiesta que esta violencia causa perturbaciones de las relaciones entre las personas, de la organización del trabajo y de todo el entorno laboral (OIT/OMS/CIE/ISP, 2002).

Desde el plano económico, se generan gastos «ingentes» (Gascón Santos, 2006, p. 29) derivados de la producción de actos violentos, que inciden sobre las economías de los países (Dorman, 2000). Hoel, Sparks, \& Cooper (2001) estiman que los costos generados por este tipo de violencia pueden representar entre el 1 y el 3,5\% del PIB anual de un país.

Los distintos estudios e investigaciones avalan la alarma suscitada al respecto. Todos los datos hacen pensar en que la violencia es muy elevada y, en consecuencia, deben tomarse medidas de forma inmediata. Los Centros para la Prevención y Control de las Enfermedades (CDC) destacan un 300\% de aumento de la violencia en el lugar de trabajo en los últimos diez años (Musayón \& Caufield, 2007). De hecho, se apunta a que se trata de un hecho que acontece a nivel mundial, incidiendo tanto en los países desarrollados como en los que están en vías de desarrollo, por lo que puede calificarse de fenómeno universal (Cooper \& Swanson, 2000).

Chappell y Di Martino (2006) hallaron que en Europa un 4\% de los trabajadores sufren violencia psicológica de algún tipo, acoso sexual un $2 \%$, e intimidación y «mobbing» un $8 \%$, todo en tasas anuales (que representan un total de 6, 3 y 12 millones de trabajadores) . 


\section{LA VIOLENCIA EN EL SECTOR SANITARIO}

No obstante, la universalidad del problema no implica que éste se manifieste de forma homogénea en todos los sectores de actividad. En algunos de ellos, su incidencia es mayor que la media, debido a sus propios factores intrínsecos.

Así, el sector servicios experimenta el fenómeno con una intensidad singular, debido principalmente al hecho de que en estas actividades se tiene un mayor contacto con el público.

Incluso, dentro del propio sector servicios, hay ámbitos en los que la incidencia resulta especialmente significativa, y ese es precisamente el caso de la sanidad.

La definición de violencia laboral en el entorno sanitario más aceptada es la adaptada por la OIT, el CIE, la OMS y la ISP en el «Programa conjunto sobre la violencia en el sector de la salud (OIT/CIE/OMS/ISP)»:

«Todos aquellos incidentes donde el personal es maltratado, amenazado o asaltado en circunstancias relacionadas con su trabajo y viceversa, con la participación de amenaza explícita o implícita a su seguridad, el bienestar o la salud» (OIT/OMS/CIE/ISP, 2002).

Aproximadamente el 25\% de la violencia laboral afecta a los trabajadores sanitarios (Di Martino, 2002), por delante de los policías y vigilantes de seguridad (dos colectivos que, en principio, estarían más enfrentados a entornos violentos de por sí). Rippon, (2000) ya encontró una tasa de $35-80 \%$ de trabajadores sanitarios que habían sido físicamente agredidos a lo largo de su carrera profesional. Miret y Martínez Larrea señalan que existen sondeos que indican una incidencia de agresiones físicas contra el personal sanitario de alrededor de un 60\% (Miret \& Martínez Larrea, 2010).

Por su parte, la VII Encuesta Nacional de Condiciones de Trabajo en España ${ }^{1}$, realizada por el Instituto Nacional de Seguridad e Higiene en el Trabajo en 2011, reveló que las conductas violentas en el trabajo suponían el $12,9 \%$ en el sector servicios, frente al 4-6\% en el resto de sectores de actividad, habiéndose producido un aumento en Administraciones Públicas con atención directa y permanente al usuario (Sanidad y Educación).

En la última Encuesta Nacional de Condiciones de Trabajo en España 2015², publicada por el Observatorio Estatal de Condiciones de Trabajo (OECT), el acoso o intimidación supuso un 7\%

\footnotetext{
${ }^{1}$ INSHT (2011)

2 “Encuesta Nacional de Condiciones de Trabajo. 6a EWCS," (2015).
} 
y las ofensas verbales un $15 \%$ en la actividad económica Salud, dentro de las actividades económicas que superan significativamente el promedio total.

La necesidad de terminar con esta situación ha llevado a la elaboración de estrategias por parte de distintas instituciones, empresas y sindicatos. En algunos países se llevan a cabo políticas de «tolerancia cero» (National Audit Office (NAO), 2003) y, de hecho, también se están intentando implantar en nuestro país (la OMC, por ejemplo, tiene en marcha una campaña en ese sentido). Por otra parte, existe igualmente la opción de dictar disposiciones legales o reformar las existentes para incluir la prevención y reacción ante las agresiones en el cuerpo normativo del país. Así lo han hecho, entre otros, Francia, Canadá, Finlandia, Polonia, Bélgica, Suecia y España (como tendremos ocasión de analizar detalladamente). 


\section{EL CAMBIO DE PARADIGMA EN LA VIOLENCIA CONTRA EL PERSONAL SANITARIO. EL INCREMENTO DE LAS AGRESIONES Y LA TOMA DE CONCIENCIA POR PARTE DE LAS INSTITUCIONES.}

La violencia externa contra los profesionales de la salud es un fenómeno que ha ido creciendo. Alarcón \& Ruiz de Aldana (2005) señalan que, con anterioridad a la década de los años 90 del pasado siglo, los sucesos violentos se circunscribían a actuaciones de enfermos mentales durante agudizaciones de sus patologías y que, posteriormente, los autores son pacientes y acompañantes sin trastornos psiquiátricos, movidos por razones muy distintas.

Lameiro et al. (2013) hablan de un «perfil cambiante», evidente en los últimos años de su investigación (2009-2012), en que observaron a su vez que los agresores ya no eran enfermos psiquiátricos, sino pacientes sin estas patologías o sus familiares y acompañantes. Este estudio destaca que ese «perfil cambiante» afecta también al tipo de agresión (más verbal que física), al cambio de los motivos de los sucesos violentos e, (Martínez-Jarreta, 2011) incluso, del perfil de los agredidos.

Algunos autores parecen sugerir que antes la violencia prácticamente no existía, ya que las relaciones asistenciales estaban basadas en una relación médico-paciente en la que la agresión a un médico (y, supuestamente a un sanitario, en general) era prácticamente impensable.

Si seguimos esta idea, deberemos aceptar como premisa que la relación médico-paciente basada en el paternalismo sería una especie de escudo protector imposible de vencer, en el que el profesional sanitario estaba completamente seguro porque la sola idea de discutir, protestar o llevar la contraria al médico, ni se le pasaba por la cabeza al paciente.

Ciertamente, en las bases de la relación clínica tradicional se encuentra un grado de sumisión importante a los dictados del médico, que el paciente no se atrevería a cuestionar jamás. El prestigio de la profesión sería equivalente a una suerte de veneración ciega, que haría impensable que el paciente simplemente se planteara dudar de sus criterios diagnósticos o terapéuticos. Este pensamiento tiene mucho de verdad, pero tampoco resulta razonable defender que la situación consistía en un idílico paraíso en el que el paciente siempre respetaba al sanitario y viceversa.

En todo caso, tenemos que aceptar que una situación así puede resultar cómoda para un galeno, pero desde luego, ni es deseable, ni sostenible en una sociedad moderna y avanzada.

Por otra parte, hablar de la relación médico-paciente supone en cierta medida excluir del concepto, desde luego, de esta situación paternalista y tradicional, al resto de los profesionales sanitarios. No cabe pensar que ese respeto reverencial le era también debido a la enfermera, celador, etc., 
porque, aunque existiera un respeto mayor al de la actualidad también hacia estos profesionales, la relación del paciente con ellos no tenía las características que adornaban el vínculo entre un médico y su paciente. Por esto, preferimos hablar generalmente de «relación clínica».

Para algunos ${ }^{3}$, el cambio en la relación clínica ha hecho que se incrementen las situaciones de agresividad y violencia. Es posible que las transformaciones en las relaciones entre profesionales y usuarios hayan tenido algo que ver en ello, puesto que todas las modificaciones que sufren las interacciones personales provocan a su vez cambios. Pero no creemos que el nuevo modelo de relación clínica haya provocado en sí mismo la creación de un ambiente de creciente violencia.

Quizás sea más cierto pensar que, aunque las situaciones conflictivas fueran menos numerosas, no por ello eran en absoluto inexistentes. No parece que partamos de una situación con cero agresiones hacia una progresión geométrica hasta el infinito en sólo una década.

Lo razonable es reconocer que efectivamente se ha realizado una rápida evolución desde una situación inicial en que las agresiones existían, pero no eran suficientes para que se considerasen un problema (o no se consideraban importantes, cuestión sobre la que incidiremos en breve) a otra fase en la que al parecer se produce un gran número de incidentes violentos.

Hoy en día prácticamente nadie duda de la importancia del fenómeno y de que resulta un problema importante que es necesario y urgente atajar, en interés del colectivo profesional afectado y también del buen servicio y funcionamiento de las organizaciones sanitarias.

Pero hay que reconocer que, desde el punto de inicio en que se consideraban las agresiones como algo anecdótico, hasta la actualidad en que se constata el problema en toda su dimensión, han acontecido sucesos y tomas de posición que contribuyeron a la sensibilización sobre este tema.

Un estudio realizado por el COMB en 2004 reveló que un tercio de los médicos encuestados sufrieron algún tipo de incidente violento durante su vida profesional (COMB, 2004).

Martínez-Jarreta et al. (2007) denunciaban que se había producido una rápida evolución hacia un aumento de las agresiones, que sostenían había suscitado una gran alarma social y calificaban de «realidad silenciosa». Estos autores consideraban que el fenómeno se enmarcaba en un patrón de creciente violencia interpersonal observada en la sociedad, cuestión que habían apuntado otros estudios con anterioridad (Alarcón \& Ruiz de Aldana, 2005)(Martínez León \& Queipo Burón, 2010).

\footnotetext{
${ }^{3}$ Martínez-Jarreta (2011) destaca que antes (en una sociedad tradicional) era impensable que los médicos, dotados de un alto prestigio social, pudieran ser víctimas de cualquier tipo de agresión.
} 
La cuestión no sólo suscitó alarma en los círculos científicos. Probablemente, el primer toque de atención decisivo fueron los gravísimos crímenes cometidos en las personas del Dr. Jimeno Tejedor en 1999 y de la Dra. Ginel en 2001, hitos que marcaron el punto de partida hacia una toma de conciencia de que el problema era verdaderamente grave y había que tomarlo en serio.

Desde hacía algún tiempo, los tribunales de la jurisdicción penal venían considerándolo así y, con la participación y la colaboración del Ministerio Fiscal, comenzaron a tipificar como delito de atentado (art. 550 y ss. CP) a las agresiones cometidas contra el personal sanitario de la sanidad pública. Evidentemente, esto no se hizo sin vacilaciones y criterios encontrados (De JuanMazuelas, 2016).

El Tribunal Supremo dictó en 2007 la trascendental STS 1030/2007, de 4 de diciembre, que, aunque provista de un voto particular, venía a señalar el camino jurisprudencial para castigar las agresiones al personal sanitario del ámbito público como delito de atentado. Este hito, fundamental para la evolución posterior, sugiere el reconocimiento oficial del problema y la necesidad de combatirlo explícitamente y con decisión desde el Derecho penal.

La Circular 2/2008 de la Fiscalía General del Estado instaba a la calificación de las agresiones a profesionales sanitarios y profesores del sector público como delito de atentado.

La orientación de la jurisprudencia siguió mayoritariamente esa dirección, aunque no de forma unánime, observándose una diferente aplicación según las resoluciones procedieran de unas Audiencias Provinciales u otras, pero marcándose una evolución clara hacia la aceptación de la utilización de este tipo penal para el tratamiento de estas agresiones (De Juan-Mazuelas, 2016).

Finalmente, con la última reforma del Código Penal (LO 1/2015), se incluye en el art. 550 explícitamente a los docentes y sanitarios públicos como sujetos pasivos del tipo de atentado.

En el empeño por conseguir una mayor protección penal para este colectivo, destaca especialmente la actuación de los Colegios Profesionales, así como de diversas organizaciones sindicales, de entre las que destacamos la labor de SATSE por ser intensa y muy temprana, sobre todo en cuanto a conseguir la inclusión de los profesionales de la sanidad en el ámbito de ampliación del delito de atentado (art. $550 \mathrm{CP}$ ), cuando sean víctimas de agresiones.

Hay que tener en cuenta que, al hablar de Colegios Profesionales, nos estamos refiriendo tanto a los Colegios de Médicos como a los de Enfermería ${ }^{4}$. Precisamente, como acabamos de señalar refiriéndonos al SATSE, estos últimos desarrollan una gran actividad desde épocas tempranas,

\footnotetext{
${ }^{4}$ En cuanto a los Colegios de Enfermería nos referimos únicamente al grupo profesional de Diplomados o Graduados en Enfermería, puesto que los auxiliares de enfermería no tienen colegiación obligatoria.
} 
bien es cierto que se trata de un sector de gran exposición a las agresiones, por su contacto directo y cotidiano con los pacientes y sus acompañantes (Martínez-Zaporta Aréchaga \& FernándezDelgado Momparler, 2008) (Gascón Santos, 2006).

La actuación de los órganos colegiales se pone de manifiesto, por ejemplo, en su impulso a la toma de posición por parte de la Fiscalía para que ésta tipifique como delitos de atentado las agresiones contra el colectivo de la sanidad pública.

También se materializa esa labor en el establecimiento de Convenios de Colaboración de actuación conjunta (Colegios-Fiscalías), lo que contribuye a su vez a promover que la Administración adopte diversas medidas: Reglamentos, creación de Observatorios, Planes de Prevención, etc.

Hay que matizar que, en principio, los Convenios de Colaboración a los que acabamos de referirnos sólo se establecían entre las Fiscalías y los Colegios de Médicos. Esta situación generó malestar en las organizaciones colegiales de enfermería puesto que consideraban que los facultativos les estaban excluyendo, a pesar de ser el colectivo posiblemente más afectado por las agresiones, como ya hemos indicado.

En cualquier caso, la actuación de los Colegios en defensa de los intereses de sus miembros, les ha llevado en ocasiones incluso a personarse como parte en procedimientos judiciales ${ }^{5}$.

En enero de 2014 tuvo lugar un encuentro (Colegio Oficial de Médicos de Sevilla), que destacamos, dada la importancia de algunas de sus conclusiones, sobre todo por considerar que los casos que salían a la luz pública a través de los medios de comunicación o los que llegaban hasta los juzgados, constituían sólo la «punta del iceberg» ${ }^{6}$ de lo que representa realmente la violencia cometida contra los profesionales de la sanidad. Es decir, señalaban como, aunque la situación en cuanto a protección penal había mejorado notablemente, aún quedaba camino por recorrer. Es notable esta afirmación, teniendo en cuenta que en el año 2014, cuando se celebra el encuentro, la aplicación por los tribunales del delito de atentado a las agresiones cometidas contra los profesionales de la sanidad pública era una tendencia ya consolidada (De Juan-Mazuelas, 2016).

\footnotetext{
${ }^{5}$ De Juan-Mazuelas (2016): Por ejemplo, SAP Baleares 376/2010, de 24 de noviembre, el Colegio de Enfermería; SAP Zamora 101/2011, de 19 de diciembre, Colegio de Médicos.

${ }^{6}$ Coinciden con esta opinión autores como Gascón Santos (2006) y (Marinas-Sanz et al., 2016a).
} 
Destaca también, en cuanto a la colaboración de las organizaciones profesionales con las Administraciones Públicas ${ }^{7}$, la creación del Observatorio Nacional de Agresiones de la OMC, después de la tragedia ocurrida en la Comunidad Autónoma de Murcia, cuando un usuario acabó con la vida de una médico residente (nos ocuparemos de este suceso ampliamente en otros capítulos de este trabajo).

Desde su fundación, este Observatorio Nacional incluye entre sus planteamientos que las agresiones que se produzcan contra este colectivo profesional sean consideradas violencia social. Por otra parte, dado que el tratamiento penal en cuanto a las agresiones es distinto dependiendo de que la víctima pertenezca a la sanidad pública o a la sanidad privada, otro de sus objetivos más relevantes es que se aplique a estos actos violentos un tratamiento homogéneo a la hora de penalizar a los agresores.

Por su parte, la OMC viene actuando también en esa línea y no sólo a través del Observatorio. Así, la propuesta para sensibilizar a la sociedad de la violencia externa que existe en el ámbito sanitario, que se materializó en la celebración del día nacional contra las Agresiones todos los años en el mes de marzo (también en recuerdo del asesinato producido en la Comunidad de Murcia al que ya nos hemos referido).

También destaca la puesta en marcha de la campaña «Tolerancia Cero», especialmente relevante anualmente en las fechas próximas a la celebración del día citado. Así, en el marco de esta campaña, el presidente de la OMC, en marzo de 2016 calificó de «...lamentable que algunas CC.AA. consideren que ocultar la realidad y disimular este tipo de violencia contra los servicios públicos sea la mejor manera de avanzar», cuando precisamente, como remarcó, «la única manera de no avanzar es tapando la realidad» (OMC. Observatorio de Agresiones, 2016). Hizo referencia, además, a las medidas que desde la OMC se estaban tomando para poner freno a estas situaciones, reiterando la necesidad de la colaboración de las Administraciones públicas con las corporaciones de profesionales sanitarios «para que, entre todos, tengamos un conocimiento real de cuál es la verdadera situación».

En cuanto a los sindicatos, como ya hemos anticipado, continúan también trabajando en esa línea de lograr una mayor cobertura de protección para los trabajadores sanitarios.

Así, el 4 de octubre de 2015, la prensa da a conocer cómo el SATSE de Euskadi-País Vasco pone en marcha una campaña de sensibilización y denuncia de las agresiones que sufre en su

\footnotetext{
${ }^{7}$ Algunos autores hablan de la formación de una especie de «triángulo protector» integrado por las Fiscalías, las Administraciones Autonómicas y los Colegios Profesionales (Martínez-Zaporta Aréchaga \& Fernández-Delgado Momparler, 2008).
} 
Comunidad Autónoma el colectivo de enfermería, campaña consistente en la publicación del «Libro del respeto», proporcionando además -a través de un blog en internet- la posibilidad de que los afectados por actos violentos den a conocer su experiencia bajo pseudónimo("Lo peor es que mi agresor también era mi paciente y tenía la obligación de atenderle”2015).

Por su parte, la sección madrileña del SATSE, en noticia publicada el 27 de mayo de 2016 por diariodicen.es, manifestaba lo siguiente:

«...el sindicato madrileño reclama al gobierno de la Comunidad de Madrid "la publicación de una normativa específica que proteja a los sanitarios de aquellas conductas no tipificadas penalmente o que sirvan para proteger al profesional sin tener que acudir al orden penal o esperar a que se produzca una agresión grave" así como "tomar medidas contundentes y eficaces para proteger a nuestros profesionales sanitarios en su ámbito laboral para que puedan desarrollar, con total seguridad, el desempeño de sus funciones"» ("SATSE Madrid reclama al gobierno autonómico la publicación de una normativa que proteja a los sanitarios contra las agresiones," 2016).

El 27 de diciembre de 2016 CSIF de Castilla-La Mancha, a raíz de una agresión producida en un centro de salud de la comunidad, ponía de manifiesto los escasos o incluso nulos medios con que cuentan algunos centros sanitarios para que quienes allí trabajan puedan hacer frente a los actos violentos, a la vez que exigía que dentro del Plan General de Riesgos Laborales se pusieran en marcha las herramientas pertinentes para evitar este tipo de situaciones ${ }^{8}$.

No se reclama únicamente la actuación de la Administración en el orden penal, como puede comprobarse. De hecho, siendo las innovaciones en materia penal lo más llamativo, las distintas ramas del ordenamiento jurídico español fueron incorporando a lo largo de este tiempo distintos textos legales y reglamentarios en orden a la protección de los profesionales sanitarios y la implantación de las medidas sancionadoras correspondientes contra los autores de los eventuales actos violentos cometidos contra ellos, como tendremos ocasión de comprobar.

\footnotetext{
8 «La Central Sindical Independiente y de Funcionarios exige la creación de herramientas, dentro del Plan General de Riesgos Laborales, para evitar este tipo de situaciones incrementando la seguridad en los centros por medio de una mayor vigilancia. Todas las medidas son pocas para acabar con la indefensión que pueden llegar a sufrir tanto los profesionales como los pacientes de los centros sanitarios, que en muchos casos no cuentan con los medios necesarios para evitar amenazas, actitudes agresivas y reacciones violentas" ("Castilla La Mancha Sanidad - CSIF pide más medios para evitar agresiones en los centros sanitarios," 2016).
} 


\section{CONSECUENCIAS DE LA VIOLENCIA EN EL ENTORNO SANITARIO.}

La violencia en el lugar de trabajo ocasiona, como hemos visto, efectos indeseables sobre el funcionamiento de las organizaciones. Gómez-Durán, Gómez-Alarcón y Arimany-Manso señalan que se produce un grave impacto global «en términos de coste, eficiencia y efectividad de los sistemas de salud» (Gómez-Durán et al., 2012, pág. 1), que lleva a un deterioro en los servicios en dos direcciones: la calidad de la asistencia y el posible abandono de los profesionales, que a su vez acarrea una reducción de los servicios disponibles.

El absentismo en el trabajo, el deterioro del ambiente laboral, el descenso de la calidad de la asistencia, el incremento de los costes por medicina defensiva y el aumento de la insatisfacción de los usuarios (que deteriora la relación clínica, provocando más disfunciones), son algunos de los efectos que producen los episodios de violencia en el entorno sanitario (Mayorca Yancán et al., 2013).

Todo ello, obviamente, incide sobre la imagen de la organización, el deterioro del servicio y de la calidad de la atención asistencial (Camerino et. al, 2007).

Este impacto sobre los servicios sanitarios proviene de las consecuencias que tiene la violencia sobre el trabajador y su entorno.

Varios autores han estudiado la importancia de la incidencia de los actos violentos sobre la salud psíquica del agredido.

En opinión de Di Martino (2003), el profesional que sufre violencia laboral suele padecer estrés, ansiedad, aislamiento, problemas de concentración, falta de motivación, síntomas psicosomáticos, pérdida de confianza y autoestima y alteración de la capacidad de resolución de conflictos.

Según la Encuesta Nacional de Condiciones de Trabajo 2015, publicada por el Observatorio de Condiciones de Trabajo, el sector de la Salud destaca como la actividad con mayor proporción de aquejados por el estrés laboral (“Encuesta Nacional de Condiciones de Trabajo. 6ªWCS,” 2015).

Las agresiones sufridas, físicas o verbales, junto al miedo a volver a sufrirlas, es una fuente de estrés laboral muy importante. El hecho de que el afectado, además, perciba falta de apoyo por parte de compañeros y directivos hace que la situación se agrave aún más (Anderson \& Parish, 2003).

Miret y Martínez Larrea (2010) señalan que la agresión continuada a la salud crea como respuesta el síndrome de desgaste profesional (SDP) o «burn-out», que genera efectos sobre la salud tanto 
física como mental y sobre las relaciones sociales de los trabajadores ${ }^{9}$. En ciertos casos, termina produciendo ansiedad, depresión y trastornos de adaptación y en la mayoría de las ocasiones, cansancio emocional y físico, disminución de la eficacia, absentismo laboral y malas relaciones laborales.

El SDP ostenta tres dimensiones: cansancio emocional, despersonalización y falta de realización personal (Atance Martínez, 1997), y su incidencia resulta especialmente alta en profesionales con un contacto directo y constante con otras personas, como sanitarios o profesores.

La primera dimensión (el cansancio emocional) perturba los mecanismos básicos de recuperación, como el sueño, lo que repercute en un cansancio físico. Las sensaciones de los afectados son de frustración de sus expectativas y el sentimiento de estar dando más de lo que reciben. En esos momentos, el trabajador ya está en situación de riesgo. Puede comenzar a distorsionar las posibles amenazas y reaccionar disfuncionalmente.

La relación clínica se deteriora y el profesional se distancia emocionalmente, entrando en la despersonalización (segunda dimensión del síndrome de «burn-out»). La despersonalización aumenta con el sentimiento de que su trabajo no es valorado por los pacientes, los compañeros o los superiores. Progresivamente, el profesional se ve cada vez más aislado, más cansado, y termina siendo incapaz de reaccionar.

La tercera fase (falta de realización personal, incompetencia personal) llega a producir una total falta de implicación en el trabajo, que deriva a la incapacidad del ejercicio de la profesión (Mayorca Yancán et al., 2013).

El SDP puede incrementar el riesgo de agresiones, porque produce efectos reactivos en los pacientes. Deteriorada la relación clínica por la actitud despersonalizada del profesional, el usuario percibe que se le trata mal, indigna y deshumanizadamente, y a su vez reacciona con quejas y agresividad. Por ello, el proceso deviene circular e interminable: el ambiente hostil de trabajo, la violencia, etc., generan en el profesional estrés y desgaste, que hacen que comience a comportarse disfuncionalmente con el usuario; éste se siente maltratado y reacciona a su vez agresivamente, lo que incrementa los niveles de sobrecarga del trabajador, y así sucesivamente ${ }^{10}$.

Gascón Santos (2006) también incide en las consecuencias de las agresiones sobre la salud del trabajador, constatando además que los episodios violentos de tipo verbal afectan a la salud de forma mucho más grave de lo que se pensaba tradicionalmente. Señala este autor que incluso se

\footnotetext{
${ }^{9}$ En esta misma línea puede verse Rippon (2000).

${ }^{10}$ Rowe y Sherlock encontraron relación entre el aumento de agresiones de tipo verbal y el síndrome de «burnout»(Rowe \& Sherlock, 2005).
} 
ha observado la producción de una sintomatología compatible con el síndrome de estrés postraumático, lo que da idea de la gravedad del problema. Numerosas investigaciones han descrito cuadros clínicos severos ocasionados por los entornos desfavorables de violencia y agresividad en el trabajo sanitario (Braga, Prats, Luna, Melamud, \& Flichtentrei, 2012).

\section{EL PROBLEMA DE LA «INFRANOTIFICACIÓN», «INFRAREGISTRO»O «INFRADENUNCIA». EL INSUFICIENTE CONOCIMIENTO DE LA INCIDENCIA DEL PROBLEMA.}

La llamada «infra-denuncia» es un fenómeno observado en la práctica totalidad de los estudios realizados en materia de violencia laboral y constituye un eje fundamental del problema de las agresiones, por varios motivos:

En primer lugar, por lo que representa en la propia concepción del problema: un incidente que no se notifica es un incidente infravalorado que no será tenido en cuenta ni por las instituciones, ni por la propia víctima pasado un tiempo (si no reviste mucha gravedad, claro está).

En segundo lugar, porque ya en su inicio el interesado que no comunica el hecho lo está ocultando, con la intención de que no trascienda. Posteriormente veremos que la víctima puede tener varios motivos para actuar así, pero el hecho es que decide que no se descubra.

En tercer lugar, con una escasa comunicación no es posible saber cuál es el tamaño real del problema ni su verdadera incidencia.

En cuarto lugar, derivado de lo anterior, podemos llegar tanto a infravalorar el fenómeno como a magnificarlo (porque, como sabemos que hay pocos incidentes notificados, imaginamos que existen muchísimos más, pero no conocemos cuántos).

En quinto lugar, la falta de comunicación de los incidentes imposibilita alcanzar una visión íntegra del fenómeno, lo que a su vez hace muy difícil realizar actuaciones preventivas eficaces.

Por último, este hecho también repercute en la toma de medidas posteriores a la agresión, las acciones encaminadas al resarcimiento de los daños, las sanciones aplicables al autor y el enjuiciamiento de los actos violentos (Marinas-Sanz, Martínez-Jarreta, Casalod, \& Bolea, 2016) (De Juan-Mazuelas, 2016).

La práctica totalidad de los estudios realizados constatan la existencia y gravedad de esta cuestión, hasta el punto de que muchos autores manifiestan que lo conocido sobre las agresiones al personal sanitario representa tan sólo la punta de un iceberg. Entre otros, Gómez-Durán et al. (2012) 
hablan de «el iceberg del problema» ${ }^{11}$. Miret \& Martínez Larrea (2010) estimaban que existe «un gran volumen de incidentes violentos sumergidos que no constan en ninguna parte» (p. 194).

Tanto las investigaciones desarrolladas por instituciones y organismos, como los trabajos científicos publicados reconocen la importancia de este asunto, llegando a recomendar la ejecución de campañas que estimulen a los profesionales para que denuncien las agresiones sufridas (OIT/OMS/CIE/ISP, 2002).

Los porcentajes de infradenuncia encontrados por la mayoría de las investigaciones son preocupantemente altos. Rippon (2000) desvelaron un 80\% y Gates, Ross, \& Mc Queen (2006) un $65 \%$ de actos violentos no comunicados de ninguna forma.

En Reino Unido, el informe publicado en 2003 por la House of Commons reveló que entre 1998 y 2002 se había producido un incremento del 30\% (National Audit Office (NAO), 2003). La APSF (Australian Patient Safety Foundation) detectó que el 70\% de las agresiones no se denuncian (Benveniste, Hibbert, \& Runciman, 2005).

El informe del Grupo de Trabajo de agresiones a profesionales del Sistema Nacional de Salud (Comisión de recursos humanos del SNS, 2014), estimó que únicamente el 10,95\% de los hechos notificados llegaban a los tribunales.

Martínez-Jarreta et al. (2007) hallaron una ausencia de denuncia de un $96,3 \%$ en caso de agresiones físicas y un $100 \%$ en amenazas e insultos, es decir, que los profesionales agredidos no denunciaban en ningún caso las agresiones verbales y psicológicas.

Martínez León, Queipo Burón, Irurtia Muñiz, \& Martínez-León (2012) encontraron un porcentaje del 90,2\% de agresiones no denunciadas y Arimany-Manso, Clos-Masó, \& Gómez-Durán (2016) afirman que únicamente se denuncian las agresiones graves y que provocan lesiones.

Almanzor Elhadad \& Martín Galán (2015) constataron que de 267 episodios de violencia detectados en su ámbito de estudio, únicamente 88 habían sido registrados.

Chagoyen Barroso (2016) halló que de 127 agresiones, sólo se habían registrado 13, lo que representaría un $90 \%$ de infraregistro en su estudio. 11 Velasco Sánchez, (2014) también utilizan el término «punta de un iceberg» para referirse a las agresiones conocidas
y al desconocimiento de las restantes, provocado por la infradenuncia. 
Una vez identificado el fenómeno, cabe preguntarse por qué se produce. Los motivos por los que las personas agredidas no comunican las agresiones han sido objeto de estudio en algunos trabajos.

La OMS considera que la principal causa de reticencia en notificar los incidentes violentos es la asunción de las agresiones como parte integrante del trabajo.

En este sentido, resulta particularmente clarificadora la siguiente afirmación de Chuliá Fernández (2014): «...la violencia está tan generalizada e interiorizada socialmente que llega a hacerse invisible, hasta el punto de considerarse alguna de sus manifestaciones como parte del contenido del puesto de trabajo» (p. 72).

Mayorca (2013) atribuye igualmente la baja tasa de comunicación a incluir como parte del trabajo los episodios violentos, sumando a esta razón la consideración por parte de los profesionales encuestados de que el registro es inútil. En esta investigación se considera el problema de modo central, señalando que se trata de un fenómeno que se produce a escala mundial.

Chagoyen Barroso (2016) encuentra que las personas agredidas manifestaban no denunciar las agresiones por considerarlas parte de su trabajo y porque no sabían dónde comunicarlo.

Gutiérrez et al.(2016) también achacan a la consideración de las agresiones como parte del trabajo habitual la baja notificación de las mismas, añadiendo que las víctimas minimizan los hechos violentos. Destacan la importancia de la denuncia y proponen campañas para alentar a comunicar todas las agresiones, a la vez que se informe de los medios disponibles en caso de agresión a los profesionales. En su estudio, observaron un incremento de las notificaciones a partir de 2011, que atribuyen a una campaña informativa llevada a cabo por su SPRL.

Hay, no obstante, otros motivos para no declarar las agresiones. Algunos autores destacan el desconocimiento de los planes de prevención (Chagoyen Barroso, 2016), de los protocolos de actuación (Ortells Abuyé, Muñoz Belmonte, Paguina Marcos, \& Morató Lorente, 2013) o de los recursos disponibles (Fernández Martín, Camacho García, Olmos Aullón, Ruiz García, \& Sanjuán Navais, 2006)(Gutiérrez, Hernández, \& Molina, 2016).

Martínez-Jarreta, (2011) enumera las siguientes razones para no denunciar: sentimiento del agredido de falta de apoyo por parte de la Administración, temor a proyectar una imagen de mal profesional incapaz de hacerse respetar por los pacientes, temor a sufrir una victimización secundaria y, también, que el resultado de la denuncia suponga una sanción tan nimia que no merezca la pena arrostrar todo el proceso. 
Igualmente, los profesionales no comunican las agresiones cuando han sido producidas por pacientes psiquiátricos o aquellos que se encuentran bajo un fuerte estrés (Gutiérrez et al., 2016) (Mayorca Yancán et al., 2013). El sentimiento de que comunicar la agresión no servirá de nada es también un motivo importante (Mayorca Yancán et al., 2013) Chagoyen Barroso (2016).

\section{LA INVESTIGACIÓN SOBRE LAS AGRESIONES CONTRA EL PERSONAL SANITARIO EN ESPAÑA}

Los estudios realizados en nuestro país son mayoritariamente descriptivos, probablemente porque su objetivo es conocer la frecuencia del fenómeno e identificar factores de riesgo (Vidal-Martí \& Pérez-Testor, 2015). Las variables más estudiadas son: agente causal, tipo de agresión, factores de predisposición y servicio donde se produjo el incidente, junto con características de los episodios violentos (Lameiro et al., 2013) y factores asociados a las agresiones (Gutiérrez et al., 2016).

Otros trabajos reflejan las medidas tomadas para abordar la cuestión ${ }^{12}$ o se interesan por las consecuencias que la violencia tiene sobre las víctimas de los ataques ${ }^{13}$.

En cuanto al grupo o grupos del colectivo de profesionales sanitarios estudiados, existen estudios sobre todo el colectivo dentro de un centro, o en grupos concretos (enfermería, médicos...) ${ }^{14}$. También algunos se centran en servicios hospitalarios de mayor riesgo ${ }^{15}$.

Se han utilizado instrumentos como formularios «ad-hoc» ${ }^{16}$ o ya avalados (Chagoyen Barroso, 2016), datos incluidos en registro ${ }^{17}$, materiales basados en otras investigaciones previas (Urruela Mora, 2016) o resoluciones judiciales (García Calvo, 2013) (De Juan-Mazuelas, 2016).

Sólo se han encontrado dos revisiones de la literatura sobre el tema, que recopilan la investigación realizada hasta el momento: Vidal-Martí \& Pérez-Testor (2015) y Sánchez-Benito et al., (2017).

Las diferentes investigaciones de tipo descriptivo (como hemos señalado, las más abundantes) adolecen de falta de homogeneidad en las definiciones de variables, instrumentos y criterios empleados. La heterogeneidad de los sistemas de registro de las agresiones dificultan igualmente la comparación de los datos entre los distintos estudios, tal como señalan (Martínez-Jarreta et al.,

\footnotetext{
${ }^{12}$ Gómez-Durán et al. (2012), Arimany-Manso et al. (2016).

${ }^{13}$ Miret \& Martínez Larrea (2010), Gascon et al. (2013), Martínez-Jarreta et al. (2007).

${ }^{14}$ Galián Muñoz (2015),Fernández Iglesias (2012), Ribera Domene et al., (1993).

${ }^{15}$ Fernández Martín et al. (2006), Mayorca Yancán et al. (2013), Villar Doncel \& Aranaz Andrés (2006).

16 Bernaldo de Quirós Aragón \& Labrador Encinas (2008), Moreno Jiménez et al. (2005),Chuliá Fernández (2014), Gascón Santos (2006).

${ }^{17}$ Gutiérrez et al. (2016), Lameiro et al. (2013), De-San-Segundo et al. (2016)Martínez León et al.(2011), Almanzor Elhadad \& Martín Galán (2015), Cervantes, Blanch, \& Hermoso (2010).
} 
$2007)^{18}$. Sánchez-Benito y col. observan, sin embargo, que existe un alto grado de coincidencia en las conclusiones obtenidas, lo que indica que los datos recogidos pueden orientar la actuación sobre el problema (M. C. Sánchez-Benito et al., 2017).

Los estudios aquí examinados plantean una serie de posibles soluciones y de sugerencias de actuación al respecto. Las más resaltables son las siguientes:

- Elaboración de protocolos de actuación médico-legal (Arimany-Manso et al., 2016) (Martínez León et al., 2012) y guías de actuación para prevenir y gestionar la violencia en el lugar de trabajo (Arimany-Manso et al., 2016), con una difusión correcta (Ortells Abuyé et al., 2013).

- Establecer campañas preventivas y de divulgación (Martínez León et al., 2012) (Chagoyen Barroso, 2016), tanto sobre la importancia de denunciar las agresiones como informando de los medios disponibles (Gutiérrez et al., 2016) (Mayorca Yancán et al., 2013).

- Mejorar la formación de los profesionales en competencias en comunicación asistencial (Moreno Jiménez et al., 2005). Esto incluiría el entrenamiento en uso de habilidades y mecanismos de defensa para afrontar situaciones conflictivas (Miret \& Martínez Larrea, 2010) (Bernaldo de Quirós Aragón \& Labrador Encinas, 2008) (Bernaldo-de-Quirós, Labrador, Piccini, Mar Gómez, \& Cerdeira, 2014). Gasco et al. (2017) informan de la impartición de talleres prácticos de autodefensa de agresiones verbales en varios hospitales de Andalucía.

- Mejora en políticas institucionales: medidas organizativas (Miret \& Martínez Larrea, 2010), educación del usuario (Marinas-Sanz et al., 2016), reducción de tiempos de espera (Moreno Jiménez et al., 2005). Mayorca Yancán et al. (2013) insisten en la necesidad de mejorar la información a los pacientes para evitar generar ansiedad y sentimiento de abandono.

- Participación de todas las instancias, instituciones y organizaciones implicadas en el problema (Gómez-Durán et al., 2012) (De Juan-Mazuelas, 2016).

- Apoyo de las empresas (Ortells Abuyé et al., 2013) y las instituciones (Moreno Jiménez et al., 2005). Potenciación de una mayor participación de los trabajadores en la planificación de la prevención y en la realización de cambios organizativos (Miret \& Martínez Larrea, 2010).

- Aplicar sanciones económicas en vía administrativa (Marinas-Sanz et al., 2016).

\footnotetext{
${ }^{18}$ Lo que también destacan Vidal-Martí \& Pérez-Testor (2015).
} 
- Garantizar la efectiva aplicación de las medidas penales existentes en los casos más graves (De Juan-Mazuelas, 2016).

El estado actual de la investigación sobre agresiones a personal sanitario en nuestro país es el que hemos resumido. Esto es con lo que contamos en la actualidad y resulta necesario reflexionar sobre qué es lo que podría hacerse a partir de ahora. Se constata la existencia de una serie de parámetros que tal vez sería conveniente que orientaran los estudios a realizar de aquí en adelante.

Las propuestas de investigación serían las siguientes:

Por una parte, como señalan Marinas-Sanz et al., (2016), sería conveniente profundizar en las investigaciones para mejorar la calidad de la evidencia científica disponible; resulta necesario, en opinión de estos autores, que se emprendan estudios de cohortes para evaluar las repercusiones de las agresiones, tanto a largo como a corto plazo.

La evaluación de las actuaciones emprendidas sería también para estos autores algo determinante: es necesario saber si las medidas tomadas son o no efectivas para profundizar en ellas o cambiar de dirección.

Para ello, han de mejorarse los sistemas de recogida de información y el funcionamiento de los diferentes registros de agresiones (Fernández Aparicio, 2008). La homogeneización de los datos obtenidos parece indispensable para poderlos cruzar y llegar a conclusiones válidas (De-SanSegundo et al., 2016).

No existen tampoco estudios de tipo descriptivo que abarquen todo el territorio nacional. A nivel estatal, la Comisión de recursos humanos del SNS (Informe del grupo de trabajo de agresiones a profesionales del SNS) afirmó en 2014 que se había encontrado con dificultades para el tratamiento de los datos y la obtención de una visión global del problema. Esto fue debido a la falta de homogeneidad de los datos recogidos y aportados por los diferentes registros de las Comunidades Autónomas.

La creación de un registro estatal que aglutinara todos los incidentes producidos en las Comunidades Autónomas sería un paso importantísimo a la hora de procurar una mejora en la investigación de la naturaleza del fenómeno y las medidas implantadas.

Pero no debemos olvidar que, de no reducirse el porcentaje de «infra-registro» existente, de nada serviría contar con un registro nacional, puesto que tampoco podríamos tener la totalidad de los sucesos a estudiar (lo cual sería lo óptimo deseable). 
Resulta, por tanto, imprescindible reducir ese porcentaje al mínimo posible, mediante campañas de concienciación y el establecimiento de medidas que aumenten la confianza de los profesionales en los sistemas de reacción ante una agresión y en las propias instituciones.

Sólo con una conciencia clara de que notificar los actos violentos es útil y eficaz, puede conseguirse que realmente se registren todos los incidentes.

Por otra parte, hay que ser consciente que las agresiones deben ser tratadas en dos momentos temporales concretos:

- Antes de producirse, precisamente para intentar evitar que acontezcan. Por definición, aquí se incluirían todas las medidas preventivas.

- Después de ocurrida la agresión. El que no se haya evitado, no tiene que llevar a abandonar la ejecución de actuaciones.

En este segundo aspecto, lo obligado es orientar la acción en dos direcciones: minimizar los efectos que se hayan producido en la salud de la víctima a todos los niveles y actuar sobre el agresor. Respecto a la primera dirección, como hemos visto, algunos estudios centran su interés en las consecuencias sobre la salud del trabajador (en especial las psíquicas, por ser este un tema tradicionalmente minusvalorado). Este es un tema que resulta de gran interés, sobre todo porque en algunos casos llama la atención sobre la posible relación entre la producción de nuevas agresiones y el estado de salud psíquica del agredido.

Hay pocos trabajos encaminados a saber cómo funcionan y qué alcance tienen los instrumentos legales aplicables sobre el autor de la agresión. Los estudios que se han hallado al respecto se enfocan hacia:

- Utilizar las denuncias presentadas para el análisis de las características de las actuaciones violentas y las penas que se impusieron (García Calvo, 2013).

- La evolución de las medidas penales aplicadas y las perspectivas ofrecidas tras la reforma del Código Penal de 2015 (De Juan-Mazuelas, 2016), junto con las consecuencias derivables de dicha reforma (Sánchez-Benito \& De Juan-Mazuelas, 2017).

- La polémica doctrinal surgida como consecuencia de la aplicación del delito de atentado a las agresiones padecidas por los profesores y personal sanitario del ámbito público ${ }^{19}$.

Creemos que la profundización en el conocimiento de las distintas normas aplicables, el tratamiento sancionador (sus consecuencias reales y su alcance disuasorio) y, en definitiva, el

\footnotetext{
${ }^{19}$ De Juan-Mazuelas (2016), Fernández Aparicio (2008), Nistal Burón (2008), Urruela Mora (2016), Martínez-Zaporta Aréchaga \& Fernández-Delgado Momparler (2008).
} 
funcionamiento del marco legal que se proyecta sobre este tipo de agresiones es una línea de investigación que debe ser desarrollada.

\section{JUSTIFICACIÓN DEL ESTUDIO Y OBJETIVOS}

La escasez en número de los trabajos que ofrecen una perspectiva jurídica de las agresiones cometidas contra el personal sanitario desvela un campo de investigación fructífero. Como acabamos de señalar, existen aún importantes parcelas de análisis en las consecuencias legales que generan las agresiones.

Por otra parte, tampoco se dispone de una visión global de los instrumentos jurídicos creados para combatir el problema y generar soluciones apropiadas, tanto para su prevención como para su tratamiento posterior.

En cuanto a los verdaderos protagonistas de la cuestión, es decir, de los afectados, no poseemos una idea cierta de cuáles son sus opiniones referentes a las medidas tomadas, las actuaciones emprendidas $\mathrm{y}$, en fin, los mecanismos legales y reglamentarios que se han puesto a su disposición. Ni tan siquiera sabemos qué grado de información tienen los profesionales sanitarios respecto a estas cuestiones y, por tanto, hasta qué punto pueden o desean hacer uso de los instrumentos habilitados para su protección y resarcimiento.

En nuestra opinión, resulta necesario ofrecer de un lado esa panorámica general de cuál es la normativa que opera en España en materia de agresiones al personal sanitario. En segundo lugar, conocer desde un punto de vista práctico cómo funcionan esas herramientas jurídicas de forma concreta.

De otro lado, consideramos de interés contar con la valoración y opiniones de las personas más directamente interesadas: los propios profesionales de la salud.

Como posibles limitaciones del estudio, debemos señalar las siguientes:

En primer lugar, las derivadas del uso de un cuestionario autoadministrado para la realización de la encuesta, así como las propias del método de encuesta como instrumento de recogida de información, aunque, como detallamos en el capítulo de «Material y métodos», se ha procurado disminuir los posibles sesgos que son bien conocidos en el uso de esta herramienta. Asimismo, hay que hacer constar que se trata de una encuesta pilotada y no validada.

En segundo lugar, existen limitaciones en la recogida de resultados en las bases de datos de jurisprudencia, por lo que no nos ha resultado posible acceder a la totalidad de las resoluciones 
que se han dictado sobre las materias objeto de examen. Por un lado, las bases de datos de las diferentes editoriales sólo hacen constar en sus contenidos aquellas resoluciones que resultan de interés práctico en cuanto a su actualidad o cuando cambia el criterio predominante de la doctrina jurisdiccional. Por otro, el CENDOJ no contiene tampoco todo el corpus jurisprudencial de las resoluciones dictadas por los distintos órganos jurisdiccionales, puesto que las Audiencias Provinciales no remiten a esta base de datos todo su material.

Por último, cabe pensar que en lo relativo al análisis causal de las agresiones, no poseemos datos de la perspectiva de los agresores, por lo que en realidad estamos dando una visión exclusivamente desde el punto de vista de los profesionales sanitarios. Esta otra perspectiva es algo que sale fuera de los objetivos de este estudio, pero que creemos muy interesante desarrollar en futuras investigaciones.

Lo que se pretende en este estudio es, por tanto, lo siguiente:

- Ofrecer una visión global y lo más completa posible de cuál es el marco jurídico existente en España en relación con las agresiones al personal sanitario.

- Entender cómo funcionan en la práctica las diferentes ramas del ordenamiento jurídico a la hora de tratar estos sucesos violentos.

- Comprender los mecanismos de ejecución de las diversas disposiciones legales que se encuentran en relación con el tema.

- Conocer cuáles son las medidas jurídico-preventivas que se llevan a efecto.

- Dar un panorama general de las distintas responsabilidades que se generan cuando se produce una agresión contra el profesional sanitario.

- Analizar las diversas medidas sancionadoras que se pueden desarrollar a partir de la producción de un hecho violento contra un trabajador sanitario.

- Conocer el funcionamiento de las acciones penales contra los autores de agresiones contra los profesionales de la salud.

- Estudiar las agresiones sufridas por los profesionales encuestados, en relación con la opinión que expresan sobre las medidas de prevención y protección adoptadas.

- Analizar la valoración por parte de estos profesionales acerca de las distintas actuaciones realizadas por diversas instituciones y colectivos contra la violencia en el sector sanitario.

- Profundizar en la evaluación realizada por los profesionales encuestados de las distintas acciones legislativas encaminadas a la punición y sanción de las conductas violentas. 
II. MATERIAL Y MÉTODOS 
Este trabajo se sustenta en dos pilares principales. EI primero, dedicado al estudio del régimen jurídico vigente en la actualidad en materia de agresiones a los profesionales sanitarios, describe y analiza las diferentes disposiciones legales y reglamentarias relativas al tema en los órdenes laboral, administrativo, civil y penal de nuestro ordenamiento jurídico, junto con la efectiva aplicación por los tribunales de esta normativa, que es estudiada a través de la jurisprudencia.

En la rama laboral, se atiende a tres núcleos principales: la regulación de la protección de los trabajadores a través de la prevención de riesgos laborales, el cuerpo normativo del accidente de trabajo y sus consecuencias y el régimen de responsabilidades empresariales derivadas de los dos núcleos legislativos anteriores (en el que se incluirán todo tipo de responsabilidades, también generadas en otras ramas del ordenamiento: penal, civil, administrativa).

El Derecho administrativo comprende en nuestro trabajo otros tres bloques: el estudio de la normativa dictada en materia de derechos y deberes de usuarios y profesionales sanitarios, el Derecho administrativo sancionador de las agresiones y la aplicación de la responsabilidad patrimonial de la Administración en esta materia.

El Derecho penal tratará de la punición de las conductas agresoras a través de los tipos penales de aplicación, con especial interés en el delito de atentado. Se incidirá, sobre todo, en el tratamiento de estas agresiones a partir de la reforma del Código Penal de 2015.

La jurisprudencia tendrá un papel importante, puesto que ilustra cómo funciona todo este marco jurídico en la práctica. El material jurisprudencial tendrá trascendencia a lo largo de todo el trabajo, pero muy especialmente en lo relacionado con el bloque de Derecho penal.

La normativa dictada por la Comunidad Autónoma de Castilla y León se incorporó en un apartado independiente, debido a que el estudio del segundo pilar del trabajo (que veremos más adelante) está centrado en profesionales que prestan sus servicios en su ámbito territorial. Por esta razón, y con la finalidad de ofrecer una visión unificada y no dispersa de las disposiciones que afectan concretamente al grupo de encuestados, se decidió dedicar un epígrafe exclusivamente a este cuerpo normativo.

Para el estudio de este primer pilar (el régimen jurídico de las agresiones al personal sanitario) se recopilaron las distintas normas vigentes al respecto, así como la bibliografía relativa a la doctrina científica correspondiente, para lo que se han utilizado principalmente las siguientes bases de datos y fuentes de información normativa:

- $\quad$ Tirant On-Line.

- Thomson-Reuters Aranzadi. 
- Lexnova.es

- www.boe.es

- www.noticiasjuridicas.com

- Boletines oficiales de las Comunidades Autónomas.

- Portales de las Consejerías de Sanidad de las Comunidades Autónomas.

- Google académico.

- Dialnet.

- Scielo.

- PubMed

- SCOPUS

La búsqueda de resoluciones judiciales aplicables a los diferentes apartados del trabajo se realizó igualmente a través de bases de datos (esta vez específicamente de rastreo de jurisprudencia):

- CENDOJ (Centro de documentación del Consejo General del Poder Judicial).

- Base de datos jurisprudencial Aranzadi digital.

- Base de datos jurisprudencial Tirant lo Blanch on line.

- Base de datos jurisprudencial Vlex.

- Base de datos jurisprudencial Iustel.

- Base de datos jurisprudencial La Ley digital.

El segundo pilar de nuestro trabajo se basa en las vivencias de los profesionales de la salud en cuanto a las agresiones que se producen contra ellos y cómo valoran las acciones emprendidas para su prevención y sanción.

Como herramienta para obtener información relacionada con estos aspectos, se utilizó un cuestionario, cuyas características se describen a continuación.

\section{ENCUESTA}

En la encuesta participaron un total de 655 profesionales de la sanidad ${ }^{20}$, de los siguientes grupos: facultativos, enfermeras, TCAE, celadores, técnicos de Emergencias, logopedas, psicólogos, fisioterapeutas y odontólogos.

\footnotetext{
${ }^{20}$ Todos ellos prestaban sus servicios en Valladolid, dentro del ámbito de gestión sanitaria del Servicio de Salud de Castilla y León (SACYL). Por esta razón, como se ha observado, se prestó una atención específica a la normativa y medidas desplegadas en esta Comunidad autónoma. De igual modo, las preguntas de la encuesta que estaban
} 
El cuestionario se colocó en una plataforma de internet, en la que permaneció disponible durante un periodo de un mes. Su difusión se realizó a través de los Colegios profesionales de Médicos, Psicólogos, Logopedas, Fisioterapeutas y Odontólogos, así como los sindicatos CCOO, CGT, CSIF, SAE, SATSE y UGT, con el objetivo de no acceder nunca a datos personales de los encuestados y garantizar así el máximo anonimato y privacidad.

Con el método de poner a disposición el formulario en internet, se pretendía dotar a los encuestados de suficiente autonomía, al permitir que cada participante pudiera rellenar el formulario a su ritmo y cuando le resultara más cómodo. Todo ello con el propósito de lograr una mayor calidad en la respuesta.

Los cuestionarios autoadministrados por internet permiten además una menor aquiescencia, menor efecto complacencia ${ }^{21}$ y una participación mayor de personas más ocupadas (como puede serlo el colectivo objeto de estudio en este trabajo).

Este cuestionario comenzaba con un breve mensaje de presentación en el que se agradecía la participación en la misma y también se recordaba que el anonimato y la privacidad quedaban absolutamente garantizados (para ver la presentación de la encuesta, remitimos al Anexo III).

Cada pantalla presentaba una sola pregunta y el encuestado avanzaba a la siguiente mediante la pulsación de un botón en la parte inferior derecha de la pantalla. En caso de que no se hubiera completado la respuesta a la pregunta (en el supuesto de que esta hubiera sido requerida obligatoriamente), aparecía un mensaje de aviso.

\section{DISEÑO Y ESTRUCTURA DEL CUESTIONARIO}

El cuestionario estaba constituido por un total de 30 preguntas, divididas en tres bloques. La duración media para completarlo fue de 15-20 minutos

Las preguntas se limitaron a una sola idea o referencia, evitando también la formulación de respuestas que contuvieran dos o más ideas diferentes.

Se procuró no utilizar preguntas que condicionaran el sentido de la respuesta de algún modo, y tampoco el uso de palabras con fuerte contenido emocional u opciones de alto consenso social,

referidas a actuaciones concretas se centraron en acciones llevadas a cabo en este ámbito territorial, por ser las que afectan a los profesionales encuestados.

${ }^{21}$ El efecto aquiescencia es aquel que se produce cuando el entrevistado tiende a contestar a las preguntas lo que cree que el entrevistador desea oír, y el de complacencia al dar respuestas más aceptadas socialmente o más «políticamente correctas». Ambos efectos se suponen de menor intensidad en un cuestionario autoadministrado por la intimidad en que se encuentra el entrevistado al responder y por un mayor anonimato. 
con la misma finalidad de no influenciar en de la respuesta o que se produjeran respuestas estereotipadas.

En cuanto a su tipología, las preguntas han sido dicotómicas, multidicotómicas y multidicotómicas de respuesta múltiple, siendo además mayoritariamente cerradas (sólo la última pregunta es abierta). Las alternativas de respuesta fueron mutuamente excluyentes y complementarias.

En aquellas en que se ofrecían respuestas estructuradas en escalas tipo Likert, se utilizó un número par de categorías, con el objeto de eliminar la opción «neutral».

Los ítems fueron redactados de forma que exigieran el menor grado de esfuerzo mental posible.

Para evitar los efectos primacía y recencia (mayor probabilidad de elegir la primera o la última opción) se utilizó un sistema de aleatorización de las categorías de respuesta, de modo que en cada acceso el orden de las mismas era diferente.

Se siguió una lógica temática, utilizando una secuencia «de embudo» (de lo más general a lo más específico).

Se utilizó un sistema de lógica de preguntas, por el que, en algunas de las cuestiones se redireccionaba al encuestado según hubiera elegido una opción u otra. En concreto, las respuestas «No» $\mathrm{y}$ «No lo sé/no estoy seguro» de la pregunta $\mathrm{n}^{\circ} 6$ dirigían a la pregunta $\mathrm{n}^{\circ} 15$, y la respuesta «No» a la pregunta $\mathrm{n}^{\circ} 15$, a la $\mathrm{n}^{\circ} 17$.

En cuanto a su estructura, el cuestionario estaba organizado en tres bloques de preguntas, como ya hemos anticipado:

El BLOQUE I tenía un objetivo clasificatorio y constaba de 5 preguntas referidas a datos personales y profesionales del entrevistado (edad, sexo, categoría profesional y ámbito sanitario en que realiza sus actividades).

En concreto, se preguntaba:

Pregunta 1: Edad.

Pregunta 2: Sexo (Hombre/Mujer).

Pregunta 3: Grupo/categoría profesional (Facultativo/Enfermera/o (ATS, DUE, CRUE)/ Auxiliar o Técnico de Enfermería/Otra. 
Pregunta 4: Presta Vd. sus servicios/realiza sus actividades en... (Sanidad Pública/Sanidad Privada/Ambas).

Pregunta 5: Trabaja Vd. en... (Atención Primaria/Atención

Especializada/Emergencias/Atención de tipo psicológico-psiquiátrico/Otros (indicar).

La opción Otros (indicar), dio como resultados: Sanidad Militar (17), Centros de reconocimiento (5), docentes (6), Medicina del Trabajo y prevención de riesgos (7), geriátricos y atención a personas mayores (26), Mutuas (4), Administración sanitaria y sindicatos (5), Gestión (4), asistencia social y ONG (4) y un conjunto de situaciones diversas en que serían destacables un jubilado, un médico forense, un sanitario del ámbito penitenciario y un profesional que se encontraba en paro en el momento de realizar la encuesta.

El BLOQUE II (11 preguntas) pretendía recabar información sobre la experiencia personal de cada encuestado en materia de agresiones: si había sido o no víctima de alguna agresión (en caso afirmativo, se interrogaba sobre la tipología de la agresión, el número de agresiones recibidas, las posibles causas, la tipología del agresor y la actuación posterior del agredido). También se inquiría sobre si el entrevistado había sido testigo de alguna agresión, y la posibilidad de ser agredido en el futuro.

Las preguntas fueron:

Pregunta 6: ¿Ha sufrido Vd. algún tipo de agresión (física o verbal) en su trabajo? (Sí/No/No lo sé-no estoy seguro/a).

La respuesta a esta pregunta condicionaba la continuación del cuestionario, remitiendo a la $\mathrm{n}^{\mathrm{o}} 6$ en caso de respuesta afirmativa y a la 15 , en las otras dos opciones.

Pregunta 7: ¿Cuántas veces ha sufrido una agresión física (golpes, empujones, zarandeos, etc.)? (Ninguna/ $1 \mathrm{vez} / 2$ veces $/ 3$ veces/más de 3 veces).

Las opciones de cantidad se establecieron en intervalos de 1 . Se consideró que más de tres veces englobaba un número suficiente para ser estimado como pluriagresión.

Pregunta 8: ¿Cuántas veces ha sufrido una agresión verbal (insultos, amenazas, etc.)? (Ninguna/1 vez/2 veces/3 veces/más de 3 veces).

En esta pregunta se optó por utilizar el término «verbal», en vez de «psíquica», porque, aunque este último término es más preciso para describir este tipo de agresiones, se entendió que «verbal» podría ser de mayor claridad conceptual y que así se eliminaba el riesgo de que el encuestado 
percibiera que se le estaba preguntando por las consecuencias psíquicas de la acción y no por el tipo de acción en sí misma.

Pregunta 9: ¿Quién o quiénes le agredieron? (Puede señalar varias opciones).

Las opciones ofrecidas fueron: Paciente/Familiar o acompañante de paciente/Compañero/a u otro miembro del personal del centro de trabajo/Otro (señalar).

Esta pregunta pretendía indagar en la tipología del agresor y se daba la posibilidad de marcar varias opciones, debido a que, en caso de que la persona hubiera sido víctima de más de una agresión, obviamente los agresores podían pertenecer a varios de estos grupos.

La opción «Otro (señalar)» devolvió como respuestas más significativas: viandantes, paciente de otro médico, personal de Emergencias sanitarias y personal de seguridad.

Pregunta 10: Por favor, señale el sexo del/a autor/a de la/as agresión/es. (Hombre/Mujer)

Como en la pregunta anterior, se daba la posibilidad de señalar varias respuestas, por idénticas razones, y podía responderse: Nunca/Una vez/dos veces/tres veces/más de tres veces.

Pregunta 11: A su juicio, los desencadenantes/motivos de la conducta agresiva pudieron ser:

Las opciones eran:

- Sin motivos aparentes.

- Disconformidad del autor con la asistencia recibida.

- Enfermedad psiquiátrica.

- Tiempo de espera prolongado.

- Peticiones insatisfechas.

- Falta de información o problemas de comunicación.

- Nerviosismo/estrés.

- El paciente valora sus derechos y no sus deberes.

El encuestado valoraba cada opción mediante una escala tipo Likert: No tuvo nada que ver/ Tuvo algo que ver/Tuvo mucho que ver/Fue sin duda el desencadenante.

Pregunta 12: Los sucesos se produjeron (puede marcar varias opciones) en:

- Urgencias.

- Pasillo. 
- Vía pública.

- Hospitalización.

- Puertas.

- Mostrador.

- Domicilio del paciente.

- Otro lugar (indicar).

Se ofrecía la posibilidad de elegir varias opciones para los casos en que se había producido más de una agresión. La elección de las opciones se realizó en base a los lugares que se muestran como ubicaciones de los actos violentos en la mayoría de los estudios. «Otro lugar» devolvió: 8 agresiones por teléfono, 5 en residencias geriátricas y 9 en diferentes espacios de los centros (salones, comedores, baños, salas de televisión, ascensor).

También se han expresado agresiones en un quirófano, en una sala de sesiones, en una habitación de residente, en una sala de diálisis, en la ambulancia, en el botiquín y en el Servicio de Atención al Paciente. Asimismo, se señalan un anónimo con amenazas y una agresión a través de la prensa escrita.

Pregunta 13: ¿Qué medidas tomó tras el suceso o sucesos? (puede marcar varias opciones).

La razón por la que se permitía optar por varias respuestas es idéntica a la de la pregunta anterior, dándose las opciones siguientes:

- Lo comuniqué a la Dirección/Coordinación del centro.

- Lo denuncié a mi Colegio Profesional.

- Lo denuncié a la Policía/Guardia Civil/Juzgado.

- No tomé ninguna medida (indique la razón).

La última opción, abierta, una vez examinadas las respuestas producidas, fue categorizada del siguiente modo:

1. Sentimiento de falta de apoyo: el encuestado manifiesta que no hizo nada porque no se sentía respaldado.

2. No servir para nada/pérdida de tiempo: respuestas que denotan que el entrevistado opina que es inútil comunicar la agresión o denunciarla.

3. Decisión personal: el encuestado dice no haber tomado medidas por propia decisión, sin explicar nada más. 
4. Temor a que empeore la situación: respuestas centradas en el miedo del encuestado a posibles represalias provenientes del agresor, a que se genere mal ambiente en su trabajo, etc.

5. Considerarlo no grave o parte del trabajo: aquí se agrupan las respuestas descriptivas de un sentimiento de que las agresiones son algo cotidiano, fútil, que hay que soportar con resignación. Algunos de los entrevistados señalan que la agresión se produjo cuando nadie daba importancia a estos hechos violentos, por ser aislados y poco frecuentes.

6. Falta de información: respuestas enfocadas en que la víctima no supo qué hacer porque no sabía las posibilidades que se le ofrecían o las medidas a tomar.

7. Violencia interna: se manifiesta que, cuando la agresión procede de un compañero, el entrevistado tiene resistencia a denunciar los hechos.

8. Enfermo psiquiátrico o en circunstancias especiales: el agredido señala que no tomó medidas porque entendió que el agresor no cometió el acto intencionalmente o con plena responsabilidad, debido a estar bajo los efectos de su propia patología psíquica, de sustancias estupefacientes, o sometido a una situación de máximo estrés.

9. Otros. Los más destacados: «Porque fui capaz de reconducir la situación» (tres casos), «Se lo comuniqué a la madre, que tomó las medidas oportunas», «Realicé una anotación subjetiva en la historia clínica», «Tomar clases de defensa personal: Krav Maga», «Dejar autobús, utilizar coche privado», «Me fui del trabajo porque no aguantaba más», «Para no dar voz al conflicto».

10. NS/NC.

Pregunta 14: Con motivo de la agresión sufrida:

- Me sentí apoyado/a por la Dirección/Coordinación del centro.

- Me sentí apoyado/a por mis compañeros/as.

- Me sentí apoyado/a por el resto del personal.

Estas tres posibles respuestas se midieron con una escala Likert de cinco puntos, que eran los siguientes:

1. Nada.

2. Poco.

3. Algo.

4. Mucho.

5. Completamente.

Aquí se trataba de medir el grado de apoyo percibido por parte del agredido, independientemente de que hubiera o no denunciado los hechos. 
Pregunta 15: ¿Ha presenciado alguna agresión (física o verbal) contra otro miembro del personal del centro? (Sí/No).

La pregunta se enfocaba en conocer la posible magnitud del fenómeno, tratando de abarcar los casos en que el encuestado ha sido o no agredido, pero además si fue testigo de otra agresión. Se intenta así recuperar información acerca de posibles agresiones no visibles en la encuesta por no participar la víctima en la misma.

La respuesta «No» dirigía a la pregunta 17.

Pregunta 16: ¿Cuántas veces ha presenciado alguna agresión (física o verbal) contra otro miembro del personal del centro? ( 1 vez/2 veces/ 3 veces/más de 3 veces).

Se trataba de cuantificar en cierta medida los actos violentos presenciados, pero no declarados por los agredidos no participantes en la encuesta.

Pregunta 17: Señale hasta qué grado cree posible ser víctima de una agresión (o volverlo a ser).

El objetivo de esta cuestión era indagar sobre si el personal sanitario percibía o no el sentimiento de que existía la posibilidad de sufrir algún tipo de ataque. Se midió mediante una escala tipo Likert de cuatro puntos: Imposible/Poco probable/Bastante probable/Con seguridad.

Por último, el BLOQUE III (13 preguntas) se centraba en obtener la opinión y valoración del encuestado sobre las medidas tomadas desde diferentes ámbitos normativos, así como el eventual uso que podría hacer de ellas. Concretamente se preguntaba sobre:

- Valoración de diferentes medidas preventivas y sancionadoras adoptadas.

- Conocimiento que declara tener el encuestado sobre sus derechos y las actuaciones que puede seguir.

- Intención de denuncia y motivos para no denunciar, en caso de respuesta negativa.

- Posible autorización a la Administración para incoar expediente sancionador y envío de carta de rechazo.

- Consideración de Autoridad del personal sanitario de Castilla y León: valoración general de la figura, consecuencias que cree el entrevistado que conlleva tal denominación, opinión sobre la no aplicabilidad a la sanidad privada.

- Valoración de la actuación de diferentes instituciones en cuanto a la defensa contra las agresiones.

- Opinión sobre eficacia de medidas sancionadoras, educativas y organizativas.

- Opinión sobre la incidencia de las últimas reformas legislativas penales. 
- Pregunta abierta: sugerencias de otras medidas a tomar para atajar las eventuales agresiones.

Pregunta 18: Por favor, indique el grado de eficacia que Vd. piensa que tienen las medidas siguientes para atajar las posibles agresiones.

- Cursos de autodefensa personal (física).

- Envío de carta de rechazo al agresor.

- Botón de alerta.

- Colocación de carteles disuasorios e informativos.

- Sanciones administrativas.

- Actuación de la Justicia (sanciones penales).

- Teléfono de asesoramiento jurídico.

- Cursos de formación: habilidades de comunicación, técnicas de detección de conductas violentas, etc.

- Reasignación de los agresores reincidentes a otros centros o profesionales.

- Salidas alternativas de las consultas.

- Existencia de personal de seguridad en el centro.

- Colocación de videocámaras.

Como se ve, se trata de una miscelánea de actuaciones de protección incluidas en diferentes Planes de Prevención, así como aquellas que establecen distintas consecuencias para los actos agresivos, entre las que se encuentran algunas de naturaleza sancionadora. La selección de estas medidas se hizo atendiendo a la frecuencia con la que se proponen en las distintas normativas autonómicas y, muy especialmente, a aquellas que se establecen en Castilla y León (ámbito autonómico al que, como hemos anticipado, pertenecían las personas encuestadas).

Los cursos de autodefensa personal (física) es una medida que se propone por parte de algunos autores. Ferro Veiga (2012) defiende la necesidad de ofrecer este tipo de formación a los profesionales, otorgándole un alto grado de eficacia. En atención a estas opiniones, decidimos preguntar a los encuestados sobre su valoración al respecto.

La evaluación de las distintas medidas propuestas se realizó mediante una escala tipo Likert de 7 puntos:

1. Completamente ineficaz.

2. Ineficaz.

3. Poco eficaz.

4. Eficaz. 
5. Muy eficaz.

6. Extraordinariamente eficaz.

7. No lo sé.

Pregunta 19: Ante una agresión:

- ¿Conoce Vd. los derechos que le asisten? (Sí/No/No lo sé).

- ¿ ¿Sabe cuáles son las actuaciones que puede Vd. seguir? (Sí/No/No lo sé).

Esta pregunta, bifurcada en dos cuestiones, pretendía indagar sobre la percepción de los encuestados acerca de si la información con la que cuentan en materia de conocimiento de sus derechos y sobre lo que deben hacer en caso de sufrir una agresión es o no satisfactoria. Es decir, no se trataba de valorar hasta qué punto están o no informados, sino si sienten que lo están. Resulta, por supuesto, una cuestión muy subjetiva, pero que deviene importante a la hora de conocer el grado de satisfacción de los profesionales respecto de las actuaciones de la Administración Pública en materia de divulgación de las medidas tomadas para atajar las agresiones $^{22}$.

Pregunta 20: ¿Denunciaría Vd. una agresión ante la Policía/Guardia Civil o Juzgado? (Sí/No).

El objetivo de esta cuestión fue la disposición de los encuestados a poner los hechos en manos de la Justicia.

La respuesta «Sí» dirigía al encuestado a la pregunta 22.

Pregunta 21: Por favor, señale el motivo por el que no denunciaría una agresión (puede elegir varios).

Esta cuestión iba dirigida a conocer las motivaciones de la resistencia del encuestado a denunciar los hechos. Obviamente, se dirigía solamente a quienes hubieran respondido «No» en la pregunta anterior.

Se permitía marcar varias opciones, puesto que varias pueden ser también las motivaciones en estos casos. Los motivos podían ser los siguientes:

- «Creo que son riesgos que forman parte del trabajo».

- «Temo posibles represalias por parte del agresor».

- «Me preocupa que se piense que no soy capaz de manejar situaciones conflictivas».

\footnotetext{
${ }^{22}$ En referencia a este punto, Ortells Abuyé et al. (2013) insisten en que la difusión de los protocolos es fundamental.
} 
- «Me parece que conlleva un esfuerzo excesivo».

- «No sirve para nada».

- Otro motivo: indíquelo.

Para seleccionar estos posibles motivos se recurrió a los hallazgos obtenidos en otras investigaciones ${ }^{23}$.

Pregunta 22: Sólo Sanidad Pública: En caso de agresión, ¿autorizaría Vd. a la Gerencia de Salud a enviar una carta de rechazo al agresor? (Sí/No. Por favor, diga la causa).

La pregunta iba dirigida, como se expresaba de forma explícita, únicamente a los profesionales de la Sanidad Pública. Esto es debido a que la llamada «carta de rechazo» es una medida instaurada por la Gerencia de Salud de Castilla y León, de aplicación exclusiva a las agresiones producidas contra su personal.

Consiste en una carta en la que se expresa al protagonista de la agresión el rechazo de la institución hacia los hechos acaecidos, se le explican las consecuencias que podrían derivarse de sus actos y se le insta a que no vuelva a repetir su conducta. La medida sólo se aplica en caso de que el agresor sea conocido (obviamente) y requiere la autorización por parte de la víctima. De ahí que la pregunta vaya dirigida a conocer si los profesionales de la Sanidad Pública del ámbito en que se ha realizado la encuesta están dispuestos a utilizar este recurso o, en caso negativo, las razones por las que no lo harían.

La opción «No» era abierta y de texto libre. Se categorizaron las respuestas según lo siguiente:

0 . No contesta.

1. Sí.

2. No. Miedo a represalias.

3. No. Ineficacia de la medida.

4. No. Desconocimiento de en qué consiste la medida.

5. No. No sabe.

6. No. Otros.

Pregunta 23: Sólo Sanidad Pública. Si sufre Vd. una agresión, ¿solicitaría de la Administración que incoe un expediente sancionador al agresor? (Sí/No. Por favor, diga la causa).

\footnotetext{
${ }^{23}$ Hemos realizado un resumen general de los resultados obtenidos por otros autores en el capítulo «Introducción y objetivos», donde puede verse cómo muchas de estas motivaciones se encuentran reflejadas en esos estudios.
} 
$\mathrm{Al}$ igual que la anterior, esta pregunta iba únicamente dirigida al personal que presta sus servicios en el ámbito de la Sanidad Pública. La razón es la siguiente: por Ley 8/2010, de 30 de agosto, de Ordenación del Sistema de Salud de Castilla y León se establece un régimen administrativo sancionador, de aplicación directa sobre las agresiones al personal sanitario en la Comunidad Autónoma en que trabajan nuestros encuestados, que se consideran infracciones administrativas y conllevan sus correspondientes sanciones. Aquí se trata de averiguar en qué medida los profesionales sanitarios afectados son partidarios de iniciar el procedimiento administrativo sancionador habilitado por la normativa citada.

Las causas por las que los encuestados manifestaron que no solicitarían la incoación de un expediente administrativo sancionado se categorizaron del siguiente modo:

0 . No contesta.

1. Sí.

2. No. Miedo a represalias.

3. No. Ineficacia de la medida.

4. No. Desconocimiento de en qué consiste la medida.

5. No. No sabe.

6. No. Otros.

Las tres preguntas siguientes $(24,25$ y 26$)$ indagan sobre el conocimiento y la evaluación por parte de los profesionales sanitarios de la atribución de la condición de Autoridad al personal sanitario de la sanidad pública en varias Comunidades Autónomas.

Pregunta 24: ¿Cómo valora Vd. la consideración del personal sanitario de la sanidad pública de Castilla y León como Autoridad?

Esta cuestión iba dirigida tanto al ámbito de la Sanidad Privada como de la Pública ya que, aunque la medida por la que se pregunta sólo es de aplicación a este último, interesa saber cómo evalúan los dos colectivos su posible efectividad.

Las opciones de respuesta se estructuraron en una escala de Likert de 5 puntos:

1. Nada importante.

2. Poco importante.

3. Importante.

4. Muy importante.

5. No lo sé.

Pregunta 25: ¿Qué consecuencias cree Vd. que pueden derivarse de esa condición de Autoridad? 
a) Genera mayor respeto y consideración por parte de los usuarios.

b) Por tener la posible víctima la condición de Autoridad, las agresiones se consideran siempre delito de atentado y se castigan con penas de prisión.

c) Se otorga presunción de veracidad a la declaración del profesional agredido en los procedimientos administrativos y penales.

d) La condición de Autoridad determina que, tras una agresión, las sanciones administrativas pueden ser más graves.

El objeto de esta pregunta era averiguar hasta qué punto los profesionales están informados sobre lo que significa poseer la condición de autoridad (otorgada a nivel autonómico). Se permitía marcar varias opciones, y lo destacable de la estrategia de esta cuestión es que dos de ellas son erróneas:

La b) plantea una premisa falsa, relacionada con el estado de confusión generada por medios de comunicación e, incluso, por declaraciones de representantes institucionales, que identifican la aplicación del delito de atentado contra funcionario público (caso del personal de la sanidad pública) con la que se da cuando la víctima tiene la condición de autoridad. Del mismo modo, el término «Autoridad» empleado por la normativa de varias Comunidades Autónomas se confunde con el concepto de «Autoridad» consagrado en el Código Penal.

Con esta opción se pretendía detectar el grado de confusión (previsiblemente alto) generado en los profesionales sobre este tema, debido a la falta de una información correcta.

La c) abunda sobre un aspecto similar: la atribución de efectos penales de una norma administrativa. La presunción de veracidad que otorga la consideración de autoridad al personal sanitario por parte de la Administración Autonómica no puede extenderse a los procesos que se sigan en la jurisdicción penal. La opción d), por el contrario, sí es correcta.

Además de todo esto, también interesaba en esta pregunta obtener información sobre si los profesionales encuestados consideran que puede ser una medida que acreciente su prestigio ante los usuarios.

Pregunta 26: Como sabrá, la consideración de Autoridad no se aplica a los profesionales de la Sanidad Privada. ¿En qué grado está de acuerdo con las siguientes afirmaciones?

- El trato es igual, en realidad. Sólo existe esa diferencia, que no es importante.

- Deberían haberse tomado otras medidas penales que afectaran por igual a la sanidad pública y privada. 
- Lo mejor es eliminar la consideración de Autoridad para que todos estén en un plano de igualdad total.

- Hay muchas más agresiones en la sanidad pública, por lo que es lógico que haya una protección mayor.

Se pedía a los encuestados que se posicionaran respecto a las frases anteriores, mediante una escala tipo Likert de cuatro puntos:

1. Nada de acuerdo.

2. Poco de acuerdo.

3. De acuerdo.

4. Muy de acuerdo.

Pregunta 27: Valore la actuación de las siguientes instituciones y colectivos en materia de defensa contra las agresiones a los profesionales sanitarios.

- Colegios Profesionales.

- Administración Autonómica (Junta de Castilla y León/SACYL).

- Administración Central (Gobierno, Ministerios, etc.).

- Sindicatos.

- Juzgados y Tribunales.

- Ministerio Fiscal.

Los participantes en la encuesta podían manifestar su evaluación al respecto mediante la elección de uno de los cuatro puntos siguientes:

1. Muy negativa.

2. Negativa.

3. Positiva.

4. Muy positiva.

5. No lo sé.

Pregunta 28: Por favor, indique en qué grado está Vd. de acuerdo con las siguientes afirmaciones:

- Las agresiones disminuirían contando con mayores medios humanos y materiales porque los usuarios estarían más satisfechos.

- Las agresiones pueden disminuir con campañas educativas e informativas.

- Aplicar penas de prisión a los agresores puede ser eficaz porque disuade de cometer nuevos actos violentos.

- Las penas de multa ejercen un efecto disuasorio en el potencial agresor. 
- Los profesionales debemos asumir nuestra parte de responsabilidad y mejorar el trato al paciente.

Mediante una escala tipo Likert de 4 puntos, el encuestado valoraba cada afirmación:

1. Nada de acuerdo.

2. Poco de acuerdo.

3. De acuerdo.

4. Muy de acuerdo.

La pregunta intentaba averiguar el grado de eficacia que atribuyen los profesionales a diferentes medidas generales que se han tomado para atajar las agresiones. Dos de ellas inquirían elementos de tipo sancionador, una de ellas incidía en la educación e información del usuario, otra sobre una mejora de cuestiones organizativas y la última sobre la percepción del profesional sobre la influencia que su actitud hacia el usuario puede tener en algún momento dado.

Pregunta 29: ¿Cree Vd. que tras las últimas reformas legislativas penales el colectivo sanitario está más o menos protegido ante eventuales agresiones? Señale si los siguientes cambios son más o menos perjudiciales/beneficiosos para esa protección:

Esta cuestión es muy concreta y se dirige a obtener información sobre qué opinan los profesionales de las medidas penales que se aplican contra las agresiones. No se trataba de averiguar hasta qué punto estaban informados de estas cuestiones (porque creíamos bastante probable que la información hubiera sido escasa o nula), sino de su valoración de cómo funciona el tratamiento de estas ofensas en la actualidad.

Por eso, se les mostraron varias consecuencias reales que operan tras la última reforma del Código Penal. Los enunciados ofrecidos para su valoración fueron solamente tres, seleccionados de entre todos los cambios en esta materia, por ser los de mayor trascendencia para el tratamiento penal de las agresiones al personal sanitario.

Se utilizó un lenguaje claro, prescindiendo en lo posible de elementos técnicos, para una correcta comprensión del contenido de las proposiciones. Con esta misma finalidad, se procuró que los enunciados fueran lo más explicativos posible, adecuando la longitud de las oraciones a la expresión de su contenido, de forma que no fueran demasiado extensas, pero que contuvieran y expresaran la información necesaria para poder valorarlas.

Para eliminar la posible connotación de términos, se optó por incluir la dicotomía «perjudicial/beneficioso», en vez de sólo uno de los dos adjetivos, que podían orientar emocionalmente en una dirección concreta la respuesta del partícipe. 
Los enunciados que los encuestados tenían que valorar eran los siguientes:

- Para que una agresión que produce lesiones pueda ser juzgada penalmente, antes no era necesario interponer denuncia y ahora sí.

- Se considera atentado a las agresiones cometidas contra el personal sanitario de la sanidad pública.

- Las injurias y vejaciones leves (insultos, etc.) salen de la Jurisdicción Penal y se enjuician por los tribunales civiles.

Se pedía su evaluación mediante una escala tipo Likert, con los puntos:

1. Muy perjudicial.

2. Perjudicial.

3. Beneficioso.

4. Muy beneficioso.

Pregunta 30: En su opinión, ¿qué otras medidas podrían aplicarse para combatir las agresiones a los profesionales sanitarios?

Esta última cuestión era abierta y buscaba indagar sobre posibles medidas no expresadas en la encuesta y que, sin embargo, los profesionales consideraran de necesaria mención.

Una vez recogidos los resultados, se procedió a categorizar las respuestas obtenidas del siguiente modo:

1. Reivindicación de un mayor apoyo por parte de la Administración/Dirección de los centros.

2. Necesidad de mejora de la calidad del sistema y de la atención al usuario.

3. Otras medidas organizativas: adecuación de los criterios de ingreso y atención, mejora de los protocolos, incidir en la relación médico-paciente, trabajar acompañado, regular de forma más estricta la entrada de visitas en los hospitales, etc.

4. Medidas de protección al trabajador.

5. Medidas enfocadas en el usuario: campañas de sensibilización, educación cívica y sanitaria, más información, etc.

6. Formación del profesional: manejo de situaciones conflictivas, habilidades de comunicación, etc.

7. Mejora del trato al paciente: respeto, empatía, etc.

8. Sanciones económicas y de prisión.

9. Otro tipo de sanciones: traslado de centro, cambio de médico, etc. 
10. Otros.

11. Imposibilidad de solucionar el problema: las agresiones son impredecibles y no se pueden atajar.

12. NS/NC.

\section{COMPROBACIÓN DE LA FIABILIDAD DEL CUESTIONARIO: PRUEBA PILOTO}

Para comprobar la fiabilidad de la encuesta, se realizó un pre-test o prueba piloto, distribuyendo el formulario entre un total de 85 profesionales sanitarios, con la finalidad de constatar si el instrumento funcionaba correctamente y afinar el propio cuestionario. El pre-test estuvo abierto durante una semana y obtuvo un total de 45 respuestas.

Los encuestados realizaron una serie de sugerencias y observaciones que fueron tenidas en cuenta para conseguir una redacción más clara de ciertas preguntas y añadir alguna opción de respuesta no contemplada en inicio.

En concreto, en las preguntas $\mathrm{n}^{\circ} 18, \mathrm{n}^{\circ} 27$, se añadió la opción «No lo sé»; en la pregunta $\mathrm{n}^{\circ} 20$ se añadió «No sabe/No contesta».

En la pregunta $n^{\circ} 20$ se sustituyó la expresión «Tengo miedo de que el agresor tome represalias» por «Temo posibles represalias por parte del agresor» porque se detectó que los encuestados no marcaban en ningún caso esta opción, posiblemente por el efecto de carga emocional de la palabra «miedo».

Se reformularon los enunciados de la pregunta $\mathrm{n}^{\circ} 20$, haciéndolos más breves y sencillos que en la versión inicial. En esta misma pregunta, fue incluida la dicotomía «beneficioso/perjudicial» en vez de uno de los dos términos, para evitar cualquier influencia positiva o negativa sobre la posible respuesta del encuestado.

Las sugerencias de varios miembros del grupo piloto también provocaron la inclusión de la opción «Los profesionales debemos asumir nuestra parte de responsabilidad y mejorar el trato al paciente» en la pregunta $\mathrm{n}^{\circ} 28$.

Se añadió más espacio de respuesta en la pregunta $n^{\circ} 30$, porque en un principio la plataforma de internet limitaba el número de caracteres, lo que no resultaba conveniente en una pregunta abierta, donde por esencia resulta necesario que el participante se exprese con total libertad y ausencia de límites de extensión. 


\section{ANÁLISIS ESTADÍSTICO}

Los datos fueron codificados en una hoja Excel y posteriormente exportados para su análisis al programa IBM SPSS Statistics 20.

En el análisis descriptivo se utilizó distribución de frecuencias para variables categóricas, y media y desviación estándar para las cuantitativas. En algunos análisis se han manejado las variables ordinales procedentes de escalas Likert como cuantitativas.

Para la comparación de medias, se utilizó la t de Student en el caso de dos categorías y ANOVA para más de dos. En este último caso se utilizó el test de Duncan como prueba para los contrastes a posteriori.

En el caso del establecimiento de la asociación de dos variables categóricas, se utilizó el test de $\chi^{2}$.

En todos los casos se consideró una $\mathrm{p}<0,05$, como nivel de significación estadística. 
III. EL DERECHO DEL TRABAJO ANTE LAS AGRESIONES AL PERSONAL SANITARIO 


\section{LA NORMATIVA SOBRE SALUD Y SEGURIDAD EN EL TRABAJO}

\section{MARCO NORMATIVO INTERNACIONAL}

El principal documento con alcance internacional suscrito por España en esta materia es el Convenio $\mathrm{n}^{\mathrm{o}} 155^{24}$, de 22 de junio de 1981, de la Organización Internacional del Trabajo sobre seguridad y salud de los trabajadores y medio ambiente del trabajo. Este Convenio, tras su ratificación, impone al Estado Español los compromisos correspondientes en la materia. Sin embargo, el Protocolo de 2002 está aún pendiente de dicha ratificación.

La importancia de este Convenio reside en su carácter general, su ámbito de aplicación muy amplio y su carácter de norma de influencia para la actual Ley de Prevención de Riesgos Laborales.

Sabadell I Bosch (2015) señala la diferenciación que establece entre dos dimensiones de la seguridad y salud laboral:

- La dimensión pública: El Convenio impone en su artículo 4 la obligación de instaurar y evaluar de forma periódica una política nacional coherente en materia de seguridad y salud de los trabajadores. Esta política tendrá como objetivo prevenir accidentes y minorizar los riesgos laborales.

- La dimensión empresarial: Se exige de los empresarios la garantía de seguridad en los lugares de trabajo, maquinaria, equipo, operaciones y procesos-Convenio núm.13, de 19 de noviembre de 1921, relativo al empleo de la cerusa ${ }^{25}$ en la pintura (instrumento de ratificación de 17 de mayo de 1924, Gaceta de 20 de mayo de 1924).

En 2003 la OIT celebró la 91 ${ }^{\text {a }}$ Conferencia Internacional de Trabajo, donde se adoptó una «Estrategia global de seguridad y salud en el trabajo». Las conclusiones de esta Estrategia se centraron en la necesaria actualización de la normativa (dotándola de mayor flexibilidad y grado de coherencia), promover la información y formación, implantar en los niveles nacionales un control eficaz del complimiento de la normativa preventiva y, como objetivo último y fundamental, reducir la siniestralidad laboral.

\footnotetext{
${ }^{24}$ Conviene aclarar que «El convenio establece principios básicos en la materia y, una vez ratificado por un Estado, tiene eficacia aplicativa directa en el mismo. La recomendación proporciona directrices más detalladas en desarrollo de un convenio existente y puede también servir como propuesta para un futuro convenio» (Sabadell I Bosch, 2015). Las recomendaciones, además, no son vinculantes para los Estados, constituyendo únicamente un complemento (aunque importante) de los convenios a los que acompañan.

${ }^{25}$ El DRAE define la cerusa como carbonato de plomo (Real Academia Española, 2001).
} 
El Convenio Núm. 187, de 15 de junio de 2006, sobre el «Marco promocional para la seguridad y salud del trabajo» (junto a la Recomendación 197 de misma fecha) se encamina de forma significativa a la promoción de la prevención y se centra en la política pública nacional (elaboración, control, aplicación y revisión de los programas nacionales de seguridad y salud que fomenten el desarrollo de una cultura preventiva). Fue ratificado por España en mayo de 2009.

\section{NORMATIVA COMUNITARIA EUROPEA}

En el seno de Europa, la normativa de defensa de los derechos de los trabajadores y, más concretamente, la protección de la seguridad y salud en el trabajo, ha tenido un objetivo de estructuración y homogeneización de las condiciones laborales entre los diferentes Estados miembros. Núñez González (2016) destaca que, junto a la humanitaria motivación de la mejora de la vida de las personas trabajadoras, coexiste otra razón más mercantilista: «...intento de que los costes productivos sean menos dispares como consecuencia de la disminución de los costes sociales (salario, seguridad social, prevención de riesgos...), con objeto de disminuir la deslocalización empresarial».

Ya en su inicio, los Tratados Fundacionales de la CEE, CECA (art. 55) y CEEA (arts. 30-39) se ocuparon de la salud y seguridad laboral, previendo actuaciones comunitarias.

Así, la normativa referente a derechos de los trabajadores en materia de seguridad tiene como principales antecedentes el propio Tratado de Roma de 1957 (fundacional de la CEE), concretamente en sus artículos 117 y 118 y también el Acta Única Europea $(1986)^{26}$.

El Tratado Fundacional otorgó a la CEE la competencia de impulsar la colaboración entre los Estados miembros en cuanto a higiene industrial y protección de accidentes de trabajo y enfermedades profesionales. Como la competencia sobre derechos y condiciones de trabajo era, en aquel momento, exclusiva de los Estados miembros, se buscaron vías alternativas en materia de protección del trabajador. El camino era propulsar una armonización técnica, con mecanismos de certificación y marca CE como requisito para la libre circulación de mercancías. La acción resultó bastante limitada debido fundamentalmente a la exigencia de unanimidad para la aprobación de medidas. El resultado de estas iniciativas tuvo, por tanto, un carácter programático, sin trascendencia en la generación de derechos para los trabajadores ni deberes para los Estados miembros.

${ }^{26}$ El artículo 118A del Acta Única Europea permite adoptar acuerdos de política social mediante mayorías cualificadas. 
El Acta Única Europea viene a modificar este panorama. Con este documento se reforma el Tratado constitutivo, reconociendo a la CEE la competencia de armonización de las normativas nacionales en los ámbitos de la protección del medio ambiente, del consumidor y de salud y seguridad. El objeto de esta modificación de competencias era el impulso al mejor funcionamiento del mercado interior. El instrumento legal será la Directiva, mecanismo de armonización legislativa. Se abandona la regla de la unanimidad, que se sustituye por la de mayorías cualificadas.

Desde ese momento, y bajo la idea de la promoción del diálogo social, asistimos a un aumento de normas de mínimos en materia de salud y seguridad laboral.

La Directiva 89/391/CEE es la que marca un antes y un después en la regulación europea sobre este tema. Por su trascendencia, se la denomina Directiva Marco y establece los mínimos preceptivos a ofrecer por parte de los Estados miembros en materia de protección de la seguridad de los trabajadores.

Las principales aportaciones de la Directiva Marco son: definición del concepto de entorno de trabajo (con referencia a la seguridad técnica y la prevención general de enfermedades, en sintonía con el Convenio 155 OIT) y establecimiento de una misma protección para todos los trabajadores (con ciertas excepciones, que recoge también la LPRL española). Se introduce el principio de adaptación del trabajo a la persona y se establecen las obligaciones empresariales y de los trabajadores en la materia.

Muy importante es la idea central de prevención, consagrando el principio de evaluación de riesgos (junto con los elementos que lo conforman: identificación del riesgo, eliminación en origen, participación de las personas trabajadoras, reevaluación periódica y documentación). Se regula, asimismo, la organización y el funcionamiento de los servicios de prevención.

Pero, siendo todo de extraordinaria importancia, quizás merezca destacarse la generación de la idea de que la seguridad afecta a todas las fases de la actividad productiva, es decir, que no es un elemento aislado, así como lo decisivo de integrar la gestión de la seguridad y salud laboral en los procesos generales de gestión empresarial.

Tras ella, fueron aprobadas varias Directivas de desarrollo. Quizás las de mayor trascendencia puedan ser las siguientes: Directiva 92/85, que protege a la trabajadora embarazada, la Directiva 91/383 sobre trabajo temporal y ETT, la Directiva 93/104 sobre el tiempo de trabajo.

Como toda Directiva, la Directiva Marco debe ser objeto de trasposición por parte de los Estados para entrar a formar parte de su ordenamiento interno, y para ello la propia Directiva concedía un 
plazo de 3 años. España no dictó norma de trasposición alguna en este sentido dentro el plazo establecido, siendo objeto de denuncia por parte de la Comisión Europea.

Finalmente, el Estado español promulgó en el año 1995 (es decir, con bastante retraso) la Ley de Prevención de Riesgos Laborales, de la que trataremos próximamente.

El Tratado de Funcionamiento de la Unión Europea (DOUE de 26 de diciembre de 2012) prevé en su artículo 151: "la Unión y los Estados miembros, teniendo presentes derechos sociales fundamentales como los que se indican en la Carta Social Europea, firmada en Turín el 18 de octubre de 1961, y en la Carta comunitaria de los derechos sociales fundamentales de los trabajadores, de 1989, tendrán como objetivo el fomento del empleo, la mejora de las condiciones de vida y de trabajo (...)", comprometiéndose a apoyar y completar la acción de los Estados miembros en “(...) la mejora, en concreto, del entorno de trabajo, para proteger la salud y la seguridad de los trabajadores"” (arts. 151 y 153).

Además debe ser considerada la existencia del Comité Consultivo para la Seguridad y la Protección de la Salud en el lugar de trabajo, con funciones de asistencia a la Comisión Europea en la preparación de actividades y aplicación de Tratados y Directivas (Decisión de 22 de julio de 2003).

Igualmente es destacable la Agencia Europea para la Seguridad y la Salud en el Trabajo (creada por Reglamento del Consejo, de 18 de julio de 1994). Su objeto es «proporcionar a los organismos comunitarios, a los Estados miembros y a los medios interesados toda la información técnica, científica y económica útil en el ámbito de la seguridad y de la salud en el trabajo». 


\section{EL ORDENAMIENTO INTERNO ESPAÑOL}

\section{LA CONSTITUCIÓN ESPAÑOLA}

La Carta Magna se constituye en auténtico eje y marco delimitador de toda la legislación en materia de protección de la salud y la seguridad en el trabajo. Además, integra en el ordenamiento constitucional los derechos humanos.

El reflejo de esta idea se encuentra concretado, en primer lugar, en el artículo 40.2 (ubicado en el Capítulo III. «Principios rectores de la política social y económica»), establece la obligación de los poderes públicos de velar por la seguridad e higiene en el trabajo.

Incardinados en este precepto, se encuentran varios artículos del texto constitucional, que remarcan, matizan y aclaran el mandato anterior.

En concreto y para empezar, el artículo 43 reconoce el derecho a la protección de la salud en su apartado 1. Incidiendo y ampliando esta cuestión, en su apartado 2 ordena a los poderes públicos «organizar y tutelar la salud pública a través de medidas preventivas y de las prestaciones y servicios necesarios», imponiendo además la reserva de Ley para su regulación.

La Constitución reconoce además una serie de derechos fundamentales, conforme a la interpretación dimanante de la Declaración Universal de Derechos Humanos y los tratados y acuerdos internacionales suscritos por España (Art. 10.2). Es dentro del Capítulo II. «Derechos y Libertades», donde encontramos uno de los artículos con más relevancia para el encuadre constitucional de la protección del trabajador.

Se trata del artículo 15, que reza literalmente: «Todos tienen derecho a la vida y a la integridad física y moral, sin que, en ningún caso, puedan ser sometidos a tortura ni a penas o tratos inhumanos o degradantes». La vida y la integridad física y moral constituyen un derecho fundamental y son merecedoras, por tanto, de la máxima protección constitucional.

El contenido de esta protección se detalla en el artículo 53, siendo de destacar la vinculación expresa de todos los poderes públicos, la reserva de ley en la regulación de los derechos y libertades recogidos en este Capítulo II, la capacidad de todo ciudadano para recabar su tutela ante los tribunales ordinarios y el TC y su carácter de informadores de la legislación positiva, la práctica judicial y la actuación de los poderes públicos.

Este derecho, como se ha señalado, es directamente invocable ante los órganos jurisdiccionales, con el límite de que se haya producido la causación de un daño o el riesgo de producción del 
mismo, siempre que esté justificado «ad casum» (Sabadell I Bosch, 2015). Señala Sala Franco (2014) que ello no significa que exista cobertura constitucional contra cualquier orden de trabajo hipotéticamente peligrosa para la salud. Pero el daño no tiene por qué haberse producido para que opere el amparo constitucional, porque de ser así se dejaría sin efecto su posible prevención, puesto que esperar a que el daño se consume hace ineficaz ex-post la tutela constitucional ${ }^{27}$.

La tutela del derecho a la vida requiere también la necesaria intervención del juicio de proporcionalidad, necesario para respetar un adecuado equilibrio en su aplicación. El citado juicio de proporcionalidad ponderará los bienes jurídicos en juego, mediante la comprobación del cumplimiento de los juicios de idoneidad, indispensabilidad y proporcionalidad estricta.

En materia de protección de la salud y seguridad del trabajador, el derecho a la vida reconocido en el artículo 15 se concreta en la obligación de no poner en peligro su salud (Nuñez González \& Estardid Colom, 2016).

Distinta es la cuestión referente al artículo 40.2, verdadero eje de la protección de la salud del trabajador, pero que no se encuadra en el Capítulo II, sino en el III. Incluido dentro de los principios rectores de la política social y económica, no goza del tratamiento privilegiado de un derecho fundamental. No obstante, informa también la legislación positiva, la práctica judicial y la actuación de los poderes públicos (Sabadell I Bosch, 2015). Concretamente, es en este artículo 40.2 en el que se basa la Ley de Prevención de Riesgos Laborales cuando impone fuertes restricciones al poder empresarial, obligando a éste a tomar medidas de prevención de riesgos para la protección del trabajador.

La inclusión del derecho reconocido en el artículo 40.2 dentro del Capítulo III determina que no se configura como un derecho subjetivo directamente exigible por parte del trabajador, sino que requiere de su desarrollo posterior por parte de los poderes públicos. No obstante, estos poderes públicos están constitucionalmente obligados a ejercitar una política activa en materia de protección de la salud y la seguridad en el trabajo.

En opinión de Sala Franco (2017), el derecho a la protección de la salud del trabajador se configura como un «derecho complejo», en parte absoluto (por la naturaleza y alcance del artículo 15) y en parte relativo. Manifiesta este autor que, en su faceta de derecho absoluto, es un derecho directamente preceptivo (artículos 53.1 y 2 CE) y de alcance general. Este alcance general significa que es aplicable a la persona en cuanto ciudadano (y no trabajador), pero ejercitable por

\footnotetext{
${ }^{27}$ STC 221/2002, de 25 de noviembre, STC 62/2007, de 27 de marzo, STC 160/2007, de 2 de julio.
} 
el trabajador dentro de su trabajo ${ }^{28}$. En su faceta de derecho relativo, posee un valor programático, con los efectos que dispone el artículo 53.3, bifurcándose en dos derechos distintos: el primero, genérico (como ciudadano), reconocido en el artículo $43 \mathrm{CE}$ y el segundo, específico (como trabajador), descrito en el artículo 40.2.

Otros preceptos constitucionales tienen también relación con la materia. Concretamente, los artículos 45.1 y 38 , que reconocen respectivamente, «el derecho a disfrutar de un medio ambiente adecuado para el desarrollo de la persona, así como el deber de conservarlo» y la libertad de empresa.

\section{EL ESTATUTO DE LOS TRABAJADORES}

El RDL 1/1995, de 24 de marzo aprueba el texto refundido del Estatuto de los Trabajadores, redacción vigente en la actualidad.

Ya en su primera redacción de 1980, el ET introduce en su artículo 19.1 el derecho a la protección en materia de seguridad e higiene laboral como una obligación contractual. También reconoce el derecho del trabajador a disfrutar de una política de seguridad e higiene adecuada y a su integridad física (artículo 4.2 letra d), reproduciendo así los preceptos constitucionales relativos a la materia. Igualmente impone a la persona trabajadora el deber de observar las medidas de seguridad e higiene adoptadas por el empresario (artículos 5 y 19.2).

\section{LEY GENERAL DE SEGURIDAD SOCIAL}

El RDL 1/1994, de 20 de junio, por el que se aprueba el texto refundido de la Ley General de la Seguridad Social tiene el siguiente contenido referente a la materia: regulación del recargo de prestaciones de la Seguridad Social por incumplimiento de las medidas de seguridad (Art. 123) y obligación de practicar reconocimientos médicos en relación con las enfermedades profesionales (Arts. 195-197).

\section{LEY DE INFRACCIONES Y SANCIONES EN EL ORDEN SOCIAL (LISOS)}

EL RDL 5/2000, de 4 de agosto, por el que se aprueba el texto refundido de la Ley sobre Infracciones y Sanciones en el Orden Social recupera la regulación de las sanciones administrativas que inicialmente fueron incluidas en la LPRL.

Regula y clasifica las infracciones administrativas de riesgos laborales en leves, graves y muy graves (artículos 11-13) y también sus sanciones (artículo 40).

\footnotetext{
28 «la celebración de un contrato de trabajo no implica, en modo alguno, la privación, para una de las partes, el trabajador, de los derechos que la Constitución le reconoce como ciudadano». STC 88/1985 (Sala Primera), de 19 de julio (Recurso de amparo 788-1984).
} 


\section{LA LEY DE PREVENCIÓN DE RIESGOS LABORALES}

La Ley 31/1995, de 8 de noviembre, de Prevención de Riesgos Laborales (LPRL) constituye la disposición central en el ordenamiento jurídico español en materia de prevención de riesgos laborales y protección de la salud del trabajador. Como se ha señalado anteriormente, fue dictada con el objetivo de trasponer al ordenamiento interno varias Directivas comunitarias ${ }^{29}$ y recoger además los compromisos asumidos por la ratificación de diversos Acuerdos y Convenios internacionales (Franco González, 2015).

Asimismo, con la LPRL se actualizan disposiciones ya obsoletas y se adaptan otras preconstitucionales al marco de la $\mathrm{CE}$, unificándose además las distintas y dispersas normativas sectoriales, que constituían un entramado complicado y de difícil aplicación práctica.

\section{CARACTERÍSTICAS}

La LPRL tiene carácter de normativa básica y constituye legislación laboral. Por ello, entra dentro de las competencias exclusivas del Estado, sin perjuicio de su eventual desarrollo de aplicación por parte de las Comunidades Autónomas.

Su extensión a todos los trabajadores por cuenta ajena alcanza al empleo en las Administraciones Públicas, por lo que es normativa básica también en el régimen administrativo o estatutario de los funcionarios públicos.

Tiene carácter de derecho mínimo indisponible (artículo 2), mejorable mediante los convenios colectivos y sirve de base para un posterior desarrollo reglamentario. Este cuerpo de derechos forma parte de los derechos básicos de los trabajadores (reconocidos en el ET, artículo 4.2) y son irrenunciables.

\section{ÁMBITO OBJETIVO}

El art. 2.1 expresa meridianamente cuál es el objeto de la LPRL: «la presente ley tiene por objeto promover la seguridad y la salud de los trabajadores mediante la aplicación de medidas y el desarrollo de las actividades necesarias para la prevención de riesgos derivados del trabajo».

Por «salud» debe entenderse el mejor estado de bienestar integral, físico, mental y social, que una persona pueda alcanzar, según la definición de la OMS. Para la OIT (Convenio 155, artículo 2), en el marco laboral, la salud «abarca no solamente la ausencia de afecciones o de enfermedad, sino también los elementos físicos y mentales que afectan a la salud».

\footnotetext{
29 Directiva 89/391/CEE, Directiva 91/533/CEE, Directiva 92/85/CEE y Directiva 94/33/CE.
} 
La protección de la salud, por tanto, se extiende hacia la existencia de un entorno de trabajo que propicie que la persona trabajadora pueda gozar de bienestar físico, mental y social. El empresario no está sólo obligado (como tradicionalmente se entendía) a evitar las enfermedades profesionales y los accidentes de trabajo. Es por esta concepción contemporánea de lo que debe entenderse incluido dentro de la protección del trabajador, por lo que tienen cabida en la misma los riesgos psicosociales.

Por todo ello, la visión es totalmente preventiva, partiendo de la actuación sobre los riesgos en origen. Esta concepción es innovadora respecto a la óptica tradicional, que perseguía principalmente el remedio de las consecuencias del daño producido. En este aspecto se encuentra en completa sintonía con la OIT (Recomendación 164, artículo 3): «dar prioridad a la supresión de los riesgos en su origen ${ }^{30} »$. En palabras de Sala Franco (2017), el enfoque es «de interiorización de que el daño es evitable».

Ha de llegarse a la conclusión, según señalan Nuñez González \& Estardid Colom (2017), de que, en la actualidad, los términos salud y seguridad en el trabajo son sinónimos a los efectos de la prevención de riesgos laborales.

\section{ÁMBITO SUBJETIVO}

El artículo 3 de la LPRL delimita su ámbito subjetivo, tomando como referencia el concepto de trabajador por cuenta ajena ${ }^{31}$. Esto supone una extensión acorde con la OIT, que declara su Convenio 155 aplicable a todos los trabajadores, definiéndolos como todas las personas empleadas, incluidas las del sector público.

La inclusión de los empleados públicos no ligados a la Administración Pública por una relación contractual de tipo laboral (funcionarios, personal estatutario y personal con contrato administrativo), determina que la LPRL tenga una doble naturaleza (laboral y administrativa) (García Valverde, 2015).

Es decir, y recapitulando, la LPRL es aplicable a dos grandes grupos de relaciones de trabajo:

- Las reguladas por el Estatuto de los Trabajadores.

- Las de carácter administrativo o estatutario del personal al servicio de las Administraciones Públicas, incluyendo al personal funcionario en sentido estricto, al

\footnotetext{
${ }^{30}$ El propio concepto de «prevención» de riesgos laborales conlleva el conocimiento del riesgo e intentar «ab initio» su eliminación (Franco González, 2015).

${ }^{31}$ García Valverde (2015) califica este artículo de «precepto oscuro, enrevesado, muy ambiguo».
} 
personal estatutario de los Servicios Públicos de Salud y al personal contratado administrativamente (art. 3.1 LPRL).

\section{LA LEY 54/2003, DE 12 DE DICIEMBRE, DE REFORMA DEL MARCO NORMATIVO DE LA PREVENCIÓN DE RIESGOS LABORALES}

Las razones de la promulgación de esta Ley se explicitan en su propia Exposición de Motivos, concretamente en los altos índices de siniestralidad laboral. Desde el punto de vista de la citada Exposición, los problemas eran:

- Una deficiente incorporación del nuevo modelo de prevención y una falta de integración de la prevención en la empresa, que se evidencia en muchas ocasiones en el cumplimiento más formal que eficiente de la normativa.

- Una falta de adecuación de la normativa de prevención de riesgos laborales a las nuevas formas de organización del trabajo, en especial en los diversos modos de subcontratación y en el sector de la construcción.

A continuación se declara que sólo se abordarán en la presente Ley aquellas medidas que necesitan norma con rango de Ley.

La Ley 54/2003 se estructura en dos Capítulos que tratan, respectivamente, de las modificaciones de la LPRL y de la LISOS.

En cuanto a la LPRL, se modifican los siguientes aspectos:

- Artículos 9 y 43: medidas de colaboración de las Administraciones Públicas con la Inspección de Trabajo.

- Obligación de la empresa de implantar y aplicar un Plan de Prevención de Riesgos Laborales (arts. 14.2, 16.1, 16.2 y 23.1 a, b y c).

- Artículo 24.6: medidas de coordinación de actividades empresariales.

- Obligación empresarial de implantar medidas de organización de los «recursos preventivos» (arts. 31.3.a y c; 32 bis)

En lo referente a la LISOS, las modificaciones son básicamente:

- Artículo 2.8: se incluye entre los sujetos responsables de infracción a los «empresarios titulares del centro de trabajo». 
- Se corrige el artículo 5.2, mencionando genéricamente «los diferentes sujetos responsables», en sustitución de la enumeración detallada de sujetos infractores que existía anteriormente.

- Se introducen en la LISOS los nuevos tipos de infracción referentes a las nuevas obligaciones empresariales incluidas por la presente Ley (párrafo anterior).

- Se añade un párrafo $\mathrm{f}$ al artículo 39 (graduación de las sanciones), en el que se incluye el incumplimiento de los requerimientos previos del Estado o CCAA (arts. 9 y 43 LPRL).

- Se añade un párrafo al artículo 42.3 de la LISOS: «los pactos que tengan por objeto la elusión, en fraude de ley, de las responsabilidades establecidas en este apartado, son nulos y no producirán efecto alguno».

- Artículo 50.2 de la LISOS: inclusión de las conductas obstructivas de los funcionarios públicos (artículo 9.2 LPRL).

- Artículo 52: se añade un apartado 3 en que se ordena al Ministerio Fiscal que comunique a la Autoridad Laboral y a la Inspección de Trabajo y Seguridad Social la existencia de un procedimiento penal sobre hechos que podrían ser constitutivos de infracción.

- Artículo 53: se añade un apartado 5. Contenido de los actos de infracción a consecuencia de informes de funcionarios públicos del art. 9.2 LPRL.

\section{REGLAMENTOS}

- Sustancialmente, se trata de las normas reglamentarias de desarrollo de la LPRL, cuyo 6.1 aclara qué materias son susceptibles de dicho desarrollo. Son de contenido más específico y técnico que la ley y su carácter es eminentemente preventivo. El desarrollo reglamentario debe ser concordante con los principios de política preventiva que establece la propia LPRL y respetar la coordinación con la normativa sanitaria y de seguridad industrial (art. 6.2 LPRL).

- El citado artículo 6.1 enumera lo que puede ser desarrollado reglamentariamente, que en la práctica alcanza prácticamente todos los ámbitos de la seguridad en el trabajo:

- Requisitos mínimos de las condiciones de trabajo para la protección de la seguridad y la salud de los trabajadores.

- Limitaciones o prohibiciones que afecten a operaciones, procesos y exposición a agentes que entrañen riesgos para la seguridad y la salud de los trabajadores.

- Condiciones o requisitos especiales (como formación previa o elaboración de un plan) en operaciones, procesos y exposición a agentes que entrañen riesgos para la seguridad y la salud de los trabajadores.

- Procedimientos de evaluación de los riesgos.

- Modalidades de organización, funcionamiento y control de los servicios de prevención.

- Condiciones de trabajo o medidas preventivas específicas en trabajos especialmente peligrosos o en atención a determinadas características o situaciones especiales de los trabajadores. 
- Procedimiento de calificación de las enfermedades profesionales y de comunicación e información a la autoridad competente de los daños derivados del trabajo. 


\section{EL DEBER DE PROTECCIÓN DEL EMPRESARIO}

El derecho del trabajador a la salud y a la seguridad se refleja en un correlativo deber del empresario de garantizarlo. Este deber se articula en torno a dos cuestiones (Palomeque López, 1996):

1.- La obligación de realizar una política de prevención de riesgos laborales por parte de las Administraciones Públicas.

2.- El reconocimiento del derecho del trabajador a una protección «eficaz», adoptando las medidas necesarias (arts. 14.1 y 2 LPRL), lo cual indica una naturaleza contractual de la obligación empresarial.

Nuñez González \& Estardid Colom (2017) manifiestan que el deber de protección del empresario nace de la delegación que la ley hace en él de la exigencia de custodiar los derechos constitucionales de la vida, integridad física y salud.

Para Rivas Vallejo (2015) es un deber que emana de la propia relación de dependencia que vincula a ambas partes, siendo por ello de naturaleza contractual. Esta relación produce que la persona trabajadora sea acreedora de la tutela de la empleadora «en atención al papel de ésta como organizadora de la actividad productiva y receptora de los resultados del trabajo y, por tanto, responsable no sólo del trabajo sino también de los elementos que en él intervienen y, fundamentalmente los que afectan a la persona trabajadora» .

Este deber venía ya reconocido por el Estatuto de los Trabajadores y también por la OIT, pero a partir de su regulación por la LPRL ofrece una mayor concreción. De aquí nace la obligación del empresario de velar por la seguridad del trabajador y la adecuación de las condiciones del trabajo a la integridad de su salud física y psicológica. Tiene su fundamento en el artículo 40.2 CE (y demás artículos de la misma incardinados en el mismo, como hemos visto en otro apartado) y en la LPRL (que a su vez traspone la Directiva 89/391/CEE, de 12 de junio, y sus Directivas de desarrollo) $^{32}$.

Se trata, según Sala Franco (2014), de una obligación contractual compleja ${ }^{33}$, pero que se concreta en una serie de obligaciones específicas previstas en la LPRL. La RPRL sirve a estas obligaciones específicas como norma de interpretación (Nuñez González \& Estardid Colom, 2016) y dichas

\footnotetext{
32 STS de 3 de diciembre de 1997, recurso núm. 1087/1997: La LPRL unifica, actualiza y contextualiza además la normativa previa dispersa.

${ }^{33}$ Nuñez González \& Estardid Colom (2017) destacan que, además, la obligación general sirve también para delimitar el «estándar de protección»: "en términos generales, se considera que el empresario es deudor de seguridad en el trabajo hasta la máxima protección que la técnica permita».
} 
obligaciones son los medios que se establecen para la consecución del fin: la seguridad y salud en el trabajo. De hecho, como señala Sala Franco (2014), al tratarse de una obligación de medio ${ }^{34}$ y no de resultado, se entenderá que dicha obligación quedará cumplida cuando lo estén las obligaciones específicas.

En este sentido, resulta significativo el párrafo 2 del artículo 14 de la LPRL:

«...en cumplimiento del deber de protección, el empresario debe garantizar la seguridad y la salud de los trabajadores a su servicio en todos los aspectos relacionados con el trabajo. A estos efectos, en el marco de sus responsabilidades, el empresario realizará la prevención de los riesgos laborales mediante la integración de la actividad preventiva en la empresa y la adopción de cuantas medidas sean necesarias para la protección de la seguridad y la salud de los trabajadores, con las especialidades que se recogen en los articulos siguientes en materia de plan de prevención, evaluación de riesgos, información, consulta y participación y formación de los trabajadores, actuación en casos de emergencia y de riesgo grave e inminente, vigilancia de la salud y mediante la constitución de una organización y de los medios necesarios en los términos establecidos en el Capitulo IV de la presente Ley».

Siguiendo a Sala Franco (2014), las obligaciones de medio que concretan la obligación genérica empresarial de protección son:

1. $\left.{ }^{a}\right)$ Obligación de evitar el riesgo [arts. 15.1.a), c) y f) L.P.R.L.].

2.a) Obligación de evaluar los riesgos que no se puedan evitar y de planificar la acción preventiva en la empresa [arts. 14.2, 15.1.b) y 4 y 16 L.P.R.L.].

3. ${ }^{\text {a) }}$ Obligación de proporcionar al trabajador los equipos de trabajo y los medios de protección individual adecuados [arts. 15.1.h) y 17 L.P.R.L.].

4. $\left.{ }^{a}\right)$ Obligación de dar información, consultar y dar participación a los trabajadores [arts. $14.1 \mathrm{y}$ 2, 15.1.i) y 3 y 18 y Capítulo V L.P.R.L.] ${ }^{35}$.

5. ${ }^{\text {a) }}$ Obligación de proporcionar formación a los trabajadores individuales en materia preventiva (arts. 14.1 y 2 y 19 L.P.R.L.).

$6^{\text {a) }}$ Obligación de elaborar un plan de emergencia (arts. 14.2 y 20 L.P.R.L.).

\footnotetext{
${ }^{34}$ Un sector de la doctrina interpreta lo contrario, es decir, que la obligación es de resultado, atendiendo a la exigencia establecida en la LPRL de que la prevención y protección sea "eficaz» (y por tanto, si se produce un resultado lesivo, tal eficacia no ha existido, máxime cuando el mandato imperativo de la ley requiere de una adaptación y actualización permanentes de las medidas de prevención).

${ }^{35}$ González Ortega \& Aparicio Tovar (1996), Sempere Navarro, Cardenal Carro, \& Alzaga Ruiz (2010).
} 
7. a) Obligación de adoptar las medidas necesarias en caso de riesgo grave e inminente para los trabajadores (arts. 14.1 y 2 y 22 L.P.R.L.).

8. $\left.{ }^{a}\right)$ Obligación de vigilar periódicamente el estado de salud de los trabajadores (art. 22 L.P.R.L.).

9. $\left.{ }^{a}\right)$ Obligación de documentación (art. 23 L.P.R.L.).

10. $\left.{ }^{a}\right)$ Obligación de proteger a los trabajadores especialmente sensibles a determinados riesgos [arts. 15.2.a), 25, 26 y 27 L.P.R.L.].

11. $\left.{ }^{a}\right)$ Obligación de constituir un sistema de prevención (arts. 14.2 y Capítulo IV L.P.R.L.).

12.a) ) Obligación de presencia en la empresa de los recursos preventivos.

Estas obligaciones son, además, obligaciones de riesgo: se entienden incumplidas cuando no se adoptan, sin necesidad de que se haya producido efectivamente una lesión (Nuñez González \& Estardid Colom, 2016).

La caracterización del deber de protección del empresario como una obligación de medios no es tema baladí porque, de no ser así (y definirse como una obligación de resultado), se entendería incumplido siempre que se produjera un resultado dañoso, con independencia de si ha adoptado o no las medidas de seguridad exigidas.

Por esta razón, y dejando de un lado discusiones doctrinales a las que ya hemos aludido, manifiestan Nuñez González \& Estardid Colom (2017) que la condición de obligación de medios ha de serle reconocida al deber de protección simplemente por una razón teleológica y de política del Derecho. Para este autor, no considerar el tema bajo esta óptica significaría un fracaso en la aplicación de la normativa de prevención, al desmotivar gravemente al empresario en su aplicación. En efecto, si el empleador percibe que de nada sirven cuantas acciones emprenda para evitar los riesgos, porque cualquier daño producido le hace responsable de incumplimiento, dejará lógicamente de aplicar las referidas medidas preventivas.

De hecho, y apuntalando la cuestión, Sala Franco (2014) señala que, aun siendo una obligación de medios y no de resultado, resulta difícil para el empresario exonerarse de responsabilidad cuando acontece un daño. Y esto, según este autor, por las siguientes razones:

- Por ser muchas las obligaciones de medio integrantes del deber general de protección eficaz por parte del empleador.

- Porque gran parte de las obligaciones concretas empresariales adolecen de una gran ambigüedad y amplitud (por ejemplo, la obligación de evitar que entrañe poco o ningún 
peligro [art. 15.1.a), c) y f) L.P.R.L.] o la obligación de velar por el uso efectivo de los medios de protección adecuados [arts. 15.1.h) y 17 L.P.R.L.]).

- Porque el artículo 15.4 de la LPRL dice textualmente que «la efectividad de los medios preventivos deberá prever las distracciones o imprudencias no temerarias que pudiera cometer el trabajador» (art. 15.4 L.P.R.L.), por lo que incluso el riesgo por imprudencias del trabajador se traslada al empresario.

- Por el carácter dinámico de la obligación empresarial (Art. 14.2 LPRL).

En cualquier caso, por parte de la Jurisprudencia ha quedado zanjado el problema, proclamándose la naturaleza de obligación de medios de este deber empresarial y destacándose la diligencia como elemento valorador del comportamiento del empleador ${ }^{36}$.

La diligencia, en palabras de Nuñez González \& Estardid Colom (2017), «se convierte en el criterio de imputación de responsabilidad, porque delimita el comportamiento obligatorio del empresario». No obstante, estos mismos autores realizan dos apreciaciones necesarias al respecto:

$\checkmark$ En cuanto al «animus probandi», quien debe excusar su responsabilidad es el empresario, demostrando que era imposible prever las circunstancias concretas (por aplicación del art. 1183 CC que impone la prueba de la diligencia debida a quien ha debido emplearla).

$\checkmark$ En referencia al «onus probandi», alegar la mera aleatoriedad no es suficiente, es preciso demostrar la imposibilidad de prever y evitar el evento lesivo.

El deber de protección empresarial es intrasferible, lo que implica que no puede trasladarse a otros sujetos. Sin embargo, este principio es compatible con la encomienda de la gestión técnica de la prevención y con la colaboración necesaria de los trabajadores. Pero el incumplimiento por parte de estos otros sujetos implicados no libera de responsabilidad al empresario.

Por último, y en lo que se refiere a la caracterización jurídica del deber de protección empresarial, hay que destacar que se trata de un deber de naturaleza mixta (público-privado). Como obligación contractual se inserta «ope legis» en el contrato, sin necesidad de estipulación específica. Por otra parte, se está tutelando no únicamente el interés de cada trabajador: la entidad de los bienes jurídicos protegidos se protege como obligación del Estado; y siendo un interés público el objeto de protección, el deber empresarial ostenta un carácter público.

Llegados a este punto, resulta imprescindible tratar de cuáles son los mínimos, lo concretamente exigible al empresario para que se entienda que cumple con su obligación de protección.

\footnotetext{
${ }^{36}$ Por ejemplo, la STSJ del País Vasco, de 30 de enero de 2007, manifiesta que la producción del riesgo no genera en sí misma automáticamente la responsabilidad empresarial, precisándose que el daño esté causado por un incumplimiento de la obligación, y que exista un nexo conector entre el daño y el incumplimiento, siendo este nexo la falta de diligencia empresarial.
} 
En este sentido, Nuñez González \& Estardid Colom (2017) hablan del «alcance de la deuda de seguridad» y fijan en el estándar de protección el punto normativo central de la acción preventiva.

Se trata de dilucidar cuál ha de ser la protección «eficaz» que exige la LPRL.

La eficacia reside en la evitación del riesgo, la eliminación de la eventual lesión o daño por el medio de anticiparse al citado riesgo. Esto constituye el ideal de la prevención: la eliminación total del riesgo y, por tanto, de toda consecuencia que pudiera adherirse a que éste se materializara. Eliminar el riesgo por completo constituye, por tanto, el primer objetivo de la prevención ${ }^{37}$.

No obstante, será necesario contemplar otras alternativas cuando eliminar el riesgo por completo no es factible, cuestión llena de realismo porque, a pesar de las buenas intenciones de la normativa, es evidente que existen múltiples factores que a la postre pueden impedir tan loable finalidad.

Cuando el riesgo resulta imposible de evitar, lo exigible se centra en haber tomado las medidas adecuadas para impedir las consecuencias. Y, finalmente, si el riesgo es grave o inminente, se impone la paralización de la actividad productiva.

De todo lo dicho, cabe resolver que el estándar de protección se asienta sobre una «razonabilidad técnica», es decir, cuándo es posible alcanzar lo «posible» en salud y seguridad laboral. Se podría enlazar este punto con la capacidad económica y técnica de cada empresario, en el sentido de que una empresa estaría obligada hasta el límite de sus recursos financieros. Pero esta no es la opción aceptada por nuestro ordenamiento jurídico: la vida y la salud de la persona trabajadora no pueden depender de los recursos económicos que la empresa tenga en cada momento ${ }^{38}$. La LPRL en su artículo 15 condiciona la razonabilidad de la protección a la «evolución de la técnica» (incluyendo este concepto dentro de los principios de la acción preventiva), lo que implica que la eficacia de la protección debe cuantificarse con la evitación del riesgo según el nivel máximo que la técnica permita en el momento en que se produzca el mencionado riesgo.

Aunque esta regla admite excepciones debido a otros factores organizativos, productivos o económicos de la empresa, Nuñez González \& Estardid Colom (2017) insisten en que «es trascendental no perder la cordura» y que lo que se pide al empresario es una actualización razonable, que incluya la máxima protección tecnológica que se encuentre al alcance en el mercado. Insiste este autor en que siempre deberá realizarse una valoración proporcional que

\footnotetext{
${ }^{37}$ El énfasis de este principio se asienta sobre el principio civil «laeterum non laedere» (Nuñez González \& Estardid Colom, 2016).

${ }^{38}$ EI TJCE (Sentencia 2007/141, de 14 de junio) interpreta que la razonabilidad de la protección no se encuentra limitada por la capacidad económica de la empresa, ni tampoco por su dimensión.
} 
tenga en cuenta los esfuerzos empresariales realizados, conforme al coste de la medida y su relación con el posible impacto en el funcionamiento de la empresa.

Finalmente, resulta necesario referirse a los tipos de responsabilidad en que puede incurrir el empresario por faltar a la obligación de protección de la salud del trabajador.

En primer lugar, puede darse una responsabilidad «in eligendo», cuando selecciona aquellas medidas que serán incorporadas y las que no van a ser implantadas en su empresa, que le es exigible a tenor del artículo 14 LPRL. Pero adicionalmente también se establece una responsabilidad «in vigilando», por cuanto la simple instalación de las medidas elegidas no agota el deber del empresario, que viene obligado a velar porque las medidas se cumplan efectivamente (Artículo 17 LPRL). Obviamente, se entiende que dicho deber de vigilancia ha de encontrarse dentro de parámetros razonables, bastando con una actividad responsable, pero que no hostigue al trabajador.

Por último, cabe señalar que esta responsabilidad se ve condicionada por otro componente: la obligación del empresario de evaluar las medidas tomadas. En efecto, no basta con la implementación de acciones preventivas, es también necesario realizar una evaluación periódica de su eficacia y sustituirlas si de la evaluación se concluye que las medidas tomadas no han sido adecuadas o no han surtido el efecto esperado, así como completarlas si resultan insuficientes. 


\section{LOS PLANES DE PREVENCIÓN DE AGRESIONES A LOS PROFESIONALES SANITARIOS.}

En este epígrafe se analizan un total de diez de los diferentes Planes de Prevención que las Comunidades Autónomas han dictado específicamente en materia de agresiones contra su personal sanitario.

Los criterios de selección de la muestra han sido, por una parte, los Planes que se diseñaron e implantaron más tempranamente, por otra, no incluir aquellos que reproducen las medidas tomadas en otros Planes sin aportar elementos nuevos.

\section{Tabla 2. Muestra de Planes de prevención específicos contra las agresiones al personal sanitario en el ámbito autonómico.}

ORDEN 212/2004, de 4 de marzo, del Consejero de Sanidad y Consumo de la Comunidad de Madrid, por la que se establecen las directrices y líneas generales para la elaboración de planes de prevención y atención frente a potenciales situaciones conflictivas con los ciudadanos en los centros e instituciones sanitarias públicas y se crea la comisión central de seguimiento.

Plan de prevención de las agresiones a los profesionales de la sanidad de la Región de Murcia (2004).

Plan Director de seguridad corporativa y de protección del patrimonio del SESCAM (Plan Perseo) (Castilla-La Mancha, 2005).

Estrategias para paliar las agresiones a todos los profesionales del Sistema Sanitario Público de Extremadura (2006).

Plan de Prevención contra la violencia en el lugar de trabajo. Departamento de Salud y Consumo del Gobierno de Aragón (2006).

Plan de prevención y atención al profesional víctima de agresiones en el trabajo. La Rioja (2008).

Pacto entre la Consejería de Sanidad y las Organizaciones Sindicales CEMSATSE, UGT, SAE-USCAL y CSI-CSIF sobre las actuaciones a desarrollar para elaborar el Plan Integral frente a las Agresiones al Personal de la Gerencia Regional de Salud de Castilla y León, firmado el 4 de febrero de 2008 (actualizado 2016).

Decreto 159/2009, de 2 de octubre, del Consell de la Generalitat Valenciana, por el que se establecen las actuaciones de los órganos de la Consellería de Sanidad en la prevención y atención de las agresiones a su personal sanitario.

El Plan de Prevención y Atención de Agresiones para los Profesionales del Sistema Sanitario Público de Andalucía (2005, actualización 2012).

Plan de Prevención y Atención ante incidentes violentos en el ámbito sanitario público de Cantabria (2014). 
Las medidas tomadas por la Comunidad Autónoma de Castilla y León se analizan en un apartado independiente debido a las razones que se expresan en la Introducción de este trabajo, por lo que forma parte de este grupo de diez Planes, pero su estudio no se encuentra reflejado en el presente epígrafe.

Debemos hacer notar que no todas las Comunidades Autónomas cuentan con un Plan de Prevención específico en la materia, siendo en ocasiones requeridas desde la Justicia para la subsanación de esta carencia. Por ejemplo, una STSJ del País Vasco obliga al Servicio Vasco de Salud-Osakidetza a implantar un Plan de prevención contra las agresiones a sus trabajadores sanitarios. La sentencia recogía la siguiente afirmación al respecto: «la política preventiva no consiste en ir a remolque de los accidentes e incidentes que se produzcan, sino que se han de prever antes de que sucedan», por lo que deben «adoptar medidas que eviten su materialización, incluso, por primera vez» ("El TSJ obliga al Servicio Vasco de Salud a implantar un plan preventivo de agresiones al personal sanitario | www.comcas.es," 2016).

Los planes de prevención de riesgos en materia de violencia externa en los centros públicos sanitarios comenzaron a desarrollarse cuando las distintas Administraciones Autonómicas tomaron conciencia de que el problema de las agresiones se había convertido en una cuestión relevante.

Así, las directrices fijadas en la Comunidad de Madrid (2004), para la elaboración de planes de prevención en esta materia dentro de su ámbito territorial de competencia, sostienen que resulta conveniente articular actuaciones para atajar un incremento evidente de las agresiones, que se ha venido observando en los últimos tiempos. Aunque se reconoce que no se cuenta en ese momento con datos estadísticos precisos, se manifiesta un aumento preocupante de «la tensión en el trato de algunos ciudadanos hacia el personal sanitario», que hace necesaria la toma de medidas al respecto.

El Plan de Prevención de Murcia (2005) reconoce como antecedentes directos los Planes de Actuación de Madrid, de Andalucía, el elaborado por el Colegio de Médicos de Barcelona y el Convenio firmado por la Generalitat Valenciana con los Colegios Oficiales de Médicos de su ámbito territorial. Este Plan de Prevención de Murcia destaca los datos de una encuesta realizada a los médicos de la región, elaborada por su Colegio Profesional, así como los ofrecidos por el Colegio de Médicos de Barcelona y los estudios realizados en el ámbito de Atención Primaria de 
Jaén y el realizado por el sindicato SATSE ${ }^{39}$. Este mismo Plan de Prevención califica el asunto como un «problema emergente».

En Castilla-La Mancha se creó en 2005 el Plan Director de seguridad corporativa y de protección del patrimonio del SESCAM (Plan Perseo), que ha venido siendo periódicamente actualizado ${ }^{40}$. Define este Plan la violencia en el lugar de trabajo como un fenómeno «creciente y de origen multifactorial», que puede evitarse y cuya prevención es indispensable y fundamental. El Plan «Perseo» se denomina así en referencia al héroe de la mitología griega que venció a Medusa. El poder de Medusa consistía en que todos los que la miraban quedaban convertidos en piedra, pero Perseo consiguió ver su reflejo en su brillante escudo Aegis, por lo que pudo matarla sin mirarla directamente. El Plan pretende, como Perseo, «prevenir, proteger y combatir el fenómeno de la violencia hacia los trabajadores, bienes y usuarios del Servicio de Salud de Castilla-La Mancha».

Las «Estrategias para paliar las agresiones a todos los profesionales del Sistema Sanitario Público de Extremadura» (2006) comienzan, como nota distintiva, integrando ya en su título a «todos los profesionales», lo que puede obedecer a la intención de que no quepa duda alguna de que ningún trabajador podrá ser excluido de su ámbito de aplicación. Declara en su introducción que las relaciones entre profesionales y usuarios se basan en el mutuo respeto y colaboración, pero que en los últimos años ese común denominador de la asistencia sanitaria se ha visto alterado por la proliferación de los incidentes de violencia.

El Plan de Prevención contra la violencia en el lugar de trabajo (30 de mayo de 2006) dictado por el Departamento de Salud y Consumo del Gobierno de Aragón, comienza con un «Manifiesto contra la violencia en el lugar de trabajo», en el que se constata la existencia de incidentes, provocados porque la prestación sanitaria «se lleva a cabo, a veces, en situaciones de fuerte emotividad en los pacientes y sus familiares y de presión asistencial para los trabajadores», concluyendo con un «rechazo a cualquier clase de violencia» y proclamando que se emprenderán las acciones correspondientes para atajar el problema.

La Rioja cuenta desde 2008 con un PPRL específico para la violencia contra sus trabajadores de la sanidad, titulado «Plan de prevención y atención al profesional víctima de agresiones en el trabajo». En su presentación, recalca que la violencia laboral «constituye una importante fuente de desigualdad, discriminación, estigmatización y conflicto en el trabajo», destacando que el

\footnotetext{
${ }^{39}$ El porcentaje de agresiones hacia los profesionales de enfermería es, según el estudio realizado por SATSE a través de su portal de Internet, de 8 de cada 10 agredidos física o verbalmente. Los porcentajes desglosados son: verbales de un $62,64 \%, 34,45 \%$ físicas y verbales y $2,8 \%$ sólo físicas.

${ }^{40}$ La última de estas actualizaciones ha consistido en el acceso al servicio de asesoramiento jurídico durante las 24 horas de los 365 días del año (Consejería de Sanidad de Castilla-La Mancha, 2017).
} 
problema es especialmente grave en el ámbito del sector sanitario porque en este campo «el capital humano es el verdadero motor de la empresa».

El Decreto 159/2009, de 2 de octubre, del Consell de la Generalitat Valenciana, por el que se establecen las actuaciones de los órganos de la Consellería de Sanidad en la prevención y atención de las agresiones a su personal sanitario, estima la necesidad de tomar medidas a raíz de la publicación de la OIT sobre el gran número de agresiones que se dan en el sector sanitario. Considera que la creación de un derecho genérico relativo a las agresiones a los trabajadores sanitarios del sector público resulta de interés prioritario.

El Plan de Prevención y Atención de Agresiones para los Profesionales del Sistema Sanitario Público de Andalucía (2005, actualización 2012) señala que las relaciones entre ciudadanos y profesionales sanitarios «no son ajenas a posibles cargas de agresividad que se manifiestan en determinadas ocasiones, alterando la relación de agencia que se debe establecer entre profesionales y ciudadanos». Manifiesta además que estas actitudes no son específicas de los servicios sanitarios y el problema es calificado como «multifactorial», por lo que justifica la dificultad de «dar una única respuesta a su prevención y control».

Este Plan invoca las experiencias andaluzas en el asunto: particularmente el Plan para la Prevención y Atención de Agresiones a profesionales de la salud del Consejo de Salud de Área de Córdoba o el Plan de Apoyo a Profesionales que atienden barriadas «con necesidades de transformación social», del SAS.

Como los anteriores, el Plan del SSPA afirma que se trata de un tema «de alta prioridad para las autoridades sanitarias». Sin embargo, ya de entrada renuncia a la posible eliminación de las agresiones. Literalmente, dice que: «hay que aceptar que las medidas que se pueden implantar desde el sistema sanitario para prevenir y contrarrestar los incidentes de violencia contra el personal sanitario pueden aspirar a reducir la incidencia y a atenuar la intensidad y las consecuencias, pero no a erradicarla, ya que su aparición está relacionada con factores sociales y culturales difícilmente abordables». En consecuencia, cabe entenderse que el SSPA parte de una situación de reconocimiento de sus propias limitaciones en la solución del problema, que incluso podría calificarse como de cierto derrotismo.

La Comunidad Autónoma de Cantabria aprueba en 2014 su «Plan de Prevención y Atención ante incidentes violentos en el ámbito sanitario público de Cantabria», lo cual no significa que anteriormente careciera de instrumentos de prevención y normativa al respecto. En concreto, ya existía un «Acuerdo Marco en Salud Laboral y participación de los trabajadores en materia de prevención de riesgos laborales en el Servicio Cántabro de Salud», aprobado el 8 de febrero de 
$2007^{41}$. Este Plan constata la gravedad del problema, declara basarse en una política de «tolerancia cero» ante las agresiones e insta a los profesionales a que comuniquen los incidentes, haciendo hincapié en que las agresiones no físicas también deben ser notificadas. Señala igualmente que la protección al personal sanitario es una «premisa básica para el éxito del sistema y sobre ella se debe sustentar todo el complejo entramado de la atención sanitaria».

\section{LAS POSIBLES RAZONES DE LAS AGRESIONES}

Resulta prácticamente unánime el convencimiento de que la comprensión de las razones por las que se produce la violencia es un factor determinante en su prevención. Por este motivo, los diferentes Planes señalan casi siempre una serie de elementos que pueden propiciar la aparición de las agresiones:

- Expectativas de los pacientes, no ajustadas con las posibilidades de que resulten satisfechas. En este sentido, se indica que los avances médicos dan «una imagen de omnipotencia de la Medicina», que determina en el usuario una disconformidad cuando los resultados no son los esperados y que esa disconformidad se personaliza en el trabajador sanitario (Murcia 2005).

- Aspectos relacionados con la información y la comunicación administrativa y sanitaria.

La Comunidad de Aragón: lo califica como factor de riesgo; La Rioja como falta de información sobre los derechos de los trabajadores.

- Factores que tienen que ver con el entorno en que se desarrolla la relación sanitaria Comunidad de Madrid (2004). Entorno sociológico en que se mueven los profesionales (Murcia, 2005).

- Otros elementos de difícil predicción: comportamientos inadecuados (Comunidad de Madrid (2004).

Se llega a señalar como origen de las agresiones «... la propia sociedad con una pérdida progresiva de valores y que utiliza la violencia como método para resolver conflictos» (Comunidad Autónoma de Murcia, 2005).

Por otra parte, también se atribuye al cambio de relación médico-paciente hacia una situación menos dependiente y más autónoma del usuario, el hecho de que haya un incremento de la

\footnotetext{
${ }^{41}$ En realidad, la toma de medidas por parte de la Comunidad Autónoma cántabra comienza en 2004, en que el Director Gerente del Servicio Cántabro de Salud dicta una Instrucción con el procedimiento a seguir por los trabajadores del SCS que deseen solicitar asistencia socio-jurídica o defensa en juicio tras sufrir una agresión. Con anterioridad, en el 2003 (actuación que prosigue en 2004), se desarrollaron una serie de iniciativas de prevención de violencia en el trabajo por parte de la Gerencia de las Áreas de Salud Torrelavega-Reinosa, que posteriormente fueron adoptadas por las Gerencias del resto de Áreas de Salud de Cantabria. Finalmente, se elaboró la «Norma de Prevención de Violencia en el Trabajo», que contiene información acerca de medidas a tomar por el profesional e instrucciones preventivas para la organización sanitaria.
} 
exigencia de ser atendido y curado («restitutio ad integrum») de cualquier mal (Comunidad Autónoma de Murcia, 2005).

El Plan de la Comunidad de Murcia reconoce que se da una mayor agresividad en situaciones de masificación de servicios y que, por tanto, deben tomarse medidas directas en este aspecto, manifestando que deben adecuarse las plantillas a las necesidades asistenciales. También señala la extensión de la violencia desde servicios que eran tradicionalmente diana de las agresiones a otros que hasta el momento eran pacíficos (Centros de Salud, consultas externas de Atención Especializada, antesalas de quirófanos, UCI, Servicios de Atención al Usuario, etc.). Constatan además que la mayoría de las agresiones se dan contra mujeres.

El Plan de Prevención de Aragón (2006) lo achaca a la situación de tensión en que en ocasiones se desarrolla la actividad asistencial: «este clima de ansiedad dificulta la comunicación y puede desembocar, en algunos casos, en violencia verbal o física».

La falta de medios personales y técnicos, las listas de espera, la falta de tiempo y el trabajo solitario son las causas principales que motivan la violencia contra el sanitario, según el Plan de Prevención de La Rioja (2008).

El Servicio Andaluz de Salud, en su Plan de Prevención (actualización de 2012) alude a un problema multifactorial, de difícil solución, condicionado a factores sociales y culturales de complicado abordaje.

\section{OBJETIVOS DE LOS PLANES DE PREVENCIÓN ESPECÍFICOS CONTRA LA VIOLENCIA EN EL SECTOR SANITARIO}

Los distintos planes se sustentan en diferentes objetivos. Comúnmente van dirigidos a la prevención del surgimiento de la propia situación de conflicto o enfrentamiento (Comunidad Autónoma de Murcia. Consejería de Sanidad., 2005) (Comunidad de Madrid, 2004) (Generalitat Valenciana, 2009) y en ciertos casos esta directriz se bifurca en la prevención de los actos de violencia contra los profesionales ${ }^{42}$.

La protección del profesional surge como otra de las finalidades propias e imprescindibles de los planes. Resulta llamativo que a veces esta actuación se anuda a la protección de los usuarios no problemáticos ${ }^{43}$. Del mismo modo, reconocida la influencia de un clima de respeto y buena

\footnotetext{
${ }^{42}$ Comunidad de Madrid (2004).

${ }^{43}$ «Proteger a los profesionales sanitarios y a los ciudadanos que hacen un uso adecuado de los servicios durante el transcurso de incidentes en los que medie violencia o agresión» (Comunidad de Madrid, 2004).
} 
comunicación en el buen funcionamiento del propio sistema, queda esto establecido como objetivo para mejorar la calidad de la asistencia sanitaria (Comunidad Autónoma de Murcia. Consejería de Sanidad., 2005). El PPR de Aragón (2006) alude a la repercusión que las consecuencias negativas de la violencia tienen sobre la salud del trabajador, «devaluando la prestación del servicio por las conductas de miedo y precaución adoptadas por la víctima». La protección del profesional sanitario se vincula al éxito de la organización en general (Plan de la Comunidad de Cantabria, 2014).

Aunque el asesoramiento jurídico de la víctima, una vez producido el acto agresivo, es nota común en prácticamente la totalidad de los Planes estudiados, en ocasiones se establece como objetivo general de las actuaciones (Comunidad de Madrid, 2004). En el Plan de Murcia, el apoyo administrativo y jurídico se entiende como herramienta para generar seguridad y confianza en el personal del sistema.

En el Plan Perseo (2005) de Castilla-La Mancha se establece un objetivo general: «establecer un sistema de prevención, protección y reacción que permita optimizar la utilización de los recursos técnicos y humanos disponibles, con el fin de prevenir proteger y controlar con rapidez cualquier situación de violencia, peligro o emergencia y minimizar sus consecuencias garantizando la continuidad de la actividad del centro, así como la de fomentar una cultura de seguridad y prevención».

Asimismo, formula una serie de objetivos específicos, de recogida de información y análisis de riesgos, con elaboración de un mapa de los mismos, la difusión de campañas de sensibilización, etc. Quizá lo más específico sea la declaración de que se realizará el establecimiento de un sistema y estructura de seguridad integral, con personas formadas y adiestradas para el control de situaciones de peligro y emergencias. Por otra parte, también incide en la potenciación de vías éticas de solución de conflictos asistenciales o interpersonales, crear «espacios amigables» y hacer efectivos los derechos de los ciudadanos a través del Servicio de Atención al Paciente.

Extremadura (2006) configura como objetivos informar sobre las medidas y recursos para prevenir y proteger ante situaciones de conflicto, generar confianza y seguridad en el personal y reducir la conflictividad (aspecto éste que relaciona con la mejora de la calidad de la asistencia sanitaria).

Aragón (2006) manifiesta que la protección de los derechos de su personal, perteneciente al Departamento de Sanidad y Consumo, debe realizarse desde la propia organización, aseverando que los trabajadores contarán con el apoyo de la Dirección. 
La Rioja (2008) proclama su decisión de formular medidas estructurales y generar un ambiente de confianza y seguridad en orden a proteger la vida, la integridad física y la salud de sus trabajadores, afirmando como colofón que su objetivo es «cuidar al que cuida».

La Generalitat Valenciana (2009) establece como una de las acciones a realizar, dentro de los principios y fines del Plan Integral de Prevención y Atención de las Agresiones a los Trabajadores del Sector Público de su ámbito competencial, «actuar en caso de agresión, dando cobertura legal y sanitaria».

Los objetivos generales del Plan de la Comunidad de Cantabria (2014) se centran en el conocimiento por parte del profesional de las actuaciones a realizar, el buen funcionamiento de los sistemas de prevención y protección, la garantía de asistencia a los trabajadores afectados y la reducción de la conflictividad (con la consecuente mejora de la calidad de la asistencia).

\section{ACCIONES DE LOS PLANES DE PREVENCIÓN}

Las actuaciones en materia de prevención se estructuran en los distintos planes de este modo:

1. Prevención de situaciones conflictivas.

2. Actuación posterior cuando se produce el incidente.

\section{PREVENCIÓN}

En este primer apartado, las medidas se orientan hacia diferentes dianas, que se corresponden con las posibles motivaciones que puede tener un agresor para cometer el hecho violento.

Uno de esos objetivos a cubrir es minimizar la posible insatisfacción del usuario.

Así, nos encontraremos con medidas encaminadas a adecuar las expectativas del ciudadano a la realidad (Comunidad de Madrid, 2004)(Comunidad Autónoma de Murcia, 2005). De aquí nace la necesidad de informarle sobre aspectos como:

- Derechos y deberes.

- Funcionamiento y organización de los servicios sanitarios, prestaciones, requisitos de acceso a los centros, etc.

- Uso adecuado de prestaciones y servicios.

- Promoción y educación para la salud.

El Plan de Prevención de Murcia incide sobre la necesidad de informar sobre todos estos aspectos, añadiendo que se difundirá que la institución sanitaria demandará al usuario que no respete al personal o las normas del centro sanitario (Comunidad Autónoma de Murcia, 2005). 
El Plan Perseo de la Castilla-La Mancha (2005) establece una red de recursos humanos encargados de la prevención y protección, ordenándose en una estructura central y otra periférica, con funciones delimitadas para cada órgano y unas acciones predeterminadas a realizar por parte de cada uno de los implicados.

Extremadura (2006) promueve el estudio y valoración de las quejas y reclamaciones de los usuarios, para detectar aspectos conflictivos que puedan generar situaciones conflictivas. Para ello, instaura un sistema de Registro de incidentes y una encuesta de satisfacción, que sirva para obtener una imagen del sistema sanitario y de su percepción por el usuario.

Igualmente, se potencia la información, educación sanitaria y sensibilización de los usuarios en el uso de las prestaciones y la importancia del respeto al profesional.

Aragón (2006) señala en su Plan de Prevención como factores de riesgo relacionados con las deficiencias en la información al usuario o la inexistencia de la misma los siguientes (que además se encuentran íntimamente entrelazados con la necesidad de que haya una correcta comunicación):

- No se atienden las demandas de pacientes y usuarios, sin razonar los motivos que impiden satisfacer sus expectativas, ya sean éstos organizacionales o de disponibilidad de recursos.

- Existen defectos en la información o en la atención a situaciones de riesgo vital o de emergencia, o son sentidos así por los familiares o acompañantes en servicios de urgencias y UCI, por ejemplo.

- El personal no está suficientemente entrenado para satisfacer las preguntas y preocupaciones previsibles del usuario en atención al motivo de su visita al centro o consulta.

La Rioja (2008) dedica un apartado a la «Potenciación de la información» (a los usuarios), manifestando que resulta fundamental este punto, «procurando adecuar, particularmente, sus expectativas de oferta y acceso». En particular, la información deberá versar sobre derechos y deberes de los ciudadanos, prestaciones y Cartera de Servicios del SERIS, Ordenación sanitaria de la Comunidad Autónoma riojana, promoción y educación para la salud, uso adecuado de la red sanitaria, organización de los centros sanitarios y unidades y gestión de reclamaciones y propuestas de mejora. La información se reforzará mediante medios tradicionales (dípticos, carteles, prensa, radio, televisión...) en salas de espera y espacios comunes de los centros sanitarios. 
Como aspecto novedoso, indica que se fomentarán acuerdos de colaboración con entidades sociales y culturales, con las que se promoverán programas formativos y se incluirán en los centros educativos de la Comunidad horas lectivas impartidas por profesionales del SERIS «que refuercen la cultura del buen uso de los sistemas sanitarios y hábitos de vida saludables» (La Rioja, 2008).

De hecho, La Rioja (2008) despliega toda una batería de medidas centradas en la mejora de la información del paciente en situaciones concretas:

- En los Servicios de Urgencia prevé una información pronta y periódica sobre el estado de salud del paciente tanto al mismo como a sus familiares, de la que se encargará personal sanitario específico. Así mismo expresa que se facilitará el acompañamiento del paciente por un familiar cuando aquel sea un niño, un anciano o cuando resulte aconsejable por sus características o patología.

- En consultas programadas o procesos sometidos a lista de espera, se garantizará una información regular al usuario sobre la situación en que se encuentra. Esta información será ofrecida en tiempo real mediante medios informáticos y telemáticos (tales medios se irán implantando gradualmente y siempre respetando la preceptiva confidencialidad).

El usuario recibirá información sobre cualquier cambio relacionado con su situación y se le recordará la cita. Se manifiesta en este apartado la importancia de concienciar a la población sobre la necesidad de comunicar cuándo no se puede acudir a las citas programadas.

Andalucía (actualización de 2012), insiste en el respeto a los derechos de los usuarios y exige no anteponer sobre ellos los derechos de los profesionales. Sin embargo, incide en lo necesario de instar al ciudadano en el cumplimiento de sus deberes, entre los cuales se encuentra el uso adecuado de los servicios sanitarios. Ello, lógicamente, debería llevar implícita una buena información al usuario sobre cuáles son esos deberes que debe cumplir.

Cantabria (2014) implanta una «Carta de Derechos y Deberes de los Ciudadanos en el Sistema Autonómico de Salud de Cantabria» y anima a recordar a los usuarios su existencia y difundir entre los mismos su contenido. Es necesario, según este documento, insistir sobre la función de los Servicios de Atención al Usuario como núcleo intermediario de las quejas y conflictos planteados y la información sobre el procedimiento para interponer reclamaciones.

La Comunidad Autónoma cántabra propone incidir en la información a los ciudadnos sobre el respeto que deben mantener en los centros respecto a las normas establecidas y a sus trabajadores y sugiere la posibilidad de recordarles que pueden imponerse sanciones cuando se den conductas impropias, como lo es la desconsideración grave de los usuarios hacia el SCS (artículo 79 de la 
Ley 7/2002 de Ordenación Sanitaria de Cantabria). Igualmente, anuncia la programación de campañas difusoras de información sobre el uso adecuado de las prestaciones sanitarias, el papel que juegan los profesionales sanitarios en el buen desarrollo de los procesos de la organización y «se recalque la importancia del mantenimiento de una relación cordial profesional-usuario basada en el respeto y la mutua confianza».

\section{MEJORA DE LA CALIDAD}

La mejora de los servicios y la atención sanitaria entra también dentro de este ámbito. A tal efecto, se establecen medidas organizativas de muy variada índole, pero enfocadas en eliminar aquellas situaciones sobre las que se reciben mayor número de quejas.

En primer lugar, los problemas suscitados por el sistema de citas. Las directrices de la Comunidad de Madrid (Comunidad de Madrid, 2004) prevén una revisión del acceso telefónico de los ciudadanos a los centros sanitarios, una adecuación paulatina de las plantillas de personal administrativo y el impulso de sistemas de cita previa alternativos para evitar al ciudadano desplazamientos innecesarios.

El Plan de Murcia (Comunidad Autónoma de Murcia, 2005) establece la necesidad de mejorar el acceso telefónico, puntos de información en los centros y la mejora de los requisitos burocráticos (gestionar todo en el mismo punto, evitando colas múltiples).

La Rioja (2008) prevé el impulso de los sistemas de cita previa alternativos (telefónicamente, SMS e internet). También «dimensionar eficazmente las plantillas de personal administrativo» de las áreas de información, citación y atención al paciente.

Respecto a los tiempos de demora en las consultas, las directrices de la Comunidad de Madrid invocan el establecimiento de medidas organizativas que palíen el problema. En concreto:

- Agendas de calidad en los Centros de Salud, formando en diseño y gestión a los profesionales «para adecuar el tiempo de cita a las necesidades de los ciudadanos».

- Garantizar la correcta valoración de los pacientes sin cita previa y urgentes en los Centros de Salud, para que la atención «no programada y urgente» interfiera lo menos posible en el resto de la asistencia.

- Optimizar el tiempo de atención en las consultas. Las interrupciones deben ser evitadas, salvo que sean debidas a la atención que se preste o a circunstancias excepcionales.

- Establecer un programa de citación personalizada en las consultas externas de Atención Primaria. Aquí también se persigue la implantación de sistemas con criterios de calidad. 
- Reducir tiempos de demora para consultas externas, exploraciones e intervenciones quirúrgicas, de acuerdo con los planes que se establezcan por la Consejería competente.

Como puede verse, lo que se fijan son objetivos, fines a los que se pretende llegar; pero las referencias a cómo se van a lograr son indirectas y apuntan al desarrollo de otras medidas, planes o estrategias.

Quizás lo más concreto en este punto es el último ítem: «adecuar las plantillas de los centros a las necesidades de atención, de conformidad con los planes y programas que a este respecto se establezcan por la Consejería de Sanidad y Consumo ${ }^{44} \gg$. Esto resulta posiblemente lo más destacable, junto con la mención sobre la adecuación de las plantillas del personal administrativo. Se está reconociendo que son necesarios más medios humanos para ofrecer una asistencia sanitaria adecuada (Comunidad de Madrid, 2004).

El Plan de Murcia (Comunidad Autónoma de Murcia. Consejería de Sanidad., 2005) dedica todo un apartado a la mejora de los tiempos de espera, estableciendo las siguientes mejoras organizativas:

- Formación de los profesionales en habilidades de comunicación y en Agendas de Calidad.

- Mejorar el acceso telefónico del usuario.

- En Centros de Salud: Valoración de pacientes sin cita y urgentes según la organización del centro, con colaboración de todos los estamentos del mismo, para garantizar su correcta atención con la mínima repercusión en las consultas.

- Optimizar el tiempo de las consultas, evitando con la colaboración de todo el equipo, las interrupciones que se producen durante la atención sanitaria, seleccionando únicamente las necesarias.

- Educar a la población para que avisen cuando no puedan asistir a las citas.

- Mejorar los cauces de comunicación entre Atención Primaria y Atención Especializada: establecimiento de circuitos protocolizados de derivación.

- Respuesta ágil y eficaz ante las reclamaciones.

Es de destacar lo similares que resultan los catálogos de actuaciones en este ámbito (mejora de tiempos de espera) entre las directrices de la Comunidad de Madrid y el Plan de Murcia.

Especialmente reseñable es la solución que ofrecen para optimizar el tiempo de cada consulta: recomiendan evitar las interrupciones innecesarias.

\footnotetext{
${ }^{44}$ Referencia actualizada a «Consejería de Sanidad», efectuada por la Disposición Adicional Única («Actualización de referencias») de la Orden 370/2017, de 24 de abril, del Consejero de Sanidad.
} 
Parece focalizarse la existencia de demoras en la existencia de interrupciones y no en la eventual falta de tiempo suficiente para atender a cada paciente. Estos documentos, a nuestro juicio, no advierten que dotar de más tiempo a cada consulta y, por tanto, disminuir el número de pacientes citados en cada sesión, probablemente ayudaría a rebajar esos tiempos de espera.

El Plan de Prevención de Aragón (2006) ${ }^{45}$ señala como factores de riesgo en este ámbito:

- Se producen demoras en la asistencia, pruebas, intervenciones, etc., sin un plan informativo que explique el motivo de la demora.

- Se producen interrupciones en las consultas - con visita ya iniciada- con interferencias de personas ajenas, llamadas telefónicas, etc., que pueden ser interpretadas como una falta de atención al usuario.

La Rioja (2008) considera necesario disminuir los tiempos de espera para el acceso a la asistencia, para ello impulsa el establecimiento de agendas de calidad y la organización de programas formativos para su adecuada gestión.

También prevé protocolizar la atención de usuarios sin cita y urgentes (especialmente en Atención Primaria), asegurando que tengan la mínima repercusión en las consultas programadas.

Reconoce asimismo la necesidad de «dimensionar eficazmente las plantillas» de los centros y reforzarlas en aquellos con riesgos específicos ${ }^{46}$ y los que se consideren tras el análisis del mapa de riesgos.

Un asunto recurrente en los distintos planes es la adecuación de los espacios físicos para hacerlos más confortables. Se supone que un entorno agradable resulta menos proclive a situaciones de brotes de descontento y agresividad ${ }^{47}$.

En las directrices formuladas por la Comunidad de Madrid (2004) se añade la necesidad de extremar la vigilancia y el control del cumplimiento de las normas internas del centro (muy en particular el consumo de tabaco, drogas o bebidas alcohólicas) en las salas de espera. Estos espacios serán dotados, además, de medios audiovisuales (pantallas) para la difusión de «mensajes sanitarios referidos a la promoción de la salud, educación sanitaria y hábitos de vida saludables y, en particular, los relacionados con el uso adecuado de los Centros y Servicios Sanitarios y el trato debido a sus profesionales».

\footnotetext{
${ }^{45}$ También lo hacen, como hemos podido observar, los de Madrid y Murcia.

${ }^{46}$ Se refiere a Urgencias y Psiquiatría.

${ }^{47}$ El Plan de Prevención de Murcia recomienda «establecer en los centros las condiciones ambientales adecuadas» (Comunidad Autónoma de Murcia. Consejería de Sanidad., 2005)
} 
Esta misma medida (monitores de televisión de circuito cerrado) se adopta por la Región de Murcia (Comunidad Autónoma de Murcia, 2005). También se prevén estos mecanismos de información en el Plan de La Rioja (2008).

Extremadura (2006) establece como una de las medidas para evitar situaciones conflictivas «asegurar o potenciar en los centros unas condiciones ambientales adecuadas, evitando la masificación, que genera un ambiente hostil e irritante».

En Aragón (2006) se implementa lo siguiente: espacio suficiente en las diferentes zonas: recepción, etc. Se incide en que las diferentes salas deben ser espaciosas y tranquilas, con mobiliario ligero y que no obstaculice (Aragón, 2006).

En este aspecto incide también el Plan de La Rioja (2008), que además detalla, respecto al mobiliario, que los mostradores deberán tener una altura y anchura adecuadas y que en controles y mostradores deberá instalarse un acristalamiento de seguridad.

Otras medidas establecidas en La Rioja (2008) a este respecto son:

- Diseño y construcción de nuevos centros y reformas en los existentes, teniendo en cuenta la seguridad de los profesionales frente a posibles agresiones.

- Gestión de llaves y cerraduras mediante llaves maestras.

- Áreas restringidas de uso del personal sanitario únicamente.

- Atención a las salas de espera, «dadas las especiales circunstancias emocionales que ante situaciones de gravedad clínica se dan en estos espacios»: dimensiones adecuadas, confortabilidad y discrecionalidad (sic).

o Perfecta identificación de las normas de comportamiento, uso de telefonía y demás normas legales.

o Acceso a zonas de lavabos, comidas y bebidas y teléfonos públicos.

o Mantenimiento de niveles de ruido dentro del mínimo posible, en evitación de tensión e irritación.

Andalucía (actualización de 2012), declara que las infraestructuras sanitarias «se realizaron de acuerdo a las exigencias de la asistencia sanitaria vigente en el momento en que fueron planificadas», pero que resulta preciso actualizar los centros, dotándolos de recursos que sin modificar su fin original (la asistencia sanitaria), «permitan además realizarlo en un ambiente de confianza y seguridad».

El Plan de Andalucía prevé también tomar en cuenta la seguridad de los profesionales para la construcción y diseño de nuevos centros y reformas de los existentes. 
Cantabria (2014) establece así mismo la adecuación de las infraestructuras e inmuebles, tanto en las reformas de los centros sanitarios, como en su nueva construcción.

Se pretende mejorar las condiciones de ingreso y estancia de los pacientes en los hospitales. Las directrices de la Comunidad de Madrid (Comunidad de Madrid, 2004) instauran el uso de protocolos de información y comunicación, sistemas de señalización interna para facilitar la circulación de los usuarios e información escrita a los pacientes en el momento de ingreso (sobre normas, cartera de servicios del centro, catálogo de derechos y deberes, instrucciones sobre visitas y familiares acompañantes). Se prevé la implantación de un Plan de Acogida.

Algunos instrumentos de prevención distinguen entre la adopción de medidas de seguridad en los centros sanitarios y las encaminadas a proteger al profesional que presta la asistencia en el domicilio del paciente (Comunidad de Madrid, 2004).

Dentro del apartado de prevención secundaria de las agresiones, se establecen medidas de seguridad activa y pasiva.

Medidas de seguridad pasiva:

- Dispositivos de alarma interna de incidencias: teléfonos, interfonos, sistemas fijos en mesas y puestos de trabajo, con desvío a un panel receptor de avisos con señal sonora y visual y, en su caso, conectados con el servicio de seguridad del centro (Comunidad de Madrid, 2004) (Comunidad Autónoma de Murcia. Consejería de Sanidad., 2005). Alarmas o interfonos en las consultas (Andalucía, 2012). Ante situaciones de riesgo claro, facilitar a los trabajadores teléfonos, buscapersonas o radios para que puedan alertar a los compañeros; sistemas de alarma silenciosos y discretos para no facilitar la escalada de la violencia con un plan fiable de respuesta ante una señal de alarma (Aragón, 2006). La Rioja (2008): Dispositivos de alarma interna de incidencias en consultas y lugares de riesgo, con conexión a centrales monitorizadoras de los avisos de llamada (teléfonos, interfonos, sistemas de alarma fijos en mesas o personales), con la misma insistencia que en el Plan de Aragón: necesidad de que estos sistemas sean discretos y silenciosos; hay que destacar que el Plan de La Rioja distinga entre dispositivos en consulta, despachos y controles de enfermería, dispositivos de alarma personal y alarma interna de incidencias. Dispositivos de alarma (timbres o interfonos) en las consultas (Cantabria, 2014).

Resulta de importancia reseñar que La Rioja (2008) fija un Protocolo de Respuesta, consistente en un «Plan fiable de ayuda inmediata ante una señal de alarma, sea del tipo que sea».

- Videocámaras con grabación en espacios comunes, de acuerdo con la normativa vigente y las normas de seguridad y confidencialidad establecidas (Comunidad de Madrid, 2004). 
En el caso de Murcia, se apunta la posibilidad de instalar web-cams en ordenadores de áreas de recepción y unidad de gestoría, por ser su coste menor que el de las videocámaras (Comunidad Autónoma de Murcia. Consejería de Sanidad., 2005). Cámaras de vigilancia en sectores potencialmente peligrosos (Aragón, 2006). Colocación de Videocámaras con grabación en espacios comunes, con garantía de intimidad y confidencialidad de acuerdo con la normativa vigente (La Rioja, 2008). Videocámaras de vigilancia en locales (Andalucía, 2012) ${ }^{48}$. Videocámaras en locales (Cantabria, 2014).

- Elaboración de un protocolo de respuesta ante potenciales conflictos(Comunidad de Madrid, 2004).

- Implantación de arcos detectores de metales en las entradas de los centros sanitarios, estando esta medida condicionada a que el centro disponga de vigilante de seguridad (Comunidad Autónoma de Murcia. Consejería de Sanidad., 2005). Esta misma medida se fija como una actuación a valorar en el Plan de La Rioja (2008), en las áreas de más riesgo, que en el citado Plan son: Servicios de Urgencias, Unidades de Psiquiatría, y PAC valorados como conflictivos, de acuerdo con el mapa de riesgos.

- Cristales irrompibles en servicios que atiendan a pacientes psiquiátricos en fases agudas (Comunidad Autónoma de Murcia. Consejería de Sanidad., 2005). Igualmente se prevé esta medida por parte del Plan riojano, dentro de las áreas con más riesgo, mencionadas en el punto anterior (La Rioja, 2008).

- $\quad$ Sistema de filtro de llamadas (Comunidad Autónoma de Murcia, 2005).

- Dos salidas en las salas de atención y, de no ser posible, que tengan una disposición que permita salir fácilmente (Aragón, 2006). Salidas alternativas en los espacios de consulta, con un sistema de doble puerta que garantice una salida eficaz (La Rioja, 2008). Salidas alternativas en los espacios de consulta (Andalucía, 2012). Salidas alternativas en los espacios de trabajo (Cantabria, 2014).

Medidas de seguridad activa:

- Procedimientos de comunicación y colaboración con las Fuerzas y Cuerpos de Seguridad. El Plan de La Rioja (2008) destina un apartado a este punto: afirma que se facilitará la comunicación fluida y el fomento de actuaciones conjuntas. El detalle de esta colaboración queda especificado en las siguientes actuaciones:

o Jornadas conjuntas de colaboración en la prevención de conflictos.

o Planes de actuación con la participación de las Fuerzas y Cuerpos de Seguridad.

\footnotetext{
${ }^{48} \mathrm{Se}$ insiste en que la instalación de este tipo de dispositivos deberá garantizar la confidencialidad e intimidad (tanto de profesionales como de usuarios). Igualmente, en el Plan cántabro se alude a la misma cuestión, «garantizando la confidencialidad e intimidad de profesionales y usuarios» (Cantabria, 2014).
} 
o Establecimiento de planes de colaboración entre los citados Cuerpos y el personal de seguridad de los centros.

o Adopción de sistemas de comunicación directa entre la Dirección de los centros y las Fuerzas y Cuerpos de seguridad.

- Asegurar la confidencialidad y salvaguarda de los ficheros y registros relativos a los datos personales de sus trabajadores (Comunidad de Madrid, 2004); medidas necesarias tendentes a preservar la confidencialidad de los datos personales de los trabajadores (Comunidad Autónoma de Murcia, 2005).

- Atención con acompañamiento de otro profesional sanitario en casos en que el usuario haya tenido comportamientos previos inadecuados (Comunidad de Madrid, 2004). Se añade a esta medida la posibilidad de llamar a seguridad o recibir al usuario con la puerta abierta (Comunidad Autónoma de Murcia. Consejería de Sanidad., 2005). Acompañamiento por parte de otro profesional en la actuación, en los casos de personas con comportamientos previos inadecuados o conflictivos (Aragón, 2006). A criterio del profesional y en caso de atención a usuarios potencialmente conflictivos, se procurará que la asistencia sea realizada con el acompañamiento de otro profesional (también puede hacerse con aviso al personal de seguridad); esta medida se extiende a la asistencia domiciliaria (La Rioja, 2008). El profesional no debe estar solo en la consulta cuando las actividades se consideren de riesgo (Andalucía, 2012). Acompañamiento del profesional en la atención a usuarios con antecedentes o patologías que presenten riesgo (Cantabria, 2014).

- Control de accesos, con reducción al mínimo de los sectores de acceso del público a las instalaciones y limitación en lo posible del acceso a los sectores reservados al personal (Aragón, 2006). Control de acceso a los Servicios o Unidades de riesgo y adecuación de áreas restringidas para uso exclusivo del personal sanitario (La Rioja, 2008).

- Vigilancia de seguridad.

o Establecimiento de protocolos eficaces e idóneos en su actuación:

- En ruta: ronda periódica a los Centros de conflictividad puntual. Reorganización del personal por parte de la empresa si los incidentes superan las posibilidades de atención de los vigilantes en ruta (Comunidad de Madrid, 2004).

- Permanente: En todos los centros hospitalarios y en centros sanitarios de conflictividad elevada (Comunidad de Madrid, 2004).

Estas actuaciones se reproducen de forma casi mimética en el Plan de Murcia. Aragón (2006) únicamente especifica que «deberá haber servicios de seguridad en cada zona que se identifique de riesgo en cada centro». 
La Rioja (2008) prevé el establecimiento de estándares en la contratación del Servicio de Seguridad; los centros deberán extremar las condiciones y funciones de sus Servicios de Seguridad; se incide en la necesidad de establecer protocolos eficaces (incluyendo la realización de simulacros periódicamente). Se fijan las funciones de los vigilantes de seguridad:

- Colaboración con las Fuerzas y Cuerpos de seguridad.

- En ruta: En centros de conflictividad puntual, vigilancia periódica. Reorganización de la vigilancia por parte de la empresa si la conflictividad supera las posibilidades de atención por parte de los vigilantes.

- Guardia permanente: En los Servicios de Urgencias de los hospitales y en centros sanitarios de elevada conflictividad.

Andalucía (actualización de 2012) incide en que se extremen los pliegos de cláusulas administrativas de los contratos de servicios de seguridad, recogiendo las funciones que deben realizarse con el máximo detalle en el contrato. Asimismo, ordena que se establecerán estándares que regulen la contratación en los centros que figuren en los mapas de riesgo y que aún no tengan contratado el servicio de seguridad.

En Cantabria (2014) se detalla lo siguiente respecto a los contratos con empresas de seguridad privadas:

- Serán individualizados, según la información aportada por el Mapa de Riesgos.

- El plan de seguridad de los hospitales será actualizado, con el fin de garantizar un personal mínimo de seguridad.

- La definición de las funciones a realizar por la empresa se incluirá con todo rigor y detalle en los contratos que se suscriban.

En el caso de asistencia sanitaria domiciliaria, se establecen medidas de seguridad y recomendaciones específicas, en atención a las especiales circunstancias en que dicha asistencia se produce (entorno desconocido y por ello mayor vulnerabilidad).

- Acuerdos con las Fuerzas y Cuerpos de Seguridad para garantizar la asistencia inmediata a los profesionales de atención domiciliaria (y también de urgencias, cuando se produzcan situaciones de riesgo) (Comunidad de Madrid, 2004). También se fomentarán estos acuerdos para la contención de los enfermos agresivos en su domicilio y posterior traslado en medios de transporte adecuados (Comunidad de Madrid, 2004). A estos efectos, la Comunidad de Murcia establece, junto con estas medidas, que se promoverá un acuerdo 
marco para el posterior desarrollo específico por áreas (Comunidad Autónoma de Murcia. Consejería de Sanidad., 2005).

- Posibilidad de poner a disposición de los profesionales un teléfono móvil institucional ${ }^{49}$ con funciones de monitorización de telepresencia, o de «buscapersonas» con alarma de localización (Comunidad de Madrid, 2004).

- Atención domiciliaria realizada por dos profesionales sanitarios, en caso de antecedentes de comportamiento inadecuado o enfermos conflictivos. Esta opción se ejercitará a criterio del profesional interesado (Comunidad de Madrid, 2004). El Plan de Murcia establece esta recomendación, pero sin manifestar explícitamente que la elección sea del profesional (Comunidad Autónoma de Murcia. Consejería de Sanidad, 2005).

- Internamiento del paciente cuando su agresividad se deba a enfermedad mental (Art. 763 de la Ley 1/2000 de Enjuiciamiento Civil). Idéntica previsión se efectúa en el Plan de Murcia, detallando que el responsable del centro deberá comunicar a la autoridad judicial la urgencia del caso y la justificación de la medida en el plazo de 24 horas (Comunidad Autónoma de Murcia. Consejería de Sanidad., 2005).

- Las medidas de seguridad adoptadas por la Comunidad Autónoma de La Rioja (2008) en este ámbito comprenden:

o Impulso de procedimientos de comunicación y colaboración con las Fuerzas y Cuerpos de Seguridad para garantizar asistencia inmediata en casos de agresión. Así mismo, fomento de colaboración con los citados organismos de seguridad para contención de enfermos agresivos y traslado de los mismos en medios de transporte adecuados. Procedimiento de Alerta (con preferible participación de las Fuerzas y Cuerpos de seguridad para casos en que existan sospechas fundadas de riesgo).

o Estudio de oportunidad de poner a disposición del SUAP y 061 un teléfono móvil institucional (con función de «buscapersonas» y alarma de localización en caso de peligro inminente).

o Pacientes con antecedentes de comportamiento inadecuado: recomendación de que la asistencia se realice con acompañamiento de otro profesional.

- Andalucía (actualización de 2012) no precisa qué actuaciones especiales iniciará en la materia, manifestando sólo que, en zonas con necesidades de transformación social, se

\footnotetext{
${ }^{49}$ El Plan de Prevención de la región de Murcia manifiesta que se evaluará conjuntamente con los profesionales la necesidad de «poner a su disposición un teléfono móvil, específicamente habilitado para su utilización en la atención domiciliaria» (Comunidad Autónoma de Murcia. Consejería de Sanidad., 2005).
} 
adoptarán «determinadas acciones que minimicen la exposición a situaciones potencialmente conflictivas».

- Cantabria (2014): Realización de las visitas acompañados por otros profesionales, solicitud de acompañamiento de la Policía Local o Guardia Civil cuando la visita implique riesgo de cierta entidad y constancia en el Centro de la dirección y teléfono de los pacientes a visitar, junto con la hora de salida y la prevista de regreso.

Formación de los profesionales sanitarios en el manejo de situaciones conflictivas y recomendaciones de actuación para prevenir agresiones o reaccionar ante las mismas cuando se producen.

Se promueve la organización de cursos de formación en este sentido, realizando también una serie de recomendaciones generales, de las que pueden destacarse:

- Mantener una escucha activa y relajada, que facilite la oportunidad de hablar posteriormente (Comunidad de Madrid, 2004).

- No responder a las agresiones verbales, ni desafiar, agredir o encararse con el agresor (Comunidad de Madrid, 2004).

- Ante la posibilidad o inminencia de una agresión, tomar una distancia de seguridad cerca de la salida, con la puerta abierta, sin dar la espalda al agresor (Comunidad de Madrid, 2004).

- Interrumpir la actividad asistencial cuando la situación no esté controlada o el profesional no se encuentre en condiciones de reanudarla. La dirección del centro deberá arbitrar un procedimiento para garantizar la atención a los ciudadanos (Comunidad de Madrid, 2004).

El Plan de Prevención de Murcia hace énfasis en la detección de personas «potencialmente generadoras de violencia» y da una serie de pautas para ello, con especial atención al lenguaje verbal y no verbal:

- Verbal: Tono alto, insultos, palabras groseras, contenido del discurso coaccionante, solicitudes poco razonables o sin sentido.

- No verbal: Contracción de músculos faciales, señalar con el dedo, cambios de postura bruscos, cabeza en flexión con mirada directa y fija, mantenimiento del contacto visual de forma prolongada, conducta destructiva con los objetos.

También señala que debe generar alertas la incongruencia entre lo verbal y lo expresado a nivel no verbal (discurso muy correcto, pero no correlativo con las manifestaciones gestuales o corporales). 
Tras la detección del usuario potencialmente agresivo, siguen las recomendaciones sobre cómo actuar ante el mismo:

- No responder a las provocaciones.

- Utilizar un tono afable y profesional ${ }^{50}$.

- Procurar explicar los motivos por los que no pueden cumplirse sus expectativas (en un lenguaje accesible para el interlocutor).

Si todo esto falla y la tensión sigue aumentando, intentar reorientar la conversación:

- Permitir hablar al usuario para que libere su tensión emocional explicando sus sentimientos, dudas, etc. El profesional en este punto deberá tener una escucha activa.

- Admitir las posibles deficiencias.

- Señalar aquello en los que ambas partes están de acuerdo (profesional y paciente), encontrando puntos comunes.

- Sobre todo cuando hay dificultades para controlar las emociones propias, verbalizar ante el paciente los sentimientos: esto puede hacerle recapacitar sobre su conducta.

Se dan a continuación una serie de recomendaciones sobre el lenguaje verbal y no verbal que debe manifestarse ante el usuario; seguidamente, si la violencia persiste, se aconseja finalizar la entrevista y proceder a la huida o a usar el timbre de alarma.

En el caso de que el agresor impida la salida: procurar ponerse fuera de su alcance, protegiéndose con elementos del mobiliario. De no ser posible, repeler la agresión haciendo uso del derecho a la legítima defensa ${ }^{51}$. De cualquier forma, estas recomendaciones insisten en la conveniencia de evitar la confrontación física directa, siempre que ello sea posible.

Cuando el agresor vaya armado, lo aconsejado es obedecer sus indicaciones hasta valorar las posibilidades de defensa efectiva, así como llamar a la policía y denunciar los hechos.

El Plan Perseo de Castilla-La Mancha (2005) tiene un «Procedimiento de identificación de las necesidades formativas para la prevención y actuación frente a la violencia en el trabajo» que pretende atender a esas necesidades, creando una cultura de prevención-protección frente a las agresiones. Se establece en este procedimiento la coordinación y acción entre diversos departamentos, en orden a la identificación análisis y valoración de las propuestas formativas en materia de seguridad.

\footnotetext{
50 «El tono frío y cortante puede aumentar la conflictividad», «El trato con el paciente debe transmitir firmeza, pero evitando la prepotencia» (Comunidad Autónoma de Murcia. Consejería de Sanidad., 2005).

51 «...siempre con la "mínima fuerza necesaria" para rechazar o neutralizar el ataque y "proporcional al daño que se pretende evitar" ( (Comunidad Autónoma de Murcia. Consejería de Sanidad., 2005), es decir, necesidad racional del medio empleado (art. 20.4 CP).
} 
Extremadura (2006) dedica un apartado a la formación continuada y específica dirigida a los profesionales de la salud. Esta formación irá dirigida hacia dos vertientes: mejorar el conocimiento de las variables ambientales modulantes de situaciones conflictivas e incrementar su capacidad para afrontarlas. En este sentido, se realizarán cursos, talleres y/o seminarios de tipo eminentemente práctico, en los que se hará especial hincapié en el Procedimiento de actuación o Protocolo frente agresiones al personal del SSPE. También se abordarán situaciones difíciles en relación con el paciente, elementos de escucha activa, asertividad, comunicación de malas noticias, autocontrol emocional, etc.

Se ofrecen, asimismo, una serie de recomendaciones a los profesionales para minimizar y evitar situaciones conflictivas, como proporcionar al ciudadano información clara, proporcionar un trato correcto y humanizado, sin intolerancia, insensibilidad, desatención o falta de escucha, evitar conflictos entre profesionales, detectar indicadores de riesgo por parte del usuario, y otra serie de consejos centrados en las habilidades de comunicación.

Es de destacar la importancia que otorga a la formación de sus profesionales el Plan de Prevención de Aragón (2006), manifestando la necesidad de que todos los trabajadores tengan información sobre los distintos tipos de violencia y las mejores prácticas para reducirla. Proclama que todos los profesionales deben formarse en habilidades sociales, gestión del conflicto, asertividad, resolución de problemas, técnicas de negociación, inteligencia emocional, gestión del estrés propio y del usuario, etc. Igualmente incide en la importancia de la formación para detectar las señales de aviso en una situación de violencia y añade que «la falta de capacidad para identificar las posibles situaciones de violencia es por sí misma un riesgo añadido» (Aragón, 2006).

El Plan de La Rioja (2008) es bastante detallado en este aspecto. En primer lugar, se potencia la formación de los profesionales sanitarios en técnicas de comunicación, derechos y deberes del usuario, manejo de situaciones críticas y pacientes conflictivos y uso del sistema sanitario. Como contenidos de referencia en la formación del personal sanitario se proponen: técnicas de información y comunicación a pacientes y familiares, manejo de situaciones críticas, consultas asertivas como habilidad social, manejo de pacientes conflictivos, circuitos de comunicación interna del SERIS, detección precoz de situaciones conflictivas, conocimiento del Plan de Prevención de Agresiones del SERIS, gestión del estrés, curso de habilidades sociales, curso de inteligencia emocional, planes de calidad, manejo de pacientes con patología mental y gestión de reclamaciones y propuestas.

El citado Plan riojano dedica, además, un apartado al «Procedimiento de actuación para la detección de situaciones potencialmente conflictivas», en el que recomienda tener en cuenta los siguientes signos o indicadores de riesgo de conducta agresiva: 
- Señalar con el dedo, apretar los puños, apretar objetos.

- Tensión muscular, flexión y cambios de postura rápidos y frecuentes, sin finalidad concreta; detención repentina de movimiento.

- Contracción labial con visualización de dientes o contracción intensa de los músculos maseteros.

- Postura cefálica baja y avanzada, barbilla hacia el pecho, cuello en flexión; adopción de postura de lucha (tipo boxeador o luchador de artes marciales).

- Mirada fija y directa, establecimiento de contacto ocular prolongado. «Cuando el ataque es inminente la mayoría de personas fijarán la mirada en el punto que agredirán».

- Discurso paranoico o coactivo.

- Conducta destructiva con los objetos.

- Peticiones sin sentido o irracionales.

- Incongruencia entre lo verbal y lo no verbal (lenguaje calmado en exceso, halagador...).

Las recomendaciones ante estos indicadores de riesgo, son las siguientes:

- No responder a las provocaciones, manteniendo el equilibrio emocional.

- Conversar con corrección (tono afable y profesional). Esto incluye la evitación de tonos bruscos y cortantes, dirigirse al paciente con firmeza (pero evitando la prepotencia), explicar con detalle y de forma razonada los motivos que hacen imposible responder a las expectativas del interlocutor.

- Reorientar la conversación en caso de que la tensión aumente:

o Hacer un contrabalance emocional: conducir al interlocutor al estado de ánimo tranquilo que mantiene el profesional.

o Liberar la tensión emocional del interlocutor: dejarle hablar para que explique sus sentimientos, manteniendo una actitud de escucha activa. Evitar gestos que puedan interpretarse como menosprecio.

o Reconocer posibles deficiencias (propias y de la organización).

o Manifestación de los propios sentimientos al interlocutor. Cuando no se pueden controlar las propias emociones (en especial cuando se han padecido insultos graves o vejaciones) puede ser conveniente mostrar los sentimientos de tristeza o malestar que ha producido el incidente. Esto llevaría al interlocutor a tomar consciencia de las posibles consecuencias de su conducta. Se aconseja no mencionar la posibilidad de denuncia.

o Evitar transmitir las siguientes señales verbales y no verbales:

- Verbales: no usar estilos comunicativos de apatía, frialdad, condescendencia, menosprecio o impaciencia, porque pueden generar hostilidad. Tampoco deben verbalizarse amenazas, coacciones o 
insultos. No minimizar la situación, quejas o críticas. No transmitir información falsa o proponer pactos irreales.

- No verbales: Evitar ponerse en pie en posición frontal, las manos en las caderas, cruzar los brazos, señalar con el dedo... No tener contacto físico o exceso de proximidad (distancia prudente: aproximadamente igual a la longitud del brazo). No mantener un contacto visual prolongado. No dar la espalda ni hacer movimientos rápidos.

o Si con todo eso no se consigue frenar la escalada de violencia:

- Dar por finalizada la visita.

- Situar mentalmente una vía de huida, localizando posibles obstáculos que puedan interceptar la salida.

- Utilizar el timbre de alarma (si se dispone del mismo).

- Salir.

- Si el agresor impide la salida:

$\checkmark$ Agresor no armado: protegerse con elementos mobiliarios. En caso de que esto no sea posible, defenderse ${ }^{52}$.

$\checkmark$ Agresor armado: intentar frenar su impulso de usar el arma, siguiendo las indicaciones del agresor hasta evaluar la posibilidad de una defensa activa.

Un punto muy interesante que se incluye en el Plan de Prevención de La Rioja es la advertencia sobre la posibilidad de que se genere violencia por parte del profesional. Se llama la atención sobre la posible presencia de patologías en el propio personal que pueden generar o dificultar la resolución de los conflictos (La Rioja, 2008).

La formación de los profesionales es sin duda el plato fuerte del Plan de Prevención de Andalucía (actualización de 2012), que dedica todo un apartado a la «Capacitación y competencias profesionales. Plan de Formación». Este Plan de Formación consiste en la realización de talleres prácticos dirigidos a todos los profesionales de la salud. Los talleres serán descentralizados (organizados en cada centro) y con la posible colaboración de colegios profesionales, asociaciones de consumidores y usuarios, organizaciones sindicales y otras administraciones.

\footnotetext{
52 Se aconseja ejercer una autodefensa que cuente con los requisitos necesarios para ser considerada "legítima defensa», como causa de modificación de la responsabilidad criminal, utilizando "la mínima fuerza necesaria» y «proporcional al daño que se pretende evitar». Del mismo modo, se advierte de la posibilidad de que la legítima defensa pueda confundirse con los supuestos de «pelea mutuamente aceptada», recomendando en último término la huida en todos los casos en que ésta sea posible.

Hay que señalar además que en el orden penal, tomar parte activa en la pelea puede suponer la pérdida de la protección que brinda el artículo $550 \mathrm{CP}$ (atentado).
} 
Los objetivos del mencionado Plan de Formación serán los siguientes:

1. Analizar la relación de los profesionales sanitarios con sus pacientes y familias en situaciones agresivas y de conflicto.

2. Debatir sobre estrategias de mejora a desarrollar por los profesionales para ser capaces de dar respuesta a esas situaciones.

3. Entrenarse en algunas habilidades básicas en la relación profesional sanitario-paciente para conseguir una atención más eficaz en dichas situaciones.

Los contenidos planteados se fijan en los principios básicos de la comunicación en situaciones difíciles, elementos que facilitan y dificultan la comunicación, técnicas de asertividad, escucha activa, comunicación no verbal, técnicas y habilidades de negociación y autocontrol y manejo del estrés.

Cantabria (2014) incluye la formación de los profesionales dentro de sus «Medidas de Prevención Primaria». Implanta una estrategia de formación e información específicas para los trabajadores sanitarios que se concreta en las siguientes actuaciones:

- Difusión del Plan de Prevención y Atención ante incidentes violentos en el ámbito sanitario (es decir, del propio documento que está estableciendo estas medidas).

- Formación de los mandos directos en tareas de notificación e investigación de incidentes. Esto es una novedad, normalmente los Planes de Prevención se centran en la formación del trabajador exclusivamente.

- Realización de seminarios o talleres sobre manejo de situaciones conflictivas, habilidades para controlarlas, reconocimiento de actitudes amenazantes. Los puntos a potenciar serán: escucha activa, asertividad, autocontrol y facilitar la participación de los pacientes en las decisiones que les afecten ${ }^{53}$.

- Coordinación de la información a través de la Comisión de Violencia del Trabajo sanitario (en la que participan las organizaciones colegiales y sindicales).

\section{PROCEDIMIENTOS DE ACTUACIÓN ANTE INCIDENTES}

Los diferentes Planes de Prevención establecen distintos procedimientos a seguir cuando se produce una agresión.

En las directrices de la Comunidad de Madrid (Comunidad de Madrid, 2004), se marcan los siguientes pasos consecutivos:

\footnotetext{
53 Punto con base en la Ley 41/2002, de 14 de noviembre, básica reguladora de la autonomía del paciente y de derechos y obligaciones en materia de información y documentación clínica.
} 
1. Solicitar ayuda del vigilante de seguridad (si lo hay), de los compañeros y especialmente del responsable del centro o servicio. El responsable debe identificarse ante quien está provocando el incidente y, seguidamente, darle órdenes claras y concretas.

2. De mantenerse la situación, se procede a alertar a las Fuerzas y Cuerpos de Seguridad.

3. Comunicación del incidente a Gerencia o al responsable del centro. Para ello, se habilita un sistema de comunicación que estará operativo las veinticuatro horas del día durante todo el año.

4. Un miembro del equipo directivo, recibida la comunicación en la Gerencia, se desplazará al centro sanitario (más o menos rápidamente, según la gravedad del incidente).

5. También es notificado el hecho a la Inspección Sanitaria. En su calidad de Autoridad Sanitaria, se desplazará al lugar de los hechos y emitirá informe que se trasladará a Gerencia o a la dirección del centro, en su caso.

6. Tramitado el informe de la Inspección Sanitaria, se llevarán a cabo las actuaciones siguientes (conjuntamente con la/s persona/s afectada/s y el responsable del centro o servicio):

a. Evaluación de la incidencia.

b. Valoración de las medidas de seguridad existentes, con análisis de posibles carencias o fallos.

c. Asesoramiento a los afectados ${ }^{54}$ sobre las alternativas de actuación que puedan adoptar, incluyendo las posibles actuaciones legales ${ }^{55}$.

7. Registro de la incidencia en la Gerencia, así como posterior notificación a la Comisión Central de Seguimiento.

8. Comunicación al Servicio de Prevención de Riesgos Laborales del Área donde se haya producido el incidente con el objeto de elaborar el mapa de riesgos ${ }^{56}$.

9. Se prevé la adopción de medidas necesarias para dispensar apoyo médico y psicológico al trabajador afectado.

Como actuaciones adicionales que se pueden llevar a cabo, previa valoración del caso, se encuentran las siguientes:

a) «Medidas organizativas especiales para identificar al ciudadano que haya originado el incidente», que llevan aparejadas las actuaciones necesarias para que se garantice su atención y la seguridad de los trabajadores que intervengan en dicha atención.

\footnotetext{
${ }^{54}$ Literalmente: «Asesoramiento, en su caso, a los afectados, ...», lo que parece indicar que no siempre se va a ofrecer este asesoramiento.

${ }_{55}$ Para ello se cuenta con el apoyo técnico de la Dirección General de Recursos Humanos y de la Secretaría General Técnica de la Consejería de Sanidad y Consumo.

${ }^{56}$ Esta información se transmite a la Comisión Central de Seguimiento cada tres meses, salvo circunstancias especiales.
} 
b) «Tramitación de cambio de médico, incluso de Centro Sanitario», con su correlativa comunicación al ciudadano ${ }^{57}$.

c) «Carta de amonestación» ${ }^{58}$.

d) «Citación del ciudadano en la Unidad Central de la Inspección Sanitaria». No se especifica el objeto de esta citación, pero cabe intuir que se tratará de razonar con el agresor, haciéndole ver lo lamentable de su conducta y posibilitando mediante el diálogo que los hechos no vuelvan a producirse. También puede tratarse, como establece el Plan de Prevención de Murcia, de citar al usuario para conocer su versión de los hechos (Comunidad Autónoma de Murcia. Consejería de Sanidad, 2005).

e) «Participación como parte interesada en las acciones legales que, en su caso, pudieran emprenderse, para reclamar la responsabilidad, tanto civil como penal, del agresor». Se prevé, por tanto, la personación de la Administración en los procesos civiles y penales que puedan seguirse contra los responsables de los sucesos violentos.

Estas últimas cinco actuaciones tienen carácter potestativo, condicionándose a una valoración previa la posibilidad de su ejecución.

El Plan de Prevención de las Agresiones a los Profesionales de la Sanidad de la Región de Murcia (Comunidad Autónoma de Murcia. Consejería de Sanidad., 2005), establece el siguiente «Procedimiento de actuación ante incidentes»:

1. Iniciar la salida de la sala o consulta y avisar al vigilante de seguridad. Si no hay vigilante, pedir ayuda a los compañeros o, si el incidente es grave, solicitar la presencia del responsable del centro o servicio. Este responsable «se identificará y dará instrucciones concretas a los que estén provocando el incidente» ${ }^{59}$.

2. Si tras la intervención del vigilante o de los compañeros la situación violenta persiste, se avisará al 112. El 112 lo comunicará a las Fuerzas y Cuerpos de Seguridad.

3. Siempre se emitirá parte de lesiones cuando se produzca una agresión, a ser posible por la Mutua de Accidentes Laborales.

4. Comunicación preceptiva del incidente o agresión al responsable del centro, mediante el «Documento de Registro de Comunicación Interna de Incidentes». Dicho responsable enviará copia a la Gerencia y al SPRL del SMS.

\footnotetext{
${ }^{57}$ Esta comunicación se efectuará por escrito y será motivada.

${ }^{58}$ Se remite por la Unidad Central de la Inspección Sanitaria (Unidad de Coordinación) y se envía copia al servicio o centro sanitario.

${ }^{59}$ Aunque parezca que se dispone exactamente lo mismo, hay una diferencia importante entre la actuación del responsable del centro o servicio en este Plan de Prevención y la contemplada en las directrices de la Comunidad de Madrid (Comunidad de Madrid, 2004): nótese cómo en estas últimas la intervención del responsable parece ser obligada, mientras que en el Plan de Murcia queda claramente condicionada a «si la gravedad lo requiere». Sin embargo, pese a que el tenor literal de la norma madrileña especifica que el responsable intervendrá en un primer momento, no es realmente así: Pedro Martínez (Fiscal de la Audiencia Provincial de Madrid) describe que el primer paso es avisar a vigilantes y compañeros, sin hacer mención a otras personas (Martínez, 2011).
} 
5. El responsable del centro puede comunicar los hechos telefónicamente para la toma de medidas inmediatas, en caso de que los hechos producidos revistan suficiente gravedad.

6. La Gerencia comunicará el incidente a la Unidad de Atención al Usuario. Esta Unidad se pondrá en contacto con el actor para conocer su versión de lo sucedido.

7. Cuando sea preciso, la Gerencia y el SPRL ofertarán apoyo psicológico y jurídico al afectado. Se contempla la posibilidad de hacer «público manifiesto de repulsa» ante esta situación violenta, «en caso de que se valore necesario».

8. Se encomienda al SPRL el mantenimiento de un Registro de Agresiones, al objeto de elaborar un mapa de riesgos «dinámico y actualizado».

La Circular 1/2007 de Instrucciones sobre Procedimiento ante situaciones de violencia, dictada por la Secretaría General del SESCAM, en desarrollo del Plan Perseo de Castilla-La Mancha (2005), establece las siguientes «Actuaciones ante un incidente violento»:

1. Solicitar la presencia de compañeros, personal de seguridad (de existir) o de los Cuerpos y Fuerzas de seguridad del Estado.

2. Puesta en conocimiento por parte del profesional agredido a su superior orgánico a la mayor brevedad, para que se tomen las medidas inmediatas que resulten necesarias.

3. Si presenta lesiones o necesita asistencia sanitaria, se personará en Urgencias. E1 facultativo que preste la asistencia cumplimentará el oportuno parte de lesiones.

4. Notificación de los hechos por el interesado a la Dirección Gerencia.

5. La Dirección Gerencia acusará recibo de la comunicación del incidente y dará traslado de la misma al Servicio de Prevención del Área. Este Servicio de Prevención procederá a su registro, análisis y propuesta de medidas preventivas de mejora.

6. Cuando pueda deducirse de los hechos ocurridos algún tipo de infracción disciplinaria, la comunicación tendrá consideración de denuncia. La Gerencia dará traslado de la misma a la Oficina Provincial de Prestaciones del ámbito territorial correspondiente.

7. En el acuse de recibo de la Dirección Gerencia se informará al trabajador sobre la disponibilidad de asistencia letrada y asesoramiento jurídico ${ }^{60}$.

El Plan Perseo de Castilla-La Mancha implanta todo un procedimiento de mediación para resolución de conflictos. Este procedimiento se activa cuando se tipifica un hecho como conflicto y se establecen una serie de requisitos para que se produzca una negociación:

- Contar con el consentimiento de los implicados.

- Que el origen o las consecuencias del conflicto tengan suficiente entidad.

- Que no se haya iniciado un procedimiento de reclamación patrimonial o contencioso, o se observen indicios de delito en los hechos.

\footnotetext{
${ }^{60}$ Para más detalle, se remite a la Circular 4/2006, de 13 de marzo, sobre Asistencia Jurídica a trabajadores del
} SESCAM. 
- Que no se trate de cuestiones de disconformidad con citaciones, demora en asistencia o cualesquiera otros aspectos asistenciales expresamente regulados por la normativa vigente.

Resumiendo mucho el citado procedimiento, podemos señalar que hay dos fases: instrucción y acuerdo; en la primera se confecciona un informe tras la recogida de información pertinente y en la segunda el equipo de intermediación estudia el asunto y establece una estrategia para la resolución o gestión del conflicto, comunicando la decisión adoptada a las partes.

Extremadura (2006) fija el procedimiento siguiente:

1. Solicitud de ayuda a compañeros o personas cercanas que le ayuden a terminar con la situación de violencia, o al vigilante de seguridad (en el caso en que lo haya). Estas personas, además, servirán de testigos de los hechos.

2. Si la agresión se produce, aviso a las fuerzas y cuerpos de seguridad o fuerzas de orden público.

3. Una vez resuelta la situación:

a. Comunicar o notificar el incidente al responsable del centro sanitario, que informará a su vez a la Gerencia.

b. El agredido deberá dirigirse al Servicio de Urgencias/Servicio de Medicina Preventiva, que:

i. Valorará las lesiones y emitirá el correspondiente parte de las mismas.

ii. Cursará la baja médica si se considera necesario e iniciará el tratamiento médico y/o psicológico.

iii. Cumplimentará el Documento de Registro de incidentes.

iv. Recabará asesoramiento jurídico y/o asistencia letrada, en su caso.

c. Denuncia por parte del profesional ante el órgano competente.

La «Pauta de actuación en caso de agresión» de Aragón (2006) contempla el siguiente procedimiento:

1. Solicitud de auxilio: El trabajador utilizará los sistemas de seguridad y aviso, solicitará ayuda a un compañero y/o al vigilante de seguridad. En función de la gravedad de la situación, se alertará las Fuerzas y Cuerpos de Seguridad.

2. Asistencia médica y comunicación de lesiones: Si es necesaria la asistencia, esta se ofrecerá en servicio de urgencias, centro de salud, hospital o mutua de referencia del trabajador. Se cumplimentará informe médico (se insiste sobre la necesidad de cumplimentarlo de forma exhaustiva) y parte de lesiones al juzgado. 
3. Comunicación del incidente o agresión:

a. El trabajador comunicará el incidente a su superior jerárquico (en caso de que el propio interesado no pudiera hacerlo, se encargará de la comunicación un compañero).

b. A su vez, el incidente será elevado al Director del Servicio Provincial, Director General, Responsable de Centro y/o Gerente del Sector. Éste, cumplimentará el manifiesto de rechazo y el modelo de notificación al juzgado de Instrucción ${ }^{61}$, informando al trabajador de las acciones legales y administrativas que pueden tomarse.

4. Valoración del incidente o agresión por la Unidad Básica de Prevención o Unidad Central de Prevención: El trabajador acudirá a su Unidad de referencia para entregar la hoja de recogida del incidente (realizada por su superior jerárquico) y, en su caso, el informe de asistencia médica. La Unidad cumplimentará los datos del incidente y actuarán según el Procedimiento de investigación establecido (que se detalla en el Anexo II del citado documento).

5. Apoyo psicológico: La Unidad Básica de Prevención o Unidad Central de Prevención valora la necesidad de apoyo psicológico al trabajador en cada caso. Si el trabajador precisara tal apoyo, se le remitirá a su centro de salud mental de referencia (con una hoja de colaboración específica en que consten los datos concretos del caso de violencia en el trabajo, para que la cita sea preferente).

6. Apoyo jurídico:

a. El responsable del centro donde haya ocurrido la agresión la comunicará a la Dirección General de Servicios Jurídicos (con independencia de las acciones legales que haya podido emprender el propio trabajador).

b. El trabajador acudirá a dichos servicios jurídicos con una copia de la denuncia presentada ante la policía y la hoja de registro del incidente.

c. El responsable emitirá un manifiesto de rechazo de agresión.

7. Registro de incidentes y agresiones:

a. La Unidad Básica de Prevención de Riesgos Laborales cumplimenta la Hoja de Registro de Agresiones en su base de datos y remite copia a la Secretaría General Técnica (vía fax o por correo electrónico).

b. Anualmente cada Unidad Básica de Prevención realiza un análisis de los datos estadísticos. La Unidad Central de Prevención elaborará una Memoria Anual de Violencia en el Trabajo de los casos ocurridos y de las medidas adoptadas en la Comunidad Autónoma de Aragón.

\footnotetext{
${ }^{61}$ Se manifiesta que esta acción se realiza «para dar cumplimiento a lo establecido en el art. 262 de la LECrim».
} 
El Plan de Prevención y Atención al Profesional del Servicio Riojano de Salud Víctima de Agresión en el Desempeño de sus Funciones (2008) prevé el siguiente procedimiento de actuación:

1. Iniciar la salida de la consulta o sala.

a. Usar los sistemas de aviso y seguridad (si lo hubiera).

b. Llamar a un compañero o persona cercana (para que le auxilie y sirva de testigo).

c. Cuando se trate de una atención domiciliaria, se irá del domicilio a la mayor brevedad.

2. Si persiste la violencia: alertar a las Fuerzas de Seguridad.

3. Resuelto el incidente:

a. Comunicación al superior presente en el centro. Éste se personará en el lugar de la agresión. En el caso de una atención domiciliaria, la comunicación se hará al responsable del centro de referencia.

b. Se facilitará una hoja de «notificación del incidente» al profesional agredido. Esta hoja será cumplimentada por él y por el responsable del centro, servicio o unidad. Será remitida a la Dirección correspondiente y al SPRL.

4. En caso de agresión física: el agredido, acompañado por su responsable, acudirá al Servicio de Urgencias. Allí se valorará su estado, se le atenderá y se cumplimentará el informe médico y el parte de lesiones (para el juzgado). Cuando proceda, el trabajador será derivado a la Mutua de Accidentes, para la extensión del parte de accidente de trabajo y baja laboral, si fuera preciso.

5. Se notificarán al SPRL del SERIS todos los incidentes de violencia (ya sean de tipo físico, verbal o psicológico). Queda especificado literalmente que esto incluye «los incidentes menores en los que no se haya causado daño». El SPRL contactará con el trabajador agredido en el primer día hábil (se entiende que se refieren al primer día hábil siguiente a la agresión), para solicitarle los datos necesarios para cumplimentar el «registro de agresiones». La investigación del accidente o incidente se llevará a cabo por el SPRL, que evaluará los hechos y emitirá un informe.

6. Como «medidas adicionales» se contemplan:

a. Medidas organizativas de identificación del agresor.

b. Tramitación de oficio del cambio de médico (incluso de centro), que deberá ser comunicado motivadamente al usuario afectado.

c. Manifiesto de rechazo: Informe emitido por la Dirección que se dirigirá al agresor. De igual modo, se informará también al afectado y al responsable del centro. 
El Plan de Prevención y Atención de Agresiones para los Profesionales del Sistema Sanitario Público de Andalucía (actualización de 9 de febrero de 2012) fija el siguiente procedimiento:

1. Situación de agresión: Solicitar ayuda del vigilante de seguridad; en caso de que no haya en su centro, pedirá la presencia de un/a compañero/a u otra persona cercana, con el objeto de que le ayude a terminar con la situación de violencia (y servir como testigo de los hechos).

2. Alertar a Fuerzas y Cuerpos de seguridad.

3. Comunicar el incidente al responsable del centro: Finalizada la situación de agresión por la intervención de cualquiera de los actores anteriormente mencionados, se notificará el hecho al responsable de centro, gerente de área, director gerente del hospital, director de distrito o director de CRTS. El responsable en cuestión se personará en el centro (según la gravedad de los hechos) «o, al menos, atenderá al profesional agredido vía telefónica».

Las actuaciones a realizar por el responsable del centro son detalladas dentro de un sub-procedimiento, que abarca los siguientes pasos:

a. Ofrecimiento de apoyo psicológico: El responsable ofrece este apoyo al agredido, que podrá aceptar o declinar este ofrecimiento. Si se inician actuaciones en este sentido, serán recogidas en un protocolo de actuación elaborado por las Unidades de Salud Mental.

b. Ofrecimiento de asesoramiento jurídico: Se realizará sobre todo si el profesional agredido ha decidido denunciar el hecho.

c. Manifiesto de rechazo de la agresión: El responsable valora la conveniencia o no de emitirlo. En caso de que decida hacerlo, el manifiesto contendrá una denuncia de la situación de violencia ocurrida, «lamentando el daño físico y/o psicológico que haya podido sufrir el profesional que desempeña su labor en el centro del cual es responsable».

d. Denuncia por parte del responsable del centro ante el órgano competente: Comunica el hecho a la Asesoría Jurídica Provincial y ésta (en función de la Guía de Asesoramiento Legal y Asistencia Jurídica) decide la actuación a seguir. En su caso, interpondrá denuncia contra el causante de la agresión, que será independiente de la que haya interpuesto el profesional agredido. En esta denuncia se incluirán los daños materiales correspondientes, en el caso de que se hayan producido.

4. Traslado al Servicio de Medicina Preventiva o Urgencias:

i. Valoración de lesiones: si se percibe su existencia, se emitirá el correspondiente parte de lesiones. 
ii. Hoja de registro de agresiones: se realizará siempre (con independencia de si se han producido o no lesiones).

1. Esta hoja de registro será remitida a la Unidad de Prevención de Riesgos Laborales.

2. Esta Unidad, dentro del primer día hábil después de la notificación de la agresión, se pondrá en contacto con el agredido. Al mismo se le solicitará la información necesaria para cumplimentar el Registro Informatizado de Agresiones (con la finalidad de elaborar un mapa de riesgo).

3. Todo el proceso, hasta la indicación de alta laboral, será supervisado por el médico de la Unidad de Prevención de Riesgos Laborales.

4. Los principios básicos de intimidad y confidencialidad del profesional agredido serán respetados a lo largo de todo este procedimiento.

5. Denuncia ante el órgano competente: Juzgado, Guardia Civil, etc.

En el Plan de Prevención de la Comunidad de Cantabria (2014), se implantan las «Actuaciones concretas ante los episodios de violencia en el trabajo» que se describen a continuación. Resulta destacable que en este documento se distingan clara y específicamente las actuaciones a realizar por los profesionales y las que han de llevarse a cabo por la Administración y/o Dirección de Gerencia. El esquema referido a los profesionales es el siguiente:

a. Ante un incidente violento:

i. Pedir a otro profesional sanitario que acuda, bien para ayudar a controlar la situación, bien como testigo de la misma.

ii. Solicitar la presencia de la vigilancia de seguridad (cuando exista en el centro).

b. Alertar a las Fuerzas de Orden Público.

c. Finalizado el incidente, el profesional agredido o los testigos informarán a su superior directo. Este superior se pondrá a disposición del trabajador para prestarle atención e informarle de los pasos a seguir.

d. El mando o responsable y/o el profesional agredido cumplimentará la hoja de registro ${ }^{62}$.

e. Si el agredido necesita asistencia sanitaria, se le trasladará a Urgencias. Allí se valorarán los posibles daños, se emitirá el parte de lesiones correspondiente y se

\footnotetext{
${ }^{62}$ Nótese cómo, a diferencia de otros protocolos, el cántabro permite que cualquiera de los tres implicados (mando, testigo o afectado) cumplimente la hoja de notificaciones, sin adscribir concretamente a uno de ellos dicha función.
} 
cumplimentará la hoja de Registro de Incidentes si aún no se ha hecho, incluyendo la información relativa a las lesiones.

f. Hoja de Registro de Incidentes Violentos. En dicha hoja se recogerá:

i. Información de los hechos y datos que permitan la identificación del causante del incidente, así como los de los testigos presenciales, si los hubiera.

ii. Se remite al Registro de la Dirección Gerencia correspondiente. En este punto, el profesional puede elegir entre lo siguiente:

1. Registro del incidente sin ulteriores actuaciones.

2. Registro del incidente y envío de carta de apercibimiento al usuario implicado, con o sin propuesta de sanción administrativa.

3. Registro del incidente junto con solicitud de denuncia vía judicial contra el agresor.

iii. Si lo desea, el profesional afectado puede informar del incidente a su Colegio profesional.

En lo referente a las actuaciones a emprender por parte de la Administración y/o Dirección Gerencia, serán las que a continuación se relacionan:

1. Mantenimiento del Registro de Incidentes de Violencia en el Trabajo Sanitario por parte de la Consejería competente.

2. Si se produce baja laboral por accidente de trabajo debido al incidente, el SPRL de la Gerencia, en coordinación con la mutua, seguirá el proceso de recuperación del trabajador hasta su alta médica.

3. La Dirección Gerencia del SCS ofrecerá asistencia sanitaria específica a través de la atención en consultas de especialistas, salud mental (si es preciso) y rehabilitación física o psicológica. En todo momento se respetarán los principios básicos de intimidad y confidencialidad del profesional agredido.

4. Asesoramiento legal y asistencia jurídica, que desarrollaremos en el apartado correspondiente.

5. Medidas de conciliación laboral: como en el punto anterior, serán descritas en otro apartado de este epígrafe.

\section{COLABORACIÓN EN LA RESOLUCIÓN DEL INCIDENTE}

Algunos Planes de Prevención tratan de la colaboración con otros órganos en cuanto al esclarecimiento de los hechos y resolución del incidente. En este ámbito se detallan las siguientes actuaciones: 
- No tocar nada del lugar del incidente, dejando los objetos tal como se encontraban ${ }^{63}$. El Plan de Murcia recomienda no tocar nada «para que la policía o el juez puedan hacerse idea cabal del incidente» (Comunidad Autónoma de Murcia. Consejería de Sanidad., 2005).

- Cooperación de los profesionales en «el registro de hechos, instrumentos, pruebas, y de testigos ${ }^{64} \gg$ (Comunidad de Madrid, 2004).

- Emisión de parte de lesiones e inicio de trámites de accidente laboral, en aquellas agresiones en que se haya causado lesión (Comunidad de Madrid, 2004).

\section{MEDIDAS DE CONCILIACIÓN LABORAL}

El Plan de Prevención de Andalucía (actualización de 9 de febrero de 2012) indica que, cuando exista una sentencia firme que fije la necesidad de protección del profesional, se podrán proponer su adscripción temporal a otro centro de trabajo por el periodo que determine la sentencia ${ }^{65}$.

El Plan de Prevención y Atención ante incidentes violentos en el ámbito sanitario público de Cantabria (2014) fija sobre esta cuestión las siguientes medidas:

- La mutua declarará en situación de IT derivada de accidente de trabajo al profesional agredido, cuando sea pertinente.

- Cambio de cupo del usuario implicado en el accidente violento, como medida de prevención de ulteriores incidentes. Con sentencia judicial de por medio, se puede incluso asignar al usuario a un centro sanitario diferente (siempre y cuando exista una justificación de que con ello se protege al profesional) ${ }^{66}$. Esta misma medida se prevé en las «Estrategias para paliar las agresiones a todos los profesionales del Sistema Sanitario Público de Extremadura» (2006), en las que se prevé la intervención de la Inspección para el cambio de cupo médico en casos en que quede constatada una alteración de la relación profesional sanitario-paciente, haciendo uso de la facultad que establece el Decreto de libre elección de médico, centro o servicio sanitario de Atención Primaria.

- Posibilidad de estudiar la adopción de medidas normativas para facilitar la renuncia del profesional a atender a determinados pacientes ${ }^{67}$.

\footnotetext{
63 «...y a disposición de las Fuerzas y Cuerpos de Seguridad, o en su caso del Juez» (Comunidad de Madrid, 2004).

${ }^{64}$ Parece indicarse que los profesionales se prestarán a testificar sobre aquellos sucesos que hayan presenciado, ofreciendo siempre su colaboración al respecto.

${ }^{65}$ Tal medida se tomará por parte del director de la institución, previo informe preceptivo del Servicio de Medicina Preventiva y/o de Prevención de Riesgos Laborales.

${ }^{66}$ Parece que, bajo la denominación «medidas de conciliación» lo que en realidad se está adoptando son medidas de seguridad o de tipo pseudo-sancionatorias.

${ }^{67}$ Al amparo del artículo 5.1. d) de la Ley 44/2003, de 21 de noviembre, de Ordenación de las Profesiones Sanitarias.
} 


\section{ASESORAMIENTO Y APOYO JURÍDICO}

Las directrices elaboradas por la Comunidad de Madrid (Comunidad de Madrid, 2004) establecen una «Cláusula de asesoramiento», formada por dos apartados:

1. Formulación de la denuncia ${ }^{68}:$ La Gerencia presta apoyo jurídico para ello y también para el resto de diligencias que la acompañen. En el caso de que el interesado no disponga de letrado, la disposición se limita a establecer que tal circunstancia será comunicada a otras instancias de la Administración para que arbitren soluciones al respecto ${ }^{69}$.

2. Representación y defensa en actuaciones judiciales: Se realiza una manifestación genérica del apoyo jurídico que será prestado al trabajador agredido, sin precisar cuáles serán las actuaciones concretas ${ }^{70}$.

Pedro Martínez, Fiscal de la Audiencia Provincial de Madrid, manifiesta que sería deseable que los letrados del Servicio Madrileño de Salud intervinieran en los procedimientos penales seguidos como consecuencia de las agresiones cometidas contra los trabajadores por parte de pacientes o familiares (Martínez, 2011).

El Plan de Prevención de las Agresiones a los Profesionales de la Sanidad de la Región de Murcia (2005) dedica todo un apartado al «Asesoramiento sobre actuaciones legales».

1. Se establece que el trabajador agredido debe ser asesorado, bien por los asesores jurídicos del centro o Gerencia a la que pertenezca, bien por el Servicio Jurídico del SMS. La información contendrá los siguientes aspectos:

a. Posibilidad de interponer denuncia penal y consecuencias de esta actuación.

b. Posibilidad de resarcimiento acudiendo a la vía penal y administrativa.

Seguidamente, pasa a aclarar las medidas que pueden tomarse tras la producción de una conducta agresiva, clasificándolas en judiciales y extrajudiciales:

a. Judiciales:

i. Penales.

ii. Civiles.

\footnotetext{
${ }^{68}$ Se procede a ella una vez efectuada la valoración preceptiva de la Inspección Sanitaria, reflejada en su informe (punto 5 del protocolo de actuación).

69 En concreto, se establece que: «se pondrá en conocimiento de la Dirección General del Instituto Madrileño de Salud o del Servicio Madrileño de Salud, según corresponda, con la finalidad de que se arbitre la solución que proceda. En su caso, se podrá solicitar el apoyo de los Servicios Centrales de la Consejería de Sanidad y Consumo». Cabe señalarse que en la «Actualización de referencias» de la Disposición Adicional Única de la Orden 370/2017, de 24 de abril, del Consejero de Sanidad, sustituye (entre otras) la referencia al Instituto Madrileño de Salud por "Servicio Madrileño de Salud» y a la Consejería de Sanidad y Consumo por «Consejería de Sanidad».

70 "La Consejería de Sanidad y Consumo, de acuerdo con los Servicios Jurídicos de la Comunidad de Madrid, arbitrará las medidas y medios necesarios para garantizar la correcta asistencia jurídica, representación y defensa de los afectados por estas situaciones».
} 
iii. Laborales $^{71}$ :

1. Tramitación, si procede, de baja laboral por accidente de trabajo.

2. «Implicación de la empresa».

3. Adopción de medidas organizativas centradas en evitar el contacto con el agresor.

b. Extrajudiciales:

i. Personal facultativo:

1. Se reconoce el derecho del médico a rechazar el seguir prestando asistencia o a «tener contacto con el acompañante», al amparo del art. 5.1d de la Ley 44/2003, de 21 de noviembre, de Ordenación de las Profesiones Sanitarias y del art. 9 del Código de Ética y Deontología Médica.

2. Cambio de médico del agresor por parte de la Gerencia (cuando lo solicite el agredido).

ii. Personal no facultativo: organización del centro de modo que la víctima no tenga que mantener contacto con el agresor.

Se contemplan también «compensaciones en el seno de instrumentos transaccionales» (disculpas, etc.).

c. Otras actuaciones:

i. Incapacitación o atención especializada del agresor (suponemos que esto se aplicará en caso de sujetos afectados de algún tipo de trastorno psiquiátrico).

ii. Incluir un documento acompañando la historia clínica en el que se advierta de la personalidad agresiva del paciente (sólo si se considera necesario).

2. Siempre que lo solicite, el agredido será acompañado cuando vaya a presentar la denuncia. Esta persona acompañante será designada por el inmediato superior o en quien este delegue.

A continuación, se realiza un resumen de los pasos y requisitos necesarios para interponer una denuncia, órganos ante los que puede presentarse, contenido de la misma, etc.

\footnotetext{
${ }^{71}$ En realidad, estas medidas laborales no entran en el ámbito de lo judicial, por lo que deberían haberse incluido
} dentro del apartado 2. 
3. Personas que deben interponer la denuncia.

a. Se informa de que los testigos tienen el deber de denunciar los hechos delictivos que presencien (art. 262 LECrim).

b. Se recomienda que la denuncia la formule:

i. El propio interesado en todos los delitos y faltas ${ }^{72}$ contra las personas.

ii. El Gerente del SMS en casos de lesiones dolosas en que se prevea que puede volverse a realizar la agresión. Esto obedece a la necesidad de no personalizar la denuncia en el agredido.

iii. Cualquier persona: delitos y faltas contra el patrimonio. En el delito por daños por imprudencia debe ser el afectado.

iv. Representante del SMS: delitos y faltas contra el orden público (atentado contra la autoridad o empleado público, alteración del orden público...).

El Plan Perseo de Castilla-La Mancha establece, por medio de la Circular 4/2006, sobre Asistencia Jurídica a trabajadores del SESCAM, una serie de instrucciones para facilitar y agilizar la obtención de dicha asistencia, que comprenderá un asesoramiento previo, así como la representación y defensa durante toda la tramitación del proceso correspondiente, incluida la ejecución. Todo ello se realizará conforme a los términos previstos en la póliza de seguro vigente.

El procedimiento será el siguiente:

- En el asesoramiento previo en supuestos de agresiones físicas o verbales, los interesados podrán contactar con los Servicios Jurídicos de la Compañía Aseguradora y el incidente deberá ser comunicado a la Gerencia u Oficina Provincial de Prestaciones para su registro y evaluación.

- En la asistencia letrada, estas solicitudes se dirigirán al Servicio Jurídico de la Secretaría General del SESCAM a través de las Gerencias, con antelación mínima de cinco días previos a la comparecencia o juicio.

Esta solicitud de asistencia letrada deberá ser autorizada por el Secretario General del SESCAM.

Se valorará la posibilidad de personación como acusación particular del SESCAM en primera instancia por la Dirección-Gerencia de este Organismo, sin perjuicio de la competencia del Consejo de Gobierno de la Junta de Comunidades de Castilla-La Mancha.

\footnotetext{
72 Suprimidas las faltas por la reforma del CP de 2015, estas deben entenderse referidas a los delitos leves que actualmente se encuentran así tipificados en el Código Penal. Esta recomendación es muy matizable, porque en las faltas de lesiones la actuación podía ser de oficio.
} 
Extremadura (2006) incluye dentro de sus «Estrategias para paliar las agresiones a todos los profesionales del Sistema Sanitario Público de Extremadura» una «Guía de orientación legal: Actuaciones generales ante una agresión». Esta guía incluye un apartado de información sobre las jurisdicciones a las que se puede acudir en caso de agresión (penal, civil o laboral) ${ }^{73}$, la diferencia entre denuncia y querella y una breve clasificación de los posibles delitos, plazo para interponer las acciones y medios de prueba. Finalmente, informa sobre los recursos que el SPSE ofrece a nivel de asesoramiento legal y de asistencia letrada. El Gabinete Jurídico de la Junta de Extremadura se personará en todo caso en los casos de delitos públicos como acusación particular, y en el caso de delitos privados lo hará a petición del Consejero de Sanidad y Consumo. Resulta destacable que se incluyen los casos de agresión a profesionales sanitarios en el ejercicio privado de su profesión, canalizando la posibilidad de asistencia jurídica y/o letrada a través del Convenio que se suscriba con los Colegios Oficiales correspondientes.

En Aragón, el Plan de Prevención (2006) dedica todo un extenso apartado, que denomina «Marco legal de aplicación» a la información sobre tipificación de delitos y faltas según el Código Penal ${ }^{74}$, agresiones en el marco jurídico del Derecho Penal y del Código Civil, incluyendo incluso en su Anexo III un formulario de comunicación de la agresión, dirigida al Juzgado de Instrucción. Específicamente, en cuanto al apoyo jurídico que se presta a sus profesionales en su ámbito, establece un punto de «Apoyo Jurídico» dentro del protocolo de actuación, que detalla lo siguiente:

- Comunicación de la agresión a la Dirección General de Servicios Jurídicos, por parte del responsable del Centro donde se haya producido dicha agresión (independientemente de si el agredido ha interpuesto o no denuncia).

- Personación del interesado (remitido por el responsable del Centro) a los antedichos servicios jurídicos, aportando denuncia presentada en la policía y el registro del incidente/accidente.

- Valoración por parte de los servicios jurídicos sobre si prestar asistencia jurídica en el momento de la denuncia.

- Constatación de los daños materiales que se hayan producido, en su caso, por el perito de la Compañía de Seguros (con posterior traslado a los servicios jurídicos).

El Plan de La Rioja (2008) proclama que ofrecerá asistencia jurídica a todo el personal de sus centros sanitarios, con independencia de la calificación penal que merezcan los hechos constitutivos de una agresión. Detalla a continuación cuál será el contenido de la mencionada

\footnotetext{
${ }^{73}$ Nótese cómo se obvia la posibilidad de que el afectado emprenda acciones contra la Administración (vía responsabilidad patrimonial de la Administración pública).

${ }^{74}$ A partir del año 2015, el término «faltas» se entiende referido a los actuales delitos leves.
} 
asistencia jurídica, comenzando por conocer la pretensión del denunciante y prestarle información sobre los cauces procesales pertinentes: «orientarle sobre si el caso expuesto tiene entidad suficiente como para ser judicializado, explicar las ventajas e inconvenientes de un proceso judicial y asumir el posible deterioro de la relación médico-paciente» ${ }^{75}$. El apoyo jurídico se le dará también durante el proceso. La Dirección General de los Servicios Jurídicos deberá tener conocimiento de los hechos cuando se curse una denuncia. Cuando haya habido daños materiales, esto servirá para que pueda personarse para entablar las acciones oportunas; en el caso de que no se hayan producido daños, pero sí lesiones corporales, se estudiará la posibilidad de que el SERIS pueda personarse en calidad de acusación particular en el proceso penal correspondiente. Además de todo lo dicho, se fomentará una relación fluida con el Fiscal Jefe de La Rioja con la finalidad de garantizar la implicación del Ministerio Fiscal en el ámbito de las agresiones sufridas por el personal sanitario de la Comunidad Autónoma (La Rioja, 2008).

El Plan de Prevención y Atención de Agresiones para los Profesionales del Sistema Sanitario Público de Andalucía (actualización de 9 de febrero de 2012) dedica un epígrafe completo a «Asesoramiento legal y asistencia jurídica. Guía de Orientación Jurídica».

En un primer momento, el responsable del centro sanitario en el que el profesional agredido trabaje, después de ser debidamente informado de lo acontecido, ofrecerá al interesado la posibilidad de asistencia jurídica:

- Por parte de un letrado del SAS (si el profesional pertenece al mismo). En este caso, la Asesoría Jurídica podrá asistirle y representarle en juicio (tras la aprobación del oportuno decreto habilitador). Para ello, debe obtenerse una autorización de los Servicios Centrales del Organismo, que precisará de:

o Escrito de petición de asistencia legal del profesional agredido al director del Distrito de Atención Primaria, director gerente de hospital o gerente de Área Sanitaria.

o Se acompañará a la petición anterior toda la documentación generada y aclaratoria de los hechos, indicando, en su caso, ante qué juzgado se ha incoado el correspondiente procedimiento.

o La documentación referida en los dos puntos anteriores será presentada ante la Asesoría Jurídica Provincial del SAS.

\footnotetext{
${ }^{75}$ Hablar únicamente de "relación médico-paciente» en un documento que pretende establecer medidas contra las agresiones a todo el personal sanitario denota un cierto «médico-centrismo».
} 
o El Jefe de la Asesoría Jurídica Provincial del SAS cursará, a través de la Subdirección de Asesoría Jurídica, toda la documentación al Director Gerente del SAS.

- Por un letrado de la Empresa Pública o Fundación (cuando el agredido sea trabajador de una de estas organizaciones).

Resulta interesante destacar que el Plan de Cantabria (2014) no se limita a especificar las medidas de asesoramiento y atención jurídica a sus profesionales (que se detallan en el apartado anterior de este capítulo), sino que destina todo un epígrafe a detallar las «Actuaciones dirigidas sobre los responsables de los incidentes violentos», dividiéndolas en dos grupos:

a) Consecuencias administrativas:

a. Remisión a la Ley de Ordenación Sanitaria de Cantabria $^{76}$ (artículo 79.3.i, que tipifica las infracciones graves en esta materia, castigadas con multa de $3.001 €$ a 15.000€). Se constata la posibilidad de apertura de procedimiento sancionador. No obstante, no se dan más detalles de cuáles hayan de ser las circunstancias en que procede la incoación del oportuno expediente o en qué casos no sería oportuno iniciarlo.

b. El apartado b) es absolutamente prescindible, por cuanto impone algo que ya está recogido en la legislación procedimental correspondiente: cuando se inicie un proceso penal sobre unos hechos violentos determinados, el órgano competente para la resolución del procedimiento administrativo deberá acordar su suspensión hasta que recaiga la resolución judicial.

b) Consecuencias judiciales. Este punto resulta en cierta medida obvio, por cuanto se limita a declarar lo que persiguen las vías penal y civil cuando se inicia el procedimiento «ad hoc» en cada una de dichas jurisdicciones. La única manifestación a reseñar procede de la declaración de que la Administración de la Comunidad de Cantabria podrá promover los citados procedimientos en orden al ejercicio de acciones cuando se produzcan daños o perjuicios en su sistema sanitario público.

\footnotetext{
${ }^{76}$ Ley 7/2002, de 10 de diciembre, de Ordenación Sanitaria de Cantabria.
} 


\section{EL ACCIDENTE DE TRABAJO Y LA VIOLENCIA CONTRA LOS PROFESIONALES DE LASALUD}

Cuando las medidas de prevención no logran evitar que la agresión se produzca, hay que emprender actuaciones orientadas a la reparación del daño causado. En materia de Derecho laboral y Seguridad Social, tales sucesos generan consecuencias inmediatas y, entre ellas, destaca la posible consideración del hecho como un accidente de trabajo. A continuación, examinaremos esta figura jurídica, adentrándonos en su delimitación, elementos y requisitos.

\section{CONCEPTO, ELEMENTOS Y TIPOS DE ACCIDENTE DE TRABAJO. EXCLUSIONES.}

La protección de los trabajadores frente a los accidentes de trabajo y las enfermedades profesionales está configurada en nuestro ordenamiento de una forma bastante generosa (M. A. Pérez Alonso, 2015), que incumbe a diferentes ramas del mismo: Laboral (con especial incidencia en lo referido a PRL, Penal y Seguridad Social). Tal protección está íntimamente ligada al artículo $15 \mathrm{CE}$, que reconoce el derecho a la vida y a la integridad física ${ }^{77}$.

El concepto de accidente de trabajo viene definido en el artículo 156.1 de la $\operatorname{LGSS}^{78}$, que establece que se reputará como tal: «toda lesión corporal que sufra el trabajador con ocasión o por consecuencia del trabajo que realice por cuenta ajena».

El artículo 4 apartado 3 de la LPRL aporta otra posible definición: «se considerarán como daños derivados del trabajo, las enfermedades, patologías o lesiones sufridas con motivo u ocasión del trabajo».

Tres elementos son los que contiene la definición: la lesión, el trabajo por cuenta ajena y el nexo causal entre ambos. El apartado 2 del artículo 156 LGSS contiene una serie de cláusulas que afectan a estos tres elementos.

\footnotetext{
77 Artículo 15 CE: «Todos tienen derecho a la vida y a la integridad física y moral, sin que, en ningún caso, puedan ser sometidos a tortura ni a penas o tratos inhumanos o degradantes [...]".

${ }^{78} \mathrm{RDL} 8 / 2015$, de 30 de octubre, por el que se aprueba el Texto Refundido de la Ley General de Seguridad Social. BOE núm. 261, de 31 de octubre de 2015.
} 


\section{El elemento objetivo: la lesión.}

La lesión (elemento objetivo) ha de ser verificada como propia del cumplimiento de su trabajo, y abarca cualquier tipo de menoscabo físico o psíquico, ${ }^{79}$ alteración funcional o anatomo-funcional, que incida sobre la salud provocando su pérdida, una incapacidad laboral o la muerte. El artículo 156.1 TRLGSS habla literalmente de «lesión corporal», lo que podría llevarnos a pensar que está referido a lesiones puramente físicas. Sin embargo, esto no es así, comprendiéndose también las dolencias funcionales, sensoriales o psíquicas (Romero Rodenas, 2017).

El concepto de lesión es flexible, no remitiéndose a la estricta producción de un traumatismo, como aclara la STS de 27 de octubre de 1992, cuando dice que abarca «cualquier menoscabo físico o fisiológico que incida en el desarrollo funcional».

Tradicionalmente, la distinción entre el accidente de trabajo y la enfermedad profesional quedaba inscrita en el carácter súbito del primero y el desarrollo lento de la segunda. No obstante, en el accidente de trabajo se comprende también el deterioro progresivo, siempre y cuando tenga su origen en la actividad laboral desarrollada.

En sede judicial se distinguen dos tipos de accidente de trabajo (M. A. Pérez Alonso, 2015): en sentido propio, aquel que se produce como consecuencia directa del trabajo y en sentido impropio, cuando la causa sea distinta a la actividad laboral, pero que no se hubiera dado de no mediar dicha actividad $^{80}$.

Cabe, por tanto, la consideración como accidentes de trabajo de las enfermedades de trabajo, las enfermedades anteriores agravadas y las enfermedades intercurrentes.

Las enfermedades de trabajo son aquellas que el empleado ha contraído por causa exclusiva de la ejecución de su actividad laboral y que no estén calificadas como enfermedades profesionales (Fernández Avilés, 2005). Se permite su reconocimiento como accidente laboral en el artículo 156.2 LGSS letra e). Están definidas, como puede verse, de forma negativa (Martínez Barroso, 2002), excluyendo aquéllas que, por estar contempladas como tales, son enfermedades profesionales.

Para que una dolencia tenga la consideración de enfermedad de trabajo debe ineludiblemente existir una relación de causalidad (del que después hablaremos) entre la patología y la actividad laboral. La carga de la prueba descansa sobre el trabajador afectado, quien deberá poner de

\footnotetext{
${ }^{79}$ En la STS 18-03-1999 se expresa que la lesión comprende «...también el trauma que produce impresiones duraderas en lo psíquico».

${ }^{80}$ Por ejemplo, cuando sin prestar los servicios, no se hubiera producido el daño: STS de 27 de octubre de 1990.
} 
manifiesto que se trata de un trastorno de etiología laboral y/o que el nexo causal no ha sido destruido. Un caso paradigmático para ilustrar esta cuestión: el infarto de miocardio ${ }^{81}$.

El artículo 156.2, en su apartado f), considera accidentes de trabajo a aquellas enfermedades padecidas anteriormente por el trabajador y que se han visto agravadas, a su vez, a consecuencia de un accidente de trabajo. Lo determinante es que exista una enfermedad previa que se agrave, agudice o desencadene ${ }^{82}$. A estos efectos, señala López Gandía (2017) que, para el Tribunal Supremo, lo relevante no es que el accidente ponga de manifiesto una enfermedad clínica, sino que se produzca una incapacidad hasta entonces inexistente (STS de 25 de enero de 2006).

Las enfermedades intercurrentes vienen contempladas en el artículo 156.2 apartado g). Son dolencias adquiridas por complicaciones de la patología generada por el accidente o aquellas «afecciones adquiridas en el nuevo medio en que se coloque al enfermo para su curación» (López Gandía \& Blasco Lahoz, 2017). Así, pueden haberse adquirido por infecciones hospitalarias, errores de tratamiento, efectos secundarios no previstos, etc (Fernández Avilés, 2005). La diferencia con las enfermedades anteriores agravadas es que en ellas existía ya una patología previa, mientras que, en el caso de enfermedades intercurrentes, el trastorno se genera «ex novo».

\section{El elemento subjetivo: el trabajo por cuenta ajena.}

Como prescribe el artículo 156.1, el trabajador que puede ser víctima de un accidente de trabajo es quien percibe retribuciones por cuenta ajena ${ }^{83}$. El artículo 7.1 LGSS delimita que ostentan tal condición aquellos «que presten sus servicios en las condiciones establecidas por el artículo 1.1 del ET en las distintas ramas de la actividad económica o asimilados a ellos, bien sean eventuales, de temporada o fijos, aún de trabajo discontinuo, e incluidos los trabajadores a domicilio, y con independencia, en todos los casos de la categoría profesional del trabajador, de la forma y cuantía de la remuneración que perciba y de la naturaleza común o especial de su relación laboral».

Desdentado Bonete señala la ajenidad y la dependencia como los dos criterios necesarios, entendiendo que el riesgo se vincula a la apropiación de los frutos del trabajo (su utilidad

\footnotetext{
${ }^{81}$ La doctrina judicial mayoritaria es considerarlo como accidente de trabajo, a menos que el infarto haya tenido lugar fuera del horario de trabajo: supuestos de disponibilidad localizable (porque no es tiempo de trabajo ni horas extraordinarias), en las SSTS de 7 de febrero de 2001 y 9 de diciembre de 2003; durante el tiempo de descanso en un hotel, de regreso de una actividad de transporte (STS de 6 de marzo de 2007); infarto manifestado antes del inicio de la jornada laboral (STS de 5 de febrero de 2007).

${ }^{82}$ SSTS de 11 de abril de 1990 y 27 de octubre de 1992, entre otras.

${ }^{83}$ No obstante, se admite la inclusión, con ciertas matizaciones, de trabajos por cuenta propia o autónomos (Romero Rodenas, 2017). El concepto de trabajador por cuenta ajena está ligado a las notas de retribución, voluntariedad, dependencia y ajenidad (Mercader Uguina, 2017).
} 
patrimonial) y el desempeño del mismo bajo la esfera de dirección del empresario (Desdentado Bonete, 1999).

Ello lleva a la exclusión de quien está ligado a la empresa por una relación no estrictamente laboral. Por ejemplo, si tiene la condición de administrador general de la sociedad y socio capitalista mayoritario ${ }^{84}$.

El contrato de trabajo debe estar plenamente vigente en el momento en que se produce la lesión. No existe accidente de trabajo cuando la relación laboral está suspendida ${ }^{85}$.

Por último, resulta de interés señalar que lo determinante en este aspecto no es la calificación que las partes hayan otorgado al contrato, sino la naturaleza de la actividad laboral desempeñada. Nada obsta a que la lesión producida durante una actividad netamente laboral, pero que se desarrolle bajo un contrato de tipo mercantil, sea considerada como accidente de trabajo.

\section{La relación de causalidad o nexo causal.}

Es necesario que exista un nexo entre el accidente y la lesión, constituyendo una relación doble: debe existir un lazo entre trabajo y lesión y, además, entre lesión y situación protegida.

En el caso de un accidente laboral propiamente dicho, probar la relación de causalidad no es dificultoso ni, por tanto, establecer el nexo causal.

La causalidad no es estricta, basta con que exista una conexión, cualesquiera que esta sea, entre los elementos que deben relacionarse: la ejecución de actividad laboral y la lesión. Debe observarse, además, que la expresión «con ocasión» de la configuración legal del accidente de trabajo, da una gran flexibilidad al nexo (causalidad indirecta) ${ }^{86}$ (Sánchez Pérez, 2012). No es exigible que el trabajo sea el motivo determinante de la lesión, basta con la exposición a riesgos conectados con la actividad laboral para que se entienda existente la relación causal (Desdentado Bonete, 1999).

\footnotetext{
${ }^{84}$ STS 30 de enero de 1997: el control de un porcentaje igual o superior al 50\% del capital social encuadra al interesado en una actividad por cuenta propia (Régimen Especial de Trabajadores Autónomos); STS 7 de mayo de 1999, en el mismo sentido.

85 STSJ Galicia, de 3 de marzo de 1995: no es calificable como accidente de trabajo el sufrido por un piquete informativo durante una huelga.

${ }^{86}$ A diferencia de las enfermedades profesionales, en las que la expresión es "como consecuencia» y, por tanto, se establece una relación de causalidad directa.
} 
No obstante, se exceptúan aquellos casos en que haya una ruptura evidente del nexo causal, es decir, cuando haya una absoluta falta de conexión entre la ejecución del trabajo y el daño producido.

Ahora bien, cuando se trata de enfermedades de trabajo la situación se complica. Debe probarse que la patología de etiología común vino a agravarse o a ponerse de manifiesto precisamente por la producción del accidente de trabajo, y no por cualquier otra causa (la propia evolución de la enfermedad, sin ir más lejos). Debe, pues acreditarse fehacientemente la relación causa-efecto entre la realización del trabajo y la aparición o agravamiento de la dolencia ${ }^{87}$.

Esta relación causal, en términos generales, ha de ser probada (como hemos señalado). Sin embargo, el apartado 3 del artículo 156 LGSS, establece que «se presumirá, salvo prueba en contrario, que son accidentes de trabajo las lesiones que sufra el trabajador durante el tiempo y lugar de trabajo». Se trata de una presunción «iuris tantum» que exime al trabajador o sus causahabientes, de probar el vínculo causal.

Queda así desplazada la carga de la prueba, que vendrá atribuida de este modo a quien niegue la existencia del accidente de trabajo, que deberá probar la absoluta falta de existencia de nexo causal entre actividad laboral y lesión. En palabras de Sánchez Pérez (2012), esta carga probatoria puede llegar a ser una auténtica «prueba diabólica» ${ }^{88}$.

Para que opere la presunción prevista en el artículo 156.3 las lesiones han de producirse «durante el tiempo y lugar de trabajo». Por tanto, tenemos un requisito de temporalidad y otro de ubicación geográfica.

Respecto al requisito de temporalidad, esto es, que la lesión debe producirse durante la jornada laboral, pueden existir algunas dificultades de delimitación.

Por ejemplo, en los casos en que el trabajador estaba en el vestuario antes del inicio de su jornada (STS de 4 de octubre de 2012: el empleado sufre un infarto de miocardio ${ }^{89}$ ).

Sin embargo, abarca el periodo intermedio entre la jornada de mañana y tarde, si el empleado hace su comida en el lugar de trabajo, entendiendo que sería ridículo que este periodo estuviera

\footnotetext{
87 Por todas, STSJ de Cataluña, de 27 de enero de 2010.

${ }^{88}$ Se llama "probatio diabolica» a aquella que se exige para probar que algo no ha existido o que un hecho no se ha producido. Era moneda común en los procedimientos juridiciales propios del Antiguo Régimen (por ejemplo, los inquisitoriales), en los que no se respetaba la presunción de inocencia. La «probatio diabolica» resulta imposible de llevar a cabo en la mayoría de las ocasiones, exigiendo probar algo que no se puede probar. En el Derecho moderno, el «onus probandi» recae, por el contrario, sobre quien ha de probar la culpabilidad o que un hecho ha sucedido.

89 Pero había fichado y debía proveerse del equipo de protección individual antes del inicio de la jornada, porque de lo contrario no se devengaría el plus de puntualidad, por lo que entra en juego la presunción de existencia de Accidente de Trabajo.
} 
cubierto en el caso de que se acercara a su domicilio para comer y no si permanece en el lugar de trabajo con la misma finalidad (STS 9 de mayo de 2006). También se estima incluido la pausa para la comida en la obra, por parte de un trabajador de la construcción (STS de 9 de mayo de 2006).

El segundo requisito (el lugar de trabajo) se entiende cumplido cuando el trabajador se encuentre en el centro donde se desarrolle la actividad laboral. No obstante, se admiten excepciones, referentes a cuando el trabajo se efectúa en otro sitio, siempre y cuando se realicen tareas laborales. Es el caso del accidente sufrido en el hotel donde se pernocta tras una cena de negocios (STS de 14 de abril de 1988).

Al hilo de la cuestión, debemos hacer referencia a varios supuestos reflejados en el apartado 2 del artículo 156 LGSS, que se constituyen en tipos individualizados de accidente laboral:

a) El accidente «in itinere». (art. 156.2 a) LGSS): es aquel que sucede fuera del horario laboral y fuera del lugar de trabajo, por el traslado del empleado desde su domicilio al lugar donde se desarrolla la actividad laboral y viceversa. Se introduce en nuestro ordenamiento a través del artículo 7 del Convenio de la OIT n ${ }^{\circ} 121$ de 1964, refiriéndose a los mismos como «accidentes sufridos en el trayecto», «en ruta» $\mathrm{o}$ «en el camino».

Resulta necesario acreditar que el trabajador había iniciado ya el itinerario y, por ello, los sucesos acaecidos dentro del domicilio del trabajador mientras se prepara para ir al trabajo, quedan fuera del supuesto. Ha de tenerse en cuenta, sin embargo, que el tema se delimita por una abundante casuística, en la que los tribunales han ido perfilando en qué supuestos se considera y cuándo no que la lesión constituye un accidente laboral «in itinere».

Así, la STS de 14 de febrero de 2011 conceptúa accidente de trabajo el sufrido en las escaleras del edificio por entender que el empleado había ya iniciado la marcha hacia su trabajo.

Se exige el nexo causal, sin interrupciones en el trayecto. No obstante, se admiten mínimas interrupciones (recogida del niño de la guardería en una breve parada).

En cuanto a qué debe entenderse por domicilio habitual, el TS ha ampliado este concepto al domicilio no habitual empleado por razón de la crisis económica como tal (STS de 26 de diciembre de 2012). La distancia que hoy en día separa habitualmente las residencias de los lugares de trabajo, implica que se acepten como laborales los acaecidos en la circulación de 
vehículos a motor (incluso se ha incluido entre los posibles vehículos en los que el trabajador se desplaza para acudir al trabajo el monopatín: STSJ de Cataluña de 12 de junio de 2014) ${ }^{90}$.

b) El accidente «en misión» (Sánchez Pérez, 2014): vendría a ser un subtipo del anterior, diferenciándose por su causa. Es, en efecto, el ocurrido durante un desplazamiento del trabajador y, por tanto, fuera del lugar de trabajo. Pero en esta ocasión, tal desplazamiento lo realiza por orden del empresario, para realizar alguna tarea encomendada por éste ${ }^{91}$.

Los perfiles de esta figura han ido conformándose a base de resoluciones judiciales, por no existir definición legal de la misma. La STS de 24 de febrero de 2014 (reafirmando lo manifestado en otras anteriores) la conceptúa como una creación jurisprudencial en que se reconoce que el desplazamiento de un trabajador para realizar una actividad encomendada por el empresario, se entiende como prestación de servicios (puesto que se encuentra sometido a las decisiones de la empresa). Esta figura amplía la presunción de laboralidad durante todo el tiempo en que el empleado permanece desplazado, ya que no debe regresar hasta que no cumpla con las tareas encomendadas (incluso respecto a alojamiento, transporte, etc.). Por estas razones, el deber empresarial de protección se extiende a estas situaciones, durante todo el desarrollo del traslado y prestación de los servicios.

«Lugar de trabajo» a estos efectos es aquel «lugar en que se está por razón de la actividad encomendada, aunque no sea el lugar de trabajo habitual» (SSTS 11 de julio de 2000, 24 de septiembre de 2001, entre otras).

Ahora bien, no todo lo que ocurre durante la misión tiene conexión con el trabajo: se exceptúan todas aquellas actividades que se entienden no realizadas «con ocasión» del mismo. A modo de ejemplo, podemos destacar los siguientes casos: actividades de carácter privado (STSJ de Cantabria de 16 de enero de 2009), descanso fuera del buque en actividad marítima pesquera (STSJ de Galicia de 7 de febrero de 2011) o los tiempos de descanso en un hotel (STS de 6 de marzo de 2007) ${ }^{92}$.

Una subespecie de este tipo de accidente de trabajo sería aquel que se produce en los desplazamientos ocasionados por el desempeño de cargos electivos sindicales, incluido en la letra b) del artículo 156.2 LGSS, que protege el derecho a la libertad sindical, abarcando aquella lesión

\footnotetext{
90 Según la STS de 28 de diciembre de 1962, los empresarios pueden limitar los medios de transporte para condicionarlos a los que sean adecuados a las necesidades del desplazamiento.

${ }^{91}$ Hay que diferenciar esta situación de la del permiso concedido por el empresario al trabajador para que éste realice actuaciones de tipo privado, que quedaría fuera del ámbito del accidente laboral. Estaría dentro de la jornada de trabajo, pero no constituiría actividad propia del trabajo ni «con ocasión» del mismo.

92 No quedan excluidos todos los tiempos de descanso: debe considerarse el tiempo en que el transportista duerme en el camión como presencial (cuidado del camión y la mercancía), puesto que además se produce durante el tiempo y en el lugar de trabajo (STS 22 de julio de 2010).
} 
sufrida por el trabajador «con ocasión o como consecuencia del desempeño de cargos electivos de carácter sindical».

c) «Los ocurridos realizando tareas distintas de su categoría profesional, que ejecute el trabajador en cumplimiento de las órdenes del empresario o espontáneamente en interés del buen funcionamiento de la empresa» (letra d) del artículo 156.2 LGSS).

En ellos queda incluido el caso de un trabajador que se desplazó a una zona que no le correspondía a realizar funciones que no eran de su competencia, a requerimiento de un compañero (STSJ de Extremadura de 13 de junio de 2013). También el fallecimiento de un conductor de autobús debido a la persecución y disputa con un pasajero infractor (STSJ de Cataluña de 1 de octubre de 1996). Igualmente, el supuesto en que un trabajador fallece al proceder a quemar con gasolina unos avisperos que podían perjudicar a la empresa (STSJ de Sevilla de 8 de octubre de 2010).

d) La letra d) del apartado 2 del artículo 156 LGSS contempla como accidentes de trabajo «Los acaecidos en actos de salvamento o análogos cuando unos y otros tengan conexión con el trabajo».

Entra dentro de esta consideración el fallecimiento de un policía debido a un infarto sufrido al tratar de impedir un hurto cuando se encontraba de vacaciones (STSJ de Andalucía/Sevilla, de 12 de diciembre de 2002).

Para cerrar la panorámica referente a la figura del accidente de trabajo, debemos referirnos a dos inclusiones explícitas que realiza la LGSS en su artículo 156.5, así como a las exclusiones, delimitadas en el apartado anterior (es decir el 4 del artículo 156).

Quedan incluidas:

1) La imprudencia profesional «que es consecuencia del ejercicio habitual de un trabajo y se deriva de la confianza que éste inspira». Esta se genera por la costumbre adquirida del trabajador al realizar la misma actividad, que le lleva a asumir ciertos pequeños riesgos (Arenas Viruez, 2011). La aceptación de esta irresponsabilidad tolerable del empleado sirve a veces para ponderar los recargos en las prestaciones de seguridad social por incumplimiento de medidas de seguridad en el trabajo. Pero el núcleo de la cuestión está en que la imprudencia no temeraria del trabajador, no excluye la reputación de una lesión como accidente de trabajo ni exime al empresario de su responsabilidad.

2) «La concurrencia de culpabilidad civil o criminal del empresario, de un compañero de trabajo del accidentado o de un tercero, salvo que no guarde relación alguna con el trabajo». 
Nada impide que se considere accidente laboral la producción de una lesión mediando la participación de un tercero. La STS de 20 de febrero de 2006 considera accidente de trabajo el supuesto del fallecimiento de un trabajador por recibir un disparo en la cabeza de camino a su domicilio tras finalizar su jornada laboral (accidente «in itinere») ${ }^{93}$. Pero no ha de olvidarse la posibilidad de ruptura del nexo causal, expresada en la última oración del artículo: si el hecho no guarda ninguna relación con el trabajo, no cabría calificarlo como accidente laboral. Esto implica la ausencia de motivaciones personales en la concurrencia de los hechos: la STS de 20 de junio de 2002 no calificó de accidente laboral el fallecimiento de un trabajador a manos de un compañero, porque el homicida actuó a causa de problemas personales acerca de la esposa de uno de ellos. Sin embargo, nada impide la consideración de accidente de trabajo cuando no existe relación previa entre agresor y trabajador agredido, por lo que debe entenderse que estarían incluidos los casos fortuitos, resultando indiferente que el daño causado fuera imprevisible o inevitable ${ }^{94}$.

El artículo 156.4 excluye de la consideración de accidente de trabajo los siguientes sucesos:

a) «Los debidos a fuerza mayor extraña al trabajo, entendiéndose por esta la que sea de tal naturaleza que no guarde relación alguna con el trabajo que se ejecutaba al ocurrir el accidente. En ningún caso se considerará fuerza mayor extraña al trabajo la insolación, el rayo y otros fenómenos análogos de la naturaleza».

b) «Los que sean debidos a dolo o a imprudencia temeraria del trabajador accidentado».

\section{EL ACCIDENTE DE TRABAJO EN LAS AGRESIONES A LOS PROFESIONALES DE LA SALUD}

Todo lo anteriormente expuesto lleva a colegir que no existe, en términos generales, ninguna dificultad para calificar las agresiones sufridas por el personal sanitario como accidente de trabajo.

Concurre, en primer lugar, el elemento objetivo: las lesiones se producen con ocasión exclusiva de la realización del trabajo y mientras éste se desempeña. Tanto cuando se ocasionan en consultas, durante una cura, en una sala de espera, como en un pasillo, las agresiones han tenido lugar en el centro de trabajo y mientras éste se realizaba (no resulta necesario que estuviera desarrollándose una actividad propiamente clínica, puesto que hay otras tareas que también forman parte del trabajo: piénsese en una enfermera que acude a llamar a los pacientes a la sala

\footnotetext{
93 Las SSTS de 14 de diciembre de 1981 y 21 de diciembre 1982: accidentes de trabajo «in itinere» dos muertes, causadas la primera por atentado terrorista y la segunda por homicidio, "en cuanto la víctima se encaminaba a su quehacer habitual al ser asesinado».

${ }^{94}$ SSTS de 4 de noviembre de 2004, de 20 de febrero de 2006; STSJ de Castilla-La Mancha de 2 de febrero de 2012, entre otras.
} 
de espera y allí es agredida, o el médico que resulta atacado en un pasillo cuando se desplazaba por las instalaciones).

En cuanto al tipo de lesión producida, puede ser -como hemos observado- tanto física como psíquica. Abarca, por tanto, todo tipo de lesiones producidas por una eventual agresión, incluidas también los trastornos psíquicos derivados de estrés post-traumático (Romero Rodenas, 2017), algo que es perfectamente posible que pueda producirse tras una agresión ${ }^{95}$.

El elemento subjetivo, esto es, el trabajo remunerado por cuenta ajena es igualmente un elemento a considerar. Tampoco cabría excluir al facultativo que ejerce en su consulta privada, por cuenta propia $^{96}$. En el caso del personal estatutario de los Servicios Sanitarios, son sujetos protegidos frente al accidente de trabajo dentro del Régimen General de la Seguridad Social, lo cual se encuentra previsto expresamente en el artículo 17.1 i) de la Ley 55/2003, de 16 de diciembre, por la que se aprueba el Estatuto Marco del Personal Estatutario de los Servicios de Salud. Por ello, este personal disfruta de la cobertura de prestaciones del antedicho Régimen General sin restricciones, con inclusión de las contingencias profesionales (Romero Rodenas, 2017).

Estaría contemplada dentro de la figura la agresión sufrida por un trabajador sanitario en el exterior del centro, cuando se dispone a regresar a su domicilio tras la finalización de su jornada laboral. Este supuesto entraría de lleno en lo considerable como accidente de trabajo «in itinere», al cumplir con todos los requisitos exigibles para su consideración.

Sería un accidente de trabajo «in itinere», asimismo, la agresión sufrida por un trabajador sanitario en el parking del hospital o del centro de salud cuando acude a recoger su automóvil para regresar a su domicilio al finalizar la jornada laboral. Estos sucesos se han producido en más de una ocasión, como tendremos ocasión de comprobar.

En nuestra opinión, no cabría calificar de accidente de trabajo «in misión» al sufrido por los profesionales sanitarios de los servicios de Emergencia durante una asistencia domiciliaria, debido a que su actividad laboral está centrada precisamente en acudir a los lugares donde son requeridos, y allí es donde realizan su trabajo ${ }^{97}$.

\footnotetext{
95 La STSJ del País Vasco de 2 de mayo de 2015 consideró accidente de trabajo un supuesto en que el cajero de un banco sufría estrés post-traumático derivado de un atraco que sufrió años antes en su trabajo.

${ }^{96}$ Estaría incluido en la figura, pero con ciertas especialidades. Y desde luego, el personal contratado para asistirle en la consulta ostentaría el requisito de trabajar por cuenta ajena.

${ }^{97}$ A este respecto, resulta paradigmática la STS de 24 de febrero de 2014: «En realidad, no estamos ante una misión específica en el marco de un trabajo que se desarrolla normalmente en un lugar determinado y se encarga al trabajador la realización de un servicio en otro lugar, sino ante una actividad de transporte -la actividad de la empresa es la realización de mudanzas-, que consiste precisamente en un desplazamiento permanente del trabajador como forma de cumplir la prestación de servicios. No se produce, por tanto, el desdoblamiento entre el trabajo y desplazamiento, que es propio de la misión típica, pues el trabajo normal consiste precisamente en el
} 
Sí cabría calificar de accidente «in misión» el padecido por un médico de Atención Primaria que acude a una urgencia domiciliaria, puesto que su puesto de trabajo se ubica en el centro de salud correspondiente, siendo esta asistencia una tarea laboral que se realiza fuera del lugar donde habitualmente realiza su trabajo.

También se ha incluido en este concepto (accidente «en misión») el sufrido por un médico mientras participaba en unas jornadas formativas ${ }^{98}$.

Es de interés señalar que en materia de accidentes de trabajo no es importante que la lesión la haya producido un tercero ajeno al entorno laboral, ni tampoco que el daño fuera o no previsible o evitable, quedando incluidos en la figura los supuestos de daño fortuito. Esta observación es relevante por cuanto en posteriores apartados nos encontraremos con situaciones muy diferentes.

Concretamente, cuando se analice el supuesto de reclamación por responsabilidad patrimonial de la Administración por el asesinato de la Dra. Eugenia Moreno en el Centro de Salud de Moratalla (Murcia).

En cuanto a las demás cuestiones analizadas en el apartado anterior, en general serían de aplicación a los supuestos concretos en que el accidente de trabajo sea producido por una agresión por parte de un usuario, salvo que concurriera alguna especialidad en algún caso puntual que llevara a la necesidad de un estudio más detallado.

desplazamiento, en la actividad de realizar el transporte. Si se consideran las normas sobre el tiempo de trabajo en el transporte por carretera, se concluye que la lesión no se ha producido ni durante el tiempo de trabajo efectivo, ni durante el tiempo de presencia, que el artículo 8.1.20 del Real Decreto 1561/1995 define como aquel en que el trabajador se encuentra a disposición del empresario, sin prestar trabajo efectivo por razones de espera, expectativas, servicios de guardia, viajes sin servicio, averías, comidas en ruta y similares».

98 STS de Castilla y León (Sala de lo Social) 25/2017 (Rec. 708/2017) (Noticias Juridicas.com, 2017). 


\section{LA RESPONSABILIDAD EN MATERIA DE PREVENCIÓN DE RIESGOS LABORALES. LOS ACCIDENTES DE TRABAJO.}

En este epígrafe analizaremos los diferentes tipos de responsabilidad susceptibles de generarse en materia de prevención de riesgos laborales, que podrá darse ante la detección del incumplimiento del empleador de las normas de prevención o ante la producción de un accidente de trabajo o enfermedad profesional.

Reflejaremos aquellos que pudieran tener trascendencia en el tema que nos ocupa (por esta razón se omitirá la responsabilidad derivada de las enfermedades profesionales). Las responsabilidades en este sentido pueden ser:

- Preventivas:

o Responsabilidad administrativa.

o Responsabilidad penal.

- Reparadoras del daño:

o Responsabilidad ante la Seguridad Social.

o Responsabilidad civil derivada de la relación laboral.

\section{RESPONSABILIDAD ADMINISTRATIVA}

a) Principios que rigen la responsabilidad administrativa en materia de PRL.

Como la penal, es una manifestación del «ius puniendi» del Estado. Ambas responsabilidades (penal y administrativa), como consecuencia de esta característica se rigen por los principios de:

$\checkmark$ Legalidad: en este caso la Ley que preceptivamente debe regular las infracciones y sanciones es la LISOS, que remite algunas materias a desarrollo reglamentario y a los convenios colectivos.

$\checkmark$ Tipicidad: queda concretado en la propia LISOS, que establece la necesidad de concretar las conductas sancionables, las sanciones propiamente dichas y su graduación.

$\checkmark$ Irretroactividad: Se aplica la norma vigente en el momento de la comisión de la infracción. Pero hay que hacer notar que esa irretroactividad (como veremos) sólo se refiere a las disposiciones desfavorables al interesado, no a las que puedan mejorar su situación.

$\checkmark$ Proporcionalidad: Debe aplicarse una sanción adecuada a la infracción cometida.

$\checkmark$ Presunción de inocencia: El dolo o culpa del infractor han de ser probados. 
$\checkmark$ «Non bis in ídem»: Una misma conducta no puede ser sancionada administrativa y penalmente.

Todos estos principios y otras cuestiones relacionadas con ellos serán analizadas con más detalle en otro apartado de este estudio (concretamente en el dedicado a la actividad sancionadora de la Administración contra las infracciones administrativas cometidas por causa de agresiones a los profesionales de la sanidad pública), por lo que remitimos a ese epígrafe.

b) Conducta infractora.

La infracción consiste en el incumplimiento de las normas preventivas de protección y seguridad de los trabajadores, tanto la obligación general como las específicas, con inclusión de las normas técnicas y convencionales. Ostenta dos características:

- Es una responsabilidad de culpa: por acción u omisión, «in eligendo» o «in vigilando» (como vimos con anterioridad).

- Es de tipo objetivo: del incumplimiento o cumplimiento defectuoso, o de no poner en marcha de las adecuadas medidas de protección se deriva la existencia de un riesgo. Se trata de una responsabilidad de riesgo, no de resultado: no es necesario que concurra lesión en el trabajador para que ésta nazca.

Las conductas infractoras quedan tipificadas en los artículos 11, 12 y 13 LISOS, que además se clasifican en leves, graves y muy graves.

c) Sujeto responsable.

Como hemos desarrollado en el epígrafe dedicado a la naturaleza de la responsabilidad en materia de riesgos laborales, el responsable es siempre el empresario. Remitimos al mencionado epígrafe para un análisis más detallado de esta cuestión.

d) Sanciones administrativas.

Como en el punto anterior, hemos abordado con más profundidad este tema en otro apartado de este trabajo (el dedicado a la actividad sancionadora administrativa). No obstante, en lo que se refiere específicamente a la PRL, debe señalarse que:

- Las sanciones son preferentemente pecuniarias (artículo 53 LPRL), sin posibilidad de aseguramiento.

- El artículo 54 LPRL prevé una sanción complementaria de tipo no pecuniario: limitación de la empresa de contratar con la Administración cuando se cometan infracciones muy graves de incumplimiento de las normas preventivas. 
Como en el caso de las infracciones, las sanciones deben ser graduadas, lo que realiza el artículo

39 LISOS, estableciendo unos criterios:

- Especial peligrosidad de la actividad productiva.

- Duración del riesgo.

- Gravedad de los daños producidos.

- Número de trabajadores afectados.

- Medidas de seguridad adoptadas.

- No tomar en cuenta la opinión de los trabajadores.

- Conducta del empresario (siniestralidad de la empresa, etc.) y su eventual reincidencia (art.

41 LISOS: infracción del mismo tipo dentro del año siguiente a la resolución firme).

\section{RESPONSABILIDAD PENAL}

Se encuentra regulada en los artículos 311 al 318 del CP ${ }^{99}$, incluidos en el Título XV «De los delitos contra los derechos de los trabajadores». Este título comprende lo que la doctrina denomina «Derecho Penal del Trabajo» (STS 1233/2002, de 29 de julio), que se desarrolla con arreglo al mandato constitucional impuesto por el art. 53.3 CE, el cual impone que los principios rectores de la política social y económica deben inspirar la legislación positiva (en este caso velar por la seguridad e higiene en el trabajo, contenido en el art. $40.2 \mathrm{CE})^{100}$.

El artículo 311 está dedicado a la represión de conductas empresariales que impongan condiciones laborales o de Seguridad Social que perjudiquen, supriman o restrinjan los derechos de los trabajadores, mediante engaño o abuso de situación de necesidad. Su apartado 2, castiga la contratación sin autorización de trabajo o sin comunicar el alta en el Régimen de Seguridad Social. El artículo 311 bis se encarga de la concreción de las penas a aplicar en cada supuesto.

El tráfico de mano de obra se contempla en el artículo 312, junto con otros supuestos de contratación ilegal (ofrecimiento de condiciones de trabajo engañosas o falsas, empleo de súbditos extranjeros sin permiso de trabajo en condiciones que restrinjan, perjudiquen o supriman sus derechos laborales). El artículo 313 es un tanto complementario del anterior, en cuanto castiga la simulación de contrato para determinar o favorecer la emigración de alguna persona a otro país.

\footnotetext{
${ }^{99}$ Ley Orgánica 1/2015, de 30 de marzo, por la que se modifica la Ley Orgánica 10/1995, de 23 de noviembre, del Código Penal (BOE núm. 77 de 31 de marzo de 2015).

${ }^{100}$ Al respecto, resulta también de interés la Instrucción 1/2001 de 9 de mayo de la Fiscalía General del Estado sobre actuación del Ministerio Fiscal en torno a la siniestrabilidad laboral.
} 
El artículo 314 prohíbe las discriminaciones en la contratación laboral, aunque se ofrece al contratante infractor la posibilidad de restablecer la situación de igualdad ante la ley, tras requerimiento o sanción administrativa, reparando los daños económicos producidos ${ }^{101}$.

La protección penal de los derechos de huelga y representación sindical se encuentra contemplada en el artículo 315, prohibiendo su impedimento o limitación mediante engaño o abuso de situación de necesidad. También se prohíbe la coacción para iniciar o continuar una huelga.

En cuanto a la materia concreta de prevención de riesgos laborales, el artículo 316 reza literalmente:

«Los que con infracción de las normas de prevención de riesgos laborales y estando legalmente obligados, no faciliten los medios necesarios para que los trabajadores desempeñen su actividad con las medidas de seguridad e higiene adecuadas, de forma que pongan asi en peligro su vida, salud o integridad fisica, serán castigados con las penas de prisión de seis meses a tres años y multa de seis a doce meses».

Como análisis de este precepto, han de realizarse las siguientes consideraciones (López Barja de Quiroga et al., 2016):

- En general:

o Para la integración de este tipo penal es necesario recurrir a la LPRL.

- Resulta un tipo penal de omisión: Por incumplimiento de las normas de seguridad reguladas en la legislación laboral (fundamentalmente en la LPRL y sus normas de desarrollo).

- Se trata de la omisión de un deber protector de la seguridad en el trabajo, entendido como la ausencia de riesgos para la vida y salud del trabajador (que constituye un bien jurídico autónomo e independiente de la lesión). El sujeto activo ostenta una posición similar a la de garante de dicho bien jurídico. Este deber de protección queda impuesto por el art. 14.2 LPRL.

- Es un delito de peligro: No resulta necesaria la producción de una lesión para que concurra el tipo (STS 1360/1998, de 12 de noviembre).

- Producido un resultado lesivo, prevalece el delito de resultado: La estructura de delito de omisión y de peligro concreto grave «lo configura autónomamente respecto de los delitos de resultado y permite la

\footnotetext{
${ }^{101}$ La discriminación se prohíbe por razón de ideología, religión o creencias, pertenencia a una etnia, raza o nación, sexo, orientación sexual, situación familiar, enfermedad o minusvalía, ostentar la representación legal o sindical de los trabajadores, parentesco con otros trabajadores de la empresa o uso de alguna de las lenguas oficiales dentro del Estado español.
} 
compatibilidad entre ambos si el resultado lesivo se produce, aplicándose como regla general el principio de consunción del artículo $8.3^{0102}$, como una manifestación lógica de la progresión delictiva (SSTS 1036/2002, de 4 de junio, 537/2005, de 25 de abril)» (López Barja de Quiroga et al., 2016, p. 1785).

- Es un tipo penal en blanco: No bastaría la infracción de cualquier norma administrativa para que el Derecho penal entrara en funcionamiento, es preciso su remisión a la norma laboral. El tipo penal exige (relación de causalidad), que la infracción ponga «en peligro grave su vida, salud o integridad física» (lo cual remite a la normativa laboral que indique las infracciones graves que llevan consigo la creación de este riesgo ${ }^{103}$ ).

- El tipo penal abarca únicamente las infracciones laborales más graves. Por los principios de mínima intervención y de seguridad jurídica, sólo serán punibles aquellas infracciones calificadas como más graves por la legislación laboral, por resultar un grave peligro para la vida, salud o integridad física.

- Sujeto activo: Es el empresario o titular de la empresa, así como los administradores o encargados del servicio (artículo $318 \mathrm{CP}$ ) ${ }^{104} 105$.

En cuanto a la responsabilidad civil dimanante del hecho que pueda considerarse incluido en este artículo 316, cabe señalar que el abono de la indemnización no hace que desaparezca el delito (STS 1233/2002, de 29 de julio).

El delito puede cometerse mediando dolo o imprudencia grave. En este segundo caso, el artículo 317 viene a establecer un criterio de disminución de la pena: «cuando el delito a que se refiere el artículo anterior se cometa por imprudencia grave, será castigado con la pena inferior en grado». El tipo subjetivo del delito de omisión imprudente se constituye por «el desconocimiento negligente de las circunstancias que fundamentaban su deber de actuar, desconocimiento que hubiera evitado el acusado si hubiera actuado diligentemente y conforme al deber de cuidado que le incumbía, inspeccionando y exigiendo las medidas de seguridad que eran requeridas» (STS $537 / 2005$, de 25 de abril).

\footnotetext{
${ }^{102}$ Artículo 8. 3ㅇ: «El precepto penal más amplio o complejo absorberá a los que castiguen las infracciones consumidas en aquél».

${ }^{103}$ STS 1233/2002, de 29 de julio.

${ }^{104}$ Artículo 318: «Cuando los hechos previstos en los artículos de este título se atribuyeran a personas jurídicas, se impondrá la pena señalada a los administradores o encargados del servicio que hayan sido responsables de los mismos y a quienes, conociéndolos y pudiendo remediarlo, no hubieran adoptado medidas para ello". Señalan al respecto Nuñez González \& Estardid Colom (2017) que: «este es un criterio material, amplio, en el que cualquier trabajador podría ser considerado autor de este delito, aunque de manera previa no tuviese más responsabilidades en la materia que su obligación de colaborar con el empresario (29 LPRL)».

105 STS 1360/1998, de 12 de noviembre.
} 


\section{RESPONSABILIDADES EN MATERIA DE SEGURIDAD SOCIAL}

Las obligaciones del empresario en materia de Seguridad Social se enmarcan dentro del necesario encuadramiento y cotización (artículo 298 LGSS). De su incumplimiento, se deriva la responsabilidad objetiva del pago de prestaciones por parte de la empresa.

Además, cuando el empresario incurre en responsabilidades en materia de PRL (como hemos visto en epígrafe anterior), se generan otro tipo de sanciones.

El recargo de prestaciones (art. 164 LGSS) se impone al empresario cuando concurran los siguientes requisitos:

- Existencia de un accidente de trabajo o enfermedad profesional.

- Que los anteriores sucedan como consecuencia del incumplimiento de una obligación preventiva por parte del empresario.

- Que exista una relación de causalidad ${ }^{106}$ entre el accidente de trabajo o la enfermedad profesional y el incumplimiento.

Consiste el recargo en el pago de un incremento de las prestaciones económicas causadas por accidente de trabajo o enfermedad profesional de un 30\% a un 50\%, según la gravedad de la falta.

El apartado 2 del artículo 164 LGSS imputa el pago directamente al empresario, descartando la posibilidad de aseguramiento y declarando la nulidad de pleno derecho de cualquier contrato efectuado a tal efecto. Para Fernández Avilés (2015) esa imposibilidad de aseguramiento dota a la figura de un «innegable elemento incentivador de la vigilancia e inversión en prevención dentro de las organizaciones productivas» (p. 413).

Se declara en el artículo 164.3 la independencia y compatibilidad de esta responsabilidad con las de todo orden, incluso penal, que puedan derivarse de la infracción.

La naturaleza del recargo ha suscitado un amplio debate doctrinal sobre si es sancionadora, prestacional o mixta. concluyéndose su carácter mixto (mitad indemnización, mitad sanción). Arastey Sahún (2015) la califica de «extraña figura», que es definida por la STS de 20 de marzo de 2007 como: «una institución específica y singular de la normativa de Seguridad Social, no subsumible plenamente en otras figuras jurídicas típicas, ni por ello, plenamente en la figura de sanción».

106 Para más información sobre el nexo causal, remitimos al epígrafe dedicado al estudio de los Accidentes de Trabajo. 
A continuación, se analiza a modo ilustrativo una resolución en que se produjo una agresión contra una trabajadora sanitaria, constitutiva de accidente de trabajo, en que se discutía la imposición de un recargo a la Administración empleadora.

STSJ de Andalucía/Granada (Sala de lo Social) 1929/2015, de 8 de octubre. El tribunal falla un recurso de suplicación interpuesto por el INSS contra la Sentencia del Juzgado de lo Social $\mathrm{n}^{\circ}$ 7 de Granada que lo condenaba (junto con el SAS) al pago de un recargo del 30\% en la prestación por incapacidad permanente total percibida como consecuencia de accidente de trabajo.

El recurso discute los fundamentos de la sentencia de instancia que, en lo que aquí interesa, se basó para dictar el pago del recargo en la existencia de responsabilidad empresarial por incumplimiento de las medidas de PRL.

La agresión se produjo contra una celadora que recibió a un enfermo mental en el Servicio de Urgencias y, acompañada por un vigilante de seguridad, lo condujo hacia una consulta, donde habrían de esperar al médico psiquiatra que le atendería. El vigilante se quedó fuera de la consulta y mientras celadora y enfermo esperaban al psiquiatra en su interior, éste último cogió por el cuello a la celadora y, tirándola al suelo, continuó intentando estrangularla. El vigilante entró entonces en la consulta, reduciendo al agresor.

La celadora solicitó el recargo de prestaciones. El informe de la ITSS propone al INSS la imposición de un recargo a la empresa (el SAS) de un 30\%. El INSS resuelve denegar esta imposición, basándose en el dictamen-propuesta del EVI que informó de que el hospital «actuó conforme al protocolo existente y la actora ya había quedado resarcida al ser indemnizada por el SAS».

Entonces la interesada presentó reclamación administrativa previa a la vía laboral, que también fue desestimada, por no apreciarse falta de medidas de seguridad e higiene en el trabajo.

El juzgado manifiesta que, en la fecha de los hechos (16 de diciembre de 2004), el hospital carecía de protocolo de acompañamiento de enfermos psiquiátricos. El Plan de Prevención y agresión al personal del Sistema Sanitario Público de Andalucía entró en vigor el 1 de abril de 2005, especificando lo siguiente: «Ante una situación de agresión en la que el profesional perciba un posible riesgo, el primer paso es solicitar ayuda del vigilante de seguridad, en el caso de que el Centro o Servicio cuente con este personal. De no ser así, el profesional solicitará la presencia de un/a compañero/a u otra persona cercana que le ayude a acabar con la situación de violencia y que al tiempo pueda servir como testigo de los hechos En caso de que la situación de violencia/agresión persista, se pasará al siguiente punto. Paso 2: Alertar a Fuerzas y Cuerpos de Seguridad: Como se ha indicado anteriormente, en el caso de que a pesar de los intentos de 
disuadir al agresor, la situación de violencia/agresión persista, se pasará a telefonear a las Fuerzas y Cuerpos de Seguridad, bien sea la Policía Autonómica, local, nacional o Guarda Civil, $y$ se les solicitará que se personen en el centro o servicio o lugar donde se encuentre en el ejercicio de su profesión se desarrollen los hechos para acabar con la situación».

Se instauró una «Guía para admisión, circulación e información de pacientes en el área de urgencias en el año 2008». En esta Guía quedaba establecido que, a los pacientes remitidos para Psiquiatría por servicios extra-hospitalarios, se les asigna un box mientras acude el psiquiatra de guardia. Allí esperará acompañado de su familia, o de un celador y personal de seguridad, si no la tuviera.

El recurso defiende, entre otros motivos, que no existió inobservancia de las medidas de prevención ni, por tanto, responsabilidad empresarial.

La Sala entra a considerar el punto fundamental de este motivo del recurso: la existencia o no del nexo causal. Para ello, examina los requisitos determinantes de la responsabilidad empresarial en el accidente de trabajo exigidos por la doctrina jurisprudencial ${ }^{107}$. A saber:

a) Que la empresa haya cometido alguna infracción consistente en el incumplimiento de alguna medida de seguridad general o especial, añadiendo que no siendo posible que el legislador concrete la variadísima gama de los mecanismos ante la imposibilidad de seguir el ritmo de creación de nuevas maquinarias, bastará que se violen las normas genéricas o deudas de seguridad, en el sentido de falta de diligencia de un prudente empleado (STS 26 de marzo de 1999).

b) Que se acredite la causación de un daño efectivo en la persona del trabajador.

c) Que exista una relación de causalidad entre la infracción y el resultado dañoso, conexión que puede romperse cuando la infracción es imputable al propio interesado (STS 6 de mayo de 1998). Semejantes prescripciones en esta materia de seguridad aparecen recogidas en el artículo 16 del Convenio 155 de la Organización Internacional del Trabajo (OIT) de 22 de junio de 1981, que impone a los empleadores, en la medida que sea razonable y factible, la obligación de garantizar que «los lugares de trabajo, la maquinaria, el equipo y las operaciones que estén bajo su control sean seguros y no entrañen riesgo alguno para la salud y seguridad de los trabajadores».

107 STS (Sala de lo Social) de 2 de octubre de 2000. 
Basándose además en los mandatos constitucionales relativos a la protección de los trabajadores y normativa internacional (que vimos en un epígrafe anterior), concluye la Sala que en el momento de producción del accidente no existía Plan de Prevención.

Añade además que el «Protocolo» existente era «notablemente insuficiente», «como lo pone de manifiesto el hecho mismo de cómo ocurrió éste, cuando las medidas de protección colectiva son insuficientes, se pone de manifiesto precisamente esa relación de causalidad precisa y necesaria para determinar el recargo de prestaciones, cuando precisamente el accidente ocurrió por la inexistencia de las mismas».

Por ello, confirma la sentencia recurrida en todos sus pronunciamientos.

\section{RESPONSABILIDAD CIVIL O PATRIMONIAL}

Este tipo de responsabilidad se refiere en el ámbito laboral, a la que se genera por el incumplimiento empresarial de sus deberes de prevención (lo que por otra parte no ofrece tratamiento especial respecto al régimen general de responsabilidad civil), por lo que nos ocuparemos de ella muy brevemente.

En realidad, este tipo de responsabilidad no debería llamarse «civil», puesto que proviene de un ilícito laboral y se sustancia ante esta jurisdicción. El objetivo de esta institución es la reparación de los daños y perjuicios producidos, mediante una compensación económica.

Esta reparación del daño debe ser integral y plena. El daño se entiende como «el detrimento, perjuicio o menoscabo que una persona sufre a consecuencia de una acción u omisión de otra que afecta a sus derechos personales o reales» (Nuñez González \& Estardid Colom, 2016).

Para ese completo resarcimiento, debe cubrirse tanto el daño emergente, como el lucro cesante. También el daño moral.

La responsabilidad civil es compatible con el resto de las responsabilidades, a excepción de las prestaciones otorgadas por la Seguridad Social (puesto que obedecen al mismo fin y es ineludible evitar un enriquecimiento injusto).

La responsabilidad civil (a diferencia de otras responsabilidades: por ejemplo, del recargo en las prestaciones de la Seguridad Social) puede ser asegurada.

El responsable es el empresario directo. El artículo 1101 CC estipula la responsabilidad contractual empresario-trabajador. Sin embargo, esto requiere al menos una matización: el 
artículo 42.3 LPRL atribuye una responsabilidad solidaria a los diferentes empresarios participantes en el proceso productivo (en el caso, obviamente, de que no exista un único empresario).

Para incurrir en responsabilidad, es necesario que exista una conducta negligente. Como hemos visto, en el régimen de PRL esta es una responsabilidad de riesgo, que se perfecciona por el incumplimiento en la adopción de medidas preventivas.

Desde diciembre de 2011 las reclamaciones por daños y perjuicios derivadas de accidentes de trabajo contra el empresario, por su posible incumplimiento de las medidas preventivas, se solventan en el orden social, poniéndose fin a la situación anterior, en que había problemas de atribución de competencias entre las jurisdicciones laboral y civil (Luque, 2014).

Como veremos, cuando las relaciones sean entre empleado público y empleador-Administración, existe un régimen distinto para dirimir las posibles indemnizaciones reparadoras: el procedimiento de responsabilidad patrimonial de la Administración.

En la siguiente resolución, se produjo una agresión contra una empleada de la Administración en régimen laboral.

\section{STSJ de Castilla-La Mancha (Sala de lo Social) 1532/2007, de 18 de octubre.}

El tribunal enjuicia una agresión sufrida por una auxiliar de enfermería (con contrato laboral) que trabajaba en la Unidad de Salud Mental de un hospital público de Castilla-La Mancha. La agresión se calificó como accidente de trabajo y la actora interpuso previamente un recurso para exigir la responsabilidad patrimonial (administrativa) del SESCAM y, después, reclamó ante la jurisdicción laboral.

El accidente laboral se produjo cuando una de las internas, en el comedor y durante la merienda, arrojó contra la auxiliar (y posteriormente contra otros miembros del personal) varias piezas de vajilla, ocasionando una lesión a la reclamante que provocó una ILT.

La sentencia de instancia, dictada por el Juzgado de lo Social n ${ }^{\circ} 1$ de Talavera, estimó su derecho a percibir indemnización por causa de accidente de trabajo, declarando probado que:

$\checkmark$ La Administración incumplió sus deberes de prevención porque el centro de trabajo carecía de un PPRL para los auxiliares sanitarios del mismo.

$\checkmark$ La trabajadora no recibió formación suficiente (un curso en el año 2003 sobre abordaje de enfermos psiquiátricos). 
$\checkmark$ Los pacientes disponían de elementos normales de vajilla (cuando los Servicios de Prevención habían aconsejado sustituirlos por otros no cortantes o punzantes), como platos de loza, vasos de vidrio y cubertería metálica.

Por ello, y con fundamentación jurídica en «la legislación de prevención de riesgos laborales y jurisprudencia sobre la obligación empresarial de resarcimiento del daño causado al trabajador por negligencia del empresario en el cumplimiento de su deber de protección», el juzgado estimó las pretensiones de la actora. El TSJ confirma la resolución de instancia en todos sus pronunciamientos, salvo uno (se había declarado que no procedían intereses de mora, lo que queda corregido en la resolución del recurso).

\section{ESPECIALIDADES EN RESPONSABILIDAD DERIVADA DE PRL: EL CASO DE LAS ADMINISTRACIONES PÚBLICAS.}

Las Administraciones Públicas ostentan, además de su carácter propio, la cualidad de empleador en cuanto a su personal laboral, estatutario y funcionarial. Esto las convierte en «empresario», desde la perspectiva de la LPRL.

Por esta razón detentan también un deber de protección respecto del personal a su servicio (art. 14 LPRL). La aplicación de la mencionada LPRL es de aplicación, aunque con algunas peculiaridades, que se prevén en el artículo 3 de dicha norma.

Para atender a estas peculiaridades se promulgan, en el ámbito estatal:

- $\quad$ El RD 707/2002, de 19 de julio, por el que se aprueba el Reglamento sobre Procedimiento Administrativo especial de actuación de la Inspección de Trabajo y Seguridad Social y para la imposición de medidas correctoras de incumplimientos en materia de Prevención de Riesgos Laborales en el ámbito de la Administración del Estado, modificado por RD $464 / 2003$, de 25 de abril ${ }^{108}$.

- $\quad$ El RD 67/2010, de 29 de enero, de adaptación de la Legislación de Prevención de Riesgos Laborales a la Administración General del Estado.

El procedimiento general sancionador no es de aplicación a las Administraciones Públicas, ni tampoco la LISOS o el RD 928/1998, de 14 de mayo, por el que se aprueba el Reglamento general sobre procedimientos para la imposición de sanciones por infracciones en el orden social y para los expedientes liquidatorios de cuotas de la SS.

${ }^{108}$ Este Real Decreto es de aplicación en el ámbito de la Administración General del Estado y también de las demás Administraciones públicas que no tengan previsto otro procedimiento (según establece su disposición adicional 2a). 
El procedimiento de aplicación en este aspecto es el RD 707/2002, de 19 de julio, por el que se aprueba el Reglamento sobre el procedimiento especial de actuación de la Inspección de Trabajo y Seguridad Social y para la imposición de medidas correctoras de incumplimientos en materia de Prevención de Riesgos Laborales en el ámbito de la Administración General del Estado, modificado por RD 464/2003, de 25 de abril.

Este procedimiento determina las siguientes cuestiones:

- Se inicia siempre de oficio (por propia iniciativa o a petición de la representación de los trabajadores).

- Se tramita por la ITSS.

- Se visita el órgano de la Administración General del Estado a controlar (en cuanto a cumplimiento de la normativa sobre PRL).

- Si se observan irregularidades, la ITSS emitirá una propuesta de requerimiento, en la que constarán dichas irregularidades, junto a las medidas propuestas para su subsanación.

- Se abrirá un plazo de alegaciones de 15 días hábiles. Transcurrido el plazo sin haberse recibido alegaciones, el requerimiento devendrá firme. Las alegaciones presentadas serán tenidas en cuenta para la emisión del requerimiento definitivo.

- La ITSS podrá decidir la paralización de la actividad del centro ante riesgo grave e inminente para la salud y seguridad de los empleados públicos.

El requerimiento firme contendrá las medidas a aplicar y plazo para hacerlo, pero el órgano administrativo puede discrepar y, en tal caso, no adoptar las mencionadas medidas. En ese supuesto, se hará constar tal circunstancia y se pondrá en conocimiento del órgano superior, quien a su vez podrá o no ejecutar las medidas consignadas en el requerimiento, y así sucesivamente hasta llegar al último órgano de la pirámide administrativa de que se trate (que en el caso de la AGE, es el Consejo de Ministros).

Quizá lo más importante a reseñar al respecto de lo descrito, es que no existen medidas coercitivas que pueda ejercitar la ITSS para compeler a la Administración a que subsane las deficiencias detectadas (Rodríguez Escanciano, 2013). Únicamente puede aconsejar un cambio de actitud.

Tal circunstancia, considera Ortega Rodríguez, «nos permite ver con claridad el trato desigual con que el legislador trata al infractor [Administración] con respecto al empresario privado» (Ortega Rodríguez, 2017).

No obstante, la jurisprudencia remarca que la Administración, en cuanto a empleador, no ostenta una posición de privilegio: «Las normas sobre responsabilidad patrimonial están referidas a la actuación de la Administración como tal, aunque sea en relaciones de derecho privado, pero no 
sucede lo propio cuando la responsabilidad puede derivarse de su comportamiento como empresario o empleador, de forma que cuando actúa en el marco de una relación laboral, como es el caso, debe recibir un tratamiento acorde con su condición de empleador o empresario, sin privilegios especiales» (STS Contencioso-Administrativo de 10 de febrero de 2005).

Las eventuales actuaciones judiciales para la percepción de indemnizaciones por daños y perjuicios tras la producción de un Accidente de Trabajo, se ejercitarán contra la Administraciónempresario por una doble vía: ante la jurisdicción laboral, en el caso de que el trabajador público accidentado lo sea por contrato laboral, y ante la jurisdicción contencioso-administrativa cuando el empleado público sea funcionario o personal estatutario. En este último supuesto (estatutarios y funcionarios) estas reclamaciones se encontrarán bajo el régimen de la responsabilidad patrimonial de la Administración, que trataremos posteriormente.

No obstante, la Ley 36/2011, de 10 de octubre, Reguladora de la Jurisdicción Social, contempla la posibilidad de enjuiciar las cuestiones litigiosas promovidas por funcionarios y personal estatutario en materia de riesgos laborales. Pero su asunción por parte de los tribunales de lo Social no se encuentra plenamente afianzada (un ejemplo en que un órgano jurisdiccional laboral sí estableció su competencia para conocer de un caso de estas características es STSJ País Vasco 1197/2013, de 25 de junio). 


\section{EL DERECHO ADMINISTRATIVO}

\section{LA NORMATIVA SOBRE DERECHOS Y DEBERES DE LOS PACIENTES Y USUARIOS DE LA SANIDAD}

\section{LA REGULACIÓN DE LOS DERECHOS DE LOS PACIENTES}

Los derechos de los pacientes tienen como origen primigenio las declaraciones de derechos proclamados en la Revolución Francesa. Como primer antecedente dispositivo, debemos citar el Código de Nuremberg de 1947, que contempla un reconocimiento del derecho a la libre autodeterminación del paciente. Tal reconocimiento se realiza a propósito del tema de la investigación científica y clínica en seres humanos.

Posteriormente, en la década de los cincuenta, se asiste en EEUU a un importante surgimiento y consolidación del Movimiento de Derechos Civiles, de gran influencia en la materia. En los sesenta presenciamos la creación de las primeras Cartas de Derechos de los Pacientes. La Comisión del Departamento de Sanidad dispuso en 1973 la difusión de Cartas de Derechos en los hospitales e instituciones dedicadas al cuidado de la salud.

Por lo que respecta a Europa, la Oficina Regional para Europa de la OMS realizó una Declaración sobre la promoción de los derechos de los pacientes en este ámbito geográfico. Resulta imprescindible la alusión al importante Convenio del Consejo de Europa, para la protección de los derechos humanos y la dignidad del ser humano con respecto a las aplicaciones de la Biología y la Medicina (llamado «Convenio de Oviedo»), aprobado por el Comité de Ministros del Consejo de Europa en $1997^{109}$.

La Constitución Española incluye al menos dos derechos íntimamente relacionados con los derechos de los pacientes: el artículo 43, referido al derecho a la salud y el deber de los poderes públicos de organizar y tutelar la salud pública y el 51, que impone a los poderes públicos la defensa de los consumidores y usuarios, «protegiendo, mediante procedimientos eficaces, la seguridad, la salud y los legítimos intereses económicos de los mismos». Ambos artículos se encuentran incluidos en el Capítulo Tercero y constituyen principios rectores de la política social y económica.

Como normativa preconstitucional referente a los derechos del paciente, podemos destacar la Orden de 7 de julio de 1972, que aprueba el Reglamento General para el Régimen, Gobierno y

109 Instrumento de ratificación hecho en Oviedo el 4 de abril de 1997 (BOE núm. 251, de 20 de octubre de 1999). 
Servicio de las Instituciones Sanitarias de la Seguridad Social y el RD 2082/1978, de 25 de agosto, sobre Garantías de los Usuarios de Hospitales Públicos.

Posteriormente, cabe destacar la Carta de Derechos y Deberes del Paciente del INSALUD de 1984 y la Ley 26/1984, de 19 de julio, General de Sanidad, marco jurídico que regula los temas referidos a obligaciones de los profesionales sanitarios y los derechos de los pacientes (Osuna Carrillo de Albornoz, 2013).

La Ley 41/2002, de 14 de noviembre, básica reguladora de la autonomía del paciente y de derechos y obligaciones en materia de información y documentación clínica (BOE núm. 274 de 15 noviembre 2002) constituye el marco normativo de esta cuestión y se desarrolla en la normativa autonómica. La importancia de esta norma radica fundamentalmente en dotar al paciente de un haz de derechos y cambiar de forma total e irreversible el papel de los actores en la relación clínica. En palabras de Javier Olave (Director de «Diario Médico»): «...culminó el destierro del tradicional paternalismo profesional a favor de una nueva relación clínica que convierte al paciente en protagonista de las decisiones asistenciales» (Olave Lusarreta, 2006, p. $\mathrm{XV})$.

La Ley 33/2011, de 4 de octubre, General de Salud Pública regula en su Título I cuestiones relacionadas con los derechos y deberes de los ciudadanos y de las obligaciones de las Administraciones en aspectos relativos a la salud pública. Los derechos reconocidos a los ciudadanos son, concretamente: derecho a la información (artículo 4), derecho a la participación (artículo 5), derecho a la igualdad (artículo 6) y derecho a la intimidad, confidencialidad y respeto de la dignidad (artículo 7).

García Calvo (2013) observa que los derechos aquí recogidos se agrupan en dos categorías:

a) Derechos de la personalidad (recogidos en la Carta Magna), que ostentan las cualidades de ser derechos absolutos («erga omnes»), innatos, irrenunciables, originarios e inseparables del sujeto al que pertenecen. Son oponibles frente a poderes públicos y particulares. Su base es la dignidad de la persona y los derechos inalienables que le son inherentes (vida, integridad física y moral y protección de la salud).

b) Otros derechos relativos a las relaciones del paciente con los profesionales de la salud y las instituciones sanitarias.

La normativa española que regula cuestiones relacionadas con los derechos de los pacientes no se agota aquí. Podemos mencionar, entre otras, las siguientes disposiciones: 
- Ley 1/1985, de 5 de mayo, sobre Protección Civil del Derecho al Honor, a la Intimidad Personal y Familiar y a la propia Imagen.

- $\quad$ LO 25/1990, de 20 de diciembre, del Medicamento.

- RD 561/1993, de 16 de abril, por el que se establecen los requisitos para la realización de ensayos clínicos de medicamentos.

- LO 15/1999, de 13 de diciembre, de Protección de Datos de Carácter Personal. RD 994/1999, de 11 de junio, de Reglamento de Medidas de Seguridad de los Ficheros Automatizados que contengan datos de carácter personal.

- Ley 16/2003, de 28 de mayo, de cohesión y calidad del Sistema Nacional de Salud.

- $\quad$ Ley 44/2003, de 21 de noviembre, de Ordenación de las Profesiones Sanitarias.

- Ley 14/2006, de 26 de mayo, sobre técnicas de reproducción asistida. 


\section{EL BINOMIO DERECHO-DEBER EN LAS RELACIONES ENTRE LOS PACIENTES Y LOS PROFESIONALES SANITARIOS. NATURALEZA JURÍDICA DE LA RELACIÓN CLÍNICA.}

De todos es conocida la transformación que en los últimos tiempos ha experimentado la relación médico-paciente. Desde un punto de partida tradicional, la conexión entre el facultativo y el enfermo era de tipo vertical, asimétrica y paternalista (Thomasma, 1983). El médico dictaba las reglas y el paciente obedecía sumisamente ${ }^{110}$. El paternalismo, pleno de buenas intenciones protectoras, pero contrario a que el enfermo tomara la responsabilidad de sus propias decisiones, venía a representar una especie de «despotismo ilustrado médico», en el sentido de que todo se hacía «por el paciente, pero sin el paciente» (García Calvo, 2013).

Los profundos cambios experimentados por nuestras sociedades han afectado también a esta relación. Jovell et al. llegan a calificarlo como un «cambio social sin precedentes en la historia de la humanidad». A esta nueva realidad obedecen modificaciones necesarias de la tradicional relación paternalista hacia un nuevo modelo, de «democracia sanitaria», basado en el principio de autonomía del paciente (Guerrero Zaplana, 2004), que exigió la creación de un marco normativo y legislativo, que acompañara a la modernización del sistema sanitario. Al comienzo de este proceso, en el que algunos autores señalaban la situación de vacío en materia de derechos de los pacientes, se hizo patente la insuficiencia de este marco legal (Leenen, 1987), que fue desarrollado progresivamente hasta alcanzar la situación actual.

Por otra parte, el modelo de paciente no es el mismo que décadas atrás, cuando se limitaba a ser un receptor pasivo de las instrucciones dictadas por su médico. En el nuevo modelo, existe el llamado «paciente informado» o «paciente activo», capaz de tomar decisiones con base a la información ofrecida y hacerse responsable de su salud (Navarro Rubio et al., 2008). La figura óptima sería el «paciente experto», más comprometido y colaborador, que «puede ayudar a otros pacientes a ejercer mejor sus derechos y puede contribuir a la mejora de la calidad de los servicios de salud» (Jovell Fernández et al. 2002, p. 1). Obviamente, esto es una panacea (pocos pacientes tendrán suficiente nivel cultural, formación y capacidades colaborativas para alcanzar ese nivel), pero lo cierto es que los pacientes asumen nuevos roles, asumiendo mayores responsabilidades respecto de su salud y la de sus familiares ${ }^{111}$.

\footnotetext{
${ }^{110}$ Sin embargo, como afirma Blas Orbán (2006), resulta excesivo decir que el paciente no tuviera ningún derecho, pues «disponía de la libertad de seguir o no sus indicaciones y la de desistir unilateralmente si se generaba una pérdida de confianza que motivara tal decisión, lo que, a decir verdad, no era frecuente» (Pág. 28).

111 Jovell Fernández et al. (2002) destacan que ese papel de cuidado de la salud de los familiares más vulnerables suele ser asumido mayoritariamente por las mujeres.
} 
Esta asunción de roles diferentes a los ejercitados en la relación clínica tradicional está influida por muchos factores, entre los que se destacan el aumento del nivel educativo del ciudadano medio, que «entiende su salud como un bien individual ante el que puede tomar sus propias decisiones» (Navarro Rubio, Gabriele Muñiz, \& Jovell Fernández, 2008, p. 367). Ello guarda relación con la transición hacia un nuevo modelo de paciente que en realidad es un cliente o consumidor de los servicios sanitarios, que ve la recuperación de la salud-bien individual no como una necesidad, sino como una satisfacción.

El acceso a una gran cantidad de información sobre salud sin limitaciones (McMullan, 2006), junto con el fomento del concepto de «democracia sanitaria», influyen igualmente en el nacimiento de este nuevo modelo de paciente.

Tampoco podemos olvidar la influencia de los medios de comunicación (que crean estados de opinión y también condicionan la relación de los pacientes con el sistema sanitario), junto con un aumento de las expectativas sobre las posibilidades de las nuevas tecnologías y los avances científicos. A esto se une que, siendo las enfermedades crónicas las de mayor prevalencia en nuestra sociedad, existe un aumento de la experiencia que el sujeto tiene como paciente (Jovell Fernández et al. 2002).

Todo ello plantea retos para el profesional, que debe adaptarse a pacientes distintos con necesidades diferentes y a las esferas políticas, que tienen que favorecer la democratización de los sistemas sanitarios (facilitando información completa y veraz, al tiempo de mecanismos formales de participación y de discrepancia razonada del paciente)(Jovell Fernández et al., 2002). No obstante, como señala O'Neill (2002), los procesos de transparencia administrativa, pueden paradójicamente minorar la confianza de los pacientes en los sistemas sanitarios, por la creación de una cultura de la sospecha.

Sería preciso no olvidar que esta transición puede llevar a un modelo científico de la medicina, en que el profesional transfiera toda la responsabilidad de decidir al paciente, llenándolo de información que no comprenda y dejando en sus manos la toma de unas decisiones que quizás no pueda o quiera tomar. Como siempre, esto dependerá mucho del tipo de paciente y el profesional deberá valorar cada situación.

El cambio radical en el modelo de relación clínica es el motor generador de catálogos de derechos de pacientes y muy posiblemente, como veremos más adelante, la razón de que el número de derechos reflejados explícitamente en la legislación sea numéricamente superior a los deberes correspondientes. 
Sin embargo, se constata que los pacientes no están bien informados sobre sus derechos (y, consecuentemente, sobre sus deberes) (Jovell et al., 2007). Por estas razones, se han adoptado algunas experiencias e iniciativas (Jovell Fernández et al., 2002) (Navarro Rubio et al., 2008), a las que no han sido ajenas las Administraciones (recordemos la inclusión en muchos PPRL de «medidas de información al usuario», que inciden, entre otros, en estos aspectos).

Debe señalarse que este cambio de relación clínica, que instaura un nuevo equilibrio en que el profesional se encuentra a la misma altura que el paciente, no tiene por qué suponer una merma ni en los derechos ni en los deberes de ninguna de ambas partes. Simplemente, se encuentran en una situación de igualdad, «a efectos de respeto y consideración» ${ }^{112}$.

La naturaleza jurídica de la relación médico-paciente (y por extensión la del resto del personal sanitario con el usuario) es contractual. Como contrato, de esta relación nacen derechos y obligaciones $^{113}$ entre las partes.

Estos derechos y obligaciones se encuentran conectados de forma correlativa, de manera bilateral. Es decir, a un derecho corresponde siempre un deber, y viceversa: una obligación lleva aparejado un derecho ${ }^{114}$. La naturaleza contractual supone una relación igualitaria y sinalagmática en el que ambas partes son titulares de derechos/deberes de forma recíproca.

Dentro de ese contrato, el profesional sanitario es deudor de una obligación de medios y esto es así por el componente aleatorio que posee su actividad (Galán Cortés, 2011). Lo que se exige de su actuación no es la producción de un resultado, sino el empleo de técnicas adecuadas y de acuerdo con la «lex artis» ${ }^{115}$.

\footnotetext{
112 Blas Orbán (2006) afirma incluso que esta nueva situación puede ser el motor que «restaure la confianza mutua en la relación médico-paciente» (p. 30), y desde tal posición «el ejercicio de la medicina puede recuperar su antigua posición en la sociedad a la que pretende servir, lo que, sin duda, repercutirá favorablemente en la eficiencia de la sanidad pública» (p. 31).

${ }^{113}$ Artículo 1091 del Código Civil.

114 García Calvo (2013) ejemplifica esta cuestión con el «principio de autonomía del paciente». El derecho a decidir que el paciente ostenta por aplicación de ese principio lleva aparejado su responsabilidad de tomar la oportuna decisión sobre su salud. Ese derecho-responsabilidad se aúna simultáneamente con el deber correlativo del profesional de proporcionarle una correcta información que le permita tomar la decisión, dentro de un proceso de deliberación conjunta entre profesional y paciente (porque agobiarle con un exceso de información excesiva y técnica, no es informar bien). Para esta autora, sólo la aceptación de este modelo de relación posibilitará «el reconocimiento recíproco que posibilita la consolidación de la relación clínica». Otro ejemplo puede verse en Sánchez-Caro \& Abellán (2006) cuando, en relación con la historia clínica, afirma que se genera un derecho del médico a constatar la realidad clínica, pero a la vez se genera un deber de buena organización de su trabajo en beneficio del paciente y que, no obstante, para la ley de autonomía del paciente (41/2002, de 14 de noviembre) es un derecho del paciente, "desde el momento en que se considera trascendental para el conocimiento veraz y actualizado del estado de salud del mismo, hasta el punto de que los médicos que desarrollen su actividad de manera individual son responsables de la gestión y de la custodia de la documentación asistencial que generen» (Sánchez-Caro \& Abellán, 2006, pp. 6-7).

115 No obstante, hay algunos casos en que la Jurisprudencia ha considerado que se trata de una obligación de resultados. Por todas, puede verse la STS de 28 de junio de 1999.
} 
Por su parte, el paciente se obliga al pago de honorarios (en el caso de que la relación sea con profesional de la sanidad privada), pero además y, sobre todo, queda obligado a cooperar. No hay que olvidar que el acto médico se encuentra presidido por el principio de buena fe y su presunción por el paciente garantiza la confianza y la asunción de sus actos por parte de los partícipes en la relación asistencial. Si existe una vulneración de este principio de «bona fides», «se anularía la obligación recíproca de responder de las consecuencias de los daños derivados de esa actuación dolosa» (García Calvo, 2013). 


\section{LOS DEBERES DE LOS PACIENTES Y USUARIOS DE LA SANIDAD}

Los deberes de los pacientes no han sido tan profusamente desarrollados en la Normativa como lo han sido sus derechos. La posible razón de este desequilibrio acaso se encuentre en aspectos anteriormente señalados: se partía de una posición inferior del paciente en el sistema sanitario.

La transformación de este modelo anterior ha dado como resultado una relación clínica en la que el paciente, bajo la presidencia del principio de autonomía, se convierte en el protagonista. Y quizá por ello, la normativa ha hecho más hincapié en el desarrollo de sus derechos, en el afán de cambiar una relación inicialmente vertical, disimétrica, por un nuevo modelo en que las partes se encuentren más equilibradas. Es decir, se ha intentado equilibrar la balanza con un despliegue de derechos del paciente muy amplio.

Algunos autores han manifestado su desacuerdo con la, a su juicio, exigua delimitación de las obligaciones del usuario en la normativa. Gascón Santos (2006) señalaba que la legislación autonómica sobre derechos de los pacientes en nada se refería a sus deberes, limitándose a sancionar los desperfectos causados al mobiliario o el mal uso de las instalaciones sanitarias.

De esa muy limitada mención a las obligaciones de los usuarios también se hacía eco MartínezJarreta (2003), quien denuncia el desequilibrio existente en cuanto a la referencia a sus derechos, pero no a sus deberes.

Como podrá verse a continuación, es posible que en las fechas en que estos autores publican sus trabajos, las referencias normativas a las obligaciones del usuario fueran pocas y que, con posterioridad, las diferentes disposiciones estatales y autonómicas hayan ampliado el abanico de estos deberes.

Sin embargo, aunque fuera cierto que hay obligaciones no específicamente recogidas en la normativa, esta falta de detalle en su reflejo no debe hacernos llegar a la conclusión de que los usuarios carecen de obligaciones o que sólo están obligados por las que se estipulan literalmente en las disposiciones legales o reglamentarias ${ }^{116}$. Del propio ejercicio de los derechos fundamentales, constitucionalmente reconocidos, surge el deber de respeto mutuo, concretándose, en el caso del paciente, su deber de solidaridad social (como en el resto de los ciudadanos) (García Calvo, 2013). Cuestión distinta es si realmente conocen o no sus deberes.

\footnotetext{
116 «...conviene recordar que el camino avanzado en materia de derechos del paciente, lleva aparejados de forma indisoluble los conceptos de deberes del paciente, así como de derechos y deberes de los profesionales» (GómezDurán, Gómez-Alarcón, \& Arimany-Manso, 2012, p. 1).
} 
Partiendo de que la atención sanitaria es una actividad de interés general de la colectividad, puede afirmarse que la exigencia de estos deberes se encuentra basada en una necesidad colectiva y en el bien común (Evans, 2007).

A continuación, examinaremos los diferentes catálogos de obligaciones de los usuarios recogidos en la legislación española:

Ley 14/1986, de 25 de abril (BOE núm. 102 de 29 de abril de 1986). En su artículo 11 relaciona brevemente una serie de deberes, referidos a los ciudadanos en sus relaciones con las Instituciones y Organismos del Sistema Sanitario:

1. Obligación de cumplir las prescripciones generales de naturaleza sanitaria, comunes a toda la población y las específicas de los Servicios sanitarios.

2. Obligación de cuidar las instalaciones y de colaborar en su mantenimiento.

3. Obligación de responsabilizarse del uso adecuado de las prestaciones ofrecidas por el sistema sanitario, fundamentalmente en la utilización de servicios, procedimientos de baja laboral o incapacidad y prestaciones terapéuticas y sociales.

4. Firmar el documento de alta voluntaria en los casos de no aceptación del tratamiento.

Obsérvese cómo, en materia de posible violencia contra los profesionales de la salud, hay un silencio absoluto. Como mucho, podría interpretarse el punto 3 como un mandato general de uso adecuado de la utilización de servicios, con lo que conlleva de respeto al personal sanitario. Sin embargo, como apuntaba Gascón Santos (2006), sí se alude al cuidado de instalaciones y su mantenimiento.

Ley 41/2002, de 14 de noviembre, básica reguladora de la autonomía del paciente y de derechos de los usuarios y pacientes. Su artículo 1 proclama que tiene por objeto la regulación de «derechos y obligaciones de los pacientes, usuarios y profesionales, así como de los centros y servicios sanitarios, públicos y privados, en materia de autonomía del paciente y de información y documentación clínica».

Ahora bien, en realidad, únicamente dedica el apartado 5 del artículo 2 a los deberes de los pacientes, del siguiente modo: «los pacientes o usuarios tienen el deber de facilitar los datos sobre su estado físico o de salud de manera leal y verdadera, y de colaborar en su obtención, especialmente cuando sean necesarios por razones de interés público o con motivo de la asistencia sanitaria»». 
La Ley 33/2011, de 4 de octubre, General de Salud Pública, titula su Capítulo II «Deberes de los ciudadanos», en el que se comprenden dos artículos:

Artículo 8. Deber de colaboración.

Los ciudadanos facilitarán el desarrollo de las actuaciones de salud pública y se abstendrán de realizar conductas que dificulten, impidan o falseen su ejecución.

Artículo 9. Deber de comunicación.

1. Las personas que conozcan hechos, datos o circunstancias que pudieran constituir un riesgo o peligro grave para la salud de la población los pondrán en conocimiento de las autoridades sanitarias, que velarán por la protección debida a los datos de carácter personal.

2. Lo dispuesto en el apartado anterior se entiende sin perjuicio de las obligaciones de comunicación e información que las leyes imponen a los profesionales sanitarios.

Son reseñables también las obligaciones que se señalan al usuario orientadas a evitar que se produzcan situaciones conflictivas en las cuestiones relacionadas con demoras y listas de espera, que están contenidas el Real Decreto 1039/2011, de 15 de julio, (BOE de 29 de agosto de 2011) ${ }^{117}$.

Como referente en este asunto, puede citarse también el Real Decreto 1039/2011, de 15 de julio, por el que se establecen los criterios marco para garantizar un tiempo máximo de acceso a las prestaciones sanitarias del Sistema Nacional de Salud (BOE de 29 de agosto de 2011). Con el objeto de garantizar la efectividad del tiempo máximo de acceso prevista, establece en su artículo siete las siguientes obligaciones para los usuarios:

a) Mantener actualizados los datos sobre su teléfono, domicilio o correo electrónico, a efectos de llamamiento, notificación o localización por parte del servicio de salud.

b) Justificar, cuando concurran motivos personales, y mediante el procedimiento que el servicio de salud a tal efecto determine, la solicitud de aplazamiento de la atención garantizada.

c) Comunicar con antelación suficiente, siempre que ello sea posible, la decisión de no presentarse a una citación.

d) Facilitar al servicio de salud la información necesaria que le sea requerida a efecto de poder asignarle la alternativa más adecuada para la realización de la atención garantizada.

${ }^{117}$ Ver «Deberes de Colaboración», en el epígrafe dedicado a los deberes al usuario que establecen en su Normativa diversas CCAA. 
e) Poner en conocimiento de los responsables de las instituciones sanitarias las irregularidades que observe en el ejercicio del derecho de la garantía de tiempo máximo de acceso, mediante el procedimiento que el servicio de salud establezca a tal efecto.

Los deberes explicitados son inferiores en número a los derechos y a éstos últimos se dedican cuatro artículos, por lo que podría pensarse en un desequilibrio entre ambos. No obstante, como hemos dicho, la falta de simetría aritmética no es determinante de que realmente existan muchos más derechos que deberes para el paciente.

En todo caso, ha de observarse que, en materia de agresiones al personal sanitario, podría bastar con la referencia explícita de unos pocos deberes para cubrir todo el abanico protector, que incluyera: el uso adecuado de las instalaciones, el respeto a las normas de los centros, el respeto a los demás usuarios y, por supuesto, el respeto al personal que presta sus servicios en la sanidad. 


\section{NORMATIVA DICTADA POR LAS COMUNIDADES AUTÓNOMAS EN MATERIA DE DEBERES DE LOS PACIENTES Y USUARIOS}

Las disposiciones dictadas por las diferentes Comunidades Autónomas incluyen prácticamente siempre un listado, más o menos extenso, de deberes que el paciente debe respetar. Pero, como acabamos de señalar, eso no impide que los derechos de los trabajadores sanitarios en materia de seguridad frente agresiones se vean siempre reflejados. Es más, podría decirse que, cuanto más temprana es la normativa, menos se contempla este aspecto.

Es por ello que se ha efectuado una selección de la normativa autonómica existente en la materia. De un lado, procurando ejemplificar la situación primigenia en que no se incluían deberes dirigidos directamente a garantizar la seguridad y el respeto de los profesionales; de otro, relacionando aquellas disposiciones de especial relevancia en cuanto a sus contenidos, y que no se limitan a reproducir casi miméticamente las normativas de otras CCAA en este ámbito regulador.

Por otra parte, hemos consideramos interesante incluir la temprana normativa de algunas Comunidades Autónomas que posteriormente vuelven a regular la materia, completándola y ampliándola, con el fin de analizar los posibles elementos de contraste entre la primera y la posterior normativización. Como en otras ocasiones, la normativa referida a Castilla y León se ha incluido en un epígrafe propio, por las razones que se explicaban en la Introducción.

Puede observarse que hay dos opciones a la hora de dictar disposiciones reguladoras sobre régimen administrativo en la defensa de los empleados públicos sanitarios: o bien construyendo una norma relativa a derechos y deberes de los pacientes, o bien refiriéndose a los deberes de los usuarios dentro de una ley de ordenación sanitaria de carácter general.

Las normas más cercanas en el tiempo comienzan a abandonar la idea de que es el paciente el único que debe ostentar derechos y obligarse con deberes, incluyendo también en sus disposiciones catálogos de derechos y deberes de los profesionales. Este es el caso, por ejemplo, de la Ley 5/2010, de 24 de junio, sobre derechos y deberes en materia de salud de Castilla-La Mancha $^{118}$.

\footnotetext{
${ }^{118}$ El antecedente de esta norma es la Ley 8/2000, de 30 de noviembre, de Ordenación Sanitaria de Castilla-La Mancha que recogía una serie de derechos y deberes de los pacientes, coincidentes con los expresados en la Ley 41/2002.
} 


\section{Tabla 3. Principales normas autonómicas en materia de deberes de los usuarios de los Sistemas Sanitarios regionales.}

Ley 10/2001, de 28 de junio, de Salud de Extremadura (BOE núm. 177, de 25 de julio de 2001) Ley 12/2001, de 21 de diciembre, de Ordenación Sanitaria de la Comunidad de Madrid. Ley 6/2002, de 15 de abril, de Salud de Aragón.

Ley $5 / 2003$ de 4 de abril, de Salud de las Illes Balears.

Ley $8 / 2008$, de 10 de julio, de Salud de Galicia.

Ley $3 / 2009$, de 11 de mayo, de los derechos y deberes de los usuarios del Sistema Sanitario de la Región de Murcia.

Ley $5 / 2010$, de 24 de junio, sobre derechos y deberes en materia de salud de Castilla-La Mancha.

Ley Foral 17/2010, de 8 de noviembre de Derechos y Deberes de las personas en materia de salud de la Comunidad Foral de Navarra.

Declaración 147/2015, de 21 de julio, por el que se aprueba la declaración sobre Derechos y Deberes de las personas en el Sistema Sanitario de Euskadi.

\section{EXPOSICIONES DE MOTIVOS Y FINALIDADES}

La promoción de la salud y la salvaguarda de los derechos y deberes en el ámbito de la salud inspiran la mayoría de las normas. Suele enlazarse esta idea con la de la protección de la colectividad. Las diferentes disposiciones se enmarcan en la Constitución, en la normativa estatal y en los tratados y acuerdos internacionales convenientemente ratificados.

La Ley 10/2001, de 28 de junio, de Salud de Extremadura, contiene una sucinta alusión a los deberes de los pacientes en los principios rectores, contenidos en su artículo 3. Su apartado j) reza literalmente: «Fomento del conocimiento sobre el ejercicio de los derechos y deberes de los ciudadanos».

La Comunidad de Madrid, en su Ley 12/2001, refleja en su preámbulo el objetivo de implicar a los ciudadanos en el sistema sanitario, contando con su colaboración. En concreto, afirma: «Se trata de introducir en el sistema sanitario madrileño un marco de responsabilidad en el uso racional de los recursos, para que sean adecuadamente utilizados en beneficio de todos, especialmente por lo que se refiere a la prestación farmacéutica y la Incapacidad Temporal». Es decir, para esta disposición, los deberes de los usuarios quedan centrados en ese uso racional de los recursos únicamente. 
En el caso de Murcia (2009) se configura además un nudo que relaciona todo lo anterior con la responsabilidad del ciudadano. Así, el artículo 2 de la Ley 3/2009 autodescribe la propia ley como «un instrumento marco de protección y responsabilidad del ciudadano, cuya finalidad esencial es promover y salvaguardar el cumplimiento de los derechos y deberes relacionados con el ámbito de la salud, de conformidad con las previsiones establecidas en la Constitución Española, en la legislación básica estatal aplicable, así como en los tratados y acuerdos internacionales ratificados por el Estado Español en la materia».

Castilla-La Mancha (2010), como ya hemos señalado, recoge por primera vez un catálogo específico de derechos y deberes de los profesionales, figurando entre sus objetivos la sistematización de contenidos normativos vigentes hasta ese momento y la profundización en el desarrollo de los derechos y deberes de usuarios y profesionales. En referencia a esta norma, manifiestan González García \& Martín Ayala (2011): «...los derechos reconocidos al paciente no han de anular a los que, de forma inherente, corresponden a los profesionales entre los que se encuentran derechos como aquellos relacionados con el respeto, la confianza y la conciencia del médico, esenciales para que la relación clínica camine hacia la excelencia» (p. 374).

Navarra, en su Ley Foral 17/2010, de 8 de noviembre, de derechos y deberes de las personas en materia de salud de la Comunidad Foral de Navarra, expresa en su Exposición de Motivos que «los ciudadanos deben ser conscientes y asumir sus responsabilidades en relación con la salud individual y colectiva».

La Declaración 147/2015 de Euskadi ${ }^{119}$ estructura el Capítulo III «Deberes de las personas» en su sistema, desglosándolos en cuatro artículos:

$\checkmark$ Artículo 14: «Deberes de las personas en relación con la organización y gestión del Sistema Sanitario de Euskadi».

$\checkmark$ Artículo 15: «Deberes de las personas en relación con las políticas sanitarias específicas».

$\checkmark$ Artículo 16: «Deberes de las personas para una participación responsable en la gestión de su propia salud».

$\checkmark$ Artículo 17: «Deberes de las personas en relaciones asistenciales en el Sistema de Salud de Euskadi».

Resulta de destacado interés en esta norma la inclusión de las «funciones de los Servicios de Atención al paciente y personas usuarias», regulado en su artículo 19, y muy especialmente las siguientes:

\footnotetext{
${ }^{119}$ Como antecedente de esta norma, cabe destacar el Decreto 175/1989, de 18 de julio de la Comunidad Autónoma del País Vasco (Carta de Derechos y Obligaciones de los pacientes y usuarios del Servicio Vasco de Salud).
} 
e) Comunicar a la dirección del centro, servicio o establecimiento sanitario la posible comisión de hechos o conductas que supongan el incumplimiento de los derechos y deberes de las personas usuarias.

f) Implantar y velar por el cumplimiento de las medidas establecidas por la dirección del centro para la prevención y atención de las agresiones a las y los profesionales sanitarios y al resto del personal que trabaja en las estructuras sanitarias, sin perjuicio de las competencias que, en materia de prevención de riesgos laborales, corresponden a los servicios de prevención existentes en los diferentes centros, servicios y establecimientos sanitarios.

Ello implica el establecimiento de un sistema de control específico que involucra a los Servicios de Atención al Paciente en el control de actos inapropiados por parte de los usuarios, así como de específicamente las agresiones que sufra el personal del Sistema de Salud.

\section{DEBERES DE LOS USUARIOS}

Estos deberes suelen estar recogidos en forma de catálogos, muy similares entre sí, bien dentro de las diferentes leyes «de derechos y deberes», bien en las leyes de ordenación general sanitaria de cada Comunidad Autónoma.

En Murcia (2009), se impone la exigibilidad de los deberes en dos facetas (artículo 61 de la norma citada en esta materia):

- La de las decisiones individuales que adopte el usuario en sus procesos de salud.

- En el comportamiento que siga en el uso y utilización de los servicios sanitarios.

Para García Calvo (2013) este artículo es claramente innovador y apoya el derecho a la intimidad de las personas y la autonomía del paciente.

Esta autonomía también exige que el interesado conozca que es deudor de respeto hacia las instituciones, normas y personal (todo ello en aras de asegurar la armonía en la relación clínica).

A continuación, vamos a referirnos a algunos deberes específicos, que consideramos de interés destacar:

\section{1.- DEBER DE RESPETO Y CONSIDERACIÓN}

Ni la Ley General de Sanidad, ni la Ley 41/2002, regulaban este deber. Sí se recoge dentro del Catálogo de la Carta de los Derechos y Deberes de los Pacientes conocida como «Declaración de Madrid» de 2004, en su apartado X: «deber de mantener el respeto debido a la dignidad personal y profesional de todo el personal que presta sus servicios en los centros sanitarios». 
La Ley 10/2001, de 28 de junio, de Salud de Extremadura dedica un apartado de su artículo a este deber: «e) Mantener el debido respeto a las normas establecidas en cada centro sanitario y sociosanitario a los usuarios y personal que preste sus servicios en los mismos». Como puede observarse, se conecta el deber de respeto al personal sanitario con este mismo deber hacia los demás usuarios y a las normas de funcionamiento de los centros.

La Ley 12/2001, de 21 de diciembre, de Ordenación Sanitaria de la Comunidad de Madrid, regula en su artículo 30 los deberes individuales de los ciudadanos. El apartado que se ocupa de exigir respeto a los profesionales, ligado al de las normas de los centros es el 5: «Mantener el debido respeto a las normas establecidas en cada centro, así como al personal que preste sus servicios en el mismo».

La Ley 6/2002, de Salud de Aragón, detalla en su artículo 5 una serie de deberes, entre los que figura: «mantener el debido respeto a las normas establecidas en cada centro sanitario y al personal que en él preste sus servicios».

La Ley 8/2008 de Galicia establece el deber de: «Mantener el debido respeto al personal que presta sus servicios en el ámbito del sistema público».

En su artículo 62, la ley murciana pasa a enumerar los deberes respecto del personal sanitario y con la salud individual y colectiva, concretándolos en los siguientes términos:

a) «guardar el debido respeto y consideración a los profesionales sanitarios y al conjunto del personal de los centros, servicios y establecimientos sanitarios, tanto en su dignidad personal como profesional».

Asimismo, La Ley 5/2009, de 30 de junio, de Servicios Sociales de Aragón impone a los usuarios «el deber de respetar la dignidad y los derechos del personal que presta los servicios que reciben».

La Ley de Castilla-La Mancha (2010) incluye en su artículo 48 un mandato parecido, pero lo hace incluyéndolo dentro de la sección de «derechos de los profesionales de los profesionales de los centros, servicios y establecimientos sanitarios». Concretamente, aparecen los siguientes derechos:

a) al respeto a su honor y prestigio profesional en el desempeño de sus funciones.

b) a su seguridad e integridad física y moral. 
c) a una adecuada protección de su salud frente a los riesgos derivados de su trabajo, según lo previsto en la normativa sobre prevención de riesgos laborales y, en particular, a la protección ante los accidentes sanitarios (...).

e) a renunciar a prestar atención sanitaria en situaciones de injurias, amenazas o agresión si no conlleva desatención.

Igualmente, la Ley Foral de Navarra (2010) opta por este camino de enfocar el respeto a los profesionales como un derecho de los mismos, en vez de como un deber del usuario ${ }^{120}$. En el artículo 75 establece que los profesionales de centros, servicios y establecimientos sanitarios tienen derecho a ser respetados en su honor y prestigio profesionales en el desempeño de sus funciones, y a su seguridad e integridad física y moral.

La Declaración de Euskadi, por su parte, impone como deber en su artículo 17, letra b: «Tratar con el máximo respeto y la mayor consideración al personal de las instituciones sanitarias, a otros y otras pacientes, así como a sus acompañantes». Como vemos, aquí también se anuda el respeto debido a los profesionales, con el debido a los demás usuarios.

\section{2.- INCLUSIÓN DEL RESPETO A LOS SANITARIOS EN LOS DEBERES ESTABLECIDOS}

Algunas de las leyes incluyen en el elenco de responsabilidades y deberes a los usuarios, de forma general.

La Ley de Murcia (2009), en su artículo 3 manifiesta que los destinatarios de la ley están «vinculados a su vez al respeto y cumplimiento de los deberes que se establezcan». De este modo, los destinatarios (que no son otros que usuarios, pacientes, familiares y/o tutores) quedan incluidos genéricamente en el haz de deberes que impone la Ley y, por tanto, se instaura un elemento de seguridad jurídica, tanto para el personal sanitario, como para la propia Administración Sanitaria (que debe velar por su cumplimiento).

La Ley 5/2010, de 24 de junio, sobre derechos y deberes en materia de salud de Castilla-La Mancha establece que «los ciudadanos deben ser conscientes de sus responsabilidades en relación con la salud, por eso la ley define sus deberes sobre el cuidado de la propia salud, la utilización adecuada de los servicios sanitarios y el respeto a los profesionales sanitarios y otros usuarios».

\footnotetext{
${ }^{120}$ En realidad, como hemos señalado, tan correcto es un planteamiento como el otro, puesto que derechosdeberes son caras de la misma moneda, que nacen de forma complementaria, recíproca y sinalagmática.
} 


\section{3.- RESPETO A LOS DEMÁS USUARIOS}

Las normas que contemplan este punto suelen enlazar este deber con otras dos obligaciones: la de respetar a los profesionales sanitarios y la del cumplimiento de las normas de los centros e instituciones.

En el caso de la región de Murcia (2009), el apartado 7 del artículo 63, estipula el deber de:

7) «Guardar el debido respeto y consideración al resto de pacientes, familiares o acompañantes».

\section{4.- RESPETO A LAS NORMAS DE FUNCIONAMIENTO DE LOS CENTROS}

En realidad, podría decirse que este aspecto provocaría la redundancia de la exigencia de otros deberes, si consideramos que el seguimiento de las normas provoca inevitablemente la ausencia de agresiones.

Como hemos visto, en la Ley 10/2001, de 28 de junio, de Salud de Extremadura se aúna este respeto a las normas con el debido al personal sanitario y al resto de los usuarios. La Ley 8/2008 de Salud de Galicia, establece el deber de: «Mantener la debida observancia de las normas establecidas en cada centro».

La Ley de Murcia (2009) se refiere concretamente a hábitos, costumbres o estilo de vida de los usuarios, «que deberá respetar las normas de funcionamiento del centro» (art. 63.6).

Euskadi, impone como deber en el apartado b) del artículo 14 de su Declaración (2015): «Cuidar las instalaciones y equipos sanitarios y colaborar en su mantenimiento, de acuerdo con las normas específicas establecidas en cada centro, servicio y establecimiento sanitario».

\section{5.- RENUNCIA A LA ATENCIÓN SANITARIA}

La renuncia a la atención sanitaria en situaciones de injurias, amenazas o agresiones se contempla en la Ley Foral de Navarra (2010). Desde el ámbito administrativo pueden tomarse medidas como el rechazo del cupo de pacientes infractores.

\section{6.- USO ADECUADO DE LOS RECURSOS SANITARIOS}

Como hemos apuntado en apartados anteriores, el buen o mal uso de los recursos de la sanidad por parte del usuario tiene una relación directa con la producción de agresiones a los profesionales sanitarios. La creencia de los ciudadanos de lo inagotable de los recursos a su disposición genera en muchas ocasiones la frustración subsiguiente cuando éstos les son negados. Por ello, resulta básica la educación en el conocimiento de las verdaderas posibilidades del sistema sanitario y su 
utilización racional y responsable ${ }^{121}$. El ciudadano debe ser consciente de cuándo sus pretensiones y demandas resultan desproporcionadas y ser tolerante ante unos recursos que no son ilimitados (Evans, 2007).

Por otra parte, hay también que tener en cuenta que el abuso en la utilización de prestaciones redunda en el perjuicio de los demás usuarios.

La Ley 10/2001, de 28 de junio, de Salud de Extremadura, en el apartado c) de su artículo 12, ordena «responsabilizarse del uso adecuado de las prestaciones ofrecidas por el sistema sanitario, fundamentalmente en lo que se refiere a la utilización de servicios, procedimientos de baja laboral o incapacidad permanente y prestaciones terapéuticas y sociales».

La Comunidad de Madrid, en su Ley 12/2001, prescribe a este respecto en el apartado 3 de su artículo 30: «Responsabilizarse del uso adecuado de los recursos, ofrecidos por el Sistema Sanitario, fundamentalmente en lo que se refiere a la utilización de los servicios, procedimientos de incapacidad laboral y prestaciones».

La Ley 6/2002, de 15 de abril, de Salud de Aragón, impone al usuario el deber de «responsabilizarse del uso adecuado de los recursos, servicios y prestaciones ofrecidos por el Sistema de Salud» (art. 5).

La Ley gallega de 2008, en su artículo 15.4, establece el deber de: «Usar adecuadamente los recursos, servicios y prestaciones ofrecidas por el sistema sanitario».

La Ley de Murcia (2009), en su artículo 63, se refiere a estas cuestiones, reclamando el uso razonable de los diferentes recursos sanitarios. Literalmente, en el apartado 3 del citado artículo exige: «Evitar los usos abusivos y no acordes a la legislación vigente en el acceso a las prestaciones sanitarias en especial en lo que se refiere a las prestaciones farmacéuticas y en el ámbito de la incapacidad laboral. Todo ello con la finalidad de impedir situaciones, que dificulten el acceso de todos a la atención sanitaria en condiciones de igualdad efectiva».

La alusión a las prestaciones farmacéuticas y a las situaciones de incapacidad laboral no es casual: muchas de las agresiones que se producen contra los profesionales sanitarios traen su causa de prescripciones de fármacos (que el usuario considera insuficientes, inadecuadas o, también, en casos de drogodependencias, por la negativa de los facultativos a prescribir opiáceos).

\footnotetext{
${ }^{121}$ García Calvo (2013) pone dos ejemplos en este sentido: el de la utilización para urgencias menores de las UCI móviles, que impiden su uso en situaciones de verdadera urgencia grave y el abuso de pruebas complementarias de elevado coste en diagnósticos que no las requieren.
} 
Motivaciones muy frecuentes son también los conflictos que surgen debido a las peticiones de prórrogas de bajas laborales ${ }^{122}$.

La Declaración de 2015 de Euskadi, incluye en su artículo 15, letra a): «Utilizar adecuadamente, de acuerdo con sus necesidades, los recursos y prestaciones ofrecidas por el sistema sanitario de Euskadi, colaborar en su sostenibilidad, así como poner en conocimiento de las y los responsables de las instituciones sanitarias las irregularidades que observe en el funcionamiento de los centros y servicios».

\section{7.- BUEN USO DE LAS INSTALACIONES}

Quizá se trate de uno de los deberes que se explicitan más temprano y con más frecuencia.

Evidentemente, el respeto al mobiliario, objetos y demás elementos de los espacios sanitarios debe ser exigido y da una idea meridiana del grado de civismo y educación de los usuarios que realizan desperfectos en los mismos. Pero, también obviamente, no puede ponerse al mismo nivel (ni mucho menos superponerse) la protección de los bienes materiales a la consideración debida al profesional.

En este sentido, es lógica la crítica que realizan Martínez-Jarreta (2003) y Gascón Santos (2006) cuando lamentan la poca atención recibida en los elencos de deberes a las agresiones al personal, que contrasta con la inclusión sistemática en los mismos del necesario respeto a las instalaciones sanitarias.

La Ley 10/2001, de 28 de junio, de Salud de Extremadura, en su artículo 12, apartado b) impone «Cuidar las instalaciones y colaborar en el mantenimiento de la habitabilidad de las instituciones sanitarias y sociosanitarias».

En la Ley 12/2001 de la Comunidad de Madrid, se indica en su artículo 30.2 lo siguiente: «Utilizar las instalaciones de forma adecuada a fin de que las mismas se mantengan en todo momento en condiciones de habitabilidad».

También la Ley de Galicia (2008) contempla el deber de «Cuidar las instalaciones y colaborar en el mantenimiento de la habitabilidad de las instituciones sanitarias».

La Ley murciana (2009) incluye esta cuestión en el apartado 6 de su artículo 63: «Hacer un uso correcto y cuidadoso de las instalaciones y servicios sanitarios con el fin de garantizar su conservación y funcionamiento para beneficio de los demás usuarios...».

${ }^{122}$ SAP Madrid 125/2017, de 24 de febrero, entre otras. 


\section{8.- DEBERES DE COLABORACIÓN}

Como también se ha señalado en apartados anteriores, resultan muy conflictivas las cuestiones relacionadas con demoras en la atención sanitaria y listas de espera. Por esta razón, hemos observado que un gran número de Planes de Prevención de Riesgos establecen medidas para intentar solventar estas situaciones. Algunas Leyes que regulan derechos y deberes también se ocupan de este tema, conscientes del problema.

En el ámbito nacional, como referente en este asunto, puede citarse el Real Decreto 1039/2011, de 15 de julio, por el que se establecen los criterios marco para garantizar un tiempo máximo de acceso a las prestaciones sanitarias del Sistema Nacional de Salud (BOE de 29 de agosto de 2011). Con el objeto de garantizar la efectividad del tiempo máximo de acceso prevista, establece en su artículo 7 las siguientes obligaciones para los usuarios:

a) Mantener actualizados los datos sobre su teléfono, domicilio o correo electrónico, a efectos de llamamiento, notificación o localización por parte del servicio de salud.

b) Justificar, cuando concurran motivos personales, y mediante el procedimiento que el servicio de salud a tal efecto determine, la solicitud de aplazamiento de la atención garantizada.

c) Comunicar con antelación suficiente, siempre que ello sea posible, la decisión de no presentarse a una citación.

d) Facilitar al servicio de salud la información necesaria que le sea requerida a efecto de poder asignarle la alternativa más adecuada para la realización de la atención garantizada.

e) Poner en conocimiento de los responsables de las instituciones sanitarias las irregularidades que observe en el ejercicio del derecho de la garantía de tiempo máximo de acceso, mediante el procedimiento que el servicio de salud establezca a tal efecto.

La Ley de Murcia (2009) lo hace en el apartado 4 de su artículo 63, que reza literalmente:

4) «Avisar al sistema sanitario, con la mayor celeridad y diligencia de la imposibilidad de acudir por cualquier causa a una cita o servicio sanitario previamente programado, en especial en el ámbito de la atención especializada. Todo ello con la finalidad de mejorar la planificación y optimización de los recursos, así como en beneficio de otros usuarios».

\section{EL RÉGIMEN SANCIONADOR ADMINISTRATIVO}




\section{LA POTESTAD SANCIONADORA DE LA ADMINISTRACIÓN}

La Administración Pública ostenta como deber básico en su actuación la protección del interés público o general y de esta obligación nace ineludiblemente su potestad sancionadora.

La tutela de ese interés público requiere de normas que fijen límites a las actuaciones de los sujetos privados y públicos, según la configuración del Estado de Derecho. El incumplimiento de esos límites lleva adheridas consecuencias. Si la contravención se encuentra tipificada como infracción, la consecuencia será la imposición de una sanción.

En esto consiste, básicamente, el ejercicio de la potestad sancionadora de la Administración Pública.

La Constitución Española establece dos potestades: punitiva y sancionadora, y las enmarca dentro de un haz de garantías individuales, garantizadas en los artículos 24, 25 y 26. La potestad punitiva es aquella que produce condenas que se traducen en penas y la sancionadora en imposición de sanciones.

Estas dos potestades conviven dentro del modelo constitucional, ostentando el Poder Judicial la punitiva en exclusividad y la Administración Pública, la sancionadora. Ambas potestades nacen del «ius puniendi» del Estado, siendo simples manifestaciones del mismo ${ }^{123}$.

La potestad sancionadora se configura como un híbrido, cruce entre Derecho Penal y Administrativo ${ }^{124}$. Es cierto que hay diferencias (terminología, distinta finalidad, menor alcance $^{125}$, etc), pero no ostenta una identidad claramente diferenciada, debiendo recurrirse para una adecuada distinción al plano de las garantías. De hecho, el TDH de Estrasburgo ha afirmado la imposibilidad de distinción entre los tipos de ilícito penal y administrativo y el TS, en el mismo sentido, constata que no existe diferencia de naturaleza entre ambos ilícitos ${ }^{126}$.

Algunos autores han alertado sobre el riesgo de que esta falta de distinción entre ambas figuras procure el empleo de la sanción administrativa como un sistema paralelo al penal (que sería material, aunque no formalmente, punitivo) ${ }^{127}$.

\footnotetext{
123 SSTC 188/2005, de 7 de julio y 77/2012, de 19 de octubre, entre otras.

${ }^{124}$ Huergo Lora (2007) habla de "carácter mestizo»

${ }^{125}$ Esto es, la imposibilidad de que una sanción administrativa pueda infringir privaciones de libertad (el art. 25.2 reserva tal medida para el Derecho Penal: sólo puede ser impuesta por una pena).

${ }^{126}$ STS de 9 de enero de 1991: manifiesta que la elección entre configurar un acto como ilícito penal o ilícito administrativo es una opción de política legislativa.

Las referencias que se hacen en este apartado respecto a la jurisprudencia del Tribunal Supremo deben entenderse realizadas a la Sala de lo Contencioso-Administrativo del mismo.

${ }^{127}$ Rando Casermeiro (2010), Díaz Fraile (2017).
} 
Antes de proseguir, deviene imprescindible fijar los conceptos de sanción e infracción administrativas:

Parejo Alfonso (2016) define sanción como «la corrección impuesta a un administrado en el ejercicio de la correspondiente potestad administrativa por un hecho o una conducta constitutivos de infracción asimismo administrativa, es decir, tipificada legal y previamente como tal».

Como puede observarse, de la definición de sanción se deriva la de infracción, que es la que provoca la primera, siendo esta la acción que contraviene un mandato, siempre y cuando se encuentre tipificada previamente por una norma con rango de ley (este aspecto lo trataremos posteriormente con más detalle).

Hay que distinguir entre infracciones y simples contravenciones (ilícitos no tipificados como infracción). Igualmente, resulta de interés la diferencia entre sanción y consecuencia desfavorable. La primera es la necesaria acompañante de la infracción tipificada y la segunda puede derivarse de una infracción o no, pero no tiene naturaleza sancionadora.

\section{PRINCIPIOS DEL DERECHO SANCIONADOR ADMINISTRATIVO}

Ya ha quedado afirmado que del «ius puniendi» del Estado nacen dos potestades: la punitiva y la sancionadora (la primera, propia y exclusiva del Derecho Penal y la segunda, del Administrativo sancionador). Pues bien, los derechos fundamentales contenidos en los artículos 24, 25 y $26 \mathrm{CE}$ (que se proyectan en garantías individuales que generan auténticos derechos subjetivos) son aplicables a ambas, de tal modo que los principios garantistas del Derecho Penal se transponen al Administrativo Sancionador.

\section{Principio de Legalidad (art. 25 LRJSP).}

Exige, en primer lugar, que una norma con rango de Ley formal atribuya la potestad sancionadora específica a una Administración Pública concreta.

Este mandato se sustenta en los artículos 25 y $103.1 \mathrm{CE}$ (el 25.1 contiene el principio de legalidad y el 103.1 lo referente a la sumisión plena de la Administración Pública a la Ley y al Derecho). Concretamente, según consolidada jurisprudencia del TC, se exige la mayor precisión posible en la predeterminación de infracciones y sanciones, abarcando las garantías de «lex scripta», «lex certa» $\mathrm{y}$ «lex previa».

La Ley debe tener carácter de formal, aunque permite la colaboración del Reglamento para su desarrollo y concreción. 
Señala Parejo Alfonso (2016) que el principio de legalidad opera con menor rigor en el campo del Derecho Administrativo sancionador que en el Penal.

En segundo lugar, la Ley debe dictarse conforme a los principios establecidos en el Cap. III del título preliminar de la LRJSP (Título IX de la LRJPAC) y por parte del órgano administrativo que tenga asignada la competencia.

En tercer lugar, existe una garantía de tipo procedimental: siempre debe seguirse un procedimiento previo a la imposición de una sanción (art. 53.2 LPAC) ${ }^{128}$. El procedimiento será, además, el normativamente preestablecido.

\section{Principio de irretroactividad.}

El artículo 9.3 CE prohíbe la irretroactividad de las disposiciones no favorables o restrictivas de derechos, lo que queda reflejado en el ordenamiento administrativo en el art. 128 LRJPAC y 26 LRJSP.

La traducción del principio al Derecho Administrativo sancionador es que sólo se pueden aplicar disposiciones tipificadoras de infracciones y sanciones que hayan entrado en vigor antes de la producción del hecho causante y que estén vigentes en el momento de que éste suceda.

Esta irretroactividad únicamente excluye los efectos desfavorables, los favorables sí podrían tener efecto (art. 26.2 LRJSP) ${ }^{129}$.

\section{Principio de tipicidad (art. 27 LRJSP).}

Sólo puede ser infracción aquel ilícito administrativo expresamente contemplado como tal en una Ley.

Tal principio es una importante concreción del principio de legalidad, y se basa en el principio de seguridad jurídica, contemplado en el art. 9.3 CE, que implica la existencia de una cierta certeza ${ }^{130}$ sobre cuáles sean las infracciones y sus sanciones aplicables, en el caso del Derecho Administrativo sancionador. Esta necesaria certeza lleva a la prohibición de cláusulas generales, genéricas o indeterminadas, que otorguen un arbitrio excesivo a la autoridad administrativa.

El apartado 2 del artículo 27 LRJSP describe la necesidad de tipificar los ilícitos administrativos. Esta tipificación, como hemos visto, deberá realizarse por medio de norma con rango de ley,

\footnotetext{
${ }^{128}$ SSTC 39/1997, de 27 de febrero, entre otras. Igualmente, en el seno de la Jurisdicción contencioso-administrativa, SSTS de 4 de marzo de 2000 y de 6 de noviembre de 2012.

129 Por todas, STC 21/1993, de 18 de enero.

130 SSTC 25/2002, de 11 de febrero y 75/2002, de 8 de abril, entre otras.
} 
calificando formalmente como infracciones los hechos que corresponda. Existe mayor margen para las sanciones, que deberán ser fijadas también por ley, aunque bastará con su delimitación.

La tipificación debe realizarse de modo que sólo por la comisión de una infracción se dé lugar a la imposición de una sanción, es decir, respetando la necesaria vinculación entre ambas.

El art. 27.3 LRJSP permite la colaboración de los Reglamentos en el proceso de tipificación. Pero esta colaboración queda limitada por lo siguiente:

- La ley establece primero el cuadro de infracciones y sanciones.

- El Reglamento debe sólo delimitar las sanciones o identificar con más precisión las infracciones, no pudiendo generar nuevas infracciones ni sanciones o alterar su naturaleza o límites.

Por último, el apartado 4 del art. 27 LRJSP prohíbe expresamente la aplicación de la analogía (en respeto al principio de seguridad jurídica consagrado en el art. 9.3 CE).

\section{Principio de responsabilidad (art. 28 LRJSP).}

Se trata de un principio estructural del Derecho Penal, también denominado «principio de culpabilidad» o «de personalidad de la sanción». La especialidad del Derecho Administrativo en cuanto a este principio es que también rige para las personas jurídicas (aunque existan algunos elementos diferenciadores).

Con la asunción de este principio se excluye la responsabilidad objetiva en el ámbito del Derecho Administrativo sancionador.

Por doctrina jurisprudencial, queda excluida la imposición de sanción sin motivación suficiente de concurrencia de responsabilidad ${ }^{131}$, requiriéndose siempre una imputación personal de la misma (en base al principio de presunción de inocencia ${ }^{132}$ ).

Como novedad en la LRJSP hay que reseñar que la exigencia de responsabilidad lo es únicamente a título de dolo o culpa (como expresa el apartado 1 del artículo 28), pero también se puede ser responsable de la comisión de infracciones de tipo administrativo por el incumplimiento de la obligación de prevenir (tipificada por una ley reguladora de régimen sancionador).

La responsabilidad puede ser solidaria (en los casos contemplados en el apartado 3 del artículo 28) y también subsidiaria en el supuesto descrito en el párrafo anterior.

\footnotetext{
${ }^{131}$ SSTS de 6 de mayo de 2010 y de 23 de abril de 2010, entre otras.

${ }^{132}$ Art. 137 LRJPAC.
} 
El artículo 28 del LRJSP positiviza el principio estableciendo que únicamente podrán ser sancionados por hechos constitutivos de infracción administrativa quienes «resulten responsables de los mismos a título de dolo o culpa», siempre que tengan capacidad infractora (que también se describe en el apartado 1 del antedicho artículo).

Resulta ineludible la necesidad de comprobar la responsabilidad del infractor a título de dolo, culpa o simple inobservancia (en este caso debido a la omisión de la diligencia exigible en el cumplimiento de la normativa, aunque únicamente respecto a sujetos con deber específico de conocimiento de la citada normativa).

Finalmente, es obligatorio destacar que la sanción no excluye la reposición en su estado originario de la situación alterada por la infracción, ni tampoco la indemnización de los daños y perjuicios causados (número 2 del artículo 28 LRJSP). Estas dos obligaciones forman parte del procedimiento sancionador y su resolución. El incumplimiento del abono de la indemnización o la reposición de la situación enerva la puesta en marcha de los medios generales de ejecución forzosa de las resoluciones administrativas.

\section{Principio de proporcionalidad (artículo 29 LRJSP).}

Este principio exige que los medios empleados se ajusten a los fines perseguidos y deriva de la interdicción de la arbitrariedad de los poderes públicos (artículo 9.3 CE), siendo consustancial al Estado de Derecho.

Resulta de gran importancia en el Derecho Administrativo sancionador, por cuanto limita el margen de apreciación de la Administración Pública e impone una adecuación entre la gravedad de la infracción y la sanción a imponer ${ }^{133}$. Concretamente, el artículo 29.3 LRJSP dice que: «se deberá observar la adecuada idoneidad y necesidad de la sanción a imponer y su adecuación a la gravedad del hecho constitutivo de la infracción».

Asimismo, quedan establecidos unos criterios preferentes para la graduación de las sanciones, explicitados en el mismo número 3 del artículo 29:

a) Grado de culpabilidad o existencia de intencionalidad.

b) Continuidad o persistencia de la conducta infractora ${ }^{134}$.

c) Naturaleza de los perjuicios causados.

\footnotetext{
${ }^{133}$ SAN de 31 de enero de 2007, STS de 14 de marzo de 2012, entre otras.

${ }^{134}$ En la LRJPAC se entendía como reiteración, consistente en comisión anterior de otras infracciones (sin necesidad, a diferencia del apartado d), de que ostenten la misma naturaleza).
} 
d) Reincidencia, por comisión en el término de un año de una infracción de la misma naturaleza cuando así haya sido declarada por resolución firme en vía administrativa.

El artículo 29 establece otras tres reglas, reflejadas en sus números 4, 5 y 6 :

- Posibilidad de que el órgano competente imponga la sanción correspondiente en su grado anterior, atendiendo a la adecuación a la gravedad de la infracción y los hechos concurrentes.

- Si la infracción deriva necesariamente de la comisión de otra u otras, se deberá imponer sólo la debida a la más grave cometida.

- La comisión de una pluralidad de acciones u omisiones que infrinjan el mismo o similares preceptos administrativos será sancionable como infracción continuada.

\section{Principio de prescripción (art. 30 LRJSP).}

El artículo 30.1 remite a las leyes que establezcan las infracciones y sanciones la fijación de los plazos de prescripción de las mismas. Sólo en caso de falta de fijación de estos plazos, se acudirá al régimen general que en este artículo se estipula:

- Infracciones:

o Muy graves a los 3 años, graves a los 2 años y leves a los seis meses.

o Cómputo del plazo: desde el día de comisión de la infracción. En caso de infracciones continuadas, a partir del día en que se cometió la última.

o El plazo se interrumpe por el inicio del procedimiento sancionador (con conocimiento del interesado). Si dicho procedimiento se paralizara durante más de un mes por causa no imputable al presunto responsable, se reanudará el plazo de prescripción.

- Sanciones:

o Muy graves a los 3 años, graves a los dos años y leves al año.

o Cómputo del plazo: desde el día siguiente en que la resolución adquiera firmeza.

o El plazo se interrumpirá por inicio del plazo de ejecución, con conocimiento del interesado, reanudándose bajo la misma regla que en el caso de las infracciones, señalada anteriormente.

o Además, «en el caso de desestimación presunta del recurso de alzada interpuesto contra la resolución por la que se impone la sanción, el plazo de prescripción de la sanción comenzará a contarse desde el día siguiente a aquel en que finalice el plazo legalmente previsto para la resolución de dicho recurso». 
Conviene añadir en materia de prescripción, que el artículo 6 RPrPs impone la declaración de oficio de la misma y el archivo de las actuaciones cuando se aprecie su concurrencia en cualquier momento.

\section{Principio «Non bis in idem».}

Se trata de un principio general del Derecho, entendiéndose incluido implícitamente en el artículo 25.1 CE, debido a su íntima relación con los principios de tipicidad y legalidad ${ }^{135}$.

Establece la férrea prohibición de que un mismo hecho pueda ser castigado con una doble (o múltiple) sanción.

Dentro del ámbito administrativo sancionador, se refiere a dos cuestiones:

- La imposibilidad de imponer sanciones administrativas y además penales si la actuación causante refiere una triple identidad: de sujeto, hecho y fundamento.

- Aunque se admite la concurrencia de dos procedimientos punitivos relativos a los mismos hechos (penal y administrativa), sólo cuando la calificación penal de los mismos no conduzca a una pena quedará libre la vía de la sanción administrativa. Se trata, por tanto, de un régimen de concurrencia imperfecta en la que la jurisdicción penal tiene absoluta preferencia. Y ello es así hasta el punto de que, cuando pueda producirse una sanción administrativa (por no haberse impuesto ninguna pena), ésta deberá respetar en todo caso el planteamiento fáctico penal ${ }^{136}$.

La doctrina constitucional, además de insistir en las cuestiones anteriores, configura el principio «non bis in ídem» como un auténtico derecho fundamental.

La interdicción de un doble proceso penal sobre el mismo objeto resulta incuestionable. No es así en el caso de coexistencia (como hemos visto) de proceso penal y procedimiento administrativo sancionador. En este último caso, es permisible la concurrencia de sanciones, siempre y cuando no concurra el requisito de identidad de sujeto, hecho y de fundamento ${ }^{137}$. Por tanto, son admisibles varias sanciones impuestas por un mismo hecho (siempre que no exista la triple identidad reseñada $\left.{ }^{138}\right)$.

De la precedencia de la autoridad judicial penal sobre la administrativa se deriva lo siguiente:

\footnotetext{
135 Por todas, SSTC 159/1985, de 27 de noviembre y 154/1990, de 15 de octubre.

136 STS 77/1983, de 3 de octubre.

${ }^{137}$ Artículo 31.1 LRJSP: «No podrán sancionarse los hechos que lo hayan sido penal o administrativamente, en los casos en que se aprecie identidad de sujeto, hecho y fundamento».

${ }^{138}$ STS de 16 de junio de 2010.
} 
- Suspensión de la actividad administrativa en tanto no exista pronunciamiento sobre el posible ilícito penal.

- Monopolio judicial sobre la declaración de los hechos. La sentencia firme fija la verdad jurídica, lo que constituye un efecto propio de la cosa juzgada. Algún sector de la jurisprudencia declara la sujeción de la Administración incluso a los hechos no probados (STS de 22 de febrero de 2011).

\section{Principio de presunción de inocencia.}

A través del derecho de defensa ${ }^{139}$ formulado en el artículo 24 CE, se articula la prohibición de indefensión.

El Tribunal Constitucional proclama (en el campo del procedimiento administrativo sancionador) la existencia de los derechos de defensa, actividad probatoria y presunción de inocencia ${ }^{140}$.

Debe contarse con una prueba de cargo válida y suficiente que elimine cualquier duda razonable para que pueda infringirse una sanción. La presunción de inocencia opera, precisamente, ante la existencia de esa duda razonable, por aplicación del principio «in dubio pro reo».

La LRJPAC, en su artículo 137.1 aclaraba, adicionalmente, que la carga de la prueba («demostración de existencia de responsabilidad») recae en la Administración Pública actuante.

\section{Garantías procedimentales por aplicación del derecho de defensa.}

El Derecho de defensa incluye el de actividad probatoria ${ }^{141}$, que presupone (según doctrina constitucional) el derecho a ser informado de la acusación y a conocer los cargos antes de la imposición de la pena o sanción ${ }^{142}$.

Toda esta necesaria información, en el procedimiento sancionatorio administrativo, tiene que proporcionarse mediante el pliego de cargos, en el que deben contenerse una serie de cuestiones: hechos y su calificación legal, derecho a no declarar contra sí mismo, derecho a asistencia letrada. De igual modo, resulta preceptiva la audiencia del interesado, así como la formulación de propuesta de resolución y su comunicación al presunto infractor.

\footnotetext{
${ }^{139}$ Este derecho lo es tanto en cuanto a la falta de defensa, como en lo relacionado con la disminución de las posibilidades de defensa.

${ }^{140}$ STC 45/1997, de 11 de marzo, entre otras.

141 Véase, por todas: STC 297/1993, de 18 de octubre.

142 STC 23/2007, de 12 de febrero y STS de 10 de mayo de 2011.
} 
Asimismo, deviene necesaria la separación entre la actividad administrativa de instrucción y la propiamente sancionadora.

10. Principios de interdicción del «solve et repete» y de la «reformatio in peius».

Debe entenderse prohibido el «solve et repete», o condicionar al pago de la sanción (o su depósito) la admisión de la impugnación de la misma.

En cuanto a la «reformatio in peius» o agravación de la situación del interesado (en este caso de la sanción impuesta) durante el procedimiento de impugnación, queda establecida su interdicción en el artículo 21.3 RPrP. 


\section{RÉGIMEN SANCIONADOR ADMINISTRATIVO DE LAS AGRESIONES DESARROLLADO POR LAS CCAA.}

En consonancia con lo anteriormente señalado, el principio de tipicidad exige que todas y cada una de las infracciones sean explícitamente expresadas. Por esta razón, (aunque se haya aludido a los deberes correspondientes que resultan incumplidos), a continuación, se detallan pormenorizadamente las infracciones, acompañadas de las sanciones correspondientes, que se incluyen dentro de las distintas disposiciones autonómicas que hemos considerado:

\section{EXTREMADURA}

La Ley 10/2001, de 28 de junio, de Salud de Extremadura establece su régimen sancionador en sus artículos 52 a $56^{143}$.

Se tipifican una serie de infracciones, clasificadas en leves, graves y muy graves. En lo que se refiere al menoscabo de los derechos de los profesionales sanitarios, no se encuentra ninguna referencia directa al problema. Quizás podría existir alguna relación en cuanto a la infracción grave $\mathrm{n}^{\mathrm{o}} 13^{144}$, en el sentido de que el correcto disfrute de los ciudadanos de los servicios sanitarios implica un correcto funcionamiento de los mismos, que puede verse limitado por las actitudes violentas. También tiene que ver con el ambiente pacífico necesario para la utilización de esos servicios. Pero lo cierto es que esta breve alusión no configura un claro elemento protector contra la violencia ejercida contra los profesionales. La falta de previsión en este aspecto se solventará por parte de la Comunidad Autónoma de Extremadura con la aprobación de la Ley 11/2015, de 8 de abril, de Autoridad de profesionales del Sistema Sanitario Público y centros sociosanitarios de Extremadura $^{145}$.

En cambio, se contempla específicamente la presión ilegítima ejercida (en forma de resistencia, coacción, amenaza, represalia, desacato, etc.), pero únicamente referida a «autoridades sanitarias o sus agentes».

\footnotetext{
${ }^{143}$ Existe otra Ley 7/2011, de 23 de marzo, de salud pública de Extremadura. Comunidad Autónoma de Extremadura DOE núm. 59, de 25 de marzo de 2011, BOE núm. 88, de 13 de abril de 2011. Utilizamos para nuestro análisis la ley anterior, para mostrar un ejemplo de normativa temprana en este sentido.

144 «Dificultar o impedir el disfrute de cualquiera de los derechos reconocidos en el título I de esta Ley a los ciudadanos respecto a los servicios sanitarios y sociosanitarios públicos o privados».

${ }^{145}$ Como veremos, esta Ley es normativa de Derecho administrativo, no pudiéndose atribuir efectos penales a esta condición de Autoridad.
} 


\section{MADRID}

Poco cabe decir del contenido del régimen sancionador implantado en la Comunidad de Madrid por su Ley de Ordenación de 2001. La única referencia de cierta relación con la materia es la letra k) del apartado 3 del artículo 144, que tipifica las infracciones. En este punto, se considera infracción sanitaria grave: Dificultar o impedir el disfrute de cualquiera de los derechos «reconocidos en la presente Ley a los ciudadanos respecto a los servicios sanitarios y sociosanitarios públicos y privados» ${ }^{146}$. Esto podría interpretarse en relación con el detrimento que sufren los servicios sanitarios como consecuencia de los incidentes violentos que, lógicamente, inciden en el correcto disfrute de los mismos por parte de los usuarios. Pero no deja de ser una relación muy tangencial. Lo que sí se expresa con total claridad es la protección otorgada a las autoridades sanitarias en y sus agentes (infracción tipificada como muy grave en el apartado 4, letra b) del artículo 144): «La resistencia, coacción, amenaza, represalia, desacato o cualquier otra forma de presión ejercida sobre las autoridades sanitarias o sus agentes».

\section{ARAGÓN}

Ley 6/2002, de 15 de abril, de Salud de Aragón. Tipifica una serie de infracciones, clasificándolas en leves, graves y muy graves en su artículo $41^{147}$. De entre ellas, sólo podría referirse a las eventuales agresiones al personal sanitario: «a) Dificultar o impedir el disfrute de cualesquiera de los derechos reconocidos en el Título II de la presente ley a los ciudadanos, respecto a los servicios sanitarios públicos o privados». En el apartado 2 del mencionado artículo 41 establece que la graduación de las infracciones quedará supeditada a una serie de cuestiones, de las que dependerá su calificación como muy graves o no.

Las sanciones pasan a regularse en el artículo 42, con la aclaración de que consistirán en multas y otras medidas previstas en la Ley 14/1986, de 25 de abril, General de Sanidad ${ }^{148}$. Son órganos competentes para la imposición de multas: Los Alcaldes (hasta 15.025,30 euros; los Directores de los Servicios Provinciales, de 12.020,25 euros a 30.050,61 euros; los Directores Generales o asimilados, desde 12.020, 25 a 30.050, 61 euros; el Consejero responsable de Salud, desde 30.050, 62 a 601.012,10 euros y el Gobierno de Aragón, desde 210.354, 24 hasta 601.012,10 euros).

El apartado 5 del artículo 42 dispone que, si los usuarios faltan a la observancia de los deberes que les impone el artículo 5 de la ley, «podrán ser sancionados económicamente por un importe

\footnotetext{
146 Prácticamente con la misma redacción que la Ley de Extremadura.

${ }^{147}$ Sin perjuicio de lo establecido en el artículo 35 de la Ley 14/1986, de 25 de abril, General de Sanidad.

${ }^{148}$ Concretamente en el artículo 36, apartados 1 y 2.
} 
máximo equivalente al coste del servicio sanitario prestado o al de los daños producidos en las instalaciones». Si observamos el contenido del artículo 5, podremos ver cuáles son los deberes cuyo incumplimiento puede ser sancionado (se eliminan de la relación los apartados a) y d) por su falta de relación con el objeto de este estudio):

b) Cuidar las instalaciones y colaborar en el mantenimiento de la habitabilidad de los centros del Sistema de Salud.

c) Responsabilizarse del uso adecuado de los recursos, servicios y prestaciones ofrecidos por el Sistema de Salud, fundamentalmente en lo que se refiere a la utilización de servicios, procedimientos de baja laboral o incapacidad permanente y prestaciones terapéuticas y sociales.

e) Mantener el debido respeto a las normas establecidas en cada centro sanitario y al personal que en él preste sus servicios.

Como se ve, el apartado e) resulta el más claramente enfocado a la prevención de las agresiones a los profesionales sanitarios, aunque también podría encontrarse una relación indirecta en la prescripción del uso adecuado de los recursos, servicios y prestaciones ofrecidos.

\section{ILLES BALEARS}

La Ley 5/2003, de 4 de abril, de Salud de las Illes Balears, establece en su Capítulo II el régimen sancionador de las infracciones tipificadas también en la antedicha ley. Como es habitual, califica las infracciones en leves, graves y muy graves, no refiriéndose explícitamente a las agresiones a los profesionales sanitarios. En su lugar, tipifica genéricamente como infracciones leves, en su artículo 55, las simples irregularidades en el cumplimiento de los deberes (sin repercusiones graves) y la falta de observancia de las prescripciones por simple negligencia y sin intencionalidad. El salto a las infracciones graves (art. 56) se produce por reiteración en la comisión de varias leves o por incumplimiento de otros deberes relativos principalmente a cuestiones de salud pública, criterios que se repiten en la tipificación de las muy graves (art. 58), que siguen la misma tónica.

Atendiendo a las infracciones tipificadas como incumplimientos de deberes de los usuarios aplicables a la cuestión de las agresiones, encontraríamos únicamente una posible referencia a la infracción de la letra e) del artículo 24, que establece el deber de respetar las normas establecidas en cada centro y al personal que preste servicios en el mismo. Como puede verse, la referencia es muy sucinta y, al estar unida al respeto a las normas, tampoco parece que se configure como una infracción demasiado destacada. Por ello, suponemos que sería en todo caso considerada como infracción leve (a salvo, claro está, de gravedad manifiesta en la producción de daños personales) 
y por tanto, merecedora de la sanción establecida en el artículo 59.1 letra a): «A las infracciones leves, amonestación escrita o multa de entre cien y seis mil euros».

\section{GALICIA}

El régimen sancionador se incluye en la Ley 8/2008, de 10 de julio, de Salud de Galicia dentro de su Capítulo IV («Infracciones y sanciones». Tras una referencia a los principios generales del régimen sancionador administrativo (artículo 39), califica en su artículo 40 a las infracciones como leves, graves y muy graves, estableciendo un sistema de graduación atendiendo a varios criterios: riesgo para la salud, cuantía del beneficio obtenido, grado de intencionalidad, gravedad de la alteración sanitaria y social producida, generalización de la infracción y la reincidencia.

La única infracción que podría tener relación en materia de agresiones sería la contemplada en la letra $\mathrm{h}$ del artículo 42 (Infracciones graves): «El dificultar o impedir el disfrute de los derechos reconocidos en la presente ley a los usuarios y usuarias del sistema sanitario, ya sea en el terreno de los servicios sanitarios o sociosanitarios públicos o privados», en tanto una agresión puede suponer una perturbación del servicio que determine ese dificultar o impedir el disfrute de sus derechos a otros usuarios. En el supuesto de entenderse así, las sanciones correspondientes, por la comisión de infracción grave (artículo 44) serían:

- Grado mínimo: de 3.005,07 a 6.010,12 euros.

- Grado medio: de 6.010,13 a 10.517,71 euros.

- Grado máximo: de 10.517,72 a 15.025,30 euros.

Las demás disposiciones confluyen en reglas generales de prescripción de infracciones y sanciones.

\section{MURCIA}

Murcia (2009) no construye un régimen sancionador propio, sino que, por medio del artículo 72 de su Ley 3/2009 remite a:

- $\quad$ El Capítulo VI del Título I de la Ley 14/1986, de 25 de abril, General de Sanidad.

- El Título VII de la Ley 15/1999, de 13 de diciembre de Protección de Datos de Carácter Personal.

- Lo dispuesto en cuanto a régimen sancionador en la Ley 29/2006, de 26 de julio de Garantías y Uso Racional de los Medicamentos y Productos Sanitarios. 
- El régimen previsto en la Ley 14/2006, de 26 de mayo, sobre técnicas de reproducción humana asistida y en la Ley 42/1988, de 28 de diciembre, de donación y utilización de embriones y fetos humanos o de sus células, tejidos u órganos.

\section{CASTILLA-LA MANCHA}

La Comunidad Autónoma de Castilla-La Mancha, dictó en 2010 la Ley 5/2010, de 24/06/2010, sobre derechos y deberes en materia de salud de Castilla-La Mancha (DOCLM 9 Julio 2010; BOE 13 de octubre de 2010), dedicando su Título V al Régimen sancionador correspondiente a las infracciones que se cometan en la materia.

Establece el artículo 51 las actuaciones que deban iniciarse, en relación con la responsabilidad penal, debiendo abstenerse la Administración (como es regla general) cuando las infracciones puedan ser constitutivas de ilícito penal. Si finalmente el órgano judicial que conociera del caso desestima la inexistencia de tal ilícito, se continuará con el expediente sancionador tomando como base los hechos declarados probados por la autoridad judicial. Se mantendrán las medidas administrativas adoptadas para salvaguardar la salud y seguridad de las personas hasta pronunciamiento sobre ellas del juez competente.

El artículo 52 se dedica a la concurrencia de sanciones, señalando (en aplicación del principio «non bis in ídem») que no se impondrá en ningún caso doble sanción administrativa a un mismo sujeto por los mismos hechos y en función de los mismos intereses públicos.

Se dedica el artículo 53 a la enumeración y graduación acciones u omisiones constitutivas de infracciones. En lo que aquí resulta de interés, debemos señalar las siguientes:

«2. Son infracciones leves:

d) La destrucción, menoscabo o deterioro de bienes, instalaciones y servicios sanitarios, siempre que no afecte al normal funcionamiento del centro, servicio o establecimiento sanitario.

f) La realización de actos que alteren o perturben el normal funcionamiento del centro, servicio o establecimiento sanitario o sus condiciones de habitabilidad.

3. Son infracciones graves:

d) La destrucción, menoscabo o deterioro de las instalaciones y equipamientos sanitarios siempre que afecte al normal funcionamiento del centro, servicio o establecimiento sanitario. 
f) La realización de actos que alteren o perturben el normal funcionamiento del centro, servicio o establecimiento sanitario o sus condiciones de habitabilidad cuando afecte a la asistencia sanitaria.

g) La resistencia, falta de respeto, amenazas, insultos, represalias o cualquier otra forma de presión ejercida contra los profesionales de los centros, servicios y establecimientos sanitarios, los pacientes o sus acompañantes siempre que no sean constitutivas de ilícito penal.

h) Cometer una infracción leve cuando se haya sido sancionado por la comisión de una o más infracciones leves en el transcurso de dos años.

4. Infracciones muy graves:

a) La realización de las conductas previstas en los apartados anteriores cuando suponga un incumplimiento consciente y deliberado de los preceptos de la presente Ley y produzca un daño grave.

b) La agresión física a profesionales de los centros, servicios y establecimientos sanitarios, a pacientes o a sus acompañantes siempre que no sea constitutiva de ilícito penal ${ }^{149}$.

c) Cometer una infracción grave cuando se haya sido sancionado por una o más infracciones graves en el transcurso de tres años».

El artículo 54 está dedicado a aclarar quiénes serán responsables de las infracciones, en concreto «las personas físicas o jurídicas que realicen las acciones u omisiones tipificadas como infracción en esta Ley». Si los autores fueren menores no emancipados o personas incapacitadas, la responsabilidad (de tipo solidario) recaerá en sus padres, tutores o representantes legales.

Las sanciones correspondientes a las infracciones enumeradas se tratan en el artículo 55:

«Artículo 55 Sanciones

1. Las infracciones de la presente Ley serán sancionadas, en su caso, con multa, sin perjuicio de lo señalado en el punto 4 de este artículo.

2. Las infracciones previstas en esta Ley serán castigadas con las siguientes sanciones:

a) Por infracciones leves:

$1^{\circ}$ En grado mínimo: multa de hasta 600 euros.

149 Puede observarse la importancia que se otorga al hecho de que la agresión sea física y no verbal o psicológica. 
$2^{\circ}$ En grado medio: multa de 601 euros hasta 1.800 euros.

$3^{\circ}$ En grado máximo: multa de 1.801 euros hasta 3.000 euros.

b) Por infracciones graves:

$1^{\circ}$ En grado mínimo: multa de 3.001 euros hasta 6.000 euros.

$2^{\circ}$ En grado medio: multa de 6.001 euros hasta 10.500 euros.

$3^{\circ}$ En grado máximo: multa de 10.501 euros hasta 15.000 euros.

c) Por infracciones muy graves:

$1^{\circ}$ En grado mínimo: multa de 15.001 euros hasta 120.000 euros.

$2^{\circ}$ En grado medio: multa de 120.001 euros hasta 350.000 euros.

$3^{\circ}$ En grado máximo: multa de 350.001 euros hasta 600.000 euros.

3. Los anteriores límites se podrán superar en el supuesto de que la sanción resulte más beneficiosa para el infractor que el cumplimiento de las normas infringidas, hasta un límite del doble del beneficio ilícito obtenido.

La graduación de las sanciones es contemplada en el artículo 56, estableciéndose tres niveles (mínimo, medio y máximo), en atención a la concurrencia de las siguientes circunstancias:

a) Las generales establecidas por las leyes de procedimiento administrativo. No obstante, cuando la reincidencia haya sido tenida en cuenta para tipificar la acción, en los supuestos del artículo 53.3.h) y 53.4.c), no se valorará tal circunstancia en el momento de graduar la sanción.

b) El grado de intencionalidad.

c) El incumplimiento de advertencias previas.

d) La gravedad de la alteración sanitaria y social producida.

e) El perjuicio causado y el número de personas afectadas.

f) La afectación directa a un colectivo de personas especialmente protegido.

g) Los beneficios obtenidos con la infracción.

h) La permanencia o transitoriedad de los riesgos.

i) La concurrencia con otras infracciones sanitarias o el haber servido para facilitar u ocultar la comisión de otra infracción.

El artículo se cierra en su apartado 2 con la procedente mención a la proporcionalidad que se seguirá entre la gravedad del hecho constitutivo de la infracción y la sanción a aplicar. 
En cuanto a los órganos competentes para imponer sanciones, el artículo 57.1 designa al Consejo de Gobierno de la Junta de Comunidades de Castilla-La Mancha como encargado de la imposición de sanciones superiores a 120.000 euros por infracciones muy graves. En el resto de los casos, la designación de los órganos competentes se remite a desarrollo reglamentario posterior (apartado 2 del artículo 57).

El artículo 58 fija el plazo de resolución de los procedimientos sancionadores en un año (sin perjuicio de lo establecido para los procedimientos simplificados) ${ }^{150}$.

Se prevé la adopción de medidas cautelares en el artículo 59, debido a «sospecha razonable y fundada de riesgo inminente y grave para la salud pública o para las personas, por circunstancias sobrevenidas o de fuerza mayor, o por incumplimiento de la normativa vigente».

Por último, el artículo 60 fija multas coercitivas para impulsar el cumplimiento de las resoluciones administrativas de la presente Ley, reiteradas por lapsos de un mes. El límite superior de las multas, se establece en 1.000 euros, para los supuestos previstos en el artículo 99.1 de la LRJAP y PAC (30/1992, de 26 de noviembre) ${ }^{151}$.

\section{NAVARRA. 2010}

La materia se regula por Ley Foral 17/2010, de 8 de noviembre, de derechos y deberes de las personas en materia de salud de la Comunidad Foral de Navarra (BOE de 28 de diciembre de 2010), y entró en vigor el 16 de noviembre de 2010.

Dedica su Título X al Régimen Sancionador (arts. 77 al 87), que se aplica a las infracciones administrativas tipificadas en la propia ley.

La concurrencia de sanciones se trata en su artículo 78 que, siguiendo el principio general del régimen sancionador administrativo, dispone que no será impuesta doble sanción administrativa por los mismos hechos y en función de los mismos intereses públicos protegidos, aunque sí por otros hechos o infracciones concurrentes.

A continuación, pasan a tipificarse las infracciones, que se contienen en el artículo 80. Las que tienen relación con el objeto de este estudio son las siguientes:

\footnotetext{
150 Esta afirmación se entiende referida al artículo 96 de la Ley 39/2015, de 1 de octubre, de Procedimiento Administrativo Común de las Administraciones Públicas, que establece un plazo de resolución para los procedimientos simplificados de treinta días.

${ }^{151}$ Las multas coercitivas se encuentran reguladas en el artículo 103 de la LPAC.
} 
1. Infracciones leves:

c) La utilización indebida, abusiva o irresponsable de los recursos y prestaciones sanitarias que no respondan a una necesidad objetiva.

d) La destrucción, menoscabo o deterioro de las instalaciones y servicios sanitarios, siempre que no afecten al normal funcionamiento del centro, servicio o establecimiento sanitario.

f) La realización de actos que alteren o perturben el normal funcionamiento del centro, servicio o establecimiento sanitario o sus condiciones de habitabilidad.

2. Infracciones graves:

d) La destrucción, menoscabo o deterioro de las instalaciones y equipamientos sanitarios siempre que afecten al normal funcionamiento del centro, servicio o establecimiento sanitario.

f) La resistencia, falta de respeto, amenazas, insultos, represalias o cualquier otra forma de presión ejercida contra los profesionales de los centros, servicios y establecimientos sanitarios, los pacientes o sus acompañantes.

g) Haber sido sancionado por la comisión de dos o más infracciones leves en el transcurso de dos años.

3. Infracciones muy graves:

a) La realización de las conductas previstas en los apartados anteriores cuando suponga un incumplimiento consciente y deliberado de los preceptos de la presente Ley Foral y produzca un daño grave.

b) La agresión física a profesionales de los centros, servicios y establecimientos sanitarios, a pacientes o a sus acompañantes.

c) Haber sido sancionado por dos o más infracciones graves en el transcurso de tres años.

Las personas responsables de infracción se detallan en el artículo 82: como autores, las personas físicas o jurídicas que realicen las acciones u omisiones tipificadas; padres o tutores solidariamente de las infracciones cometidas por menores de edad; subsidiariamente, administradores de las personas jurídicas de las infracciones cometidas por éstas.

Las sanciones correspondientes a las infracciones tipificadas están recogidas en el artículo 83, que reza: 
1. Las infracciones de la presente Ley Foral serán sancionadas, en su caso, con multa, sin perjuicio de lo señalado en el apartado 4 de este artículo.

2. Las infracciones previstas en esta Ley Foral serán castigadas con las siguientes sanciones:

A.- Por infracciones leves:

a) En grado mínimo: multa de hasta 600 euros.

b) En grado medio: multa de 601 euros hasta 1.800 euros.

c) En grado máximo: multa de 1.801 euros hasta 3.000 euros.

B.- Por infracciones graves:

a) En grado mínimo: multa de 3.001 euros hasta 6.000 euros

b) En grado medio: multa de 6.001 euros hasta 10.500 euros.

c) En grado máximo: multa de 10.501 euros hasta 15.000 euros.

C.- Por infracciones muy graves:

a) En grado mínimo: multa de 15.001 euros hasta 120.000 euros.

b) En grado medio: multa de 120.001 euros hasta 350.000 euros.

c) En grado máximo: multa de 350.001 euros hasta 600.000 euros.

4. Las personas sancionadas por infracciones tipificadas en el artículo 80. apartado 2 letra f) y apartado 3 letra b) podrán ser sancionadas también con el cambio de centro sanitario con adscripción forzosa al centro que se le asigne, y la prohibición de elección de nuevo centro en tres años.

El artículo 84 establece la necesidad de respetar la proporcionalidad entre la infracción cometida y la sanción impuesta, implantando además un sistema de graduación, por el que las sanciones tendrán un nivel mínimo, medio o máximo, de acuerdo con las circunstancias siguientes:

a) Las generales establecidas por las leyes de procedimiento administrativo.

b) El grado de intencionalidad.

c) El incumplimiento de advertencias previas.

d) La gravedad de la alteración sanitaria y social producida.

e) El perjuicio causado y el número de personas afectadas.

f) La afección directa a un colectivo de personas especialmente protegido. 
g) Los beneficios obtenidos con la infracción.

h) La permanencia o transitoriedad de los riesgos.

i) La concurrencia con otras infracciones sanitarias o el haber servido para facilitar o encubrir su comisión.

Los órganos sancionadores competentes (art. 85) serán el Gobierno de Navarra (para imponer sanciones superiores a 120.000 euros por infracciones muy graves, el Departamento de Salud para las comprendidas entre 15.000 euros y 120.000 euros y el Director-Gerente del Servicio Navarro de Salud-Osasunbidea para las inferiores a 15.000 euros.

Por último, se establece un plazo de seis meses para la resolución de estos procedimientos sancionadores (art. 86) y se prevé la imposición de multas coercitivas reiteradas para el cumplimiento de estas resoluciones administrativas, que no excederán de 1.000 euros (art. 87).

\section{VISIÓN DE CONJUNTO}

García Calvo (2013) recomienda incidir en la información y formación al usuario en sus deberes, con el objetivo de conseguir un mejor nivel de responsabilidad y que los ciudadanos colaboren, utilizando mejor los recursos sanitarios.

Por otra parte, también señala que la aplicación del régimen sancionador es escasa y aboga por un mayor uso de este sistema ante el incumplimiento de los deberes, por su valor como medio disuasorio.

Por nuestra parte, a modo de conclusión, vamos a hacer una breve síntesis comparativa de las principales características y propuestas de la normativa que acabamos de enumerar, estableciendo como punto de inflexión el año 2010:

1.- Antes de 2010:

1.- La normativa de Extremadura y Madrid

a.- Son las de aparición más temprana

b.- Sus planteamientos son muy similares

c.- Ambas son más prolijas en lo relacionado con las «autoridades sanitarias», que en lo que afecta a los sanitarios.

2.- La de Aragón es algo más prolija que las anteriores, pero:

a.- Sigue las mismas pautas establecidas en ellas

b.- Sus referencias a los sanitarios son indirectas o interpretables

3.- Galicia. Más o menos en la línea de lo que estamos indicando hasta ahora. 
2.- El año 2010: es el año en que se dictan las normativas de Castilla y la Mancha y Navarra

a.- Son ambas ya más prolijas en general (infracciones, sanciones...)

b.- Explicitan las agresiones a sanitarios

Castilla la Mancha:

G.- Infracciones graves

b. Infracciones muy graves

Navarra:

f.- Infracciones graves

b.- Infracciones muy graves

c.- Navarra incluye una especificidad. El posible cambio de centro para el agresor (Punto 4: «Las personas sancionadas por infracciones tipificadas en el artículo 80. apartado 2 letra f) y apartado 3 letra b) podrán ser sancionadas también con el cambio de centro sanitario con adscripción forzosa al centro que se le asigne, y la prohibición de elección de nuevo centro en tres años». 


\section{LAS LEYES DE AUTORIDAD}

Además de la normativa autonómica dictada en materia de imposición de deberes a los usuarios, y sus correspondientes sanciones en caso de incumplimiento (así como el establecimiento de PPRL específicos en la materia, que hemos contemplado en otro capítulo de este trabajo), algunas Comunidades Autónomas consideraron oportuno aprobar medidas adicionales.

Las Comunidades Autónomas de Aragón, Castilla y León, Valencia y Extremadura decidieron dotar a sus profesionales sanitarios de la condición de Autoridad. Para ello, emplearon técnicas legislativas diferentes: Aragón y Extremadura promulgaron sendas leyes «ad hoc», mientras que Castilla y León introdujo una modificación a la Ley de Ordenación de su sistema de salud en su artículo 34, añadiendo el apartado 3, en el que se realizaba la reforma correspondiente ${ }^{152}$ y Valencia incluyó la cuestión dentro de su Ley 10/2014, de 29 de diciembre de Salud de la Comunitat Valenciana (Capítulo IV artículo 16).

Estas iniciativas obedecen a diversas finalidades, más o menos explicitadas en las propias normas, principalmente en sus preámbulos o exposiciones de motivos.

Una de las motivaciones fue sin duda la alarma suscitada por el continuo aumento del número de incidentes y agresiones producidas contra los profesionales de la salud. Con el loable propósito de reforzar la protección de los mismos, estas administraciones autonómicas dictaron normativa en orden a dotar a su personal de la condición de Autoridad.

Así, en el Preámbulo de la Ley 9/ 2013, de 28 de noviembre, de Autoridad de Profesionales del Sistema Sanitario y de Servicios Sociales Públicos de Aragón ${ }^{153}$, se manifiesta que, aunque no se conoce la dimensión real del problema, éste constituye un motivo de preocupación para los profesionales. Afirma a continuación lo inadmisible de las conductas violentas, rompedoras del vínculo de confianza en la relación clínica, afectando negativamente a la consecución de los objetivos de la citada relación, en la que deben garantizarse además los derechos de ambos (profesional y paciente). Por todo ello, el propósito de la ley es reforzar los instrumentos jurídicos para el desempeño de las tareas sanitarias en un contexto de máxima confianza, respeto y seguridad $^{154}$.

\footnotetext{
152 La modificación se realizó, como se ha dicho, en el apartado 3 del artículo 34 de la Ley 8/2010, de 30 de agosto, de Ordenación del Sistema de Salud de Castilla y León. Esta modificación tuvo lugar por Ley 11/2013, de 23 de diciembre, de Medidas Tributarias y de Reestructuración del Sector Público Autonómico.

153 Ley 9/ 2013, de 28 de noviembre, de Autoridad de Profesionales del Sistema Sanitario y de Servicios Sociales Públicos de Aragón (BOA núm. 243, de 12 de diciembre de 2013).

${ }^{154}$ Se añade además que esto aumentará la calidad de los servicios.
} 
Por su parte, la Ley 11/2015, de 8 de abril, de Autoridad de Profesionales del Sistema Sanitario Público y Centros Sociosanitarios de Extremadura ${ }^{155}$ declara que su intención es «reforzar los instrumentos jurídicos necesarios que permitan conseguir que los profesionales sanitarios puedan desempeñar sus tareas en un ambiente de máxima confianza, respeto y seguridad para ellos y para el sistema sanitario, lo que supondrá, en consecuencia, el aumento de la calidad de los servicios». Lo que se añade a lo expresado por la Ley aragonesa es aludir al sistema sanitario como partícipe del contexto de máxima confianza, respeto y seguridad que se quiere obtener y la anudación de estas actuaciones a la calidad de los servicios.

La Ley extremeña también afirma que las agresiones «han supuesto y suponen un motivo de preocupación para dichos profesionales y por ende de todo el sistema sanitario público extremeño». Puede observarse de nuevo cómo la redacción es prácticamente idéntica a la Ley de Aragón (y lo será a lo largo de bastantes puntos de la Ley extremeña), con la adición de la preocupación del propio sistema sanitario a la de los profesionales afectados. Insiste también en que las actuaciones violentas han de ser impedidas porque «rompen el vínculo de confianza que debe existir en la relación de los profesionales con los pacientes», remachando que esto es fundamental para que la relación clínica alcance sus objetivos y «queden garantizados los derechos de profesional y paciente». Como se ve, la redacción es casi mimética a la Ley aragonesa.

Con la atribución de la condición de autoridad se pretende también estimular el reconocimiento social de los profesionales sanitarios. Así lo entiende en su Preámbulo la ley de Aragón, que anuda este prestigio a la prestación de las actividades que tienen encomendadas y, en fin, a la calidad y mejora del servicio. El apartado 3 del artículo 34 de la Ley de Ordenación del Sistema de Salud de Castilla y León reza literalmente: «Los profesionales de los centros sanitarios incluidos en el anexo a la presente ley gozarán, en el ejercicio de sus funciones y responsabilidad, del derecho a ser respetados, recibir un trato adecuado y ser valorados por los usuarios del sistema sanitario, sus familiares y acompañantes y por la sociedad en general».

Otro propósito, sin duda encomiable, que alienta estas disposiciones es alimentar el sentimiento de protección de sus empleados, buscando que éstos se sientan más apoyados y defendidos por la Administración. Así lo reconoce la Ley de Autoridad de Aragón en su artículo 1, que declara que tiene como uno de sus objetivos «reconocer y apoyar a los profesionales del sistema sanitario y social de Aragón». El mismo objeto establece la Ley extremeña: «reconocer y apoyar a los profesionales del sistema sanitario público de Extremadura...»y expresa algo similar «...contemplar expresamente una especial protección para estos profesionales, que suponga su

155 Ley 11/2015, de 8 de abril, de Autoridad de Profesionales del Sistema Sanitario y Centros Sociosanitarios de Extremadura (DOE núm. 68, de 10 de abril de 2015; BOE núm. 108, de 6 de mayo de 2015). 
plasmación positiva en el ordenamiento jurídico y les confiera una mayor confianza en su ámbito laboral».

Del mismo modo, se entiende que la atribución de esta condición puede reforzar su autoridad ${ }^{156}$ y procurar la protección y el respeto debidos a los profesionales. La Ley de Extremadura también declara como objeto reforzar su autoridad.

En cuanto al ámbito de aplicación, La Ley de Autoridad de Aragón se circunscribe, lógicamente, a los profesionales de su sistema público sanitario (y social ${ }^{157}$ ), cuando se encuentren en el ejercicio de sus funciones ${ }^{158}$. La Ley de Extremadura incluye a los profesionales de sus sistemas público sanitario y sociosanitario, con explícita mención a las actividades desarrolladas por éstos, derivadas de sus funciones, tanto en el interior de los centros, como en el exterior de los mismos. Queda excluida la actividad privada concertada de forma expresa, tanto en la Ley de Autoridad de Aragón como en la de Extremadura.

Castilla y León introduce un anexo a su Ley 8/2010, especificando los profesionales a los que se atribuye la condición de autoridad (artículo 34.3), siendo los siguientes:

$\checkmark$ Los profesionales determinados en los artículos 2,3, 6 y 7 de la Ley 44/2003, de 21 de noviembre, de Ordenación de las Profesiones Sanitarias.

$\checkmark$ Personal directivo de centros e instituciones sanitarias del Servicio de Salud de Castilla y León.

$\checkmark$ Trabajadores Sociales.

$\checkmark$ Personal de Gestión y Servicios.

En cuanto a la ley valenciana, su artículo 16 se centra específicamente en delimitar los medios personales de que disponen las instituciones sanitarias del Sistema Valenciano de Salud, enumerando los distintos colectivos incluidos en su número 2 y aclarando en su número 4 que «son profesionales de la salud pública aquellos que por su formación especializada desarrollan actividades relacionadas directa o indirectamente con la salud pública».

\footnotetext{
${ }^{156}$ Quizá sea algo ingenuo confiar en que la denominación de "autoridad» sea capaz de aumentar la autoridad de los profesionales, pero esto es lo que parece afirmar el artículo 1 de la Ley 9/2013 de Aragón. En la misma dirección, se afirma en el principio general h) del artículo 3 que es necesario «disponer de un referente de autoridad claro y expresamente definido».

${ }^{157}$ Aragón opta por incluir en la misma Ley a los profesionales sanitarios y a los de servicios sociales.

${ }^{158}$ Se reconocerá tal circunstancia cuando «se produzca un ataque a su integridad física o moral derivado de su condición profesional».
} 
Debe notarse que, a diferencia de esta ley -que parece excluir a los trabajadores de la sanidad pública que no ostenten la condición de sanitarios--, el resto de las normas mencionadas, de un modo más o menos manifiesto, sí incluyen a otro tipo de empleados de estas instituciones.

Entre los principios generales que se declaran explícitamente en las distintas leyes que atribuyen la condición de autoridad a los profesionales sanitarios, cabe destacar:

a) El derecho a la protección de la salud reconocido en el artículo 43.1 de la Constitución española (Ley de Aragón, 2013), Ley de Extremadura (2015).

b) La calidad permanente de los servicios y las prestaciones sanitarias para lograr la máxima eficacia y eficiencia en la asignación, utilización y gestión de los recursos, así como la satisfacción de los usuarios, fomentando la mejora continua de dichos servicios (Ley de Extremadura 2015). La Ley de Aragón (2013) incorpora este principio en el apartado c), siendo en ambas leyes de redacción idéntica.

c) El reconocimiento de las funciones de los profesionales de los centros sanitarios y sociosanitarios como factor esencial en la calidad de los servicios (Ley de Extremadura, 2015). La Ley de Aragón (2013) incorpora este principio en el apartado d), siendo en ambas leyes de redacción idéntica, salvo porque la Ley aragonesa habla de «centros sanitarios y sociales».

d) Garantizar el ejercicio efectivo de las funciones de los profesionales incluidos en el ámbito de aplicación de esta ley (Ley de Extremadura, 2015). La Ley de Aragón (2013) incorpora este principio en el apartado e), siendo en ambas leyes de redacción idéntica.

e) El reconocimiento, la tolerancia, el respeto de los valores democráticos, la asunción de los valores de convivencia, el ejercicio correcto y la efectiva garantía de los derechos y deberes de todos los usuarios del sistema y, en particular, los recogidos en la Ley 41/2002, de 14 de noviembre, básica reguladora de la autonomía del paciente y de derechos y obligaciones en materia de información y documentación clínica, y en la Ley $3 / 2005$, de 8 julio, de información sanitaria y autonomía del paciente de Extremadura (Ley de Extremadura, 2015). La Ley de Aragón (2013) incorpora este principio en el apartado f), siendo en ambas leyes de redacción idéntica, salvo por la alusión a su propia ley autonómica: «...en particular, los recogidos en la Ley 41/2002, de 14 de noviembre, básica reguladora de la autonomía del paciente y de derechos y obligaciones en materia de información y documentación clínica».

f) El impulso por parte de la Administración sanitaria y social de la Comunidad Autónoma de Aragón de los mecanismos y medios necesarios para facilitar y permitir el ejercicio, y las funciones derivadas del mismo, de los profesionales y su reconocimiento, respeto y prestigio 
social (Ley de Extremadura 2015). En la Ley de Aragón (2013) este principio se recoge en la letra g) y queda redactado en los siguientes términos: «El impulso por parte de la Administración sanitaria de la Comunidad Autónoma de Extremadura de los mecanismos y medios necesarios para facilitar y permitir el ejercicio, y las funciones derivadas del mismo, de los profesionales y su reconocimiento, respeto y prestigio social».

g) La necesidad de disponer en los procedimientos sanitarios, sociales y sancionadores de un referente de autoridad claro y expresamente definido, sin perjuicio del respeto a los preceptos que garantizan el ejercicio de los derechos y el cumplimiento de los deberes consagrados por el ordenamiento jurídico de los usuarios del sistema sanitario y de los servicios sociales (Ley de Extremadura 2015). La Ley de Aragón (2013) incorpora este principio en el apartado h), siendo en ambas leyes de redacción idéntica.

h) Fortalecer la sensibilización ciudadana en aras de la prevención de conflictos con los profesionales incluidos en esta ley, favoreciendo las medidas y los mecanismos necesarios para poder propiciar la resolución pacífica de esos conflictos. La Ley de Aragón (2013) incorpora este principio en el apartado i), siendo en ambas leyes de redacción idéntica

i) Coordinar los diversos recursos e instrumentos de los distintos poderes públicos y ámbitos de la Administración para prevenir y evitar posibles situaciones de conflictividad. La Ley de Aragón (2013) incorpora este principio en el apartado j), siendo en ambas leyes de redacción idéntica

j) Impulsar la competencia, la participación y la responsabilidad de pacientes y de profesionales en el aprendizaje y la praxis de la convivencia democrática. La Ley de Aragón (2013) incorpora este principio en el apartado k), siendo en ambas leyes de redacción idéntica

k) Promover la participación de todos los sectores de la comunidad sanitaria y social para lograr el buen desarrollo de la convivencia en nuestros centros, garantizando el conocimiento y el ejercicio de los derechos y deberes de profesionales y usuarios implicados en el aprendizaje y en la aplicación de la convivencia democrática. La Ley de Aragón (2013) incorpora este principio en el apartado 1), siendo en ambas leyes de redacción idéntica

1) Desarrollar medidas que protejan a aquellos que vean menoscabados los derechos reconocidos en esta ley. La Ley de Aragón (2013) incorpora este principio en el apartado m), siendo en ambas leyes de redacción idéntica.

Los profesionales a los que se les otorga la condición de autoridad, ven reconocidos programáticamente una serie de derechos, que se incluyen en las diferentes disposiciones analizadas en este apartado. 
Las Leyes de Autoridad de Aragón y Extremadura explicitan los siguientes en el artículo 4 de dichas leyes:

a) A ser respetados, reconocidos, recibir un trato adecuado y ser valorados por los pacientes y usuarios del sistema sanitario o social, por sus familiares y acompañantes y por la sociedad en general en el ejercicio de su profesión y de sus funciones.

b) A desarrollar sus funciones en un ambiente adecuado, donde sean respetados sus derechos, especialmente su derecho a la integridad física y moral.

c) Al apoyo por parte del departamento con competencias en materia de sanidad y servicios sociales del Gobierno de Aragón, que velará para que la consideración, el respeto y el trato recibidos por estos profesionales sean conformes a la importancia social de la función que desempeñan (redacción de la Ley de Aragón). Al apoyo por parte de la Consejería con competencias en materia de sanidad de la Junta de Extremadura, que velará para que la consideración, el respeto y el trato recibidos por estos profesionales sean conformes a la importancia social de la función que desempeñan (redacción de la Ley de Extremadura).

d) A la protección jurídica adecuada en el cumplimiento de sus actos profesionales y de sus funciones.

e) A disponer de los medios materiales necesarios para el adecuado ejercicio de su labor sanitaria y social.

Este catálogo de derechos resulta de importancia, por cuanto viene a actualizar y completar la muy exigua relación de derechos que en este tema efectuaba la Ley 6/2002, de 15 de abril, de Salud de Aragón (recordemos que se encontraban ubicados en el artículo 5 y que sólo uno de ellos era de clara referencia al necesario respeto a los profesionales sanitarios).

Como hemos visto, las declaraciones de derechos y deberes tienen una concreción práctica, por cuanto, si su inobservancia es tipificada como infracción administrativa, lleva aparejada una sanción, bajo el ámbito del Derecho administrativo sancionador.

Igualmente, seguimos en el mismo terreno cuando la normativa autonómica dota a algunos de sus empleados de la condición de autoridad.

Aquí resulta absolutamente imprescindible recalcar que la Administración Autonómica está legislando en estas materias dentro de sus competencias, esto es, en el ámbito del Derecho Administrativo, nunca en el del Derecho Penal. 
El Derecho Penal es competencia exclusiva del Estado y no puede una Comunidad Autónoma extender la condición de autoridad, concedida a sus empleados, a los efectos que en materia penal se operan bajo el amparo del art. 550 y ss. CP.

Por lo tanto, en realidad, la condición de autoridad otorgada por las Administraciones Autonómicas no tiene más alcance que el que se les dé dentro de su propia normativa y con las consecuencias que establezcan, exclusivamente dentro del ámbito del Derecho Administrativo Sancionador.

Los derechos obtenidos por la adquisición de la condición de autoridad son:

- Presunción de veracidad:

o La Comunidad de Castilla y León, la de Aragón y la de Extremadura manifiestan con cierto énfasis que los hechos constatados por los profesionales con condición de autoridad «gozarán de la presunción de veracidad cuando se formalicen por escrito en documento que cuente con los requisitos establecidos según la normativa que resulte de aplicación en cada caso». Lo que deja claro esta afirmación es que la citada presunción sólo operará en las declaraciones escritas, pero el resto de la oración resulta algo ambigua, porque la «normativa que resulte de aplicación en cada caso» es una afirmación vaga que puede incluir cualquier tipo de disposición y orden jurídico. Puede significar, simplemente, que cuando lo que proceda sea interponer una denuncia y el caso pase a la jurisdicción penal (por ejemplo), la presunción de veracidad será eficaz según las reglas del antedicho ordenamiento jurídico. Si este es el significado de la frase, en realidad sería irrelevante que el denunciante tuviera o no condición de autoridad reconocida por la Administración Autonómica (y lo mismo sucedería en el orden civil, laboral o contencioso-administrativo, puesto que se aplicarían las reglas del procedimiento que en cada caso fueran procedentes).

- Protección:

o La Comunidad de Aragón parece otorgar un «plus» de protección a sus empleados por el hecho de haberles otorgado la condición de autoridad. Los términos con los que se expresa la Ley aragonesa de autoridad son los siguientes: «...gozarán de la protección reconocida a tal condición por la legislación vigente». Esto mismo es lo que manifiesta, literalmente y punto por punto, la Junta de Extremadura, así como también la de Castilla y León. Esto nos lleva a dilucidar cuál sea esa protección, y la conclusión es que no puede ser otra que la que la propia Comunidad Autónoma decida prestar a estos empleados mediante su legislación administrativa: la legislación penal, como ya hemos aclarado, 
protegerá a los profesionales por ser funcionarios públicos, pero no autoridad (condición que no se les reconoce en este ordenamiento jurídico).

o Por su parte, en la misma línea pero con más dosis de ambigüedad, la ley de la Comunidad Valenciana, al referirse a los efectos que produce la declaración de «autoridad pública» que atribuye a sus trabajadores sanitarios, simplemente manifiesta que «...gozarán de la protección reconocida a tal condición por la legislación vigente».

- Asistencia jurídica:

o Aragón dedica el artículo 9 de su Ley 9/2013, de 28 de noviembre, a reiterar las medidas de protección que brindará a sus empleados sanitarios ${ }^{159}$.

- Extremadura prevé las mismas actuaciones en el artículo 11 de la Ley 11/2015, de 8 de abril.

En consecuencia, resulta claro que las leyes dictadas por las Comunidades Autónomas, otorgando a sus profesionales sanitarios la condición de autoridad, aunque hayan sido elaboradas bajo propósitos encomiables (como el intento de refuerzo de la protección, etc.), no aportan nada verdaderamente eficaz en las medidas legislativas ante la violencia contra el personal sanitario.

De hecho, resulta ilustrativo que la ley valenciana tenga mucho cuidado en aclarar que la condición de autoridad pública que concede, lo es «sin perjuicio de lo previsto en el título VIII». Ese título está dedicado a la «autoridad pública sanitaria». Parece evidente que el legislador tiene muy claro las distinciones entre una y otra figura jurídica y se preocupa en que el otorgamiento de la condición de «autoridad pública» a su personal sanitario no se confunda con las funciones y atribuciones propias de la «autoridad pública sanitaria».

\footnotetext{
159 «1. La Administración promoverá que los profesionales incluidos en esta ley cuenten con la adecuada asistencia jurídica y protección que resulte preceptiva en los procedimientos que se sigan ante cualquier órgano jurisdiccional como consecuencia del ejercicio legítimo de sus funciones o cargos públicos.

2. Si se incurriera en conductas que pudiesen ser tipificadas como infracción penal contra dichos profesionales, la Administración sanitaria y de servicios sociales las pondrá en conocimiento del Ministerio Fiscal, oídas la dirección del centro y las personas afectadas, sin perjuicio de la adopción de las medidas cautelares oportunas. Cuando los hechos pudieran ser constitutivos de infracción administrativa, incoará, si procede, el correspondiente procedimiento administrativo sancionador o disciplinario.

3. La asistencia jurídica se proporcionará prestándose de forma gratuita también al personal que preste servicios en los centros sociales y sanitarios del Gobierno de Aragón en labores de gestión, admisión y administración relacionadas con la tramitación del acto médico o de atención social.

Dicha asistencia jurídica consistirá en la representación y defensa en juicio, adoptándose medidas que garanticen a los profesionales objeto de la agresión la cobertura de responsabilidad civil que se derive del ejercicio de sus funciones.

4. El departamento competente en materia de sanidad y asuntos sociales desarrollará medidas para apoyar a las víctimas de violencia, y para ello contarán con:

a) El apoyo psicológico y médico necesario cuando así lo requieran.

b) La protección necesaria para que se garantice su derecho a la intimidad.

c) La asistencia necesaria para los profesionales y personal de administración y servicios de sanidad y asuntos sociales que puedan ser víctimas de violencia, desde su solicitud y durante todo el proceso».
} 
Cabe la posibilidad de que, por motivos de gestión política, estas CCAA consideraran en un momento dado que el dictado de esta normativa de atribución de la condición de autoridad dentro de su ámbito competencial, serviría de acicate y estímulo para que el Estado concediera esta condición a los profesionales sanitarios en la reforma del Código Penal que se avecinaba.

Pero, en cualquier caso, de ser estos los cálculos que se hicieron, resultaron incorrectos. La reforma del Código Penal (como veremos más tarde) incluyó a los profesionales de la sanidad y la enseñanza públicas dentro de la protección del tipo de atentado. Pero no como autoridad, sino en base a su condición de funcionarios.

A pesar de ello, tanto los medios de comunicación como los representantes de instituciones diversas, insisten una y otra vez en afirmar que el Código Penal reconoce al personal de la sanidad pública la condición de autoridad. Los ejemplos de esto son interminables y debe afirmarse que no se trata de un simple equívoco terminológico: se están atribuyendo consecuencias falsas a las agresiones.

Todo ello genera expectativas lógicas en los profesionales interesados, que no se corresponden con la realidad, amén de proporcionarles una información inexacta y confusa.

No olvidemos que los profesionales tienen derecho a estar informados verazmente y a conocer sus derechos y el modo efectivo de ejercitarlos.

Por todo lo anterior, cabe concluir que se trata de una normativa falta de consecuencias prácticas importantes y que además resulta reiterativa respecto al reconocimiento de derechos y medidas ya adoptadas. Además, si tenemos en cuenta la tremenda confusión suscitada con la palabra «autoridad» en otros ámbitos, resulta lógico afirmar que ha representado un ingrediente más que ha contribuido a aumentar los malentendidos y las inexactitudes. 


\section{MARCO NORMATIVO DE AGRESIONES AL PERSONAL SANITARIO EN LA COMUNIDAD AUTÓNOMA DE CASTILLA Y LEÓN}

\section{Tabla 4. Resumen de la normativa sobre agresiones contra el personal sanitario de Castilla y León}

Ley 1/1993, de 6 de abril, de Ordenación del Sistema Sanitario de Castilla y León: carta de derechos en el Título $I$.

Real Decreto 1480/2001, de 27 de diciembre, de traspaso de funciones y servicios del Instituto Nacional de la Salud a Castilla y León.

Ley $8 / 2003$, de 8 de abril, sobre Derechos y Deberes de las personas en relación con la salud.

Ley 2/2007, de 7 de marzo, del Estatuto Jurídico del Personal Estatutario del Servicio de Salud de Castilla y León.

LO 14/2007, de 30 de noviembre, de Reforma del Estatuto de Autonomía de Castilla y León.

Pacto entre la Consejería de Sanidad y las Organizaciones Sindicales CEMSATSE, UGT, SAE-USCAL y CSI-CSIF sobre las actuaciones a desarrollar para elaborar el Plan Integral frente a las Agresiones al Personal de la Gerencia Regional de Salud de Castilla y León, firmado el 4 de febrero de 2008.

Decreto 48/2009, de 16 de julio, por el que se crea y regula el Observatorio de Agresiones al personal de la Gerencia Regional de Salud de Castilla y León (derogado por Decreto 52/2014, de 16 de octubre, por el que se crea y regula el Observatorio de la Comunidad de Castilla y León).

Ley 8/2010, de 30 de agosto, de Ordenación del Sistema de Salud de Castilla y León.

Ley 11/2013, de 23 de diciembre, de Medidas Tributarias y Reestructuración del Sector Público Autonómico.

Decreto 52/2014, de 16 de octubre, por el que se crea y regula el Observatorio de la Comunidad de Castilla y León.

Resolución de 2 de noviembre de 2016, de la Dirección General de Trabajo y Prevención de Riesgos Laborales, por la que se dispone la inscripción en el Registro Central de Convenios Colectivos de Trabajo, y la publicación, del Pacto de 20 de noviembre de 2016, entre la Gerencia Regional de Salud de Castilla y León y las organizaciones sindicales SATSE-FSES, CESM, UGT y USAE, por el que se aprueban las estrategias de actuación en prevención de riesgos laborales de la Gerencia Regional de Salud de Castilla y León 2016/2020. 


\section{Ley $8 / 2003$, de 8 de abril, sobre derechos y deberes de las personas en relación con la salud.}

Lo destacable en lo que respecta a estas cuestiones dentro de esta ley es:

- Carta de derechos de los pacientes bastante exhaustiva.

- Título VI «Deberes»: El Título preliminar declara que este Título VI «parte de la base de que una sociedad democrática avanzada debe regirse por un principio de corresponsabilidad sobre la salud individual y colectiva. Así, el respeto a la propia salud y a la de los demás impone el necesario acatamiento de determinadas prescripciones y medidas sanitarias, el correcto uso de las instalaciones y servicios, o el debido respeto al personal y a otros usuarios, favoreciendo la concienciación ciudadana y la evitación de situaciones de abuso o ejercicio antisocial del derecho».

Aquí radica el núcleo central de las disposiciones que afectan a la protección frente a las agresiones al personal sanitario. Concretamente, en sus artículos 44, 45 y 46.

En el artículo 44 se establece: «Los poderes públicos de Castilla y León velarán por la efectividad y promoverán el cumplimiento de los deberes relativos a la adecuada utilización de los recursos y prestaciones del Sistema de Salud, de acuerdo con las necesidades de salud y en función de las disponibilidades de dicho Sistema, y actuarán para la evitación de situaciones de utilización poco diligente, irresponsable o abusiva que dificulte el acceso de todos a la atención sanitaria en condiciones de igualdad efectiva». Por su parte, el artículo 45 vela por el uso correcto de las instalaciones y servicios y el 46 («Respeto debido a las personas») se centra claramente en el ámbito objeto de este estudio, manifestando: «En el ámbito de la presente Ley, todas las personas tienen el deber de mantener el respeto debido al personal de los centros, servicios y establecimientos, tanto en su dignidad personal como profesional, debiendo respetar asimismo a los otros pacientes, familiares o acompañantes».

- Igualmente, aclara el Título preliminar, respecto al Título VII de esta ley («Régimen de Garantías» lo siguiente: «se centra en el papel de la Administración Sanitaria como garante de los derechos en relación con la salud a través de las correspondientes potestades de autorización y registro, evaluación, inspección y control, y las sancionadoras».

En el desarrollo reglamentario de esta Ley, destaca la Orden SAN/559/2007, de 26 de marzo, por la que se aprueba el Plan de Garantía de los derechos de las personas en relación con la salud, que establece siete líneas estratégicas en orden a garantizar el efectivo desarrollo de estos derechos. En su Preámbulo destaca la declaración de la exigencia de «el aprendizaje de un nuevo modelo de relación clínico-asistencial en el que el paciente ya no es un mero sujeto pasivo, sino que adquiere un protagonismo creciente y participa en la toma de decisiones 
sobre su salud». Asimismo, también se manifiesta la necesidad de «trabajar para sensibilizar a los profesionales en relación con los derechos de pacientes y usuarios, así como para que se conciencien sobre las cautelas que han de tener en cuenta...». En esta norma únicamente se potencia el ámbito de los derechos del usuario, sin referencia alguna a los correlativos deberes.

2. Orden SBS/1325/2003, de 3 de septiembre, por la que se publican las cartas de derechos y deberes de las Guías de Información al usuario. Esta Orden establece los contenidos que se incluirán en las Guías de Información al usuario, que han de estar a su disposición en todos los centros sanitarios. En lo que aquí interesa, se especifican los siguientes deberes:

5.- Deber de uso correcto de las instalaciones y servicios sanitarios, conforme a las normas generales de utilización y las establecidas por los centros, servicios y establecimientos.

6.- Deber de mantener el respeto debido al personal de los centros, servicios y establecimientos, $\mathrm{y}$ a los otros pacientes, familiares y acompañantes.

3. Decreto $40 / 2003$, de 3 de abril, relativo a las guías de información al usuario y a los procedimientos de reclamación y sugerencia en el ámbito sanitario.

La norma se promulga al amparo de la LGS y la Ley de Ordenación del Sistema Sanitario de Castilla y León y, concretamente, en desarrollo de los derechos de los usuarios a la información y a la presentación de reclamaciones y sugerencias.

El objetivo inmediato de este Decreto es proporcionar un instrumento a los usuarios de conocimiento de derechos y obligaciones, así como de las características principales de los centros y servicios. Para ello, se propone regular las Guías de información al usuario y los procedimientos de reclamaciones y sugerencias.

Asimismo, se declara el valor de dichas reclamaciones y sugerencias, en el sentido de servir para encauzar procesos de mejora en la prestación de servicios, alejándose de la simple justificación de la norma por imperativo legal.

4. Pacto entre la Consejería de Sanidad y las Organizaciones Sindicales CEMSATSE, UGT, SAE-USCAL y CSI-CSIF sobre las actuaciones a desarrollar para elaborar el Plan Integral frente a las Agresiones al Personal de la Gerencia Regional de Salud de Castilla y León, firmado el 4 de febrero de 2008.

Pone en marcha el Plan Integral frente a las agresiones al personal de la Gerencia Regional de Salud de Castilla y León.

Marco normativo en que se fundamenta/apoya: 


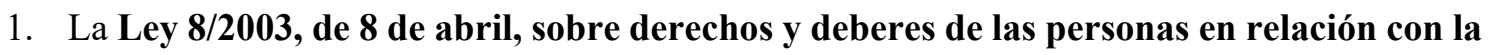
salud.

- Promoción del cumplimiento de los derechos y deberes en relación con la salud.

- Las actuaciones del Sistema de Salud estarán orientadas a:

o Humanización de la asistencia.

o Ofrecer una atención individual y personalizada.

o Promover la comodidad, el bienestar físico y psíquico, la comprensión y el trato adecuado del paciente y de sus familiares o personas vinculadas.

- Título VI «Deberes»:

o Una sociedad democrática avanzada debe regirse por un principio de corresponsabilidad sobre la salud individual y colectiva:

- El respeto a la propia salud y la de los demás:

- Necesario acatamiento de determinadas prescripciones y medidas sanitarias.

- Correcto uso de las instalaciones y servicios.

- Debido respeto al personal y otros usuarios.

- Favoreciendo la concienciación ciudadana y la evitación de situaciones de abuso o ejercicio antisocial del derecho.

«La calidad de un sistema sanitario y el buen ambiente laboral depende en gran medida de conservar y generar la debida confianza entre sus trabajadores para que puedan desarrollar su actividad profesional en un marco de entendimiento con los usuarios, de respeto por los derechos y de cumplimiento por los deberes que nos asisten a todos».

2. La Ley 31/1995, de 8 de noviembre, de prevención de riesgos laborales: Artículo 14.2 «El empresario deberá garantizar la seguridad y la salud de los trabajadores a su servicio en todos los aspectos relacionados con el trabajo».

3. La Directiva-Marco 89/391/CEE de Aplicación de medidas para promover la Seguridad y Salud de los trabajadores. «obliga a la prevención de la violencia en el trabajo y hace responsables a los empresarios de velar para que los trabajadores no sufran daños en el medio laboral». 


\section{CONTENIDO DEL PACTO}

\section{OBJETIVO GENERAL}

«Establecer las líneas de actuación frente al riesgo de agresión y frente a las agresiones y situaciones conflictivas generadas por usuarios, familiares o acompañantes, a nuestros profesionales en el ámbito de las Instituciones sanitarias y centros dependientes de la Gerencia Regional de Salud, así como en cualquier otro entorno en el que se desarrolle su actividad profesional».

\section{OBJETIVOS ESPECÍFICOS}

- Evaluación del riesgo de agresión, análisis y estudio de las situaciones y lugares con mayor incidencia y potencialidad de agresión.

- Puesta en marcha de medidas preventivas y de protección a los trabajadores con los medios materiales y humanos disponibles.

- Desarrollar procedimientos de prevención del riesgo de agresión y trasmitir pautas de actuación concretas en el supuesto de incidentes.

- Garantizar al personal agredido asistencia sanitaria, asesoramiento y defensa jurídica y, en su caso, apoyo psicológico.

- Tratamiento e investigación de la agresión por los servicios de prevención de riesgos laborales.

- Generar seguridad y confianza en los profesionales de la Gerencia Regional de Salud.

\section{ACTUACIONES}

Se establecen tres tipos de actuaciones a realizar, que se ordenan por fases, siguiendo una lógica de intervenciones previas a la eventual agresión, posteriores y de seguimiento:

$1^{\circ}$. Análisis y estudio de los lugares de trabajo con mayor riesgo potencial de agresión (los realiza la Gerencia Regional de Salud).

$2^{\circ}$. Actuaciones preventivas frente al riesgo de agresión.

$3^{\circ}$. Actuaciones posteriores a la agresión.

$4^{\circ}$. Seguimiento de las actuaciones seguidas frente a la agresión.

$1^{\circ}$. En la primera fase (Análisis y estudio de riesgo), se efectúan dos tipos de actuaciones:

- Detección de puntos críticos con mayor incidencia del riesgo de agresión: el objetivo es contar con un mapa de situación que sirva de base objetiva para establecer medidas concretas en esos puntos más conflictivos. 
- Evaluación inmediata del riesgo de agresión en todos los centros de trabajo: se trata de conocer el riesgo de agresiones en la totalidad de los lugares, evaluarlo y tomar las medidas preventivas apropiadas a cada uno de ellos.

$2^{\circ}$. La segunda fase (actuaciones preventivas) se establece en desarrollo al deber de la Administración de velar por la seguridad y salud de sus trabajadores y de aplicar medidas por su deber general de prevención. En esta sección se ejecutarán las siguientes medidas:

a) Estudio, elección e implantación de medidas de seguridad.

Se efectuará un previo análisis de cada lugar de trabajo. Es de destacar el mayor hincapié que se otorga a Servicios de Urgencias, Unidades de Psiquiatría, Centros de Salud, atención domiciliaria, aunque no es un listado cerrado.

Tras ese estudio, se implantarán, según se considere conveniente, las siguientes medidas (tampoco es un listado cerrado):

- Seguridad pasiva: dispositivos de alarma, videocámaras, etc. La implantación de estos mecanismos siempre atenderá a criterios de adecuación y proporcionalidad respecto a la situación de riesgo detectada.

- Seguridad activa: comunicación y coordinación con las Fuerzas y Cuerpos de Seguridad del Estado y con empresas de seguridad (seguridad en ruta, rondas de seguridad y/o guardia permanente).

b) Acciones de formación.

Con base en el art. 19 de la Ley 31/1995 de Prevención de Riesgos Laborales, por el que se establece la obligación del empresario a garantizar la formación de sus trabajadores, se establece un programa formativo. Se realizarán cursos dirigidos a todos los profesionales, pero especialmente en aquellos ámbitos con alto índice de incidencia del riesgo.

El programa formativo se someterá a negociación colectiva y entrenará a los profesionales en dos ámbitos:

o Técnicas de afrontamiento directo frente a situaciones de agresión e información sobre aspectos legales.

o Habilidades de comunicación e información a usuarios y familiares.

c) Campañas de concienciación y sensibilización.

Se manifiesta explícitamente que se realizará una campaña de sensibilización para promover el desarrollo de «una cultura y conducta preventiva frente a las agresiones».

La campaña tratará de conseguir «la generación de un clima de confianza, respeto y seguridad en las relaciones profesional-usuario». 
d) Medidas organizativas.

Se podrán implantar las siguientes (realizando previamente un estudio antes de su adopción):

o Atención a los usuarios, con especial incidencia en los pacientes conflictivos con antecedentes.

o Sistema de información y acogida de pacientes y familiares.

o Tiempos de espera de los pacientes.

o Acceso telefónico a centros e instalaciones.

o Mejora del entorno de acogida a usuarios y pacientes.

o Adecuación de cargas en la organización del trabajo.

o Optimización del tiempo de consultas.

o Sistema de citaciones.

En el texto del Pacto se asume que los ámbitos de mayor incidencia del riesgo son: Atención Primaria, Servicios de Urgencias y Emergencias Sanitarias, Servicios de atención directa al usuario y Unidades Psiquiátricas.

\section{$3^{0}$. Actuaciones posteriores.}

En este Pacto las agresiones a los profesionales sanitarios se consideran como accidente de trabajo. Tal calificación se argumenta en base al artículo 115 de la Ley General de Seguridad Social, que define accidente de trabajo como «toda lesión corporal que el trabajador sufra con ocasión o por consecuencia del trabajo que ejecute por cuenta ajena». Debe observarse que la óptica desde la que se tratan las agresiones en este documento excluye los ataques verbales (insultos, amenazas, etc.).

Se prevé la aplicación del Protocolo de actuación que se incluye en el anexo I del Pacto, y que se analizará posteriormente.

Las actuaciones previstas con carácter general ante una agresión ya producida son las siguientes:

1. Asistencia sanitaria y apoyo psicológico, en su caso, al profesional.

- Asistencia sanitaria:

Habrá de tener carácter inmediato, se llevarán a cabo las actuaciones necesarias con la mayor celeridad posible y dentro de la prioridad que marquen las lesiones sufridas.

- $\quad$ Apoyo psicológico:

Si fuera necesario, el agredido recibirá asistencia psicológica inmediata.

Se proyecta la puesta en marcha de un «Programa de intervención y apoyo psicológico a los profesionales», dirigido a aquellos que hayan sido víctimas de alguna agresión y 
tengan necesidad de asesoramiento clínico-psicológico para superar las secuelas que se hayan podido producir.

Las Gerencias del Servicio de Salud de Castilla y León (previo informe del médico de trabajo del Servicio de Prevención de Riesgos correspondiente) quedan obligadas a facilitar el acceso y derivar a los profesionales al programa de atención psicológica.

Incluso se prevé la movilidad del puesto de trabajo del profesional agredido si ello se derivara del tratamiento psicológico.

Acciones de asesoramiento y defensa jurídica.

Quedan establecidas dos vías:

a) Acciones generales:

Se encuadran dentro del marco general de asistencia jurídica a los empleados de la Administración Autonómica. La Normativa de referencia en este ámbito es:

o Decreto 203/1997, de 23 de octubre, sobre asistencia judicial del personal al servicio de la Administración Autonómica.

o Orden de 27 de octubre de 1997 de la Consejería de Presidencia y Administración Territorial.

Los Letrados de la Comunidad Autónoma actuarán con los mismos derechos, prerrogativas y deberes que cuando lo hagan en defensa y representación de la propia Administración Autonómica. Su intervención tendrá lugar tanto en procesos civiles como penales.

Los profesionales tienen derecho a elegir y designar asistencia letrada propia conforme a las reglas generales del proceso judicial. Por ello, salvo que existan derechos o intereses de la Administración Autonómica directamente afectados, el Letrado de la Comunidad se apartará del proceso.

b) Acciones específicas:

o Mantenimiento de la póliza de seguro de defensa jurídica ya suscrita. Esta póliza cubre al personal funcionario, estatutario y laboral y contempla garantías sobre reclamación de daños por agresión verbal o física, defensa de la responsabilidad penal y constitución de fianzas penales y asistencia jurídica.

o Estudio por parte de la Administración Autonómica del desarrollo de un marco normativo "ad hoc" para emprender acciones judiciales contra los agresores. La finalidad es contar con instrumentos legales para poder emprender acciones judiciales por propia iniciativa o a instancia del trabajador agredido. Se añade una posible 
opción dirigida a proteger la identidad de la víctima (siempre con su consentimiento), consistente en personarse en su nombre.

2. Relaciones con otras Instituciones.

Queda establecido que la Gerencia Regional de Salud dirigirá una solicitud formal a la Fiscalía del Tribunal Superior de Justicia de Castilla y León en orden a requerir de dicho organismo la calificación como delito de atentado contra funcionario público de estas agresiones (arts. 550 y 551.1 del CP).

También se estipula que dicha Gerencia mantendrá contactos con la Consejería de Justicia e Interior para colaborar conjuntamente en la toma de medidas conjuntas para atajar el problema.

3. Estudio de acciones contra el agresor.

La Administración Regional «propondrá la manera de establecer normativamente actuaciones dirigidas a sancionar a los usuarios o familiares que cometan una agresión.

4. Registro y notificación del accidente (aunque se incluye dentro del capítulo de medidas posteriores, su contenido se detalla en el apartado siguiente).

\section{$4^{0}$. Seguimiento de las actuaciones desarrolladas frente a las agresiones.}

El organismo encargado del seguimiento y evaluación del Pacto es el Comité Intercentros de Seguridad y Salud Laboral de la Junta de Castilla y León (Decreto 143/2000, de 29 de junio, de adaptación de la legislación de prevención de riesgos laborales de la Junta de Castilla y León). Se prevé la puesta en marcha de dos herramientas:

a) Observatorio de agresiones al personal de la Gerencia Regional de Salud de Castilla y León.

Tiene como finalidades:

o Conocer, analizar y evaluar la situación de riesgo de agresiones.

o Proponer actuaciones de prevención e intervención para mejorar «la convivencia en la relación profesional-usuario».

Se detalla un listado no exhaustivo de funciones (de ahí el punto final «y otras que se desarrollen») para la consecución de sus fines:

- Realizar estudios que permitan un mejor conocimiento de la situación de las agresiones en su ámbito, elaborando una memoria anual de sus actividades en la que se recojan los datos e informaciones más relevantes. 
- Impulsar planes formativos que incluyan la metodología de actuación ante la violencia en el sector sanitario, el trato correcto y la comunicación fluida entre usuario-profesional.

- Promover encuentros entre profesionales y expertos para facilitar intercambio de experiencias, investigaciones y trabajos en esta materia.

- Orientar a todos los profesionales de SACYL en la resolución de situaciones de conflictividad en su ámbito de actuación.

- Elevar las propuestas a la Administración sanitaria para la disminución de la conflictividad y mejora de la convivencia.

- Analizar el sistema de seguimiento y control de las agresiones con el objeto de revisar continuamente los datos y mejorar su explotación.

- Y otras que se desarrollen.

b) Registro informático de agresiones.

Su creación se ampara en la normativa siguiente:

- LO 15/1999, de 13 de diciembre, de Protección de Datos de Carácter Personal.

- Decreto 11/2003, de 23 de enero, por el que se regulan los ficheros de carácter personal susceptibles de tratamiento automatizado de la Comunidad de Castilla y León.

El Registro está creado con el objetivo principal de conocer de una forma precisa y homogénea los datos concretos de los incidentes violentos que se produzcan. Con esa información, se pretende elaborar un mapa de agresiones de la Comunidad, tomando medidas en consecuencia.

Queda establecido el mandato de concretar un procedimiento propio para su utilización por parte de quienes deban registrar las agresiones, siempre sometido a criterios de responsabilidad y confidencialidad.

Se indica un listado de datos de carácter personal mínimo y ampliable, que necesariamente serán incluidos en el citado registro, que a continuación se relacionan:

- Datos identificativos del trabajador agredido (nombre, apellidos, NIF, edad, sexo, domicilio, teléfono).

- Datos profesionales del trabajador agredido (centro de trabajo, puesto de trabajo, categoría profesional).

- Datos de salud (lesiones producidas, asistencia sanitaria, tramitación de incapacidad y formación en la materia).

- Datos identificativos de los testigos (nombre, apellidos, NIF, domicilio, teléfono) o de otras personas intervinientes (compañeros, policía, personal de seguridad, otros usuarios, etc.).

- Datos identificativos del registrador (nombre, apellidos, NIF, teléfono). 
- Datos profesionales del registrador (centro de trabajo, puesto de trabajo, categoría profesional).

- Datos identificativos del presunto agresor (sexo, edad, antecedentes, etc.).

- Posibles causas desencadenantes de los hechos.

- Descripción de los hechos.

- Resultado del conflicto.

- Daños materiales y cuantificación económica de los mismos.

El Pacto se acompaña de un Protocolo de actuación de los profesionales ante una situación de agresión.

El Protocolo se estructura en:

1. Identificación de lo que se considera un «incidente violento»: «El incidente violento en el lugar de trabajo supone una actitud de amenaza, abuso verbal o físico, comportamiento intimidatorio, ataque físico, coacción o ataque sexual que comete un paciente, familiares o acompañantes, contra un profesional en el ejercicio de su profesión y que cause un daño físico o psicológico en la persona o perjudique la propiedad».

2. Actuaciones a seguir por parte del agredido, según se trate de:

a. Violencia controlada (sin ataque físico inminente): «El profesional intentará calmar la situación e invitará al usuario o paciente a que abandone el lugar de trabajo».

b. Violencia incontrolada:

Se recomienda actuar de varias formas alternativas:

o Intentar salir rápidamente del espacio físico del lugar de trabajo ${ }^{160}$.

o Pedir ayuda a los vigilantes de seguridad del centro.

o Poner en marcha los sistemas antipánico (si los hubiere).

o Solicitar ayuda de los compañeros u otras personas.

Si con estas reacciones no cesa la conducta agresiva, «se pasará a contactar con las Fuerzas y Cuerpos de Seguridad del Estado» a través del teléfono urgencias 112.

En caso de que la situación de peligro inminente (ya sea violencia controlada o incontrolada) cesase sin que hubiera agresión, no por ello debe olvidarse el incidente. El Protocolo indica que es necesario que se comunique al superior inmediato del centro el incidente, quien también deberá cursar comunicación de lo sucedido a la Gerencia correspondiente (Atención Especializada, Primaria, Salud de Área, Emergencias Sanitarias, Regional de Salud). Estas Gerencias, a su vez, informarán del episodio a:

\footnotetext{
${ }^{160}$ La redacción literal dice: «si el profesional se encuentra dentro de su lugar de trabajo, intentará la salida rápida de la misma y solicitará ayuda...». Como puede verse, es una redacción un tanto confusa.
} 
o Su respectiva Gerencia de Área.

o Servicio de Prevención de Riesgos Laborales.

o Servicio de Salud Laboral de la Gerencia Regional de Salud.

En el caso de que finalmente la situación de peligro inminente dé lugar a una agresión, se producen las siguientes consecuencias:

o Si es necesaria asistencia sanitaria y/o psicológica, el responsable del centro facilitará esa atención de modo inmediato.

o Si se producen lesiones, se solicitará el correspondiente parte de lesiones.

- El trabajador agredido debe comunicar la agresión a su superior inmediato. Se genera para el citado superior la obligación de comunicarlo a su vez (vía telefónica o personalmente) a las Gerencias que corresponda.

o Las Gerencias deben entonces:

1. Dar de alta el incidente violento producido en el Registro de Agresiones.

2. Ofrecer asesoramiento jurídico inmediato. Si el trabajador interpone denuncia:

- Se producen las acciones civiles a título individual.

- En ocasiones, también acciones judiciales penales. En este caso:

o Pueden actuar los letrados de la Póliza de seguro de defensa jurídica del personal de la Gerencia Regional de Salud (salvo que el denunciante no utilice esta vía, sino que designe letrado por su cuenta).

o Los letrados de la Junta de Castilla y León actuarán como acusación particular.

3. Ofrecer apoyo psicológico al agredido (si le es prescrito).

4. Comunicar los hechos a:

- Servicio de Prevención de Riesgos Laborales: investigará los hechos y revisará las medidas preventivas propuestas y puestas en marcha. En el caso de que la agresión se produjera en los Servicios Centrales de la Gerencia Regional de Salud, estas acciones serán tomadas por el Servicio de Salud Laboral de la Gerencia Regional de Salud.

- Gerencia de Salud de Área correspondiente. Cuándo ésta conoce los hechos:

o Emprenderá acciones judiciales, si procede en Derecho.

- Por propia iniciativa.

- A instancia del trabajador. 
- Personándose en nombre del trabajador para «proteger su identidad» ${ }^{161}$.

\section{Instrucciones de 12 de septiembre de 2012 del Director Gerente de la Gerencia Regional} de Salud por la que se desarrollan distintos aspectos del Plan Integral frente a las agresiones al personal de la Gerencia Regional de Salud (medidas debatidas en el seno del Observatorio de Agresiones, en sesión celebrada el 5 de junio de 2012).

Mediante estas Instrucciones se toman nuevas medidas y se modifican algunas de las ya implantadas en el Plan Integral frente a las agresiones al personal de la Gerencia Regional de Salud de Castilla y León. Estas actuaciones fueron debatidas en la reunión del Observatorio de Agresiones del 5 de junio de 2012.

a) Refundición de los Anexos I (comunicación) y II (registro). Se considera una duplicación innecesaria que «suponía una carga para el trabajador y un retraso en el registro». Por ello, para simplificar el trámite, se unifican ambos anexos en uno solo.

Además, con el fin de garantizar el fácil acceso de todos los posibles afectados al nuevo modelo, queda establecido que el nuevo Anexo I estará a disposición del personal de todos los centros y que se colgará en el Portal Salud Castilla y León y en las páginas web de las Gerencias.

b) Unificación de los puntos de registro:

- Se detecta que se han producido retrasos y dispersión de la información por causa de la existencia de 35 puntos diferentes de registro y 35 de supervisión. Además, también se manifiesta que ello implica la utilización de más personal del necesario.

- Por estas razones, se acuerda la centralización del registro en los Servicios de Prevención de Riesgos Laborales de las Áreas de Salud. La justificación de esta concreta atribución se centra en que estos Servicios deben participar de forma obligada cuando se producen agresiones (investigación del suceso y propuesta de medidas preventivas). En consecuencia, los registradores deberán pertenecer al citado Servicio, designándose dos por cada Gerencia de Salud de Área. No obstante, la supervisión queda en cada Gerencia y la validación en la Dirección General de Recursos Humanos.

- Queda configurado un nuevo procedimiento de registro, supervisión y validación de las agresiones, debiéndose seguir los siguientes pasos sucesivos:

\footnotetext{
${ }^{161}$ Se refiere más bien a proteger su anonimato.
} 
- El trabajador agredido presenta a su superior jerárquico (Jefe de Servicio o Unidad, coordinador de EAP o UME) el Anexo de comunicación y registro. El responsable debe facilitarle el modelo en caso de que no disponga del mismo.

- El superior jerárquico envía el Anexo a la Gerencia correspondiente mediante correo ordinario $^{162}$. Debe hacerlo en la misma fecha en que el trabajador lo haya presentado.

- El Gerente remite el citado Anexo de comunicación y registro:

o Por email escaneado a:

- La Gerencia de Salud de Área.

- El Servicio de Prevención de Riesgos Laborales.

- Los delegados de prevención.

o El original al Servicio de Prevención.

- Uno de los registradores del Servicio de Prevención:

o Introduce los datos en el Registro de Agresiones.

o Comunica el registro al supervisor.

El Servicio de Prevención archiva el documento en papel en el expediente del trabajador.

- El supervisor de la Gerencia:

o Comprueba el registro.

o Lo envía al validador.

o Si observa algún error, lo devuelve al registrador para su subsanación.

- El validador de la Dirección General de Recursos Humanos confirma el registro.

Se afirma que el objetivo es que todo el proceso se complete en un máximo de 7 días. Lo cierto es que el procedimiento parece bastante farragoso y que un plazo de siete días puede ser excesivo, si tenemos en cuenta que lo es simplemente para que la agresión conste en el Registro de Agresiones, supervisada y validada. Dado que este es un paso previo y necesario para el ejercicio de actuaciones concretas ante la agresión producida, creemos que puede significar una demora importante en esa toma de medidas. El procedimiento debería simplificarse.

162 Es sorprendente que en nuestros días se utilice el correo ordinario para una comunicación que se supone urgente, medio que debe usar el superior jerárquico. Sin embargo, el Gerente remite este documento por email escaneado a la Gerencia de Salud, el Servicio de Prevención y los Delegados de Prevención. 
c) Nuevo Protocolo de actuación para los profesionales:

Se instaura un nuevo Protocolo que declara ser más sencillo y con información actualizada. Este Protocolo:

o Se facilitará a todos los trabajadores de nuevo ingreso.

o Se hará llegar a los trabajadores mediante email (a las cuentas de las que se disponga).

o Se colocará en un lugar visible de cada centro o servicio, en las páginas web de las Gerencias y en el Portal Salud Castilla y León.

d) Protocolo de actuación para los responsables del SACYL. Los Servicios de Prevención lo entregarán a:

a. Todo el personal directivo.

b. A través de las Direcciones correspondientes:

i. A los Jefes de Servicio y Unidad.

ii. Supervisores.

iii. Coordinadores de EAP y UME.

e) Modelo de carta al agresor: su contenido informa al agresor de las posibles consecuencias de sus actos. Se trata de un modelo personalizable con las características concretas del incidente, pero siempre respetando el espíritu del modelo.

El envío de la carta dependerá de lo siguiente:

a. Que el agresor sea conocido.

b. Que el agresor no sea:

i. Paciente con problemas psiquiátricos.

ii. Paciente menor de edad: en este caso puede valorarse el envío a los familiares del paciente ${ }^{163}$.

c. Que los hechos no sean constitutivos de ilícito penal.

d. Que no se haya realizado la petición razonada de incoación de expediente sancionador conforme a la Instrucción de 14 de marzo de 2011.

e. Que el profesional agredido preste su consentimiento al envío de dicha carta.

f) Modificación del modelo de carta al profesional agredido: según el documento, «se ha modificado ligeramente» este modelo de carta, que es de «apoyo e información al profesional».

g) Nueva fase de la campaña «Espacio de Salud Espacio de Respeto»:

\footnotetext{
163 Sería aconsejable un mayor precisión en este punto: debería incluirse la posibilidad de que el agresor sea un acompañante del paciente $y$, en cuanto a los menores, cuando se habla de "familiares», sería más correcto puntualizar que el envío se realizaría a quien ejerza la patria potestad.
} 
- Se mantienen los elementos de la campaña que finalizó en marzo de 2011, siempre que su estado de conservación sea aceptable (cartelería, «displays» y adhesivos de suelo y cristal). Las lonas en las fachadas también se mantendrán, asegurando la seguridad de los anclajes $^{164}$.

- Se inicia una segunda fase bajo el mismo lema, pero incorporando un mensaje más directo. En esta fase sólo se colocarán carteles de $50 \times 70 \mathrm{~cm}$, que se ubicarán en zonas de gran visibilidad para los usuarios.

h) Nueva relación de puntos conflictivos en Atención Primaria:

- En atención especializada: módulos penitenciarios, urgencias y psiquiatría.

- En atención primaria:

o Valladolid Este: CS Barrio España, CS Canterac, CS La Victoria, CS Magdalena, CS Rondilla I, CS San Pablo, CS Tórtola, PAC Pilarica, PAC Rondilla.

o Valladolid Oeste: CS Arturo Eyríes, CS Delicias I, CS Delicias II, CS Plaza del Ejército.

\section{Decreto 48/2009, de 16 de julio, por el que se crea y regula el Observatorio de Agresiones al personal de la Gerencia Regional de Salud de Castilla y León.}

Se apoya en las siguientes disposiciones:

- Artículo 40.2 de la Constitución Española: encomienda a los poderes públicos velar por la seguridad e higiene en el trabajo (principio rector de la política social y económica).

- Convenio 155 de la OIT, sobre seguridad y salud de los trabajadores y ambiente de trabajo, ratificado por España mediante Instrumento de 26 de julio de 1985.

- Directiva 89/391/CEE relativa a la aplicación de las medidas para promover la mejora de la seguridad y de la salud de los trabajadores en el trabajo: contiene el marco jurídico general de la política de prevención comunitaria.

- Ley 31/1995, de 8 de noviembre, de Prevención de Riesgos Laborales (dictada al objeto de desarrollar el mandato constitucional mediante una política de protección de los trabajadores). Igualmente, traspone al Derecho español la Directiva anteriormente citada.

- $\quad$ RD 39/1997, de 17 de enero, por el que se aprueba el Reglamento de los Servicios de Prevención. Vincula en igual medida a las empresas y a las Administraciones Públicas en cuanto a los objetivos a lograr, aunque deja más libertad a estas últimas respecto a las formas de conseguirlos.

164 Creemos que una campaña anterior no se puede «aprovechar» porque pierde toda eficacia. El usuario se acostumbra a ver los mismos carteles con los mismos mensajes y pasan a ser parte del escenario o paisaje, perdiendo cualquier poder de comunicación. 
- Decreto 143/2000, de 29 de junio, modificado por el Decreto 44/2005, de 2 de junio, de la Comunidad de Castilla y León. Adapta a su ámbito la legislación estatal de prevención de riesgos laborales.

- Ley 8/2003, de 8 de abril, sobre derechos y deberes de las personas en relación con la salud. Señala que «el respeto a la propia salud y a la de los demás impone el necesario acatamiento de determinadas prescripciones y medidas sanitarias, el correcto uso de las instalaciones y servicios, o el debido respeto al personal y a otros usuarios, favoreciendo la concienciación ciudadana y la evitación de situaciones de abuso o ejercicio antisocial del derecho».

- Pacto de 4 de febrero de 2008 entre la Consejería de Sanidad y Organizaciones sindicales para elaborar el Plan integral frente a las agresiones al personal de la Gerencia Regional de Salud de Castilla y León. En él se contempla la puesta en marcha de un Observatorio, como herramienta para el seguimiento de las actuaciones emprendidas y propuesta de otras nuevas.

El Observatorio de Agresiones tiene naturaleza de órgano colegiado de carácter consultivo y también con las funciones de seguimiento, propuesta, participación, análisis y evaluación de las situaciones de riesgo de agresión en la Gerencia Regional de Salud de Castilla y León, quedando adscrito a la misma.

Su finalidad consiste en analizar, conocer y evaluar estas situaciones de riesgo, proponiendo actuaciones de prevención e intervención dirigidas a la mejora de la relación entre profesionales y usuarios. Se proclama su vocación de servir de foro de diálogo entre Administraciones y otros representantes de la sociedad, para asegurar una participación activa.

Como funciones, el Observatorio ostenta las siguientes:

a) Realizar estudios que permitan un mejor conocimiento de la situación de las agresiones en su ámbito, elaborando una memoria anual de sus actividades en la que se recojan los datos e informaciones más relevantes.

b) Impulsar planes formativos que incluyan la metodología de actuación ante la violencia en el sector sanitario, el trato correcto y comunicación fluida entre profesionales y usuarios.

c) Promover encuentros entre profesionales y expertos para facilitar intercambio de experiencias, investigaciones y trabajos en esta materia.

d) Orientar a todos los profesionales de la Gerencia Regional de Salud en la resolución de situaciones de conflictividad en su ámbito de actuación.

e) Elevar a la Administración sanitaria propuestas para la disminución de la conflictividad y mejora de la convivencia. 
f) Analizar el sistema de seguimiento y control de las agresiones con el objeto de revisar continuamente los datos y mejorar su explotación.

g) Esta es una función de cierre, que busca garantizar que el órgano pueda asumir nuevas funciones, distintas a las encomendadas a través de este Decreto.

Se establecen dos organismos de actuación, Pleno y Comisión Técnica. No obstante, pueden ser creadas por el Pleno diversas comisiones de trabajo. También es competencia del Pleno aprobar sus propias normas de funcionamiento interno, si resultara necesario.

La Comisión Técnica (artículo 6) tiene tres cometidos específicos: emitir informes y propuestas, preparar los trabajos que se debatirán en el Pleno y ejercer las funciones que se le encomienden por este último. Se reúne dos veces al año como mínimo (pueden convocarse más reuniones si las circunstancias lo exigieran o a propuesta de alguno de sus miembros). Actúa como Secretario quien lo sea del Pleno y la preside el titular de la Dirección General de Recursos Humanos de la Gerencia Regional de Salud (o persona en quien delegue) y los titulares (o personas en quienes deleguen) de las siguientes Direcciones Generales:

- De Asistencia Sanitaria.

- De Desarrollo Sanitario.

- De Administraciones e Infraestructuras.

- De Planificación, Calidad, Ordenación y Formación.

El órgano más importante del Observatorio es el Pleno, al que corresponde el ejercicio e impulso de las funciones encomendadas al Observatorio. $\mathrm{Su}$ composición es bastante numerosa, ejerciendo como Presidente el Consejero de Sanidad, como Vicepresidente el Director Gerente de la Gerencia Regional de Salud, y como Secretario un funcionario adscrito a la Gerencia Regional de Salud (designado por el Vicepresidente y con voz, pero sin voto). Se designan los siguientes vocales:

- Los titulares de las Direcciones Generales de Recursos Humanos; Asistencia Sanitaria; Desarrollo Sanitario; Administración e Infraestructuras; Planificación Calidad, Ordenación y Formación (todas ellas también representadas en la Comisión Técnica); y de Salud Pública e Investigación, Desarrollo e Innovación.

- Los titulares de la Dirección General con competencias en materia de Función Pública y además en materia de Trabajo y Prevención de Riesgos Laborales.

- El titular de la Agencia de Protección Civil y Consumo, el del Comisionado Regional para la Droga de la Consejería de Familia e Igualdad de Oportunidades y el del Servicio de Coordinación y Prevención de Riesgos Laborales de la Consejería de Administración Autonómica.

Todas estas vocalías pueden ser objeto de delegación. 
- Una persona en representación de:

o La Delegación del Gobierno en Castilla y León.

o La Fiscalía de la Comunidad Autónoma de Castilla y León.

o La Federación Regional de Municipios y Provincias.

o El Consejo Castellano y Leonés de Consumidores y Usuarios.

- Un representante de cada uno de los siguientes Colegios Oficiales en el ámbito de la Comunidad de Castilla y León: Médicos, Diplomados ${ }^{165}$ en Enfermería, Diplomados en Trabajo Social y Asistentes Sociales, Fisioterapeutas, Odontólogos y Estomatólogos, Farmacéuticos y Psicólogos.

- Un representante por cada una de las Organizaciones Sindicales más representativas en el ámbito autonómico, y el mismo número de representantes de Organizaciones Empresariales (CECALE). Así mismo, un representante de cada una de las Organizaciones Sindicales presentes en la Mesa Sectorial no comprendidas en el apartado anterior.

Así pues, los representantes de las diferentes Administraciones territoriales y corporativas suman 22 vocales, a los que queda añadir un número no determinado de representantes sindicales y empresariales. Además, se prevé la convocatoria de expertos en la materia, que actuarán con voz y sin voto.

Esta numerosa composición del Pleno parece obedecer al deseo de lograr una representatividad máxima de los diferentes colectivos y ámbitos afectados, en aras a conseguir que todos participen en las propuestas y soluciones a arbitrar. No obstante, una composición numérica tan alta, quizá en la práctica resulte un obstáculo para la operatividad del propio órgano.

En cuanto a su funcionamiento, se reunirá en dos sesiones ordinarias anuales, y en las reuniones extraordinarias que se precisen (convocadas por el Presidente o a propuesta de una tercera parte de sus miembros como mínimo). El Presidente tiene voto dirimente en caso de empate.

\section{Ley 8/2010, de 30 de agosto, de Ordenación del Sistema de Salud de Castilla y León.}

Esta ley se promulga como adecuación a las nuevas leyes sectoriales, a las transferencias ya materializadas del Instituto Nacional de la Salud (RD 1480/2001, de 27 de diciembre, con efectos de 1 de enero de 2002) y al propio cambio en el Estatuto de Autonomía (que establece el derecho

165 Todas las referencias a Diplomaturas universitarias deben entenderse referidas también a los nuevos Grados. 
a la salud dentro del epígrafe de derechos sociales y enumera los derechos y deberes de los usuarios del sistema sanitario).

Varias cuestiones en esta ley son aquí de especial interés:

- Reconocimiento y motivación de todos los trabajadores del ámbito de la salud: sin desarrollo, pero que se reconoce como principio informador de los poderes públicos (regulado en la Ley 2/2007, de 7 de marzo, del Estatuto Jurídico del Personal Estatutario del Servicio de Salud de Castilla y León). En concreto, se establece como principio rector del Sistema de Salud «el reconocimiento y la motivación de los profesionales del Sistema de Salud» (apartado k del art. 2)

- Remite a la Ley $8 / 2003$, de 8 de abril lo referido a los derechos y deberes en el sistema de salud, pero además crea la figura del Defensor del Usuario del Sistema de Salud de Castilla y León (art. 5).

- Se atribuyen competencias sancionadoras a la Consejería competente en materia de sanidad (art. 7, epígrafe q) y a los Ayuntamientos (art. 8.2).

De gran importancia es, en lo referente al tema que nos ocupa, el Título X, dedicado al Régimen Sancionador. Se establecen tres categorías de infracciones (leves, graves y muy graves), seguidas de sus correlativas sanciones, aplicables tras la incoación del oportuno expediente (sin perjuicio, por supuesto, de las responsabilidades que pudieran concurrir en otros ámbitos del ordenamiento jurídico).

En cuanto a las infracciones leves, detalladas en el artículo 72, son de nuestro interés las numeradas como 5 y 6 :

5.- La falta de respeto debido al personal de los centros dependientes del Servicio de Salud de Castilla y León.

6.- El incumplimiento del deber relativo al correcto uso de las instalaciones y servicios sanitarios con el fin de garantizar su conservación y funcionamiento, que no perjudique gravemente la prestación de los servicios sanitarios.

Las infracciones leves pueden sancionarse con multas entre 300 y 3.000 euros.

El artículo 73 prosigue con la enumeración de las infracciones graves, siendo destacables las siguientes:

6.- La coacción, amenaza o represalia dirigida a los profesionales de las instituciones sanitarias y centros dependientes del Servicio de Salud de Castilla y León en el ejercicio de sus funciones.

9.- Dificultar o impedir el disfrute de cualquiera de los derechos reconocidos en la presente Ley a las personas. 
10.- El incumplimiento del deber relativo al correcto uso de las instalaciones y servicios sanitarios con el fin de garantizar su conservación y funcionamiento, que perjudique gravemente la prestación de los servicios sanitarios.

Las infracciones graves pueden ser castigadas con multa de 3.001 a 60.000 euros.

Por último, la lista de infracciones muy graves se encuentra en el artículo 74. Las que se refieren a nuestro foco de interés son:

3.- Las agresiones a los profesionales de las instituciones sanitarias y centros dependientes del Servicio de Salud de Castilla y León.

4.- La resistencia, coacción, amenaza, represalia, desacato o cualquier forma de presión ejercida sobre las autoridades sanitarias del Sistema Público de Salud de Castilla y León o sus agentes.

Es de subrayar que esta última se refiere específicamente a las «autoridades sanitarias», es decir, las definidas en el artículo 70 de esta ley, y no al personal al que se atribuye la condición de «autoridad pública» por mor del apartado 3 de su artículo 34, introducido por la Disposición Adicional séptima de la Ley 11/2013, de 23 de diciembre). Y esto es así por cuanto el citado artículo 70 especifica con detalle quiénes son «autoridades sanitarias y sus agentes» de forma muy clara ${ }^{166}$.

El castigo de las infracciones muy graves son multas de importe comprendido entre los $60.001 \mathrm{y}$ los 600.000 euros.

La calificación de las infracciones (leves, graves, muy graves) se realiza, por mandato del apartado 2 del artículo 75, de acuerdo a los siguientes criterios:
a) Intencionalidad.
b) Reiteración.
c) Reincidencia.
d) Número de personas afectadas.
e) Perjuicios causados.
f) Beneficios obtenidos a causa de la infracción.
g) Permanencia o transitoriedad de los riesgos.

De esta forma, el sistema de sanciones está establecido sobre un mecanismo de graduación de las infracciones, que permite su adecuación a la casuística de cada episodio producido y facilita una

\footnotetext{
166 Ley 10/2010, de 27 de septiembre, de Salud Pública y Seguridad Alimentaria de Castilla y León (BOCYL núm. 196 de 8 de octubre de 2010 y BOE núm. 283, de 23 de noviembre de 2010.

«En su capítulo I se concreta quiénes son autoridad sanitaria y se introduce en nuestro ordenamiento jurídico la condición del agente de la autoridad sanitaria para los profesionales de salud pública que participan en las funciones de inspección y control oficial y vigilancia epidemiológica. La ley determina para qué están facultados los mencionados agentes en el ejercicio de sus funciones».
} 
adecuación de la sanción a su gravedad, teniendo en cuenta los diversos factores que se hayan dado en cada ocasión.

La competencia sancionadora en materia de sanidad se atribuye según criterio de gravedad de la infracción. De este modo, queda establecido lo siguiente (art. 77):

8. Infracciones muy graves:

i. Cuando la sanción esté comprendida entre $300.001 €$ y 600.000 euros: Junta de Castilla y León.

ii. El resto son potestad del titular de la Consejería competente en materia de sanidad.

9. Infracciones graves: titulares de órganos directivos de la Consejería competente en materia de sanidad.

10. Infracciones leves: titulares de las Delegaciones Territoriales de la Junta de Castilla y León.

El procedimiento en materia sancionadora sigue las pautas del procedimiento administrativo común y lo establecido en el Decreto 189/1994, de 25 de agosto, por el que se aprueba el Reglamento Regulador del Procedimiento Sancionador de la Administración de la Comunidad de Castilla y León.

\section{Ley 11/2013, de 23 de diciembre, de Medidas tributarias y Reestructuración del Sector Público Autonómico. Consideración de autoridad pública.}

Se efectúa una modificación en la disposición adicional séptima de la Ley 8/2010, de 30 de agosto, de Ordenación del Sistema de Salud de Castilla y León, añadiendo un nuevo apartado 3 en el artículo 34:

«3. Los profesionales de los centros sanitarios incluidos en el anexo a la presente ley gozarán, en el ejercicio de sus funciones y responsabilidad, del derecho a ser respetados, recibir un trato adecuado y ser valorados por los usuarios del sistema sanitario, sus familiares y acompañantes y por la sociedad en general.

A estos efectos, tendrán la consideración de autoridad pública y gozarán de la protección reconocida a tal condición por la legislación vigente.

Los hechos constatados por los mencionados profesionales, gozarán de la presunción de veracidad cuando se formalicen por escrito en documento que cuente con los requisitos establecidos según la normativa aplicable en cada caso.»

Las categorías profesionales que pasan a ostentar la condición de autoridad pública son las siguientes:

- Los profesionales determinados en los artículos 2, 3, 6 y 7 de la Ley 44/2003, de 21 de noviembre, de Ordenación de las Profesiones Sanitarias. 
- Personal directivo de centros e instituciones sanitarias del Servicio de Salud de Castilla y León.

- Trabajadores Sociales.

- Personal de Gestión y Servicios.

Es decir, la consideración de «autoridad pública» va más allá del personal sanitario, incluyendo también a otros profesionales del Servicio de Salud de Castilla y León. Se equipara, por tanto, a todos estos trabajadores, ofreciéndose para todos ellos idénticas medidas en caso de sufrir una agresión.

Nótese que el artículo 3 no explicita en qué consiste la protección jurídica a que da derecho la condición de «autoridad pública», limitándose a remitir genéricamente a «la protección reconocida a tal condición por la legislación vigente». Una frase tan poco concreta no detalla qué tipo de protección pueden esperar los trabajadores de la sanidad pública de esta medida.

Lo que sí se determina con total claridad es la presunción de veracidad que se otorga a las declaraciones escritas por parte de los profesionales respecto a estos sucesos. Hay que destacar que, no obstante, esas declaraciones deberán realizarse «en documento que cuente con los requisitos establecidos según la normativa aplicable a cada caso», lo que parece remitir a formularios aprobados reglamentariamente por la propia Administración, denuncias ante la Policía y escritos admitidos dentro de un procedimiento judicial.

\section{Decreto 52/2014, de 16 de octubre, por el que se crea y regula el Observatorio de la} Comunidad de Castilla y León.

Se sustenta en el Acuerdo 22/2014, de 30 de enero, de la Junta de Castilla y León, que aprobó medidas de reforma de carácter organizativo de la Administración autonómica, para agilizar y simplificar su funcionamiento.

Entre estas medidas aprobadas, se encuentra la unificación de los diferentes Observatorios existentes en uno único. Del mismo modo, se pretende «la clarificación del concepto de observatorio, atribuyendo tal denominación únicamente a aquel órgano colegiado que tenga como finalidad el estudio, análisis y seguimiento de realidades de la sociedad de Castilla y León».

Se crea el Observatorio de la Comunidad de Castilla y León, con tres secciones permanentes:

1. Género.

2. Convivencia escolar. 
3. Agresiones al personal de la Gerencia Regional de Salud de Castilla y León.

La inclusión del antiguo Observatorio de agresiones en una de las secciones permanentes del nuevo órgano unificado garantiza su existencia y continuidad, especificando que su finalidad se ejercerá en estos tres ámbitos de forma particular. Queda, asimismo, organizado en formaciones permanentes, una de las cuales es la «Sección de agresiones al personal de centros sanitarios» (artículo 1.2).

De su comité permanente (artículo 5) formarán parte, entre otros miembros, «una persona en representación de cada una de las consejerías competentes en materia de mujer, educación y sanidad, designadas por sus titulares», representantes de cada uno de estos tres ámbitos que se atienden de forma preferencial.

La composición de la Sección de agresiones al personal de centros sanitarios se detalla en el artículo 8:

1. El presidente del Comité permanente.

2. Igual número de vocales que los que forman el Comité permanente y con idéntica representación.

3. Los siguientes vocales, designados por las organizaciones y entidades a las que representan:

i. Una persona en representación de la Gerencia Regional de Salud de Castilla y León.

ii. Una persona en representación del Consejo de Colegios Profesionales de Médicos de Castilla y León, de Diplomados en Enfermería de Castilla y León, de Diplomados en Trabajo Social y Asistentes Sociales de Castilla y León, de Fisioterapeutas de Castilla y León, de Odontólogos y Estomatólogos existentes en Castilla y León, de Psicólogos de Castilla y León.

iii. Una persona en representación de cada una de las organizaciones sindicales con representación en el Mesa Sectorial que no estén representadas en el Comité permanente.

Las funciones de la Sección serán, en relación con la materia de agresiones al personal de centros sanitarios y aquellas que en este ámbito le encomiende el Comité permanente, las indicadas en el artículo 3.1, es decir:

a) Estudiar, analizar y difundir información que permita un mejor conocimiento de la realidad existente en las diferentes áreas y realidades y su evolución.

b) Asesorar a la Administración de la Comunidad de Castilla y León y, en su caso, a las Administraciones Públicas que lo soliciten.

c) Formular propuestas a la Administración de la Comunidad.

d) Promover encuentros entre profesionales y personas expertas para facilitar el intercambio de experiencias, investigaciones y trabajos. 
e) Proponer a todos los profesionales criterios orientativos de actuación en determinados ámbitos.

f) Impulsar planes de formación.

g) Elaborar, anualmente, un informe en el que se recojan los datos e informaciones más relevantes de los trabajos realizados.

h) Cualquier otra que le sea encomendada.

Queda establecido el régimen de funcionamiento (artículo 10), con reuniones ordinarias preceptivas dos veces al año y extraordinarias bajo convocatoria del presidente o por propuesta de al menos una tercera parte de los vocales. Se establecen también los requisitos para su válida constitución y el régimen de toma de acuerdos.

Es de destacar la participación de expertos, regulada en el artículo 9. Se prevé que el observatorio pueda solicitar a la Fiscalía de la Comunidad Autónoma su participación, así como la de titulares de la Administración de la Comunidad y personas expertas en las materias a tratar.

Entre las normas que este Decreto deroga se encuentra el Decreto 48/2009, de 16 de julio, por el que se crea y regula el Observatorio de Agresiones al personal de la Gerencia Regional de Salud de Castilla y León.

10. Pacto de 20 de septiembre de 2016 por el que se aprueban las estrategias de actuación en prevención de riesgos laborales de la Gerencia Regional de Salud de Castilla y León 2016$2020^{167}$.

La normativa en que se sustenta este Pacto es la siguiente:

- Ley 31/1995, de 8 de noviembre, de Prevención de Riesgos Laborales, modificada por la Ley 54/2003, de 12 de diciembre.

- Ley 2/2007, de 7 de marzo, del Estatuto Jurídico del personal estatutario del Servicio de Salud de Castilla y León.

- Decreto 80/2013, de 26 de diciembre.

- Acuerdo 135/2015, de 12 de diciembre, de la Junta de Castilla y León por el que se aprueba el Plan de Prevención de Riesgos Laborales de la Administración de Castilla y León.

\footnotetext{
${ }^{167}$ Resolución de 2 de noviembre de 2016 de la Dirección General de Trabajo y Prevención de Riesgos Laborales, por la que se dispone la inscripción en el Registro Central de Convenios Colectivos de Trabajo, y la publicación, del Pacto de 20 de septiembre de 2016, entre la Gerencia Regional de Salud de Castilla y León y las organizaciones sindicales SATSE-FSES, CESM, UGT y USAE, por el que se aprueban las estrategias de actuación en prevención de riesgos laborales de la Gerencia Regional de Salud de Castilla y León 2016/2020. BOCYL núm. 218, de 11 de noviembre de 2016.
} 
- Instrucción 1/2016/DGP, de 4 de enero, del Director Gerente de la Gerencia Regional de Salud, por el que se recogen los compromisos adquiridos por el Acuerdo anteriormente citado, de entre los que destacan los siguientes:

a) Integrar la prevención de riesgos laborales dentro del conjunto de actividades que se llevan a cabo en el sistema general de actividades de la Gerencia Regional de Salud.

b) Implantar una verdadera cultura preventiva.

c) Mantener una dotación adecuada y suficiente de los medios humanos y materiales necesarios para la acción efectiva de la prevención.

A continuación, nos referiremos exclusivamente a los apartados que en este Pacto se dedican a las agresiones al personal sanitario.

En lo referente a materia de agresiones, el Pacto realiza un informe de las actuaciones seguidas en desarrollo del Pacto de 2008, reflejando los datos aportados en cuanto a la evolución del fenómeno por el Registro de agresiones. En el gráfico que allí se adjunta, se constata una disminución en el año 2012 y un nuevo repunte en los 2013, 2014 y 2015, donde se obtienen las cifras más altas. No se comenta el gráfico, pero se percibe claramente una tendencia al alza en la producción de estos episodios:

Año 2011: 351 incidentes, 426 trabajadores agredidos.

Año 2012: 331 incidentes, 389 trabajadores agredidos.

Año 2013: 360 incidentes, 432 trabajadores agredidos.

Año 2014: 375 incidentes, 435 trabajadores agredidos.

Año 2015: 389 incidentes, 461 trabajadores agredidos.

Seguidamente, se citan las principales actuaciones realizadas. Es necesario destacar que se trata de una simple enumeración, sin comentario ni análisis alguno sobre su posible incidencia o nivel de eficacia alcanzados:

1. Nuevas instrucciones del Director Gerente de 12 de septiembre de 2012.

2. Elaboración de un Protocolo de Actuación para los Responsables.

3. Nuevo Protocolo de Actuación para los Profesionales.

4. Portal Salud de Castilla y León: 15.612 entradas en el apartado Plan Integral frente a las Agresiones (desde 1 de junio de 2013).

5. Implantación del Servicio de atención telefónica del 012 en materia de agresiones: Desde su puesta en marcha en febrero de 2014 ha recibido un total de 37 llamadas.

6. Actualización cada dos años del Mapa de Riesgos. 
7. Medidas de seguridad: Vigilantes, cámaras, alarmas. Implantación del Botón de Alarma en los equipos informáticos de 133 centros de Atención Primaria. Este sistema ha sido utilizado en 19 ocasiones desde 2012.

8. Formación: 3.067 trabajadores formados en 182 cursos sobre Técnicas de detección de conductas violentas, manejo de pacientes con problemas psíquicos y habilidades de comunicación.

9. Campaña de sensibilización en medios de comunicación y centros: Campaña de dignificación del personal de los centros sanitarios en noviembre de 2012.

10. Medidas organizativas: Unidades de atención al usuario, Informador de Urgencias, triaje en los Servicios de Urgencias de los hospitales.

11. Carta de apoyo a los profesionales agredidos.

12. Seguro de defensa jurídica.

13. Procedimientos judiciales: En Castilla y León se han dictado 167 sentencias condenatorias, 40 de ellas condenan al agresor por delito.

14. Colaboración con la Fiscalía de la Comunidad de Castilla y León, a quien se remiten todas las denuncias presentadas por personal del SACYL.

15. Consideración del personal de los centros sanitarios como Autoridad Pública.

16. Firma de Convenios de Colaboración con otras instituciones.

17. Carta de rechazo al agresor.

18. Expedientes administrativos sancionadores por conductas agresivas.

19. Constitución de la Sección de Agresiones del Observatorio de la Comunidad de Castilla y León, que sustituye y asume las funciones del Observatorio de Agresiones al personal de la Gerencia Regional de Salud.

20. Participación de los delegados de prevención a través de los Comités de Seguridad y Salud.

21. Participación de los profesionales: Realización de una encuesta en Atención Primaria.

Otra mención a las agresiones se encuentra en la Sección V, «Reducción de la siniestralidad», donde se declara que «Se prestará especial atención a los accidentes biológicos, “in itinere” e "in misión" y los derivados de las agresiones al personal de los centros sanitarios».

La última referencia explícita al tema que nos ocupa se sitúa en el punto 21: «Reducción de la incidencia de las agresiones». La dinámica establecida consiste en seguir desarrollando el Plan Integral frente a las Agresiones de la Gerencia Regional de Salud, aunque introduciendo modificaciones en el procedimiento de actuación (no se especifica cuáles). También queda establecido que se concederá prioridad a las medidas de prevención, teniendo en cuenta las 
propuestas de la Sección de Agresiones al personal de los centros sanitarios del Observatorio de Castilla y León y de «los foros específicos de prevención de riesgos laborales».

\section{Seguro de defensa jurídica.}

El objeto del contrato es la cobertura de:

17. Costes de reclamaciones por daños y perjuicios judiciales y extrajudiciales contra terceros a consecuencia de:

1. Agresión verbal (insulto, amenaza, intimidación o coacción).

2. Agresión física (contra el asegurado o bienes de su propiedad).

- Cuando se encuentre en el desarrollo de sus funciones.

- Siempre que exista un tercero responsable de los daños conocido o identificable.

18. Gastos de defensa penal en procesos contra el asegurado por imprudencia, impericia o negligencia por hechos derivados de su actividad como empleado de la Gerencia Regional de Salud de Castilla y León.

Incluye asesoramiento jurídico telefónico a través de un número 902 (aunque la llamada puede ser derivada desde el 112 y en este caso será gratuita), activo las 24 horas del día, en el que abogados en ejercicio asesorarán al interesado sobre los pasos a seguir en caso de sufrir una agresión. 


\section{LA RESPONSABILIDAD PATRIMONIAL DE LAS ADMINISTRACIONES PÚBLICAS}

La institución de la responsabilidad patrimonial de la Administración Pública posee rango constitucional (artículo 106.2 CE), constituyendo su característica preeminente el ostentar un carácter extracontractual y específico, similar al de la responsabilidad exigible en el ordenamiento Civil ${ }^{168}$.

El art. 32.1 LRJSP especifica que es directa y objetiva. Directa, porque la Administración Pública responde de las actuaciones efectuadas por sus agentes; objetiva, puesto que no responde a través de la existencia de culpa o dolo, sino por el simple funcionamiento normal o anormal de la Administración.

La cualidad de objetiva de la responsabilidad patrimonial de la Administración Pública es lo que mayor debate doctrinal ha suscitado. Medina Alcoz (2007) puntualiza que «objetiva» no es equiparable a «universal» o a un seguro a todo riesgo. García de Enterría (2005) subraya que el tipo de actuación o funcionamiento del servicio público no debe ser indiferente a la consecuencia de que se produzca un hecho indemnizable.

\section{LA LESIÓN RESARCIBLE. ANTIJURICIDAD.}

Este es el concepto clave en la materia. No es susceptible de reparación cualquier lesión producida. Sólo son indemnizables aquellas que se encuentran definidas en el texto legal (García de Enterría, 2005). Por tanto, para que una lesión sea resarcible, han de cumplirse los requisitos delimitados en los artículos 32.2 y 34.1 LRJSP, que veremos a continuación.

Por otra parte, ha de tenerse en cuenta que el concepto de lesión resarcible por la Administración Pública no es equivalente al daño o perjuicio reclamable en el ámbito del Derecho Civil. En este caso, ese daño o perjuicio debe encontrarse investido de la nota de antijuricidad.

La lesión debe ser, por tanto, antijurídica para ser resarcible. Ello supone que se haya producido un daño o perjuicio que el sujeto no tenga el deber, de acuerdo con la ley, de soportar ${ }^{169}$. Por tanto, resulta meridiano que lo importante no es si la acción u omisión productora del resultado ha sido correcta o incorrecta: lo decisivo es si el sujeto está obligado o no legalmente a soportar la

\footnotetext{
168 La responsabilidad Patrimonial de la Administración se regula en la LRJSP y en los artículos 121 y 122 de la Ley de Expropiación Forzosa, «que determinan el derecho de los particulares a ser indemnizados por el Estado de toda lesión que sufran siempre que sea consecuencia del funcionamiento normal o anormal de los servicios públicos, y el daño sea efectivo, evaluable económicamente e individualizado» (STS de 10 de abril de 2008).

Las referencias a sentencias del TS en este apartado se entenderán realizadas a la Sala de lo ContenciosoAdministrativo.

169 SSTS de 18 de junio y 3 de diciembre, entre otras.
} 
consecuencia producida en su esfera patrimonial. Así pues, la ausencia de título justificativo ${ }^{170}$ del daño o perjuicio ocasionado determina la procedencia de su reparación.

Además de este requisito central, para que una lesión devenga indemnizable, deben concurrir las siguientes circunstancias:

- Que derive de hechos que hubieran podido evitarse o preverse (según el estado de los conocimientos de la ciencia o la técnica en el momento de su producción). Si no es así, es decir, si lo acontecido era impredecible o inevitable, se excluye su antijuridicidad.

- El daño o perjuicio no debe incidir en expectativas, sino en bienes o derechos presentes y reales.

- La lesión debe ser efectiva, actual, no simplemente posible.

- Debe ser evaluable económicamente.

- El daño ha de ser individualizado con relación a una persona o grupo de personas.

Por lo tanto, no estamos ante una obligación ilimitada de la Administración. Como expresa el Consejo Consultivo del Principado de Asturias, en su Dictamen 19/2014, de 6 de febrero: «Este derecho [el de reparación] no implica, sin embargo, que la Administración tenga el deber de responder, sin más, por todo daño que puedan sufrir los particulares, sino que, para que proceda la responsabilidad patrimonial de la Administración Pública, deberán darse los requisitos que legalmente la caracterizan, analizando las circunstancias concurrentes en cada caso».

La responsabilidad patrimonial no debe generalizarse más allá del principio de causalidad adecuada, resultando imprescindible una imputación del daño jurídicamente correcta (no sólo material o fáctica), sin que la objetividad del daño deba entenderse como una extensión ilimitada que abarque cualquier suceso dañoso sufrido con ocasión de la prestación de un servicio público. «Ello, entre otras consecuencias, supone que la prestación por parte de la Administración de un determinado servicio público, o su titularidad de la infraestructura material necesaria para su prestación, no implica que aquélla se convierta en aseguradora universal de todos los riesgos materializados con ocasión del funcionamiento de dicho servicio, de forma que deba resarcir cualquier eventualidad desfavorable o dañosa para los administrados, producida con independencia del actuar administrativo, ya que en tal caso el actual sistema de responsabilidad patrimonial se transformaría en un sistema providencialista no contemplado en nuestro ordenamiento jurídico» (STS, Sala $3^{\text {a }}$, de 5 de junio de 1998).

170 Pueden verse en este sentido, entre otras: SSTS de 18 de diciembre de 2009 y 22 de junio de 2012. 


\section{LA RELACIÓN DE CAUSALIDAD}

Resulta necesario que exista un nexo de causalidad que ligue la actuación administrativa con el daño o perjuicio producido.

Esa relación ha de ser directa, inmediata y exclusiva.

Directa, en cuanto a que la Administración ha debido obrar por sí misma, sin intermediación. Ha de señalarse, no obstante, que esta cualidad del nexo causal es un tanto laxa cuando se consideran los casos en que se produce el daño por la conducta de un agente de la Administración Pública ${ }^{171}$.

Inmediata supone ser una actuación presente, no alejada del tiempo en que se produce el hecho generador del daño.

Por exclusividad se entiende que no haya injerencia extraña, lo que precisa de algunas matizaciones:

- La participación de la propia víctima a título de culpa exonera de responsabilidad a la Administración.

- La interferencia en el hecho de un tercero puede llegar a exonerar también a la Administración, pero sólo cuando la conducta de ese tercero sea la única determinante de la lesión. Por otro lado, esa intervención da entrada a una valoración de concurrencia de responsabilidades, en orden al reparto de las cuantías indemnizatorias.

\section{LA REPARACIÓN DE LA LESIÓN RESARCIBLE}

La lesión patrimonial, una vez reconocida como tal, provoca la indemnización correspondiente. La LRJSP, en su artículo 34.4, permite dos formas de indemnizar: en metálico y en especie. Pero el mecanismo preferente será el abono de una sola vez de la cantidad devengada, puesto que el resto de las formas previstas precisan de acuerdo expreso con el interesado.

El artículo 34 LRJSP prevé una serie de reglas de valoración del daño o perjuicio producido:

- Se utilizarán las reglas de valoración propias de la legislación de expropiación forzosa, fiscal y demás de pertinente aplicación, con la ponderación de las valoraciones predominantes en el mercado, en su caso. En supuestos de muerte o lesiones corporales,

\footnotetext{
171 Aunque el TS ha desarrollado una corriente jurisprudencial restrictiva en este aspecto, indicando que la responsabilidad de la Administración Pública no puede ser tan amplia que incluya los daños derivados de actos personales y no relacionados con el servicio de sus empleados.
} 
podrá tomarse como referencia la valoración de los baremos de la normativa vigente en materia de seguros obligatorios y Seguridad Social.

- El cálculo de la cuantía de la indemnización se realizará en referencia al día en que se produjo la lesión. Esta cuantía se actualizará a la fecha de finalización del procedimiento de responsabilidad, con arreglo al Índice de Garantía de la Competitividad fijado por el INE y a los intereses de demora que procedan.

\section{ACCIÓN DE RESARCIMIENTO CONTRA LA ADMINISTRACIÓN PÚBLICA}

Las acciones de reclamación en vía administrativa referentes a responsabilidad patrimonial se seguirán conforme al procedimiento administrativo común regido por la LPAC, con algunos artículos específicamente referidos a la responsabilidad patrimonial (art. 67 en solicitudes o art. 81 en materia de requerimiento de informes y dictámenes, arts. 91 y 92 respecto a resolución de este tipo de procedimientos).

Para el ejercicio de la acción de resarcimiento, se podrá interponer reclamación en vía administrativa en el plazo de un año desde la producción del hecho causante. Este plazo es de prescripción, no de caducidad (por lo que resulta susceptible de interrupción, de acuerdo con el artículo 1973 CC). Por otro lado, resulta importante establecer el «dies a quo» para su cómputo:

- Regla general: desde el día en que se produjo el hecho (como hemos dicho).

- Excepciones:

o Cuando se han producido daños personales, de tipo físico o psíquico: comenzaría a iniciarse la prescripción desde la curación del perjudicado o la determinación del alcance de las secuelas sufridas (art. 67.1 LPAC).

o Responsabilidad por actos o disposiciones administrativas que hayan sido anulados: desde la fecha en que se dictó la sentencia definitiva o del acto administrativo que acordara la anulación.

o En casos de responsabilidad del Estado Legislador: desde la publicación de la sentencia que declare la inconstitucionalidad de la norma o su contradicción con el Derecho de la UE en el BOE o en el DOUE (en su caso).

A modo de resumen en cuanto a requisitos de apreciación de concurrencia de responsabilidad patrimonial de la Administración, utilizamos el que elabora la STS de 10 de abril de 2008 (Ponente: Margarita Robles Fernández): 
a) La efectiva realidad del daño o perjuicio, evaluable económicamente e individualizado en relación a una persona o grupo de personas.

b) Que el daño o lesión patrimonial sufridos por el reclamante sean consecuencia del funcionamiento normal o anormal -es indiferente la calificación- de los servicios públicos en una relación directa e inmediata y exclusiva de causa a efecto, sin intervención de elementos extraños que pudieran influir, alterando el nexo causal.

c) Ausencia de fuerza mayor.

d) Que el reclamante no tenga el deber jurídico de soportar el daño cabalmente causado por su propia conducta.

A estos requisitos, cabe añadir las siguientes puntualizaciones ${ }^{172}$ :

- «La Jurisprudencia ha homologado como servicio público ${ }^{173}$ toda actuación, gestión, actividad o tareas propias de la función administrativa que se ejerce, incluso por omisión o pasividad con resultado lesivo».

- «La responsabilidad es objetiva o de resultado, de manera que lo relevante no es el proceder antijurídico de la Administración, sino la antijuricidad del resultado o lesión».

- «Es imprescindible que exista nexo causal entre el funcionamiento normal o anormal del servicio público y el resultado lesivo o dañoso producido». «La apreciación del nexo causal es una cuestión revisable en casación, si bien tal apreciación ha de basarse siempre en los hechos declarados probados por la Sala de instancia».

- «El daño causado ha de ser efectivo, evaluable económicamente e individualizado, siendo sólo indemnizables las lesiones producidas provinientes (sic) de daños que no haya el deber jurídico de soportar de acuerdo con la ley» ${ }^{174}$.

\footnotetext{
172 STS de 10 de abril de 2008.

${ }^{173}$ SSTS de 5 de junio de 1989 y 22 de marzo de 1995.

174 Cita las SSTS de 22 de abril de 1994, que cita las de 19 de enero y 7 de junio de 1988, 29 de mayo de 1989, 8 de febrero de 1991 y 2 de noviembre de 1993, según la cual: «esa responsabilidad patrimonial de la Administración se funda en el criterio objetivo de la lesión, entendida como daño o perjuicio antijurídico que quien lo sufre no tiene el deber jurídico de soportar, pues si existe ese deber jurídico decae la obligación de la Administración de indemnizar» (en el mismo sentido sentencias de 31 de octubre de 2000 y 30 de octubre de 2003).
} 


\section{RESPONSABILIDAD PATRIMONIAL DE LA ADMINISTRACIÓN PÚBLICA EN LAS AGRESIONES A SUS EMPLEADOS}

En el caso de los profesionales sanitarios del Sector Público, la reclamación de responsabilidad patrimonial de la Administración Pública ha de entenderse como una de las vías posibles.

Además de los requisitos y reglas anteriormente detalladas, debemos realizar algunas consideraciones respecto a los casos en que este tipo de reclamaciones se formulen respecto a daños personales sufridos por el personal al servicio de la Administración, en este caso sanitaria.

En primer lugar, los empleados públicos han de ser resarcidos de los daños sufridos en el desempeño de su actividad, en virtud del llamado principio de indemnidad (que ha sido afirmado reiteradamente por el Consejo de Estado).

En virtud de este principio, los servidores públicos deben quedar indemnes en el ejercicio de sus funciones. Ello viene sustentado por la Ley 30/1984, de 2 de agosto, de Medidas para la Reforma de la Función Pública y por el EBEP ${ }^{175}$. Al amparo del principio de indemnidad, el desempeño de las funciones propias del puesto de trabajo no puede generar para el empleado público ningún perjuicio patrimonial, que no tenga el deber de soportar, si no ha mediado culpa o negligencia por su parte.

Ha de distinguirse en este punto el supuesto en que se produce un funcionamiento normal o anormal de la Administración pues, aunque la normativa establece que ambos se encuentran cubiertos por la responsabilidad patrimonial, esto no resulta indiferente en ciertos casos como, sin ir más lejos, cuando un empleado público sufre lesiones en el desempeño de su actividad.

Tal distinción entra en conexión con el deber legal de soportar el perjuicio. En el primer caso (funcionamiento normal del servicio), según establece la jurisprudencia, «en el caso de funcionamiento normal, el servidor público ha asumido voluntariamente un riesgo que, de acuerdo con la ley, tiene el deber jurídico de soportar, por lo que el daño no sería antijurídico y la Administración no vendría obligada a indemnizarle por el concepto de responsabilidad patrimonial sino con las prestaciones previstas expresamente en el ordenamiento jurídico aplicable a su relación estatutaria, siendo éste el criterio mantenido también en la Sentencia de esta Sala de 10 de abril de 2000» ${ }^{176}$.

$\mathrm{Si}$, por el contrario, ha existido un funcionamiento anormal, la situación es muy distinta: «Por el contrario, y en el caso de funcionamiento anormal del servicio público, se debe discernir si la

\footnotetext{
175 Ley 7/2007, de 12 de abril, del Estatuto Básico del Empleado Público.

${ }^{176}$ STS de 1 de febrero de 2003, reproducida por la de 6 de julio de 2005.
} 
deficiencia o anormalidad es consecuencia exclusivamente de la propia actuación del servidor o funcionario público, en cuyo caso su misma conducta sería la única causante del daño o perjuicio sufrido, con lo que faltaría el requisito del nexo causal, requerido por el apartado 1 del artículo 139 de la mencionada Ley de Régimen Jurídico de las Administraciones Públicas y del Procedimiento Administrativo Común para que nazca la responsabilidad patrimonial de la Administración, o si la deficiencia o anormalidad del servicio obedece a otros agentes con o sin la concurrencia de la conducta del propio perjudicado. Como añadíamos en aquella sentencia, en el caso de que ninguna participación hubiese tenido el funcionario o servidor público perjudicado en el resultado producido, debe ser cabalmente resarcido e indemnizado por la Administración Pública de todos los daños y perjuicios que se le hubiesen irrogado hasta alcanzar su plena indemnidad, pero en el supuesto de que hubiese cooperado en el funcionamiento anormal del servicio, la indemnización en su favor habrá de moderase en atención a su grado de participación». (STS de 24 de enero de 2006) ${ }^{177}$.

Debe señalarse que, cuando exista otra regulación específica que cubra los daños y perjuicios causados (vía indemnizaciones por razón del servicio, por ejemplo), será ésta la que tendrá que remediar la lesión ${ }^{178}$. En caso contrario, deberá ser el instituto de la responsabilidad patrimonial de la Administración el cauce por el que se haga efectivo el resarcimiento correspondiente. Es decir, únicamente en ausencia de otros medios reparadores, entrará en juego la responsabilidad patrimonial de la Administración Pública ${ }^{179}$.

Sobre esta última afirmación es necesario realizar una puntualización importante. Cabe la posibilidad de que el perjudicado haya obtenido algún tipo de reparación por otros medios. Pero el principio de indemnidad exige que ésta sea completa ${ }^{180}$, por lo que el resarcimiento ha de ser íntegro, debiendo suplirse mediante indemnización proveniente de la responsabilidad patrimonial administrativa lo que reste hasta alcanzar esa completa reparación ${ }^{181}$.

\footnotetext{
$177 \mathrm{Ha}$ de hacerse notar que esta sentencia se refiere a un supuesto en el que el perjudicado es un miembro de las Fuerzas Armadas, cuyo régimen en este sentido es harto más estricto, reconociéndose sin embargo su derecho a ser indemnizado por un daño injusto en el ejercicio de su actividad, debido al funcionamiento anormal del servicio público. Lo que nos lleva a subrayar que, si a estos profesionales, sometidos a restricciones más severas en esta materia, les es reconocido tal derecho (siempre que confluyan los requisitos pertinentes), nada obsta a que también puedan optar a tales beneficios el resto de los empleados públicos.

178 Dictamen del Consejo de Estado 337/2005, de 11 de mayo: "Según doctrina reiterada de este Consejo, las indemnizaciones solicitadas en el seno de específicas relaciones -como es la funcionarial- se definen y sustancian en el seno de esa relación y según su régimen propio, de manera que la indemnización pretendida no cae bajo el imperio de las normas generales sobre responsabilidad extracontractual de la Administración».

179 Dictamen del Consejo de Estado 945/1999, de 27 de mayo de 1999: «en el caso de funcionarios o personas unidas a la Administración por una especial relación, de sujeción, no puede prosperar una reclamación de responsabilidad, cuando resulta que el interesado ha sido ya indemnizado por tal concepto y título de acuerdo con el régimen especial previsto para los funcionarios o para aquella concreta relación jurídica».

${ }^{180}$ En la jurisprudencia se habla de «plena indemnidad o reparación integral de los daños y perjuicios causados» (STS de 12 de noviembre de 2007).

181 Dictamen del Consejo de Estado 3832/2000, de 1 de diciembre.
} 
Sin embargo, ha de tenerse en cuenta que la duplicidad de indemnizaciones no debe nunca conducir a un enriquecimiento injusto.

Cabe la concurrencia de responsabilidades, e incluso la responsabilidad subsidiaria. En su Dictamen 900/2011, de 28 de julio, el Consejo Consultivo de Castilla y León dirime el caso de una agresión producida contra un vigilante de seguridad por parte de un paciente ingresado en la planta de Psiquiatría de un hospital. El ataque se produjo en el entorno siguiente: «En el supuesto dictaminado se describía una situación tensa entre el personal sanitario de planta y el enfermo que, altamente alterado e infiriendo insultos y amenazas, no respondía de forma positiva ante las indicaciones del personal sanitario que le conminaba a volver a su habitación. Así mismo también hacía caso omiso a las indicaciones del reclamante que, una vez desprovista de munición el arma reglamentaria, entró en la zona de control». Las lesiones al vigilante se produjeron durante las maniobras de contención que ejerció sobre el paciente. El Consejo Consultivo señala que «el reclamante actuó conforme al protocolo establecido» y resuelve declarar la existencia de responsabilidad de la Administración sanitaria (sin perjuicio de la posibilidad de repetir contra la empresa de seguridad, a la que estaba unida por relación laboral la víctima) ${ }^{182}$.

En cuanto a la decisiva concurrencia del nexo causal, debe manifestarse lo siguiente:

1) El nexo causal ha de ser siempre establecido, como hemos visto. La culpa o negligencia del empleado perjudicado elimina esta conexión.

2) También desaparece el nexo causal en los casos en que la actuación del perjudicado se haya producido al margen de su condición de empleado público ${ }^{183}$.

3) En los casos de agresiones a profesionales sanitarios, según los supuestos a los que hemos tenido acceso, la prueba de existencia del nexo causal se dirime en el campo de la prevención de riesgos laborales. Como comentamos en un capítulo anterior, los efectos de la responsabilidad de la Administración en este aspecto devienen similares, aunque no idénticos, a los que ostenta el empresario particular (según la LPRL). En la normativa, ambas responsabilidades son exactamente las mismas pero los criterios de exigibilidad no son miméticos.

Pues bien, tal falta de identidad en cuanto a los efectos prácticos de la responsabilidad del empresario y de la Administración (respecto a su exigibilidad en la práctica), encuentra una cierta

\footnotetext{
182 Queda aclarado que en los pliegos de prescripciones técnicas estaba establecida la responsabilidad de la empresa por las incidencias que pudieran surgir al personal a su servicio.

183 Por ejemplo, Dictamen 271/2004, de 3 de junio, del Consejo Consultivo de Castilla y León: un inspector de educación fue agredido por un profesor de un centro educativo (ambos tenían la condición de funcionarios públicos). Se resuelve que los hechos no ocurrieron «durante el ejercicio de la función educativa, ni tampoco se produjeron en el centro educativo".
} 
compensación en materia de responsabilidad patrimonial por la vía de la configuración del nexo causal lesión-responsabilidad en el caso de daños personales contra los servidores públicos.

El núcleo de la apreciación del nexo causal se centra específicamente en concretar si la Administración fue o no suficientemente diligente en la debida protección a su trabajador. La forma de comprobar este extremo es dirigirse al efectivo cumplimiento de la LPRL y los planes de prevención debidamente implantados.

En STSJ 232/2014 de la Comunidad Valenciana (Sala de lo Contencioso-Administrativo), de 7 de abril, es sometido a juicio el caso de un profesional sanitario que trabaja en el Servicio de Anatomía Patológica de un hospital que resulta lesionado por la movilización de un cadáver. La sentencia estima la pretensión del recurrente, estableciendo la existencia de un nexo causal derivado de la preceptiva inexistencia de evaluación de riesgos laborales, por la que no se detectó la ausencia de medios mecánicos que minoraran el riesgo (grúas u otros elementos que ayudaran en el manejo del cadáver). La sentencia recurre para fundamentarse al artículo 16.2 LPRL, que obliga a la Administración a efectuar una evaluación general de los riesgos (que no se estimó realizada) y a los artículos 18 y 19 de la antedicha ley (información y formación de los empleados).

En el Dictamen del Consejo Consultivo de Castilla y León 988/2006, de 2 de agosto, se traen a colación los daños sufridos por una ATS de un centro sanitario público, que resultó lesionada por caerle encima la caja de una persiana mal colocada. Aunque la interesada no tenía condición de funcionaria, existía un vínculo concreto y jurídico con la Junta de Castilla y León en virtud de un contrato eventual que la ligaba a esta Administración. En su dictamen, el Consejo Consultivo afirma que el daño sufrido por un empleado público ha de ser indemnizado (salvo culpa o negligencia del interesado), en virtud del principio de indemnidad ${ }^{184}$. A continuación, declara que se trata de un riesgo conectado a la prestación del servicio. Y, en cuanto al nexo causal, que los hechos contravienen los derechos de los trabajadores (conforme a lo establecido en el art. 14 LPRL, 15 del mismo texto legal: principios de acción preventiva y también el 16, relativo a evaluación de riesgos).

Continúa con una extensa argumentación justificativa ${ }^{185}$ del papel de la normativa de Prevención de Riesgos Laborales en la evaluación sobre la existencia o no de nexo causal y, por tanto, de efectiva responsabilidad patrimonial de la Administración Pública.

\footnotetext{
${ }^{184}$ Este Consejo Consultivo manifiesta que sigue criterios reiterados y firmes del Consejo de Estado.

185 Esta argumentación se sustenta en los enunciados de la STS de 8 de octubre de 2001.
} 
Concretamente, afirma que del juego de tres preceptos (art. 14.2, 15.4 y 17.1 LPRL) se constata lo incondicionado y prácticamente ilimitado del deber de protección del empresario. Por ello, concluye, la Administración se convierte en la única responsable de los daños sufridos por la accidentada.

Ha de concluirse, por tanto, el papel fundamental que ostenta la diligencia debida de la Administración en cuanto a la protección a sus empleados (al amparo de lo dispuesto en la LPRL) en la determinación de la existencia o no del nexo causal, fundamental para estimar la confluencia de responsabilidad patrimonial de la Administración.

En el Dictamen 19/2014, de 6 de febrero, del Consejo Consultivo del Principado de Asturias, se examina la agresión sufrida por una auxiliar de enfermería a manos de una paciente ingresada en una planta de hospitalización de Psiquiatría. La reclamante expresa que se trató de un funcionamiento anormal del servicio por carencia de las preceptivas medidas de seguridad (un sistema de aviso a seguridad poco eficiente) y por escasez de personal.

El Consejo Consultivo dictamina que la reclamación debe ser desestimada, con base en los siguientes argumentos:

- No resultar probado que «un sistema más perfeccionado de aviso al servicio de seguridad o una mayor dotación de personal hubiera evitado el suceso».

- No quedar acreditado un anormal funcionamiento del servicio público y, por ello, «no cabe establecer una relación de causalidad entre este y el daño que aquí se reclama, que se debió al riesgo de agresión por parte de una paciente ingresada en una unidad de hospitalización de agudos en la que desempeñaba sus funciones la reclamante; riesgo que es inherente a las características de estas unidades y por ello mismo inevitable».

El Dictamen 240/16 del Consejo Consultivo de la Región de Murcia, de 5 de septiembre, informa sobre un caso de agresión producida a una profesora por parte de un alumno. Constata el Dictamen la producción de un daño antijurídico, por resultar de la agresión un daño que la profesora no tenía el deber jurídico de soportar. No se produjo culpa o negligencia por parte de la empleada pública, aunque a los docentes se les exige una diligencia estricta (adopción de medidas idóneas para evitar el daño) por lo que no se rompe el nexo causal. Se considera asimismo que la agresión tuvo lugar con ocasión del servicio, al ocurrir en un periodo de recreo, que forma parte 
de la actividad lectiva o formativa por desarrollarse dentro del horario escolar y en el centro educativo $^{186}$.

Entiende que se trató de un daño producido «como consecuencia» del servicio público porque el autor no podía ser considerado un tercero ajeno al centro, ya que los alumnos «se integran en la organización administrativa mientras el servicio esté en funcionamiento y se ejercite sobre ellos las facultades de vigilancia a las que se refiere el artículo 1903 del Código Civil».

Por último, el Dictamen señala que el hecho de que el alumno agresor estuviera afectado por un trastorno grave de desarrollo, unido a los antecedentes violentos del mismo (había agredido anteriormente a tres miembros del personal del centro y provocado catorce actos violentos en los dos últimos años, según informó el SPRL), quizás impida (como afirma el Director del colegio) que se puedan prever sus reacciones, pero no significa que no se tenga conocimiento de que puede ser agresivo y violento.

Como colofón a este apartado, cabe examinar un caso concreto en que fue reconocida la responsabilidad patrimonial de la Administración en cuanto a la agresión que sufrió una auxiliar de enfermería por parte de un paciente.

Se trata del Dictamen 906/2009, de 1 de octubre, del Consejo Consultivo de Castilla y León. La reclamación de la interesada exponía que, durante el desempeño de sus funciones, recibió una bofetada (que provocó la rotura de sus gafas) cuando intentaba contener a un paciente agresivo que golpeaba al personal y a otros pacientes.

El Consejo Consultivo declara que hubo daño cierto y comprobado, recibido por la interesada sin culpa ni negligencia propia. En concreto afirma que en el caso analizado quedó acreditado que el daño sufrido por la reclamante «fue a consecuencia de la realización de su actividad laboral, sin que tenga el deber jurídico de soportarlo». Una vez reconocida la existencia del nexo causal, dicho organismo dictamina de manera favorable la reclamación, en aplicación del principio de indemnidad.

\footnotetext{
${ }^{186}$ Se cita la propia producción del Consejo Consultivo en esta materia: «Así, se dictaminó favorablemente la estimación de la responsabilidad patrimonial respecto de los daños alegados por un docente con motivo del lanzamiento de un balón por parte de un alumno, cuando el profesor desempeñaba sus labores de vigilancia en el recreo (Dictamen núm. 247/2002), en un supuesto de daños sufridos por una profesora cuando recibió un puñetazo en la cara al tratar de separar a dos alumnos que discutían (Dictamen núm. 58/2007), o cuando la docente sufrió la agresión física de un alumno (Dictamen núm. 188/2002)».
} 


\section{LOS PROCEDIMIENTOS SEGUIDOS EN EL CASO DEL ASESINATO DE MORATALLA (MURCIA).}

Todos los años se celebra en marzo el Día contra las agresiones al personal sanitario. La fecha fue fijada como homenaje a la Dra. $\mathrm{M}^{\mathrm{a}}$ Eugenia Moreno, que murió como consecuencia del ataque de un paciente, que le disparó con un arma de fuego cuando se encontraba de guardia en el centro de salud donde trabajaba (Moratalla). Tan lamentable suceso tuvo lugar el 11 de marzo de 2009.

A continuación, reproducimos el relato fáctico incluido en el Dictamen 87/14 del Consejo Jurídico de la Región de Murcia:

«El día 11 de marzo de 2009, sobre las 0.20 horas se personó en el Centro de Salud de Moratalla $\mathrm{x}$, portando un revólver que carecía de marca, modelo y número de serie, encontrándose con la celadora $\mathrm{x}$, quien se encontraba en la puerta de entrada al referido centro de salud, preguntándole qué le ocurría, contestándole el imputado que se encontraba fatigado. Ante esta circunstancia, x procedió a llamar a la doctora que se encontraba de guardia, $\mathrm{x}$, pidiéndole ésta que avisara al enfermero para ponerle al imputado una nebulización, avisando x al enfermero, escuchando en ese momento cuatro disparos que impactaron en el cuerpo de la fallecida doctora, pudiendo ver x como salía de la consulta médica el ambulanciero, $\mathrm{x}$, quien también resultó herido».

Personados tres agentes de la policía local de Moratalla, uno de ellos (que entró primero) pudo ver al imputado portando un revólver con las dos manos en la entrada principal del centro de salud. Requerido por el agente, soltó el arma, dejándola caer al suelo y siendo reducido a continuación.

La médico agredida, como consecuencia de los disparos y a pesar de los esfuerzos terapéuticos realizados, falleció sobre las 15:15 horas del día 11 de marzo de 2009.

El SMS realizó las siguientes actuaciones: comunicación urgente de accidente de trabajo con grado de lesión de fallecimiento, registro informático de agresiones, notificación a la abogada de la compañía con la que estaba suscrita la póliza de agresiones, para su personación; personación como parte acusadora del SMS, con nombramiento de letrado perteneciente a los Servicios Jurídicos de la Comunidad Autónoma y concesión de las indemnizaciones y ayudas por el fallecimiento de la empleada pública. 
Por parte de la titular del Juzgado de Instrucción $\mathrm{n}^{\circ} 1$ de Caravaca de la Cruz fueron incoadas Diligencias Previas núm. 447/2009 (auto de 11 de marzo de 2009), en virtud del Atestado instruido por el equipo de la Policía Judicial de la Guardia Civil del puesto de Caravaca de la Cruz, por dos delitos de asesinato, uno de ellos en grado de tentativa y otro de ellos consumado, por otro presunto delito de tenencia ilícita de armas y por un delito de amenazas. La víctima del delito de asesinato desarrollaba su trabajo como residente del último año (MIR) en el Centro de Salud de Moratalla.

Se dicta Providencia el 27 de octubre de 2009, teniendo por personado y parte al Letrado de la Comunidad Autónoma de la Región de Murcia, en nombre y representación del Servicio Murciano de Salud. El 16 de diciembre del mismo año se acuerda proceder a la tramitación de la causa conforme al Procedimiento Sumario Ordinario. La Audiencia Provincial (Procedimiento Ordinario 67/2010) dicta Auto el 22 de febrero de 2010, confirmando el de conclusión del sumario dictado por el instructor y acordando abrir juicio oral contra el procesado.

El procesado murió en el Hospital Virgen de la Arrixaca de Murcia en abril de 2011, declarándose extinguida por Auto de 4 de mayo la acción penal por fallecimiento del acusado. El mismo Auto indicó la subsistencia de la acción civil, ejercitable contra los herederos y causahabientes ante la jurisdicción civil. La causa se archiva por Diligencia de Ordenación de 16 de mayo de 2011.

\section{LA RECLAMACIÓN EN VÍA ADMINISTRATIVA}

Los herederos de la doctora fallecida interponen reclamación de responsabilidad patrimonial de la Administración contra el Servicio Murciano de Salud. Por delegación de la Consejera de Sanidad y Política Social, el Director Gerente del SMS, realiza una petición de consulta ${ }^{187}$ al Consejo Jurídico de la Región de Murcia, que emite y aprueba su Dictamen 87/2014 el 31 de marzo.

Los fundamentos en que se apoya la reclamación de los herederos son los siguientes:

- La víctima no estaba obligada a sacrificarse ni a arrostrar los daños irreparables que su fallecimiento irrogó a los reclamantes, dado que la agresión sufrida no forma parte de los riesgos inherentes al ejercicio de su profesión.

- Por esta razón, y porque no tuvo intervención en el actuar administrativo, la agresión fue antijurídica $^{188}$.

\footnotetext{
187 Como prescribe el artículo 81 LPAC.

${ }^{188}$ Se cita como soporte de la reclamación, entre otras, SSTS (Sala 3a) de 1 de febrero de 2003, de 23 de abril y de 3 de noviembre de 2008.
} 
- En el supuesto de funcionamiento normal del servicio público, el trabajador asume un riesgo que tiene el deber jurídico de soportar conforme a la Ley (y la Administración sólo vendría obligada a indemnizarle a través de las prestaciones aplicables a la relación estatutaria). Pero en caso de funcionamiento anormal, ha de discernirse si esa anormalidad es imputable a la actuación del funcionario público o si se produce por la actuación de otros agentes (con participación o no del perjudicado). De no mediar participación alguna, la Administración deberá repararle hasta su plena indemnidad.

- La Administración Pública «es conocedora de las cargas de agresividad existentes en las relaciones entre ciudadanos y profesionales en el ámbito de la prestación sanitaria, debiendo desarrollar actuaciones tendentes a analizar, evitar y paliar dichos perjuicios».

El montante del petitum (una vez calculado el quebranto económico que supuso el fallecimiento de la víctima para la unidad familiar) se estima en: lucro cesante 1.264.471,71 euros y daño moral para el cónyuge, hijo y madre 60.000 euros por cada uno de ellos (180.000 euros en total). Por ambos conceptos, la cantidad final reclamada asciende a 1.444.471,71 euros, más los intereses de demora que procedan ${ }^{189}$.

La parte reclamante solicita, como medio de prueba, la documentación relacionada en el artículo 23 de la LPRL relativa al Centro de Salud de Moratalla, correspondiente a los años 2008, 2009, 2010. Asimismo se pide informe referente al cumplimiento de las medidas de prevención de riesgos en dicho centro (tanto estatales como autonómicas). El Servicio de Prevención de Riesgos emite el informe, pero manifestando que la citada documentación solicitada (la relacionada en el artículo 23 LPRL) no debe facilitarse a los particulares, estando a disposición únicamente de la autoridad laboral o sanitaria ${ }^{190}$.

El informe del SPRL contiene los siguientes puntos relevantes:

1) El SMS elaboró un PPRL en noviembre de 2007, que configura los principios, organización y líneas de actuación principales de la PRL, constituyendo el elemento marco de las acciones a desarrollar por procedimientos e instrucciones.

\footnotetext{
${ }^{189}$ Como sabemos, resulta imprescindible precisar el importe de los daños reclamados, ya que estos han de ser concretos y evaluables.

190 Esto no es exacto pues, aunque el apartado 4 del artículo 23 LPRL establece que: «La documentación a que se hace referencia en el presente artículo deberá también ser puesta a disposición de las autoridades sanitarias al objeto de que éstas puedan cumplir con lo dispuesto en el artículo 10 de la presente Ley y en el artículo 21 de la Ley 14/1986, de 25 de abril, General de Sanidad», esto no significa que sólo las autoridades sanitarias puedan tener acceso a esta información. Sin ir más lejos, los delegados de prevención tienen derecho a recibir información, al amparo del artículo 18 del mismo texto legal.
} 
2) Anteriormente, en 2005, se había elaborado el Plan de Prevención de Agresiones a los profesionales de la Sanidad de la Región de Murcia, que incluía medidas de prevención, formación, apoyo psicológico y asesoramiento jurídico.

3) En marzo de 2007 se elaboró un Protocolo Marco de Actuación específico para los centros de Atención Primaria. Este protocolo es un modelo para la elaboración de cada centro de su propio protocolo interno de actuación ante situaciones violentas.

4) Se enumeran las acciones más importantes puestas en marcha por el Plan de Agresiones: implantación de un sistema informático de registro inmediato de agresiones, asistencia médica y apoyo psicológico al agredido, e igualmente asesoramiento jurídico; desarrollo de un plan de formación en la gestión de situaciones de hostilidad, a base de cursos on line complementados por talleres presenciales; establecimiento de cauces de comunicación con las fuerzas de seguridad de cada Ayuntamiento para la asistencia en caso de agresión y, por último, creación de una comisión de seguimiento.

5) En septiembre de 2005 se realizó la evaluación de riesgos del Centro de Salud de Moratalla por parte del SPRL. Se solicitó a la Gerencia de Área de Salud IV la planificación de la actividad preventiva de ese centro. Cuando se produjeron los hechos, se disponía de botón de alarma en las consultas.

6) El total de agresiones en el Centro de Salud de Moratalla desde enero de 2006 (fecha en que se puso en funcionamiento el sistema de registro de agresiones) hasta 2011 fue de nueve. Dos fueron físicas y siete verbales. En ese mismo periodo, el centro de salud que más agresiones sufrió, contabilizó un total de treinta y nueve.

7) El SPRL realiza también un relato fáctico de lo acaecido, que se reproduce a continuación:

«Los hechos ocurridos según el informe de investigación fueron los siguientes: en la madrugada del miércoles 11 de marzo de 2009, sobre las 00,15 horas, un usuario solicitó asistencia médica en urgencias del Centro de Salud de Moratalla. Cuando estaba siendo atendido en su consulta por la Dra. $\mathrm{x}$ se oyeron disparos. Cuando los compañeros acuden ante la alarma, encuentran a la doctora herida. El usuario dispara también al conductor de la ambulancia e intenta disparar al enfermero. El agresor que disparó no había manifestado previamente conducta agresiva en el Centro, por lo que no se pudo tomar precauciones como hubiera sido atender al agresor en compañía de otro compañero o llamar a la policía. Tampoco hubiese evitado el accidente la presencia de un guardia de seguridad. Asimismo la existencia de pulsadores de alarma tampoco ayudó a la protección de la Dra. $\mathrm{X} »$. 
8) El informe concluye refiriendo que el accidente sufrido por la víctima «por sus características, no pudo ser previsto, por lo que las medidas de protección existentes no resultaron suficientes para evitarlo, ni lo habrían sido otras que se hubieran implantado».

Junto a su informe, el SPRL aporta la planificación de actividades en el Centro de Salud de Moratalla, que se adoptaron en fecha posterior a la concurrencia del suceso.

El órgano instructor informa a los reclamantes (mediante oficio de 18 de julio de 2012) de la admisión parcial de los medios de prueba, rechazando los siguientes: documentación relacionada en el artículo 23 LPRL y certificación sobre los procedimientos penales en los que el SMS se hubiese personado durante los años 2007 a 2012 (por considerarlo irrelevante en relación con los hechos). La admisión parcial de la prueba es recurrida por parte del letrado que representa a los reclamantes, por medio de escrito (17 de septiembre de 2012) en que se alega que la misma carece de motivación, causando una grave indefensión a sus representados. El mismo letrado presenta un nuevo escrito, con fecha 26 de septiembre, en el que dice «que la aportación de las actuaciones penales no fue propuesta por sus representados, y que tanto el Servicio Murciano de Salud, como la Compañía Aseguradora, se personaron en las actuaciones, siendo de su exclusiva competencia remover los obstáculos para su obtención».

El órgano instructor solicita el 16 de octubre de 2012 informe a la Inspección Médica. Esta Inspección lo remite el 30 de noviembre. Contiene el siguiente juicio crítico y conclusiones: «La finalidad principal de los informes técnicos sanitarios de la Inspección de Servicios Sanitarios es analizar lo que ha pasado y su relación con el daño reclamado, emitiendo un juicio acerca de si la actuación de los profesionales sanitarios ha sido adecuada o no a "lex artis"». Como en la reclamación no se pide este tipo de pronunciamiento, la inspectora médico declara que únicamente puede valorar lo realizado en el ámbito asistencial, concluyendo que, «...pese a los esfuerzos médicos realizados, no fue posible salvar la vida de la víctima debido a la gravedad de las heridas que presentaba, adecuándose la actuación de los profesionales sanitarios a la normopraxis» ${ }^{191}$.

El letrado que representa a los reclamantes presenta nuevo escrito con fecha 18 de enero de 2013, pidiendo información de las actuaciones realizadas a partir de su último escrito (el del 26 de septiembre de 2012). El órgano instructor informa del traslado del expediente a la Inspección Médica.

${ }^{191}$ Resulta evidente que la petición de este informe a la Inspección Médica fue superfluo e improcedente. 
La Correduría de Seguros da traslado del siniestro a la Compañía Aseguradora (a la que se remite copia del expediente, para su valoración).

La letrada de la Compañía de Seguros aporta copia de los antecedentes judiciales, tras haberse reiterado la petición de la remisión de la copia de las Diligencias Previas 447/09 al Juzgado de Instrucción núm. 1 de Caravaca de la Cruz.

Se otorga trámite de audiencia a las partes interesadas. El letrado que representa a los reclamantes presenta escrito en el que formula alegaciones (15 de abril de 2013):

- Estima que queda acreditado que cuando se produjeron los hechos, la planificación de actividades preventivas no se había ejecutado, porque el informe de investigación del técnico de prevención (16 de abril de 2009) recomendaba: «realizar la planificación de las actividades preventivas de la evaluación de riesgos inicial (2005)».

- Manifiesta que se evidencian «incumplimientos de la normativa aplicable y graves errores de valoración». El PPRL de julio de 2005 del SMS establecía como parte de sus objetivos la realización de la evaluación de riesgos de los puestos de trabajo y la elaboración de una planificación de actividades preventivas, pero «esa segunda parte no fue realizada en aquellos momentos por el responsable del Centro de Moratalla».

- Considera que no se había ejecutado la planificación de la actividad preventiva del centro, exigible desde septiembre de 2005, por parte del responsable de la Gerencia del Área IV y «como quiera que la planificación de la actividad preventiva tiene como propósito eliminar o reducir riesgos detectados, su omisión sólo puede calificarse de gravemente negligente».

- Señala que la denegación del acceso a la documentación relacionada con el artículo 23 LPRL impide a la parte valorar si la evaluación fue correcta o no, puesto que entre la citada documentación se encuentra la evaluación de los riesgos, la planificación de la acción preventiva y las medidas de protección a adoptar.

- Afirma que, si lo que se discute es la previsibilidad o no de la conducta del agresor:

o Hay que subrayar que la Administración Pública es perfectamente consciente de que en la prestación de servicios sanitarios, las relaciones están sujetas a «posibles cargas de agresividad». «Por ello, existiendo este conocimiento notorio, no se puede mantener la imprevisibilidad de la conducta agresiva hacia el personal sanitario».

o Defiende que, de las declaraciones incluidas en las diligencias penales, se evidenciaba el carácter irascible del autor de los disparos, demostrado en los hechos previos al ataque. Se alega igualmente que ese carácter irascible no fue 
suficientemente valorado por el personal "posiblemente por su falta de preparación" ${ }^{\prime 192}$.

o Ante la manifestación de la Coordinadora de PRL de que la presencia de un guardia de seguridad tampoco hubiera evitado el resultado de la agresión, dice que el criterio por el que se dotaron a otros centros de salud de guardias jurado fue puramente económico (puesto que no se había producido una agresión con arma de fuego tampoco en los que fueron dotados con tal medida de seguridad).

o Por todo lo dicho al respecto, estima que el criterio que debe seguirse no es el de imprevisibilidad, sino el de «la nula obligación del personal médico de soportar las consecuencias de un comportamiento inadecuado de los pacientes. El Servicio Murciano de Salud debía garantizar a la Dra. X el ejercicio profesional en condiciones de seguridad, pues no entraba dentro de sus obligaciones perder la vida, fuera un suceso previsible o imprevisible».

- El escrito de alegaciones termina con la solicitud de la práctica de diligencias:

o Informe de la Gerencia del Área IV de las causas por las que no se elaboró con anterioridad al año 2009 la «Planificación de Actividades Preventivas» de la evaluación de riesgos inicial (2005) del Centro de Salud de Moratalla.

o Relación de cursos de formación y simulacros de autoprotección, de habilidades comunicativas y sociales para prevenir y afrontar agresiones y de preparación y entrenamiento para responder a situaciones conflictivas, realizados en el antedicho centro de salud antes del año 2009 (con aceptación y firma de todo el personal adscrito al citado centro).

o Protocolos de respuesta ante posibles conflictos y de coordinación con las Fuerzas y Cuerpos de Seguridad del Estado antes del 2009 y comunicados al personal del centro.

El órgano instructor recaba entonces del SPRL respuesta a las cuestiones planteadas. Mediante comunicación interior de 29 de abril de 2013 se manifiestan las siguientes afirmaciones principales:

- La emisión del informe de investigación del accidente, en el que se recomienda la adopción de medidas preventivas, no supone que se estuviera incumpliendo la normativa de riesgos laborales.

\footnotetext{
192 «Considera que no se atendieron ninguna de las recomendaciones del Plan de Prevención de las Agresiones a los Profesionales de la Sanidad de la Región de Murcia por la falta de preparación del personal en habilidades comunicativas y sociales para prevenir y afrontar situaciones de hostilidad».
} 
- El SMS dispone de un Plan de Formación en PRL anual, en el que se incluyen cursos sobre prevención de agresiones. Añade: «no se dispone en el Servicio de Prevención de información sobre los cursos concretos que realizó el personal del Centro de Salud de Moratalla».

- El citado centro de salud dispone de un Plan de Autoprotección elaborado en 2006. Dentro de dicho Plan, se impartió formación sobre emergencias y evacuación y un simulacro el 30 de noviembre de $2006^{193}$.

- El Servicio de Prevención informó a la Gerencia del Área IV (competente para la confección de un documento de planificación de actividades preventivas para el Centro de Salud de Moratalla) de la obligación de elaborar el mencionado documento. El Servicio de Prevención ignora las causas por las que no se realizó.

Ante este informe, se requiere de la Gerencia del Área de Salud IV información referida al último punto. Sumariamente, responde esta Gerencia que en 2005 la gestión de los centros de Atención Primaria estaba centralizada en las Gerencias de Atención Primaria, añadiendo que «por dichos Servicios se elabora el Plan de Prevención de Agresiones a los Profesionales de la Sanidad de la Región de Murcia en julio de 2005 y el Plan de Prevención de Riesgos Laborales en noviembre de 2007. En lo concerniente a los Centros de Atención Primaria y en concreto al Centro de Salud de Moratalla, desde Servicios Centrales se evalúan los riesgos». Finaliza refiriéndose al periodo comprendido entre abril de 2007 y marzo de 2009. En ese lapso de tiempo, el Director Médico de la Gerencia era el responsable de la puesta en marcha del Plan de Autoprotección, sobre el cual emitió un informe en octubre de 2008, comunicando que «se está a la espera de conseguir los fondos necesarios para su despliegue, en todos los centros del Área IV».

Continúa su informe el SPRL, explicando las actividades formativas ofertadas para el Área IV, aclarando que tienen carácter voluntario y requieren solicitud previa. En cuanto a los cursos realizados por la víctima, se tiene constancia de que solicitó y cursó en 2008 «Ventilación Mecánica no Invasiva» durante los días 12, 19 y 21 de mayo, en horario de tarde y el día 27 de mayo en horario de mañana y tarde.

Declara a continuación desconocer la existencia de un protocolo formal sobre coordinación con las Fuerzas y Cuerpos de Seguridad del Estado antes del 2009 en el Área IV. Pero, afirma, los profesionales están informados de los recursos disponibles y del procedimiento a seguir ante situaciones conflictivas.

${ }^{193}$ Esta información resulta irrelevante, por cuanto no tiene nada que ver con lo que se ha pedido, que es lo relativo a la formación en prevención de agresiones, no sobre emergencias y evacuación. 
El informe del SPRL concluye insistiendo en la imprevisibilidad e inevitabilidad de los hechos: «Un suceso tan lamentable como el ocurrido en el Centro de Salud de Moratalla nunca se puede prever $\mathrm{y}$, ante hechos de ese tipo, cualquier medida de prevención y protección que se hubiera podido adoptar habría resultado insuficiente».

El órgano instructor pide entonces nuevo informe al SPRL para que aclare la causa por la que no se elaboró la «Planificación de actividades preventivas» de la evaluación inicial de 2005 para el Centro de Salud de Moratalla, antes del año 2009.

El SPRL responde a esta cuestión afirmando que el Servicio de Prevención realizó la evaluación de riesgos en septiembre de 2005 y la remitió a la Gerencia, que debía cumplimentar el modelo de Planificación de actividades preventivas, incluido en el documento de evaluación de riesgos. En aquellos momentos existía una Gerencia de Atención Primaria (que fue sustituida por la Gerencia única del Área de Salud IV en 2007). Era, por tanto, la Gerencia de Atención Primaria la encargada de elaborar la Planificación de actividades preventivas del Centro de Salud de Moratalla.

Se otorga nuevo trámite de audiencia a las partes interesadas, no formulándose alegaciones.

El 16 de julio de 2013 se dicta propuesta de resolución, que indica la procedencia de desestimar la reclamación de responsabilidad patrimonial por dos motivos:

1. Prescripción de la acción para reclamar.

2. Inexistencia de nexo causal entre la actuación del servicio público y el daño producido.

\section{EL DICTAMEN 87/14 DEL CONSEJO JURÍDICO DE LA REGIÓN DE MURCIA}

El 25 de julio de 2013 se recaba el Dictamen preceptivo ${ }^{194}$ del Consejo Jurídico, que realiza una serie de consideraciones previas sobre la legitimación activa que ostentan los reclamantes, que reconoce, aunque finalmente dice que sólo los daños sufridos como consecuencia del funcionamiento del servicio serían reparables dentro del marco de la responsabilidad patrimonial

\footnotetext{
${ }^{194}$ El informe tiene carácter preceptivo en virtud del artículo 12.9 de la Ley 2/1997, de 19 de mayo, del Consejo Jurídico de la Región de Murcia (LCJ), en relación con el 12 del Real Decreto 429/1993, de 26 de marzo, por el que se aprueba el Reglamento de los Procedimientos de las Administraciones Públicas en materia de Responsabilidad Patrimonial (RRP).
} 
de la Administración, y no aquellos padecidos por los funcionarios con ocasión del cumplimiento de sus funciones.

\section{EL PROCEDIMIENTO}

En materia de procedimiento realiza las observaciones siguientes:

- El plazo máximo para resolver ha excedido el máximo previsto (artículo 13.3 RRP).

- La inadmisión por el órgano instructor de la documentación relacionada en el artículo 23

LPRL como medio de prueba, no genera indefensión a los reclamantes, debido a que:

o El SPRL proporciona la información relevante al respecto (mediante el informe de la Coordinadora de 5 de julio de 2012), así como también la proporciona el informe de investigación del accidente de trabajo y los PPRL y protocolos de actuación que se aportan.

o Esa información ha servido de base para la formulación de alegaciones sobre falta de prevención de riesgos laborales y la propuesta de nuevas pruebas referidas a este extremo. En el segundo trámite de audiencia, no se formularon nuevas alegaciones.

- La notificación del accidente de trabajo a la Inspección de Trabajo y Seguridad Social (artículo 23.1 e) LPRL) no obra en el expediente.

En cuanto a la prescripción de la acción de reclamación (que es, como vimos, uno de los motivos por los que se recomienda la desestimación de la reclamación en la propuesta de resolución), el órgano instructor considera el «dies a quo» a efectos de prescripción la fecha del fallecimiento de la médico. Por ello, y dado que la acción de responsabilidad patrimonial se ejercita el 2 de mayo de 2012, la reclamación sería extemporánea por sobrepasarse el plazo anual establecido en la norma. Esta consideración nace de estimar que el procedimiento penal (declarado extinto mediante Auto de 4 de mayo de 2011) no tuvo el efecto de interrumpir la prescripción, puesto que no se ejercitaba acción alguna contra el SMS.

Examinando su propia doctrina, el Consejo Jurídico realiza una extensa reflexión sobre el asunto, de la que reflejamos los puntos principales:

- Al ser un plazo de prescripción y no de caducidad, es susceptible de interrupción. No es necesariamente computable desde la fecha en que se produjo el suceso dañoso, puesto que pueden estar en marcha otras actuaciones destinadas a restablecer la situación alterada. El plazo «habrá de iniciarse cuando la finalización de las mismas permita ejercitar el derecho con pleno conocimiento de los elementos que lo definen» (STS, Sala $3^{\text {a }}$, de 2 de noviembre de 1994). 
- La prescripción de la acción se da «en beneficio de la certidumbre y la seguridad jurídica», por lo que, en virtud del principio «pro actione» ${ }^{195}$ debería imponerse con cierta flexibilidad, en evitación de que se produzcan situaciones de desamparo.

- La prescripción se interrumpe en virtud de cualquier reclamación (Dictamen 21/2008), salvo que sea manifiestamente inidónea o improcedente.

- Las actuaciones penales interrumpen el plazo de prescripción (por todos, Dictamen 46/1998). El Consejo de Estado (Dictamen 983/2002) establece que los efectos interruptivos de las actuaciones penales operan «no sólo cuando la determinación de los hechos sea necesaria sino cuando razonablemente hubiera podido serlo».

Con base en esta argumentación, el Consejo Jurídico declara que puede entenderse interrumpido el plazo de prescripción para el ejercicio de la acción de responsabilidad patrimonial de la Administración «dado que los hechos que pudieran probarse en el mismo eran de indudable relevancia para la propia exigencia de responsabilidad patrimonial frente a la Administración, tales como la actuación de un tercero responsable en la ruptura del nexo causal o en la cuantía de la concreción del daño reclamable frente a la Administración, desconociéndose, no obstante si los ahora reclamantes ejercitaron acciones civiles frente a los causahabientes del acusado fallecido».

Por ello, toma como «dies a quo» el Auto de 4 de mayo de 2011 por el que se declaró extinguida la acción penal por el fallecimiento del acusado. La acción se ejercitó el 2 de mayo de 2012 (es decir, dentro de plazo).

Ha de observarse que el propio órgano instructor no parece tener mucha fe en la declaración de extinción de la acción de responsabilidad patrimonial que realiza, por cuanto, a pesar de declarar tal extremo, entra a valorar el fondo del asunto.

\section{ANÁLISIS DE LOS ELEMENTOS DE LA RESPONSABILIDAD PATRIMONIAL}

El Consejo Jurídico de la Comunidad de Murcia procede a continuación a examinar las alegaciones formuladas por la parte reclamante en cuanto a la concurrencia de estos elementos.

Los reclamantes afirman la inexistencia de deber jurídico de soportar el daño por parte de la víctima, puesto que la agresión no formaba parte de los riesgos inherentes al ejercicio de su profesión. Igualmente, detallan la falta de obligación de sacrificarse ni de asumir los daños que su fallecimiento les ocasionó. Sostienen que en el caso de anormal funcionamiento del servicio público, el empleado público ha de ser resarcido si no ha provocado dicho anormal funcionamiento.

195 Dictámenes 21/2008, 142/2010 y 251/2013. 
Ante la falta de ejecución de la planificación de actividades preventivas en el Centro de Salud de Moratalla, defienden que existió un incumplimiento del PPRL y que la situación de violencia podía haberse evitado, sustentando tal aseveración en que las diligencias penales comprobaron «cómo la conducta maligna y despiadada tuvo un antecedente inmediato, que fue su resistencia a atender las indicaciones del enfermero en la anterior visita, alrededor de las 4,30 horas o 5 horas de la misma tarde (...) En aquel momento evidenció su carácter irascible, que no fue suficientemente valorado por el personal, posiblemente por su falta de preparación. Por ello no puede compartir la afirmación de la Coordinadora de Prevención de Riesgos Laborales, cuando en la página 4 de su informe afirma (...) no habiendo manifestado previamente conducta agresiva en el Centro. Por lo que no se pudieron tomar precauciones". Es decir, existía falta de preparación del personal en habilidades comunicativas y sociales para prevenir y afrontar situaciones de hostilidad (...)».

La propuesta de resolución sostiene, en contrario, que no hubo incumplimiento de la legislación de prevención de riesgos y que las medidas propuestas en el Plan de Agresiones regional son simples mejoras aplicables de forma escalonada. Declara, además, que en el Centro de Salud de Moratalla estaban implantadas las medidas siguientes en el momento de producción de la agresión: 6 pulsadores de alarma (mandos a distancia) en el centro de salud y 3 pulsadores de alarma (mandos a distancia) en la zona de urgencias, todos ellos conectados a la empresa de seguridad. El detalle del funcionamiento de los pulsadores, reflejado en la propuesta de resolución, es que estos dispositivos emiten una señal que llega a la central de la empresa, ésta llama por teléfono al centro para averiguar qué sucede; si el teléfono no responde, comunican con el teléfono móvil de la Subdirectora Médica del Hospital de Caravaca.

Pero resulta obligado señalar que en esa noche los dispositivos no fueron activados.

La propuesta de resolución declara que el hecho fue imposible de prever desde la perspectiva de Prevención de Riesgos Laborales, aseverando que «El agresor disparó a la Médico x, en su consulta con un arma de fuego, no habiendo manifestado previamente conducta agresiva en el centro. Por lo tanto, no se pudieron tomar precauciones, como hubiera sido atender al agresor en compañía de otro sanitario o llamar a la policía. Tampoco hubiese evitado el accidente la presencia de un guardia de seguridad. Así mismo, la existencia de pulsadores de alarma tampoco ayudó a la protección de la víctima».

Debido a que, según pretende, el lamentable hecho estuvo determinado por causas «imprevisibles y ajenas al funcionamiento del servicio público», propone el órgano de instrucción la desestimación de la reclamación interpuesta, justificando esta decisión en la presunta falta de nexo causal. 


\section{EXAMEN DEL NEXO CAUSAL}

El Consejo Jurídico reconoce la condición de lesión antijurídica en la agresión que ocasionó la muerte de la Dra. Moreno.

Pero a continuación pasa a dilucidar si el daño derivó del funcionamiento del servicio público o si el nexo causal resultó roto por la actuación delictiva de un tercero, afirmando que la antijuricidad del daño no es bastante para reconocer la responsabilidad del SMS, siendo necesaria la concurrencia de otros requisitos determinantes (muy especialmente la relación causal entre el funcionamiento del servicio público y la lesión producida).

El Consejo Jurídico afirma que, del relato fáctico contenido en el Auto de 22 de diciembre de 2009 , se infiere que el fallecimiento de la víctima del ataque no tuvo causa en el funcionamiento del servicio público (aunque no se hubiera cumplido el PPRL en el Centro de Salud de Moratalla). La intervención de un tercero ajeno a este funcionamiento en la producción del daño causa, según este Consejo, la ruptura del nexo causal.

Continúa insistiendo en la imprevisibilidad de los hechos, ratificando el informe del SPRL. Resulta significativo que el Dictamen invoque la presencia de pulsadores de alarma y reconozca a la vez que éstos no estaban activados aquella noche, apoyándose después en la rapidez con que al parecer acudió la policía ${ }^{196}$. Este último extremo sirve también, con arreglo al criterio del Consejo Jurídico, para colegir que la existencia de un vigilante de seguridad en el centro de salud tampoco hubiera evitado que se produjera la agresión ${ }^{197}$. Sin embargo, tras el luctuoso suceso, se instalaron una serie de mecanismos de prevención, como botón informático antipánico, mampara acristalada en la administración y presencia de vigilante de seguridad. Cabe preguntarse por qué se implementaron medidas que a priori ya se estaban considerando inútiles para prevenir hechos $\tan$ graves.

En cuanto a la alegación de parte referente a la posible falta de formación del personal y su conexión con el hecho de que nadie detectara el posible comportamiento homicida del atacante, el Dictamen la califica de «meras conjeturas carentes de certeza», remitiéndose a «otras

\footnotetext{
196 «...fue un evento lesivo imposible de prevenir desde este ámbito de la prevención (informe de investigación del citado Servicio, folio 164 reverso), siendo significativo a este respecto que, pese a la presencia de pulsadores de alarma -interconectados con la empresa de seguridad-, no fueron activados en aquel momento, llegando los policías locales de Moratalla en uno o dos minutos al lugar, según sus declaraciones, por encontrarse el Centro de Salud en zona urbana del municipio».

${ }^{197}$ Considera el Dictamen que la inexistencia de vigilante de seguridad no fue un incumplimiento del PPRL, puesto que en su implantación no estaba prevista su presencia en ese concreto centro de salud: "Respecto al vigilante de seguridad que se contrató posteriormente, el Plan de Prevención de las Agresiones de los Profesionales de la Sanidad de la Región de Murcia no incluía a este Centro de Salud entre los de conflictividad elevada (Anexo I) para disponer de vigilantes, por lo que en este concreto aspecto no se puede dar por probado el incumplimiento de esta particular medida de prevención a la vista del referido Plan».
} 
declaraciones testificales» que apoyan la imposibilidad de predecir este comportamiento. A continuación, se reproducen tres testificales para ilustrar esta afirmación:

- La primera, un médico del centro de salud que prestaba sus servicios en la noche de autos: «(...) Preguntado para que diga si sabe las causas de la agresión, dice que esta tarde sobre las cuatro, la persona que ha detenido la Policía Local se ha presentado en el Centro de Urgencias requiriendo una asistencia al enfermero, diciéndole el enfermero que esa asistencia se prestaba a las siete de la tarde, y por lo que le ha comentado el enfermero esa persona insistía en dicha asistencia, pero que al decirle el enfermero que era a las siete de la tarde esa persona se ha ido». Además de ratificarse en su declaración, en la posterior comparecencia ante el Juzgado de Instrucción núm.1 de Caravaca de la Cruz ante las preguntas del abogado defensor del acusado, expresa: «Que cuando el imputado llegó a las cuatro de la tarde el declarante no notó alterado al imputado, cuando escuchó la conversación que mantuvieron el imputado y el enfermero».

- La segunda, declaración de una celadora del centro de salud que también se encontraba de servicio aquella noche: «Sobre las 0,20 horas aproximadamente la manifestante se encontraba en la puerta de entrada al Centro de Salud, viendo venir a un vecino de Moratalla, por lo que se ha esperado para atenderlo, preguntándole que es lo que le pasaba, diciendo que venía un poco fatigado, apreciándole la manifestante que en realidad venía fatigado, por lo que ha llamado a la médico que se encontraba en la cochera recogiendo unas cosas de su coche, desplazándose la médico a la sala de consultas donde ha empezado a atender al enfermo, comentando la médica que necesitaba al enfermero para ponerle una nebulización al paciente, yendo la manifestante a avisar al enfermero (...). Preguntada si cuando la persona que ha detenido la Policía Local esta noche fue al Centro le vió algún tipo de arma, dice que no (...)". Preguntada para que diga si sabe las causas que hayan podido llevar a la agresión, dice que no lo sabe porque la doctora lo ha atendido correctamente (...)». En su declaración testifical en el Juzgado de Instrucción núm.1 citado se ratifica en la anterior y ante una pregunta del letrado de la defensa contesta «que vió al imputado llegar al Centro de Salud y no llegó muy nervioso, ya que al imputado le vió hablar bien y decirle que iba fatigado (...)».

- En tercer lugar, un enfermero de guardia aquella noche: «(...) Preguntado para que diga si ese hombre lo había visto antes, dice que sí, que sobre las 4,30 horas o las 5 de la tarde esa persona estuvo en el centro de salud para ponerse una inyección y una nebulización, habiéndole atendido anteriormente la doctora, contestándole esa persona muy mal diciendo "que si lo iban atender en el pasillo". Cuando el manifestante atendió por la tarde al paciente le dijo que el horario de atención de las nebulizaciones y de los 
inyectables era a partir de las 19 horas, diciendo esta persona que se estaba ahogando, por lo que le pidió el volante para ponerle el tratamiento, comprobando que no era urgente, porque se lo podía haber puesto esta mañana cuando se la mandaron, diciendo entonces el paciente que se iba a Caravaca de la Cruz a que se lo pusieran, respondiendo el manifestante que no hacía falta que volviera a las 19 horas y se le pondría su tratamiento, no diciendo nada más el paciente y marchándose del centro, asomándose a la ventana y observando que esta persona se sentó en un banco en el jardín, terminado ahi el episodio de la tarde, por lo que sospecha que esa persona fue a la noche por él».

Estas declaraciones informan de la existencia de un suceso anterior a la producción del asesinato: el atacante estuvo aquel mismo día por la tarde en el Centro de Salud, reclamando un servicio que le fue negado. Además su comportamiento era ya agresivo («contestándole esa persona muy mal, diciendo "que si lo iban a atender en el pasillo"»), pero el hecho de que nadie viera un arma (algo lógico, porque las armas suelen portarse ocultas) hace deducir al Consejo, una vez más, que la agresión era impredecible. Abundando en el mismo argumento, considera que el hecho de que el enfermero no se intranquilizara cuando el paciente se fue y se sentó en el parque, remite a una situación normal a la que no dio importancia ${ }^{198}$.

Y, como colofón de la reiterada y recurrente afirmación de que nadie pudo prever ni imaginar el incidente, declara: «Téngase en cuenta que un suceso de tales características con arma de fuego no se había producido en la Región con anterioridad, como indica la parte reclamante». De lo que cabe deducirse que, según el Consejo Jurídico, sólo son predecibles aquellos hechos o situaciones que ya han sucedido con anterioridad en alguna ocasión y en el ámbito geográfico del que se trate.

En cuanto a la existencia o inexistencia del nexo causal, el Dictamen examina la jurisprudencia presentada por la parte reclamante en apoyo de sus tesis, concluyendo que en su totalidad se trata de resoluciones que entienden de supuestos en que se produjo un funcionamiento anormal del servicio público, pero sin intervención de un tercero ${ }^{199}$.

\footnotetext{
198 «...cuyo comportamiento tampoco debió intranquilizar al enfermero, que por su edad se presume que tenía experiencia en la asistencia sanitaria, puesto que, en caso contrario, habría avisado a los compañeros o a la Policía Local cuando vio al agresor sentado en un parque de enfrente cuando se marchó del Centro de Salud por la tarde». 199 «STS, Sala 3, de 1 de febrero de 2003, sobre las lesiones sufridas por un artificiero en el desarrollo de las prácticas profesionales para las que era ineludible el uso de indumentaria y equipamiento de protección adecuados, se advirtieron claras omisiones o deficiencias en dichas prácticas, consecuencia de un funcionamiento anormal del servicio público, reconociéndose la responsabilidad patrimonial de la Administración. En igual sentido, por las deficiencias en los elementos materiales de un centro sanitario donde trabajaba la empleada que sufrió graves lesiones por el desprendimiento de la cabina del ascensor, chocando con el amortiguador emplazado en el sótano, la STS, Sala 3ạ, de 3 de noviembre de 2008 reconoce la responsabilidad patrimonial por ser la Administración titular del elemento causante del daño y por tener la obligación de verificar su funcionamiento, reconociendo culpa in vigilando. Asimismo la STS, Sala 3ạ, de 23 de abril de 2008, estima la responsabilidad patrimonial de la Administración por los daños sufridos por el conductor de un vehículo del Parque de Bomberos a quien se le entregó un camión para la
} 
Afirma que es doctrina consolidada de ese Consejo Jurídico que deben distinguirse los daños ocasionados por un tercero durante el cumplimiento del servicio y aquellos en que no ha habido esa participación extraña. Se sustenta en el Dictamen 936/1997, del Consejo de Estado, que estableció lo siguiente:

«En el desempeño de sus funciones, un miembro de las Fuerzas y Cuerpos de Seguridad del Estado puede sufrir daños y perjuicios que a veces serán causados por un tercero, y otras podrán ser como consecuencia del funcionamiento del propio servicio de la Administración General del Estado. Hay que diferenciar, pues, los daños sufridos con ocasión del cumplimiento de un servicio pero causados por un tercero, y los padecidos como consecuencia del propio funcionamiento de la Administración General del Estado. Mientras que los primeros son imputables al tercero que los haya causado (con ocasión del servicio), los segundos podrán ser jurídicamente atribuidos a la Administración General del Estado como persona jurídica (como consecuencia del servicio)».

Continúa con un Dictamen propio (181/2007), en el que reitera esta posición: cuando el funcionario padece unos daños como consecuencia del funcionamiento del servicio, esos daños son indemnizables en el marco de la responsabilidad patrimonial de la Administración; ahora bien, si el empleado público padece esos daños en el desempeño de sus funciones y con ocasión de ellas, pero son causados por un tercero, la reparación sería a cargo del régimen de indemnizaciones previsto en la legislación funcionarial de indemnizaciones por razón del servicio $^{200}$.

La intervención del agresor constituye para el Consejo Jurídico una ruptura del nexo causal, afirmando que: «En realidad, aunque a efectos meramente dialécticos consideráramos probada la existencia de nexo causal entre el funcionamiento del servicio público con los daños alegados, en la producción de los mismos tuvo una intervención decisiva la acción del agresor, que de forma inopinada comenzó a disparar a la doctora que le atendía en aquel momento».

Concluye que la reclamación debe ser desestimada, puesto que:

- Los daños reclamados no son atribuibles a defectos de los elementos materiales en los que se desarrolla el servicio público.

prestación de dicho servicio, pero que no estaba dotado de suficientes elementos de seguridad para su conducción por las vías públicas».

200 En el Dictamen emitido por este Consejo 240/16, de 5 de septiembre, al que ya nos hemos referido, se informa sobre la agresión producida contra una profesora por parte de un alumno en un centro educativo, concluyéndose que un alumno no puede ser considerado "tercero ajeno» al servicio, ya que los alumnos "se integran en la organización administrativa mientras el servicio esté en funcionamiento y se ejercite sobre ellos las facultades de vigilancia a las que se refiere el artículo 1903 del Código Civil». 
- No ha concurrido «culpa in vigilando» (que establecería un nexo causal con el funcionamiento del servicio público).

- Derivan de la intervención de un tercero, que provoca una ruptura del nexo causal.

- Aun cuando se hubieran omitido medidas preventivas que posteriormente se adoptaron ${ }^{201}$, no se hubiera podido evitar el suceso.

\section{LA STSJ DE MURCIA 790/2016, DE 18 DE NOVIEMBRE.}

La STSJ de Murcia 790/2016 (Recurso 331/2014), Sala de lo Contencioso-Administrativo (sección primera), de 18 de noviembre de 2016. TOL5.981.449. Ponente: D. Indalecio Cassinello Gómez Pardo.

Comparecen como partes demandantes la madre y el viudo (por sí mismo y en representación de su hijo menor de edad), como demandada la Comunidad Autónoma de la Región de Murcia (Consejería de Sanidad) y como co-demandada la Compañía de seguros Zurich España.

Se combate la Orden de 16 de abril de 2014 de la Excma. Sra. Consejera de Sanidad y Política Social (dictada por delegación por el Sr. Director Gerente del SMS), que constituye la resolución desestimatoria de la reclamación de responsabilidad patrimonial interpuesta por los demandantes con ocasión del asesinato de la Dra. Mª Eugenia Moreno.

La pretensión de la demanda es que se declare nula la Orden anteriormente citada y se declare el derecho a la indemnización reclamada, debiendo abonarla la Administración demandada, junto con las costas del proceso.

Se reproducen los antecedentes del caso, no habiendo sido objeto de discusión por ninguna de las partes.

La demanda se basa centralmente en que el hecho de que el presunto asesino fuera ajeno al servicio público, ello no obsta para que la Administración no ostente responsabilidad en la producción del suceso luctuoso. Los demandantes imputan a la Administración una actuación negligente, por cuanto el riesgo había sido detectado por los SPRL del SMS, y sin embargo se dejaron de tomar medidas contempladas en su PRL, que no fueron implantadas en el Centro de Salud de Moratalla (no se formó al personal en estrategias de conciliación en situaciones conflictivas, ni en habilidades comunicativas frente a situaciones de hostilidad, ni tampoco se ampliaron las medidas de seguridad mediante la implantación de un servicio de vigilancia de seguridad). El total del «Petitum» lo fijan en 1.444.471,70 euros.

\footnotetext{
${ }^{201}$ Nótese que parece haber un reconocimiento implícito de que esas medidas debían haber estado implantadas.
} 
La oposición al recurso, formulada por la Administración y la Compañía aseguradora, manifiesta que:

- El carácter objetivo de la responsabilidad patrimonial de la Administración no supone que deba responder ante todo resultado lesivo producido en el ámbito del servicio público, debiendo poder imputarse la lesión al funcionamiento del servicio. Añaden que la Administración queda exonerada cuando «la intervención de tercero o del propio perjudicado reviste la suficiente intensidad para resultar determinante del resultado lesivo, quebrando la relación con el servicio público en cuyo ámbito se han producido los hechos, aun cuando el funcionamiento del mismo sea defectuoso» ${ }^{202}$. Alegan, por tanto, la ruptura del nexo causal.

- Respecto a la imputación de falta de medidas de seguridad, señalan la generalidad de la violencia que sufre la sociedad actual y la imprevisibilidad de estas conductas, que no obedecen a comportamientos lógicos, por lo que se ignora cuándo y dónde van a producirse, quién los protagonizará y la intensidad con la que se darán «ya que lo mismo pueden darse en un centro sanitario u otra dependencia pública, en un comercio, en la vía pública o incluso en un entorno doméstico» ${ }^{203}$. Continúan expresando que muchos establecimientos contratan servicios de seguridad para disuadir de la comisión de actos violentos, pero que esto no les convierte en garantes de la ausencia de conductas delictivas en dichos lugares «ya que estas conductas que se intentan disuadir tienen, como única causa, la voluntad y el proceder incívico y asocial de quienes las llevan a cabo ${ }^{204}$, máxime en un centro sanitario al que se acude para recibir asistencia médica, siendo impensable, por excepcional y desproporcionado, que uno de sus usuarios vaya a disparar un arma de fuego contra uno de los miembros del personal sanitario que lo atiende, ya que no parece responder a la lógica y al sentido común que se agreda a quien trabaja para que recuperemos la salud, por lo que ninguna normativa sobre prevención de riesgos laborales puede prever ese riesgo en todo caso antijurídico». Agregan que no constaba ningún suceso anterior de tal envergadura y que ninguna de las medidas de seguridad que después se adoptaron habría evitado la producción del daño: los botones de pánico hubieran sido inútiles, así como los timbres, cámaras de vigilancia, porque al agresor no le importaba

202 Utilizan para sustentar su argumento: SSTS de 27 de diciembre de 1999, de 9 de mayo de 2001, de 21 de marzo, 23 de mayo, 10 de octubre y 25 de noviembre de 1995, 25 de noviembre y 2 de diciembre de 1996,16 de noviembre de 1998, 20 de febrero, 13 de marzo y 29 de marzo de 1999.

203 Nótese cómo con esta afirmación parece estarse negando la incidencia de la violencia contra los profesionales sanitarios en el entorno laboral, asimilándola a otras situaciones de violencia común. Lo cual no se compadece con que precisamente el SMS fuera una de las Administraciones que primero adoptara medidas de prevención para atajar estas agresiones en el ámbito sanitario (2005).

${ }^{204}$ Se focaliza en una única causa la producción de agresiones en los centros sanitarios: el incivismo. Debe observarse que, además, se podría interpretar que se están estimando inútiles cuantas medidas de seguridad se han tomado desde el SPRL, puesto que explícitamente queda manifestado que todo es impredecible y nada puede ser evitado. 
ser identificado. Tampoco, continúan, hubiera servido de nada la presencia de un vigilante de seguridad, porque estos vigilantes no portan armas de fuego en estos servicios ${ }^{205}$, ni están presentes en las consultas, «ni pueden sospechar las conductas más o menos violentas de los usuarios mientras están siendo asistidos».

- Reconocen que los profesionales sanitarios no tienen el deber jurídico de soportar agresiones, pero niegan que concurra ningún tipo de responsabilidad en la Administración, defendiendo que los únicos responsables de estos actos son sus autores.

Visto lo alegado y tras la formulación del contexto jurídico en que se mueve la causa (es decir, los requisitos de apreciación de responsabilidad patrimonial de la Administración, que reseñamos en otro apartado), la sentencia argumenta lo siguiente:

- El daño sufrido por la doctora fue antijurídico, pero «la intervención de un tercero ajeno al Servicio público provocó la ruptura del hipotético nexo causal que pudiera considerarse existente entre la prestación del servicio y el daño producido».

- De los hechos contenidos en el Auto de procesamiento de 22 de diciembre de 2009, se desprende que la muerte de la Dra. Eugenia Moreno se produjo por el acto de un tercero ajeno al servicio público.

Su violenta actuación resultaba imprevisible «dada la inusual e irracional desproporción de su ilegítima conducta, lo inopinado del ataque y su carácter indiscriminado contra la citada doctora y un conductor de ambulancia, pese a no haber surgido incidente alguno con ellos y sin que mediara provocación alguna por parte de éstos» y también inevitable por haberse producido a cara descubierta «despreciando su autor y haciendo ineficaces cuantas medidas de vigilancia y control pudieran haberse adoptado» y porque la hipotética actuación de un vigilante de seguridad tampoco la hubiera impedido «dada la inmediatez de la agresión, el carácter indeterminado de las víctimas, la imposibilidad de su presencia en las consultas y al tener estos que prestar sus servicios sin portar armas».

Por lo antedicho, el recurso se desestima íntegramente, con expresa imposición de costas a los demandantes hasta un importe máximo de mil euros.

Se interpone a continuación recurso de casación contra la sentencia anteriormente descrita. El Auto de 6 de febrero de 2017 de la Sala de lo Contencioso-Administrativo del TSJ de Murcia tiene por preparado el mencionado recurso y emplaza a las partes para su comparecencia ante la Sala de lo Contencioso-Administrativo del Tribunal Supremo.

\footnotetext{
${ }^{205}$ Artículo 14 Ley 23/1992 vigente en el momento de los hechos, artículo 40 Ley 5/2014.
} 
Por Providencia de 5 de mayo de 2017, en relación al Recurso de Casación núm. 983/2017, la citada Sala del Tribunal Supremo acuerda su inadmisión a trámite, con expresa imposición de las costas procesales. 
V. EL DERECHO PENAL Y SU TRATAMIENTO DE LAS AGRESIONES A LOS PROFESIONALES SANITARIOS 


\section{EL DERECHO PENAL ANTES Y DESPUÉS DE LA REFORMA DEL CP DE 2015 EN RELACIÓN CON LAS AGRESIONES AL PERSONAL SANITARIO}

Las agresiones a los profesionales de la sanidad han venido aumentando en España durante las últimas décadas, en un contexto de violencia social y laboral que no es ajeno, por otra parte, a otros países de nuestro entorno cultural, como ya hemos reflejado en otros capítulos.

Por lo que respecta al ordenamiento punitivo, hasta la promulgación del Código Penal de 1995 estas agresiones solían considerarse generalmente como faltas, de diversa etiología: lesiones, amenazas, injurias, etc. No era frecuente que se tipificasen como delito.

A partir de la publicación del antedicho Código, el ordenamiento penal brinda la posibilidad de que tales agresiones sean consideradas como delito de atentado, definido en el artículo $550 \mathrm{CP}$, todo ello en relación con el artículo 24.2 del mismo texto legal. Pero sólo en el caso de los profesionales de la Sanidad pública y sin que se haga inclusión expresa de ellos, únicamente por estar en posesión de la condición de funcionario en las condiciones que determina precisamente el art. 24.2 antes citado, cuestión que durante mucho tiempo no ha sido pacífica ni por parte de la doctrina ni tampoco por lo que atañe a la actuación de los tribunales (De Juan-Mazuelas, 2016).

\section{1.- Estado de la cuestión en la legislación penal anterior a la reforma de 2015.}

\section{A) EL ELEMENTO OBJETIVO}

Entendemos por elemento objetivo los tipos de ilícito susceptibles de aplicación. Hay que hacer notar que el delito de atentado, en la el CP de 1995 anterior a la reforma de 2015, contenía cuatro modalidades diferentes de ilícito: Acometimiento, empleo de fuerza, intimidación grave y resistencia activa y grave. Transcribimos el tenor literal del artículo $550 \mathrm{CP}$ en ese momento:

«Son reos de atentado los que acometan a la autoridad, a sus agentes o funcionarios públicos, o empleen fuerza contra ellos, los intimiden gravemente o les hagan resistencia activa también grave, cuando se hallen ejecutando las funciones de sus cargos o con ocasión de ellos».

De estas cuatro figuras delictivas, las tres primeras eran susceptibles de ser aplicadas a los actos violentos llevados a cabo contra el personal sanitario. No ocurría lo mismo con la cuarta, dado que esta modalidad supone la existencia de algún tipo de autoridad en la persona que recibe la agresión, requisito que, salvo excepciones, no se da en estos profesionales ${ }^{206}$.

\footnotetext{
${ }^{206}$ Entre otras excepciones, podrían citarse los supuestos comprendidos en la LO 3/1986 de medidas especiales en materia de salud pública; ley 41/2002, en los casos que comprende el art. 9.2; Ley 33/2011 General de la Salud Pública, supuestos del art. 53 .
} 
Tanto el acometimiento como el empleo de fuerza suponen el ejercicio de «vis física», llegue o no a completarse la acción y haya o no resultados, pues se trata de delitos de mera actividad. La intimidación presupone «vis moral» porque consiste en generar en la víctima, utilizando los medios más diversos, un estado anímico perturbado gravemente.

El delito de atentado podía tipificarse de forma autónoma o en concurso ${ }^{207}$ con otros ilícitos ya fueran delitos o faltas. Ese concurso era posible por ser diferentes los bienes jurídicos objeto de protección del delito de atentado y los restantes ilícitos aplicables. Mientras que en el delito de atentado la protección penal trata de asegurar el correcto funcionamiento de las prestaciones y servicios relativos al interés general que debe ofrecer la Administración, los delitos y faltas contra las personas (lesiones, amenazas, injurias...) tienen como objeto de protección la vida e integridad del ser humano en todos los ámbitos, no sólo en el plano físico.

\section{B) EL ELEMENTO SUBJETIVO.}

Al hablar de elemento subjetivo nos referimos a quienes pueden ser sujetos pasivos del delito de atentado.

Como ya hemos anticipado, la posibilidad de considerar a los profesionales de la sanidad pública sujetos pasivos de delitos de atentado está vinculada a su calificación como funcionarios públicos, en relación con lo que dispone el artículo $24.2 \mathrm{CP}^{208}$ :

«Se considerará funcionario público todo el que por disposición inmediata de la Ley o por elección o por nombramiento de autoridad competente participe en el ejercicio de funciones públicas».

Anteriormente, ya la jurisprudencia los había considerado como tales pero sobre todo en supuestos en los que actuaban como sujetos activos de los delitos y sólo excepcionalmente había estimado que pudieran ser sujetos pasivos de delito de atentado (Véase por todas STS Sala Segunda de 20 de mayo de 1993).

Esta consideración no fue acogida de forma pacífica por parte de la doctrina y tampoco por los tribunales, vinculándose gran parte de la discusión sobre todo a las dudas en torno a si podían ser considerados funcionarios públicos al tratarse de personal estatutario (De Juan-Mazuelas, 2016).

\footnotetext{
207 El concurso generalmente será entendido como ideal.

${ }^{208}$ No ha sufrido modificación en la reforma operada por la LO 1/2015 de 30 de marzo.
} 
Hitos importantes, aunque no decisivos pues el debate continuó aún durante algunos años más, fueron: la STS 1030/2007, de 4 de diciembre así como la FGE a raíz de la Consulta 2/2008, de 25 de noviembre ${ }^{209}$.

\section{2.- El planteamiento a partir de la reforma del ordenamiento Penal en 2015.}

La LO 1/2015, de 30 de marzo, ha introducido sustanciales modificaciones en el régimen penal aplicable a los actos de violencia que se lleven a cabo contra profesionales de la sanidad pública.

\section{A) ELEMENTO OBJETIVO}

En cuanto al delito de atentado, el artículo 550.1 del Código reformado varía el número y tipología de las modalidades delictivas que le componen, que han pasado a ser tres: Agresión, resistencia grave con intimidación grave o violencia, acometimiento. El citado artículo dice así:

«Son reos de atentado los que agredieren o, con intimidación grave o violencia, opusieren resistencia grave a la autoridad, a sus agentes ofuncionarios públicos, o los acometieren, cuando se hallen en el ejercicio de las funciones de sus cargos o con ocasión de ellas».

Lo más significativo, al menos en principio y en referencia a los profesionales objeto de nuestro estudio, es que la intimidación, al haber dejado de ser figura delictiva autónoma y quedar vinculada a la resistencia, quizá sea de difícil aplicación a partir de ahora a este colectivo por las razones que anteriormente expusimos.

Por tanto, agresiones frecuentes en el ámbito sanitario como las amenazas ${ }^{210}$, al no poderse vincular a la intimidación como modalidad de atentado, pasarán a ser consideradas como mucho delito, e incluso, delito leve o menos grave, lo que supone una disminución en la carga punitiva pues no se penaliza del mismo modo el delito de atentado que los restantes tipos de ilícitos penales de susceptible aplicación (De Juan-Mazuelas, 2016)(Sánchez-Benito \& De Juan-Mazuelas, 2017).

El delito de atentado puede suponer condena a prisión de seis meses a tres años. Los delitos graves de lesiones pueden conllevar remisión a prisión durante tres meses a tres años, con la posibilidad alternativa de imposición de multa de seis a doce meses.

\footnotetext{
209 De Juan-Mazuelas (2016), Urruela Mora (2017).

210 Salvo en casos de específica gravedad.
} 
Los demás delitos (menos graves y leves), suponen únicamente condena pecuniaria, ya que con la reforma ha desaparecido también la posibilidad de que les fuera aplicada la limitada privación de libertad que suponía la localización permanente ${ }^{211}$. En el caso de los delitos leves, la multa a imponer será generalmente de uno a tres meses, excepción hecha del maltrato de obra al que se asigna multa de uno a dos meses.

Siendo esto destacable, creemos quizá de mayor relevancia la supresión total de las Faltas ${ }^{212}$, que han pasado a constituir en su mayor parte delitos menos graves o leves. Algunos autores señalan la dificultad que puede generarse sobre todo por la mutación de algunos delitos menos graves en leves (Corcoy Bidasolo \& Mir Puig, 2015). Conversión de la que también se hace eco la FGE en la Circular 1/2015 (Libano Beristain, 2017).

Además, algunas figuras delictivas antes tipificadas como Faltas incluso han sido expulsadas del ordenamiento penal siendo remitidas al ordenamiento civil o al administrativo. Tal es el caso, por ejemplo, de las injurias leves y las vejaciones también leves que pasan al ámbito civil ${ }^{213}$.

Así pues, en el caso de los ilícitos que con mayor frecuencia se cometen contra profesionales de la sanidad (sobre todo lesiones, amenazas, coacciones, maltrato de obra, injurias y vejaciones leves), aquellas que se mantienen tras la reforma en el ordenamiento penal, tendrán en todo caso una pena pecuniaria ${ }^{214}$.

\section{B) ELEMENTO SUBJETIVO}

El artículo 550.1 de la nueva redacción del CP, determina su inclusión explicita como sujetos pasivos del delito de atentado (junto con los profesores de la enseñanza pública), lo que constituye una de las novedades más destacables por lo que atañe a los profesionales de la sanidad pública:

«En todo caso, se considerarán actos de atentado los cometidos contra los profesionales docentes o sanitarios que se hallen en el ejercicio de las funciones propias de su cargo, o con ocasión de ellas».

Esta inclusión viene a confirmar «ex lege» lo que ya venía siendo doctrina muy aceptada por la jurisprudencia, al considerar que estos profesionales son funcionarios, en relación con lo que dispone el artículo 24.2 CP, como ya ha quedado expuesto (De Juan-Mazuelas, 2016).

\footnotetext{
211 La localización permanente persiste en el Código Penal (artículo 35).

212 Se ha suprimido íntegramente el Libro III en el que se regulaban estos ilícitos.

${ }^{213}$ Se exceptúan los casos en que la conducta injuriosa tenga lugar en el ámbito doméstico.

${ }^{214}$ Siempre que no sean considerados como delitos graves.
} 
Por esa razón, una parte de la doctrina entiende que es redundante dicha explicitación ${ }^{215}$, en tanto que otro sector lo valora positivamente porque viene a eliminar cualquier discusión ante los tribunales al respecto ${ }^{216}$. Hay quien, aun considerándola innecesaria, reconoce su valor simbólico dada la situación de violencia existente (Cuerda Arnau, 2015).

Es de hacer notar que a pesar de que ya la aceptación de la condición funcionarial en los profesionales de la sanidad pública venía siendo aceptada mayoritariamente por los tribunales, no era sin embargo cuestión absolutamente pacífica, al menos desde los recursos de apelación (De Juan-Mazuelas, 2016) en los que, en ocasiones, ha continuado siendo vigente esta polémica (SAP Pontevedra 302/2016, de 23 de mayo).

Ciertamente, esta inclusión deja fuera del ámbito de la protección penal del delito de atentado, ya de forma indiscutible, a los profesionales de la sanidad privada.

También viene a zanjar desde la ley, en principio, la confusión existente en cuanto a la posible consideración de estos profesionales no como funcionarios, sino como Autoridad, lo que supondría una mayor caga punitiva si se produjeran agresiones contra ellos dado que las penas de prisión que pueden imponerse en este caso oscila entre uno y cuatro años.

El artículo $24.1 \mathrm{CP}^{217}$ explicita aquellos que son considerados penalmente como autoridad, sin incluir en esa condición a los funcionarios. Dice así literalmente:

«A los efectos penales se reputará autoridad al que por sí solo o como miembro de alguna corporación, tribunal u órgano colegiado tenga mando o ejerza jurisdicción propia. En todo caso, tendrán la consideración de autoridad los miembros del Congreso de los Diputados, del Senado, de las Asambleas Legislativas de las Comunidades Autónomas y del Parlamento Europeo. Se reputará también autoridad a los funcionarios del Ministerio Fiscal».

Esta confusión ha venido siendo mantenida por diferentes sectores, tanto institucionales como de opinión y también por la literatura científica y corporaciones como los Colegios profesionales, ya desde antes de la reforma ${ }^{218}$.

Quizá una de las causas haya sido la confusión entre los ámbitos administrativo y penal, puesto que diversas CCAA han legislado en sus respectivos campos de competencias, reconociendo ese

\footnotetext{
215 Alcalá Pérez-Flores, Jaén Vallejo, Martínez Arrieta Vázquez Prado, \& Perrino Pérez (2015), De Lorenzo (2015).

${ }^{216}$ Marinas-Sanz, Martínez-Jarreta, Casalod, \& Bolea (2016).

${ }^{217}$ Este artículo mantiene la redacción anterior a la reforma introducida en el ordenamiento penal por la LO 1/2015.

218 De Juan-Mazuelas (2016).
} 
carácter a estos profesionales. Los efectos de este reconocimiento, con ser importantes, sólo tienen vigencia en el ámbito administrativo, dada la autonomía del ordenamiento penal ${ }^{219}$.

Lo cierto es que, incluso después de la entrada en vigor del Código reformado, continúa produciéndose esa confusión, lo que supone, entre otros efectos adversos, una frustración en las expectativas del sector (por los efectos penológicos más intensos que conlleva ese tipo de agresiones, como ya hemos anticipado) y porque contribuye a ahondar aún más si cabe, la brecha entre el sentimiento de desprotección de los profesionales de la sanidad privada respecto a los de la pública, ya que los primeros ni siquiera quedan bajo la protección del delito de atentado por la exigibilidad de la condición funcionarial que ellos no pueden detentar en el actual estado de la cuestión (De Juan-Mazuelas, 2016).

No obstante, en atención a lo que dispone el artículo 554, podrían asimilarse las consecuencias penológicas de agresiones cometidas contra ellos, si esto ocurre estando en auxilio de quienes pueden ser sujetos pasivos (autoridad, agentes, funcionarios) que estuvieran en peligro durante y a causa del ejercicio de su profesión. Éste es su tenor literal:

«1. Los hechos descritos en los artículos 550 y 551 serán también castigados con las penas expresadas en ellos cuando se cometieren contra un miembro de las Fuerzas Armadas que, vistiendo uniforme, estuviera prestando un servicio que le hubiera sido legalmente encomendado.

2. Las mismas penas se impondrán a quienes acometan, empleen violencia o intimiden a las personas que acudan en auxilio de la autoridad, sus agentes o funcionarios.

3. También se impondrán las penas de los artículos 550 y 551 a quienes acometan, empleen violencia o intimiden gravemente:

a) A los bomberos o miembros del personal sanitario o equipos de socorro que estuvieran interviniendo con ocasión de un siniestro, calamidad pública o situación de emergencia, con la finalidad de impedirles el ejercicio de sus funciones.

b) Al personal de seguridad privada, debidamente identificado, que desarrolle actividades de seguridad privada en cooperación y bajo el mando de las Fuerzas y Cuerpos de Seguridad».

En esas circunstancias, el ordenamiento penal actual asimila a los sujetos integrados en el ámbito del artículo $24 \mathrm{CP}$ a determinados colectivos y personas físicas de en general (como pueden ser lógicamente los sanitarios privados), en cuanto al alcance de las penas a imponer a quienes les ocasionaran violencia. Pero esto queda limitado a esa condición de auxilio y siempre que se den los elementos objetivos que el artículo 550.2 y sobre todo el 550.3 determinan.

${ }^{219}$ De Juan-Mazuelas (2016), Urruela Mora (2017). 
En cualquier caso, también la aplicación de este artículo puede generar controversia, como tendremos ocasión de comprobar cuando nos ocupemos en este capítulo de la actuación de los tribunales ${ }^{220}$.

\section{3.- Conclusiones}

Una de las cuestiones que, a nuestro juicio, pueden ser más controvertidas, es la cuestión de si la reforma del ordenamiento penal de julio de 2015, supone una mayor protección penal para los profesionales de la sanidad.

En cuanto a los que pertenecen al ámbito privado, y al margen de la frustración que supone para ellos que no se les haya incluido en el ámbito de protección del atentado tal como reclamaban (y aún reclaman, incluso desde los Colegios Profesionales a los que también pertenecen), posiblemente les sea beneficioso el aumento de la cuantía de las multas por delitos leves, excepto en los supuestos de lesiones dado que éstas, aunque también se han incrementado las cuantías aplicables a ellas, han pasado a ser considerados delitos semipúblicos, lo que supone la necesaria denuncia de parte (de Juan-Mazuelas et al., 2017).

En el caso de los profesionales de la sanidad pública, aun reconociendo como positiva su inclusión explícita en el artículo 550, como sujetos pasivos del delito de atentado, la problemática que conlleva la supresión de la intimidación grave como modalidad autónoma dentro del ilícito de atentado puede limitar la tipificación de las agresiones contra ellos cometidas, derivándose determinados supuestos a la figura de amenazas que, incluso siendo consideradas delito (excepto en supuestos de manifiesta gravedad), suponen una carga punitiva menor.

En cuanto a las lesiones antes consideradas como faltas y ahora delitos leves, las observaciones que acabamos de señalar para la sanidad privada son también de aplicación a este colectivo. La necesidad de denuncia de parte, al margen del alivio en cuanto a carga de trabajo y agilidad en las resoluciones para el Ministerio Fiscal y los Tribunales, pueden incrementar el fenómeno de la «infradenuncia» que ya de suyo venía siendo considerable, a lo que puede unirse la expulsión del ordenamiento penal de ilícitos tan frecuentes en el ámbito sanitario en general como las injurias ${ }^{221}$.

Si bien es cierto que en el ordenamiento civil o en el administrativo las sanciones económicas pueden alcanzar mayor nivel que las que suelen imponerse en el ámbito penal, también lo es que el poder disuasorio que pueden suponer estas sanciones es menor ya que la fuerza coercitiva de

\footnotetext{
220 Es el caso de la SAP Madrid (Sección29a) 104/2016, de 25 de febrero.

${ }^{221}$ De Juan-Mazuelas (2016).
} 
estos sectores del ordenamiento es inferior a la de lo penal, en el caso de incumplimiento o impago de las multas impuestas (de Juan-Mazuelas et al., 2017).

¿Podría asegurarse, por consiguiente, que se ha reducido con la reforma la punición en general y la del atentado en particular?

Una parte de la doctrina entiende que no e, incluso, que ha aumentado (Faraldo Cabana, 2015) (J. L. González Cussac, 2015) (Vives Antón, 2015). De hecho, en todos los casos (incluidos los delitos leves), se ha incrementado el límite superior de las penas a imponer, ya sean de prisión o pecuniarias.

Hay también opiniones en contrario, puesto que, en el caso de las antiguas faltas de lesiones, muy frecuentes y ahora tipificadas en su mayoría como delitos leves, a pesar de elevarse el límite superior como en el resto de los ilícitos qua los que nos venimos refiriendo, la necesidad de denuncia de parte resta efectividad en la práctica a ese incremento en las multas que se impongan («infradenuncia») y, además, la punición ha quedado circunscrita únicamente a las penas pecuniarias, perdiéndose la posibilidad de que los juzgadores optaran entre ello o la localización permanente que, aunque en grado mínimo, supone una limitación de la libertad y, por consiguiente, en la mayor parte de los casos, una mayor carga penológica con poder disuasorio mayor también.

Pero, quizá lo más importante a tener en cuenta en esta discusión, es que en los supuestos considerados como delito, inclusión hecha del delito de atentado, se ha rebajado el límite inferior que, según algunos autores, era el que más frecuentemente venían aplicando los tribunales (De Juan-Mazuelas, 2016).

También puede resultar problemática, durante el período transitorio, la actuación de los tribunales al aplicar a los casos ya juzgados, pero todavía no firmes (por estar en trámite de recurso) el ordenamiento más beneficioso para el reo. Lo que puede suponer que se rebaje la carga penológica ya impuesta e incluso, que queden sin punición algunos supuestos que sí la tenían. Es el caso, por ejemplo, de los casos tipificados como faltas a los que en el trámite de revisión el tribunal aplique el nuevo Código: al considerar que ya no existen las faltas, puede quedar revocada la sentencia y la multa que llevaba aneja, manteniéndose únicamente el pago de indemnización en concepto de responsabilidad civil y eso en el supuesto de que no se hubiera renunciado a ella. Por eso, entre otras razones, hay quien opina que con esta nueva situación ciertas agresiones pueden salir baratas en el caso de la pública e incluso gratis o casi gratis en el de la sanidad privada (De Juan-Mazuelas et al., 2017). 
A la vista de este planteamiento, consideramos conveniente verificar cómo está siendo la actuación de los órganos jurisdiccionales a este respecto. 


\section{LA JURISPRUDENCIA PENAL SOBRE AGRESIONES AL PERSONAL SANITARIO TRAS LA REFORMA DEL CP DE 2015}

A continuación, vamos a comprobar el comportamiento de los órganos jurisdiccionales cuando aplican la reforma del ordenamiento penal que entró en vigor el 1 de julio de 2015. Nuestro objetivo es verificar, como hemos indicado en el epígrafe anterior, si se ha producido a partir de entonces y desde la actuación de la jurisprudencia, un incremento en la imposición de penas en casos de agresiones a los profesionales de la sanidad pública (tal como opinan algunos autores), o si, por el contrario, parece confirmarse la hipótesis de quienes desde la doctrina apuntan a una disminución de la carga punitiva con la aplicación del CP reformado.

En orden a conseguir este objetivo, nos vamos a apoyar en un conjunto de resoluciones judiciales. Algunas se han extraído a partir de referencias incluidas en diversas fuentes. No obstante, en la mayor parte de los casos, el estudio se lleva a efecto directamente sobre las propias sentencias dictadas por los tribunales.

Para poder establecer conclusiones al respecto, estructuraremos este análisis en diversos apartados.

Veremos, por una parte, los supuestos en que los órganos jurisdiccionales tipifican los hechos como constitutivos de delito de atentado y aplican las condenas a prisión por encima del límite inferior, en cuyo caso, podemos hablar de incremento penológico.

En otro apartado, consideramos aquellas resoluciones en las que, al estimar el tribunal la existencia de delito de atentado, aplica el límite inferior de la condena, incluyendo casos en los que esto tiene lugar en segunda instancia y ya la sentencia recurrida había fijado dicho límite inferior en las penas a imponer. Teniendo en cuenta estos supuestos, podemos determinar que, efectivamente, se está rebajando la carga punitiva.

Para completar el análisis de lo relativo al delito de atentado, veremos también algunos supuestos en los que, finalmente, no se estimó que los hechos juzgados estuvieran comprendidos en alguna de las modalidades de este ilícito.

Hay que considerar también otras figuras delictivas, sobre todo las relacionadas con las antiguas faltas porque, al desaparecer como tales del ordenamiento penal después de la reforma de 2015 interesa comprobar si se les aplica o no las disposiciones del nuevo CP con carácter retroactivo. Esto es importante, no sólo por su repercusión en la cuantía de las penas impuestas sino porque, además, puede ser un indicador que permita detectar si los tribunales actúan o no de forma homogénea. 
La falta de homogeneidad en esa actuación puede suponer una desigual aplicación de la ley penal con consecuencias negativas para las partes y, al mismo tiempo, contribuir a generar de algún modo inseguridad jurídica, tal y como ocurriera antes de la reforma en cuanto a la diferencia de criterios de los tribunales sobre la posesión o no de la condición de funcionarios por los profesionales de la sanidad pública ${ }^{222}$.

También veremos algunos supuestos que pudieran considerarse como "problemáticos", desde tres puntos de vista: en primer lugar, porque se utiliza terminología discutible en cuanto a los ilícitos que en ellos se estiman; en segundo lugar, porque persiste la controversia sobre si los sanitarios de la sanidad pública pueden ser sujetos pasivos del delito de atentado (a pesar de su inclusión explícita en el artículo $550 \mathrm{CP}$ ). En tercer lugar y de modo muy especial, porque se incide en la calificación de estos profesionales como Autoridad, lo que contribuye a mantener el «confusionismo» que doctrina y profesionales mantienen al respecto ${ }^{223}$.

Para llevar a cabo un estudio lo más exhaustivo posible, únicamente analizaremos en cada uno de los apartados aquellos aspectos de las resoluciones estudiadas que tengan relación con el tema que allí se trate. Pero para poder disponer de una visión global de dichas sentencias, incluiremos en el Anexo $\mathrm{I}^{224}$ el resumen de todas y cada una de ellas, integrando en él los aspectos más importantes de su contenido.

\section{1.- EL DELITO DE ATENTADO}

\section{A. Los hechos juzgados se tipifican como delito de atentado}

En este apartado únicamente tenemos en cuenta, como ha quedado dicho, los aspectos que hacen relación con el delito de atentado, aunque en las resoluciones analizadas se estimasen también otros ilícitos.

\footnotetext{
222 Este hecho era relevante porque en gran medida dependía de ello que se tipificaran o no como atentado las agresiones llevadas a cabo contra ese colectivo profesional (De Juan Mazuelas, 2016).

${ }^{223}$ Este aspecto se ha tratado ya, no solamente en el ámbito penal, sino también al hablar de otros aspectos relacionados con el orden Administrativo.

${ }^{224}$ Este tratamiento se aplicará exclusivamente a las resoluciones que no se hayan obtenido mediante una fuente indirecta.
} 


\section{Resoluciones en las que los tribunales no aplican el límite inferior}

\section{a.- Sentencias.}

\section{1.- SAP Alicante 415/2015, de 31 de julio.}

Esta sentencia confirma la dictada por el Juzgado de lo Penal n 8 de Alicante (05/03/2015), en la que se condena, por delito de atentado cometido contra funcionario público, a un hombre que atacó a un celador en un centro de salud de dicha ciudad. El acusado estaba molesto porque consideraba que el perjudicado trataba mal a su hermano, razón por la que se produce la agresión:

«...se dirigió al mismo diciéndole que si le pasaba algo a su hermano le mataría, llegando a forcejear con dicho celador exhibiéndole un objeto punzante. Finalmente, el hermano del acusado separó a este último del perjudicado, siendo este último quien avisó a la Policía, mientras el acusado intentaba darse a la fuga del lugar, dejando tras de sí al acusado con su ropa dañada».

La condena fue a dieciséis meses de prisión. En este caso, ni el juzgador de instancia ni después la AP aplican el límite inferior ${ }^{225}$. Aunque se mantienen las condenas de ambas instancias por debajo de la media del tramo legal que, tanto la LO de 1995 como la 1/2015 permiten ${ }^{226}$.

\section{2.- SAP Ourense 326/2015, de 25 de septiembre.}

La AP de Ourense confirma íntegramente la sentencia dictada por el Juzgado de lo Penal $\mathrm{n}^{\mathrm{o}} 2$ (15/05/2015), que condenó a un año de prisión por delito de atentado a la agresora de una facultativa en un centro médico, a donde había acudido por padecer dolor de oídos.

En cualquier caso, un año era el límite inferior según el ordenamiento de 1995 (que es el que aplica el juzgador «a quo»). Al confirmarlo, la AP no opta por el nivel inferior que establece el CP de 2015, aunque se mantiene por debajo de la media del tramo legal en él establecido, en todo caso. Hay que tener en cuenta también el escaso espacio de tiempo transcurrido entre la entrada en vigor de la reforma y la fecha en la que la AP dicta sentencia, así como que venía siendo tendencia bastante arraigada en los tribunales la aplicación de un año en las condenas a prisión por delito de atentado.

\footnotetext{
${ }^{225}$ Un año en cuanto a lo que disponía el CP de 1995 y seis meses en el nuevo ordenamiento.

${ }^{226}$ De esta sentencia se hace eco el Observatorio de Agresiones (13/10/2015), como si se tratara de una novedad cuyo precedente sería, según esta misma fuente, la dictada en el año 2010 por el Juzgado de lo Penal no 5 de Murcia. Puede verse en: https://www.cmb.eus/observatorio-de-agresiones-2/la-agresion-a-un-celador-se-tipifica-comodelito-de-atentado.
} 


\section{3.- SAP Badajoz 70/2015, de 30 de septiembre.}

Resuelve el recurso de apelación interpuesto contra la sentencia del Juzgado de lo Penal $\mathrm{n}^{\mathrm{o}} 2$ de dicha ciudad (de 25/05/2015), que había condenado al agresor de un médico como autor de un delito de atentado a funcionario público, a un año de prisión.

En el recurso de apelación interpuesto contra esta sentencia se solicita, que no se consideren los hechos como delito de atentado alegando, entre otros argumentos ${ }^{227}$, que existía relación de subordinación entre el agredido y un enfermero que actuaba como testigo.

La AP desestima la alegación con la que se pretendía descalificar la prueba testifical:

«Esto es un auténtico disparate: Primero no existe esa relación de subordinación ciega del enfermero al médico (...). Por cierto, que médico y enfermero casi ni se conocían; pues se trataba de un médico sustituto para un periodo vacacional, que llevaba poco tiempo atendiendo en esa consulta, y era el último día del enfermero en su puesto de trabajo, antes de disfrutar de sus vacaciones estivales».

Reconoce además la Sala que existió delito de atentado porque, en su valoración de los hechos ${ }^{228}$, hubo agresión física:

«y lo que no hay que olvidar en ningún momento es que las personas presentes en el momento de la agresión - porque coger del cuello a una persona es agredirla...».

En consecuencia, y, a pesar de apreciar la existencia de dilaciones indebidas ${ }^{229}$, confirma la resolución de primera instancia, al entender que, si bien es cierto que esas dilaciones existieron y constituyen un atenuante que puede aplicarse para rebajar la pena, en este caso ya fueron tenidas en cuenta por el juzgador «a quo».

En este supuesto, si bien el Juzgado aplicó el límite inferior de la pena a prisión, que en la fecha en que se celebró la vista (mayo de 2015) ${ }^{230}$ era de un año para los delitos de atentado, la AP al mantener los términos de esa resolución no está considerando el nivel inferior que después de la

\footnotetext{
227 También alega que no se dan todos los elementos objetivos que precisa el ilícito del art. 550, sino, en todo caso, los de la falta tipificada en el art. 639 del CP de 1995.

${ }^{228}$ En todo momento tiene una importancia decisiva e informe del Ministerio Fiscal, de tal modo que una gran parte de la argumentación de la Sala se elabora en base a ese informe

${ }^{229}$ Hubo un período de cinco años en la tramitación y resolución del proceso, desde la comisión de los hechos. La Sala realiza un interesante y amplio estudio de lo que suponen las dilaciones indebidas, incluso antes de su entrada en el Código Penal en el año 2010. Analiza los instrumentos legales en los que se apoya, a nivel internacional, así como la diferencia entre «dilaciones indebidas» y «plazo razonable».

${ }^{230}$ Antes de la reforma era bastante frecuente que los tribunales aplicasen el límite inferior de la condena a prisión en los delitos de atentado. (De Juan Mazuelas, 2016).
} 
reforma se establece en seis meses (aunque sí que se mantiene por debajo de la mitad del tramo legal que la nueva normativa permite).

\section{4.- SAP Jaén 375/2015, de 10 de diciembre.}

La AP de Jaén desestima íntegramente el recurso de apelación interpuesto contra la resolución del Juzgado de lo Penal $n^{\circ} 3$ de esa ciudad (21/05/2015).

El juzgador de instancia estimó que constituía delito de atentado la agresión de un paciente a una médico en un centro de salud, porque quería que le atendieran de inmediato sin esperar a su turno. Se le condena, como autor de un delito de atentado, a un año de prisión, después de aplicarle la atenuante simple de drogadicción.

«En el momento de los hechos el acusado se encontraba bajo los efectos de sustancias psicotrópicas que mermaban levemente sus facultades intelectivas y volitivas».

También este supuesto se juzgó en primera instancia aplicando el ordenamiento penal anterior a la reforma.

\section{5.- SAP Málaga 120/2016, de 23 de febrero.}

La AP confirma la sentencia condenatoria dictada por el Juzgado de lo Penal $\mathrm{n}^{\mathrm{o}} 3$ de esa ciudad (01/07/2015), que impuso la pena de dieciocho meses de prisión al hombre que había atacado a personal sanitario de un Hospital Materno Infantil, donde era ingresado frecuentemente su hijo.

Este colectivo profesional ya había remitido quejas en este sentido a la Dirección del centro, si bien era remiso a interponer denuncias «por temor a represalias», como recoge la resolución de instancia y transcribe en el primero de los Antecedentes de Hecho la SAP:

«la situación de terror en que ha de desarrollar su labor asistencial debido a las amenazas y agresiones físicas que sufren, asi como el temor a denunciar por miedo a las represalias».

El juzgador «a quo» insistía en señalar la constante agresividad que durante años venía desarrollando contra este personal:

«...sometiendo a dicho personal a una tensión constante, hasta el punto de que han evitado interponer denuncias por miedo a represalias, alterando el normal funcionamiento de la referida Unidad de Cuidados Críticos y Urgencias Pediátricas, por la constante intervención del servicio de seguridad privado de la empresa (...) para el establecimiento del orden, e incluso con intervención policial». 
La amplitud de la condena en ambas instancias se debe por tanto a la reincidencia del acusado, que venía amedrentando, amenazando e incluso atacando física y verbalmente al personal del hospital desde años anteriores a esta condena ${ }^{231}$.

\section{6.- SAP Pontevedra 302/2016, de 23 de mayo.}

El Juzgado de lo Penal $n^{\circ} 1(06 / 10 / 2015)$ de dicha ciudad había condenado a un año de prisión por delito de atentado al agresor de una enfermera en el servicio de Urgencias de un hospital público, a pesar de reconocerse que estaba bajo la influencia del alcohol en el momento de llevar a cabo los hechos:

«...lo que mermaba su forma de actuar levemente».

En este supuesto, ni la Sala ni el juzgador de instancia aplican la pena a prisión en su nivel inferior, a pesar del estado de embriaguez del acusado (aunque las resoluciones de ambas instancias se mantienen por debajo de la media del tramo legal que permite el CP de 2015).

\section{7.- SAP Les Illes Balears 118/2016, de 25 de julio.}

El Juzgado de lo Penal n ${ }^{\circ} 1$ de Mahón (01/09/2015) condenó a un año de prisión, como autor de un delito de atentado, a un hombre que agredió gravemente a una enfermera en la Unidad de Psiquiatría de un hospital, teniendo que intervenir otros pacientes, así como compañeros de la afectada e incluso el personal de seguridad.

El hombre había sido ingresado por orden judicial y desde el primer momento mostró gran agresividad:

«...siendo que desde dicho ingreso no voluntario tuvo en todo momento un comportamiento altivo, insolente, insultante y amenazante hacia los demás internos y hacia los profesionales que trabajan en dicha Área».

A pesar de que el recurso de apelación interpuesto por la representación legal del acusado solicitaba la revocación de la sentencia o subsidiariamente la disminución de la pena por aplicación o bien de la circunstancia eximente o bien de la atenuante de anomalía psíquica, la Sala, descarta la existencia de la circunstancia eximente ${ }^{232}$, y, aunque aprecia la atenuante,

\footnotetext{
${ }^{231}$ Ya había sido condenado por la agresión a un enfermero de este hospital, según se pone de manifiesto en los Hechos Probados de la sentencia del juzgado.

232 «En conclusión, no se aprecia que existe base médica que dictamine que el recurrente, en el momento de los hechos tenía anuladas completamente sus facultades mentales. Ello descarta por completo la aplicación de la eximente solicitada».
} 
mantiene los términos de la condena a prisión impuesta por la resolución del juzgador de instancia:

"...la cual revoca únicamente en el sentido de apreciar la circunstancia atenuante análoga de anomalía o alteración psíquica en D. Faustino, manteniendo las penas impuestas» ${ }^{233}$.

También, en este caso, los términos de ambas sentencias se encuentran comprendidos en el tramo más bajo de las condenas que la LO 1/2015 permite, pese a no aplicarse el límite inferior ${ }^{234}$.

\section{8.- SAP Alicante 303/2016, de 29 de julio.}

El Juzgado de lo Penal $n^{\circ} 1$ de Alicante (03/02/2016) condena a una mujer como autora de delito de atentado a 20 meses de prisión ${ }^{235}$. La AP confirma la sentencia en cuanto a este pronunciamiento.

La amplitud de la condena a prisión, aunque se mantiene en la mitad inferior del tramo legal que el ordenamiento penal permite, está relacionada con la violencia que alcanzaron los hechos ${ }^{236}$, en los que tuvieron que intervenir incluso agentes de la autoridad, así como a que fueron dos los facultativos agredidos: una médico del servicio de Urgencias del Hospital General Universitario y un médico que intentó apartar de ella a la agresora ${ }^{237}$.

De todos modos, la sentencia hace hincapié en que, a pesar de todo y aunque no se está aplicando el límite inferior tal como se solicitaba en el recurso de apelación ${ }^{238}$ (debido a esa brutalidad y a la duplicación del número de víctimas ${ }^{239}$ ), se está considerando «la mitad inferior de la pena legal típica, incluso con la rebaja introducida por la LO 1/2015 en el mínimo legal».

\footnotetext{
${ }^{233}$ Modifica parcialmente la sentencia estimando el recurso de apelación que el abogado de la CCAA interpone en representación de la víctima, solicitando un aumento en la cantidad indemnizatoria, a lo que la Sala accede.

${ }^{234}$ Teniendo en cuenta, además, que la agresión había sido muy violenta, provocando consecuencias lesivas de larga duración en la víctima. De hecho, el juzgador de instancia consideró que existía delito de atentado en concurso ideal con un delito de lesiones, por el que fue condenado también a un año de prisión.

${ }^{235}$ Cita expresamente que se ciñe a lo establecido en la reforma del ordenamiento penal que entró en vigor en julio de 2015.

${ }^{236}$ En expresión de la Sala, refiriéndose a cómo se produjeron los hechos: «lo que denota una violencia e insidia en el ataque que sin duda justifica la exasperación punitiva que, en todo caso, se mantiene en la mitad inferior».

${ }^{237}$ La agresión tuvo lugar cuando ambos se encontraban en el mostrador y fue especialmente duro en cuanto a la facultativa, a la que acusaba de ser la culpable de un aborto que había sufrido puesto que había sido ella la que la atendió en Urgencias.

238 Dice así la SAP: «Una vez más el recurso pretende hacer estado de la cuestión, y pese a que motivadamente se ha rechazado que el aborto sufrido por la paciente días antes pudiera tener influencia alguna en su imputabilidad, el recurso insiste en que se valore para la imposición, no de la pena en su mitad inferior, sino en su mínima expresión legal, pese a la brutalidad del ataque».

${ }^{239}$ Como puede verse en esta otra cita tomada de la misma SAP: «No es cierto que solo valore la condición de la facultativa, como persona indefensa en su puesto de trabajo, sino que además pondera de manera expresa la brutalidad y gravedad objetiva de la conducta que se refleja no solo del cúmulo de golpes y zonas afectadas del cuerpo de la médico, sino en la existencia de dos facultativos agredidos».
} 
Parece como si la propia Sala estuviera reconociendo que la penalización disminuye con la reforma.

\section{b.- Resoluciones tomadas a partir de diversas fuentes}

En todas ellas observamos que la condena a prisión sobrepasa el límite inferior, aunque se mantienen, como en los supuestos anteriores, por debajo de la media del tramo establecido por la legislación penal.

1.- El Juzgado de lo Penal $\mathrm{n}^{\circ} 1$ de Cáceres condena a un año de prisión a una mujer que agredió a una médico pediatra ${ }^{240}$ en un centro de salud. La médico había atendido antes a su hija menor y madre e hija se fueron, Sin embargo, a los pocos minutos, la mujer volvió a la consulta descontenta por cómo habían sido tratadas por la facultativa y fue entonces cuando se produjo la agresión.

La noticia es de 5 de septiembre de 2015 y, aunque la fuente no especifica la fecha de celebración del juicio, sí dice que el juzgado «acaba de condenar», por lo que entendemos que ha habido cierta inmediatez entre la publicación de la sentencia y la aparición de la noticia ("Una madre es condenada por agredir a una pediatra en Cáceres . hoy.es,” 2015).

2.-El Juzgado de lo Penal $\mathrm{n}^{\mathrm{o}} 28$ de Barcelona (14/11/2015) condena a un año de prisión por cometer delito de atentado, a una mujer que agredió a una enfermera en el Hospital Clínico de Barcelona ("Condena de un año de cárcel a una paciente por agredir, escupir e insultar a una enfermera del Hospital Clínic de Barcelona | iSanidad," 2016). La acusada ya era conocida en el hospital por provocar incidentes. La noticia aparece en diversos medios de comunicación que coinciden básicamente en los hechos y pormenores de la sentencia, aunque discrepan en lo relacionado con la fecha de producción de los hechos ${ }^{241}$.

La fuente está fechada en 19 de abril de 2016.

3.- Alerta Digital publica el 25 de septiembre de 2016, que el Juzgado de lo Penal $\mathrm{n}^{\circ} 8$ de Alicante, en sentencia luego confirmada por la AP de dicha ciudad, condenó a dieciséis meses de prisión al agresor de un celador en un centro de salud ${ }^{242}$, al que amenazó llegando a exhibir un objeto punzante. Al parecer estaba molesto por el trato que, en su opinión, estaba recibiendo su hermano

\footnotetext{
240 Los hechos ocurrieron el 5 de junio de 2014.

${ }^{241}$ La cita que hemos recogido en el texto se refiere al 24 de noviembre de 2014 . Otras fuentes, en cambio, refieren los hechos al 26 de ese mismo mes. En esta línea, véanse:

http://www.lainformacion.com/policia-y-justicia/magistratura/Carcel-insultar-enfermera-HospitalClinic_0_908309545.html.http://www.elmundo.es/cataluna/2016/04/16/57122caf268e3e274c8b465b.html.-

https://www.cmb.eus/observatorio-de-agresiones-2/carcel-para-una-paciente-por-agredir-insultar-y-escupir-a-unaenfermera-del-hospital-clinic

242 Los hechos tuvieron lugar en agosto de 2014.
} 
por parte de la víctima ("Una sentencia considera un atentado la agresión a un médico fuera del hospital - Alerta Digital,” 2016).

\section{CONCLUSIONES}

En todos los supuestos analizados se aprecia que los tribunales no han aplicado el límite inferior (seis meses), frente a lo que venía siendo tendencia antes de entrar en vigor la reforma: la aplicación del límite inferior que, de acuerdo con aquel ordenamiento, era de un año.

Por consiguiente, parece que quiebra la tendencia a aplicar la menor pena posible en el caso de que la condena sea a prisión, lo que supondría que no se ha reducido la penalidad con el CP reformado.

Sin embargo, las penas que con más frecuencia se imponen son de un año ${ }^{243}$. Es decir, parece denotarse en la actuación de los tribunales una tónica de continuidad con dicha tendencia de fuerte arraigo en la etapa anterior. En cualquier caso, a partir de estos supuestos podría concluirse que la penalidad no disminuye pero tampoco aumenta, en contra de lo que opinan algunos autores como ya se ha indicado, pues no se supera en ninguno de los supuestos analizados la mitad inferior del tramo legal establecido en el CP de 2015.

Por otra parte, las resoluciones que superaron la condena a un año de prisión, corresponden a agresiones protagonizadas por personas reincidentes, o a actos de violencia notable o que se produjeron contra pluralidad de personas, situación que en alguna sentencia denota el propio Tribunal para justificar el incremento en las penas.

Pero, incluso en estos casos, las penas se mantienen por debajo de la media del tramo que la legislación penal permite, como hace notar el órgano jurisdiccional en un supuesto en el que expresamente había reconocido la violencia extrema de los hechos juzgados ${ }^{244}$.

\footnotetext{
${ }^{243}$ Ese era el límite inferior en el anterior ordenamiento.

${ }^{244}$ SAP Alicante 303/2016, de 29 de julio.
} 


\section{Resoluciones en las que los tribunales aplican el límite inferior}

\section{a.- Sentencias}

\section{1.- SAP Madrid 509/2015, de 6 de julio.}

El Juzgado de lo Penal $n^{\circ} 2$ de Getafe (22/04/2015), había estimado la existencia de delito de atentado en la agresión de una mujer a dos enfermeras y una celadora ${ }^{245}$ en un hospital público, donde había sido ingresada por ingesta medicamentosa (parece desprenderse del recurso que incluso alcohol y cannabis) mostrando una actitud agresiva. La sentencia determinó nueve meses de prisión, después de aplicar una eximente incompleta y la atenuante de dilaciones indebidas ${ }^{246}$.

La Sala desestima en principio los motivos expuestos en el recurso de apelación interpuesto contra la sentencia, en solicitud de penas de duración y cuantías menores. Sin embargo, al aplicar de oficio lo previsto en la LO de 2015, revoca parcialmente la sentencia de instancia ${ }^{247}$. En lo referente al delito de atentado, fija la condena no en nueve sino en cuatro meses de prisión.

«la Ley Orgánica 1/2015, de 30 de marzo, introduce una nueva redacción en los arts. 550 y 551 del Código Penal, estableciendo una penalidad para el delito de atentado a funcionarios que no tienen la condición de autoridad, cuyo límite mínimo, de seis meses, es inferior al año que fijaba la redacción anterior, vigente en el momento de los hechos. Esta norma debe ser aplicada retroactivamente, conforme al art. 2.2 del Código Penal y la disposición transitoria tercera de la citada Ley Orgánica, por resultar más beneficiosa para la acusada». ${ }^{248}$

En este supuesto, por lo que hace relación con el delito de atentado la aplicación de la reforma supone una disminución de la punición, cuando se aplica en su límite inferior.

\section{2.- SAP Cádiz 206/2015, de 20 de julio.}

La AP de Cádiz confirma íntegramente la sentencia dictada por el Juzgado de lo Penal $n^{\circ} 3$ de dicha ciudad (30/03/2015), que consideró la existencia de un delito de atentado de en la agresión que llevó a cabo una mujer (que estaba muy alterada) contra uno de los cirujanos que habían

\footnotetext{
245 La narración de los hechos es confusa en cuanto a la celadora porque a veces se refiere la sentencia a ella aplicándole un nombre propio correspondiente a un varón.

${ }^{246}$ Los hechos habían tenido lugar en 2010 y la causa estuvo paralizada desde 2012 hasta 2014.

247 La condena venía ya de instancia situada por debajo del límite inferior, que en aquel momento era de un año.

248 La sentencia continúa diciendo: "La rebaja en un grado de la nueva penalidad del delito de atentado, por la concurrencia de las dos circunstancias atenuantes, nos lleva necesariamente a una duración de la pena de prisión de entre tres y seis meses, dentro de lo cual, siguiendo los mismos criterios que en la sentencia apelada, se estima procedente establecer dicha pena en cuatro meses».
} 
intervenido quirúrgicamente a su hijo, cuando estos salían del quirófano a informarla. Se la condena a seis meses de prisión ${ }^{249}$.

Hay que hacer notar que la sentencia del juzgador de instancia se había dictado estando aún vigente el CP de 1995, es decir, ya estaba por debajo del límite inferior generalmente aplicado atendiendo a aquel ordenamiento.

\section{3.- SAP Las Palmas 162/2015, de 17 de septiembre.}

La AP de Las Palmas revoca parcialmente la sentencia del Juzgado de lo Penal $\mathrm{n}^{\mathrm{o}} 2$ de la ciudad (12/02/2015), que de acuerdo con el CP de 1995 había condenado al agresor de un celador como autor de delito de atentado a nueve meses de prisión.

Los hechos violentos se produjeron en un centro hospitalario y alcanzaron también a otras personas. En primera instancia se había aplicado ya el límite inferior que en esos momentos preveía el ordenamiento penal, rebajándose la pena en un grado por apreciarse la existencia de una anomalía física, a pesar de que el acusado era reincidente. La condena quedó fijada en nueve meses de prisión por el delito de atentado.

Pero la Sala entiende que la anomalía era de mayor intensidad que lo que el juzgador «a quo» había estimado y procede a rebajar la pena de prisión en dos grados sobre el límite inferior que determina la LO 1/2015.

En consecuencia, por lo que respecta al atentado, la condena a prisión con la rebaja aplicada por la Sala a partir del límite inferior (seis meses), sería de dos meses y quince días. Al ser esta condena inferior a tres meses, queda sustituida por una multa ${ }^{250}$.

Puede el tribunal optar por multa o por localización permanente, pero se inclina por lo primero entendiendo que la localización permanente, al suponer privación de libertad, resulta más onerosa para el acusado. También puede sustituirse la prisión por la realización de trabajos en beneficio de la comunidad, pero la Sala lo descarta pues para esto es necesario el consentimiento del acusado $^{251}$.

\footnotetext{
${ }^{249}$ Se aplicó la atenuante de dilaciones indebidas, dado que los hechos habían tenido lugar en 2009.

${ }^{250} \mathrm{El}$ acusado solicitaba también el recurso que se derivase la responsabilidad civil que él pudiera tener al Servicio Canario de Salud, por entender que los hechos ocurrieron en un centro dependiente de la Administración y sus empleados no lo impidieron convenientemente. La AP lo desestima.

251 «Como quiera, por tanto, que estamos ante una pena inferior a la de tres meses de prisión, de conformidad con las previsiones del art.71 la misma deberá ser necesariamente sustituida considerando la Sala que dicha sustitución debe serlo por multa (dado que la pena de trabajos en beneficio de la comunidad no se puede fijar sin consentimiento del penado y la de localización permanente sería más perjudicial por ser privativa de libertad) a razón de dos días multa por cada día de prisión con una cuota diaria de seis euros que se estima razonable en la generalidad de los casos».
} 
En definitiva, la punición del delito de atentado queda reducida al pago de novecientos euros. Es decir que, por lo que se refiere a este ilícito, la disminución de la condena con respecto al régimen penal anterior a la reforma parece incuestionable.

\section{4.- Sentencia del Juzgado de lo Penal $\mathbf{n}^{0} 10$ de Madrid de 1 de octubre de $2015^{252}$.}

El Juzgado de lo Penal $n^{\circ} 10$ de Madrid condena a 3 meses de prisión por delito de atentado (aplicando la circunstancia atenuante de dilaciones indebidas ${ }^{253}$ ) a un hombre que insultó y amenazó a un médico en un centro de salud porque éste se había negado a extenderle unas recetas $^{254}$.

En el recurso de apelación interpuesto contra esta sentencia se solicita, entre otras cosas, que no se consideraran atentado unos hechos de tan poca gravedad, en opinión del recurrente:

«...puesto que la conducta del hoy apelante se limitó a proferir insultos por lo que los hechos sólo pueden ser calificados, a lo sumo, de una falta de injurias, destacándose que en el auto de incoación de abreviados se calificó como delito de amenazas y no de atentado, por todo lo cual lo que procede es la libre absolución» ${ }^{255}$.

\section{5.- SAP Granada 627/2015, de 26 de octubre.}

El Juzgado de lo Penal $n^{\circ} 4$ de Granada (24/11/2014), estima que existe atentado en la actitud agresiva de algunos familiares de una anciana de 90 años, en estado terminal, contra una enfermera en un hospital público.

Los hechos tuvieron lugar cuando los allegados de la enferma pretendían que se le aplicara rápidamente la sedación prescrita por un médico a causa de los dolores que estaba padeciendo.

El juzgador de instancia condena a cada uno de los dos familiares implicados en la agresión a catorce meses de prisión (teniendo en cuenta el estado emocional en que se encontraban aunque sin llegarlo a considerar como circunstancia eximente).

La Sala revoca parcialmente la sentencia, en lo concerniente al delito de atentado. Absuelve de él a la familiar acusada, por entender que un repiqueteo de los dedos en la espalda carece de la gravedad suficiente para que pueda ser considerado el acto como constitutivo de atentado.

\footnotetext{
252 Procedimiento Abreviado 209/2013.

253 Los hechos tuvieron lugar en octubre de 2012.

254 Parece que, además, existía una falsificación de recetas aunque no se acredita su autoría

255 La AP estima el recurso y procede a la libre absolución del acusado. Ver SAP Madrid 104/2016, de 25 de febrero.
} 
«los golpecitos en la espalda de la enfermera con un dedo, no pueden integrar el delito de atentado que por su rigurosidad está sometido a una interpretación restrictiva. La acción de "percutir" un dedo sobre la espalda, más bien dirigida a hacer una llamada de atención o a molestar, no puede integrarse en forma alguna en la acción de acometer, emplear fuerza, intimidar o resistirse, conductas todas ellas descritas en el delito de atentado».

Considera, por el contrario, al otro acusado responsable del ilícito ${ }^{256}$, condenándole a la pena de prisión en el límite inferior previsto, es decir, seis meses.

\section{6.- Sentencia Juzgado de lo Penal $\mathbf{n}^{0} 3$ de Bilbao, de 26 de noviembre de 2015.}

El Juzgado de lo Penal n 3 de Bilbao ${ }^{257}$ había condenado a siete meses de prisión, como autora de un delito de atentado, a la agresora de una enfermera en un hospital público.

Según la versión de la víctima, corroborada por el testimonio de una compañera (que no estaba presente en el lugar de los hechos cuando estos acaecieron):

«...la acusada Hernán (...) cogió a su bebé e hizo amago de tirarlo al suelo, interviniendo la enfermera Vicenta, quien logró agarrar a la niña con el brazo izquierdo, momento en que la acusada, con ánimo de menoscabar el legítimo ejercicio de la autoridad de Vicenta, le propinó un golpe en el brazo derecho».

La resolución del juzgador de instancia se inscribe en la tendencia a señalar como penas las que se determinan en el límite inferior ${ }^{258}$.

\section{7.- SAP de Alicante 582/2015, de 22 de diciembre.}

El Juzgado de lo Penal $n^{\circ} 7$ de Alicante (20/10/2015) condenó como autora de delito de atentado a la agresora de una auxiliar de clínica en la Unidad Polivalente de Salud Mental de un centro público. Por el delito de atentado, teniendo en cuenta el estado mental de la agresora, la condena es la siguiente:

«Debo CONDENAR Y CONDENO a Tamara (...), concurriendo la circunstancia eximente incompleta del art.21.1 en relación con el art.20.1 CP, EN RELACIÓN CON EL DELITO DE

\footnotetext{
${ }^{256}$ En este caso, hubo acometimiento dado que el acusado agarró por el brazo a la enfermera y la lanzó contra la pared.

257 Procedimiento abreviado 270/15.

${ }^{258}$ Aunque posteriormente la AP revoca íntegramente esta sentencia. Véase SAP Bizkaia 90101/2016 (sic), de 16 de marzo. Documento TOL5.736.498
} 
ATENTADO a la pena de 6 meses de prisión (...) así como a la medida de internamiento en régimen cerrado en Centro adecuado a su salud mental durante un máximo de 3 años».

La AP confirma íntegramente la sentencia recurrida. Por consiguiente, por lo que se refiere al atentado, la Sala mantiene la condena impuesta por el juzgador de instancia, la cual está ya en el límite inferior establecido por el ordenamiento penal de 2015.

\section{8.- SAP Madrid 871/2015, de 30 de diciembre.}

El Juzgado de lo Penal no 22 de Madrid (09/10/2015) ${ }^{259}$ había condenado por delito de atentado a cinco meses de prisión (después de aplicar la eximente incompleta de enajenación mental) a una mujer de Perú, con permiso de residencia, que agredió a una psiquiatra en la planta de Psiquiatría del hospital público donde estaba ingresada. Los hechos ocurrieron en el año $2010^{260}$.

Se interpone por parte de la acusada recurso de apelación contra esta sentencia y la AP entiende que el juzgador de instancia ha debido de atribuir más relevancia al estado mental de la recurrente.

En consecuencia, procede a absolverla de la comisión de delito de atentado, revocando parcialmente la sentencia de instancia:

«...que procede revocar parcialmente en el extremo de absolver a la acusada del delito de atentado, por aplicación del eximente de trastorno mental transitorio, y a acordar la medida de seguridad de sumisión a tratamiento externo en Centro médico o establecimiento adecuado al tipo de anomalía o alteración psíquica que padece la acusada por el tiempo que sea preciso, que no podrá exceder de seis meses».

\section{9.- SAP Cuenca 25/2016, de 16 de febrero.}

El Juzgado de lo Penal no 2 de Cuenca (22/07/2015), estimó que un paciente, acusado de mantener una actitud violenta contra un enfermero y varios agentes de la autoridad en un centro de salud, era autor de un delito de atentado:

"con la concurrencia de la eximente incompleta, a la pena de 3 meses de prisión con la inhabilitación especial para el ejercicio del derecho de sufragio pasivo durante el tiempo de la condena y a la libertad vigilada consistente en la obligación de seguir tratamiento médico externo o de someterse a un control médico periódico por un periodo de 2 años y costas».

\footnotetext{
259 Sentencia que se aclara posteriormente mediante Auto de fecha 28 de octubre de 2015.

260 Existe una especie de confusión en la fecha, dado que el texto de la sentencia se refiere a veces a 2010 y en otras ocasiones a 2009. En cualquier caso, no se habla de la circunstancia atenuante de dilaciones indebidas en ningún momento. Tampoco se alega por la parte acusada al interponer recurso de apelación.
} 
El juzgador «a quo» impone el límite inferior de la pena a prisión, reducido además por la aplicación de la eximente incompleta. La AP confirma la resolución de instancia en todos sus pronunciamientos.

\section{0.- SAP Granada 158/2016, de 14 de marzo.}

La AP de Granada resuelve el recurso de apelación ${ }^{261}$ interpuesto contra la sentencia dictada por el Juzgado de lo Penal no 3 de esa ciudad (31/03/2015), revocándola parcialmente.

El juzgador de instancia había tipificado como delito de atentado la agresión física y verbal de un hombre a una enfermera en un hospital público, teniendo ésta que reclamar ayuda para librarse del agresor:

«Tras estos hechos Genoveva llamó al supervisor de guardia, a la policía y a los vigilantes de seguridad que se personaron y acompañaron al acusado Melchor hasta la salida del Hospital».

El juzgador «a quo» condena al acusado por el delito de atentado a un año de prisión. Hay que tener en cuenta que el juicio tiene lugar antes de la entrada en vigor de la reforma ( 1 de julio de 2015) y que el juzgador de instancia está aplicando el límite inferior de la posible pena de acuerdo con el CP entonces vigente.

La AP confirma la existencia de atentado pero aplica a su vez el límite inferior que establece la LO 1/2015, quedando en consecuencia reducida esa pena de prisión de un año a seis meses ${ }^{262}$.

\section{1.- SAP Sevilla 158/2016, de 26 de abril.}

La AP de Sevilla confirma la sentencia del Juzgado de lo Penal no 7 de dicha ciudad (08/10/2015), que condenó como autora de delito de atentado a una mujer por causa de la agresión que llevo a cabo contra una enfermera en un hospital público. La condena por este delito fue a seis meses de prisión y queda en suspenso a condición de que no vuelva a delinquir en el plazo de dos años.

\footnotetext{
${ }^{261}$ En el recurso, según las manifestaciones de la Sala, se llega incluso a considerar que existe «corporativismo» para restar validez a los testimonios de algunas compañeras de la víctima que actuaron como testigos en apoyo de sus declaraciones.

262 Procede a rebajar también la indemnización a la víctima que, en concepto de responsabilidad civil por las consecuencias derivadas de la agresión, se fijaron por el juzgador «a quo» en 1000 euros, quedándola reducida a 500 euros por considerar la Sala que la perjudicada ya padecía una patología previa a los hechos.
} 
Los hechos ocurrieron cuando la acusada, que acompañaba a su marido que era el paciente, entró en la consulta ${ }^{263}$ y agredió a la enfermera aunque, como parece desprenderse del texto de la SAP, no tenía cita con ella ${ }^{264}$.

\section{2.- Sentencia Juzgado de lo Penal $n^{0} 10$ de Valencia 243/2016, de 23/05.}

El Juzgado de lo Penal $n^{\circ} 10$ de Valencia ${ }^{265}$ estimó que había cometido atentado el autor de una agresión a un médico: los hechos ocurrieron ${ }^{266}$ en las dependencias del Juzgado de Primera Instancia e Instrucción $n^{\circ} 4$ de Requena, lugar al que el acusado había ido a declarar en unas diligencias previas ${ }^{267}$ abiertas por una denuncia contra el facultativo, porque los padres le responsabilizaban de la muerte de su hija de once años ${ }^{268}$. El fallecimiento ocurrió ${ }^{269}$ tras ser atendida la menor por ese médico en el centro de atención primaria donde trabajaba y los padres le culpaban de lo ocurrido:

«se le imputaba la posible comisión de un delito de homicidio por imprudencia profesional en relación con la asistencia médica prestada a la niña».

Los padres y el denunciado no habían vuelto a encontrarse desde la muerte de la niña y el día de autos, tras prestar ellos declaración esperaron al médico en las dependencias del juzgado y cuando éste iba a abandonarlas el padre le amenazó y agredió físicamente.

El médico ${ }^{270}$ en el año 2012, solicitó y obtuvo traslado de su puesto de trabajo, por miedo a ser víctima de alguna agresión:

«solicitó a la Agencia Valenciana de Salud que se tomaran las medidas oportunas para evitar el riesgo de agresión y garantizar la seguridad en su puesto de trabajo, siendo reasignado a otro destino».

\footnotetext{
${ }^{263}$ Al parecer había visto como otra persona iba a entrar en la sala de curas de la enfermera y, según se desprende del texto de la sentencia, interpretó que estaba posponiendo tratar a su marido.

264 "ese día no tenía cita con la enfermera sino con un médico del Centro"

265 Juicio Oral 474/2015-MT

${ }^{266} \mathrm{El}$ ataque se produjo a mediodía del 24 de noviembre de 2011.

267 Diligencias previas 1.351/2010.

268 La niña murió a causa de un shock séptico y peritonitis aguda.

269 La fecha del fallecimiento fue el 27 de diciembre de 2010.

270 "estuvo acudiendo a la unidad de neuropsiquiatría del centro de especialidades de Monteolivete recibiendo tratamiento por un cuadro clínico compatible con diagnóstico de trastorno adaptativo mixto con ansiedad y ánimo depresivo desde el 27 de diciembre de 2011 hasta febrero de 2012, continuando posteriormente en tratamiento psiquiátrico (...)».
} 
El padre de la fallecida, por su parte, cuando ocurrieron los hechos tomaba medicación y asistía a tratamiento psicológico a raíz de la pérdida de su hija ${ }^{271}$ :

«En dicho contexto, el encuentro del acusado con él en los Juzgados de Requena el día de los hechos supuso un estímulo muy poderoso para el mismo que comprometió seriamente sus capacidades intelectivas y volitivas sin llegar a anularlas».

Aunque la agresión se tipifica como delito de atentado ${ }^{272}$, se le condena a un mes y quince días de prisión y al pago de una indemnización a la víctima ${ }^{273}$. Pero la disminución de la pena se ha aplicado a partir del límite inferior del tramo legal que el ordenamiento permite para estos supuestos.

\section{3.- SAP Almería 272/2016, de 10 de junio.}

La AP de Almería confirma íntegramente la sentencia del Juzgado de lo Penal $\mathrm{n}^{\circ} 3$ de dicha ciudad (25/11/2015), que condenó como autor de un delito de atentado a un paciente que, ingresado ${ }^{274}$ en la Unidad de Hospitalización de Salud Mental de un hospital público, agredió a varias enfermeras y enfermeros de la planta ${ }^{275}$.

La condena, por lo que hace relación con el delito de atentado, fue a seis meses de prisión (el límite inferior establecido por la reforma).

\section{4.- SAP Murcia 417/2016, de 1 de julio.}

El Juzgado de lo Penal $\mathrm{n}^{\circ} 5$ de dicha ciudad (15/12/2015) estimó la existencia de delito de atentado en la actuación violenta de un hombre que agredió a un médico en un centro de salud ${ }^{276}$. Por el delito de atentado le condena a seis meses de prisión.

La parte acusada interpone contra esta sentencia recurso de apelación, en el que se alega, entre otras razones la falta de imparcialidad por parte de la juzgadora (motivo que la Sala desestima):

\footnotetext{
271 «siendo tratado en la época de en que sucedieron los hechos en consultas externas de psiquiatría del Hospital General de Almansa, tomando medicación a tales efectos, y acudiendo asimismo a consulta de psicología periódicamente para abordar su trauma y proceso de duelo»."

272 También se le considera autor de un delito leve de lesiones, por el que se le impone multa de diez días a razón de diez euros de cuota diaria.

${ }^{273}$ Se aplicó la atenuante de dilaciones indebidas además de tenerse muy en cuenta su estado emocional.

${ }^{274}$ Había sido ingresado, con su consenso, a través del servicio de Urgencias del hospital.

275 En la sentencia se recoge como el personal tenía "temor y desasosiego», a causa de las amenazas.

${ }^{276}$ El hombre buscaba asistencia para su madre y había ido a buscar al médico varias veces al bar donde estaba almorzando con otros compañeros.
} 
«En primer lugar denuncia al amparo del art. 790.2, nulidad del juicio por infracción de garantías procesales que causaren la indefensión del recurrente: falta de imparcialidad de la Magistrada al adelantar el fallo condenatorio y realizar funciones de acusación al realizar pregunta incriminatoria que luego traspasa a la sentencia para fundamentar la condena por lesiones. art. 24.1 Constitución Española en relación con el art. 241 LOPJ derecho al Juez imparcial».

La AP revoca parcialmente la sentencia pero mantiene en todos sus términos lo relacionado con la estimación de delito de atentado y la pena que venía aplicada desde instancia ${ }^{277}$.

\section{5.- SAP Madrid 540/2016, de 18 de julio.}

En el Centro Integral de Apoyo a la Drogodependencia, dependiente del Servicio Madrileño de Salud, un hombre agrede a un médico porque no estaba de acuerdo con el cambio de dosis de su tratamiento con metadona que le estaba prescribiendo.

"...al no estar de acuerdo con el cambio de dispensación de sus dosis que le prescribió el facultativo, se abalanzó contra el doctor y le propinó un puñetazo en la mandíbula izquierda y, seguidamente se subió a la mesa y le agarro al médico por el cuello y le propinó un segundo puñetazo en la misma zona».

El Juzgado de lo Penal no 22 de Madrid (21/03/2016), consideró los hechos como constitutivos de delito de atentado y condenó por esa causa al agresor a tres meses de prisión, después de aplicar la circunstancia atenuante de dilaciones indebidas ${ }^{278}$.

La Sala confirma íntegramente la sentencia de instancia.

\section{6.- SAP Madrid 125/2017, de 24 de febrero.}

El Juzgado de lo Penal n ${ }^{\circ} 15$ de Madrid (04/11/2016) dictó sentencia condenando a seis meses de prisión (después de aplicar la atenuante de dilaciones indebidas ${ }^{279}$ ) a un hombre que agredió a un médico de la Clínica FREMAP ${ }^{280}$. También le impone la obligación de indemnizar al perjudicado.

\footnotetext{
${ }^{277}$ No se alega en ningún momento la existencia de dilaciones indebidas, aunque los hechos tuvieron lugar en el año 2012.

278 Los hechos ocurrieron en febrero de 2013. El procedimiento estuvo paralizado por causas ajenas al acusado desde octubre de 2013 a septiembre de 2015.

${ }^{279}$ La agresión tuvo lugar el 26 de junio de 2012.

280 Mutua de Accidentes de Trabajo y Enfermedades Profesionales de la Seguridad Social.
} 
El agresor acudió allí con su hija, para solicitar la baja laboral de ésta ya que había sido dada de alta el día anterior. Cuando el facultativo se negó a ello (después de examinar a la solicitante y comprobar sus circunstancias físicas), el acusado agredió física y verbalmente a la víctima.

La AP desestima el recurso de apelación interpuesto contra esta resolución y la confirma en todos sus pronunciamientos.

\section{b.- Resoluciones tomadas a partir de diversas fuentes}

1.- El Colegio de Médicos de Vizcaya da noticia (7 de septiembre de 2015) de una sentencia dictada por el Juzgado de lo Penal $n^{\circ} 1$ de Cáceres. Se condena a seis meses de prisión (teniéndose en cuenta el estado de embriaguez en que se encontraba) a un hombre que entró borracho en un centro de salud y agredió a una facultativa que trabajaba allí ("Una madre es condenada por agredir a una pediatra en Cáceres - Observatorio de Agresiones -" 2015).

2.- El Juzgado de lo Penal $\mathrm{n}^{\circ} 5$ de Bilbao condena a seis meses de prisión como autor de un delito de atentado a un hombre que agrede a una médico en un centro de salud. Los hechos ocurrieron en diciembre de 2014.

La pena queda en suspenso salvo que el acusado vuelva a delinquir en el plazo de dos años.

La fuente de la noticia es DEIA y la fecha: 4 de noviembre de 2015 ("Condenan a seis meses de prisión a un paciente que agredió a una médico en Erandio. Deia, Noticias de Bizkaia,” 2015).

3.- En Jerez de la Frontera, el Juzgado de lo Penal $\mathrm{n}^{\circ} 2$ condena a seis meses de prisión, como autor de un delito de atentado, al hombre que agredió a una facultativa en un centro de salud.

Los hechos ocurrieron en 2013 y el acusado intentaba que la médico atendiera a su hijo político «con rapidez». El hombre continuó con insultos hacia la víctima incluso después de que hubiera sido atendido su yerno.

La noticia se publica en ABC, el 1 de enero de 2016 ("Condenado por agredir a una doctora para que atendiera «con rapidez» a su yerno,” 2016).

4.- $\underline{\text { Un Juzgado de lo Penal }}{ }^{281}$ condena como autor de un delito de atentado al hombre que agredió a una médico en un Punto de Atención Continuada de Irún. Los hechos tuvieron lugar en 2011.

${ }^{281}$ La fuente no aporta ningún dato sobre cuál pueda ser este juzgado. 
Se le condena a siete meses de prisión que queda en suspenso, condicionada a que el agresor no vuelva a delinquir en el plazo de dos años.

La fuente de la noticia es Diario Vasco y la fecha el 4 de enero de 2016 ("Condenado por arrojar dos papeleras contra una doctora en una consulta de Irun . diariovasco.com,”2016).

5.-El Juzgado de lo Penal $\mathrm{n}^{\mathrm{o}} 2$ de Albacete condena a seis meses de prisión por la comisión de delito de atentado a un hombre que insultó e intentó agredir de un puñetazo a un médico en un centro de salud.

No lo consiguió y tampoco le causó lesiones. Los hechos ocurrieron el 28 de abril de 2013. El denunciante renunció a cualquier indemnización que pudiera corresponderle. La pena aplicada corresponde al límite inferior del tramo que la LO 1/2015 permite para los supuestos de atentado contra agente de la autoridad o funcionario, como en este caso.

La noticia se recoge en Médicos y Pacientes, el 18 de abril de 2016 ("Condena de seis meses de prisión por insultar e intentar agredir a un médico | Médicos y Pacientes,”2016).

6.- Un Juzgado de lo Penal ${ }^{282}$ condenó a seis meses de prisión como autora de un delito de atentado, a la agresora de una médico en un centro de salud.

Posteriormente la reclamación se interpuso en la vía Social para demandar al Servicio Extremeño de Salud por falta de medidas preventivas. El Juzgado de lo Social $\mathrm{n}^{\circ} 3$ de Badajoz condena al SES a pagar una indemnización a la víctima por los daños consecuencia de la agresión por no haber cumplido la normativa de prevención de riesgos laborales en el centro sanitario.

7.- La noticia se recoge en Diario Médico el 20 de marzo de 2017 (Carrasco, 2017). No se especifican detalles sobre la sentencia en la que el Juzgado de lo Penal $n^{\circ} 1$ de Badajoz condena como autor de delito de atentado, a un hombre que acudió a una Mutua en solicitud de la prórroga para su baja laboral.

"El agresor profirió amenazas como "te voy a matar"; "voy a hacer daño a tus hijos", "te vas a enterar" y acto seguido se abalanzó sobre él golpeándole fuertemente en el pecho y en el cuello».

282 No se aportan datos sobre este juzgado en la fuente; pero sí respecto al juzgado de lo social. ("El riesgo de agresión exige un plan preventivo - Observatorio de Agresiones," 2016) 
Tampoco se especifica la cuantía de la condena, sólo que: «El agresor ha sido condenado a indemnizar no sólo por los daños corporales y lesiones, sino también por el quebranto moral sufrido».

Sin embargo, dada la tendencia que venimos apreciando en la época en que se produce presumiblemente la sentencia, consideramos que se habrá aplicado el límite inferior de la posible condena a prisión.

\section{B.- Los hechos juzgados no se tipifican como delito de atentado}

\section{a.- Sentencias}

\section{1.- SAP Santa Cruz de Tenerife 315/2015, de 3 de julio.}

El Juzgado de Instrucción $n^{\circ} 2$ de San Cristóbal de La Laguna (30/03/2105), condenó a dos mujeres como autoras de una falta del art. $620 \mathrm{CP}$, imponiendo a cada una de ellas multa de diez días a razón de tres euros diarios.

Las dos mujeres se habían agredido mutuamente en el transcurso de una discusión en un hospital público, siendo una de ellas enfermera y la otra la hija de una paciente ingresada.

La enfermera recurre la sentencia por entender que debía considerarse, por su condición de funcionaria, la existencia de delito de atentado.

La AP desestima esa pretensión ${ }^{283}$ además de absolver a ambas acusadas de las faltas por las que habían sido condenadas.

\section{2.- SAP Madrid 104/2016, de 25 de febrero.}

La Sala estima el recurso interpuesto contra la sentencia del Juzgado de lo Penal $n^{\circ} 10$ de Madrid (01/10/2015) que revoca íntegramente, absolviendo en consecuencia al acusado de cometer delito de atentado por agredir a una psiquiatra en un hospital público, al entender que no existe encaje

\footnotetext{
283 «Con carácter previo, debe desestimarse la pretensión de nulidad aducida por la parte apelante, quien alega que los hechos denunciados deberían haberse tramitado como diligencias previas por ser susceptibles de incardinarse en un delito de atentado previsto y penado en el artículo 550 del Código Penal. Así, Mediante Auto de 25 de febrero de 2015 se acordó la incoación de Juicio de Faltas, resolución que ha devenido firme, sin que la parte ahora apelante formulase recurso alguno».
} 
de los hechos en la figura del delito de atentado del artículo 550 tras la reforma operada en 2015, porque en el nuevo ordenamiento la intimidación se vincula a la resistencia y ésta no se produjo:

«la intimidación no estuvo vinculada a un acto de resistencia sino que, por el contrario, fue una conducta activa y directa originada porque la doctora se negó a extender la receta que quería el hoy apelante. Por lo tanto, los hechos enjuiciados están despenalizados conforme a la actual regulación penal introducida por la LO 1/2015, que debe ser aplicada de forma retroactiva de conformidad con lo establecido en el artículo 2.2 del Código Penal y en la Disposición Transitoria 1.1 de la LO 1/2015. En consecuencia y sin necesidad de analizar los restantes motivos del recurso procede su estimación y la libre absolución del denunciado del delito de atentado».

Con esta aplicación de la reforma a los hechos juzgados por parte de la AP, la actuación violenta del acusado no tuvo penalización.

\section{3.- SAP Madrid 115/2016, de 7 de marzo.}

El Juzgado de lo Penal no 21 de Madrid, dictó sentencia (24/07/2015), en la que absolvía de los delitos de atentado y lesiones por los que venía siendo acusado, aplicando la eximente del artículo 20.1, puesto que padecía esquizofrenia paranoide, al paciente que agredió a la médico psiquiatra $^{284}$, que le estaba tratando desde hacía más de un año, en un centro de salud ${ }^{285}$.

El juez «a quo» le impone internamiento en un centro de media estancia para recibir tratamiento psiquiátrico por un máximo de tres años, así como la obligación de indemnizar a la víctima por las lesiones que le fueron causadas.

La AP revoca parcialmente la sentencia de instancia: al estimar algunas de las peticiones formuladas en el recurso de casación que la parte acusada interpuso contra dicha resolución, sustituye el internamiento por tratamiento ambulatorio a la vez que rebaja la cuantía de las indemnizaciones a percibir por la víctima.

\section{4.-SAP Bizkaia 90101/2016, de 16 de marzo ${ }^{286}$.}

La AP de Bizkaia absuelve a la agresora de una enfermera en un hospital público, a la que el Juzgado de lo Penal no 3 de Bilbao (26/11/2015) había condenado, como autora de un delito de

\footnotetext{
${ }^{284}$ Los hechos ocurrieron en el año 2009.

285 Un centro que, como puede colegirse de la sentencia, carecía de medios de seguridad «ni personal ni de otro tipo».

${ }^{286}$ Documento TOL5.736.498
} 
atentado a siete meses de prisión y a cuatro más por un delito de lesiones, además de la obligación de indemnizar a la víctima por los daños sufridos.

Contra ella se interpone recurso de apelación que la AP estima. La Sala inadmite los Hechos Probados que se relatan en la sentencia de instancia, entendiendo además que no ha sido valorada correctamente en instancia la prueba practicada.

«En definitiva, la declaración de la denunciante, elemento central de la valoración de la prueba efectuada, no ofrece la seguridad que se señala en la sentencia, tanto por los puntos dudosos que ofrece como por la inexistencia de referencias objetivas externas que la doten de verosimilitud».

En consecuencia, procede a revocar íntegramente la sentencia recurrida a la vez que absuelve a la acusada de todos los cargos por los que venía imputada.

\section{5.- SAP Madrid 125/2017, de 24 de febrero.}

Dos personas (padre e hija) vienen acusados de cometer varias faltas y también delito de atentado, porque habían agredido física y verbalmente en una clínica al médico de una Mutua de la Seguridad Social que no había accedido a conceder la baja laboral que la hija solicitaba.

La AP de Madrid confirma la sentencia del Juzgado de lo Penal $\mathrm{n}^{\circ} 15$ de dicha ciudad (04/11/2016) que no consideró a la acusada autora de delito de atentado, aunque sí tipifica como tal la agresión por parte del padre ${ }^{287}$.

\section{b.- Recursos obtenidos a partir de fuentes diversas.}

1.- Redacción Médica se hace eco (21/05/2015) de una SAP de Valladolid, confirmando otra previa (que no se cita) por la que se condena a la hija de un paciente por insultar a una médico valoradora de una empresa (MAZ). Como se recoge en la fuente consultada (Martínez Platel, 2015):

«...hubo expresiones que ponían en duda su profesionalidad, dentro de su espacio laboral y con motivo de su ejercicio profesional, y le fue dirigido el calificativo de "sinvergüenza", repetido en varias ocasiones, una de ellas llegando a oídos de una enfermera, expresión por su propio sentido gramatical es inequívocamente insultante».

\footnotetext{
${ }^{287}$ Absuelve a ambos, sin embargo, de las diversas faltas que también se les imputaban.
} 
Se la condena a multa de noventa euros (a razón de seis euros diarios durante veinte días). En la fuente se considera que sale casi gratis proferir insultos contra un profesional de la sanidad privada.

En cualquier caso, no ha lugar a la tipificación de los hechos como delito de atentado porque, sin entrar a valora la gravedad y entidad de lo ocurrido, este colectivo sanitario no puede ser considerado sujeto pasivo del delito de atentado por no poseer la condición de funcionario.

2.- Paciente que amenaza de muerte a una médico en su consulta de un centro de Salud. La noticia viene fechada a 13 de junio de 2016.

El Juzgado de Instrucción n 6 de Las Palmas de Gran Canaria condenó a un hombre por esas agresiones verbales, ocurridas el 29 de abril de ese mismo año.

Dice la fuente consultada ${ }^{288}$ :

«Según informa el Colegio de Médicos de Las Palmas, en concreto, la Sala ha dictado orden de alejamiento o comunicarse con su médico por un plazo de seis meses por delito leve de amenazas, además de una pena de dos meses de multa».

Y también que los Servicios Jurídicos del Colegio se hicieron cargo de la defensa de la víctima de la agresión.

Puede apreciarse cierta confusión en la fuente en cuanto a la consideración de estos hechos como delito de atentado:

«El Colegio de Médicos expuso que se trata de una de las primeras condenas en la provincia de Las Palmas que aplica la modificación artículo 550.1 del Código Penal en el que considera una agresión a un médico, fisica o verbal, un atentado...».

La sentencia, considerada en los términos en que se reproduce en la propia fuente, no recoge en absoluto la posibilidad de aplicar a este supuesto el artículo citado, es decir, la existencia de delito de atentado, puesto que se está hablando de delito leve de amenazas.

\section{CONCLUSIONES}

En todos los casos que hemos analizado en este apartado cuando se tipificaron los hechos como constitutivos de delito de atentado, observamos como los tribunales tienden a aplicar en las condenas a prisión penas incluidas en la mitad inferior del tramo legal que para estos delitos prevé

288 (“Un paciente que amenazó a su médica no podrá acercarse a ella en 6 meses - Observatorio de Agresiones," 2016) 
el ordenamiento penal posterior a la reforma del año 2015, aplicándose sobre todo el límite inferior (seis meses).

Sin entrar a valorar aún lo que ocurre con otras figuras delictivas, de las que nos ocuparemos a continuación, por lo que se refiere al ilícito del artículo 550, parece que sí puede establecerse que se está produciendo desde la actuación jurisprudencial una disminución en la penalidad, puesto que en las penas de prisión son más frecuentes incluso las comprendidas en el límite inferior.

Por consiguiente, la reforma del ordenamiento penal, aunque ha aumentado el tramo por el límite superior (tres años en la actualidad) no supone un efectivo incremento de la punición dado que el que más se viene aplicando es el límite inferior y éste ha sido reducido respecto al ordenamiento penal de 1995.

Hay que tener en cuenta además la posibilidad que brinda el actual ordenamiento, de que pueda ser suspendido el cumplimiento de las condenas a prisión, aunque sea bajo condición de no delinquir el acusado en el plazo de dos años ${ }^{289}$.

También debemos resaltar que, en algunos supuestos, la aplicación de las disposiciones de la LO 1/2015 por parte de las AP, al resolver los recursos de apelación interpuestos contra sentencias provenientes de instancia, puede suponer incluso la desestimación de la existencia de delito de atentado y de la condena a prisión que llevaba aneja, pudiendo llegarse a la absolución del $\operatorname{acusado}^{290}$.

En última instancia, y aun teniendo en cuenta, como hemos comprobado, que en ocasiones se dictan sentencias con penas de un año (tendencia, por otra parte, bastante arraigada en la etapa anterior), estas se mantienen por debajo de la mitad del tramo legal de la condena que el ordenamiento actual permite.

Por consiguiente, al menos respecto al delito de atentado, la punición o se mantiene en los niveles anteriores a 2015 o, lo que es aún más frecuente, disminuye con respecto a esa etapa. Pero, frente a lo que parte de la doctrina afirma, no aumenta la penalidad de este ilícito tras la reforma.

\footnotetext{
${ }^{289}$ Artículo $80 \mathrm{CP}$.

290 Véase: SAP Madrid 104/2016, de 25 de febrero.
} 


\section{2.- LAAPLICACIÓN RETROACTIVA DE LA REFORMA}

En este apartado consideramos mayoritariamente figuras delictivas no integradas en el delito de atentado. Nuestro principal objetivo es comprobar las consecuencias que pueden derivarse de aplicar o no aplicar esta reforma, con especial atención a las antiguas faltas, que fueron suprimidas del CP a raíz de su entrada en vigor, aunque la mayor parte de ellas tengan aún consecuencias penales al ser consideradas en el nuevo ordenamiento como delitos (frecuentemente delitos leves), como ya se ha señalado.

También podremos verificar si existe o no homogeneidad en la actuación de los tribunales en cuanto a la aplicación retroactiva de la reforma.

\section{A.- Resoluciones en las que no se aplica la retroactividad}

\section{a.- Sentencias}

\section{1.- SAP Cádiz 2016/2015, de 20 de julio.}

El Juzgado de lo Penal $\mathrm{n}^{\circ} 3$ de dicha ciudad (30/03/2015) estimó como autora de un delito de atentado y falta de lesiones a la mujer que golpeó en el pecho a uno de los dos cirujanos que habían intervenido quirúrgicamente a su hijo (menor), cuando los facultativos salían a informarla.

Además de las penas que correspondan al delito de atentado, se la condena a multa de treinta días a razón de seis euros diarios por una falta de lesiones, así como a indemnizar a la víctima.

La AP confirma íntegramente la sentencia, que se había dictado antes de la entrada en vigor de la reforma.

Aparte de lo que hace relación con el delito de atentado ${ }^{291}$, estamos ante un ejemplo de falta de homogeneidad en la actuación de los tribunales, porque en otros supuestos (como veremos) en relación con las faltas se aplica la reforma de forma retroactiva o analógica y pueden llegar incluso a quedar sin penalización ${ }^{292}$.

\footnotetext{
${ }^{291}$ Se estudia en el epígrafe correspondiente.

292 Ver el apartado dedicado a los efectos de la aplicación de la retroactividad en ilícitos no integrados en alguna de las modalidades de atentado.
} 


\section{2.- SAP Alicante 415/2015, de 31 de julio.}

Un hombre ataca a un celador en un centro de salud. El Juzgado de lo Penal $\mathrm{n}^{\circ} 8$ de Alicante (05/03/2015) tipifica los hechos ${ }^{293}$ como constitutivos de delito de atentado, imponiéndole además de condena a prisión, obligación de indemnizar al perjudicado en la cantidad de treinta euros por los daños que al forcejear con él le había producido en la ropa.

El recurso de apelación que el acusado interpone ante la AP solicita la revocación de esta sentencia, alegando principalmente lo siguiente:

«...la falta de testigos presenciales o el hecho de que el arma presuntamente utilizada no haya sido encontrada».

La AP confirma íntegramente la sentencia de instancia sin considerar una posible disminución en la condena a prisión que la rebaja del límite inferior establecido por la LO 1/2015 permite.

\section{3.- SAP Ourense 326/2015, de 25 de septiembre.}

El Juzgado de lo Penal $n^{\circ} 2$ de dicha ciudad (15/05/2015) condenó como autora de un delito de atentado a una mujer que agredió a una facultativa en un centro médico. La acusada había acudido allí a consulta y la víctima no era su médico habitual.

Además de la pena que corresponde por el delito de atentado, se la condena por una falta de lesiones a un mes de multa a razón de cinco euros diarios.

La Sala confirma íntegramente la sentencia y es otro caso de falta de homogeneidad en la actuación de los tribunales especialmente en cuanto al tratamiento de la falta de lesiones, al no proceder (como en otros supuestos) a aplicar retroactivamente lo que en lo relativo a las antiguas faltas determina el CP reformado.

\section{4.- SAP Badajoz 70/2015, de 30 de septiembre.}

Un hombre agrede a un médico y el Juzgado de lo Penal n 2 de Badajoz le condena, como autor de un delito de atentado sin estimar las faltas de lesiones y amenazas que también se le imputaban.

El acusado interpone recurso de apelación ante la AP. La Sala desestima el recurso y confirma la sentencia de instancia, manteniendo la duración de la condena a prisión que le había sido impuesta y que en este caso era de un año (el límite inferior que el ordenamiento penal de 1995 permitía),

\footnotetext{
293 Los hechos ocurrieron en agosto de 2014.
} 
sin aplicar la posible reducción que hubiera resultado de tener a su vez en cuenta el nuevo límite establecido por la LO 1/2015 en seis meses.

\section{5.- SAP Jaén 375/2015, de 10 de diciembre.}

La AP de Jaén confirma íntegramente la sentencia dictada por el Juzgado de lo Penal $n^{\circ} 3$ de esa ciudad (21/05/2015), en la que se condenaba al agresor de una médico en un centro de salud como autor de delito de atentado, así como a multa de un mes a razón de cuatro euros diarios por una falta de lesiones, además de la obligación de indemnizar a la víctima.

Los hechos tuvieron lugar en el año $2011^{294}$, cuando el usuario, descontento porque quería que le atendieran sin esperar su turno ${ }^{295}$ insultó y amenazó a la médico, forcejeando con ella y golpeándola además con la puerta de la consulta.

Tampoco en este caso la AP aplica la retroactividad a la falta de lesiones. Otro ejemplo de la falta de homogeneidad en la actuación de los tribunales que en otros casos, aplican por analogía el nuevo régimen penal para las antiguas faltas, lo que supone en algunos casos su absolución.

\section{6.- SAP Pontevedra 302/2016, de 23 de mayo.}

La AP confirma íntegramente la sentencia dictada por el Juzgado de lo Penal $\mathrm{n}^{\circ} 1$ de dicha ciudad $(06 / 10 / 2015)^{296}$ que estimó la existencia de atentado en la agresión que sufre una enfermera del servicio de Urgencias de un hospital público a manos de un paciente.

La condena por la falta de lesiones se fijó en seis días de localización permanente, además de la obligación de indemnizar a la víctima.

Un caso más de falta de homogeneidad en la actuación de los tribunales, pues no se aplican a las lesiones el nuevo régimen que para las antiguas faltas determina la reforma insistiendo incluso en la pena de localización permanente en lugar de imponer una condena pecuniaria.

\section{b.-Resoluciones tomadas de diversas fuentes.}

1.- Un hombre agrede a un médico en su consulta de un centro de salud en diciembre de 2014. El Juzgado de lo Penal $\mathrm{n}^{\circ} 5$ de Bilbao le condena como autor de un delito de atentado y también a multa por una falta de lesiones.

\footnotetext{
${ }^{294}$ En el recurso de apelación interpuesto contra la sentencia, la defensa solicita se tenga en cuenta la circunstancia atenuante de dilaciones indebidas, pero la Sala desestima el motivo al entender que no se paralizó el procedimiento, aunque reconoce que hubiera sido deseable su duración fuera inferior.

295 Había sido citado previamente.

296 Las sentencias de ambas instancias son posteriores a la entrada en vigor de la reforma.
} 
La fuente de la noticia es DEIA y la fecha: 4 de noviembre de $2015^{297}$. En todo caso, atendiendo a los datos que la fuente aporta, no se ha aplicado el régimen establecido en el nuevo ordenamiento, ya en vigor en la fecha de celebración del juicio, en el que se suprimen las faltas como figuras delictivas.

2.- El juzgado de lo Penal no 28 de Barcelona (14 de noviembre de 2015) condena a una paciente, que había ingresado por Urgencias, por agredir a una enfermera en el Hospital Clínico de Barcelona, cuando estaba ya en planta ("Condena de un año de cárcel a una paciente por agredir, escupir e insultar a una enfermera del Hospital Clínic de Barcelona | iSanidad," 2016).

Por una falta de lesiones se le condena a multa de ciento treinta euros, así como a pagar una indemnización a la víctima (además de considerarla autora de un delito de atentado) ${ }^{298}$.

Se observa también en este supuesto la falta de homogeneidad de los tribunales al tratar las lesiones, pues no se les aplican las disposiciones de la reforma en tanto que en ocasiones se hace e incluso de oficio, como hemos venido indicando con anterioridad.

\section{B.- Resoluciones que aplican la LO 1/2015 con retroactividad.}

\section{a.- Sentencias}

\section{1.- SAP Santa Cruz de Tenerife 315/2015, de 03 de julio.}

El Juzgado de Instrucción $n^{\circ} 2$ de San Cristóbal de La Laguna (30/03/2105), condenó a dos mujeres:

«...como autoras responsables de una FALTA del artículo 620 del Código Penal, a la pena de multa de 10 días de multa a razón de 3 euros».

Los hechos ocurrieron en un hospital público cuando las acusadas (una de ellas enfermera e hija de una paciente ingresada la otra) mantuvieron una discusión.

La AP absuelve a ambas acusadas, aplicando retroactivamente las disposiciones del CP de 2015 en relación con las antiguas faltas:

\footnotetext{
297 (“Condenan a seis meses de prisión a un paciente que agredió a una médico en Erandio. Deia, Noticias de Bizkaia," 2015)

${ }^{298}$ Al parecer ya había protagonizado más incidentes en ese mismo hospital.
} 
" $2^{\circ}$.- Al haberse despenalizado la falta tipificada en el artículo 620.2 del Código Penal, procede absolver a las acusadas Ruth y Eva María de dicha imputación».

\section{2.- SAP Madrid 509/2015, de 6 de julio.}

El Juzgado de lo Penal $n^{\circ} 2$ de Getafe (22/04/2015), condena a una mujer que agredió a dos enfermeras y a un celador en un hospital público, como autora de tres faltas de lesiones, a seis días de localización permanente ${ }^{299}$ por cada una de ellas e indemnizaciones a las víctimas (también se la condena por cometer delito de atentado).

La AP revoca parcialmente la sentencia, no por los motivos aducidos en el recurso de apelación sino al aplicar el nuevo ordenamiento retroactivamente.

En cuanto a las faltas de lesiones, se la absuelve de las condenas que por ellas le fueron impuestas, excepto en lo que hace relación con la responsabilidad civil:

«En consecuencia, y dado que las lesionadas han mantenido en el juicio sus pretensiones acerca de la responsabilidad civil frente a la acusada, procede dejar sin efecto la condena a las penas correspondientes a las tres faltas y mantener exclusivamente los pronunciamientos condenatorios de carácter civil».

Un supuesto en el que se puede constatar que, al menos en lo que hacer referencia a las antiguas faltas, la aplicación del ordenamiento de 2015 a los casos juzgados en la etapa anterior y en vía de recurso es más beneficiosa para el reo, respecto a la imposición de penas.

Al mismo tiempo, se pone de manifiesto también la falta de homogeneidad en la actuación de los tribunales, pues en otros casos las AP mantienen las sentencias de instancia en los mismos términos, generalmente de mayor intensidad en cuanto a la punición ${ }^{300}$, al no aplicar las disposiciones del nuevo ordenamiento, como hemos podido comprobar en el apartado anterior al hablar de la no aplicación de la retroactividad.

\section{3.- SAP Valencia 570/2015, de 27 de julio.}

El Juzgado de Instrucción $n^{\circ} 11$ de Valencia (14/05/2015) condenó a la pena de un mes de multa a razón de ocho euros diarios, como autora de una falta contra el orden público del art. $634 \mathrm{CP}$, a una mujer que causó problemas en la consulta de una médico pediatra en un centro médico:

\footnotetext{
${ }^{299}$ El Código Penal vigente era el anterior a su reforma de 2015.

${ }^{300}$ Esto es aplicable no sólo a las faltas sino a otros ilícitos, especialmente al delito de atentado.
} 
«...negándose a abandonar la consulta a pesar de las reiteras peticiones en este sentido realizadas por la pediatra».

La AP de Valencia absuelve a la acusada y revoca íntegramente la sentencia recurrida, pero no por las razones aducidas en el recurso sino por la aplicación de las Disposiciones Transitorias de la reforma penal de $2015^{301}$ :

«No obstante, la entrada en vigor de la Ley Orgánica 1/2015 de 30 de marzo, que modifica la Ley Orgánica 10/1995, de 23 de noviembre, del Código Penal, derogó el artículo 634 del Código Penal, y despenalizó la conducta que castigaba dicho precepto penal, por lo que será obligado aplicar la nueva redacción del Código Penal».

También en este supuesto la aplicación de la reforma con carácter retroactivo, al producir la libre absolución de la acusada, supone no ya una disminución sino la supresión de la penalidad.

\section{4.- SAP Las Palmas 162/2015, de 17 de septiembre.}

El Juzgado de lo Penal n 2 de Las Palmas (12/02/2015 302 ), condena al agresor de un celador en el servicio de Urgencias (Área de Psiquiatría) de un hospital público, como autor de delito de atentado en concurso ideal con una falta de lesiones. Por la falta de lesiones le condena a ocho días de localización permanente.

Puesto que también atacó a agentes de la autoridad, se le condena por delito de resistencia en concurso ideal con delito de lesiones y falta de lesiones, a cuatro meses de prisión (delito de resistencia), nueve meses de prisión (delito de lesiones) y ocho días de localización permanente (falta de lesiones).

A todo ello se unen las indemnizaciones correspondientes.

La AP estima parcialmente el recurso de apelación interpuesto contra la sentencia, aplicando además de forma retroactiva la reforma. Por lo que se refiere a los delitos leves de lesiones ( faltas aún en la sentencia de instancia), opta por la multa (por ser más beneficiosa para el reo que la localización permanente ${ }^{303}$ ) en su nivel inferior: diez días, con una cuota diaria de seis euros en cada uno de ellos ${ }^{304}$.

\footnotetext{
301 Las Disposiciones aplicadas son la Transitoria una y la Transitoria tres.

302 El juzgado actúa estando vigente el CP de 1995. Por tanto, las penas y la terminología cuando se habla de «faltas» son acordes con el texto del citado Código.

303 Por suponer esta en todo caso limitación de la libertad.

${ }^{304}$ En cuanto al delito de resistencia y al de lesiones, se aplican los mismos criterios que suponen una reducción de la punición. Por la resistencia, el Juzgado determinó cuatro meses de prisión que a la AP reduce a multa de dos meses y
} 
Como puede comprobarse, en lo relativo al delito leve de lesiones (en general a todos los cargos por los que venía siendo acusado), la aplicación de la reforma a la sentencia recurrida supone una sustanciosa disminución en la punición: no sólo por la limitación de la multa al nivel inferior que el ordenamiento prevé para estos ilícitos, sino porque, siempre teniendo en cuenta el mayor beneficio para el reo ${ }^{305}$, se sustituye la privación de libertad, aunque sea en el grado mínimo que supone la localización permanente, por penas pecuniarias que la Sala y la jurisprudencia estiman como menos gravosas generalmente para los condenados ${ }^{306}$.

\section{5.- SAP Granada 627/2015, de 26 de octubre.}

La AP de Granada revoca parcialmente la sentencia del Juzgado de lo Penal $n^{\circ} 4$ de dicha ciudad (24/11/04) que había condenado como autores de varios ilícitos, entre ellos el delito de atentado, a dos familiares de una anciana enferma, en estado terminal, que pretendían se le aplicara rápidamente la sedación prescrita para que no sufriera tantos dolores. La agresión se produjo contra una enfermera en un hospital público. También se condena a cada uno de ellos por una falta de lesiones a multa de cuarenta días a razón de cuatro euros diarios.

La Sala, confirma la sentencia de instancia en cuanto al ilícito de lesiones, pero la punición se reduce al aplicar la reforma retroactivamente al delito de atentado ${ }^{307}$. Además, la falta de vejaciones que la propia defensa solicitaba subsidiariamente a la tipificación de los hechos como delito de atentado ya no se reconoce como ilícito penal en el ordenamiento de 2015.

\section{6.- SAP Cuenca 25/2016, de 16 de febrero.}

Un paciente, en un centro de salud, agrede a un enfermero, aunque sin que se produjeran lesiones. Mantiene una actitud tan violenta que hubo de intervenir la guardia civil a quienes sí causó lesiones.

El Juzgado de lo Penal $n^{\circ} 3$ de dicha ciudad 16/02/2016), aprecia la existencia de delito de atentado con consecuencia de lesiones. En cuanto a éstas se pronuncia de la siguiente manera:

"como autor responsable de tres faltas de lesiones previstas en el artículo 617.1 del código penal LO 10/1995 de 23 de noviembre, que de conformidad con la Disposición Transitoria Cuarta, no procede pronunciamiento en el ámbito penal».

quince días a razón de seis euros diarios. El delito de lesiones, penado por el juzgador «a quo» con nueve meses de prisión, queda reducido por la Sala a multa de un mes y quince días a razón de seis euros diarios.

305 Incluso la AP procede a penalizar los diferentes delitos por separado, por ser también más beneficioso para el reo.

306 De Juan Mazuelas (2016). Véase también SAP Las Palmas 162/2015, de 17 de septiembre.

307 Lo hacemos constar para que pueda apreciarse con más intensidad el efecto de la aplicación retroactiva de la reforma. 
En consecuencia, únicamente procede la indemnización por responsabilidad civil ${ }^{308}$. La AP confirma íntegramente esta sentencia de instancia.

Es evidente la disminución de la penalización ${ }^{309}$ al aplicar la reforma a unos hechos que habían sido instruidos bajo la vigencia del CP de $1995^{310}$, cuando sí se contemplaba la punición penal de las lesiones consideradas como falta, sin que fuera obligada la denuncia de parte.

\section{7.- SAP Granada 158/2016, de 14 de marzo.}

El Juzgado de los Penal $n^{\circ} 3$ de Granada (31/03/2015), condena a un hombre como autor de un delito de atentado, por las amenazas e intentos de agresión a una enfermera en un hospital público: «le dijo te vas a enterar cuando salgas, que la iba a esperar fuera y le iba a destrozar la cara, llegando a agarrarle del hombro para acercarla y al zafarse el acusado intentó morderle en la mano».

Se le absuelve de la falta de maltrato del art. 634 (CP de 1995) por la que también venía acusado. Pero se le condena a pagar a la víctima una indemnización de mil euros por daños morales.

En el recurso de apelación se llega incluso a hablar de «corporativismo» para neutralizar el valor de las declaraciones de una testigo que interviene en favor de la víctima.

La Sala además de la rebaja de la penalización que estima en cuanto a la condena impuesta por instancia en relación con el delito de atentado al aplicar el nuevo ordenamiento, rebaja también la indemnización de mil a quinientos euros.

En este supuesto, hacemos especial referencia a lo relativo a la penalización por el delito de atentado para que resulte aún más evidente la actuación de la retroactividad, dado que los juzgadores no estimaron tampoco la existencia de otros ilícitos, como el de maltrato, que sí se contemplaban en el ordenamiento anterior a la reforma.

\footnotetext{
308 En cuanto a la aplicación de las disposiciones de la LO 1/2015 por Audiencias Provinciales, despenalizando hechos que en instancia fueron tipificados como delito de atentado, véase por todas: SAP Madrid 104/2016, de 25 de febrero. ${ }^{309}$ En realidad, fueron los agentes de la autoridad las víctimas de las lesiones. Sin embargo, nos interesa dejar constancia de este dato puesto que viene a confirmar la reducción de la penalidad, al menos en cuanto a estos ilícitos, con la aplicación de la reforma.

${ }^{310}$ La SAP recoge este dato: "autos de Juicio Oral no 306/2014, (que dimanan del P.A. no 44/2014 del Juzgado de Instrucción no 1 de Tarancón)».
} 


\section{8.- SAP Almería 272/2016, de 10 de junio.}

El Juzgado de lo Penal n ${ }^{\circ} 3$ de Almería condenó a un paciente que había agredido a enfermeros y enfermeras de la planta de hospitalización de Salud Mental de un hospital público. Le considera autor de un delito de atentado.

Le condena también a multa de ciento veinte euros (veinte días a razón de seis euros diarios) por un delito leve de lesiones y a otra multa de la misma cuantía (en razón a los mismos parámetros de tiempo y cantidad a pagar diariamente) por un delito leve de amenazas, reconociendo que las amenazas proferidas por el acusado causaron a los sanitarios «lógico temor y desasosiego».

En cambio entiende que ya no ha lugar a la consideración penal de las injurias por las que también venía acusado ${ }^{311}$ :

«Se declara extinguida la responsabilidad penal respecto de la falta de injurias (Disposición Transitoria $1^{a}$ y $4^{a}$ de la LO 1/15)».

La AP de Almería desestima íntegramente el recurso de apelación que había sido interpuesto contra esta sentencia, la cual confirma.

En cuanto a las antiguas faltas, la extinción de la responsabilidad penal de las injurias (por otra parte, insistimos en que son muy frecuentes en el ámbito sanitario) supone una disminución de la penalidad en general y concretamente en lo referente a este supuesto, porque sí hubieran podido ser apreciadas al aplicar el CP de 1995, que era el vigente cuando tuvieron lugar los hechos (18 de enero de 2013).

\section{9.- SAP Murcia 417/2016, de 1 de julio.}

Un hombre agredió a un médico en un centro de salud y el Juzgado de lo Penal $n^{\circ} 5$ de Murcia (15/12/2015), le condena como autor de un delito de atentado así como de un delito leve de lesiones $^{312}$.

Las penas que se le imponen por las lesiones son de multa de un mes a razón de tres euros diarios.

La Sala revoca parcialmente la sentencia de instancia en cuanto a la despenalización de las lesiones al aplicar las Disposiciones Transitorias de la reforma ${ }^{313}$.

\footnotetext{
${ }^{311}$ Las injurias han sido expulsadas del ordenamiento penal por la reforma de 2015, excepto en los supuestos previstos en el art.173.4 CP de 2015, en relación con el art. 173.2.

312 La letrada de la defensa incluso alega falta de imparcialidad por parte de la juez de instancia.

313 «Por lo que las faltas públicas que en virtud de la citada reforma penal han quedado sometidas al régimen de denuncia previa (este caso se limita a los delitos leves de lesiones y malos tratos del art. 147.2 y $3 \mathrm{CP}$, antes previstos
} 
«Por dicha razón motivo (sic), aun confirmando la sentencia objeto del presente recurso, debe quedar sin efecto la condena penal por el delito leve de lesiones en el que la Juzgadora de instancia erróneamente reconvirtió la falta de lesiones objeto de acusación (del art 617.1 del Código Penal)».

En este caso, la despenalización por este ilícito llega a ser total, porque el perjudicado había renunciado a lo que pudiera devengarse a su favor en concepto de responsabilidad civil ${ }^{314}$.

«....sin que se deban ejecutar los aspectos civiles de la misma al haber renunciado el perjudicado Pablo Jesús en el acto de la vista según consta claramente en el minuto 50'56' del vídeo $1^{\circ}{ }^{\circ}$.

\section{0.- SAP Madrid 540/2016, de 18 de julio.}

El Juzgado de lo Penal no 22 de Madrid (21/03/2016) condena por delito de atentado al autor de una agresión a un médico en el Centro Integral de Apoyo a la Drogodependencia ${ }^{315}$. Le absuelve de una falta de lesiones por la que también venía acusado.

La AP de Madrid confirma íntegramente la sentencia del juzgador de instancia.

La aplicación de la reforma en este caso, supone que las lesiones quedan sin penalización, porque al aplicar la Disposición Transitoria cuarta de la LO 1/2015, sólo cabe que el tribunal se pronuncie en cuanto a los delitos leves de lesiones por el concepto de responsabilidad civil, como hemos visto en el caso anterior. Pero si el perjudicado ha renunciado a ella o no la ha reclamado, no ha lugar a ninguna punición penal por este ilícito (lo que ha ocurrido en éste y en el supuesto analizado antes).

\section{1.- SAP Alicante 303/2016, de 29 de julio.}

Una mujer agrede a dos médicos en el Hospital Clínico. La agresión es especialmente violenta en relación con la facultativa, a la que acusa de ser la responsable de un aborto que había sufrido puesto que fue precisamente ella quien la atendió en el Servicio de Urgencias de dicho centro hospitalario.

El Juzgado de lo Penal $n^{\circ} 1$ de Alicante (03/02/2016) entiende que es autora de un delito de atentado además de dos delitos leves de lesiones, por los que la condena a multa de dos meses a

en el art. $617(P)$ ), la acción penal para su persecución ha de estimarse decaída por imperativo de la ley, con arreglo a lo previsto en la Disposición transitoria cuarta, apartado segundo, de la LO 1/2015, que de manera inequívoca establece que el procedimiento continuará a los solos efectos de enjuiciar la acción civil»

${ }^{314}$ Lo único sobre lo que el tribunal podría pronunciarse en el caso de que, como ocurre en este supuesto, se aplique la reforma retroactivamente a este tipo de ilícitos.

315 Dependiente del Servicio Madrileño de Salud. 
razón de seis euros por día (por las lesiones producidas a la médico) y multa de un mes con la misma cuantía diaria (por las lesiones causadas al facultativo), con la obligación de indemnizar a ambos.

La AP confirma parcialmente la sentencia de instancia:

«Debemos REVOCAR y REVOCAMOS dicha resolución, en el solo sentido de suprimir las penas por los delitos leves de lesiones, manteniendo el pronunciamiento de responsabilidad civil y todos los demás de la sentencia impugnada».

La Sala ha tomado en consideración de modo especial la STS 13/ 2016 de 25 de enero $^{316}$, que afirma:

«...solo cabe pronunciamiento condenatorio en relación con la responsabilidad civil».

Se aplica de esta manera la reforma de forma retroactiva a la sentencia de instancia, y, en consecuencia, se absuelve de las consecuencias penales de las lesiones producidas, dejando a salvo únicamente la responsabilidad civil.

Esto abona la teoría de que la reforma reduce la penalidad, porque, al menos en cuanto a las lesiones, no sólo se reducen las consecuencias penales a penas pecuniarias, excluyéndose la condena a localización permanente por suponer privación de libertad, sino que, además, puede darse el caso de que queden totalmente impunes ${ }^{317}$ si los perjudicados han renunciado en instancia a indemnización en concepto de responsabilidad civil ${ }^{318}$.

\section{2.- SAP Madrid 125/2017, de 24 de febrero.}

La AP desestima el recurso de apelación interpuesto contra la resolución del Juzgado de lo Penal $n^{\circ} 15$ de dicha ciudad (04/11/2016), confirmándola íntegramente.

Se había encausado a un hombre que, acompañado de su hija, agredió de palabra y obra a un médico de una Mutua de la Seguridad Social, cuando negó a ésta una baja laboral que solicitaba ${ }^{319}$.

Al padre se le condena por delito de atentado pero se absuelve a ambos de las faltas por las que se venían siendo imputados en aplicación de las disposiciones de la reforma ${ }^{320}$. Subsiste

\footnotetext{
${ }^{316}$ En relación con las Disposiciones Transitorias de la LO 1/2015 y la Circular 1/2015 FGE.

${ }^{317} \mathrm{Al}$ menos durante la vigencia del Régimen Transitorio de aplicación de la reforma.

${ }^{318}$ Entre otras: SAP Murcia 417/2016, de 1 de julio.SAP Madrid 540/2016, de 18 de julio.

319 Los hechos tuvieron lugar en el año 2012.

${ }^{320}$ En cuanto a la hija, falta contra el orden público y falta de injurias. En lo relativo al padre: falta de lesiones y falta de amenazas.
} 
únicamente la obligación del agresor en cuanto a indemnizar a la víctima en concepto de responsabilidad civil, por las consecuencias producidas a causa de las lesiones que le infirió.

\section{CONCLUSIONES}

Tal como habíamos podido apreciar al tratar el tema del delito de atentado, la aplicación de la reforma de forma retroactiva a este ilícito y a otras figuras no integradas en el artículo $550 \mathrm{CP}-$ tanto en los casos que únicamente habían sido instruidos como sobre todo en supuestos ya juzgados, pero en vía de recurso- suponen, por lo general, una disminución en la penalización de los ilícitos.

Ocurre así porque, o bien se reducen las penas que venían siendo impuestas desde instancia, al aplicar generalmente el límite inferior del tramo de punición establecido por el ordenamiento, o bien, en el caso de las antiguas faltas, se elimina incluso la penalidad de forma absoluta al aplicar las Disposiciones Transitorias, considerando que no se puede penalizar a ningún imputado por una figura delictiva que ya no tiene cabida en el Código Penal. Sobre todo, si el perjudicado no ha solicitado indemnización en concepto de responsabilidad civil o ha renunciado a ella.

Además, algunos ilícitos ya no están integrados en el ámbito penal, al haber sido expulsados a otros ordenamientos como el civil o el administrativo.

Así mismo, hemos constatado una cierta falta de homogeneidad en la actuación de los tribunales, al no aplicar en algunos supuestos la reforma en tanto que en otros proceden a hacerlo incluso de oficio. Esta falta de homogeneidad puede repercutir negativamente en las dos partes: en relación con el perjudicado, si se disminuye la punición de las agresiones de que ha sido víctima, pero no ocurre lo mismo en otras de similar tipología y entidad, juzgadas por tribunales que no han tenido en cuenta esa retroactividad. En cuanto a la parte condenada, al no ver reducida su condena por no ser de aplicación a su caso el nuevo ordenamiento, en tanto que sí se aplicó a otros supuestos que tuvieron la misma tipificación y, en consecuencia, disminuyeron las cuantías de las condenas que les habían sido impuestas. 


\section{3.- RESOLUCIONES EN RELACIÓN CON LA CONDICIÓN DE AUTORIDAD}

\section{a.- Sentencias}

\section{1.- SAP Badajoz 70/2015, de 30 de septiembre.}

El Juzgado de lo Penal $n^{\circ} 2$ de dicha ciudad (de 25/05/2015), condenó al agresor de un médico como autor de un delito de atentado, absolviéndole de las faltas de lesiones y amenazas por las que también venía siendo acusado.

La AP, al resolver el recurso de apelación que la parte acusada interpuso contra esa resolución, dice en el Tercero de los Fundamento de Derecho de su sentencia ${ }^{321}$ :

«Consecuentemente la conducta enjuiciada es constitutiva de delito de atentado y no puede tener acogida el motivo de recurso.

Añádase a lo anterior que el médico, en el ejercicio de sus funciones en la sanidad pública, constituye autoridad y, por tanto, puede ser sujeto pasivo del delito de atentado».

\section{2.- SAP Sevilla 158/2016, de 26 de abril.}

El Juzgado de lo Penal $n^{\circ} 7$ de Sevilla (08/10/2015) había estimado la existencia de delito de atentado en la agresión de una mujer a una enfermera en un hospital público, cuando acompañaba a su marido a la consulta de la víctima.

Los hechos ocurrieron cuando la acusada entró en la consulta de la enfermera y allí la agredió ${ }^{322}$.

La Sala confirma íntegramente la resolución de instancia a la vez que manifiesta lo siguiente:

«Como es sabido, el delito de atentado del artículo 550 del C.P. requiere un acometimiento contra agente de la autoridad o funcionario público en el ejercicio sus funciones con conocimiento del sujeto activo que acomete a agente de la autoridad o funcionario público».

Curiosamente, en esta sentencia la Sala omite el concepto de autoridad al describir quienes pueden ser sujetos pasivos del delito de atentado, pues el artículo $550 \mathrm{CP}$ especifica que pueden serlo: la

\footnotetext{
${ }^{321}$ El Juzgado había considerado la existencia de delito de atentado contra funcionario público. Por su parte, la Sala realiza en el Fundamento de Derecho citado una amplia digresión sobre la evolución jurisprudencial en cuanto a las consideraciones de principio de autoridad y de bien jurídico protegido por el delito de atentado.

${ }^{322}$ Al parecer había visto como otra persona iba a entrar en la sala de curas de la enfermera y, según se desprende del texto de la sentencia, interpretó que estaba obviando tratar a su marido.
} 
autoridad, sus agentes o los funcionarios públicos, y en esta resolución únicamente se habla de agente de la autoridad o funcionario público.

\section{3.- SAP Murcia 417/2016, de 1 de julio.}

Se había condenado a un hombre por agredir a un médico en un centro de salud, como autor de un delito de atentado a pena de seis meses de prisión y un delito leve de lesiones. El Juzgado de lo Penal $n^{\circ} 5$ de Madrid, encargado de enjuiciar los hechos, dictó sentencia (15/12/2015), condenándole a pena de seis meses de prisión por el delito de atentado y a multa de un mes a razón de tres euros diarios, por el delito leve de lesiones.

La parte condenada interpuso recurso de apelación, alegando, entre otros argumentos, que no podía existir delito de atentado al existir extralimitación por parte del médico:

«...el incumplimiento del médico de sus obligaciones legales supone una clara extralimitación, al realizar conductas antijurídicas que le privan de la condición de autoridad».

La AP desestima el motivo de alegación, pero no por entender que el médico, como funcionario, no posee la condición de autoridad, sino porque no admite que hubiera extralimitación en su comportamiento:

«Pues bien, entiende la Sala, a la vista del resultado de la prueba, que de forma extensa pormenoriza tanto la sentencia como el recurso y las oposiciones, que en ningún caso se produjo tal extralimitación por parte del médico».

\section{4.- SAP Zaragoza 423/2016, de 9 de septiembre.}

El Juzgado de Instrucción n ${ }^{0} 10$ de Zaragoza (26/05/2016), absolvió del delito leve de amenazas a un hombre internado en una Residencia desde hacía dos años, que había sido declarado incapaz civil absoluto y bajo tutela ${ }^{323}$. El acusado se dirigió a una enfermera de forma violenta, con amenazas e insultos.

La víctima aducía en su recurso (entre otros argumentos) que al tener la calificación de autoridad pública por una Ley de Aragón ${ }^{324}$ al menos las injurias deberían constituir un delito de los tipificados en el artículo 208.2 del CP.

\footnotetext{
${ }^{323}$ El paciente fue trasladado a otro centro puesto que la enfermera había firmado una queja contra él ante la Dirección de la Residencia.

${ }^{324}$ Artículo 6 de la ley 9/2013 de 28 de noviembre de autoridad de profesionales del sistema sanitario y servicios sociales públicos de Aragón.
} 
La Sala desestima ${ }^{325}$ este argumento en los términos siguientes:

«...y aunque los sanitarios sean autoridad por la ley antes mencionada por el recurrente, esto se refiere al delito de atentado, ya que el artículo 550 del código penal, si los incluye, pero en forma alguna nos encontramos con este supuesto».

Queda, a nuestro entender, cuando menos confusa, la relación que la AP establece entre el concepto de autoridad contenido en esa Ley autonómica, que está dentro del ámbito administrativo y carece de efectos penales ${ }^{326}$ y el artículo 550 del CP donde se regulan las distintas modalidades del delito de atentado y en el que la reforma de julio de 2015 declara expresamente como sujetos pasivos de este ilícito a los sanitarios y docentes, pero no por ser autoridad sino en cuanto a su condición de funcionarios públicos.

\section{b.- Resoluciones tomadas a partir de diversas fuentes}

1.- Una sentencia de la AP de Valladolid confirma la multa que venía impuesta a una mujer por insultar una médico valoradora de una empresa (MAZ).

Esta noticia aparece en Redacción Médica (25 de mayo de 2015). La misma fuente consultada (Martínez Platel, 2015) manifiesta que, a la vista de esta sentencia, insultar a un profesional de la sanidad privada resulta ser prácticamente gratis.

Pero lo que hace relación con este apartado son las siguientes afirmaciones del artículo respecto a la supuesta posesión de la condición de autoridad desde el punto de vista penal por parte de los profesionales de la sanidad pública:

«Esta situación pone de manifiesto la situación de desigualdad que viven los médicos que trabajan en el ámbito público al privado, ya que desde la reforma del Código Penal los primeros son considerados autoridad pública, y la sanción por este tipo de acciones es mayor».

2.- Un hombre llevó a cabo agresiones verbales contra un médico en un centro de salud ${ }^{327}$. Por estos hechos, el Juzgado de Instrucción $\mathrm{n}^{\circ} 6$ de Las Palmas de Gran Canaria le condenó a la pena de dos meses de multa, a la vez que dicta una orden de alejamiento por un plazo de seis meses.

\footnotetext{
${ }^{325}$ Respecto al delito leve de amenazas del que la Juez de Instrucción absolvió al acusado manifiesta lo siguiente: «En cuanto al delito de amenazas la Juez ha considerado que la frase relativa a "Lo vas a pagar" no reúne los requisitos de dicha infracción penal, y por ello procedió a dictar una sentencia absolutoria».

${ }^{326}$ Las CCAA no pueden promulgar legislación penal porque esa competencia corresponde al Estado.

327 El suceso tuvo lugar el 29 de abril de dicho año.
} 
La fuente incluye un error relativo a la condición de autoridad por parte de los médicos, al hablar del delito de atentado:

«El Colegio de Médicos expuso que se trata de una de las primeras condenas en la provincia de Las Palmas que aplica la modificación artículo 550.1 del Código Penal en el que considera una agresión a un médico, fisica o verbal, un atentado a la autoridad pública».

Noticia fechada el 13 de junio de 2016 ("Un paciente que amenazó a su médica no podrá acercarse a ella en 6 meses - Observatorio de Agresiones," 2016).

3.- En el artículo que publica Alerta Digital (25 de septiembre de 2016) ${ }^{328}$, al comentar la sentencia que el Juzgado de lo Penal $n^{\circ} 8$ de Alicante, dicta contra el agresor de un celador en un centro de salud de dicha ciudad, la fuente citada afirma lo siguiente:

«Otra de carácter novedoso (sólo tiene un precedente anterior en Murcia) consideró autoridad, y por tanto víctima de un delito de atentado, a un celador de Alicante».

Y posteriormente, al reproducir e interpretar algunas de las manifestaciones de la sentencia a la que alude, insiste en esa atribución al celador de la condición de autoridad:

«La resolución repasa cómo, hasta el momento, la legislación y la jurisprudencia conceden la condición de autoridad a «médicos, enfermeras y farmacéuticos», pero estima el fallo que la realización de «funciones públicas», la base de considerar a un profesional como autoridad, es un «criterio de gran amplitud» (...) el juzgado estima acreditada su condición de autoridad».

4.- El 20 de marzo de 2017 recoge Diario Medico noticia de la condena por delito de atentado a un hombre que agredió al médico de una Mutua (Carrasco, 2017). La sentencia la dicta el Juzgado de lo Penal $n^{\circ} 1$ de Badajoz y la fuente aporta muy poca información al respecto.

Pero deja entrever que la resolución del Juzgado incurre en la confusión que venimos detentando en cuanto a la atribución a los profesionales de la sanidad pública la condición de autoridad:

«La novedad del fallo, que es firme, es que equipara al facultativo con los funcionarios sanitarios a la hora de reconocerle la potestad de una autoridad».

328 (“Una sentencia considera un atentado la agresión a un médico fuera del hospital - Alerta Digital,” 2016). 


\section{CONCLUSIONES}

La confusión en cuanto a la posibilidad de que los profesionales de la sanidad pública pudieran ostentar la condición de autoridad, alcanzó amplias dimensiones antes de la reforma del ordenamiento penal de la LO 1/2015 (De Juan-Mazuelas, 2016).

Como puede verse a partir de las resoluciones que hemos seleccionado, continúa existiendo después de su entrada en vigor, lo que entre otras consecuencias puede generar en estos profesionales falsas expectativas y frustración, pues la penalidad susceptible de ser aplicada a los delitos de atentado es mayor en el caso de cometerse contra autoridad que si se llevan a efecto sobre un funcionario público.

Por otra parte, pudiera contribuir a abrir una brecha entre los colectivos de la sanidad pública y la privada, al entender éstos que no sólo no pueden ser tutelados por el atentado y la punición que éste conlleva, sino que la diferencia penológica entre las agresiones cometidas contra unos y otros, si se considera esa condición de autoridad en los sanitarios públicos es manifiestamente mayor $^{329}$.

\section{4.- SENTENCIAS CON TERMINOLOGÍA O CONCEPTOS DISCUTIBLES}

\section{a.- Sentencias}

\section{1.- SAP Las Palmas 162/2015, de 17 de septiembre.}

La AP de Las Palmas revoca parcialmente la sentencia del Juzgado de lo Penal $\mathrm{n}^{\mathrm{o}} 2$ de la ciudad (12/02/2015), que había condenado como autor de un delito de atentado en concurso ideal con una falta de lesiones al hombre que agredió a un celador y a unos funcionarios policiales en un hospital público.

La sentencia de instancia le considera también responsable de un delito de resistencia en concurso ideal con delito de lesiones y falta de lesiones.

No se especifica por cuál de las agresiones se consideró la existencia de delito de atentado. En nuestra opinión, podría deducirse que se tipifica así la violencia ejercida contra el celador, puesto que se habla en la resolución también de delito de resistencia y éste no puede cometerse contra funcionario (esa era la condición del celador) sino contra agentes de la autoridad.

Por otra parte, la AP mantiene en su sentencia la denominación de faltas que ya ha desaparecido del ordenamiento penal con la entrada en vigor de la LO 1/2015.

\footnotetext{
${ }^{329}$ Ver el supuesto № 1 de este mismo epígrafe, en: «Resoluciones tomadas a partir de diversas fuentes».
} 
«Y en lo que hace a la falta de lesiones en concurso ideal con el delito de atentado la pena de multa de diez días con una cuota diaria de seis euros.

En lo que respecta al delito de resistencia en concurso ideal con un delito de lesiones y una falta de lesiones una pena de multa de dos meses y quince días con una cuota diaria de seis euros por el delito de resistencia, una pena de un mes y quince días multa con cuota diaria de seis euros por el delito de lesiones y una pena de diez días multa con cuota diaria de seis euros por la falta de lesiones».

\section{2.- SAP Valencia 570/2015, de 27 de julio.}

El Juzgado de Instrucción $n^{\circ} 11$ de dicha ciudad (14/05/2015) condenó, como autora de una falta de desorden público del art. 634 CP de 1995, la actuación violenta de una mujer ante la médico pediatra de un centro médico ${ }^{330}$, en enero de 2015 . Se le impone una multa de un mes a razón de ocho euros diarios ${ }^{331}$.

El recurso de apelación que se interpone ante la AP argumenta que un funcionario no puede ser sujeto pasivo del artículo citado. Ciertamente, la letra del texto penal de 1995 no les incluía en el art. 634, pero la jurisprudencia no mantenía en cuanto a esto una postura uniforme y, de hecho, lo aplicaba en ocasiones a supuestos que tenían a funcionarios como sujetos pasivos ${ }^{332}$.

La Sala estima el recurso y revoca la sentencia recurrida al aplicar las disposiciones de la reforma penal de $2015^{333}$, absolviendo a la acusada ${ }^{334}$.

Un ejemplo más de reducción de la penalidad a partir de la entrada en vigor de la reforma.

\section{3.- SAP Badajoz 70/2015, de 30 de septiembre.}

La defensa de un hombre, que por agredir a un médico fue condenado como autor de delito de atentado a un año de prisión por el Juzgado de lo Penal no 2 de Badajoz (25/05/2015), interpone recurso de apelación en el que entre otras alegaciones estima que no existe delito de atentado sino, en todo caso, la falta del art. $639 \mathrm{CP}$.

\footnotetext{
${ }^{330}$ En la sentencia de instancia se define a la facultativa como "personal estatutario».

${ }^{331}$ El juzgador «a quo» determina que el pago de la indemnización se efectuará de una sola vez.

332 De Juan Mazuelas (2016).

333 Las Disposiciones aplicadas son la Transitoria una y la Transitoria tres.

${ }^{334}$ "TERCERO.- Procede, en consecuencia, ante la despenalización de la conducta castigada en el art. 634 del Código Penal, absolver a la apelante como autora responsable de la falta que se le imputaba».
} 
La Sala desestima ese motivo del recurso ${ }^{335}$ y entiende que existe efectivamente el ilícito del art. $550 \mathrm{CP}$ por darse todos los elementos que integran ese delito. Pero no alude a que, en todo caso, no hubiera tenido cabida la aplicación de una falta, por haber desaparecido esta figura delictiva del CP.

\section{4.- SAP Granada $627 / 2015$, de 26 de octubre.}

Dos familiares de una anciana, ingresada en estado terminal en un hospital público, agreden a una enfermera. El Juzgado de lo Penal $n^{\circ} 4$ de Granada (24/11/04) les condena como autores de un delito de atentado.

Los acusados interponen recurso de apelación contra esta sentencia, intentando que se les exculpe de la comisión de atentado por considerar que los hechos encajan más bien en el art. 634 CP.

La Sala desestima esta consideración del modo siguiente:

«se rechaza la aplicación del invocado antiguo art. 634 del C.P. pues la redacción del precepto no incluye a los funcionarios, solo a la autoridad y sus agentes».

A diferencia de lo que ocurre en SAP Valencia analizada anteriormente, en este caso el tribunal entra a valorar el contenido del art. $634 \mathrm{CP}$ y lo interpreta de forma literal, puesto que el texto legal no incluye expresamente a los funcionarios, condición que como enfermera de la sanidad pública posee la víctima. Pero ya antes de la reforma pueden encontrarse supuestos en que los tribunales sí aplican ese artículo a agresiones llevadas a cabo contra profesionales de la sanidad pública (De Juan Mazuelas, 2016).

\section{5.- SAP Alicante 582/2015, de 22 de diciembre.}

La AP de Alicante confirma íntegramente la sentencia dictada por el Juzgado de lo Penal $\mathrm{n}^{\circ} 7 \mathrm{de}$ dicha ciudad (20/10/2015) que tipificaba como delito de atentado la agresión que llevó a cabo una mujer contra una auxiliar de clínica en la Unidad Polivalente de Salud Mental de un hospital público.

Además en ambas instancias se la considera responsable de un delito de lesiones por el que se la condena a tres meses de prisión ${ }^{336}$. Hay que hacer notar que antes de la reforma eran severas las exigencias de los tribunales a la hora de estimar lesiones como delito en lugar de como falta. A

\footnotetext{
335 "Consecuentemente la conducta enjuiciada es constitutiva de delito de atentado y no puede tener acogida el motivo de recurso".

${ }^{336}$ Se dispone la medida de internamiento en régimen cerrado en un centro adecuado a su salud mental por un máximo de tres años.
} 
pesar de que ya comenzaba a verse una leve tendencia a la suavización de estos requisitos ${ }^{337}$, los tribunales ponían énfasis en que no bastaba con la primera asistencia sanitaria y, asimismo, eran reticentes a admitir como tratamiento posterior el farmacológico, por ejemplo.

En este supuesto, sin embargo, se admite una primera asistencia y tratamiento posterior de tipo farmacológico, ortopédico y fisioterapeútico, no llegándose siquiera a acreditar que la víctima llegase a recibir efectivamente las sesiones de fisioterapia.

\section{6.- SAP Madrid 871/2015, de 30 de diciembre.}

La defensa de la acusada interpone recurso de apelación contra la sentencia dictada por el Juzgado de lo Penal $n^{\text {o }} 22$ de Madrid (09/10/2015) $)^{338}$, que la había considerado autora de un delito de atentado.

Entre otras alegaciones, se solicita a la AP en ese recurso que, en todo caso, se consideren los hechos como falta del art. $634 \mathrm{CP}$. La Sala no lo estima así porque entiende que los hechos son efectivamente constitutivos del ilícito del artículo $550 \mathrm{CP}$.

Lo que queremos destacar es que la defensa utiliza el término «falta», estando ya en vigor la LO $1 / 2015$, que suprime esas figuras delictivas.

\section{7.- SAP Cuenca 25/2016, de 16 de febrero.}

En un centro de salud, un hombre agrede a un enfermero y a varios agentes de la autoridad. El Juzgado de lo Penal $n^{\circ} 3$ de Cuenca (16/02/2016) dicta sentencia, que confirma posteriormente la AP, tipificando los hechos como constitutivos de delito de atentado.

No se precisa en ninguna de las dos instancias por cuál de las agresiones se estiman los hechos como atentado. La sentencia es confusa porque el ataque se produce contra los agentes de la Guardia Civil a los que los sanitarios llaman y también contra un enfermero.

«Igualmente llegó a agredir al agente número NÚM003, así como a Benedicto, el cual se encontraba desempeñando sus funciones de enfermero en el centro de salud».

Los agentes sufrieron lesiones y el enfermero no, pero estamos ante delitos de mera actividad en los que no se exige causación de resultados.

\footnotetext{
${ }^{337}$ Se admiten como tratamiento quirúrgico los puntos de aproximación, por ejemplo. Véase STS (Sala Segunda) 519/2016, de 15 de junio. (De Juan Mazuelas, 2016)

338 Sentencia que se aclara posteriormente mediante Auto de fecha 28 de octubre de 2015.
} 
También hay que tener en cuenta que, habiendo unidad de acción (como en este caso) el delito de atentado se considera uno sólo aunque fueran varios los agredidos, puesto que el bien jurídico a proteger es el mismo: asegurar el correcto funcionamiento de la Administración al servicio de los intereses generales. Además, el artículo 550.1 del CP entiende que las agresiones a agentes de la autoridad y a funcionarios (como el enfermero) tendrán la misma punición si se estima que fueran sujetos pasivos de un delito de atentado ${ }^{339}$. A pesar de todo, en nuestra opinión, en este este aspecto puede entrañar confusión, especialmente al exponer los hechos la resolución de instancia.

\section{8.- SAP Málaga 120/2016, de 23 de febrero.}

Un hombre agrede al personal sanitario de un hospital público, perturbando el buen funcionamiento del servicio, siendo, además, reincidente en estos hechos.

El Juzgado de lo Penal n 3 de esa ciudad (01/07/2015) le condena a dieciocho meses de prisión por considerarle autor de un delito de atentado, a multa de veinte días (a razón de seis euros diarios) por una falta de coacciones del art. 620 CP y a multa de seis meses a razón de seis euros diarios por un delito de desórdenes públicos del art. 558 CP. La AP ratifica la sentencia condenatoria dictada por el juez de instancia.

Hay que destacar que el juzgador «a quo» está aplicando el CP de 1995, donde se contemplaban las faltas como figuras delictivas. La reforma, que entra en vigor precisamente el día en que se dicta la resolución, elimina esos ilícitos. Podemos entender que la sentencia se publica en esa fecha pero que todo el procedimiento viene informado con anterioridad.

Pero tiene más relevancia que la Sala, al confirmar la resolución de instancia, no alude en absoluto a ese hecho además de no aplicar retroactivamente las disposiciones contenidas en la reforma.

Esto incide en la apreciación, ya efectuada en anteriores epígrafes, de la falta de homogeneidad en la actuación de los tribunales porque, en otros supuestos sí se ha aplicado esa retroactividad incluso de oficio.

\section{9.- SAP Madrid 104/2016, de 25 de febrero.}

Un hombre insulta y amenaza a un médico en un centro de salud, por lo que el Juzgado de lo Penal $n^{\circ} 10$ de Madrid (01/10/2015) le condena como autor de un delito de atentado.

\footnotetext{
${ }^{339}$ El CP prevé penas de prisión en estos casos de entre seis meses y tres años. Sólo son superiores las condenas si el sujeto pasivo del delito de atentado es autoridad: de un a cuatro años.
} 
La Sala le absuelve de ese delito, porque entiende que la modalidad de atentado que se le atribuía ya no está recogida como tal en el ordenamiento penal ${ }^{340}$.

Es el propio tribunal el que señala las contradicciones que puede entrañar este tema atendiendo a lo que dispone el nuevo CP:

"Ciertamente el nuevo tipo penal resulta contradictorio porque en el artículo 554 del Código Penal la intimidación grave realizada de modo directo y activo se castiga como atentado cuando se produce contra bomberos, personal sanitario o equipos de socorro con ocasión de un siniestro, calamidad pública o situación de emergencia y cuando se produce contra el personal de seguridad privada que actúe en cooperación y bajo el mando de las Fuerzas y Cuerpos de Seguridad, pero no cuando se produce frente a autoridades o agentes de la autoridad, puesto que en estos casos la intimidación grave debe estar vinculada a un acto de resistencia (artículo 550 $C P) »$.

Como en este supuesto no existió esa vinculación, estima el recurso, sin analizar más alegaciones, absolviendo en consecuencia al acusado.

\section{0.- SAP Las Palmas 175/2016, de 20 de mayo.}

El Juzgado de Instrucción $n^{\circ} 7$ de dicha ciudad (24/02/2015), condena a una mujer que agredió a personal sanitario cuando la estaban atendiendo ${ }^{341}$ :

«...como autora criminalmente responsable de una falta de maltrato de obra del artículo 617.2 del CP a la pena de localización permanente de cuatro días».

Esta resolución se dicta durante la vigencia del CP de 1995, en el que las faltas aún tenían consecuencias penales.

La AP revoca la sentencia de instancia y procede a la libre absolución de la acusada por entender que no existió dolo al cometer estos actos. Es decir, la Sala no está considerando la derogación de las antiguas faltas que trae consigo el CP de 2015, sino que no se da el tipo porque falta el elemento subjetivo sustancial en la actuación de la acusada. Esto significa que la AP no está

\footnotetext{
340 «El recurrente considera que los hechos carecen de relevancia típica y este tribunal considera que es así pero por razones distintas a las invocadas en el recurso y que deber ser apreciadas de oficio. En efecto, la intimidación grave ejercida de forma directa y activa sobre autoridad o funcionario público, ha desaparecido del Código Penal como modalidad del atentado de acuerdo con la modificación introducida por la Ley Orgánica 1/2015, dado que la intimidación grave debe estar vinculada a un acto de resistencia grave».

${ }^{341}$ En la SAP no se incluye relación de los hechos, excepto esa afirmación.
} 
teniendo en cuenta que carece de importancia ya que se cumpla o no el tipo, pues la figura delictiva como tal ha quedado obsoleta desde el punto de vista penal.

\section{1.- SAP Pontevedra 302/2016, de 23 de mayo.}

Se condena al agresor de una enfermera en el servicio de Urgencias de un hospital público a un año de prisión, como autor de un delito de atentado. La sentencia, dictada por el Juzgado de lo Penal $n^{\circ} 1(06 / 10 / 2015)$, es confirmada por la AP en todos sus pronunciamientos.

Se le había considerado también responsable de una falta de lesiones a la que se aplica la pena de seis días de localización permanente.

Tanto la sentencia de instancia como la procedente de la AP, se dictaron en fechas posteriores a la entrada en vigor de la reforma de julio de 2015, en la que se suprimen los ilícitos considerados faltas. La Sala mantiene lo dispuesto por el juzgador «a quo» sin aplicar las disposiciones de la reforma en este aspecto, sobre todo si se tiene además en cuenta que la pena impuesta supone pérdida de libertad (localización permanente) régimen que asimismo ha sido eliminado para los delitos leves en el CP de 2015 sustituyéndose por penas pecuniarias, consideradas por los tribunales como menos gravosas para el reo.

La parte acusada discutía también en su recurso de apelación que siendo personal estatutario pueda ser sujeto pasivo del delito de atentado y que lo contrario sería hacer una interpretación extensiva de la ley en perjuicio del reo ${ }^{342}$. Renueva así la discusión sobre un tema que tuvo mucha fuerza incluso para los tribunales estando vigente el anterior ordenamiento penal, pero que ya había sido superada por los órganos jurisdiccionales años antes de entrar en vigor la reforma ${ }^{343}$. La AP desestima la alegación.

\section{2.- SAP Zaragoza 423/2016, de 9 de septiembre.}

La AP confirma la sentencia del Juzgado de Instrucción $n^{0} 10$ de Zaragoza (26/05/2016), que absolvió del delito leve del que se le acusaba a un internado en una Residencia, que había sido declarado incapaz civil absoluto y bajo tutela.

\footnotetext{
342 «En concreto se refiere la parte recurrente a la cualidad de funcionario público de la denunciante, pues ésta, enfermera de profesión, es personal estatuario de modo que, siendo de aplicación el art. 550 del CP en su redacción anterior a la reforma -LO 1/2015-, considera que resulta que ésta, dado el concepto de funcionario público recogido en el art. 24 del CP, no puede ser sujeto pasivo de tal delito, por lo que entiende que en la Sentencia se hace una interpretación extensiva de la Ley en perjuicio del reo».

${ }^{343}$ De Juan Mazuelas (2016).
} 
En nuestra opinión, al resolver el recurso de apelación interpuesto contra la resolución de instancia, la Sala se expresa en términos cuando menos confusos en cuanto al concepto de autoridad penal y administrativo, así como en lo relacionado con el alcance del artículo $550 \mathrm{CP}^{344}$.

\section{b.- Resoluciones tomadas a partir de diversas fuentes}

1.- DEIA recoge el 4 de noviembre de 2015, la noticia de que el Juzgado de lo Penal $\mathrm{n}^{\mathrm{o}} 5$ de

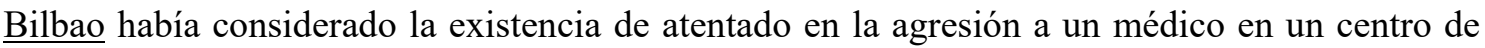
salud ("Condenan a seis meses de prisión a un paciente que agredió a una médico en Erandio. Deia, Noticias de Bizkaia," 2015).

Según la fuente, se le condena también por una «falta de lesiones». Hay que tener en cuenta que el juicio tuvo lugar después de la entrada en vigor de la reforma, por consiguiente, no puede hablarse ya de «faltas».

2.- La noticia del 19 de abril de 2016 recoge que el Juzgado de lo Penal $\mathrm{n}^{\circ} 28$ de Barcelona $(14 / 11 / 2015)$ condena a la agresora de una enfermera en las Urgencias de un hospital público en Barcelona, como autora de un delito de atentado y de una falta de lesiones ${ }^{345}$.

El ilícito de falta ya no se contempla en el nuevo ordenamiento y, en este caso como en el anterior, tanto la información como la fecha en que tuvo lugar el juicio, son posteriores a la entrada en vigor de la reforma. Por consiguiente, no cabe ya hablar de «faltas».

3.- El Diario de Cádiz publica (10 de enero de 2016) que el Juzgado de Instrucción $\mathrm{n}^{\circ} 4$ de Jerez condenó a un hombre, acusado de amenazar a un ATS en un hospital público ${ }^{346}$, a multa de quince días a razón de seis euros diarios, así como a la prohibición de acercarse al agredido a una distancia menos de veinte metros durante un tiempo que la fuente no determina.

Nos importa esta noticia porque se recoge que la condena fue por «falta» de amenazas:

«El juzgado de Instrucción número 4 de Jerez ha condenado a una persona como autor de una falta de amenazas».

\footnotetext{
344 "...y aunque los sanitarios sean autoridad por la ley antes mencionada por el recurrente, esto se refiere al delito de atentado, ya que el artículo 550 del código penal, si los incluye, pero en forma alguna nos encontramos con este supuesto».

${ }^{345}$ Los hechos tuvieron lugar en el año 2014. La noticia fue: (“Condena de un año de cárcel a una paciente por agredir, escupir e insultar a una enfermera del Hospital Clínic de Barcelona | iSanidad," 2016)

${ }^{346}$ Los hechos ocurrieron cuando el ATS recriminó recordó al acusado que estaba prohibido fumar en las dependencias del hospital, como él hacía en esos momentos. Entonces le amenazó verbalmente levantando además la muleta que llevaba, en ademán de golpearle. ("Condenado por amenazar a un ATS que le recriminó que fumase en el hospital," 2016)
} 
Resulta improcedente la terminología empleada porque la resolución se dicta en diciembre de 2015 y ya está operativa la supresión de esos ilícitos del ordenamiento penal.

\section{CONCLUSIONES}

Hemos encontrado tres aspectos interesantes a reseñar en relación con el objetivo de este apartado.

Comprobamos en primer lugar cómo en ocasiones se utilizan en las resoluciones terminología o conceptos jurídicos discutibles.

Así ocurre con la persistencia en el empleo del término «faltas», que, en todo caso, debieran ser denominadas delitos leves ${ }^{347}$.

En el caso de los supuestos extraídos de diversas fuentes ${ }^{348}$, este confusionismo puede deberse a la propia información, si bien hemos encontrado también resoluciones en que los tribunales se manifiestan en esos términos, como acabamos de señalar.

Continúa el debate en cuanto al ámbito de aplicación del artículo $634 \mathrm{CP}$, bien por alguna de las partes implicadas en el procedimiento ${ }^{349}$, o bien por la estimación del propio tribunal ${ }^{350}$ (como ocurría antes de la entrada en vigor de la reforma), lo que puede generar falta de homogeneidad en la actuación de los tribunales.

Sigue vigente la controversia, al menos por parte de las defensas de los acusados, en torno la imposibilidad de que los profesionales de la sanidad pública, por ser personal estatutario, puedan poseer la condición de funcionario público ${ }^{351}$. Es ésta una cuestión que la jurisprudencia había superado ampliamente antes de la entrada en vigor de la LO 1/2015 (De Juan-Mazuelas, 2016).

Los propios tribunales se hacen eco de las posibles contradicciones que puede entrañar el nuevo ordenamiento, sobre todo en el caso de la interpretación de alguna de las modalidades del ilícito de atentado en relación con las disposiciones del actual $\mathrm{CP}^{352}$.

\footnotetext{
${ }^{347}$ Así: SAP Las Palmas 162/2015, de 17 de septiembre. SAP Badajoz 70/2015, de 30 de septiembre. SAP Madrid 871/ 2015, de 30 de diciembre. SAP Málaga 120/2016, de 23 de febrero. SAP Las Palmas 175/2016, de 20 de mayo. SAP Pontevedra 302/2016, de 23 de mayo.

${ }^{348}$ Es el caso de las tres noticias que se recogen como «Resoluciones tomadas de diversas fuentes» en este mismo epígrafe.

${ }^{349}$ Véase: SAP Valencia 570/2015, de 27 de julio.

350 En este sentido: SAP Granada 627/2015, de 26 de octubre.

${ }^{351}$ Así: SAP Pontevedra 302/2016, de 23 de mayo.

352 Véase: SAP Madrid 104/2016, de 25 de febrero.
} 
Hemos encontrado también la interpretación, cuando menos confusa, que un tribunal hace de la conexión de los ordenamientos administrativo y penal en relación con el concepto de Autoridad, así como en cuanto al contenido del artículo $550 \mathrm{CP}^{353}$.

En segundo lugar, detectamos algunas veces narraciones fácticas en las que los hechos se presentan de manera poco clara ${ }^{354}$, lo que complica su interpretación a la hora de llevar a cabo su análisis.

Finalmente, en tercer lugar, apreciamos un cambio de tendencia en cuanto al tratamiento del delito de lesiones en una resolución en la que, para tipificar los hechos como el citado ilícito, se toma en consideración únicamente la existencia de una primera asistencia sanitaria y tratamientos posteriores no médicos ni quirúrgicos. Pudiera entenderse que tampoco existe exigibilidad en cuanto a la totalidad de dichos tratamientos; eso al menos parece desprenderse de la lectura del primero de los Antecedentes de Hecho de la sentencia ${ }^{355}$. En todo caso, es cierto que esta tendencia de la jurisprudencia a suavizar los requerimientos que el CP exige para estimar la existencia de dichas figuras delictivas había comenzado ya antes de la reforma, aunque no en esos términos ${ }^{356}$.

\footnotetext{
353 Es el caso de: SAP Zaragoza 423/2016, de 9 de septiembre.

354 En este sentido: SAP Las Palmas 162/2015, de 17 de septiembre. SAP Cuenca 25/2016, de 16 de febrero.

355 Así: SAP Alicante 582/2015, de 22 de diciembre, en la que se toman en consideración tratamientos de tipo farmacológico, ortopédico y de rehabilitación, «no resultando suficientemente acreditado que realmente llegase a recibir sesiones de fisioterapia tras ser atendida por el Médico Forense».

356 Véase: STS (Sala Segunda) 519/2016, de 15 de junio de 2016, en relación con la técnica quirúrgica de aproximación (De Juan Mazuelas, 2016).
} 
VI. RESULTADOS 
En la encuesta participaron un total de 655 profesionales sanitarios, pertenecientes a las categorías siguientes: Facultativos (35,9\%), Enfermeras/os y TCAE (Personal de enfermería) (38,2\%), Psicólogos (15,1\%), Fisioterapeutas (4\%), Odontólogos (3,7\%), Logopedas (1,8\%), Celadores y Técnicos de Emergencias (1,4\%). Para el tratamiento de los datos, se unieron los grupos de Fisioterapeutas, Odontólogos, Logopedas, Celadores y técnicos de emergencias (Otros).

La edad media de los participantes fue de 45 años, con una edad mínima de 22 y máxima de 85 (se permitía la participación de personas jubiladas, puesto que podían tener experiencia en materia de agresiones y, desde luego, una opinión valiosa sobre las medidas tomadas en esta materia).

\section{Gráfico 1. Edad de los encuestados.}

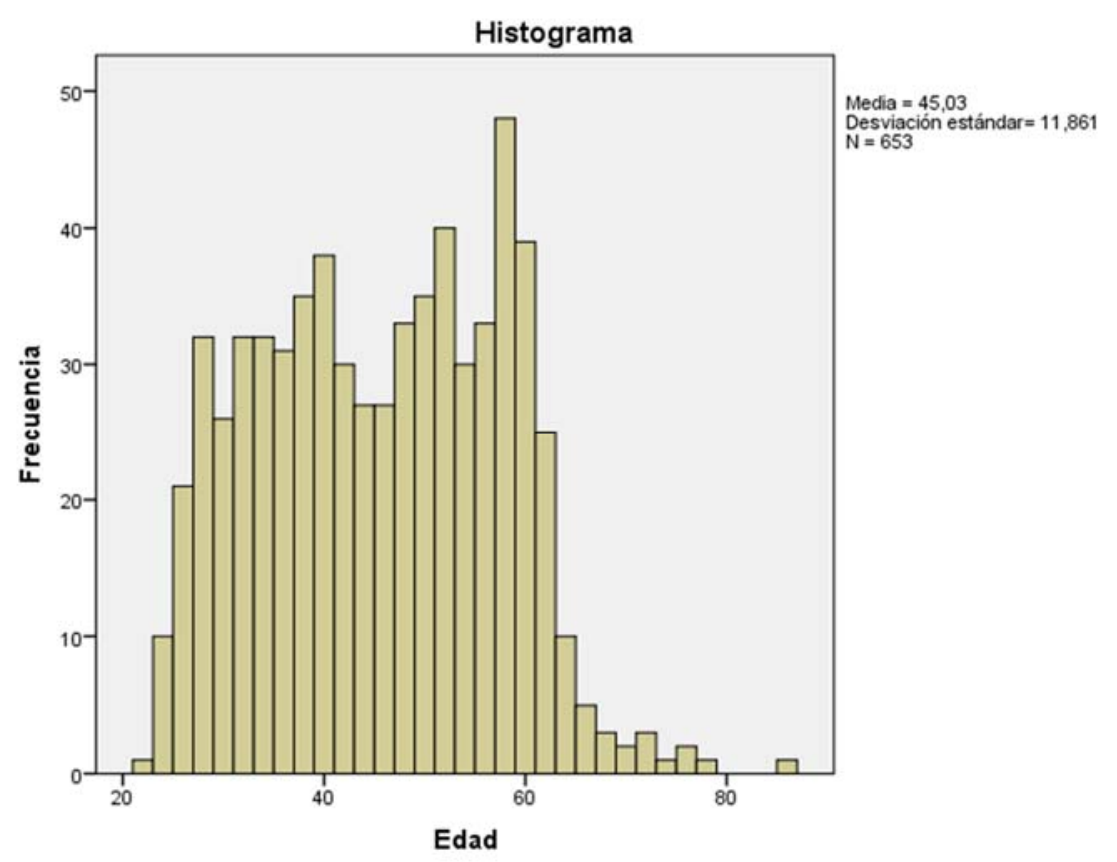

En cuanto al sexo, un $27,3 \%$ de los encuestados eran hombres y un $72,7 \%$ mujeres.

Un $66,7 \%$ prestaban sus servicios en la sanidad pública, el $25,2 \%$ en la privada y un $8,1 \%$ compaginaba su trabajo entre ambas.

El 18,2\% realizaba sus labores asistenciales en Atención Primaria, el 56,6\% en Atención Especializada, el 4,9\% en Emergencias, el 3,4\% en atención de tipo psicológico y el 16,9\% en otro tipo de centros o servicios.

Preguntados sobre si a lo largo de su vida profesional habían experimentado alguna agresión de cualquier tipo, el 55,5\% manifestó haberla sufrido, contra un 39,4\% que respondió negativamente y un $5,2 \%$ que no lo sabía o no estaba seguro (NS/NS). 
Tabla 5. ¿Ha sufrido alguna agresión en su vida profesional?

\begin{tabular}{lr|r|r|r} 
& Frecuencia & Porcentaje & $\begin{array}{c}\text { Porcentaje } \\
\text { válido }\end{array}$ & $\begin{array}{c}\text { Porcentaje } \\
\text { acumulado }\end{array}$ \\
\hline Sí & 363 & 55,5 & 55,5 & 55,5 \\
\hline No & 258 & 39,4 & 39,4 & 94,8 \\
\hline NS/NS & 34 & 5,2 & 5,2 & 100,0 \\
\hline Total & 655 & 100,0 & 100,0 & \\
\hline
\end{tabular}

La relación entre edad del sujeto encuestado y si había experimentado o no alguna agresión arrojó lo siguiente (relación no significativa estadísticamente):

Gráfico 2. Agresiones por edades.

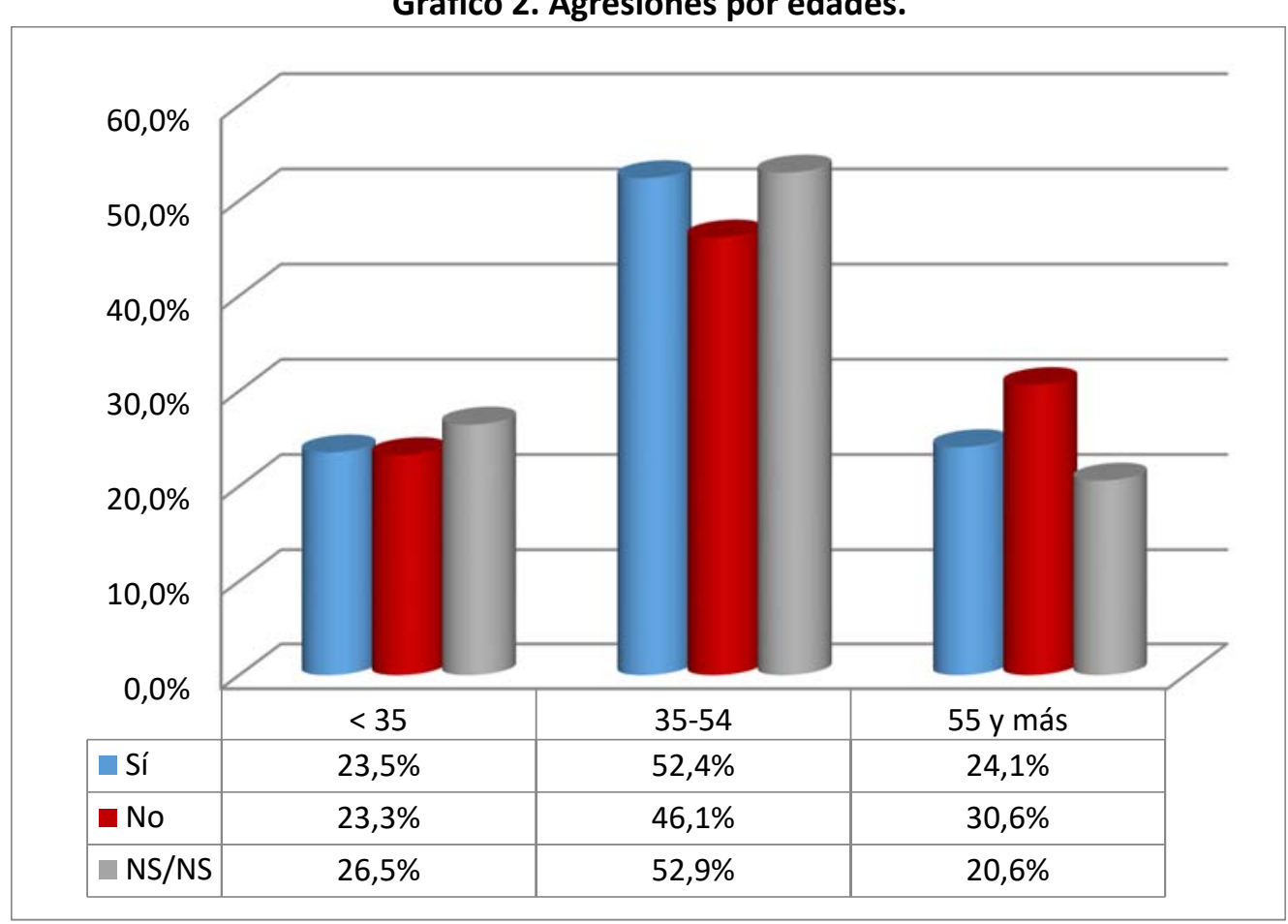

El grupo más castigado es el de edades comprendidas entre los 35-54 años que, por otra parte, también constituye la mayoría de la muestra (como vimos en el histograma anterior). También es el porcentaje más alto de quienes no saben si lo que experimentaron fue o no agresión.

Se encontró una relación estadísticamente significativa (Coeficiente Chi-Cuadrado Pearson $0,000)$ entre las agresiones sufridas y los grupos profesionales, que se ilustra mediante el siguiente gráfico: 
Gráfico 3. Agresiones por categoría profesional

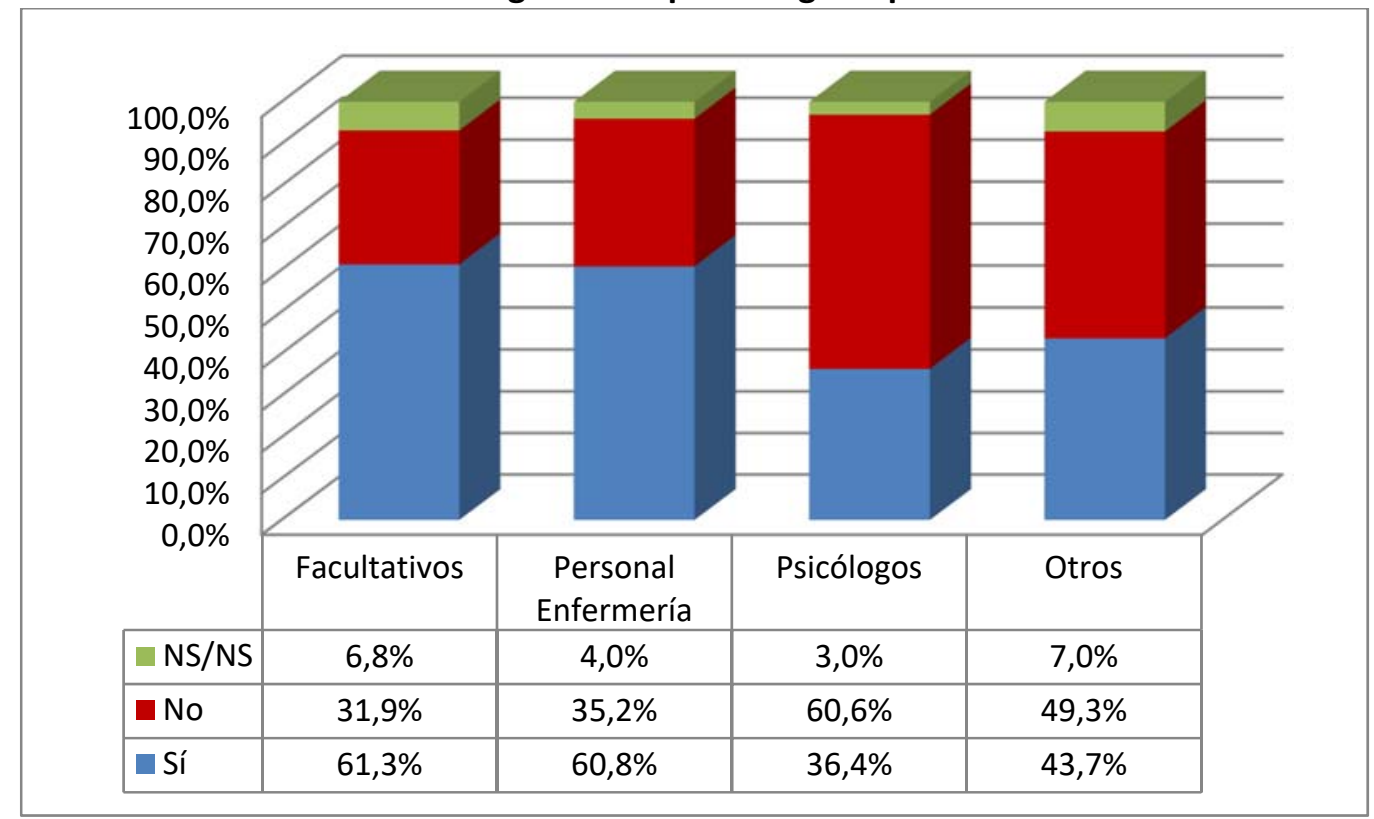

Los colectivos más castigados son los facultativos $(61,3 \%)$ y personal de enfermería $(60,8 \%)$.

También se encontró una relación significativa (Coeficiente Chi-Cuadrado $=0,000$ ) entre las agresiones sufridas según la víctima trabajara en la sanidad pública, la privada o compartiera su trabajo entre ambas. Los datos obtenidos fueron los siguientes:

Gráfico 4. Agresiones por sectores de actividad.

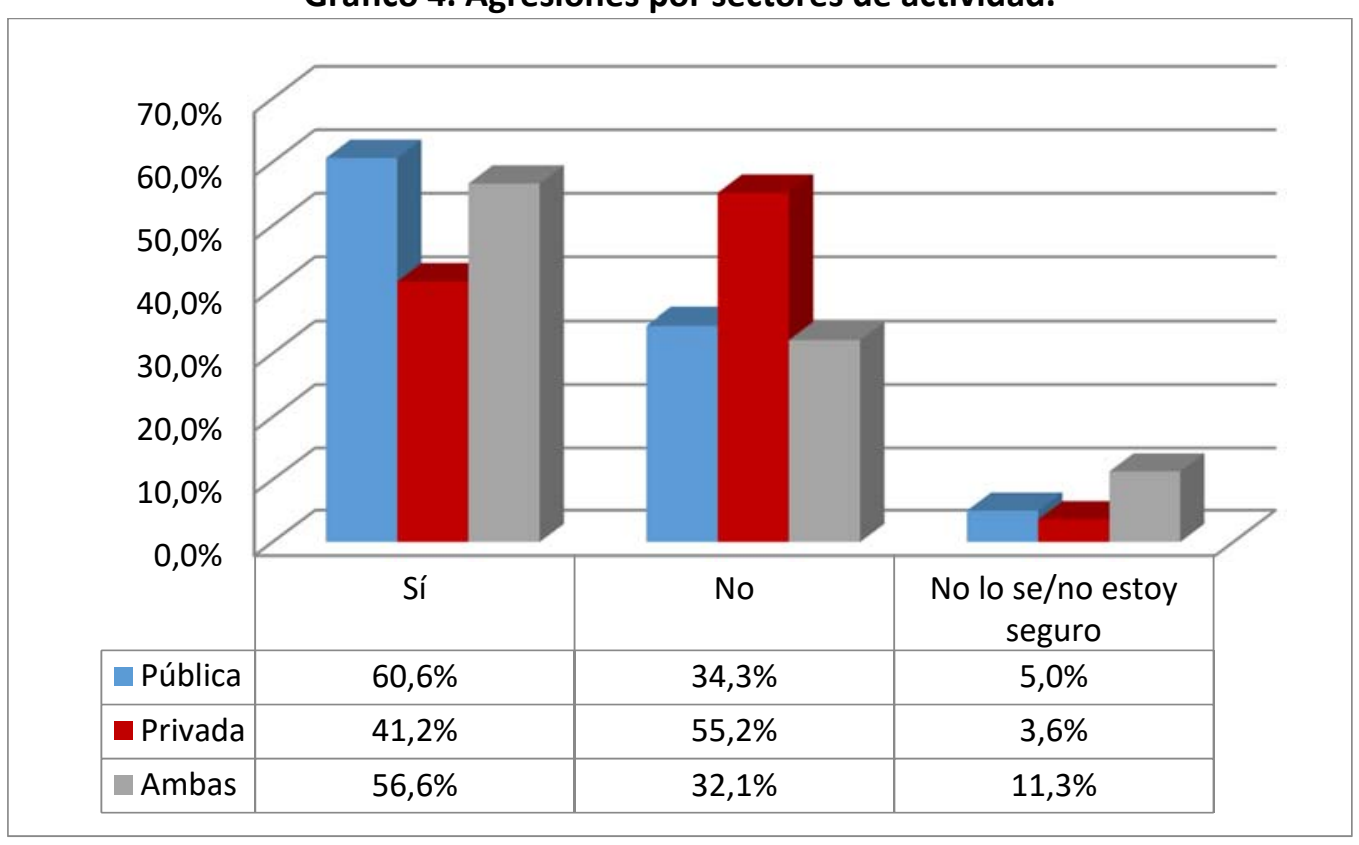

El número de agresiones padecidas por los profesionales de la sanidad pública es mayor que el que se observa en el caso de la privada (60,6\% frente a $41,2 \%)$. Cuando el trabajador compagina sus actividades en ambas, se obtiene una cifra intermedia (56,6\%). De todos modos, debemos tener presente que los índices de participación en la encuesta por parte de la sanidad privada son 
menores que la pública, y que los que comparten ambos sectores de actividad participan en un porcentaje de sólo un $8,1 \%$. Debido a ello cabe preguntarse si esa cifra de 56,6\% no representa un porcentaje relativamente elevado y a qué sector de ambos correspondería la mayoría de las agresiones.

Por otra parte, cabe observar que en este último grupo (quien trabaja en las dos parcelas, pública y privada, de la salud) se da un porcentaje del $11,3 \%$ que reconoce no estar seguro sobre si ha sufrido o no agresiones.

También se encontraron resultados estadísticamente significativos en relación a las agresiones sufridas y el tipo de asistencia sanitaria prestada (Atención Primaria, Atención Especializada, Emergencias, atención psicológico-psiquiátrica y otros). El índice de Chi-Cuadrado de Pearson fue de 0,007).

\section{Gráfico 5. Agresiones por grupos asistencia sanitaria.}

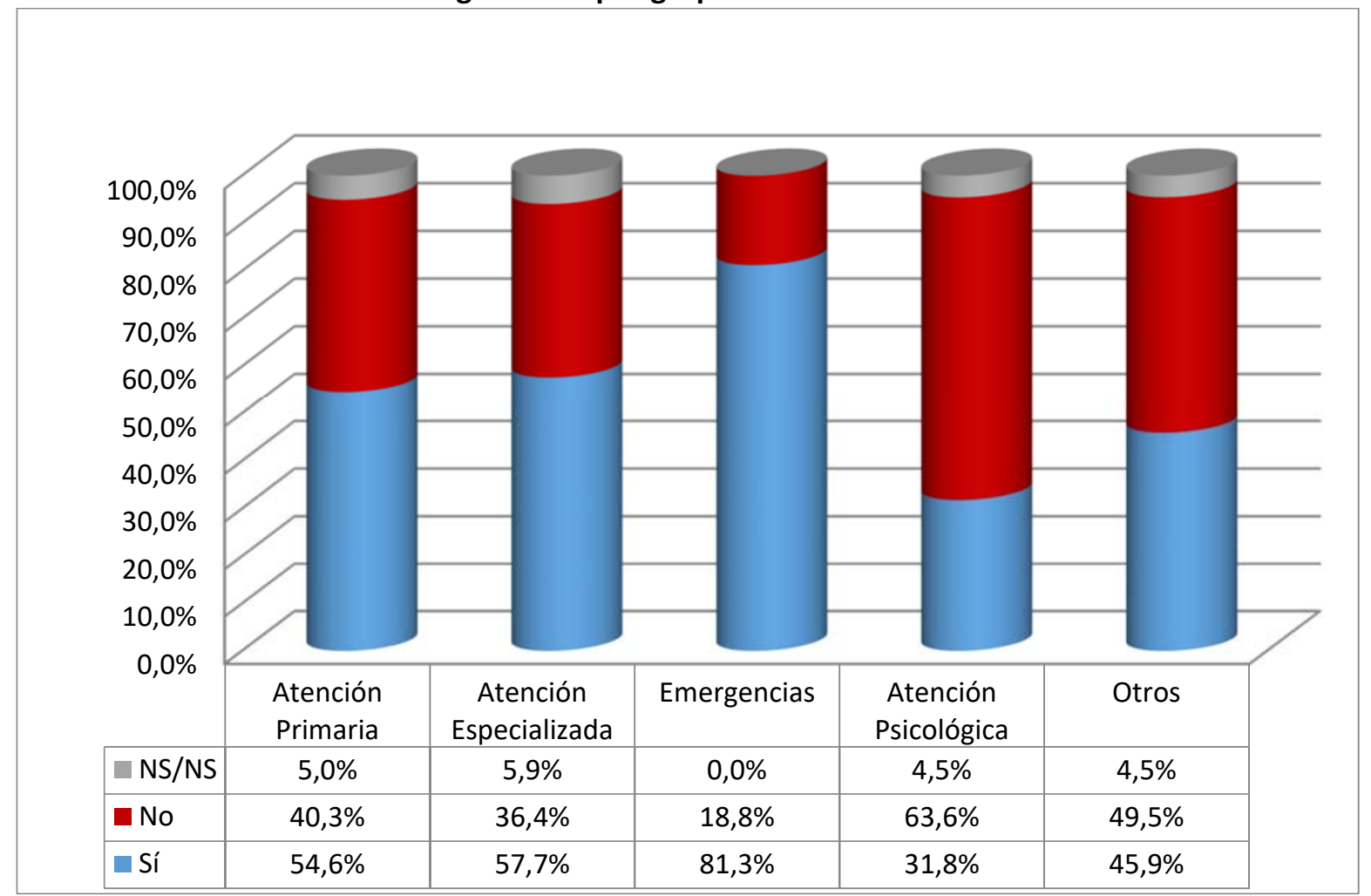

Emergencias obtiene el mayor porcentaje de las incidencias mostradas, con nada menos que el $81,3 \%$, seguido de un 57,7\% de Atención Especializada y un 54,6\% de Atención Primaria. A diferencia de otros estudios, no hemos encontrado una especial incidencia en la asistencia psiquiátrico-psicológica, que se encuentra incluso por debajo del grupo «otros», posiblemente porque este grupo engloba situaciones que pueden ser conflictivas: residencias de ancianos, etc. 
Al 55,4\% de personas que habían afirmado que sí les habían agredido alguna vez (Tabla 5. ¿Ha sufrido alguna agresión en su vida profesional?) se les inquirió sobre la frecuencia con que la agresión o agresiones habían sido físicas, encontrando los siguientes porcentajes:

Tabla 6. Frecuencia de agresiones físicas

\begin{tabular}{lr|r|r|r} 
& Frecuencia & Porcentaje & $\begin{array}{c}\text { Porcentaje } \\
\text { válido }\end{array}$ & $\begin{array}{c}\text { Porcentaje } \\
\text { acumulado }\end{array}$ \\
\hline Ninguna & 520 & 79,4 & 79,4 & 79,4 \\
\hline Una vez & 63 & 9,6 & 9,6 & 89,0 \\
\hline Dos veces & 22 & 3,4 & 3,4 & 92,4 \\
Tres veces & 6 & 0,9 & 0,9 & 93,3 \\
\hline Más de tres & 44 & 6,7 & 6,7 & 100,0 \\
veces & 655 & 100,0 & 100,0 & \\
\hline Total & & & & \\
\hline
\end{tabular}

Encontramos que un 20,6\% manifestaron haber sido objeto de agresiones físicas.

De estos datos, quizá lo más relevante sea que el mayor porcentaje de las agresiones físicas se produce sólo una vez $(9,6 \%)$, seguidas de las agresiones físicas que se han producido más de tres veces contra la misma persona $(6,7 \%)$.

La misma pregunta se hizo, referida esta vez a la cantidad de agresiones verbales (que englobaban a las psíquicas), obteniendo lo siguiente:

Tabla 7. Frecuencia de agresiones verbales

\begin{tabular}{l|r|r|r|r|r} 
& Frecuencia & Porcentaje & $\begin{array}{c}\text { Porcentaje } \\
\text { válido }\end{array}$ & $\begin{array}{c}\text { Porcentaje } \\
\text { acumulado }\end{array}$ \\
\hline Ninguna & 300 & 45,8 & 45,8 & 45,8 \\
\hline Una vez & 63 & 9,6 & 9,6 & 55,4 \\
\hline Dos veces & 73 & 11,1 & 11,1 & 66,6 \\
\hline Tres veces & 29 & 4,4 & 4,4 & 71,0 \\
\hline Más de tres veces & 190 & 29,0 & 29,0 & 100,0 \\
\hline Total & 655 & 100,0 & 100,0 & \\
\hline
\end{tabular}

En esta ocasión, encontramos un índice de agresiones verbales de un 54,1\% de los encuestados que refirieron haber sufrido algún tipo de violencia.

La mayoría de estas agresiones se produjeron más de tres veces (29\%), seguidas de las sufridas en dos ocasiones $(11,1 \%)$. 
Resulta evidente que las agresiones verbales superan a las físicas $(54,1 \%$ frente a $20,6 \%)$. Las agresiones múltiples también son más numerosas en el caso de las verbales: un 44,5\% $(11,1 \%+4,4 \%+29 \%)$ contra un $11 \%(3,4 \%+0,9 \%+6,7 \%)$.

\section{TIPOLOGÍA DEL AGRESOR}

En cuanto a la tipología del agresor, encontramos los siguientes datos respecto a cuando quien agrede es el propio paciente:

Tabla 8. Agresor paciente

\begin{tabular}{llr|r|r|r} 
& Frecuencia & Porcentaje & $\begin{array}{c}\text { Porcentaje } \\
\text { válido }\end{array}$ & $\begin{array}{l}\text { Porcentaje } \\
\text { acumulado }\end{array}$ \\
\hline & No & 182 & 27,8 & 42,4 & 42,4 \\
\cline { 2 - 6 } & Sí & 247 & 37,7 & 57,6 & 100,0 \\
\hline Total & 429 & 65,5 & 100,0 & \\
\hline Perdidos & Sistema & 226 & 34,5 & & \\
\hline
\end{tabular}

En el caso de que el agresor fue un familiar o acompañante, se obtuvieron los siguientes datos:

Tabla 9. Agresor familiar o acompañante

\begin{tabular}{llr|r|r|r} 
& & Frecuencia & Porcentaje & $\begin{array}{c}\text { Porcentaje } \\
\text { válido }\end{array}$ & $\begin{array}{c}\text { Porcentaje } \\
\text { acumulado }\end{array}$ \\
\hline \multirow{3}{*}{ No } & 191 & 29,2 & 44,5 & 44,5 \\
\cline { 2 - 6 } & Sí & 238 & 36,3 & 55,5 & 100,0 \\
\hline Total & 429 & 65,5 & 100,0 & \\
\hline Perdidos & Sistema & 226 & 34,5 & & \\
\hline
\end{tabular}

Se observan porcentajes similares en ambos casos: 57,6\% agresor paciente, frente a 55,5\% agresor acompañante, con un pequeño incremento a favor del agresor paciente.

Cuando hablamos de violencia interna (el agresor es un compañero o superior del encuestado), se observa que un 16,1\% manifiesta haber sido víctima alguna vez de algún tipo de agresión en este sentido.

Aunque parezca una cifra no demasiado alta, por comparación con los porcentajes que hemos encontrado de violencia externa, no debemos olvidar la gravedad de que dentro del propio entorno de trabajo haya nada menos que un $16,1 \%$ de agresiones: 
Tabla 10. Agresor compañero

\begin{tabular}{llr|r|r|r} 
& & Frecuencia & Porcentaje & $\begin{array}{c}\text { Porcentaje } \\
\text { válido }\end{array}$ & $\begin{array}{c}\text { Porcentaje } \\
\text { acumulado }\end{array}$ \\
\hline \multirow{3}{*}{ No } & 360 & 55,0 & 83,9 & 83,9 \\
\cline { 2 - 6 } & Si & 69 & 10,5 & 16,1 & 100,0 \\
\cline { 2 - 5 } & Total & 429 & 65,5 & 100,0 & \\
\hline Perdidos & Sistema & 226 & 34,5 & & \\
\hline Total & & 655 & 100,0 & & \\
\hline
\end{tabular}

Cuando el agresor fue otra persona (ni familiar, ni acompañante, ni perteneciente al entorno del trabajo) se halló lo siguiente:

Tabla 11. Agresor otro

\begin{tabular}{llr|r|r|r} 
& & Frecuencia & Porcentaje & $\begin{array}{c}\text { Porcentaje } \\
\text { válido }\end{array}$ & $\begin{array}{c}\text { Porcentaje } \\
\text { acumulado }\end{array}$ \\
\hline Válido & Sí & 8 & 1,2 & 100,0 & 100,0 \\
\hline Perdidos & Sistema & 647 & 98,8 & & \\
Total & & 655 & 100,0 & & \\
\hline
\end{tabular}

El porcentaje es realmente bajo (1,2\%). Ha de tenerse en cuenta que en «otro» se incluyen los casos por exclusión, es decir, cuando el agresor no pertenecía a ninguno de los grupos anteriores, como un modo de reflejar aquellos supuestos de violencia cometida por terceros ajenos a la relación asistencial.

\section{SEXO DEL AGRESOR}

A continuación, se presentan los resultados de la relación entre agresiones sufridas y sexo del autor o autora.

Tabla 12. Número de ocasiones en que el autor de la agresión fue un hombre.

\begin{tabular}{l|r|r|r|r} 
& Frecuencia & Porcentaje & $\begin{array}{c}\text { Porcentaje } \\
\text { válido }\end{array}$ & $\begin{array}{c}\text { Porcentaje } \\
\text { acumulado }\end{array}$ \\
\hline Ninguna & 321 & 49 & 49,0 & 49,0 \\
\hline Una vez & 97 & 14,8 & 14,8 & 63,8 \\
\hline Dos veces & 89 & 13,6 & 13,6 & 77,4 \\
\hline Tres veces & 31 & 4,7 & 4,7 & 82,1 \\
\hline Más de tres & 117 & 17,9 & 17,9 & 100,0 \\
veces & 655 & 100,0 & 100,0 & \\
\hline Total & & & &
\end{tabular}


En un $51 \%$ de las ocasiones, el agresor era de sexo masculino. En cuanto al número de ocasiones en que la agresión fue producida por un hombre, en un $14,8 \%$ de los casos lo fue una vez, dos veces en un $13,6 \%$, tres veces un $4,7 \%$ y un $17,9 \%$ lo fue más de tres veces.

Respecto a las mujeres agresoras, lo fueron en un 39,9\% de las ocasiones en que se produjo una agresión. En un 16\% de los casos se realizó una sola agresión, dos veces un 7,9\%, bajando a un $2,7 \%$ de las ocasiones en que se produjo tres veces y volviendo a subir hasta un $13,3 \%$ cuando las mujeres agredieron más de tres veces.

Tabla 13. Número de ocasiones en las que la autora fue una mujer.

\begin{tabular}{lr|r|r|r} 
& Frecuencia & Porcentaje & $\begin{array}{c}\text { Porcentaje } \\
\text { válido }\end{array}$ & $\begin{array}{c}\text { Porcentaje } \\
\text { acumulado }\end{array}$ \\
\hline Ninguna & 393 & 60 & 60,0 & 60,0 \\
\hline Una vez & 105 & 16,0 & 16,0 & 76,0 \\
\hline Dos veces & 52 & 7,9 & 7,9 & 84,0 \\
\hline Tres veces & 18 & 2,7 & 2,7 & 86,7 \\
\hline Más de tres & 87 & 13,3 & 13,3 & 100,0 \\
veces & 655 & 100,0 & 100,0 & \\
\hline Total & & & & \\
\hline
\end{tabular}

En términos absolutos, los hombres agreden más que las mujeres y lo hacen con más frecuencia (obsérvese cómo las agresiones masculinas sólo se encuentran en un porcentaje inferior a las femeninas en los casos en que se produjeron una sola vez):

Una vez: $14,8 \%$ hombre- $16 \%$ mujer

Dos veces: $13,6 \%$ hombre- $7,9 \%$ mujer.

Tres veces: $4,7 \%$ hombre- $2,7 \%$ mujer.

Más de tres veces: $17,9 \%$ hombre- $13,3 \%$ mujer.

También hay un porcentaje mayor de agresiones múltiples (más de una vez) en el caso de los hombres $(36,2 \%)$ que en el de las mujeres $(23,9 \%)$.

Se encontró una relación significativa entre sexo del/a agresor/a y agredido/a (índice ChiCuadrado 0,002).

En el gráfico siguiente puede verse con más claridad la relación existente entre estas variables: 
Gráfico 6. Relación entre sexo del/a agresor/a y sexo de la víctima.

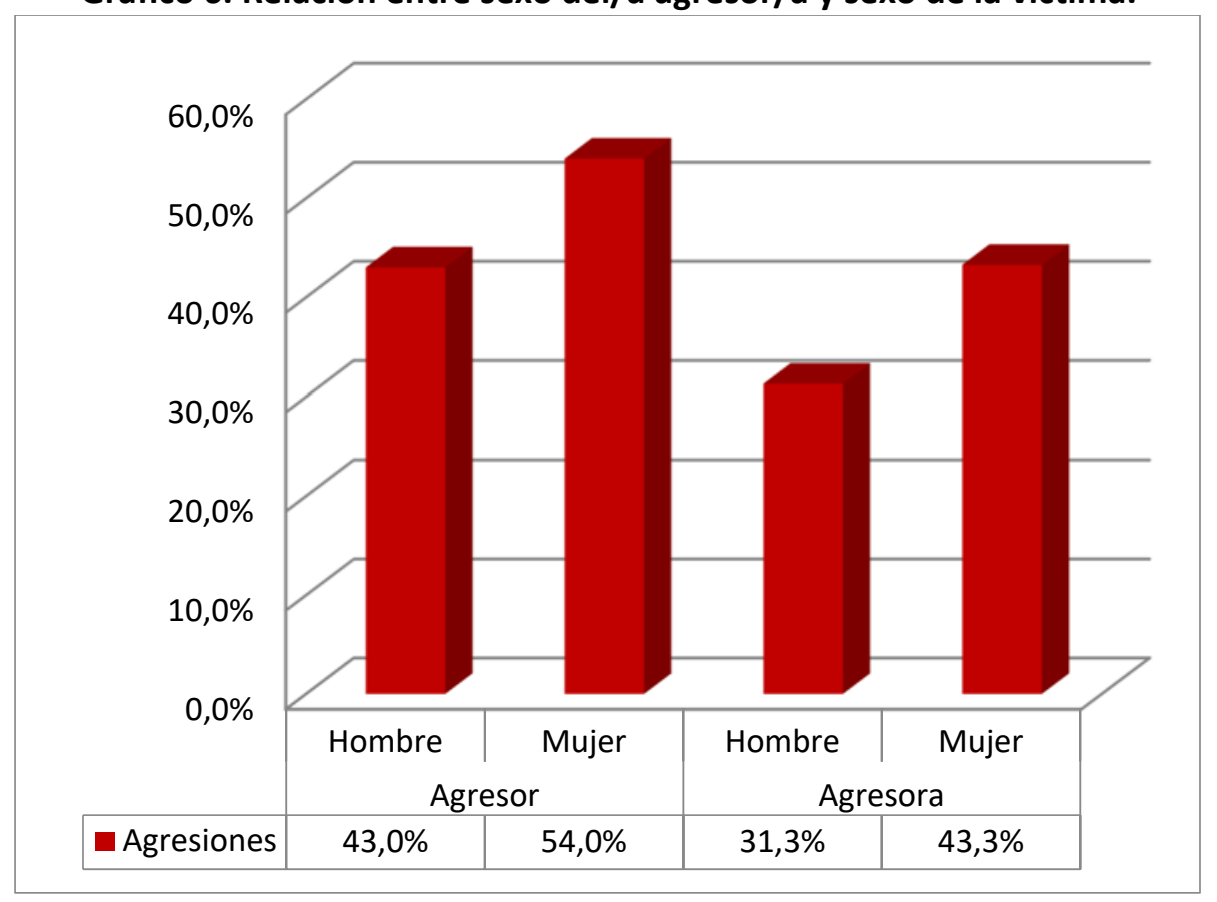

Como se observa, el mayor porcentaje se da en hombres que atacan a mujeres (54\%). A cierta distancia, las mujeres que agreden a mujeres $(43,3 \%)$ y los hombres que agreden a hombres (43\%). El porcentaje menor (31,3\%) responde a casos en que una mujer es agresora de un hombre.

Establecimos una relación (que resultó ser significativa: $\mathrm{P}=0,002$ ) entre las personas que habían sufrido una agresión y su sexo. Resultó que, de entre la población que había sufrido una agresión la mayoría eran mujeres $(59,7 \%)$, porcentaje que sobrepasa al del número total de agredidos $(55,4 \%)$.

Gráfico 7. Relación de las agresiones con el sexo de la víctima.

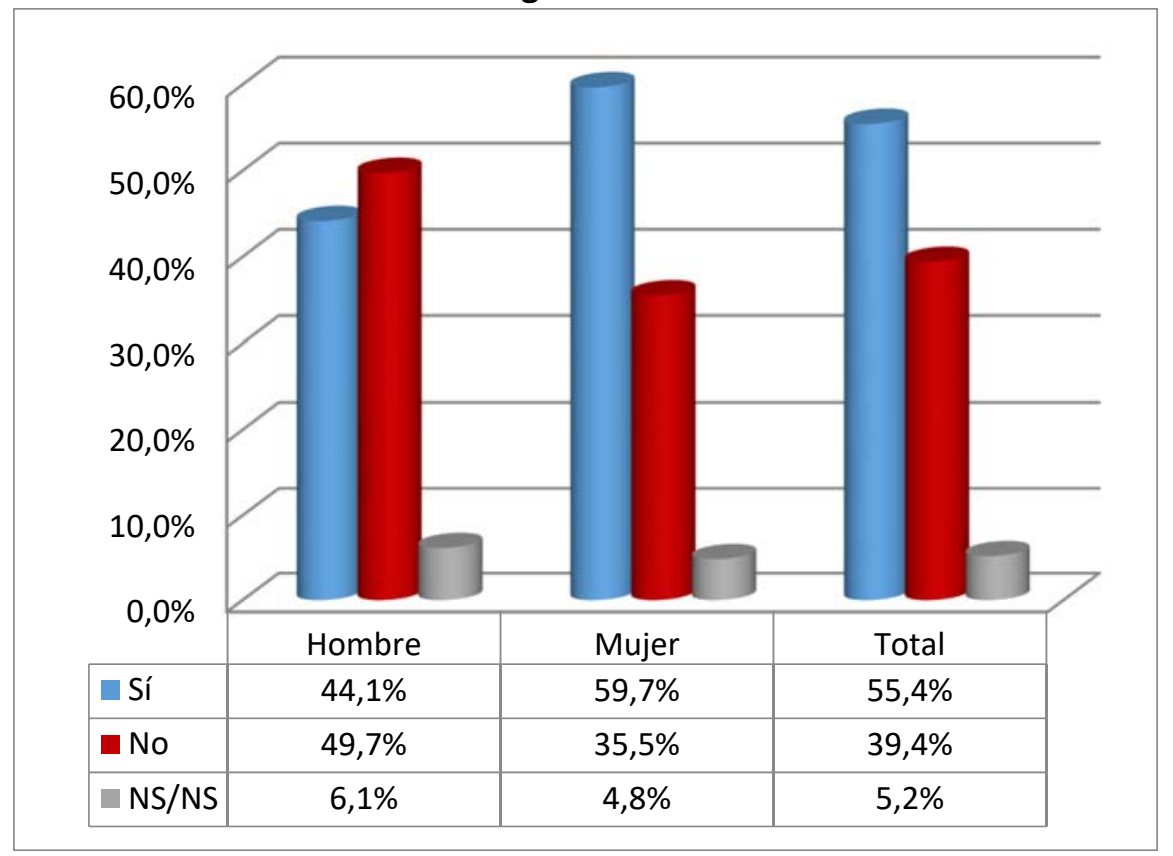


Esto puede llevarnos a pensar en que el riesgo de sufrir agresión sería mayor si se es mujer que si se es hombre. Los porcentajes obtenidos de personas no agredidas son igualmente más elevados en los hombres (superándose también la cifra global de personas que no han sufrido agresión) y más bajos en las mujeres.

\section{POSIBLES MOTIVOS DEL AGRESOR}

A continuación, se intentó dilucidar a qué atribuyen las víctimas la producción de las agresiones sufridas. Para ello se utilizó un listado de posibles razones, que el encuestado valoraba mediante una escala tipo Likert.

En primer lugar, se les preguntó sobre si la agresión pudo tener lugar sin razón ninguna, sin motivo aparente, fruto de la pura improvisación.

Tabla 14. Motivo de la agresión: sin razón aparente.

\begin{tabular}{llr|r|r|r} 
& Frecuencia & Porcentaje & $\begin{array}{c}\text { Porcentaje } \\
\text { válido }\end{array}$ & $\begin{array}{c}\text { Porcentaje } \\
\text { acumulado }\end{array}$ \\
\hline & 207 & 31,6 & 56,9 & 56,9 \\
\hline & $\begin{array}{l}\text { No tuvo nada } \\
\text { que ver }\end{array}$ & 81 & 12,4 & 22,3 & 79,1 \\
$\begin{array}{l}\text { Tuvo algo que } \\
\text { ver }\end{array}$ & 43 & 6,6 & 11,8 & 90,9 \\
\hline $\begin{array}{l}\text { Tuvo mucho } \\
\text { que ver }\end{array}$ & 33 & 5,0 & 9,1 & 100,0 \\
\hline $\begin{array}{l}\text { Sin duda fue la } \\
\text { razón }\end{array}$ & Total & 364 & 55,6 & 100,0 & \\
\hline Perdidos & Sistema & 291 & 44,4 & & \\
\hline Total & 655 & 100,0 & & \\
\hline
\end{tabular}

Un 56,9\% respondió de forma negativa y, por tanto, atribuyendo algún tipo de motivación a la agresión. Sumando los porcentajes de quienes pensaron que «tuvo mucho que ver» y «sin duda fue la razón», se obtiene un $20,9 \%$, que podríamos interpretar como el porcentaje de quienes piensan que las agresiones se produjeron de modo fortuito. Hay que tener en cuenta que este tipo de agresiones resulta, por propia naturaleza, impredecible e inevitable. Estaríamos, por ello, ante un $20,9 \%$ de agredidos que opina que las agresiones no se pudieron prevenir, ni podría haberse hecho nada para evitarlas.

A continuación, se ofreció como posible razón de la agresión la disconformidad con la asistencia prestada por el profesional agredido: 
Tabla 15. Motivo de la agresión: disconformidad con la atención recibida

\begin{tabular}{llr|r|r|r} 
& Frecuencia & Porcentaje & $\begin{array}{c}\text { Porcentaje } \\
\text { válido }\end{array}$ & $\begin{array}{l}\text { Porcentaje } \\
\text { acumulado }\end{array}$ \\
\hline & 107 & 16,3 & 29,4 & 29,4 \\
& $\begin{array}{l}\text { No tuvo nada } \\
\text { que ver } \\
\text { Tuvo algo que } \\
\text { ver }\end{array}$ & 109 & 16,6 & 29,9 & 59,3 \\
\hline & $\begin{array}{l}\text { Tuvo mucho } \\
\text { que ver }\end{array}$ & 83 & 12,7 & 22,8 & 82,1 \\
\hline $\begin{array}{l}\text { Sin duda fue el } \\
\text { motivo }\end{array}$ & 65 & 9,9 & 17,9 & 100,0 \\
\hline Potal & 364 & 55,6 & 100,0 & \\
\hline Total & Sistema & 291 & 44,4 & & \\
\hline
\end{tabular}

Un $29,4 \%$ no achaca a este motivo la producción de la agresión, mientras un $17,9 \%$ se la atribuye por completo. Pero si sumamos los porcentajes de «sin duda fue el motivo» $(17,9 \%)$ y «tuvo mucho que ver» $(22,8 \%)$, obtendremos un $40,7 \%$ de personas que estiman que esta pudo ser la razón que movió al agresor a la acción, que resulta un porcentaje nada desdeñable. Además, un $29,9 \%$ reconoce que algo tuvo que ver.

Es decir, los que entienden que sí es relevante este motivo (en mayor o menor medida) conforman un total de $70,6 \%$, porcentaje que supera ampliamente a los que no le conceden importancia.

Preguntados sobre si la agresión pudo ser causada por algún tipo de patología psiquiátrica del paciente/acompañante que le atacó, obtuvimos los siguientes resultados:

Tabla 16. Motivo de la agresión: enfermedad psiquiátrica

\begin{tabular}{|c|c|c|c|c|c|}
\hline \multicolumn{3}{|c|}{ Frecuencia } & Porcentaje & $\begin{array}{l}\text { Porcentaje } \\
\text { válido }\end{array}$ & $\begin{array}{l}\text { Porcentaje } \\
\text { acumulado }\end{array}$ \\
\hline & $\begin{array}{l}\text { No tuvo nada } \\
\text { que ver }\end{array}$ & 164 & 25,0 & 45,1 & 45,1 \\
\hline & $\begin{array}{l}\text { Tuvo algo que } \\
\text { ver }\end{array}$ & 71 & 10,8 & 19,5 & 64,6 \\
\hline & $\begin{array}{l}\text { Tuvo mucho } \\
\text { que ver }\end{array}$ & 64 & 9,8 & 17,6 & 82,1 \\
\hline & $\begin{array}{l}\text { Sin duda fue el } \\
\text { motivo }\end{array}$ & 65 & 9,9 & 17,9 & 100,0 \\
\hline & Total & 364 & 55,6 & 100,0 & \\
\hline Perdidos & Sistema & 291 & 44,4 & & \\
\hline Total & & 655 & 100,0 & & \\
\hline
\end{tabular}


Un $45,1 \%$ descarta que ese fuera el motivo. El 35,5\% (17,6\%+17,9\%) atribuye a esta causa lo sucedido, aunque sólo un 17,9\% está completamente seguro de que esta fue la razón única de la agresión. Un 19,5\% estima que quizá el estado mental del paciente/acompañante pudo influir en su actividad agresora.

Muchos planes de prevención inciden sobre la influencia de las demoras y los prolongados tiempos de espera en el surgimiento de la violencia. Nuestros resultados a este respecto son los siguientes:

Tabla 17. Motivo de la agresión: tiempo de espera prolongado

\begin{tabular}{|c|c|c|c|c|c|}
\hline & tor & Frecuencia & Porcentaje & $\begin{array}{l}\text { Porcentaje } \\
\text { válido }\end{array}$ & $\begin{array}{l}\text { Porcentaje } \\
\text { acumulado }\end{array}$ \\
\hline & $\begin{array}{l}\text { No tuvo nada } \\
\text { que ver }\end{array}$ & 205 & 31,3 & 56,3 & 56,3 \\
\hline & $\begin{array}{l}\text { Tuvo algo que } \\
\text { ver }\end{array}$ & 63 & 9,6 & 17,3 & 73,6 \\
\hline & $\begin{array}{l}\text { Tuvo mucho } \\
\text { que ver }\end{array}$ & 63 & 9,6 & 17,3 & 90,9 \\
\hline & $\begin{array}{l}\text { Sin duda fue el } \\
\text { motivo }\end{array}$ & 33 & 5,0 & 9,1 & 100,0 \\
\hline & Total & 364 & 55,6 & 100,0 & \\
\hline Perdidos & Sistema & 291 & 44,4 & & \\
\hline Total & & 655 & 100,0 & & \\
\hline
\end{tabular}

Como puede verse, nada menos que un $56,3 \%$ de los encuestados no atribuyen la agresión sufrida a la espera prolongada.

Únicamente un 9,1\% entiende que esta fue la razón exclusiva, y el 17,3\% piensa que tuvo bastante influencia en los hechos, mientras que el mismo porcentaje se da entre quienes creen que tuvo alguna influencia.

En total, quienes piensan que de algún modo pudo ser el motivo $(17,3 \%+17,3 \%+9,1 \%)$ suman un $43,7 \%$.

Podemos deducir que la mayoría de nuestros entrevistados no creen que los tiempos de espera prolongados hayan sido el motivo principal por el que sufrieron la agresión.

Las peticiones insatisfechas (por ejemplo, la renovación de una baja laboral o la expedición de determinadas recetas, entre otras) pueden ser también el desencadenante de una conducta agresiva. 
Tabla 18. Motivo de la agresión: peticiones insatisfechas

\begin{tabular}{|c|c|c|c|c|c|}
\hline & & Frecuencia & Porcentaje & $\begin{array}{l}\text { Porcentaje } \\
\text { válido }\end{array}$ & $\begin{array}{l}\text { Porcentaje } \\
\text { acumulado }\end{array}$ \\
\hline & $\begin{array}{l}\text { No tuvo nada } \\
\text { que ver }\end{array}$ & 113 & 17,3 & 31,0 & 31,0 \\
\hline & $\begin{array}{l}\text { Tuvo algo que } \\
\text { ver }\end{array}$ & 85 & 13,0 & 23,4 & 54,4 \\
\hline & $\begin{array}{l}\text { Tuvo mucho } \\
\text { que ver }\end{array}$ & 86 & 13,1 & 23,6 & 78,0 \\
\hline & $\begin{array}{l}\text { Sin duda fue el } \\
\text { motivo }\end{array}$ & 80 & 12,2 & 22,0 & 100,0 \\
\hline & Total & 364 & 55,6 & 100,0 & \\
\hline Perdidos & Sistema & 291 & 44,4 & & \\
\hline Total & & 655 & 100,0 & & \\
\hline
\end{tabular}

Los encuestados que no achacaron a este motivo la producción de agresiones alcanzaron un porcentaje del $31 \%$. Para un 22\% esa fue la única causa, un 23,6\% lo encontró su razón principal y un $23,4 \%$ pensó que quizás tuvo algo que ver en la agresión. El $69 \%(23,4 \%+23,6 \%+22 \%)$ cree que este fue un motivo influyente en las agresiones.

Por tanto, nuestros encuestados valoran este motivo de agresión como más relevante que el relativo a los tiempos de espera.

Preguntados sobre si la principal causa pudo ser un fallo en la comunicación con el agresor, respondieron lo siguiente:

Tabla 19. Motivo de la agresión: fallo en la comunicación con el agresor

\begin{tabular}{llr|r|r|r} 
& Frecuencia & Porcentaje & $\begin{array}{c}\text { Porcentaje } \\
\text { válido }\end{array}$ & $\begin{array}{l}\text { Porcentaje } \\
\text { acumulado }\end{array}$ \\
\hline & 198 & 30,2 & 54,4 & 54,4 \\
& $\begin{array}{l}\text { No tuvo nada } \\
\text { que ver }\end{array}$ & 99 & 15,1 & 27,2 & 81,6 \\
$\begin{array}{l}\text { Tuvo algo que } \\
\text { ver }\end{array}$ & 39 & 6,0 & 10,7 & 92,3 \\
\hline $\begin{array}{l}\text { Tuvo mucho } \\
\text { que ver }\end{array}$ & $\begin{array}{l}\text { Sin duda fue el } \\
\text { motivo }\end{array}$ & 28 & 4,3 & 7,7 & 100,0 \\
\hline Potal & 364 & 55,6 & 100,0 & \\
\hline Total & Sistema & 291 & 44,4 & & \\
\hline
\end{tabular}

Un 54,4\% no cree que fuera el motivo en absoluto y tan sólo un 7,7\% piensa que fue la razón determinante. Únicamente un $18,4 \%(10,7 \%+7,7 \%)$ atribuye a los fallos de comunicación la consecución de los hechos, siendo un $27,2 \%$ el porcentaje de quienes les dan algún tipo de 
influencia. La mayoría $(54,4 \%$ frente a $45,6 \%)$, por tanto, estima que la carencia o defectos en la comunicación no tienen gran efecto en que se dé un acto agresivo.

El estrés y nerviosismo influyen en ocasiones en la conducta del usuario, que puede volverse agresivo ante situaciones que le provoquen este tipo de estado psíquico.

La cuestión sobre si se atribuían a este motivo las agresiones, arrojó los siguientes datos:

Tabla 20. Motivo de la agresión: alto estrés y nerviosismo del agresor

\begin{tabular}{ll|r|r|r|r} 
& Frecuencia & Porcentaje & $\begin{array}{c}\text { Porcentaje } \\
\text { válido }\end{array}$ & $\begin{array}{c}\text { Porcentaje } \\
\text { acumulado }\end{array}$ \\
\hline & $\begin{array}{l}\text { No tuvo nada } \\
\text { que ver } \\
\text { Tuvo algo que }\end{array}$ & 66 & 10,1 & 18,1 & 18,1 \\
\hline & 123 & 18,8 & 33,8 & 51,9 \\
\hline & $\begin{array}{l}\text { Tuvo mucho } \\
\text { que ver }\end{array}$ & 113 & 17,3 & 31,0 & 83,0 \\
\hline & $\begin{array}{l}\text { Sin duda fue el } \\
\text { motivo }\end{array}$ & 62 & 9,5 & 17,0 & 100,0 \\
\hline & Total & 364 & 55,6 & 100,0 & \\
\hline Perdidos & Sistema & 291 & 44,4 & & \\
\hline Total & & 655 & 100,0 & & \\
\hline
\end{tabular}

El porcentaje mayor observado corresponde con los encuestados que estimaban que «tuvo algo que ver» $(33,8 \%)$. Un $48 \%$ achaca la agresión a este motivo $(31 \%+17 \%)$.

Por el contrario, un 18,1\% afirma que el estrés y/o nerviosismo del agresor no tuvo nada que ver en el ataque.

Se observa mayor peso $(81,8 \%)$ de los que en mayor o menor medida dan relevancia a este motivo de agresión $(48 \%+33,8 \%)$.

Algunos estudios señalan que muchos usuarios del sistema sanitario tienen un conocimiento claro de los derechos que les asisten, pero no son conscientes de que estos derechos llevan aparejados también deberes y manifiestan que una de las razones por las que se producen las agresiones es precisamente esta actitud. 
Tabla 21. Motivo de la agresión: percepción del agresor de tener derechos, pero no deberes

\begin{tabular}{|c|c|c|c|c|c|}
\hline & & Frecuencia & Porcentaje & $\begin{array}{l}\text { Porcentaje } \\
\text { válido }\end{array}$ & $\begin{array}{l}\text { Porcentaje } \\
\text { acumulado }\end{array}$ \\
\hline & $\begin{array}{l}\text { No tuvo nada } \\
\text { que ver }\end{array}$ & 86 & 13,1 & 23,6 & 23,6 \\
\hline & $\begin{array}{l}\text { Tuvo algo que } \\
\text { ver }\end{array}$ & 67 & 10,2 & 18,4 & 42,0 \\
\hline & $\begin{array}{l}\text { Tuvo mucho } \\
\text { que ver }\end{array}$ & 128 & 19,5 & 35,2 & 77,2 \\
\hline & $\begin{array}{l}\text { Sin duda fue el } \\
\text { motivo }\end{array}$ & 83 & 12,7 & 22,8 & 100,0 \\
\hline & Total & 364 & 55,6 & 100,0 & \\
\hline Perdidos & Sistema & 291 & 44,4 & & \\
\hline Total & & 655 & 100,0 & & \\
\hline
\end{tabular}

Los encuestados que opinan que la agresión sufrida no tuvo nada que ver con la falta de percepción de ser titular de deberes por parte del usuario alcanzan un porcentaje del 23,6\%. El $58 \%$ otorga a esta razón bastante importancia $(22,8 \%+35,2 \%)$. Los que creen que tuvo algo que ver suponen el $18,4 \%$. Por tanto, los que dan importancia a este motivo representarían un $76,4 \%$ $(58 \%+18,4 \%)$ frente a los que no $(23,6 \%)$.

\section{Gráfico 8. Motivos a los que se atribuyen las agresiones}

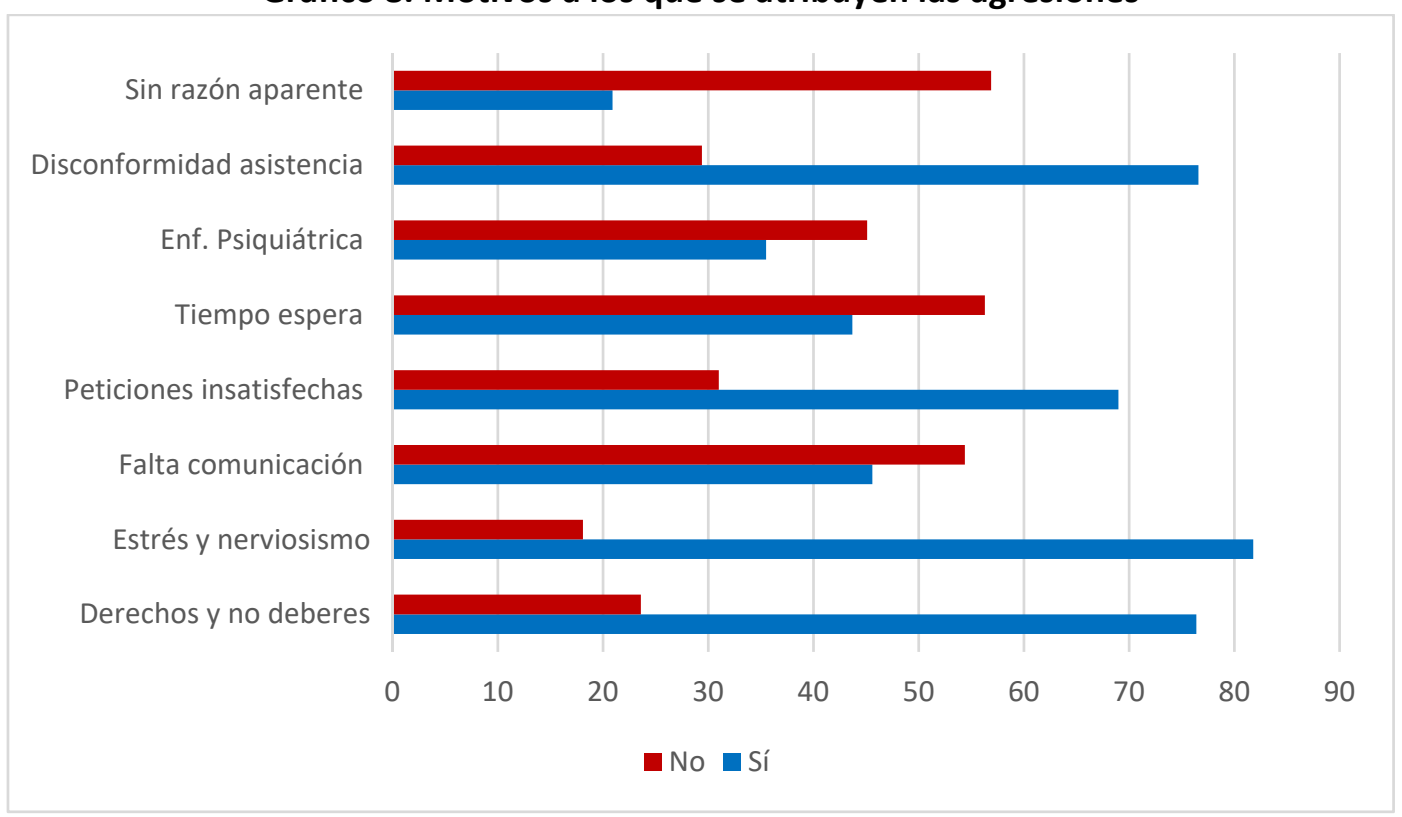

En conjunto, los encuestados estiman que la razón más frecuente por la que se produjeron las agresiones fue el estrés y nerviosismo del paciente o acompañantes $(81,8 \%)$, seguido de la disconformidad con la asistencia recibida (76,6\%), la apreciación de ostentar derechos sin deberes correlativo $(76,4 \%)$ y las peticiones insatisfechas $(69 \%)$. Después se encuentran la falta de comunicación $(45,6 \%)$ y los tiempos de espera prolongados $(43,7 \%)$, la influencia de 
enfermedades psiquiátricas en el comportamiento violento $(35,5 \%)$ y, por último, la ausencia de razones para cometer la agresión (20,9\%).

\section{LUGARES EN QUE SE COMETIERON LAS AGRESIONES}

El mayor porcentaje de agresiones se ubicaron en las consultas $(39,3 \%)$, seguido de hospitalización $(28,5 \%)$ y urgencias $(26,9 \%)$. En los pasillos la incidencia fue de un $22 \%$ y los porcentajes bajan a partir de ahí: $8,2 \%$ en mostrador, $4,7 \%$ en el domicilio del enfermo, $3,3 \%$ en la vía pública y $2,3 \%$ en puertas. Un $6,9 \%$ se agrupó en otros lugares diversos.

La panorámica de esta cuestión puede verse en el siguiente gráfico:

Gráfico 9. Lugares en que se ubicaron las agresiones

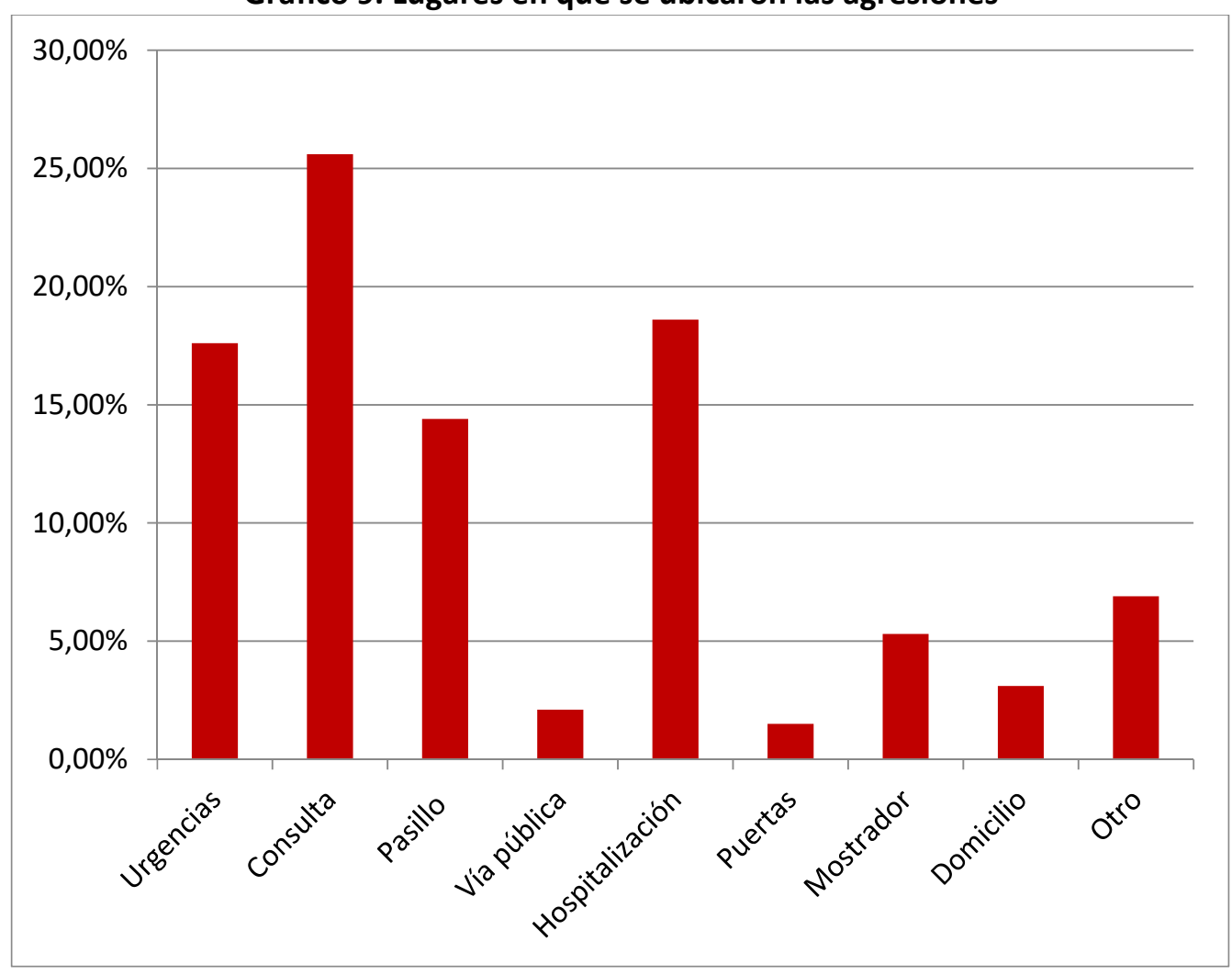

\section{MEDIDAS TOMADAS POR LA VÍCTIMA TRAS LA AGRESIÓN}

Respecto a las medidas tomadas tras el suceso, un 49,3\% manifestó que lo había comunicado a la Dirección/Coordinación de su centro de trabajo, tan sólo un 3,3\% lo hizo a su Colegio Profesional, un 9,4\% lo denunció a la Policía/Guardia Civil y, por último, un 38\% no tomó medida alguna. 
Gráfico 10. Medidas tomadas por la víctima tras la agresión.

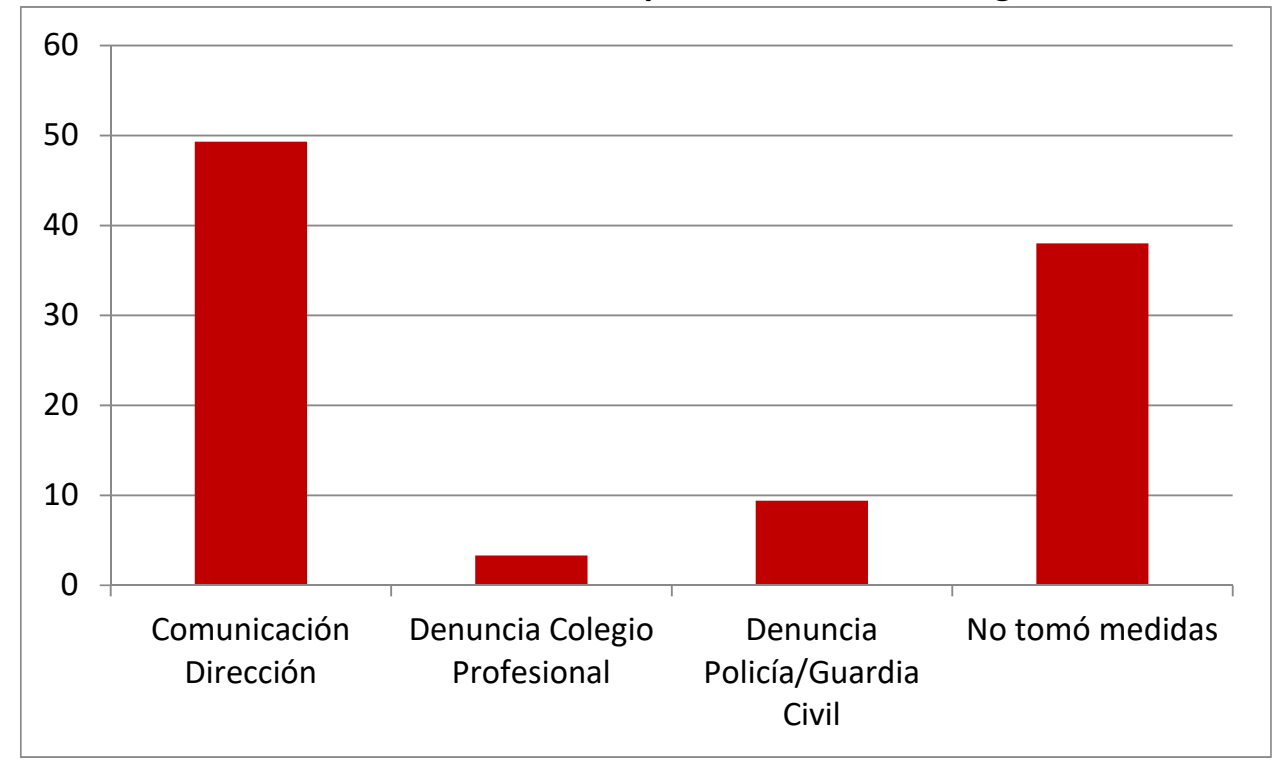

Como se ve claramente, la comunicación a la Dirección o Coordinación del centro de trabajo sobrepasa al resto de las medidas tomadas por los agredidos ampliamente.

Resulta llamativo el alto porcentaje de quienes decidieron no hacer nada ante la agresión.

La pregunta de por qué no habían tomado ninguna medida era de tipo abierto, por lo que se agruparon las respuestas tomando como base la temática aducida por los encuestados.

Las categorías resultantes fueron las siguientes:

- Percepción de falta de apoyo por parte de los órganos superiores: 10,8\%.

- $\quad$ No servir para nada tomar medidas: $10,2 \%$.

- Decisión personal (sin más explicaciones): 4,8\%.

- Temor a que la situación empeorara: 4,2\%.

- Considerar lo sucedido como no grave o parte del trabajo: $24 \%$.

- Falta de información: 5,4\%.

- Violencia interna: 3\%.

- Agresor enfermo psiquiátrico o bajo situación de mucho estrés: 10,2\%.

- Otros: motivos variados no agrupables. 24,6\%.

- $\quad \mathrm{NS} / \mathrm{NC}: 3 \%$. 
Gráfico 11. Razones por las que el agredido no tomó ninguna medida.

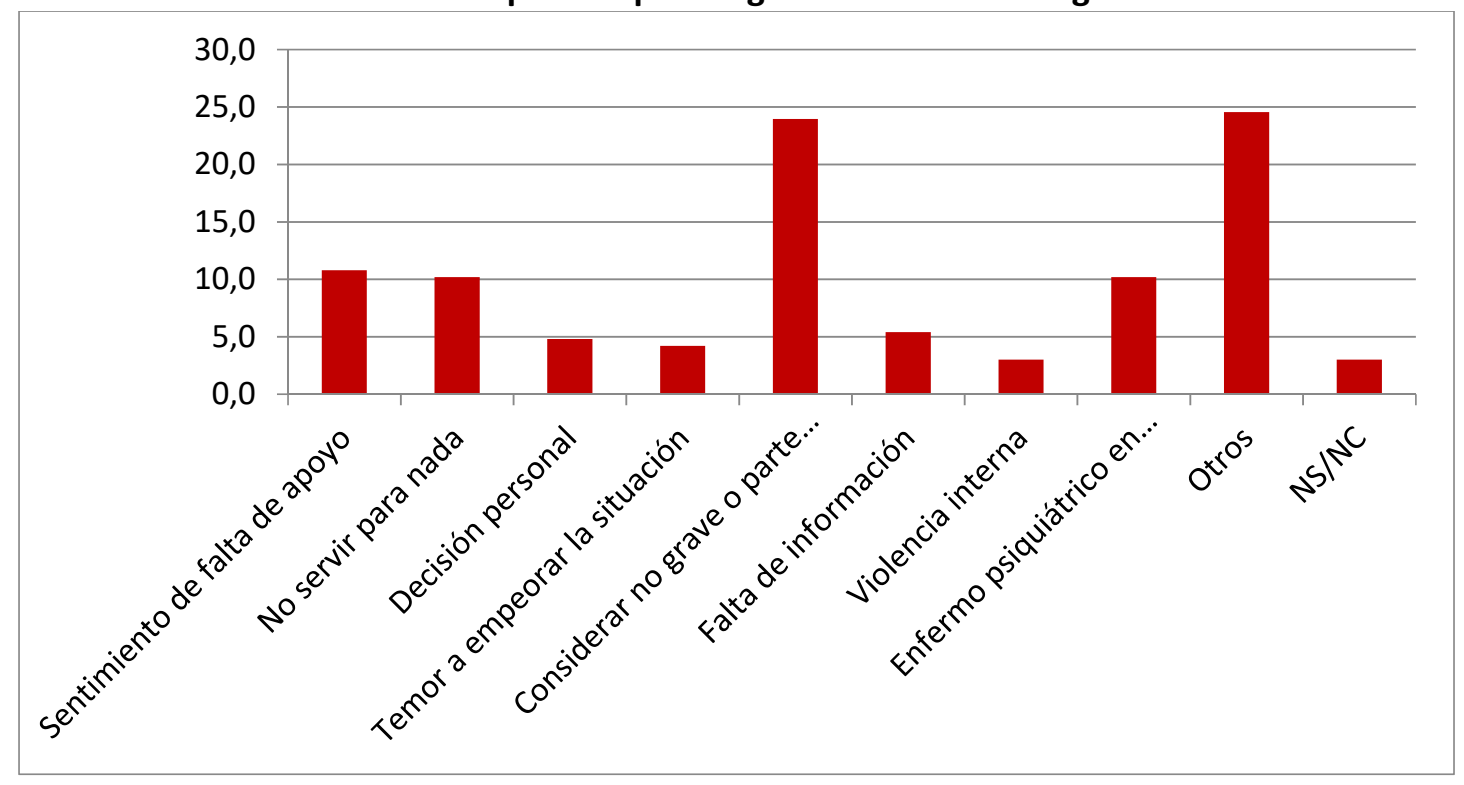

Sin lugar a dudas, el motivo más aducido es el de haber considerado la agresión como no grave o parte del trabajo.

En esta última opción, se aportaron una serie de respuestas que interesa reflejar literalmente:

- «La vez que denuncié facilitaron mi dirección y teléfono al agresor». Esto, que constituye una garantía procesal para el denunciado, resulta sin duda un elemento disuasorio para que la víctima se decida a denunciar los hechos.

- «Las agresiones verbales no se pueden demostrar». Resulta interesante en cuanto a la importancia que cobra la presunción de veracidad de la declaración del agredido, efecto que se produce en caso de que éste ostente la condición de autoridad en un procedimiento administrativo (reconocida por la Administración Autonómica).

- «Nuestros pacientes están sujetos a la jurisdicción penitenciaria y al régimen disciplinario»».

- «Verbal lo haría en caso de recidiva. Física, no lo sé, probablemente lo haría a la primera vez».

- «El hospital no apoya al trabajador en conflicto con un paciente».

- «Falta de apoyo institucional. Sólo te protegerían dentro del recinto de trabajo».

\section{APOYO PERCIBIDO POR EL PROFESIONAL TRAS LA AGRESIÓN}

Seguidamente, se preguntaba a los profesionales agredidos hasta qué punto se habían sentido apoyados por diferentes instancias. 
El apoyo percibido por parte de la Dirección o Coordinación del centro de trabajo arrojó los resultados siguientes:

Tabla 22. Apoyo percibido de la Dirección/Coordinación por parte del agredido.

\begin{tabular}{|c|c|c|c|c|c|}
\hline & & Frecuencia & Porcentaje & $\begin{array}{l}\text { Porcentaje } \\
\text { válido }\end{array}$ & $\begin{array}{l}\text { Porcentaje } \\
\text { acumulado }\end{array}$ \\
\hline & Nada & 115 & 17,6 & 35,3 & 35,3 \\
\hline & Poco & 60 & 9,2 & 18,4 & 53,7 \\
\hline & Algo & 62 & 9,5 & 19,0 & 72,7 \\
\hline & Mucho & 31 & 4,7 & 9,5 & 82,2 \\
\hline & Completamente & 58 & 8,9 & 17,8 & 100,0 \\
\hline & Total & 326 & 49,8 & 100,0 & \\
\hline Perdidos & Sistema & 329 & 50,2 & & \\
\hline Total & & 655 & 100,0 & & \\
\hline
\end{tabular}

La falta total de apoyo percibida alcanza un $35,3 \%$, que sumada a la escasa $(18,4 \%)$ llega a un total de $53,7 \%$ que no se ha sentido apoyado por la Dirección de su centro. Un 17,8\% se sintió completamente apoyado, a lo que cabe añadir quienes notaron un gran apoyo (9,5\%). Es decir, la percepción de un buen apoyo alcanzó un 27,3\% (17,8\%+9,5\%). Por último, un 19\% se sintió algo apoyado.

En conclusión, los que creen que no fueron apoyados prácticamente son un 53,7\% frente al 46,3\% $(27,3 \%+19 \%)$ que sí lo creyeron en alguna medida.

En lo referente al apoyo de los compañeros, esto fue lo que contestaron los encuestados:

Tabla 23. Apoyo percibido de los compañeros por parte del agredido.

\begin{tabular}{ll|r|r|r|r} 
& & Frecuencia & Porcentaje & $\begin{array}{c}\text { Porcentaje } \\
\text { válido }\end{array}$ & $\begin{array}{c}\text { Porcentaje } \\
\text { acumulado }\end{array}$ \\
\hline \multirow{4}{*}{ Nada } & 22 & 3,4 & 6,4 & 6,4 \\
\hline & Poco & 27 & 4,1 & 7,8 & 14,2 \\
\hline & Algo & 51 & 7,8 & 14,8 & 29,0 \\
\cline { 2 - 6 } & Mucho & 115 & 17,6 & 33,3 & 62,3 \\
\cline { 2 - 7 } & Completamente & 130 & 19,8 & 37,7 & 100,0 \\
\cline { 2 - 7 } & Total & 345 & 52,7 & 100,0 & \\
\hline Perdidos & Sistema & 310 & 47,3 & & \\
\hline Total & & 655 & 100,0 & & \\
\hline
\end{tabular}


Aquí la tendencia se invierte por completo. El apoyo total mostrado por los compañeros alcanza un $37,7 \%$ que, junto a un $33,3 \%$ que se sintieron muy apoyados, da un total de $71 \%$ de agredidos que notaron que los compañeros les brindaban todo su apoyo. Sólo un 6,4\% no notó apoyo de ninguna índole y un 7,8\% percibió un escaso apoyo. El 14,8\% obtuvo algo de apoyo. Sumando todos los porcentajes de los que entendieron que de alguna manera habían sido apoyados por sus compañeros, se obtiene un total de $93,6 \%$.

Esto confirma la inversión de la tendencia con respecto al sentimiento de apoyo por parte de la dirección.

En cuanto al apoyo percibido por parte del resto del personal del centro, sigue una tendencia parecida al de los compañeros:

Tabla 24. Apoyo percibido del resto del personal por parte del agredido.

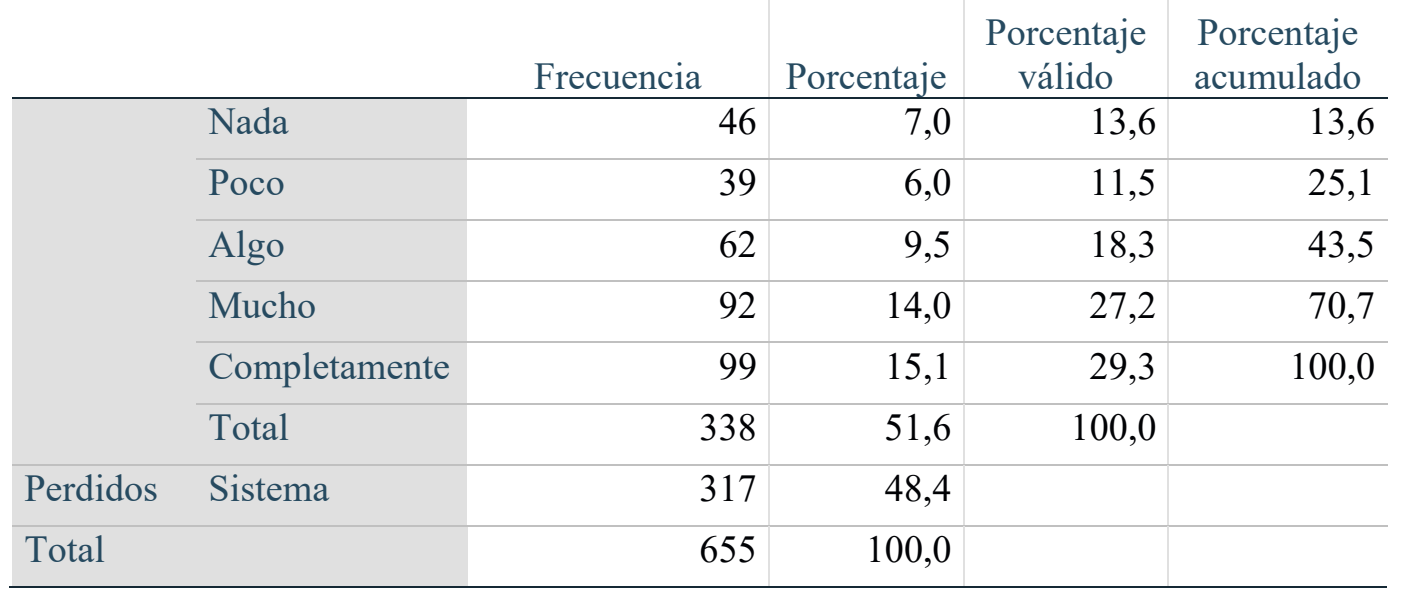

El 29,3\% se sintió completamente apoyado por el resto del personal y un 27,2\% muy apoyado. Ambos porcentajes sumados dan un grado muy alto de apoyo percibido: el 56,5\% (algo más bajo que el referido a los compañeros, pero elevado). Un 13,6\% no se sintió nada apoyado por el resto del personal, un $11,5 \%$ fue poco apoyado y el 18,3\% sintió cierto apoyo. Si sumamos los que percibieron apoyo por parte del resto del personal en cualquier grado, obtendremos un $86,4 \%$.

El resumen del grado de apoyo percibido puede verse en el siguiente gráfico: 
Gráfico 12. Grado de apoyo de diferentes sectores percibido por el agredido.

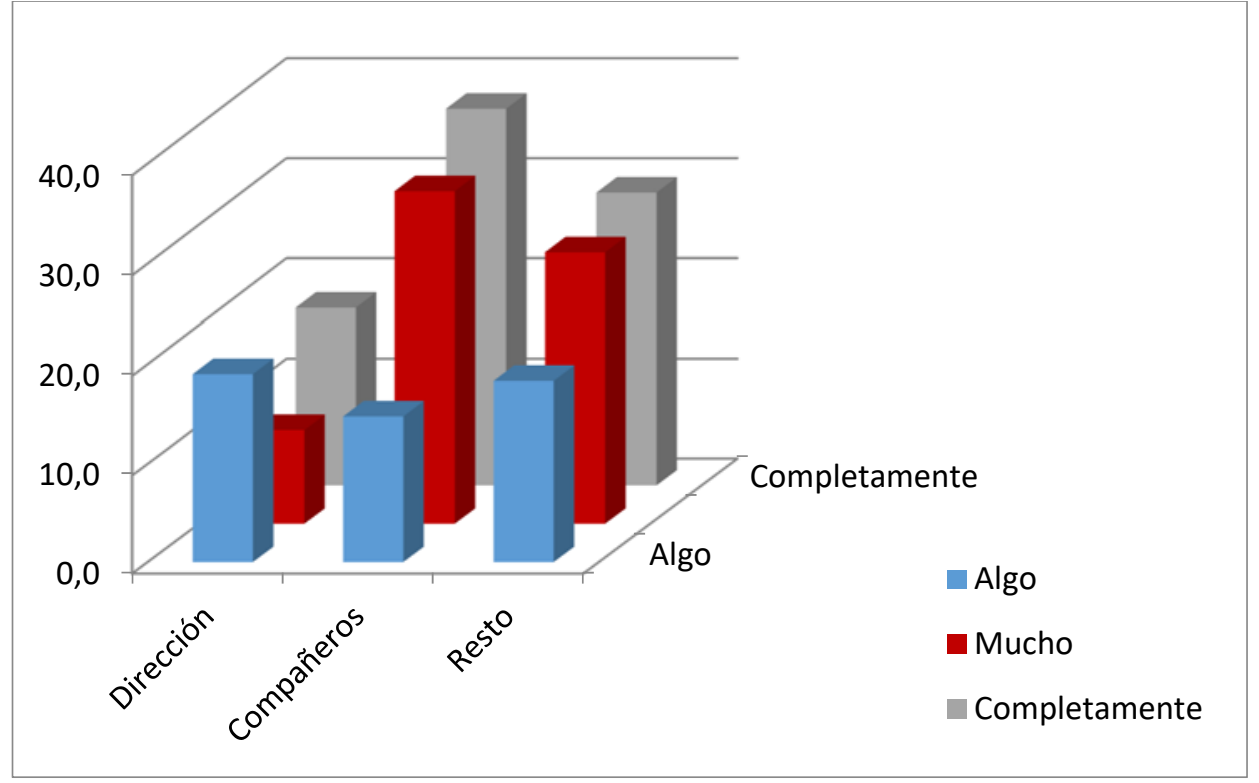

Y el grado de falta de apoyo, en este otro:

Gráfico 13. Grado de falta de apoyo percibida por el agredido.

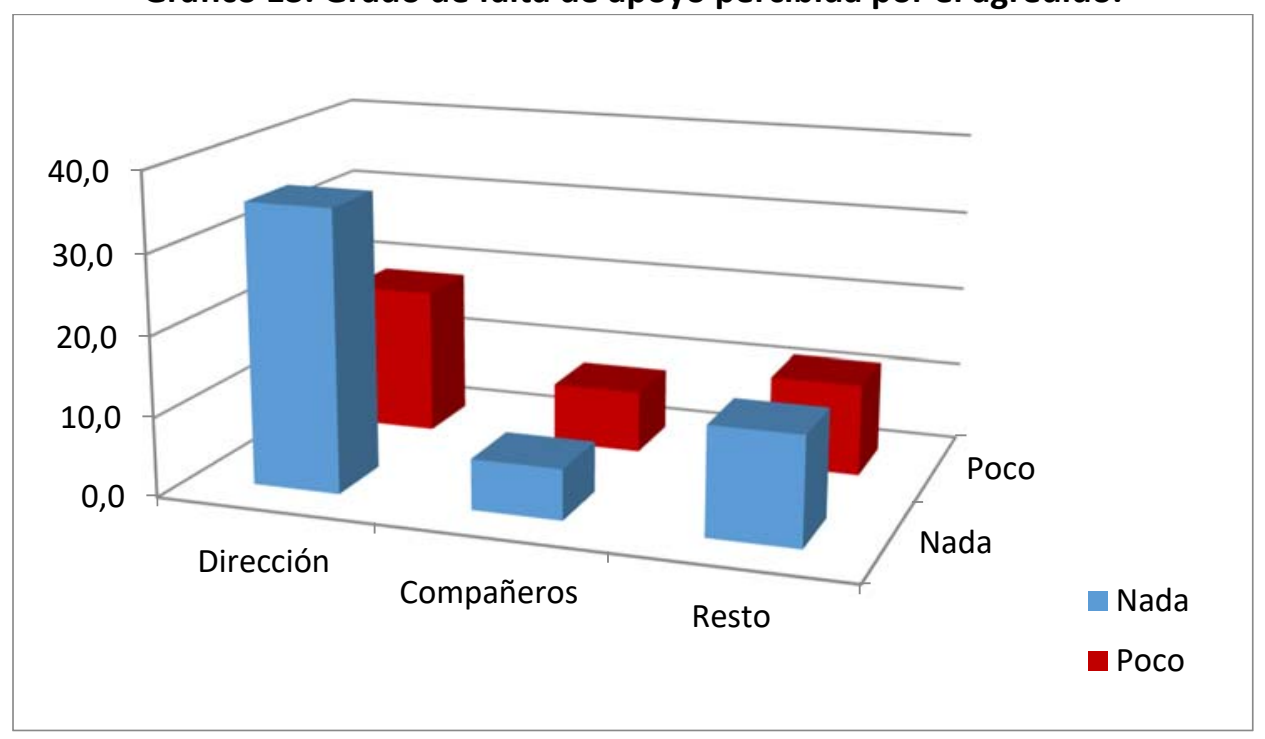

\section{TESTIGOS DE OTRA AGRESIÓN}

Preguntados por si habían sido testigos de alguna agresión (independientemente de haber sufrido alguna), los resultados fueron: 
Tabla 25. Profesionales que fueron testigos de otra agresión.

\begin{tabular}{l|r|r|r|r} 
& Frecuencia & Porcentaje & $\begin{array}{c}\text { Porcentaje } \\
\text { válido }\end{array}$ & $\begin{array}{c}\text { Porcentaje } \\
\text { acumulado }\end{array}$ \\
\hline Sí & 375 & 57,3 & 57,3 & 57,3 \\
\hline No & 280 & 42,7 & 42,7 & 100,0 \\
\hline Total & 655 & 100,0 & 100,0 & \\
\hline
\end{tabular}

Tabla 26. Frecuencia con la que fueron testigos de agresiones.

\begin{tabular}{|c|c|c|c|c|c|}
\hline & & Frecuencia & Porcentaje & $\begin{array}{l}\text { Porcentaje } \\
\text { válido }\end{array}$ & $\begin{array}{l}\text { Porcentaje } \\
\text { acumulado }\end{array}$ \\
\hline & Una vez & 69 & 10,5 & 18,4 & 18,4 \\
\hline & Dos veces & 81 & 12,4 & 21,6 & 40,0 \\
\hline & Tres veces & 30 & 4,6 & 8,0 & 48,0 \\
\hline & $\begin{array}{l}\text { Más de tres } \\
\text { veces }\end{array}$ & 195 & 29,8 & 52,0 & 100,0 \\
\hline & Total & 375 & 57,3 & 100,0 & \\
\hline Perdidos & Sistema & 280 & 42,7 & & \\
\hline Total & & 655 & 100,0 & & \\
\hline
\end{tabular}

Un porcentaje nada despreciable de un $57,3 \%$ han presenciado una agresión contra otro profesional en el trabajo, frente a un $42,7 \%$ que declararon lo contrario. De ese $57,3 \%$, un $60 \%$ $(8 \%+52 \%)$ dijo haber sido testigo de una agresión en tres o más ocasiones. Y es alarmante que ese $52 \%$ corresponda a los que han presenciado más de tres agresiones. Un $21,6 \%$ vio otras agresiones en un par de ocasiones y un $18,4 \%$ lo fue una sola vez.

Esto nos puede dar una idea del elevado porcentaje de infra-notificación existente.

Parecía de interés establecer si existía o no una relación significativa entre la pertenencia a la sanidad privada, pública o trabajar en ambos sectores y la percepción de agresiones en otros compañeros. La relación fue significativa $(\mathrm{P}=0,000)$ y ofreció los siguientes datos: 
Gráfico 14. Profesionales que han sido testigos de agresiones según sector de actividad.

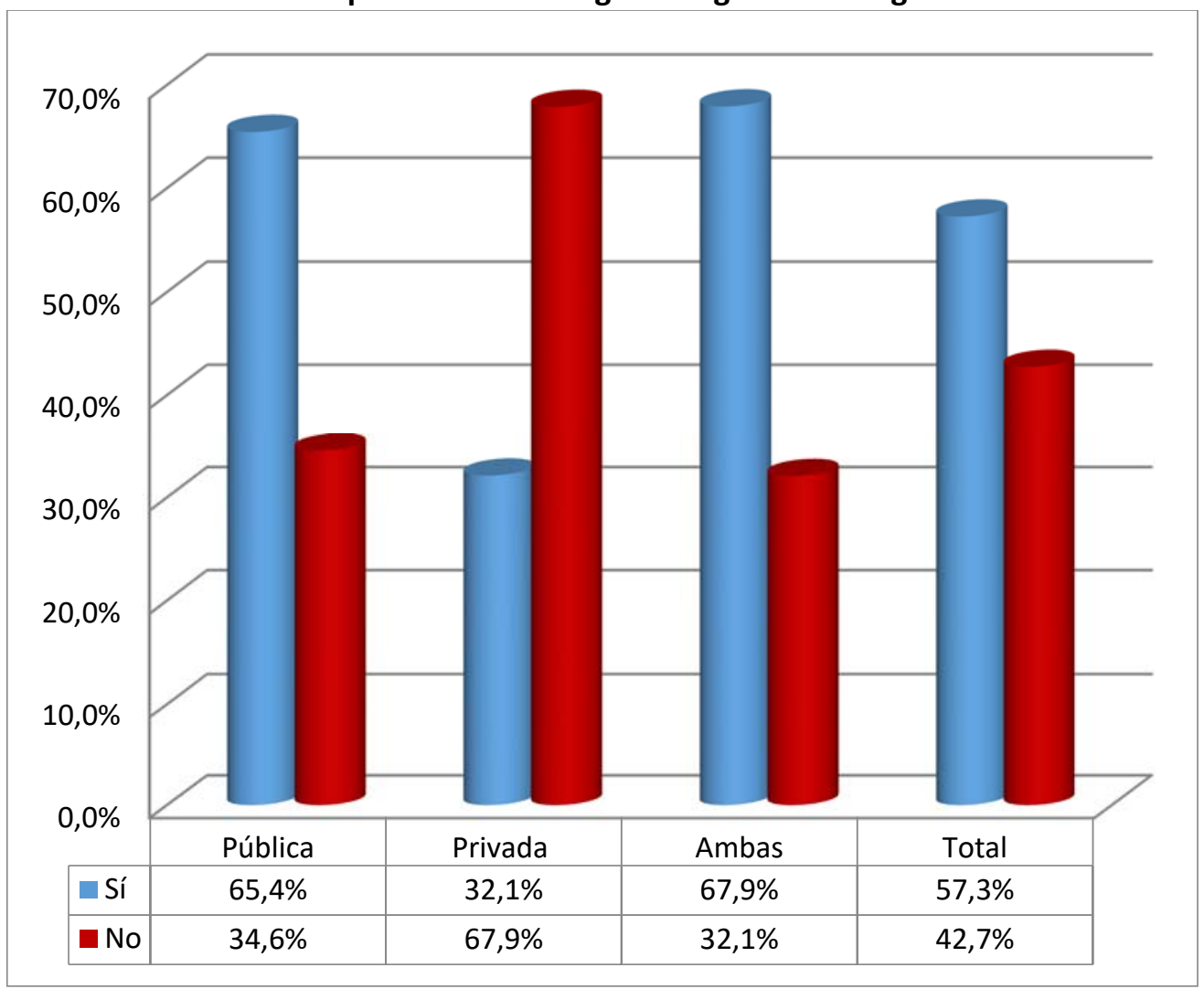

El grupo que comparte trabajo en los sectores público y privado es el que más veces ha sido testigo de una agresión (67,9\%), seguido de un 65,4\% en la sanidad pública y un 32,1\% en la privada. No podemos conocer qué porcentaje de estas agresiones vistas por otros fueron efectivamente notificadas, pero da la sensación de que, como afirma la mayoría de los autores, hay un gran número de agresiones no declaradas.

Por otra parte, parece que la incidencia de agresiones sigue siendo mayor en la pública (y más si aceptamos que sería posible que un buen número de las presenciadas por el grupo «mixto» lo hayan sido en centros públicos). Aun prescindiendo de esa consideración, el porcentaje es claramente mayor.

\section{POSIBILIDAD PERCIBIDA DE SUFRIR UNA AGRESIÓN}

Los profesionales encuestados, ante la pregunta de en qué grado temían ser víctimas de una agresión en el futuro, respondieron lo siguiente: 
Tabla 27. Posibilidad percibida de sufrir una agresión.

\begin{tabular}{l|r|r|r|r} 
& Frecuencia & Porcentaje & $\begin{array}{c}\text { Porcentaje } \\
\text { válido }\end{array}$ & $\begin{array}{c}\text { Porcentaje } \\
\text { acumulado }\end{array}$ \\
\hline Imposible & 6 & 0,9 & 0,9 & 0,9 \\
\hline Poco probable & 292 & 44,6 & 44,6 & 45,5 \\
\hline $\begin{array}{l}\text { Bastante } \\
\text { probable }\end{array}$ & 265 & 40,5 & 40,5 & 86,0 \\
\hline $\begin{array}{l}\text { Con seguridad } \\
\text { Total }\end{array}$ & 92 & 14,0 & 14,0 & 100,0 \\
\hline
\end{tabular}

En general, parece que no consideran probable que suceda algún tipo de incidente violento (un $44,6 \%$ lo considera poco probable), aunque no lo descartan (sólo un $0,9 \%$ lo cree imposible). El $40,5 \%$ cree que sufrirá una agresión con bastante probabilidad y un $14 \%$ lo cree seguro. Aglutinando los porcentajes, podemos ver que la sensación de poder ser agredido existe en un $54,5 \%(40,5 \%+14 \%)$, que supera el $45,5 \%(0,9 \%+44,6 \%)$ que ven más lejana o imposible esa posibilidad.

\section{VALORACIÓN DE LAS MEDIDAS DE PROTECCIÓN}

Los encuestados fueron requeridos para realizar una valoración de la eficacia de una serie de medidas, que debían puntuar según una escala tipo Likert.

1. La primera de las medidas a valorar fue la impartición de cursos de autodefensa física, para repeler una posible agresión.

Tabla 28. Valoración de cursos de autodefensa física.

\begin{tabular}{l|r|r|r|r} 
& Frecuencia & Porcentaje & $\begin{array}{c}\text { Porcentaje } \\
\text { válido }\end{array}$ & $\begin{array}{c}\text { Porcentaje } \\
\text { acumulado }\end{array}$ \\
\hline $\begin{array}{l}\text { Completamente } \\
\text { ineficaz }\end{array}$ & 89 & 13,6 & 13,6 & 13,6 \\
\hline Ineficaz & 83 & 12,7 & 12,7 & 26,3 \\
\hline Poco eficaz & 191 & 29,2 & 29,2 & 55,4 \\
\hline Eficaz & 159 & 24,3 & 24,3 & 79,7 \\
\hline Muy eficaz & 58 & 8,9 & 8,9 & 88,5 \\
\hline $\begin{array}{l}\text { Extraordinariamente } \\
\text { eficaz }\end{array}$ & 25 & 3,8 & 3,8 & 92,4 \\
\hline No lo sé & 50 & 7,6 & 7,6 & 100,0 \\
\hline Total & 655 & 100,0 & 100,0 & \\
\hline
\end{tabular}

El porcentaje más alto lo alcanza la opción de que esta medida es poco eficaz (29,2\%), seguida de eficaz (24,3\%), completamente ineficaz $(13,6 \%)$ e ineficaz $(12,7 \%)$. El porcentaje acumulado de los valores de ineficacia llega a un $55,4 \%$, por lo que hemos de concluir que los profesionales 
encuestados consideran este tipo de cursos ineficaz como medida de protección contra las agresiones, frente a los que sí les conceden eficacia, un $37 \%(24,3 \%+8,9 \%+3,8 \%)$.

2. La siguiente cuestión fue la valoración del envío de la llamada «carta de rechazo» al agresor, que le remite la Administración, manifestando su repulsa por los hechos y amonestándole.

Tabla 29. Valoración de la «carta de rechazo» al agresor.

\begin{tabular}{l|r|r|r|r} 
& Frecuencia & Porcentaje & $\begin{array}{c}\text { Porcentaje } \\
\text { válido }\end{array}$ & $\begin{array}{c}\text { Porcentaje } \\
\text { acumulado }\end{array}$ \\
\hline $\begin{array}{l}\text { Completamente } \\
\text { ineficaz }\end{array}$ & 143 & 21,8 & 21,8 & 21,8 \\
\hline Ineficaz & 112 & 17,1 & 17,1 & 38,9 \\
\hline Poco eficaz & 195 & 29,8 & 29,8 & 68,7 \\
\hline Eficaz & 109 & 16,6 & 16,6 & 85,3 \\
\hline Muy eficaz & 36 & 5,5 & 5,5 & 90,8 \\
\hline $\begin{array}{l}\text { Extraordinariamente } \\
\text { eficaz }\end{array}$ & 16 & 2,4 & 2,4 & 93,3 \\
\hline No lo sé & 44 & 6,7 & 6,7 & 100,0 \\
\hline Total & 655 & 100,0 & 100,0 & \\
\hline
\end{tabular}

Los que responden que les parece poco eficaz alcanzan el más alto de los porcentajes $(29,8 \%)$, al que siguen los que lo consideran completamente ineficaz $(21,8 \%)$ e ineficaz $(17,1 \%)$.

Sólo un 16,6\% lo considera eficaz, el 5,5\% muy eficaz y un 2,4\% extraordinariamente eficaz. El $6,7 \%$ manifiesta no saber el grado de eficacia de esta medida.

Considerando que el porcentaje acumulado de las respuestas que consideran ineficaz la medida alcanza nada menos que un $68,7 \%(21,8 \%+17,1 \%+29,8 \%)$, parece claro que los encuestados no confían en que la carta de rechazo al agresor sirva de mucho, contra los que sí lo consideran eficaz, que alcanzan un $24,5 \%(16,6 \%+5,5 \%+2,4 \%)$.

2. A continuación, pasamos a la valoración de los botones de alerta (también llamados «antipánico»). Los resultados fueron: 
Tabla 30. Valoración de los botones de alerta.

\begin{tabular}{l|r|r|r|r} 
& Frecuencia & Porcentaje & $\begin{array}{c}\text { Porcentaje } \\
\text { válido }\end{array}$ & $\begin{array}{c}\text { Porcentaje } \\
\text { acumulado }\end{array}$ \\
\hline $\begin{array}{l}\text { Completamente } \\
\text { ineficaz }\end{array}$ & 22 & 3,4 & 3,4 & 3,4 \\
\hline Ineficaz & 34 & 5,2 & 5,2 & 8,5 \\
\hline Poco eficaz & 100 & 15,3 & 15,3 & 23,8 \\
\hline Eficaz & 242 & 36,9 & 36,9 & 60,8 \\
\hline Muy eficaz & 157 & 24,0 & 24,0 & 84,7 \\
\hline $\begin{array}{l}\text { Extraordinariamente } \\
\text { eficaz }\end{array}$ & 66 & 10,1 & 10,1 & 94,8 \\
\hline No lo sé & 34 & 5,2 & 5,2 & 100,0 \\
\hline Total & 655 & 100,0 & 100,0 & \\
\hline
\end{tabular}

Aquí el sentido de las respuestas es muy diferente a lo reflejado en las dos medidas anteriores. El valor más alto $(36,9 \%)$ lo dan quienes piensan que es eficaz, seguido del porcentaje de aquellos que opinan que es muy eficaz (24\%). Un 15,3\% lo ve poco eficaz y un $10,1 \%$ extraordinariamente eficaz. El 5,2\% lo considera ineficaz y el 3,4\% completamente ineficaz. Un 5,2\% no cree saber si es eficaz o no. Acumulando los porcentajes, la valoración de que sí resulta eficaz, muy eficaz o extraordinariamente eficaz alcanza un $71 \%(36,9 \%+24 \%+10,1 \%)$, frente a las opiniones de ineficacia, que llegan sólo a un $23,9 \%(15,3 \%+5,2 \%+3,4 \%)$.

Por lo tanto, el botón de alarma resulta una medida bien valorada.

4. La colocación de carteles disuasorios e informativos sobre la necesidad de respetar a los profesionales fue la siguiente medida a valorar:

Tabla 31. Valoración de colocación de carteles disuasorios e informativos

\begin{tabular}{l|r|r|r|r} 
& Frecuencia & Porcentaje & $\begin{array}{c}\text { Porcentaje } \\
\text { válido }\end{array}$ & $\begin{array}{c}\text { Porcentaje } \\
\text { acumulado }\end{array}$ \\
\hline $\begin{array}{l}\text { Completamente } \\
\text { ineficaz }\end{array}$ & 81 & 12,4 & 12,4 & 12,4 \\
\hline Ineficaz & 70 & 10,7 & 10,7 & 23,1 \\
\hline Poco eficaz & 243 & 37,1 & 37,1 & 60,2 \\
\hline Eficaz & 173 & 26,4 & 26,4 & 86,6 \\
\hline Muy eficaz & 56 & 8,5 & 8,5 & 95,1 \\
\hline $\begin{array}{l}\text { Extraordinariamente } \\
\text { eficaz }\end{array}$ & 16 & 2,4 & 2,4 & 97,6 \\
\hline No lo sé & 16 & 2,4 & 2,4 & 100,0 \\
\hline Total & 655 & 100,0 & 100,0 & \\
\hline
\end{tabular}

El valor más alto en términos absolutos es el 37,1\% que ofrecen quienes consideran la medida poco eficaz, seguido del $26,4 \%$ que la consideran eficaz. Un $12,4 \%$ creen que es completamente 
ineficaz, e ineficaz un $10,7 \%$. Los que piensan que es muy eficaz representan un $8,5 \%$ y extraordinariamente eficaz un 2,4\% (el mismo porcentaje arroja el grupo que afirma no saber de la eficacia de la medida).

La acumulación de los porcentajes de ineficacia alcanza un 60,2\% $(12,4 \%+10,7 \%+37,1 \%)$, oponiéndose al $37,3 \%(2,4 \%+8,5 \%+26,4 \%)$ que cree en su eficacia. Por lo tanto, la mayoría piensa que la medida no es eficaz.

5. Seguidamente, se preguntó sobre la aplicación de sanciones administrativas a los agresores.

Estos fueron los resultados:

Tabla 32. Valoración de la imposición de sanciones administrativas al agresor.

\begin{tabular}{l|r|r|r|r} 
& Frecuencia & Porcentaje & $\begin{array}{c}\text { Porcentaje } \\
\text { válido }\end{array}$ & $\begin{array}{c}\text { Porcentaje } \\
\text { acumulado }\end{array}$ \\
\hline $\begin{array}{l}\text { Completamente } \\
\text { ineficaz }\end{array}$ & 16 & 2,4 & 2,4 & 2,4 \\
\hline Ineficaz & 21 & 3,2 & 3,2 & 5,6 \\
\hline Poco eficaz & 75 & 11,5 & 11,5 & 17,1 \\
\hline Eficaz & 197 & 30,1 & 30,1 & 47,2 \\
\hline Muy eficaz & 172 & 26,3 & 26,3 & 73,4 \\
\hline Extraordinariamente & 150 & 22,9 & 22,9 & 96,3 \\
\hline eficaz & & & & \\
\hline No lo sé & 24 & 3,7 & 3,7 & 100,0 \\
\hline Total & 655 & 100,0 & 100,0 & \\
\hline
\end{tabular}

Un 30,1\% manifestó que le parecía eficaz, seguido del 26,3\% que creía que era muy eficaz y un $22,9 \%$ extraordinariamente eficaz. El 11,5\% valoró la medida como poco eficaz, un 3,2\% ineficaz y un $2,4 \%$ completamente ineficaz. El 3,7\% no sabía si es eficaz o no lo es.

Los porcentajes de eficacia sumados dieron un total de $79,3 \%(30,1 \%+26,3 \%+22,9 \%)$ y los de ineficacia un $17,1 \%(2,4 \%+3,2+11,5 \%)$. No cabe llegar a otra conclusión que la alta valoración que los profesionales otorgan a la aplicación de sanciones administrativas contra los agresores.

El siguiente objetivo era fijar si haber sufrido una agresión anteriormente tenía alguna influencia en la valoración de la imposición de sanciones administrativas al agresor. Se obtuvo un coeficiente de Pearson de 0,006 y los siguientes resultados: 
Gráfico 15. Relación entre valoración de sanciones administrativas y haber sido agredido.

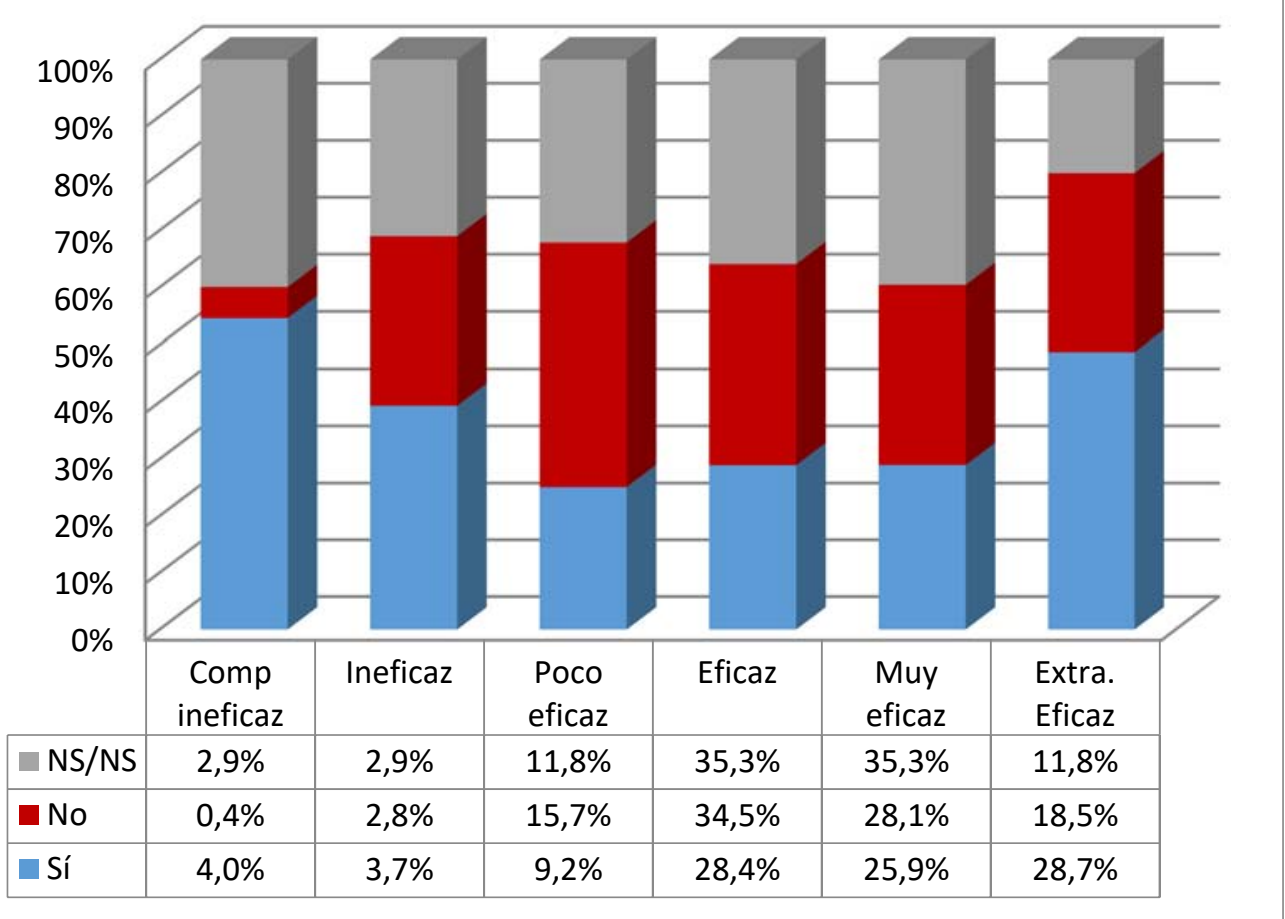

Las opiniones de quienes han sufrido agresiones previamente parecen inclinarse hacia la eficacia de las sanciones administrativas, aunque los términos están bastante igualados.

6. La intervención de la justicia penal ante las agresiones, con la aplicación de las correspondientes penas, arrojó los siguientes resultados:

Tabla 33. Valoración de la intervención de la justicia penal contra el agresor.

\begin{tabular}{lr|r|r|r} 
& Frecuencia & Porcentaje & $\begin{array}{c}\text { Porcentaje } \\
\text { válido }\end{array}$ & $\begin{array}{c}\text { Porcentaje } \\
\text { acumulado }\end{array}$ \\
\hline $\begin{array}{l}\text { Completamente } \\
\text { ineficaz }\end{array}$ & 13 & 2,0 & 2,0 & 2,0 \\
\hline Ineficaz & 15 & 2,3 & 2,3 & 4,3 \\
\hline Poco eficaz & 46 & 7,0 & 7,0 & 11,3 \\
\hline Eficaz & 152 & 23,2 & 23,2 & 34,5 \\
\hline Muy eficaz & 178 & 27,2 & 27,2 & 61,7 \\
\hline Extraordinariamente & 217 & 33,1 & 33,1 & 94,8 \\
\hline eficaz & & & & \\
\hline No lo sé & 34 & 5,2 & 5,2 & 100,0 \\
\hline Total & 655 & 100,0 & 100,0 & \\
\hline
\end{tabular}

Un $33,1 \%$ lo considera extraordinariamente eficaz, un $27,2 \%$ muy eficaz y un $23,2 \%$ eficaz. El $7 \%$ cree que es poco eficaz, ineficaz un 2,3\% y completamente ineficaz un $2 \%$. El 5,2\% no valora la cuestión. 
El porcentaje de eficacia es aquí también muy alto: $83,5 \%(23,2 \%+27,2 \%+33,1 \%)$. Por el contrario, el de ineficacia cae hasta el 11,3\% $(2 \%+2,3 \%+7 \%)$. Esto significa que la intervención de la justicia penal ante las agresiones resulta muy valorada por los profesionales encuestados.

Como en el caso anterior, se intentó conocer la influencia que podía tener el haber sufrido una agresión anterior en la valoración de la intervención de la justicia penal. Se halló una relación estadísticamente significativa (coeficiente Pearson: 0,001).

\section{Gráfico 16. Relación entre la valoración de la Justicia penal y haber sido agredido.}

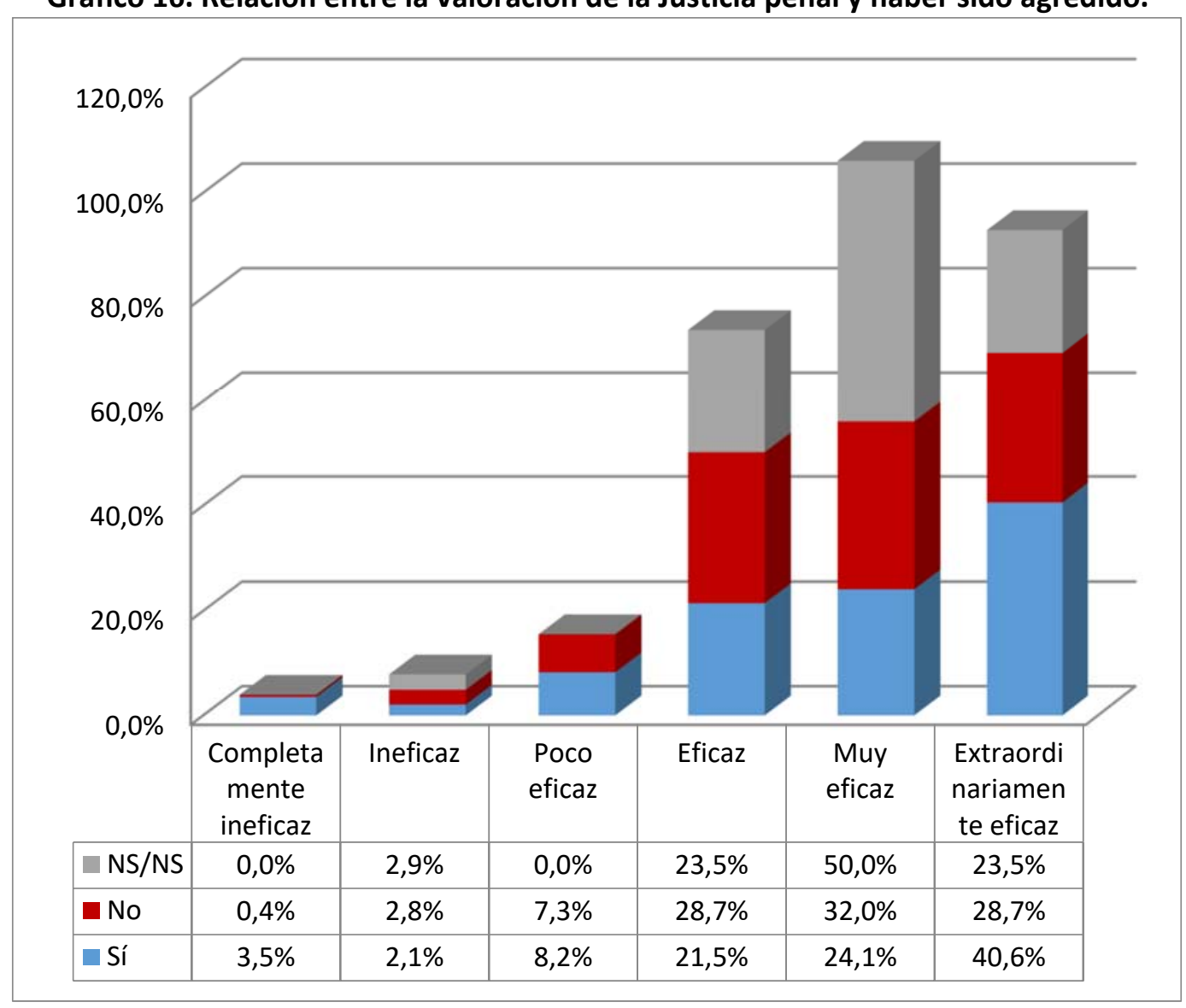

Las personas ya agredidas mostraron una tendencia a valorar más positivamente la intervención de la justicia penal (40,6\% que la califican de «extraordinariamente eficaz»).

No obstante, el porcentaje que ofrece la opinión de que resulta «muy eficaz» por parte de quienes no han sufrido agresiones anteriores tampoco es desdeñable (32\%), dentro del conjunto de valores mostrados.

7. Seguidamente, se propuso la valoración de la implantación del teléfono de asesoramiento jurídico para las víctimas de agresiones. 
Tabla 34. Valoración del teléfono de asesoramiento jurídico para las víctimas.

\begin{tabular}{l|r|r|r|r} 
& Frecuencia & Porcentaje & $\begin{array}{c}\text { Porcentaje } \\
\text { válido }\end{array}$ & $\begin{array}{c}\text { Porcentaje } \\
\text { acumulado }\end{array}$ \\
\hline $\begin{array}{l}\text { Completamente } \\
\text { ineficaz }\end{array}$ & 24 & 3,7 & 3,7 & 3,7 \\
\hline Ineficaz & 32 & 4,9 & 4,9 & 8,5 \\
\hline Poco eficaz & 107 & 16,3 & 16,3 & 24,9 \\
\hline Eficaz & 253 & 38,6 & 38,6 & 63,5 \\
\hline Muy eficaz & 135 & 20,6 & 20,6 & 84,1 \\
\hline Extraordinariamente & 60 & 9,2 & 9,2 & 93,3 \\
eficaz & & & & \\
\hline No lo sé & 44 & 6,7 & 6,7 & 100,0 \\
\hline Total & 655 & 100,0 & 100,0 & \\
\hline
\end{tabular}

El teléfono de asesoramiento fue eficaz para el 38,6\% y muy eficaz por el 20,6\%. Un 16,3\% opinó que es poco eficaz. El 9,2\% creía que es extraordinariamente eficaz. Un 4,9\% pensaba que es ineficaz y un 3,7\% completamente ineficaz. El 6,7\% no valoró la medida.

El $68,4 \%(38,6 \%+20,6 \%+9,2 \%)$ de los encuestados consideraron de eficacia la medida, frente a un $24,9 \%(3,7 \%+4,9 \%+16,3 \%)$ que la creyeron ineficaz en mayor o menor grado.

8. La impartición de cursos de formación a los profesionales sanitarios, referidos a habilidades de comunicación, empatía, tratamiento de situaciones conflictivas, etc. se valoró por los encuestados del siguiente modo:

Tabla 35. Valoración de formación en manejo de situaciones conflictivas.

\begin{tabular}{l|r|r|r|r} 
& Frecuencia & Porcentaje & $\begin{array}{c}\text { Porcentaje } \\
\text { válido }\end{array}$ & $\begin{array}{c}\text { Porcentaje } \\
\text { acumulado }\end{array}$ \\
\hline $\begin{array}{l}\text { Completamente } \\
\text { ineficaz }\end{array}$ & 19 & 2,9 & 2,9 & 2,9 \\
\hline Ineficaz & 24 & 3,7 & 3,7 & 6,6 \\
\hline Poco eficaz & 115 & 17,6 & 17,6 & 24,1 \\
\hline Eficaz & 232 & 35,4 & 35,4 & 59,5 \\
\hline Muy eficaz & 158 & 24,1 & 24,1 & 83,7 \\
\hline $\begin{array}{l}\text { Extraordinariamente } \\
\text { fficaz }\end{array}$ & 83 & 12,7 & 12,7 & 96,3 \\
\hline No lo sé & 24 & 3,7 & 3,7 & 100,0 \\
\hline Total & 655 & 100,0 & 100,0 & \\
\hline
\end{tabular}


Un 35,4\% lo creyó eficaz, seguido de quienes pensaron que es muy eficaz (24,1\%). El 17,6\% cree que es poco eficaz. Para un 12,7\% resulta extraordinariamente eficaz. Es ineficaz para el 3,7\% y completamente ineficaz para el 2,9\%. El 3,7\% manifestó no saber de la eficacia o no de la medida.

El porcentaje acumulado de eficacia alcanza un $72,2 \%(35,4 \%+24,1 \%+12,7 \%)$, frente al $24,2 \%$ $(2,9 \%+3,7 \%+17,6 \%)$ de ineficacia. Los cursos de formación en estas materias son, por tanto, bien valorados por los profesionales encuestados.

9. La siguiente medida a valorar fue la posibilidad de reasignación del agresor a otro profesional o a otro centro, tras la producción de la agresión.

Tabla 36. Valoración reasignación del agresor a otro profesional o centro.

\begin{tabular}{l|r|r|r|r} 
& Frecuencia & Porcentaje & $\begin{array}{c}\text { Porcentaje } \\
\text { válido }\end{array}$ & $\begin{array}{c}\text { Porcentaje } \\
\text { acumulado }\end{array}$ \\
\hline $\begin{array}{l}\text { Completamente } \\
\text { ineficaz }\end{array}$ & 58 & 8,9 & 8,9 & 8,9 \\
\hline Ineficaz & 60 & 9,2 & 9,2 & 18,0 \\
\hline Poco eficaz & 175 & 26,7 & 26,7 & 44,7 \\
\hline Eficaz & 160 & 24,4 & 24,4 & 69,2 \\
\hline Muy eficaz & 84 & 12,8 & 12,8 & 82,0 \\
\hline $\begin{array}{l}\text { Extraordinariamente } \\
\text { eficaz }\end{array}$ & 67 & 10,2 & 10,2 & 92,2 \\
\hline No lo sé & 51 & 7,8 & 7,8 & 100,0 \\
\hline Total & 655 & 100,0 & 100,0 & \\
\hline
\end{tabular}

Un 26,7\% valoró la medida como poco eficaz. El 24,4\% consideró que es eficaz, el 12,8\% muy eficaz y el $10,2 \%$ extraordinariamente eficaz.

Para un $9,2 \%$ resulta ineficaz y un $8,9 \%$ cree que es completamente ineficaz. La medida no fue valorada por un $7,8 \%$.

El acúmulo de los porcentajes que reflejan la creencia de eficacia es de un $47,4 \%$ $(24,4 \%+12,8 \%+10,2 \%)$, frente a un $44,8 \%(8,9 \%+9,2 \%+26,7 \%)$ que opina lo contrario. La consideración de lo eficaz de la medida vence por muy poco.

10. Las salidas alternativas de las consultas para posibilitar la huida en caso de agresión fue la siguiente medida propuesta para su valoración: 
Tabla 37. Valoración de salidas alternativas.

\begin{tabular}{l|r|r|r|r} 
& Frecuencia & Porcentaje & $\begin{array}{c}\text { Porcentaje } \\
\text { válido }\end{array}$ & $\begin{array}{c}\text { Porcentaje } \\
\text { acumulado }\end{array}$ \\
\hline $\begin{array}{l}\text { Completamente } \\
\text { ineficaz }\end{array}$ & 23 & 3,5 & 3,5 & 3,5 \\
\hline Ineficaz & 35 & 5,3 & 5,3 & 8,9 \\
\hline Poco eficaz & 145 & 22,1 & 22,1 & 31,0 \\
\hline Eficaz & 209 & 31,9 & 31,9 & 62,9 \\
\hline Muy eficaz & 105 & 16,0 & 16,0 & 78,9 \\
\hline $\begin{array}{l}\text { Extraordinariamente } \\
\text { eficaz }\end{array}$ & 53 & 8,1 & 8,1 & 87,0 \\
\hline No lo sé & & & & \\
\hline Total & 85 & 13,0 & 13,0 & 100,0 \\
\hline
\end{tabular}

El $31,9 \%$ piensa que se trata de una medida eficaz. Es poco eficaz para un 22,1\%. El $16 \%$ cree que es muy eficaz y un $8,1 \%$ extraordinariamente eficaz. El 5,3\% opina que es ineficaz y el 3,5\% completamente ineficaz. El porcentaje de encuestados que no valora este punto alcanza el 13\%.

Los porcentajes de eficacia acumulados arrojan un 56\% $(31,9 \%+16 \%+8,1 \%)$, frente a un $30,9 \%$ $(3,5 \%+5,3 \%+22,1 \%)$ de ineficacia. Por lo tanto, hemos de deducir que las salidas alternativas de las consultas son bien valoradas.

11. A continuación, se pidió a los encuestados que valoraran la dotación de personal de seguridad en los centros de trabajo, con el fin de prevenir y combatir las eventuales agresiones. Estos fueron los resultados obtenidos:

Tabla 38. Valoración de dotación de personal de seguridad.

\begin{tabular}{l|r|r|r|r} 
& Frecuencia & Porcentaje & $\begin{array}{r}\text { Porcentaje } \\
\text { válido }\end{array}$ & $\begin{array}{c}\text { Porcentaje } \\
\text { acumulado }\end{array}$ \\
\hline $\begin{array}{l}\text { Completamente } \\
\text { ineficaz }\end{array}$ & 16 & 2,4 & 2,4 & 2,4 \\
\hline Ineficaz & 11 & 1,7 & 1,7 & 4,1 \\
\hline Poco eficaz & 52 & 7,9 & 7,9 & 12,1 \\
\hline Eficaz & 223 & 34,0 & 34,0 & 46,1 \\
\hline Muy eficaz & 171 & 26,1 & 26,1 & 72,2 \\
\hline $\begin{array}{l}\text { Extraordinariamente } \\
\text { eficaz }\end{array}$ & 162 & 24,7 & 24,7 & 96,9 \\
\hline No lo sé & & & & \\
\hline Total & 20 & 3,1 & 3,1 & 100,0 \\
\hline
\end{tabular}


El valor más elevado es de un $34 \%$ que opina que se trata de una medida eficaz, seguido de quienes manifiestan que es muy eficaz $(26,1 \%)$ y extraordinariamente eficaz $(24,7 \%)$. Un $7,9 \%$ cree que es poco eficaz, un $2,4 \%$ completamente ineficaz y un $1,7 \%$ ineficaz. El $3,1 \%$ afirma no saber qué grado de eficacia tiene la medida.

Nada menos que un $84,8 \%(34 \%+26,1 \%+24,7 \%)$ es el valor que arroja el acúmulo de porcentajes de eficacia, contra sólo un $12,1 \%(2,4 \%+1,7 \%+7,9 \%)$ de los de ineficacia. La valoración, en consecuencia, de la dotación con personal de seguridad, es muy alta en los profesionales encuestados.

12. La última medida propuesta para valoración fue la colocación de videocámaras de seguridad:

Tabla 39. Valoración de colocación de videocámaras.

\begin{tabular}{l|r|r|r|r} 
& Frecuencia & Porcentaje & $\begin{array}{c}\text { Porcentaje } \\
\text { válido }\end{array}$ & $\begin{array}{c}\text { Porcentaje } \\
\text { acumulado }\end{array}$ \\
\hline $\begin{array}{l}\text { Completamente } \\
\text { ineficaz }\end{array}$ & 15 & 2,3 & 2,3 & 2,3 \\
\hline Ineficaz & 24 & 3,7 & 3,7 & 6,0 \\
\hline Poco eficaz & 103 & 15,7 & 15,7 & 21,7 \\
\hline Eficaz & 216 & 33,0 & 33,0 & 54,7 \\
\hline Muy eficaz & 150 & 22,9 & 22,9 & 77,6 \\
\hline Extraordinariamente & 112 & 17,1 & 17,1 & 94,7 \\
eficaz & & & & \\
\hline No lo sé & 35 & 5,3 & 5,3 & 100,0 \\
\hline Total & 655 & 100,0 & 100,0 & \\
\hline
\end{tabular}

El valor más alto se da entre quienes consideran que es una medida eficaz (33\%), seguido por aquellos que creen que es muy eficaz (22,9\%) y extraordinariamente eficaz (17,1\%). Un 15,7\% afirmó que es poco eficaz, el 3,7\% ineficaz y el 2,3\% completamente ineficaz. No valoró la medida un $5,3 \%$.

Los porcentajes de eficacia, una vez sumados, dan un resultado de un $73 \%(33 \%+22,9 \%+17,1 \%)$, frente al 21,7\% $(2,3 \%+3,7 \%+15,7 \%)$ de ineficacia. La colocación de cámaras de vigilancia es una medida valorada positivamente por los encuestados.

La visión general de la valoración realizada sobre las diferentes medidas propuestas se resume en el siguiente gráfico (Gráfico 17. Comparativa de la valoración de las medidas.). Como puede verse, las más valoradas son, por este orden: presencia de vigilantes de seguridad, actuación de la justicia penal, imposición de sanciones administrativas, cámaras de seguridad, cursos de formación y botones antipánico. Las peor valoradas son: colocación de carteles disuasorios, carta de rechazo al agresor y cursos de autodefensa personal. El teléfono de asesoramiento legal, las 
salidas alternativas de consultas y la reasignación del agresor obtienen resultados más discretos, pero en cualquier caso altos, sobre todo las salidas (pues superan el 50\%) y aún más el teléfono de asesoramiento, que alcanza un $68,4 \%$.

Gráfico 17. Comparativa de la valoración de las medidas.

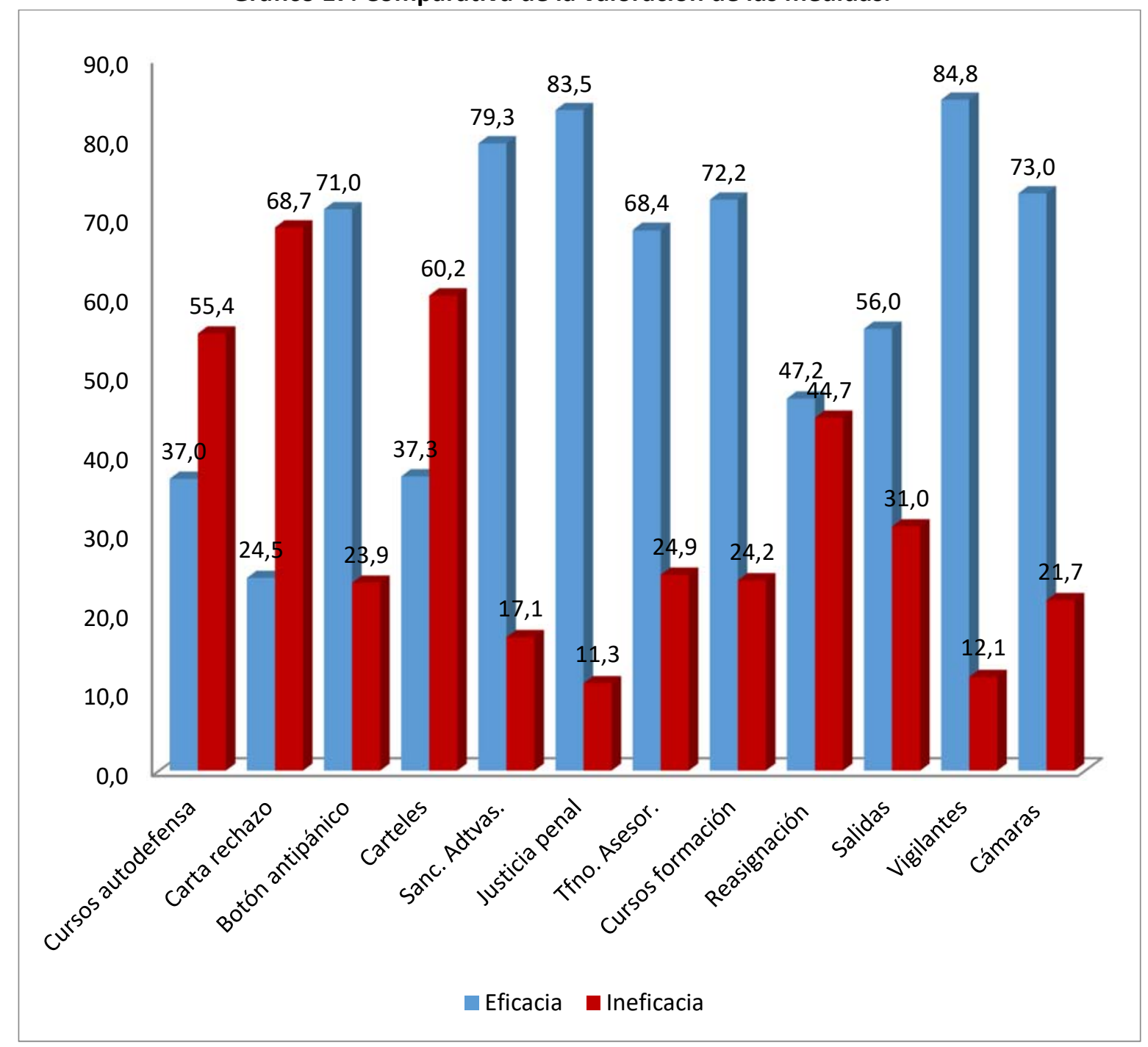


CONOCIMIENTO DE LOS DERECHOS PROPIOS Y DE LAS ACTUACIONES A SEGUIR EN CASO DE AGRESIÓN.

Se preguntó a los entrevistados hasta qué punto creían conocer los derechos que les asisten ante una agresión. Como se refleja en la siguiente tabla, un 44,6\% afirmó que conocía sus derechos, un $35,6 \%$ que no, y un $19,8 \%$ no estaba seguro.

Tabla 40. Conocimiento de los encuestados de los derechos que les asisten.

\begin{tabular}{l|r|r|r|r} 
& Frecuencia & Porcentaje & $\begin{array}{c}\text { Porcentaje } \\
\text { válido }\end{array}$ & $\begin{array}{c}\text { Porcentaje } \\
\text { acumulado }\end{array}$ \\
\hline Sí & 292 & 44,6 & 44,6 & 44,6 \\
\hline No & 233 & 35,6 & 35,6 & 80,2 \\
\hline No lo sé & 130 & 19,8 & 19,8 & 100,0 \\
\hline Total & 655 & 100,0 & 100,0 & \\
\hline
\end{tabular}

En la siguiente cuestión, se repetía la pregunta, pero referida al conocimiento de las actuaciones a seguir en caso de producirse una agresión. Veamos los resultados:

Tabla 41. Conocimiento de los encuestados sobre actuaciones a seguir en caso de agresión.

\begin{tabular}{l|r|r|r|r} 
& Frecuencia & Porcentaje & $\begin{array}{c}\text { Porcentaje } \\
\text { válido }\end{array}$ & $\begin{array}{c}\text { Porcentaje } \\
\text { acumulado }\end{array}$ \\
\hline Sí & 299 & 45,6 & 45,6 & 45,6 \\
\hline No & 247 & 37,7 & 37,7 & 83,4 \\
\hline No lo sé & 109 & 16,6 & 16,6 & 100,0 \\
\hline Total & 655 & 100,0 & 100,0 & \\
\hline
\end{tabular}

El 45,6\% manifestó saber qué actuaciones seguir, contra un 37,7\% que no las conocía.

Un $16,6 \%$ no estaba seguro.

Los porcentajes en ambas preguntas son muy similares y lo que quizás resulte más llamativo es que en ninguno de los dos casos el porcentaje de quienes dicen conocer sus derechos y las actuaciones correspondientes alcance la mitad de los encuestados.

La información de que dispone el personal sanitario respecto a estas dos importantes cuestiones no parece muy completa, desde su propio punto de vista.

En cuanto a cómo se distribuyen estos porcentajes en el caso de que el encuestado trabaje en la sanidad pública, privada, o compagine ambas, esta es la situación: 


\section{Gráfico 18. Relación entre sector de actividad y conocimiento de los derechos.}

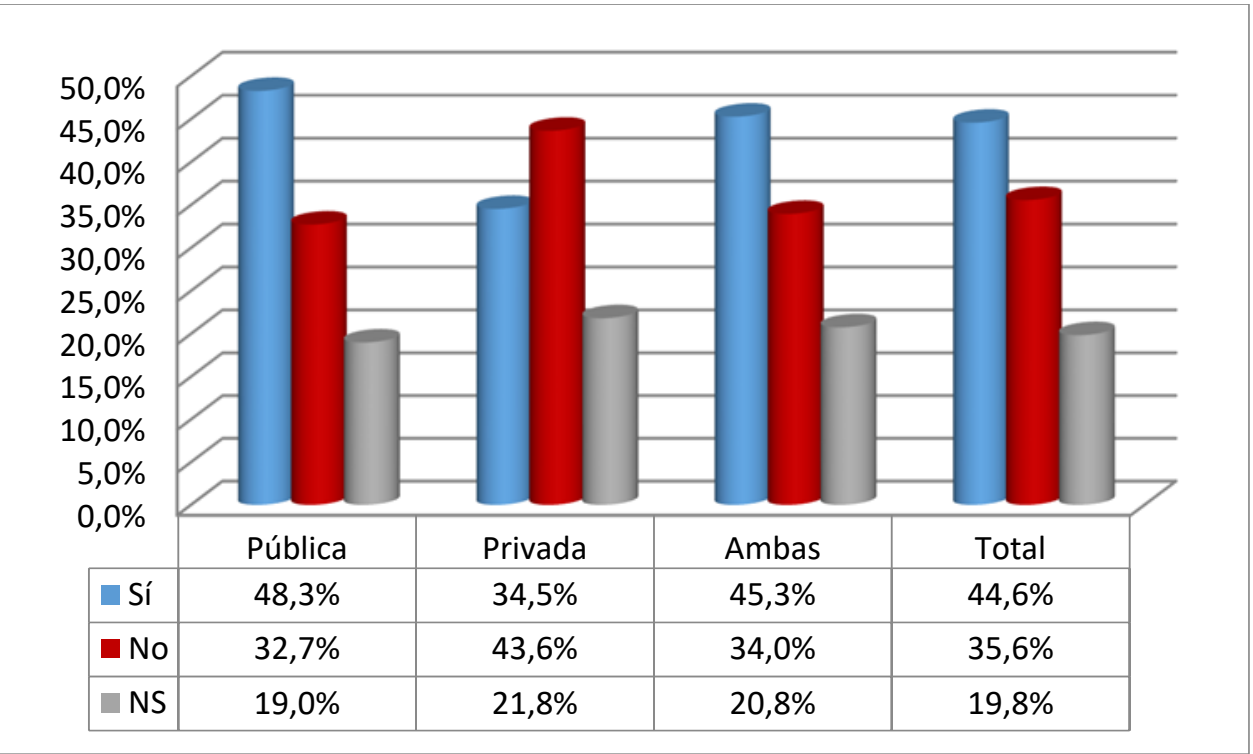

Como puede verse, el sector público cree conocer mejor sus derechos (48,3\%), porcentaje al que sigue la opción «ambas» (45,3\%), frente al $34,5 \%$ de la sanidad privada. De todas formas, ha de observarse que no se alcanza el $50 \%$ en ningún caso. Los resultados fueron estadísticamente significativos: $\mathrm{P}=0,047$.

En la misma cuestión, pero referida al conocimiento de las actuaciones a seguir en caso de agresión, se obtuvo lo siguiente:

\section{Gráfico 19. Relación entre sector de actividad y conocimiento de las actuaciones en caso de} agresión.

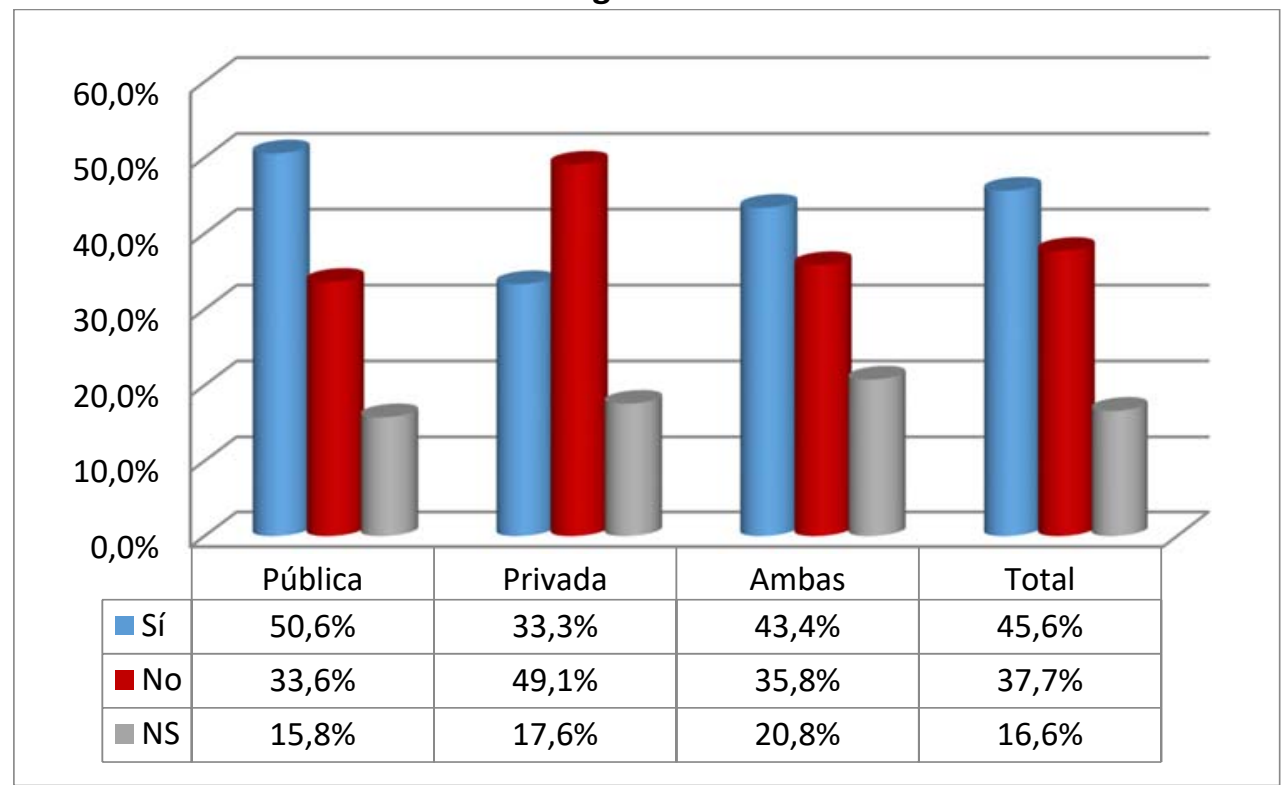

Las actuaciones a emprender parecen ser mejor conocidas por los encuestados pertenecientes al sector público (50,6\%). En el privado, un alarmante 49,1\% declararon no saber qué debían hacer 
si sufrían una agresión, es decir, prácticamente el mismo porcentaje que en el público dice conocerlos. El resultado es estadísticamente significativo $(\mathrm{P}=0,003)$.

\section{LA DISPOSICIÓN DE LOS PROFESIONALES A DENUNCIAR LAS AGRESIONES}

Se preguntó a los encuestados si, ante una agresión, la denunciarían y, en caso de respuesta negativa, cuáles serían sus razones para no interponer denuncia.

En la primera pregunta, se obtuvieron estos resultados:

Tabla 42. ¿Denunciaría en caso de agresión?

\begin{tabular}{l|r|r|r|r} 
& Frecuencia & Porcentaje & $\begin{array}{c}\text { Porcentaje } \\
\text { válido }\end{array}$ & $\begin{array}{c}\text { Porcentaje } \\
\text { acumulado }\end{array}$ \\
\hline Sí & 573 & 87,5 & 87,5 & 87,5 \\
\hline No & 82 & 12,5 & 12,5 & 100,0 \\
\hline Total & 655 & 100,0 & 100,0 & \\
\hline
\end{tabular}

Como puede verse, una amplia mayoría (87,5\%) afirma que, en caso de sufrir una agresión, interpondría la denuncia correspondiente. Sólo un 12,5\% (82 personas) no lo haría.

Estos 82 profesionales respondieron a la siguiente pregunta, que planteaba (como hemos dicho) las razones por las que no denunciarían.

Se les ofrecieron varias opciones:

a) Por considerar que la agresión forma parte del trabajo y que hay que conformarse.

b) Por temor a posibles represalias por parte del agresor.

c) Por evitar que pueda pensarse que el agredido no sabe manejar las situaciones que pueden darse en su trabajo y se dude de su profesionalidad.

d) Por representar un esfuerzo excesivo.

e) Por no valer para nada.

f) Otros.

El 22,4\% afirmó que no denunciaría por considerar que no sirve de nada, el temor a posibles represalias obtuvo un $16,3 \%$, considerarlo un esfuerzo excesivo un $9,7 \%$, el cuestionamiento del prestigio profesional porque pueda pensarse que no se saben manejar esas situaciones un 4,6\% y considerarlo como algo inherente al trabajo un 1,4\%. Un 2,9\% agrupó otras cuestiones variadas muy minoritarias. 


\section{Gráfico 20. Razones por las que no denunciarían una agresión.}

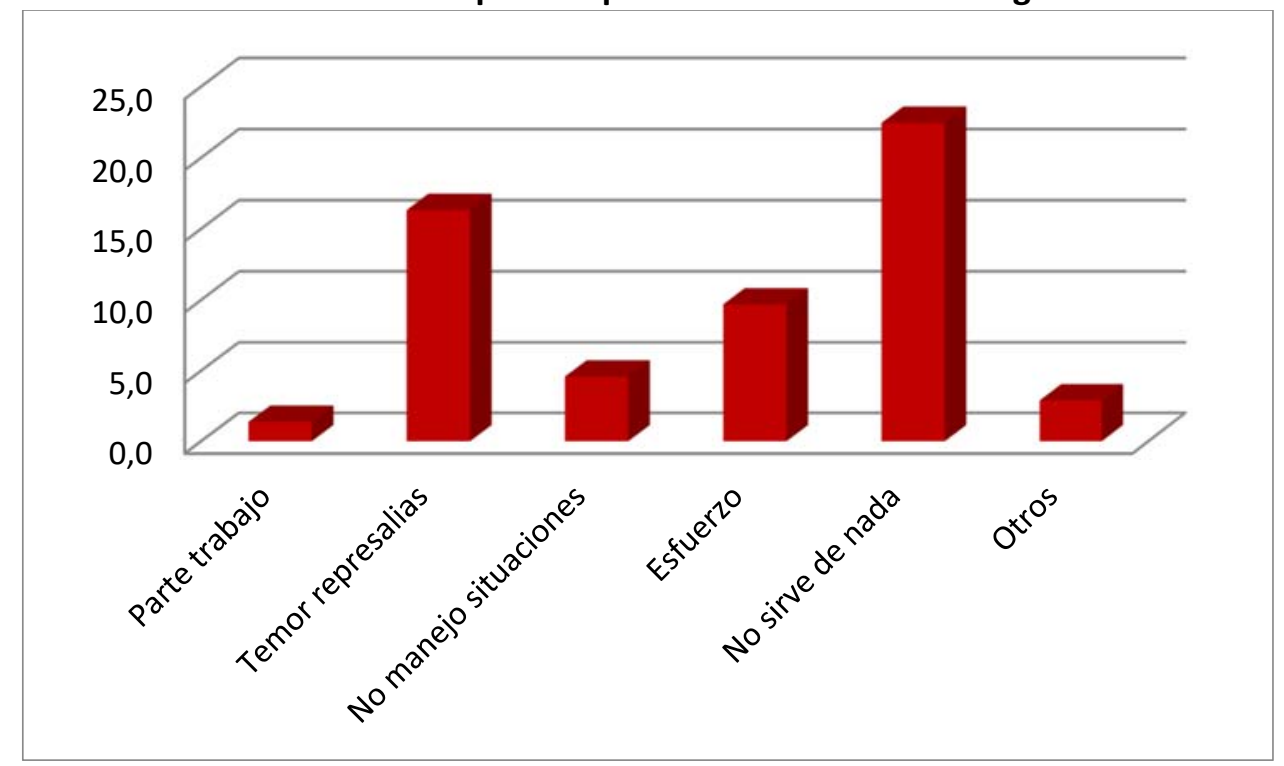

Por último, quisimos saber qué relación podía tener la predisposición a interponer una denuncia con el hecho de haber sido agredido o no anteriormente.

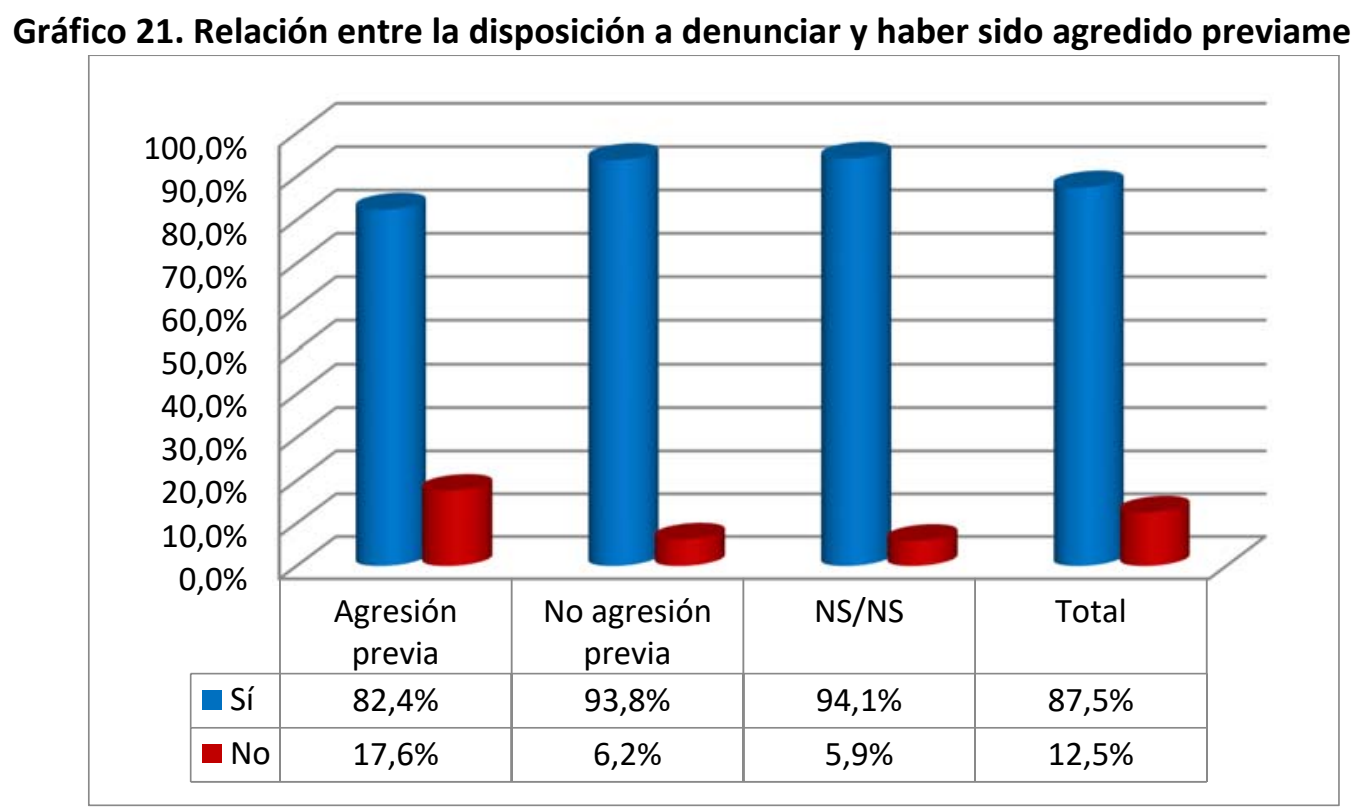

Paradójicamente, quienes no han sido víctimas de agresiones se encuentran más dispuestos a denunciar $(93,8 \%)$ que quienes sí lo han sido $(82,4 \%)$. No obstante, también se obtiene un porcentaje de bastante alto $(94,1 \%)$, entre los que declaran que no saben si fueron agredidos o no. De cualquier modo, los índices son altos en todos los casos (superan el 80\%). Los resultados fueron significativos $(\mathrm{P}=0,000)$. 
A continuación, nos propusimos conocer la opinión de los encuestados acerca del otorgamiento de la condición de autoridad por parte de la Administración Autonómica de Castilla y León a su personal sanitario.

La primera pregunta pedía una valoración general, mediante una escala tipo Likert. Los resultados fueron:

Tabla 43. Valoración de la figura de «Autoridad».

\begin{tabular}{lr|r|r|r} 
& Frecuencia & Porcentaje & $\begin{array}{c}\text { Porcentaje } \\
\text { válido }\end{array}$ & $\begin{array}{l}\text { Porcentaje } \\
\text { acumulado }\end{array}$ \\
\hline $\begin{array}{l}\text { Nada } \\
\text { importante }\end{array}$ & 55 & 8,4 & 8,4 & 8,4 \\
\hline $\begin{array}{l}\text { Poco } \\
\text { importante }\end{array}$ & 132 & 20,2 & 20,2 & 28,5 \\
\hline $\begin{array}{l}\text { Importante } \\
\text { Muy } \\
\text { importante }\end{array}$ & 206 & 31,5 & 31,5 & 60,0 \\
\hline No lo sé & 208 & 31,8 & 31,8 & 91,8 \\
\hline Total & 54 & 8,2 & 8,2 & 100,0 \\
\hline
\end{tabular}

El 31,8\% consideró la atribución de la condición de autoridad «muy importante», porcentaje seguido del 31,5\% que lo consideran «importante». El 20,2\% lo creyó poco importante y un 8,4\% nada importante. Cierra el cuadro un $8,2 \%$ que no se pronunció al respecto.

Así pues, el 63,3\% (sumados los dos porcentajes más altos: 31,5\%+31,8\%) le da importancia a la medida, frente al $28,6 \%(20,2 \%+8,4 \%)$ que no la considera importante.

Tras esa valoración general, quisimos incidir en cuál era las consecuencias que los encuestados atribuían a la condición de autoridad.

Para ello, se les preguntó sobre:

- Si la condición de autoridad promovía un mayor respeto del usuario

- Si la autoridad era lo que provocaba que pudiera juzgarse al agresor por delito de atentado. Esta es una premisa falsa y se introdujo con el propósito de conocer hasta qué punto está difundida la creencia de que los profesionales sanitarios son autoridad a efectos penales).

- Si la autoridad proporcionaba el reconocimiento de presunción de veracidad en las declaraciones del agredido.

- Si la autoridad provoca la aplicación de sanciones administrativas mayores al agresor.

Se obtuvo lo siguiente: 


\section{Gráfico 22. Posibles consecuencias que se derivan de la posesión de la condición de autoridad.}

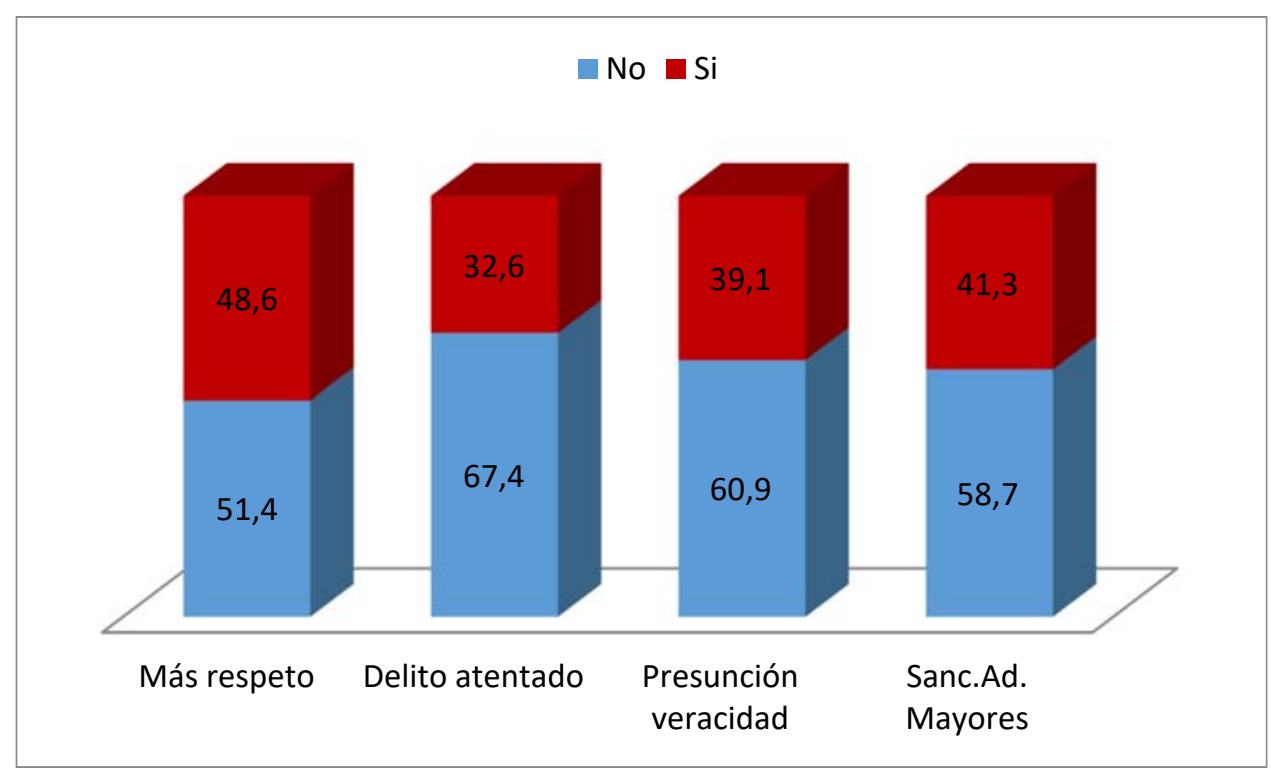

En general, no parece que los encuestados atribuyan a la condición de autoridad de forma clara las consecuencias propuestas (en ningún caso se alcanza el 50\% de los encuestados).

Quizá un mayor número de ellos sí crea que hará que exista un mayor respeto por parte de los usuarios (48,6\%), grupo seguido de quienes creen que habrá sanciones administrativas más graves $(41,3 \%)$.

En cuanto a la presunción de veracidad, sólo un $39,1 \%$ piensa que se obtiene realmente por medio de la condición de autoridad. Preguntados sobre si se aplican sanciones administrativas más graves al agresor por el hecho de que la víctima sea autoridad, un 58\% afirmó que así era, frente a un $41,3 \%$ que negó esta consecuencia. Por último, cabe afirmar que los encuestados no otorgan a la autoridad el efecto de provocar que las agresiones se conviertan en delito de atentado (únicamente un $32,6 \%$ lo cree así).

Seguidamente, abordamos la cuestión de la no aplicación de la condición de autoridad a los profesionales de la sanidad privada. Para que valoraran el asunto, se ofrecieron varias opciones, que tenían que evaluar mediante una escala tipo Likert de cinco puntos.

La primera opción manifestaba que no importaba que la autoridad no pudiera atribuirse a los profesionales de la sanidad privada, porque no había efectos en la práctica que hicieran decisiva tal condición. Esto fue lo que se obtuvo: 
Tabla 44: La no atribución de la condición de autoridad carece de importancia para el sector privado por carencia de efectos prácticos.

\begin{tabular}{lr|r|r|r} 
& Frecuencia & Porcentaje & $\begin{array}{c}\text { Porcentaje } \\
\text { válido }\end{array}$ & $\begin{array}{c}\text { Porcentaje } \\
\text { acumulado }\end{array}$ \\
\hline $\begin{array}{l}\text { Nada de } \\
\text { acuerdo }\end{array}$ & 304 & 46,4 & 46,4 & 46,4 \\
$\begin{array}{l}\text { Poco de } \\
\text { acuerdo }\end{array}$ & 209 & 31,9 & 31,9 & 78,3 \\
\hline $\begin{array}{l}\text { De acuerdo } \\
\text { Muy de } \\
\text { acuerdo }\end{array}$ & 93 & 14,2 & 14,2 & 92,5 \\
\hline Total & 49 & 7,5 & 7,5 & 100,0 \\
\hline
\end{tabular}

Un 46,4\% se mostró nada de acuerdo con la afirmación, seguido de un 31,9\% que estaba poco de acuerdo. El 14,2\% estuvo de acuerdo y el 7,5\% muy de acuerdo.

El porcentaje acumulado de los que no aceptaban que careciera de importancia el hecho de ser autoridad o no serlo alcanzó un 78,3\% (46,4\%+31,9\%), frente al 21,7\% (14,2\%+7,5\%) que sí se la daban.

La segunda opción afirmaba que hubiera sido mejor adoptar otras medidas alternativas a la atribución de la condición de autoridad, puesto que la sanidad privada no puede acceder a tal condición.

Tabla 45. Autoridad: hubiera sido mejor adoptar medidas alternativas que incluyeran a la sanidad privada.

\begin{tabular}{lr|r|r|r} 
& Frecuencia & Porcentaje & $\begin{array}{c}\text { Porcentaje } \\
\text { válido }\end{array}$ & $\begin{array}{c}\text { Porcentaje } \\
\text { acumulado }\end{array}$ \\
\hline $\begin{array}{l}\text { Nada de } \\
\text { acuerdo }\end{array}$ & 17 & 2,6 & 2,6 & 2,6 \\
\hline $\begin{array}{l}\text { Poco de } \\
\text { acuerdo }\end{array}$ & 40 & 6,1 & 6,1 & 8,7 \\
\hline $\begin{array}{l}\text { De acuerdo } \\
\text { Muy de }\end{array}$ & 313 & 47,8 & 47,8 & 56,5 \\
\hline $\begin{array}{l}\text { acuerdo } \\
\text { Total }\end{array}$ & 285 & 43,5 & 43,5 & 100,0 \\
\hline
\end{tabular}

Aquí la situación se invierte por completo: un 47,8\% declara estar de acuerdo, un 43,5\% muy de acuerdo. El 6,1\% está poco de acuerdo y el 2,6\% nada de acuerdo.

Los partidarios de esta opción suman un 91,3\% (47,8\%+43,5\%), frente a un 8,7\% $(2,6 \%+6,1 \%)$ que no consideran la opción correcta. Por tanto, según los encuestados, no debería haberse concedido la condición de autoridad a los sanitarios públicos, debido a que la sanidad privada queda fuera de la medida y habría sido mejor optar por otras acciones que sí les incluyeran. 
La tercera opción manifestaba que, puesto que los profesionales de la sanidad privada no pueden tener la condición de autoridad, lo mejor sería eliminar esta condición, a fin de que todos estuvieran en igualdad.

Tabla 46. Autoridad: es mejor eliminar la figura para garantizar una posición de igualdad para la sanidad privada.

\begin{tabular}{lr|r|r|r} 
& Frecuencia & Porcentaje & $\begin{array}{c}\text { Porcentaje } \\
\text { válido }\end{array}$ & $\begin{array}{c}\text { Porcentaje } \\
\text { acumulado }\end{array}$ \\
\hline $\begin{array}{l}\text { Nada de } \\
\text { acuerdo }\end{array}$ & 437 & 66,7 & 66,7 & 66,7 \\
$\begin{array}{l}\text { Poco de } \\
\text { acuerdo }\end{array}$ & 127 & 19,4 & 19,4 & 86,1 \\
\hline $\begin{array}{l}\text { De acuerdo } \\
\text { Muy de } \\
\text { acuerdo }\end{array}$ & 64 & 9,8 & 9,8 & 95,9 \\
\hline Total & 27 & 4,1 & 4,1 & 100,0 \\
\hline
\end{tabular}

El 66,7\% no está de acuerdo en absoluto con esta afirmación, seguido del 19,4\% que está poco de acuerdo. Un 9,8\% está de acuerdo y un 4,1\% muy de acuerdo.

El porcentaje acumulado de los que están en contra alcanza el 86,1\% $(66,7 \%+19,4 \%)$, frente al escaso $13,9 \%(9,8 \%+4,1 \%)$ que está a favor.

Es decir, los profesionales encuestados no están a favor de suprimir la condición de autoridad.

La cuarta y última cuestión planteaba que resultaba lógico que la autoridad se aplicara únicamente en la sanidad pública, puesto que es en ella donde se da el mayor número de agresiones. Se obtuvieron los siguientes resultados:

Tabla 47. Es lógico que la autoridad se refiera sólo a la sanidad pública, porque registra mayor número de agresiones.

\begin{tabular}{lr|r|r|r} 
& Frecuencia & Porcentaje & $\begin{array}{c}\text { Porcentaje } \\
\text { válido }\end{array}$ & $\begin{array}{c}\text { Porcentaje } \\
\text { acumulado }\end{array}$ \\
\hline $\begin{array}{l}\text { Nada de } \\
\text { acuerdo }\end{array}$ & 173 & 26,4 & 26,4 & 26,4 \\
\hline $\begin{array}{l}\text { Poco de } \\
\text { acuerdo }\end{array}$ & 228 & 34,8 & 34,8 & 61,2 \\
\hline $\begin{array}{l}\text { De acuerdo } \\
\text { Muy de }\end{array}$ & 177 & 27,0 & 27,0 & 88,2 \\
\hline $\begin{array}{l}\text { acuerdo } \\
\text { Total }\end{array}$ & 77 & 11,8 & 11,8 & 100,0 \\
\hline
\end{tabular}

El 34,8\% se manifestó poco de acuerdo. De acuerdo, un 27\%. El 26,4\% nada de acuerdo. El $11,8 \%$ muy de acuerdo.

Sumando los porcentajes de los que están muy de acuerdo y de acuerdo con la afirmación, obtenemos un $38,8 \%(27 \%+11,8 \%)$. 
Realizando la misma operación con los que no se encuentran nada de acuerdo o poco de acuerdo, el resultado es de $61,2 \%(26,4 \%+34,8 \%)$.

Por tanto, parece que los encuestados no consideran que la atribución de la condición de autoridad a la sanidad pública esté justificada por el mayor número de agresiones que se dan en la misma.

A continuación, se intentó establecer una relación entre estas valoraciones y el desarrollo de las actividades asistenciales de los encuestados en la sanidad pública o privada (o ambas). Para ello, fue utilizada una escala Duncan 1-4.

Se obtuvieron relaciones estadísticamente significativas en la valoración de que se «podrían haber tomado otras medidas, en vez del nombramiento de Autoridad» $(\mathrm{P}=0,002)$ y en la opción «eliminar la Autoridad para dejar al mismo nivel a las sanidades pública y privada» $(\mathrm{P}=0,000)$. Las otras dos opciones no fueron estadísticamente significativas.

\section{Gráfico 23. Relación entre opciones de valoración de la figura de "Autoridad» y sector de actividad.}

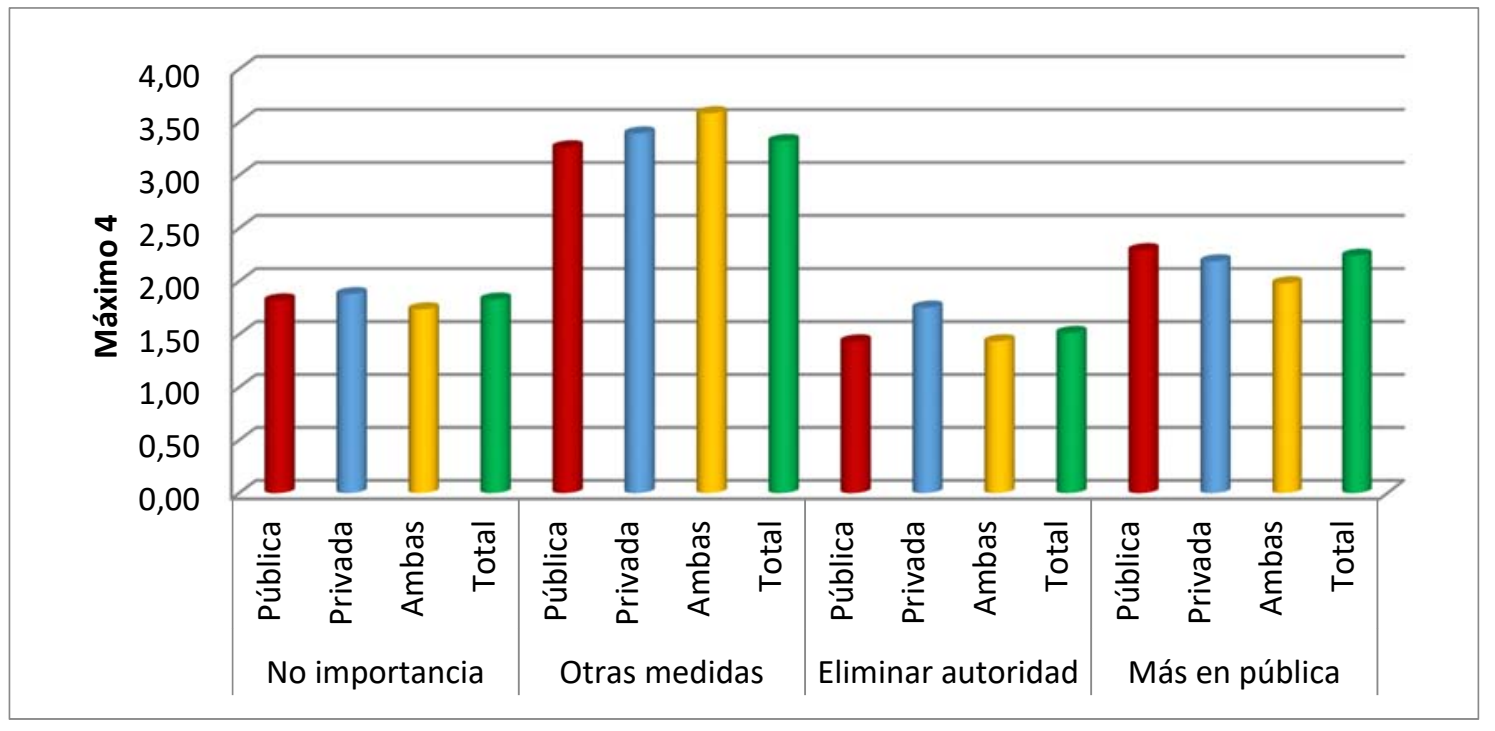

En la primera opción (no importancia a efectos prácticos de la condición de autoridad), el sector privado se manifestó más de acuerdo $(1,88)$ que el público $(1,82)$.

La segunda opción (deberían haberse tomado otras medidas a los que la sanidad privada hubiera podido tener acceso) alcanza las puntuaciones más altas, con un total de 3,32. Con esta afirmación están más de acuerdo los profesionales que comparten sanidad pública-privada $(3,58)$, seguidos de los que trabajan en la privada $(3,39)$ y, finalmente, la pública $(3,26)$.

La tercera opción (la condición de autoridad debería eliminarse, y así estarían todos al mismo nivel) es más popular entre la sanidad privada $(1,75)$, frente un 1,43 de la pública y la misma 
puntuación para los que trabajan en ambos sectores. En cualquier caso, puede observarse que los índices son bajos y el total sólo alcanza 1,51.

La cuarta opción (es justo que la condición de autoridad sólo se aplique en la pública, puesto que es en este sector donde se dan la mayoría de las agresiones) es más valorada por la sanidad pública $(2,29)$, aunque la privada alcanza 2,19. Los que comparte actividad en los dos sectores puntúan un 1,98 y el total de la opción es de un 2,24.

\section{VALORACIÓN DE LA ACTUACIÓN DE LAS INSTITUCIONES EN MATERIA DE AGRESIONES}

A continuación, se procedió a preguntar a los encuestados sobre la opinión que les merecía la actuación de diferentes instituciones ante las agresiones al personal sanitario. Se utilizó al efecto una escala tipo Likert.

Las instituciones propuestas para su valoración fueron:

- Colegios profesionales.

- SACYL.

- Administración central.

- Sindicatos.

- Tribunales.

- $\quad$ Ministerio Fiscal.

En lo referente a la actuación de los Colegios profesionales, los resultados fueron los siguientes:

Tabla 48. Valoración de la actuación de los Colegios Profesionales en materia de agresiones.

\begin{tabular}{l|r|r|r|r} 
& Frecuencia & Porcentaje & $\begin{array}{c}\text { Porcentaje } \\
\text { válido }\end{array}$ & $\begin{array}{c}\text { Porcentaje } \\
\text { acumulado }\end{array}$ \\
\hline Muy negativa & 30 & 4,6 & 4,6 & 4,6 \\
\hline Negativa & 108 & 16,5 & 16,5 & 21,1 \\
\hline Positiva & 222 & 33,9 & 33,9 & 55,0 \\
\hline Muy positiva & 71 & 10,8 & 10,8 & 65,8 \\
\hline No lo sé & 224 & 34,2 & 34,2 & 100,0 \\
\hline Total & 655 & 100,0 & 100,0 & \\
\hline
\end{tabular}

Un $33,9 \%$ considera su actuación positiva, seguido de un 16,9\% que la considera negativa, el $10,8 \%$ muy positiva y el $4,6 \%$ muy negativa. El porcentaje de personas que declararon no saber si la actuación había sido buena o mala alcanzó un 34,2\%. 
Un 44,7\% (33,9\%+10,8\%) da la actuación de los Colegios profesionales como positiva, contra un $21,1 \%(16,5 \%+4,6 \%)$ que expresa lo contrario. Ha de tenerse en cuenta el elevado porcentaje de quienes no lo valoran, que en este caso puede deberse a que algunos profesionales encuestados no están colegiados y, por tanto, se abstienen de opinar.

Por tanto, los encuestados dan una discreta valoración de sus Colegios profesionales (no llega a la mitad), aunque esta esté por encima de la que se otorga a otras instituciones que analizaremos después.

También hay que tener en cuenta la incidencia de la baja evaluación que hacen de su Colegio los profesionales de Enfermería, como veremos a continuación.

Seguidamente, mediante una escala Duncan (1-4) se pretendía conocer cómo valoraba cada grupo profesional a los diferentes Colegios. Los resultados fueron estadísticamente significativos $(\mathrm{P}=0,000)$.

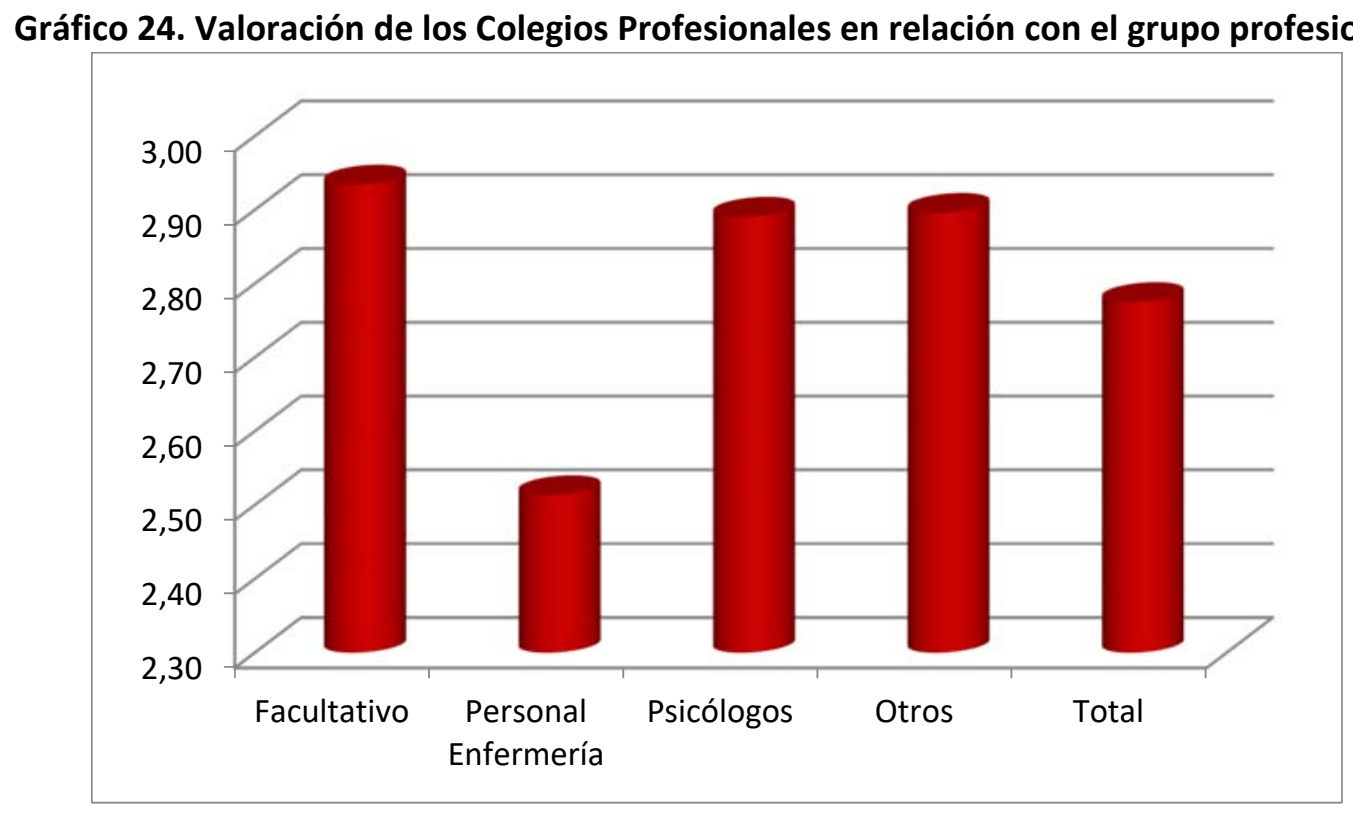

Los facultativos son los que mejor valoran la actuación de los Colegios $(2,93)$, y el personal de enfermería el que peor $(2,51)$. Los psicólogos otorgan una puntuación de 2,89 y el grupo otros (en engloba a los odontólogos, fisioterapeutas y logopedas), un 2,9.

La puntuación global no es alta (teniendo en cuenta que el máximo es cuatro, no llega más que al 2,77). 
La valoración de la actuación del SACYL aportó lo siguiente:

Tabla 49. Valoración de la actuación del SACYL en materia de agresiones.

\begin{tabular}{l|r|r|r|r|r} 
& Frecuencia & Porcentaje & $\begin{array}{c}\text { Porcentaje } \\
\text { válido }\end{array}$ & $\begin{array}{c}\text { Porcentaje } \\
\text { acumulado }\end{array}$ \\
\hline Muy negativa & 46 & 7,0 & 7,0 & 7,0 \\
\hline Negativa & 162 & 24,7 & 24,7 & 31,8 \\
\hline Positiva & 184 & 28,1 & 28,1 & 59,8 \\
\hline Muy positiva & 36 & 5,5 & 5,5 & 65,3 \\
\hline No lo sé & 227 & 34,7 & 34,7 & 100,0 \\
\hline Total & 655 & 100,0 & 100,0 & \\
\hline
\end{tabular}

El $28,1 \%$ entiende su actuación positiva, pero el $24,7 \%$ la cree negativa. Un $7 \%$ piensa que es muy negativa y un 5,5\% muy positiva. El porcentaje de los que se abstienen de valorar por no conocer la situación es de un $34,7 \%$.

Un 33,6\% (28,1\%+5,5\%) valoraría positivamente esta actuación, pero un 31,7\% $(24,7 \%+7 \%)$ lo haría de forma negativa: no hay demasiada diferencia entre una postura y otra (lo cual concuerda con el elevado porcentaje de abstención). Pero es cierto que los porcentajes son bajos, por lo que parece que los encuestados no estiman demasiado positiva la actuación del SACYL. Esta valoración es sensiblemente más baja que la otorgada a los Colegios profesionales porque, no solamente ha disminuido el porcentaje de evaluación positiva, sino que ha aumentado la negativa. En primer caso un $44,7 \%$ (Colegios) frente a un 33,6\%; en el segundo caso un 21,1\% (Colegios) frente a un $31,7 \%$.

En cuanto a la actuación de la Administración Central, se obtuvo:

Tabla 50. Valoración de la actuación de la Administración central (estatal) en materia de agresiones.

\begin{tabular}{l|r|r|r|r} 
& Frecuencia & Porcentaje & $\begin{array}{c}\text { Porcentaje } \\
\text { válido }\end{array}$ & $\begin{array}{c}\text { Porcentaje } \\
\text { acumulado }\end{array}$ \\
\hline Muy negativa & 58 & 8,9 & 8,9 & 8,9 \\
\hline Negativa & 188 & 28,7 & 28,7 & 37,6 \\
\hline Positiva & 144 & 22,0 & 22,0 & 59,5 \\
\hline Muy positiva & 19 & 2,9 & 2,9 & 62,4 \\
\hline No lo sé & 246 & 37,6 & 37,6 & 100,0 \\
\hline Total & 655 & 100,0 & 100,0 & \\
\hline
\end{tabular}

Como puede verse, aquí los porcentajes son más bajos aún. Un $28,7 \%$ considera negativa su actuación. El 22\% cree que es positiva. En los polos opuestos, un 8,9\% piensa que es muy negativa y un $2,9 \%$ muy positiva. El porcentaje de los que dicen no saber si es positiva o negativa es de un $37,6 \%(8,9 \%+28,7 \%)$. 
Por tanto, el 24,9\% $(22 \%+2,9 \%)$ creería que la Administración Central ha emprendido acciones positivas, contra el $37,6 \%$ que las valora negativamente (el mismo porcentaje que el arrojado en la abstención).

En este caso, parece claro que la actuación de la Administración Central es aún peor valorada por los encuestados que en el caso del SACYL (todavía más baja la valoración positiva 24,9\% frente al $33,6 \%$ del SACYL y se ha incrementado nuevamente la negativa $(37,6 \%)$ contra el $31,7 \%$ del SACYL).

La evaluación sobre la actuación llevada a cabo por los sindicatos fue:

Tabla 51. Valoración de la actuación de los sindicatos en materia de agresiones.

\begin{tabular}{|l|r|r|r|r|r} 
& Frecuencia & Porcentaje & $\begin{array}{c}\text { Porcentaje } \\
\text { válido }\end{array}$ & $\begin{array}{c}\text { Porcentaje } \\
\text { acumulado }\end{array}$ \\
\hline Muy negativa & 55 & 8,4 & 8,4 & 8,4 \\
\hline Negativa & 141 & 21,5 & 21,5 & 29,9 \\
\hline Positiva & 202 & 30,8 & 30,8 & 60,8 \\
\hline Muy positiva & 54 & 8,2 & 8,2 & 69,0 \\
\hline No lo sé & 203 & 31,0 & 31,0 & 100,0 \\
\hline Total & 655 & 100,0 & 100,0 & \\
\hline
\end{tabular}

El $30,8 \%$ la considera positiva, frente a un $21,5 \%$ que piensa que es negativa. En los extremos, un $8,4 \%$ cree que es muy negativa y un $8,2 \%$ muy positiva (porcentajes, como se ve, muy similares). El 31\% no sabe si la actuación fue positiva o negativa.

Los votos positivos se agrupan en un 39\% (30,8\%+8,2\%), siendo los negativos de un $29,9 \%$ $(21,5 \%+8,4 \%)$. Con un $9,1 \%$ de diferencia entre ambas posturas, es difícil declarar la situación en tablas.

La valoración positiva está por debajo de la de los Colegios profesionales, pero por encima de la que se otorga a ambas Administraciones. Y es también más baja la valoración negativa que la asignada tanto al SACYL como a la Administración central.

No obstante, se vuelve a constatar el elevado porcentaje de abstención, aunque también aquí, como en el caso de los Colegios profesionales, puede deberse a que los no sindicados hayan preferido no opinar.

Seguidamente, se pidió a los encuestados que evaluaran la actuación seguida por los tribunales de justicia. Se obtuvieron los resultados siguientes: 
Tabla 52. Valoración de la actuación de los tribunales de justicia en materia de agresiones.

\begin{tabular}{l|r|r|r|r} 
& Frecuencia & Porcentaje & $\begin{array}{c}\text { Porcentaje } \\
\text { válido }\end{array}$ & $\begin{array}{c}\text { Porcentaje } \\
\text { acumulado }\end{array}$ \\
\hline Muy negativa & 28 & 4,3 & 4,3 & 4,3 \\
\hline Negativa & 107 & 16,3 & 16,3 & 20,6 \\
\hline Positiva & 211 & 32,2 & 32,2 & 52,8 \\
\hline Muy positiva & 65 & 9,9 & 9,9 & 62,7 \\
\hline No lo sé & 244 & 37,3 & 37,3 & 100,0 \\
\hline Total & 655 & 100,0 & 100,0 & \\
\hline
\end{tabular}

El 32,2\% entendió su actuación como positiva. Un 16,3\% pensó que era negativa. En los polos extremos, un $9,9 \%$ la dio como muy positiva y un $4,3 \%$ como muy negativa. Como en anteriores ocasiones, el porcentaje de quienes afirmaron desconocer la cuestión es alto: 37,3\%.

Darían una valoración positiva un $42,1 \%(32,2 \%+9,9 \%)$, frente a la negativa de un $20,6 \%$ $(16,3 \%+4,3 \%)$ (menor que el porcentaje de abstención). Esta es una valoración positiva, más cercana a la que se otorga a los Colegios profesionales, y que está por encima de la otorgada tanto a los sindicatos como a las Administraciones.

Por último, se pidió la opinión sobre la actuación del Ministerio Fiscal, obteniendo lo siguiente:

Tabla 53. Valoración de la actuación del Ministerio Fiscal en materia de agresiones.

\begin{tabular}{lr|r|r|r} 
& Frecuencia & Porcentaje & $\begin{array}{c}\text { Porcentaje } \\
\text { válido }\end{array}$ & $\begin{array}{c}\text { Porcentaje } \\
\text { acumulado }\end{array}$ \\
\hline Muy negativa & 34 & 5,2 & 5,2 & 5,2 \\
\hline Negativa & 105 & 16,0 & 16,0 & 21,2 \\
\hline Positiva & 180 & 27,5 & 27,5 & 48,7 \\
\hline Muy positiva & 58 & 8,9 & 8,9 & 57,6 \\
\hline No lo sé & 278 & 42,4 & 42,4 & 100,0 \\
\hline Total & 655 & 100,0 & 100,0 & \\
\hline
\end{tabular}

El 27,5\% considera positiva la actuación de los fiscales. Un 16\% la cree negativa. En los extremos, un $8,9 \%$ piensa que es muy positiva y un $5,2 \%$ muy negativa.

Aquí el porcentaje de los que afirman desconocer la actuación a valorar se dispara: un 42,4\%. Sumando los porcentajes, la valoración positiva tendría un $36,4 \%(27,5 \%+8,9 \%)$ y la negativa un $21,2 \%(5,2 \%+16 \%)$. Se aprobaría su actuación, pero con unos valores muy bajos y la abstención más elevada de todas las evaluaciones de las instituciones propuestas, quizá porque su actuación es menos conocida. 
Globalmente, esta sería la visión general de la valoración de las diferentes instituciones:

Gráfico 25. Panorámica de la valoración de las instituciones en materia de agresiones.

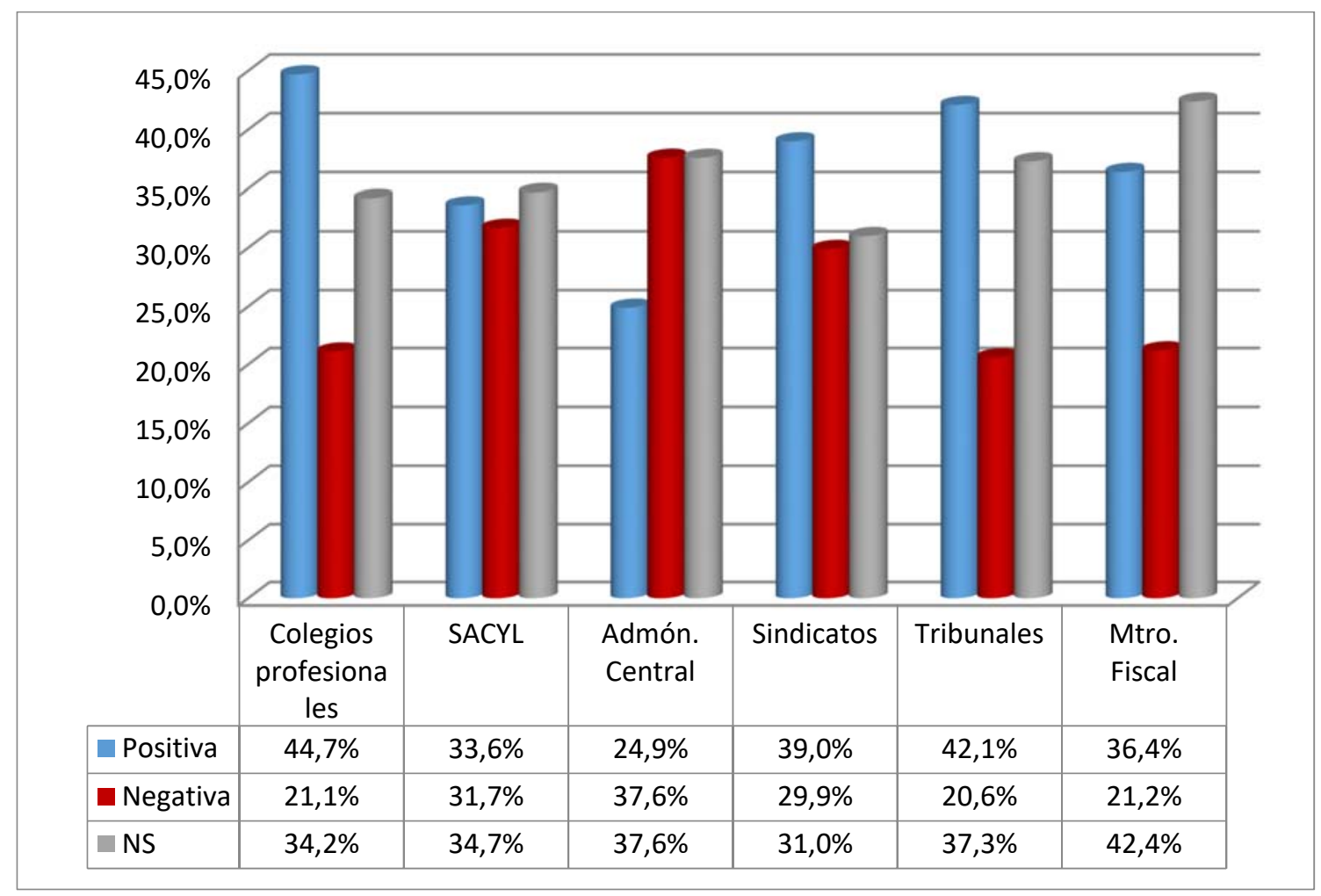

Hay que destacar que en todos los casos los porcentajes son bastante discretos (no llegan ni al $50 \%$ ) y el índice de respuestas NS es bastante elevado proporcionalmente. Esto podría decir que los profesionales no conocen las actuaciones realizadas y, por ello, no se atreven a valorarlas. Resulta especialmente llamativo el caso del Ministerio Fiscal, donde el porcentaje de los que dicen «no saber» alcanza un $42,4 \%$.

Dejando esto aparte, la institución mejor valorada (aunque los porcentajes no son altos) serían los Colegios Profesionales (con un 44,7\%), seguida de Tribunales, Ministerio Fiscal y sindicatos. Los últimos puestos los obtendrían las Administraciones autonómica y central.

\section{ACTUACIONES MÁS ADECUADAS PARA COMBATIR LAS AGRESIONES}

Con el propósito de conocer las actuaciones que los profesionales creen que tendrían mayor efectividad contra las agresiones, se les propuso una serie de medidas generales, que debían evaluar mediante una escala tipo Likert. 
Las medidas propuestas fueron:

1. Dotar de más medios humanos y materiales a los servicios sanitarios, al objeto de mejorar la atención clínica.

2. Implantación de campañas educativas para los usuarios.

3. Imposición de penas de prisión a los agresores.

4. Imposición de penas de multa a los agresores.

5. Mejorar el trato al paciente.

1. Dotación de más medios materiales y humanos.

Tabla 54. Dotación de más medios humanos y materiales.

\begin{tabular}{lr|r|r|r} 
& Frecuencia & Porcentaje & $\begin{array}{c}\text { Porcentaje } \\
\text { válido }\end{array}$ & $\begin{array}{c}\text { Porcentaje } \\
\text { acumulado }\end{array}$ \\
\hline $\begin{array}{l}\text { Nada de } \\
\text { acuerdo }\end{array}$ & 31 & 4,7 & 4,7 & 4,7 \\
\hline $\begin{array}{l}\text { Poco de } \\
\text { acuerdo }\end{array}$ & 161 & 24,6 & 24,6 & 29,3 \\
\hline $\begin{array}{l}\text { De acuerdo } \\
\text { Muy de }\end{array}$ & 309 & 47,2 & 47,2 & 76,5 \\
\hline $\begin{array}{l}\text { acuerdo } \\
\text { Total }\end{array}$ & 154 & 23,5 & 23,5 & 100,0 \\
\hline
\end{tabular}

El 47,2\% declaró estar de acuerdo con este aumento de dotación. El 24,6\% estuvo poco de acuerdo. Un $23,5 \%$ se manifestó muy de acuerdo y, finalmente, un $4,7 \%$ no estuvo nada de acuerdo.

El 70,7\% $(47,2 \%+23,5 \%)$ parece apoyar la medida, frente a un $29,3 \%(24,6 \%+4,7 \%)$.

2. Campañas educativas dirigidas a los usuarios.

Tabla 55. Campañas educativas dirigidas a los usuarios.

\begin{tabular}{lr|r|r|r} 
& Frecuencia & Porcentaje & $\begin{array}{c}\text { Porcentaje } \\
\text { válido }\end{array}$ & $\begin{array}{l}\text { Porcentaje } \\
\text { acumulado }\end{array}$ \\
\hline $\begin{array}{l}\text { Nada de } \\
\text { acuerdo }\end{array}$ & 23 & 3,5 & 3,5 & 3,5 \\
\hline $\begin{array}{l}\text { Poco de } \\
\text { acuerdo }\end{array}$ & 164 & 25,0 & 25,0 & 28,5 \\
\hline $\begin{array}{l}\text { De acuerdo } \\
\text { Muy de }\end{array}$ & 379 & 57,9 & 57,9 & 86,4 \\
\hline $\begin{array}{l}\text { acuerdo } \\
\text { Total }\end{array}$ & 89 & 13,6 & 13,6 & 100,0 \\
\hline
\end{tabular}


El 57,9\% manifestó estar de acuerdo con la implantación de esta medida. Un $25 \%$ estuvo poco de acuerdo. El 13,6\% afirmó estar muy de acuerdo y el 3,5\% nada de acuerdo.

Los que apoyarían la adopción de campañas educativas representarían un 71,5\% (57,9\%+13,6\%), frente al $28,5 \%(25 \%+3,5 \%)$ que parecen no estar a favor.

3. Imposición de penas de prisión a los agresores.

Tabla 56. Condenas de prisión para los agresores.

\begin{tabular}{l|r|r|r|r} 
& Frecuencia & Porcentaje & $\begin{array}{c}\text { Porcentaje } \\
\text { válido }\end{array}$ & $\begin{array}{c}\text { Porcentaje } \\
\text { acumulado }\end{array}$ \\
\hline $\begin{array}{l}\text { Nada de } \\
\text { acuerdo }\end{array}$ & 23 & 3,5 & 3,5 & 3,5 \\
\hline $\begin{array}{l}\text { Poco de } \\
\text { acuerdo }\end{array}$ & 142 & 21,7 & 21,7 & 25,2 \\
\hline $\begin{array}{l}\text { De acuerdo } \\
\text { Muy de }\end{array}$ & 335 & 51,1 & 51,1 & 76,3 \\
\hline $\begin{array}{l}\text { acuerdo } \\
\text { Total }\end{array}$ & 155 & 23,7 & 23,7 & 100,0 \\
\hline
\end{tabular}

El 51,1\% está de acuerdo con enviar a la cárcel a los agresores, seguido de un 23,7\% que está muy de acuerdo. Un $21,7 \%$ declara estar poco de acuerdo y un 3,5\% nada de acuerdo.

En este caso, parece claro que la opción es muy valorada: un $74,8 \%(51,1 \%+23,7 \%)$ apoya las penas de prisión, frente a un $25,2 \%(3,5 \%+21,7 \%)$ que no lo hace.

4. Imposición de penas de multa a los agresores.

Tabla 57. Imposición de multas a los agresores.

\begin{tabular}{lr|r|r|r} 
& Frecuencia & Porcentaje & $\begin{array}{c}\text { Porcentaje } \\
\text { válido }\end{array}$ & $\begin{array}{c}\text { Porcentaje } \\
\text { acumulado }\end{array}$ \\
\hline $\begin{array}{l}\text { Nada de } \\
\text { acuerdo }\end{array}$ & 12 & 1,8 & 1,8 & 1,8 \\
\hline $\begin{array}{l}\text { Poco de } \\
\text { acuerdo }\end{array}$ & 97 & 14,8 & 14,8 & 16,6 \\
\hline $\begin{array}{l}\text { De acuerdo } \\
\text { Muy de }\end{array}$ & 334 & 51,0 & 51,0 & 67,6 \\
\hline acuerdo & 212 & 32,4 & 32,4 & 100,0 \\
\hline Total & 655 & 100,0 & 100,0 & \\
\hline
\end{tabular}

El $51 \%$ está de acuerdo con multar a los agresores y muy de acuerdo un $32,4 \%$. El 14,8\% se encuentra poco de acuerdo y nada de acuerdo lo está un $1,8 \%$.

El apoyo a esta actuación es indiscutible: un $83,4 \%(51 \%+32,4 \%)$ se muestra partidario, frente a sólo un $16,6 \%(14,8 \%+1,8 \%)$ que no aprueba la medida. 
5. Dispensar un mejor trato al paciente.

Tabla 58. Dispensar un mejor trato al paciente.

\begin{tabular}{lr|r|r|r} 
& Frecuencia & Porcentaje & $\begin{array}{r}\text { Porcentaje } \\
\text { válido }\end{array}$ & $\begin{array}{l}\text { Porcentaje } \\
\text { acumulado }\end{array}$ \\
\hline $\begin{array}{l}\text { Nada de } \\
\text { acuerdo }\end{array}$ & 49 & 7,5 & 7,5 & 7,5 \\
\hline $\begin{array}{l}\text { Poco de } \\
\text { acuerdo }\end{array}$ & 115 & 17,6 & 17,6 & 25,0 \\
$\begin{array}{l}\text { De acuerdo } \\
\text { Muy de }\end{array}$ & 346 & 52,8 & 52,8 & 77,9 \\
\hline $\begin{array}{l}\text { acuerdo } \\
\text { Total }\end{array}$ & 145 & 22,1 & 22,1 & 100,0 \\
\hline
\end{tabular}

Un $52,8 \%$ se declara de acuerdo, seguido de un $22,1 \%$ que manifiesta estar muy de acuerdo. El $17,6 \%$ está poco de acuerdo y un 7,5\% nada de acuerdo.

El 74,9\% $(52,8 \%+22,1 \%)$ opina, por tanto, que ofrecer un mejor trato al paciente sería una buena medida para evitar agresiones. Un $25,1 \%(7,5 \%+17,6 \%)$ cree que no.

Queríamos saber si existía relación entre la valoración de las medidas propuestas y el hecho de haber sufrido o no una agresión. Se utilizó una escala Duncan (1-4), obteniéndose lo siguiente (relevancia significativa para la valoración de la pena de multa: 0,003):

\section{Gráfico 26. Relación entre la valoración de las medidas propuestas y haber sufrido una} agresión.

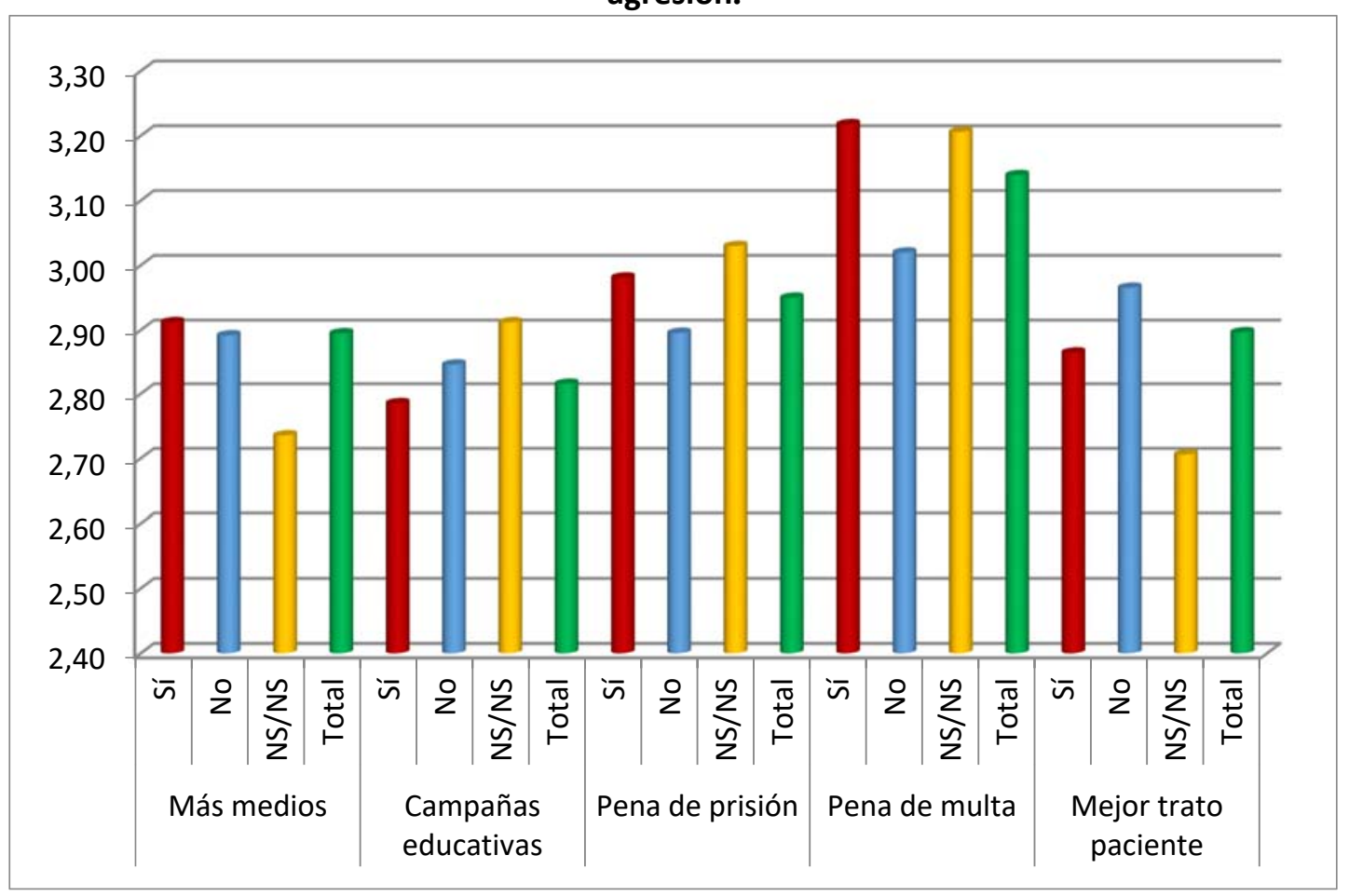


La pena de multa es la más valorada entre los agredidos $(3,22)$, seguida de la pena de prisión $(2,33)$. También valoran más la dotación de medios materiales y humanos $(2,91)$.

Los que no han sufrido agresiones también valoran sobre todo las penas de multa $(3,02)$ y las penas de prisión $(2,90)$, casi al mismo nivel que la dotación de más medios $(2,89)$. Entre los no agredidos hay también una buena puntuación en el mejor trato al paciente $(2,97)$.

Entre el grupo que no sabe si ha sufrido agresiones, la propuesta más valorada es también la pena de multa $(3,14)$ y la de prisión $(3,03)$.

Las campañas educativas obtienen resultados más discretos, exceptuando este último grupo, en que se da un 2,91 .

Parece que la experiencia en agresiones impulsa a la petición de medidas concretas y punitivas contra los agresores, aunque en general todos los grupos se inclinen más hacia estas medidas.

\section{VALORACIÓN DE MEDIDAS LEGISLATIVAS REFERENTES A LAS AGRESIONES.}

A continuación, se requirió de los profesionales que evaluaran una serie de medidas legislativas relacionadas con las agresiones al personal sanitario. Se utilizó para ello una escala tipo Likert.

En primer lugar, se pidió a los profesionales que opinaran sobre la actual necesidad de que el interesado agredido denuncie cuando se producen lesiones, en vez de que la persecución del acto se realice de oficio. Estos fueron los resultados:

Tabla 59. Valoración de la necesaria denuncia de parte cuando se produce lesión.

\begin{tabular}{lr|r|r|r} 
& Frecuencia & Porcentaje & $\begin{array}{c}\text { Porcentaje } \\
\text { válido }\end{array}$ & $\begin{array}{c}\text { Porcentaje } \\
\text { acumulado }\end{array}$ \\
\hline Muy perjudicial & 63 & 9,6 & 9,6 & 9,6 \\
\hline Perjudicial & 313 & 47,8 & 47,8 & 57,4 \\
\hline Beneficioso & 255 & 38,9 & 38,9 & 96,3 \\
\hline $\begin{array}{l}\text { Muy } \\
\text { beneficioso }\end{array}$ & 24 & 3,7 & 3,7 & 100,0 \\
\hline Total & 655 & 100,0 & 100,0 & \\
\hline
\end{tabular}

Un 47,8\% cree perjudicial que sea necesaria la presentación de denuncia por parte del interesado, en vez de la iniciación de las actuaciones de oficio; un 38,9\% lo considera beneficioso. El 9,6\% piensa que es muy perjudicial y un 3,7 muy beneficioso.

El porcentaje acumulado de quienes consideran negativa la cuestión es de un 57,4\% $(9,6 \%+47,8 \%)$, contra un $42,6 \%(38,9 \%+3,7 \%)$ que le dan un matiz positivo. Mayoritariamente (más de la mitad) cree que la necesidad de denunciar la agresión productora de lesiones no es beneficiosa para la víctima. Pero existe un porcentaje nada desdeñable de personas que lo considera positivo. 
La segunda cuestión versó sobre si consideraban beneficiosa o no la aplicación del delito de

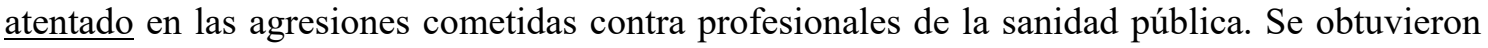
los resultados siguientes:

Tabla 60. Valoración de aplicación del delito de atentado a la sanidad pública.

\begin{tabular}{l|r|r|r|r} 
& Frecuencia & Porcentaje & $\begin{array}{c}\text { Porcentaje } \\
\text { válido }\end{array}$ & $\begin{array}{c}\text { Porcentaje } \\
\text { acumulado }\end{array}$ \\
\hline Muy perjudicial & 13 & 2,0 & 2,0 & 2,0 \\
\hline Perjudicial & 65 & 9,9 & 9,9 & 11,9 \\
\hline Beneficioso & 440 & 67,2 & 67,2 & 79,1 \\
\hline $\begin{array}{l}\text { Muy } \\
\text { beneficioso }\end{array}$ & 137 & 20,9 & 20,9 & 100,0 \\
\hline Total & 655 & 100,0 & 100,0 & \\
\hline
\end{tabular}

El $67,2 \%$ dijo que es beneficioso, seguido de un 20,9\% muy beneficioso. Para un $9,9 \%$ es perjudicial y para un $2 \%$ resulta muy perjudicial.

En este caso, la situación se manifiesta de forma clara: un $88,1 \%(67,2 \%+20,9 \%)$ piensa en términos positivos y únicamente el $11,9 \%(2 \%+9,9 \%)$ cree que resulta negativa esta aplicación. Por lo tanto, estamos ante una valoración muy positiva de la aplicación del delito de atentado ante las agresiones cometidas contra el personal de la sanidad pública.

La tercera y última cuestión de este bloque estaba enfocada en la salida del Derecho penal de las injurias y otros comportamientos ilícitos anteriormente tratados como faltas en esa jurisdicción. Lo que se planteaba es cómo valoran los profesionales sanitarios el hecho de que una injuria (básicamente un insulto) y otro tipo de ofensas verbales ya no sean perseguibles desde el Derecho penal, sino desde otras ramas del ordenamiento jurídico (el Derecho civil, principalmente).

Los resultados obtenidos fueron los siguientes:

Tabla 61. Valoración de la salida del Derecho penal de injurias y otras antiguas faltas.

\begin{tabular}{lr|r|r|r} 
& Frecuencia & Porcentaje & $\begin{array}{c}\text { Porcentaje } \\
\text { válido }\end{array}$ & $\begin{array}{c}\text { Porcentaje } \\
\text { acumulado }\end{array}$ \\
\hline Muy perjudicial & 53 & 8,1 & 8,1 & 8,1 \\
\hline Perjudicial & 340 & 51,9 & 51,9 & 60,0 \\
\hline Beneficioso & 240 & 36,6 & 36,6 & 96,6 \\
\hline $\begin{array}{l}\text { Muy } \\
\text { beneficioso }\end{array}$ & 22 & 3,4 & 3,4 & 100,0 \\
\hline Total & 655 & 100,0 & 100,0 & \\
\hline
\end{tabular}


El 51,9\% lo consideró perjudicial, aunque el 36,6\% lo vio como beneficioso. En los extremos, un $8,1 \%$ cree que es muy perjudicial y un $3,4 \%$ muy beneficioso.

Nos encontramos, por tanto, con un $60 \%(8,1 \%+51,9 \%)$ de encuestados que encuentran perjudicial la reforma legal en mayor o menor medida, frente a un $40 \%(36,6 \%+3,4 \%)$ que la cree beneficiosa.

La mayoría muestra, probablemente, cierta preocupación respecto a la falta de persecución que puedan tener estas conductas a partir de ahora, fuera del ámbito penal y sujetas sólo a una posible reclamación de indemnización en la vía civil, en la mayor parte de los casos.

En cuanto a la última pregunta, en la que se pidió a los encuestados que sugirieran otras medidas para combatir las agresiones, se categorizaron las respuestas como se detalla en capítulo «Material y métodos». Los entrevistados también respondieron a esta pregunta insistiendo en medidas ya propuestas. A continuación, se ofrece una selección de la miscelánea obtenida en las categorías 9 «Otro tipo de sanciones» y $10 «$ Otros»:

\section{Categoría 9:}

- «Que el paciente, si comete agresión, no pueda ser vuelto a citar con ese profesional y note de alguna manera (tener que pedir otra cita con distinto profesional de nuevo, con su consiguiente espera) para que vea que, si no cumple con sus obligaciones, dicho acto tiene consecuencias directas».

- «Una denuncia pública y que el usuario dejase de poder recibir atención en un centro sanitario». «Tras una agresión física o verbal el paciente no podrá ser atendido en el mismo hospital». «...sanciones de prestaciones en casos concretos de abusos de los servicios sanitarios». «Privación de ciertas prestaciones en agresiones leves, proporcionales a la gravedad de la agresión».

- «Acto de mediación que facilite el pedir disculpas por parte del agresor».

- «Establecer una especie de "Carnet Por Puntos" del paciente. Las agresiones, denuncias y sanciones irían restando puntos. Los médicos podrían saber si un paciente (que muchas veces procede de otro centro o región) es problemático y tendente a la agresión (verbal y/o física) en función de su saldo de puntos. Al perder los puntos debería ser obligatorio hacer algún cursillo de re-educación, control de agresividad, etc... por parte de esta clase de pacientes. Por debajo de un determinado nivel de puntos crítico el Sanitario debería poder ejercer un derecho a veto previo, o poder reclamar la presencia en consulta de personal de seguridad antes de atender a ese paciente, o poder grabar la conversación desde el inicio de la asistencia (previo aviso)». 
- «...expulsar al agresor del sistema sanitario público o al menos obligarle al pago (por "morder la mano que le da de comer")». «...sanciones de exclusión de la asistencia sanitaria». «Penalizar al agresor impidiéndole la utilización del sistema sanitario público durante un tiempo como ya marca la ley pero no se aplica. O si lo tuviera que utilizar que abonara el coste». «Sería necesario impedir a los agresores la asistencia sanitaria salvo en caso de urgencia vital». «Retirar la asistencia sanitaria durante un periodo, con aviso de próxima sanción penal». «La penalización de asistencia o cobertura sanitaria durante un tiempo en proporción a la agresión». «El derecho a no ser atendidos. El pago de un importe».

- «Órdenes de alejamiento y traslados de T.S. [Técnicos Sanitarios] a ZBS [Zonas Básicas de Salud] más alejadas».

En la categoría «10. Otros» se agruparon una serie de medidas heterogéneas. A continuación, por su interés, se transcriben algunas respuestas que aportan sugerencias distintas a las actuaciones propuestas y que, en ciertos casos, constituyen auténticas denuncias:

- «Que en el protocolo de agresión a personal sanitario público se pudiese dejar constancia del nombre del agresor que no se puede hacer actualmente salvo que sea vía penal, lo que resulta absolutamente injusto, ya que cuando es un paciente el que interpone una queja, va a tu nombre».

- Señalar la importancia de alcanzar un conocimiento real del fenómeno para poder atajarlo: «Creo que tenemos que entender lo que provoca estas agresiones».

- Llamada a la agilidad en la implantación de las medidas: «Las que plantea la presente encuesta son suficientes; pero se deben concretar en el plazo más corto posible».

- «Los sanitarios debemos actuar como verdaderos profesionales y me refiero a todos los trabajadores que tenemos contacto con pacientes y acompañantes, muchas veces hacemos comentarios en el ámbito laboral que llegan los pacientes/acompañantes que generan inseguridad y falta de respeto hacia los propios sanitarios».

- «Advertencia en su tarjeta sanitaria de agresión penada en los últimos años».

- «Hacerse respetar».

- «Debería entregarse una carta de deberes, entre otros el respeto al personal, a los pacientes».

- «En la privada tenemos que tener libro de reclamaciones, de información sanitaria, si concertamos pacientes con la Seguridad Social. Es obligatorio controles de calidad donde cada paciente contesta a preguntas sobre la atención recibida: puntualidad, satisfactorio en el resultado, cómo ha sido informado y puede exponer cualquier reclamación. El 
personal, desde facultativos a administrativos, nada. Si no acuden a la cita, si no tratan con el respeto debido, si dejan de ir sin avisar, nada».

- «Es fundamental volver a retomar la confianza y el afecto que se tenía al profesional. Ahora, y de eso se han ocupado mucho los políticos y los sindicatos, se ha conseguido que los profesionales de la salud pierdan su autoridad».

- No medidas diferentes, pero que se pongan en práctica: «Que no se quede en el papel, sino que se cumpla alguna sanción al agresor, de manera que entre las personas se tenga el precedente y piensen en las consecuencias, antes de agredir sin pensar al personal sanitario». «Cumplir la ley». Y mayor severidad en la actuación: «Mano dura contra los agresores profesionales o pacientes».

- «Que sean incluidas como riesgo profesional, dentro de los planes de prevención de los mismos, totalmente inexistentes en emergencias sanitarias de Castilla y León, lo cual es vergonzoso».

- Pago de la atención en Urgencias cuando no estaba indicada: «Un gran número de ellas se producen por la demanda de atención que el paciente considera urgente. Es probable que, si los servicios de urgencias pudieran facturar las actuaciones que no lo son, disminuiría la presión asistencial y por tanto la posibilidad de que está provocase agresiones».

- «Creo que todas las posibilidades han sido contempladas en este estudio, solo se me ocurre: traslado del profesional a otro centro en caso de agresión para evitar contacto con agresores en la zona de salud donde trabaja».

- Combatir la infradenuncia/infraregistro: «Concienciar al personal de la importancia de registrar todas las agresiones para que se valore la magnitud del problema».

- Queja de que los pacientes agreden más al personal de Enfermería porque los médicos ostentan más poder sobre ellos: «...lo que sucede es que, ante cualquier pequeña contrariedad, el paciente sabe que no puede agredir al médico, que es quien pone las normas. Así que lo paga con el personal que le trata y cuida directamente. Y no tiene ningún problema en expresarlo así. Y nos insulta, intimida o agrede, ya sea de forma verbal o física».

- Autocontrol: «Escuchar y tranquila...tiempo».

Al final se incluye el Anexo II, que contiene un repertorio de respuestas más representativas que se obtuvieron en esta última pregunta del cuestionario. 
VII. DISCUSIÓN 


\section{JUSTIFICACIÓN Y ESTRUCTURA}

En la Introducción de este trabajo definíamos cuál sería el ámbito material, el perfil humano sobre el que iba a incidir, así como las motivaciones que impulsaban esta investigación y los objetivos que pretendíamos conseguir con ella.

El ámbito material versaría sobre las agresiones que se producen en el ámbito sanitario.

El perfil humano, estaría conformado por los profesionales de la salud, entendiendo como tales a quienes desarrollan su actividad profesional en relación con actividades sanitarias sin importar el tipo de actividad, el lugar donde ésta se desarrolla, la categoría profesional o la pertenencia a la sanidad pública o privada.

Las motivaciones nos orientaban hacia una triple línea de investigación:

Por un lado, se trataba de contribuir a paliar la escasez de trabajos que se ocupan del problema de estas agresiones desde una perspectiva jurídica no sectorial sino global, intentando con ello ofrecer una panorámica de los instrumentos jurídicos existentes en cuanto a la prevención de esta violencia.

Por otra parte, verificar el comportamiento de estos instrumentos en la práctica, cuando ya se ha producido efectivamente una agresión, puesto que este enfoque también adolece de lagunas. Se ha venido tratando con más amplitud lo que acontece en el orden penal, no tanto qué ocurre en otras parcelas de nuestro ordenamiento jurídico. Encontramos en esa escasez de estudios otro motivo para emprender nuestra investigación, sin que esto suponga obviar la actuación de los tribunales de lo penal cuando un supuesto de agresión llega a ellos.

La tercera línea de investigación, no por ello menos importante, porque tampoco existe un conocimiento a nuestro juicio suficiente en relación con ello, se orientaría a proporcionar a los afectados un medio para expresar su grado de información y su opinión sobre la existencia y la eficacia de los mecanismos legales que la Administración pone a su disposición, a la hora de prevenir los actos violentos o de resarcirles cuando han sido víctimas de ellos. Esto podría permitirnos además realizar una valoración crítica de todos los aspectos tratados en nuestro estudio.

Esta triple motivación informaba los objetivos del trabajo que nos proponíamos elaborar, objetivos que podríamos sintetizar en dos grupos:

1.- Ofrecer una visión global de ese marco jurídico tanto desde el punto de vista teórico como desde su funcionamiento en la práctica, que abarcara las medidas dirigidas a la prevención del 
problema, pero también las que se orientan a delimitar las responsabilidades (incluso las de la propia Administración) así como las que se ocupan de imponer las sanciones correspondientes.

2.- Conocer, analizar y valorar con sentido crítico la opinión de los propios profesionales no sólo en cuanto al problema de la violencia en sí sino también y, sobre todo, en relación con las medidas legales que en relación con este tema puedan existir.

Al exponer la Metodología que íbamos a utilizar para la consecución de esos objetivos, planteamos que todo el trabajo se fundamentaría sobre dos pilares, correlativos con ambos grupos de objetivos:

El primero, estaría dedicado a estudiar el régimen jurídico actual en materia de agresiones a los profesionales de la sanidad, analizándolo a partir de la disposiciones legales y reglamentarias de los ordenamientos laboral, administrativo y penal. Pero teniendo en cuenta así mismo la aplicación de esa normativa en el caso de surgir conflictos que se dirimen ante los tribunales, es decir, atendiendo también a la jurisprudencia existente sobre la materia.

El segundo pilar se basaría precisamente en la valoración de las experiencias de los profesionales de la salud sobre las agresiones que se producen contra ellos y también en su evaluación de las medidas preventivas y las sancionadoras que pueden ponerse en marcha en el caso de producirse estos acontecimientos violentos. El instrumento fundamental para efectuar este análisis sería la realización de una encuesta a través de la cual los profesionales de la salud pudieran manifestar todas esas opiniones.

Hemos comprobado que esta metodología ha sido eficaz a la hora de conseguir los objetivos propuestos.

En relación con el primer grupo de objetivos, nos ha permitido realizar una evaluación crítica del marco normativo y reglamentario actualmente existente en nuestro ordenamiento, en cuanto al tratamiento de este tipo de conflictos.

También hemos podido valorar el funcionamiento en la práctica de la aplicación de estos instrumentos, a partir de la actuación de los tribunales fundamentalmente.

De ambos aspectos trataremos en los epígrafes dedicados a las consideraciones sobre la actuación del Derecho laboral, administrativo y penal frente a las agresiones a los profesionales sanitarios.

Por otra parte, en cuanto al segundo grupo de objetivos, el análisis de las opiniones obtenidas a partir del cuestionario propuesto, nos ha permitido formular una valoración crítica de la opinión 
de esos profesionales y también llevar a cabo una revisión de nuestro propio análisis sobre la normativa y su aplicación práctica, contenido en el apartado anterior.

Todo esto tendrá su desarrollo en «Experiencia ante las agresiones y valoración por los profesionales de las medidas tomadas».

En consecuencia, como acabamos de anticipar, vamos a estructurar este Capítulo dedicado a la Discusión en dos grandes apartados:

En el primero, con fundamento en el desarrollo pormenorizado expuesto en anteriores capítulos sobre lo que determinan los distintos ordenamientos en materia de agresiones a los profesionales de la salud, plantearemos un análisis crítico de sus principales contenidos en el orden laboral, administrativo y penal, con inclusión del tratamiento jurisprudencial, especialmente en lo que atañe a este último orden jurídico.

El segundo apartado, se destina a ponderar la valoración de los encuestados a partir de la cual realizaremos un examen crítico tanto de la realidad de las agresiones como del marco normativo que hemos expuesto en el apartado anterior, incluyendo una aplicación práctica de la actuación preventiva, patrimonial y sancionadora de la Administración tomando como referencia un supuesto concreto: el asesinato de Doña Eugenia Moreno en la Comunidad Autónoma de Murcia (Moratalla, año 2009). 


\section{LAS AGRESIONES EN LOS DISTINTOS ORDENAMIENTOS}

\section{CONSIDERACIONES SOBRE EL DERECHO LABORAL ANTE LAS AGRESIONES AL PERSONAL SANITARIO.}

El Derecho Laboral se proyecta en las agresiones a los profesionales sanitarios a través de tres núcleos jurídicos fundamentales: la prevención de riesgos laborales, la institución del accidente de trabajo y la responsabilidad empresarial en los órdenes laboral y de Seguridad Social, penal y administrativo.

En primer lugar, el derecho a la salud y la seguridad de los trabajadores ${ }^{357}$-reconocido constitucionalmente- se conforma como la piedra angular que determina todo el sistema de Prevención de Riesgos Laborales ${ }^{358}$. Este sistema está constituido por una serie de disposiciones, encabezadas por la LPRL de $1995^{359}$-norma básica y normativa laboral-, que configura el régimen general en esta materia. Así mismo es norma básica en Derecho administrativo, por alcanzar también al régimen de prevención de riesgos de los funcionarios y el personal estatutario (en cuanto que estos colectivos son también trabajadores por cuenta ajena y entran, por ello, en el ámbito de aplicación de la Ley).

Pues bien, las agresiones al personal sanitario, como actos que violentan y repercuten sobre la salud y la seguridad del trabajador, se constituyen en riesgos laborales que deben ser abordados y evitados, dentro de este marco jurídico general de prevención.

Del derecho a la salud del trabajador surge el correlativo deber del empresario de garantizarlo. Este deber empresarial se traduce en una obligación general: la de procurar a sus trabajadores una protección eficaz, encaminada a evitar el riesgo en su origen. Esto significa que ese riesgo ha de ser eliminado de raíz, antes de que se materialice; es decir, hay que prevenirlo.

Por tanto, para que el empresario cumpla con esa obligación genérica, para que esa protección sea realmente «eficaz», en teoría sería exigible que los riesgos jamás se realizaran. Podríamos concluir, de hecho, que si algo ha sucedido finalmente es porque la prevención no fue eficaz.

Para dilucidar este problema debemos atender a cuál sea la naturaleza de la obligación genérica de protección empresarial. Si entendemos que nos encontramos ante una obligación de resultado,

\footnotetext{
${ }^{357}$ Se trata de un derecho básico e irrenunciable.

358 De igual forma, los Convenios y acuerdos internacionales suscritos sobre la materia, así como la normativa Comunitaria, encuadran el régimen de prevención de riesgos laborales vigente en nuestro ordenamiento jurídico.

${ }^{359}$ Complementada y reformada por la Ley 54/2003, de 12 de diciembre, de Reforma del Marco Normativo de la Prevención de Riesgos Laborales.
} 
la doctrina antes expuesta sería la correcta y el empresario devendría responsable siempre que ocurra realmente el riesgo que se había pretendido evitar (puesto que la prevención no tuvo éxito).

Por el contrario, si la obligación fuera de medios, bastaría con la toma de medidas razonables para la evitación del suceso, quedando el empresario exonerado de responsabilidad si el hecho que se pretendía que no sucediera finalmente sucedió.

Un sector de la doctrina defiende la primera opción ${ }^{360}$, pero la mayoría de los autores optan por la segunda, por entender que sería una exigencia draconiana que, además, actuaría como elemento disuasor de que el empresario se involucrara realmente en la adopción de medidas preventivas ${ }^{361}$. Además, esta es la línea predominante y pacífica en la jurisprudencia.

Por ello, debe afirmarse que el empresario está obligado a tomar las medidas preventivas necesarias y eficaces para prevenir los riesgos y que con ello cumple con la obligación, por ser ésta de medios (también llamada «de riesgo»).

No obstante, observan algunos autores (Sala Franco, 2014) que no resulta fácil que el empresario se exonere de toda responsabilidad cuando se produce un daño, debido a las numerosas obligaciones de medio integradas en el deber general de protección, porque muchas obligaciones concretas son muy amplias y algo ambiguas, porque el riesgo por imprudencias del trabajador se traslada al empresario y porque la obligación empresarial tiene un carácter dinámico.

El objetivo primario en prevención es siempre eliminar el riesgo, en aplicación del principio de Derecho civil «laeterum non laedere» (Nuñez González \& Estardid Colom, 2016). Entendemos que ésta es, pues, la clave.

Por consiguiente, constituye un deber ineludible del empresario (o de la Administración Pública en el caso de que sea el empleador) proteger a sus empleados y, en este caso, a los profesionales sanitarios, frente a los riesgos que se produzcan en su entorno laboral. Y esto debe hacerlo de forma diligente.

Esa diligencia se traduce en la adopción de las medidas adecuadas y razonables para la evitación de los riesgos, no pudiéndose considerar como tales las que se ajusten a las posibilidades económicas de cada empresa, sino las que sean conformes a la «evolución técnica».

\footnotetext{
360 Principalmente, González Ortega \& Aparicio Tovar (1996) y Sempere Navarro, Cardenal Carro, \& Alzaga Ruiz (2010)(Sempere Navarro et al., 2010).

${ }^{361}$ Nuñez González \& Estardid Colom (2017) señalan que si el empresario percibe que, haga lo que haga, si cuando se produce un daño tiene siempre que responder por el mismo, decidirá no tomar medidas preventivas o hacerlo con desmotivación, puesto que no servirán nunca para exonerarle de responsabilidad.
} 
Deducimos a partir de ese planteamiento que deben usarse medidas acordes con el máximo nivel técnico de protección en cada momento.

El empresario puede incurrir en responsabilidad «in eligendo», por la adecuación a la prevención del riesgo concreto de las medidas que decidió o no implantar. También cabe la responsabilidad «in vigilando» porque debe revisar el funcionamiento de las acciones preventivas y si están o no correctamente implantadas. A todo ello se añade la obligación empresarial de realizar evaluaciones periódicas que permitan cambiar o modificar aquellas medidas que no estén funcionando correctamente.

La forma de cumplimiento de este deber genérico se concreta específicamente en la implantación de Planes de Prevención enfocados a los riesgos que se pretende evitar.

En cuanto al objetivo de nuestro trabajo, las agresiones al personal sanitario, en principio no se entendían como riesgos de tal magnitud e incidencia que requirieran de planes de prevención o protocolos específicos. Por ello, hasta un momento dado no se encuentran documentos que de forma especializada se dediquen a la prevención de agresiones a los profesionales de la salud.

Sólo cuando comienza a observarse la relevancia del problema se empiezan a elaborar protocolos de prevención de agresiones y, posterior o simultáneamente, auténticos planes de prevención encauzados a esta materia concreta.

\section{LOS PLANES DE PREVENCIÓN ESPECÍFICOS DE LAS COMUNIDADES AUTÓNOMAS}

Distintas Comunidades Autónomas han ido desarrollando una amplia actividad en este sentido, con la adopción de Planes de Prevención dirigidos de forma específica a la prevención de las agresiones al personal sanitario a su servicio.

Para evaluar su incidencia, tomamos una muestra de los Planes de Prevención y documentos de desarrollo y aplicación de los mismos de diez Comunidades Autónomas ${ }^{362}$, seleccionadas por lo temprano de su reacción ante el problema o por las innovaciones que posteriormente pudieron aportar a los materiales anteriores.

Después de proceder a su análisis y comparación, con el fin de contrastar los distintos mecanismos y medidas que hayan podido implantar y si existen diferencias sustanciales entre los diferentes Planes, hemos comprobado que, en realidad, la propuesta de las medidas concretas depende

362 Madrid, Murcia, Castilla y León, Aragón, La Rioja, Valencia, Andalucía, Cantabria, Castilla-La Mancha y Navarra. 
básicamente de la fecha en que fueron aprobados: conforme pasa el tiempo, las Comunidades Autónomas van incorporando más herramientas de prevención que las que figuraban en los primeros Planes.

Las justificaciones para la aprobación de los distintos documentos -cuando se incluyen- son similares, subrayando en todos ellos la importancia del problema.

Murcia (2005), por ser una de las primeras que adopta un PPRL específico contra las agresiones al personal sanitario, lo califica de «problema emergente».

Madrid, un año antes, ya manifestaba en sus «Directrices y líneas generales para la elaboración de los planes de prevención y atención frente a potenciales situaciones conflictivas con los ciudadanos» que existía una gran preocupación por el aumento de la tensión en el trato ciudadanos-profesionales sanitarios.

Aragón (2006) ponía de manifiesto su rechazo a la violencia, conectando las agresiones a la presión asistencial y a las situaciones de fuerte emotividad que se dan en el ámbito clínico.

La Rioja (2008) expresa la necesidad de actuar específicamente en el sector sanitario, puesto que ahí el capital humano es el «verdadero motor de la empresa».

Valencia (2009) afirma haber tomado medidas a raíz de la llamada de atención por parte de la OIT sobre el aumento de la violencia en el trabajo.

Andalucía (2012) lo califica de fenómeno multifactorial que no sólo afecta al ámbito sanitario, reconociendo la gravedad del problema (algo que también hace Cantabria (2014), añadiendo que efectuará una política de «tolerancia cero» ante las agresiones).

El contenido de las acciones contempladas en estos Planes de Prevención específicos podría estructurarse del modo que se ilustra en el Gráfico 27. «Estructura-tipo de los Planes de Prevención específicos contra las agresiones al personal sanitario». 


\section{Gráfico 27. Estructura-tipo de los Planes de Prevención específicos contra las agresiones al personal sanitario}

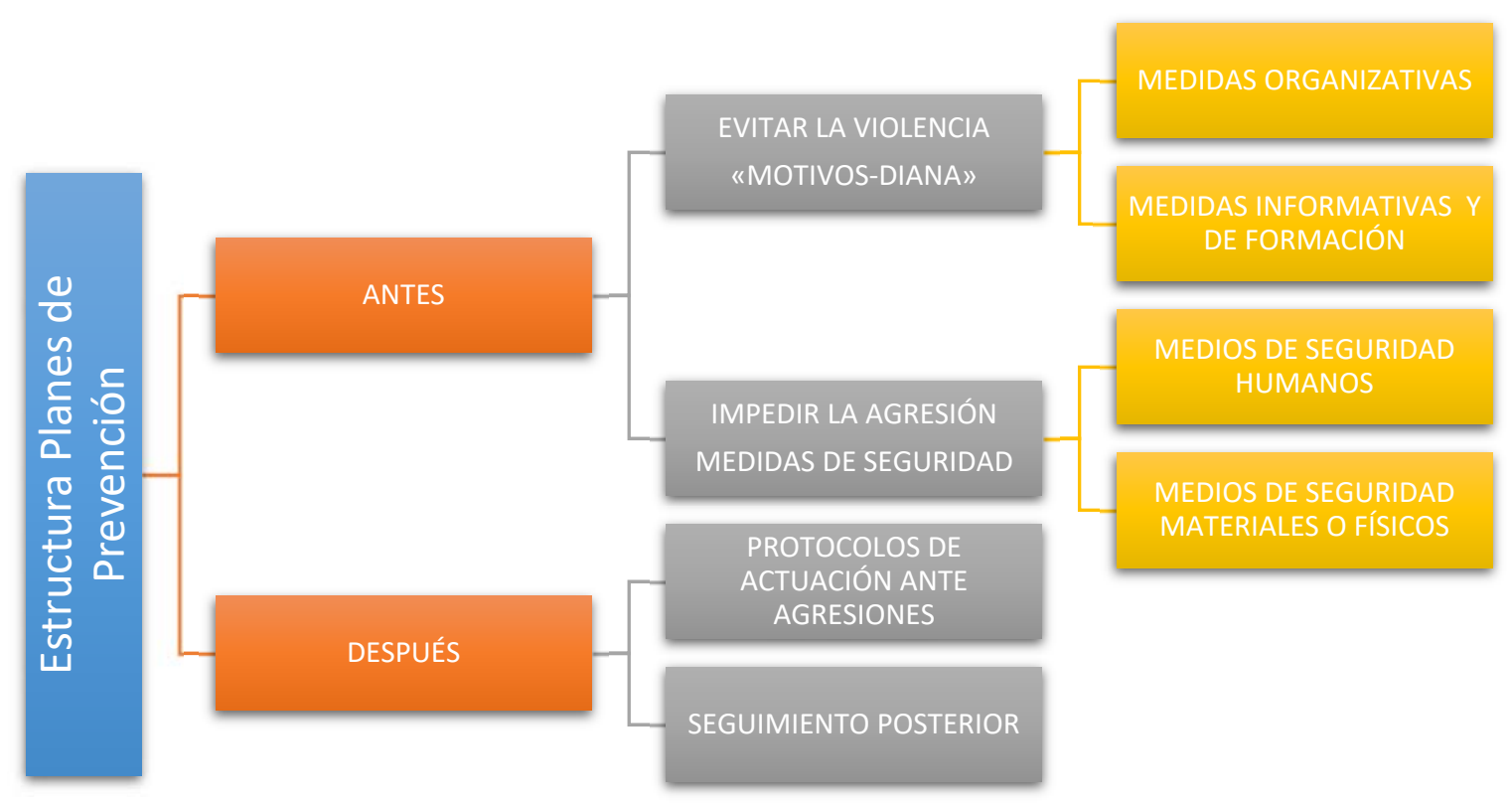

Como puede comprobarse en este gráfico, inicialmente se establecen dos tiempos de actuación: anteriores y posteriores a la agresión (si ésta se produce).

- En cuanto a las actuaciones anteriores a la eventual producción de un episodio de violencia, nos encontramos con dos tipos diferentes:

En primer lugar, unas medidas que responden a los objetivos básicos establecidos en los Planes de Prevención: evitar el riesgo incluso antes de que el riesgo se produzca. Son actuaciones eminentemente preventivas y orientadas a que la agresión no se manifieste ni siquiera como posibilidad («motivos-diana»).

En segundo lugar, se establecen medidas de seguridad (que a su vez serán activas y pasivas) en orden a la protección del profesional ante la manifestación de la agresión, para frenarla antes de que se produzca, porque ya ha surgido esa posibilidad.

- Las actuaciones posteriores (cuando no ha sido posible evitar la agresión) son de dos clases: las determinadas en los distintos protocolos de actuación y las de seguimiento posterior.

Vamos a sintetizar a continuación los puntos más relevantes del contenido y estructura de esas medidas, valorando su posible eficacia en cuanto a lograr los objetivos que se proponen. 


\section{ACTUACIONES PREVIAS: EVITAR LA AGRESIÓN.}

\section{1/ Actuaciones previas: "motivos-diana» (identificación de los riesgos e implantación de acciones concretas).}

El objetivo de estas actuaciones es la supresión «ab initio» del eventual comportamiento agresivo. $\mathrm{Su}$ construcción está dirigida por las posibles motivaciones de las conductas violentas, que se constituyen en «dianas» donde dirigir la actuación para eliminar el riesgo en origen.

Hemos de aclarar previamente que en este contexto entendemos por «dianas» los riesgos identificados.

Así, la insatisfacción del usuario, que puede terminar generando un episodio de violencia, está provocada por varios posibles «motivos-diana»: largos tiempos de espera, expectativas desproporcionadas, espacios incómodos, sensación de desatención y abandono, percepción de mala calidad de la asistencia recibida, etc.

Contra estas «dianas» se dirigirán dos grupos de actuaciones (medidas organizativas y medidas de formación y sensibilización), que serán concretadas en acciones específicas: mejora de la información al usuario, adecuación de salas de espera, formación en comunicación de los profesionales, aumento de medios materiales y humanos, etc.

Por lo tanto, en cuanto a las medidas dirigidas a la supresión de la conducta violenta los distintos Planes de Prevención señalan los motivos que generan la diana (es decir, el riesgo) hacia la cual dirigir las acciones concretas.

Debemos dejar aparte comentarios sobre los condicionantes culturales genéricos que promocionan la violencia en todos los ámbitos sociales, porque se sitúan en el universo de las reflexiones abstractas y no llevan a la concreción de actuación alguna ${ }^{363}$.

¿Cómo y cuáles son esos «motivos-diana»? Este es el interrogante que nos planteamos para poder luego comprender cuáles serán las medidas concretas a adoptar.

La lógica de nuestra argumentación es la siguiente: si identificamos el motivo por el que se producen las agresiones, podemos «disparar» contra esa diana y resultaría coherente esperar que ese riesgo quedara neutralizado.

\footnotetext{
${ }^{363}$ El Plan de la Comunidad murciana (2005) manifiesta que lo que sucede es fruto de una pérdida progresiva de valores en una sociedad que fomenta el uso de la violencia para solucionar conflictos; en parecidos términos se expresa el documento de Andalucía (2012), que achaca las agresiones a un complejo de factores sociales y culturales de complicado abordaje.
} 
Los «motivos-diana» bajo los que actúan los Planes de Prevención se pueden agrupar en varios núcleos:

1. Expectativas irreales de los usuarios fomentadas por la creencia de que la medicina es omnipotente, de una mayor disponibilidad de recursos que los verdaderamente disponibles y una supra-valoración de sus propios derechos.

2. Fallos en comunicación administrativa y sanitaria, teniendo además en cuenta que en ciertas situaciones se produce un clima de ansiedad que dificulta la comunicación.

3. Percepción de ser tratado de forma deficiente o directamente maltratado.

4. Saturación del sistema y necesidad de mayores medios materiales y personales para mantener la calidad del servicio.

5. Otras situaciones virtualmente generadoras de violencia, pero de difícil predicción (por ejemplo, entornos socio-económicos conflictivos).

En realidad, todos estos motivos podrían englobarse en uno solo y general: la insatisfacción del usuario con el servicio prestado.

Lo que ocurre es que todas estas cuestiones precisan medidas de diferente carácter: la mayor parte de ellas serán de tipo organizativo, otras necesitarán de la mejora de la formación de los profesionales y de la información prestada al ciudadano.

Podríamos agrupar las actuaciones propuestas de carácter organizativo que hemos encontrado en estos Planes de Prevención en varios núcleos de acciones que se enfocan a los objetivos-diana antes mencionados (Ver Gráfico 28. Medidas previas: evitar el riesgo actuando sobre los «motivos-diana». Pág. 387).

A continuación, haremos una síntesis de las medidas previstas en los distintos Planes (cuestión que se desarrolla con amplitud y detalle en «Los Planes de Prevención de agresiones a los profesionales sanitarios»).

1. Información al usuario: aquí tenemos un abanico de dianas a alcanzar.

a. Debe instaurarse una comunicación asistencial correcta, explicando fiable y comprensiblemente lo que el paciente y/o acompañante tiene que saber sobre el proceso clínico de que se trate: razonar los motivos de las decisiones tomadas, responder preguntas y solventar dudas de forma inteligible y siempre motivada.

b. La información en cuanto al funcionamiento del sistema debe ser clara: ha de dotarse al ciudadano de una visión realista respecto a los recursos disponibles y la limitación de los mismos. Esta información tiene que ser, igualmente, muy 
clara y razonada, en lo referente a las reglas de funcionamiento de los centros y servicios.

c. El ciudadano ha de tener constancia de sus derechos y deberes, y se le debe ofrecer también información al respecto. Algunos Planes de Prevención hacen hincapié en lo imprescindible de informar sobre los cauces de reclamación y mejorar los servicios de Atención al Usuario, en cuanto son el eslabón intermediario de quejas y conflictos ${ }^{364}$. Del mismo modo, se contempla la posibilidad de incluir en la información al ciudadano las posibles medidas sancionadoras que pueden adoptarse en caso de agresión ${ }^{365}$.

En materia de información, insistimos en que lo crucial es que sea siempre razonada, que el usuario pueda percibir que detrás de las normas y de las decisiones clínicas u organizativas existen motivos de peso para que éstas sean adoptadas. Es importante también que el paciente se sienta seguro, no abandonado por un sistema complejo que no conoce y que le resulta extraño e incomprensible. Algunos Planes llaman la atención sobre la necesidad de formar a los profesionales en comunicación asistencial (Aragón, entre otros).

La información debe alcanzar a situaciones concretas y especialmente estresantes: las esperas en urgencias sin que los acompañantes del familiar enfermo tengan noticias de su estado de salud (por ejemplo) puede desencadenar situaciones violentas que podrían haberse evitado con una información periódica ${ }^{366}$. En algunos documentos se prevé la instalación de monitores que emitan información regular sobre estos aspectos en las salas de espera.

En cuanto a la información sobre derechos y deberes, puede incluirse también la adopción de campañas informativas. Por ejemplo, Castilla y León establece la realización de una campaña de sensibilización con la finalidad de que propulsar una «cultura y conducta preventiva frente a las agresiones».

\footnotetext{
${ }^{364}$ Resulta un aspecto muy interesante, que destaca concretamente el Plan de Cantabria (2014). En efecto, se debería prestar una gran atención a los servicios de atención al paciente, porque en realidad un buen funcionamiento de los mismos generaría en los usuarios la percepción de que sus reclamaciones son tenidas en cuenta y solucionadas, lo que probablemente eliminaría muchas acciones violentas (las que se producen porque el ciudadano percibe que una reclamación por los cauces oficiales no va a servir para nada).

${ }^{365}$ Nada impide que se advierta de las consecuencias de las actuaciones ilícitas, y quizás ejercería en algunos agresores un efecto disuasorio.

${ }^{366}$ El Plan de La Rioja determina que habrá una persona en los servicios de Urgencias específicamente dedicada a proporcionar información periódica a los acompañantes. Igualmente garantiza que, en consultas programadas y procesos sometidos a listas de espera, se mantendrá informado al interesado sobre la situación en que se encuentra.
} 
2. Mejora de la calidad del servicio:

a. Perfeccionar el sistema de citas, mediante una planificación más eficiente y con expresa mención en algunos Planes de una adecuación de la plantilla administrativa (Madrid, Murcia y La Rioja, entre otros ${ }^{367}$ ).

b. Reducir el tiempo de espera en las consultas, evitando interrupciones y «optimizando» los tiempos de atención (Murcia, Madrid, etc.). La Comunidad de Madrid pretende implantar agendas de calidad en los Centros de Salud, formando en gestión a los profesionales «para adecuar el tiempo de cita a las necesidades de los ciudadanos».

En este aspecto resulta de interés destacar que lo que parece formularse son objetivos, pero las actuaciones con las que se pretende llegar a esos fines son indirectas: no se adoptan acciones claras y precisas que digan qué se va a hacer concretamente para mejorar esos tiempos de atención.

Quizá la planificación de Madrid ofrezca un punto concreto: «adecuar las plantillas de los centros a las necesidades de atención, de conformidad con los planes y programas que a este respecto se establezcan por la Consejería de Sanidad y Consumo ${ }^{368} »$, con lo que al menos sabemos que se va a actuar sobre las plantillas de personal y se reconoce de alguna manera que es necesario más medios humanos para atender a la demanda.

Por otro lado, las manifestaciones de algunos Planes de Prevención (Madrid y Murcia, entre ellos) parecen indicar que las demoras en la asistencia obedecen a la existencia de interrupciones y a la falta de tiempo para atender correctamente a cada paciente. Un hecho que se soslaya es que, con menos citas, se puede dar a la consulta un tiempo adecuado sin necesidad de hacer esperar al resto de los pacientes. Pero ello sólo sería posible con un aumento de medios personales.

Es decir, sería necesaria en nuestra opinión, una nueva medida que, como podemos comprobar, se reconoce indirectamente en algunos Planes pero no se lleva a efecto en la práctica: el incremento de los efectivos humanos.

\footnotetext{
${ }^{367}$ La Rioja habla de «dimensionar» las plantillas, lo que parece referirse a un cambio de tamaño en las mismas, aunque sin aclarar si se van a aumentar o no.

${ }^{368}$ Referencia actualizada a «Consejería de Sanidad», efectuada por la Disposición Adicional Única («Actualización de referencias») de la Orden 370/2017, de 24 de abril, del Consejero de Sanidad.
} 
3. Adecuación de espacios físicos:

a. Se trata de dotar a los centros de condiciones ambientales adecuadas, que reduzcan el estrés y la posibilidad de que se produzcan brotes de violencia (porque un entorno agradable, al menos en teoría, es menos proclive a generar descontento y agresividad). Una de las medidas es que las salas deben ser espaciosas y tranquilas, con mobiliario ligero, (Madrid y Aragón, entre otros). La Rioja (2008) presta especial atención a las salas de espera, «dadas las especiales circunstancias emocionales que ante situaciones de gravedad clínica se dan en estos espacios». Resulta también importante el mantenimiento de un ambiente tranquilo y confortable, evitando el exceso de ruido, calor excesivo y otros aspectos que puedan elevar los niveles de irritabilidad.

b. Dotación de los espacios con máquinas expendedoras de bebida y comida, acceso a lavabos, teléfonos públicos, etc.

Entendemos que, en todo caso, habrá que tener en cuenta las restricciones que determina la legislación sobre la dispensación de cierto tipo de productos, como el alcohol o el tabaco en determinados lugares (entre los que se encuentra los centros sanitarios).

c. Algunos Planes relacionan estas medidas con la instalación de pantallas para la difusión de mensajes sanitarios e información en torno al uso adecuado de Centros y Servicios (lo que incidiría en las medidas del punto 2.b).

d. La adecuación de las instalaciones se prevé en algunos Planes tanto en las reformas a realizar en los espacios físicos ya existentes, como en la toma en consideración de todos estos factores a la hora de diseñar nuevas construcciones e instalaciones.

En resumen, con las medidas contenidas en este tercer grupo, lo fundamental es aumentar el confort de las instalaciones, procurando que el ambiente donde se desarrollan las actividades clínicas o las esperas de los usuarios sea lo más agradable posible.

En el siguiente gráfico recogemos el conjunto de estas medidas que en los Planes de Prevención analizados se han generado con el objetivo de hacer frente a los «motivos-diana». 
Gráfico 28. Medidas previas: evitar el riesgo actuando sobre los «motivos-diana».
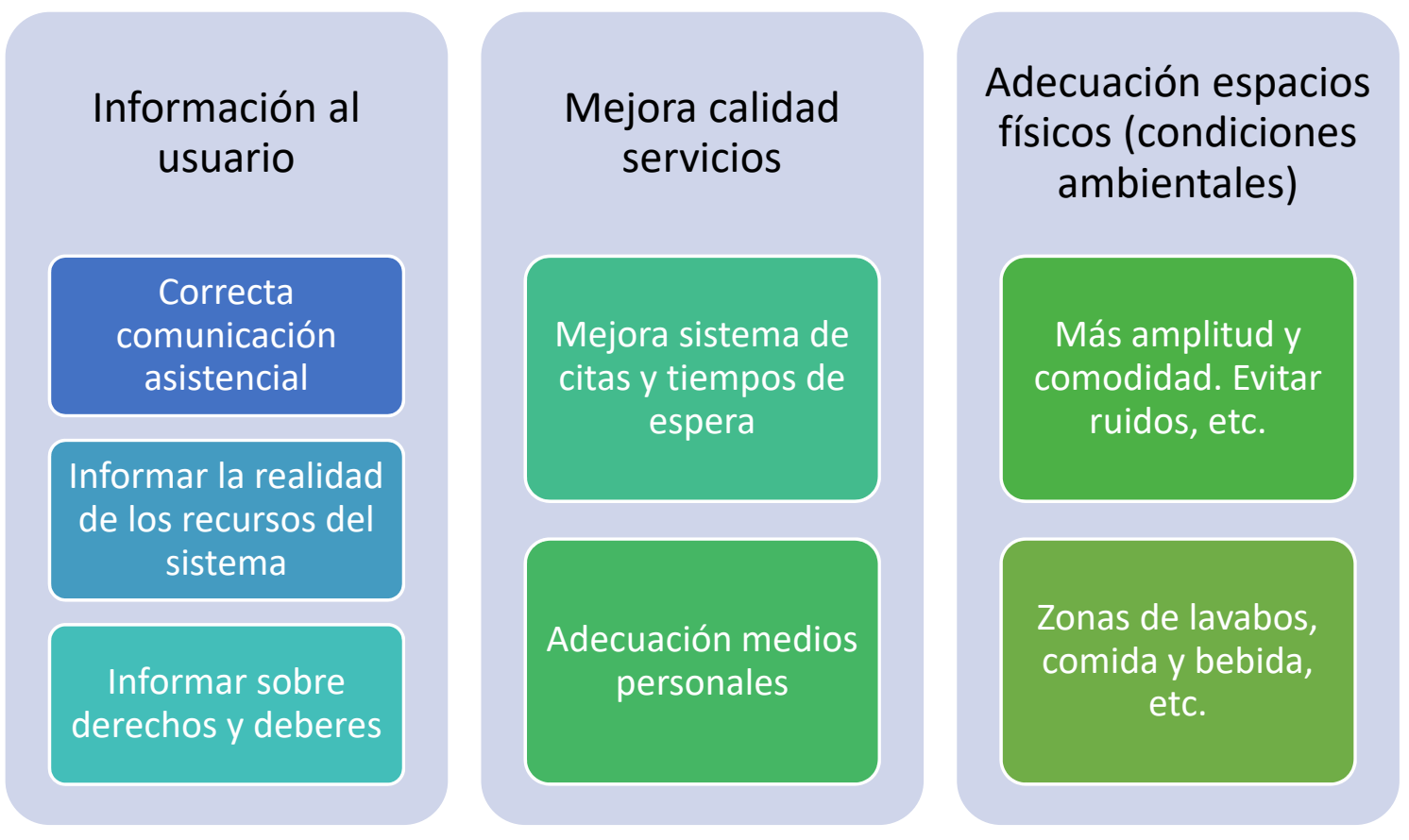

\section{2/ Actuaciones previas: medidas de seguridad.}

Las medidas de seguridad están encauzadas a evitar la agresión cuando está a punto de producirse, es decir, cuando ya no se trata sólo de una posibilidad.

La clasificación clásica de estas medidas se basa en distinguir entre seguridad activa y seguridad pasiva. También algunos Planes (por ejemplo, Madrid, 2004) distinguen entre la protección dispensada a los profesionales cuando prestan servicios en los centros sanitarios y cuando lo hacen en el domicilio del paciente ${ }^{369}$.

Para la sistematización de estas medidas que planteamos a continuación, hemos preferido no utilizar la clásica clasificación entre seguridad activa y pasiva, sino que atendemos preferentemente al agente que provee la seguridad. Siguiendo este criterio, podemos diferenciarlas en medios humanos y medios físicos, según sea humano o material el medio empleado (Ver Gráfico 29. Seguridad: medios humanos y físicos. p.390).

\footnotetext{
${ }^{369}$ La causa de estas diferenciaciones reside en la mayor vulnerabilidad del personal sanitario que presta asistencia domiciliaria: se encuentra en un entorno ajeno, con ciertas posibilidades de incomunicación y sin conocer el espacio, ni el entorno, ni la situación con la que va a encontrarse. En la mayoría de las ocasiones, se insiste que este tipo de asistencia se realice en compañía (algo bastante improbable de conseguir en los casos en que el personal de Atención Primaria acude a atender a un paciente a su domicilio).
} 
Los medios humanos que pueden intervenir en la medida de seguridad serán, en primer lugar, los servicios de vigilancia contratados y la colaboración con las Fuerzas y Cuerpos de Seguridad (estatales, autonómicas y locales).

Hemos comprobado que la contratación de servicios de vigilancia y seguridad están contemplados en la práctica totalidad de los Planes de Prevención. Distinguen entre dos modalidades contractuales: en ruta y guardia permanente. La modalidad de guardia permanente se implanta en los centros y servicios que han sido calificados como de máxima conflictividad, según los mapas de riesgo que se establecen.

Son servicios de interés relevante. Entendemos que esa relevancia se pone de manifiesto en el hecho de que algunos de los Planes (La Rioja, Cantabria, entre otros) insisten en que se fijen específicamente las funciones de estos servicios en los pliegos de cláusulas administrativas y que también se recojan en el contrato correspondiente con el mayor detalle (Andalucía, 2012).

En cuanto a la colaboración con las Fuerzas y Cuerpos de Seguridad, constatamos que se suelen establecer también en todos los Planes. De especial mención resulta quizás, por su desarrollo más preciso, lo previsto por el Plan de La Rioja (2008), que especifica actuaciones concretas como: planes de actuación con participación de las Fuerzas y Cuerpos de Seguridad, jornadas conjuntas de colaboración o sistemas de comunicación directa. En este sentido, recientemente, el Ministerio del Interior ha establecido un protocolo de cara a la colaboración estrecha de los las fuerzas y cuerpos de seguridad del Estado en este tema ${ }^{370}$.

Otra medida de seguridad que se observa en varios planes (como en el de Madrid, Aragón y Andalucía, entre otros), es el acompañamiento por parte de otro profesional sanitario tanto en consulta como en atención domiciliaria, siempre en caso de que el usuario haya mostrado con anterioridad comportamientos inadecuados.

$\mathrm{Al}$ respecto de la atención domiciliaria, se destacan algunas especialidades en dos Planes: el de Andalucía y el de Cantabria.

En el Plan de Andalucía, se contempla la adopción de acciones en caso de asistencia en «zonas con necesidades de transformación social». Creemos de interés resaltar que no se llegan a concretar las acciones a adoptar $\mathrm{y}$, también, la terminología con la que se refiere a zonas conflictivas denominándolas: «zonas con necesidades de transformación social».

\footnotetext{
370 «Interior se compromete con un protocolo de actuación de la policía y guardia civil contra agresiones a sanitarios» (OMC, 2017).
} 
En cuanto al Plan de Cantabria (2014), concreta medidas extremas a adoptar: prevé visitas acompañadas por la Policía o Guardia Civil cuando la prestación de la asistencia sanitaria implique riesgo de cierta entidad y la constancia en el centro de la dirección y teléfono del paciente a visitar, así como de la hora de salida y la hora prevista de retorno del equipo sanitario.

Por último, incluimos la formación de los profesionales en el manejo de situaciones conflictivas en este apartado porque, en realidad, se trata de una medida de seguridad en que el agente es humano, aunque se trate del propio interesado y sea un medio de autodefensa. La mayoría de los Planes contemplan esta perspectiva e, incluso, algunos de ellos recogen en sus textos amplios repertorios de recomendaciones de actuación ante un episodio violento (para el desarrollo detallado de algunos de estos Planes remitimos al capítulo dedicado a este tema).

Los medios físicos comprenden la instalación de una serie de medidas, algunas de ellas instrumentales o de tipo técnico. Destacaremos sólo las más utilizadas:

- Dispositivos de alarma de incidencias: teléfonos, interfonos, etc., a veces conectados al sistema de seguridad del centro (Planes de Madrid, Murcia, Andalucía, etc.). Son lo que comúnmente ha venido a llamarse «botones antipánico» o «botones de alarma», que el profesional acciona cuando se ve en peligro para que otras personas (el servicio de seguridad si existe en el centro) acudan a ayudarle.

Consideramos interesante destacar, en este aspecto, la observación que se realiza en el Plan de Aragón (2006) de que ese aviso sea silencioso y discreto «para no facilitar la escalada de la violencia».

- Salidas alternativas de las consultas o disposición de las salas que permita una huida fácil.

- Videocámaras de grabación.

En nuestra opinión resulta imprescindible observar que estos dispositivos no pueden ser instalados en cualquier parte, debido al necesario respeto a la intimidad de las personas ${ }^{371}$. Por otra parte, a modo de anécdota, cabe señalar que el Plan de Murcia (2005) insinúa la posibilidad de instalar webcams en vez de videocámaras, por ser las primeras más baratas.

Para concluir, incluimos el siguiente gráfico en el que recogemos el conjunto de estas medidas:

\footnotetext{
${ }^{371}$ Habrá de estarse a lo dispuesto en la Ley Orgánica 15/1999, de 13 de diciembre de protección de los datos de carácter personal (LOPD) y Ley 5/2014, de 4 de abril, de Seguridad Privada. BOE núm. 83, de 5 de abril de 2014, págs. 28975 a 29024 .
} 
Gráfico 29. Seguridad: medios humanos y físicos.

\section{Medios humanos}

- Vigilancia de seguridad.

- Colaboración con fuerzas y cuerpos de seguridad.

- Acompañamiento de otros profesionales.

- Formación en resolución de situaciones conflictivas.

- Internamiento de pacientes psiquiátricos (art. 763 LEC).
Medios físicos

- Dispositivos de alarma de incidencias.

- Buscapersonas, telepresencia, teléfono móvil...

- Salidas alternativas.

- Videocámaras.

\section{ACTUACIONES POSTERIORES A LA AGRESIÓN}

Tras la agresión, cuando ésta no ha podido evitarse, deben entrar en juego las medidas posteriores al hecho. Las actuaciones que prevén los Planes de Prevención se recogen en dos grupos:

a) Protocolos de actuación ante agresiones.

b) Seguimiento posterior.

El seguimiento posterior se orienta hacia acciones que evalúen todo lo que se hizo en su momento y valoren futuras posibilidades de actuación.

Las ideas clave de estas medidas para el seguimiento posterior a la producción de una agresión son: no dejar abandonado al profesional que sufre la agresión y, además, extraer enseñanzas de lo sucedido para abordar otras situaciones.

Los protocolos de actuación comparten la misma finalidad: dado que no se pudo evitar, resulta imprescindible reaccionar ante lo acontecido.

De entre todos los protocolos que se examinan detalladamente en el epígrafe correspondiente, debemos seleccionar el diseñado por la Comunidad Autónoma de Castilla y León porque es el ámbito Autonómico en el que se integran los profesionales encuestados y, lógicamente, su valoración estará referida a esa actuación concreta. 
Por ello, es este protocolo el que debemos tomar como referencia de la evaluación llevada a cabo por nuestros entrevistados.

El desarrollo detallado del Protocolo de Actuación ante agresiones al personal sanitario de Castilla y León se encuentra en el capítulo en que tratamos la normativa dictada por esta Comunidad Autónoma («Marco normativo de agresiones al personal sanitario en la Comunidad Autónoma de Castilla y León»).

Aquí nos limitaremos a mostrar un esquema que comprenda las actuaciones previstas en el mismo, para que sirva de síntesis clarificadora de dichas actuaciones y, a la vez, de conexión con las valoraciones que respecto a ellas se hayan reflejado en nuestra encuesta. 
Gráfico 30. Protocolo ante agresiones del SACYL

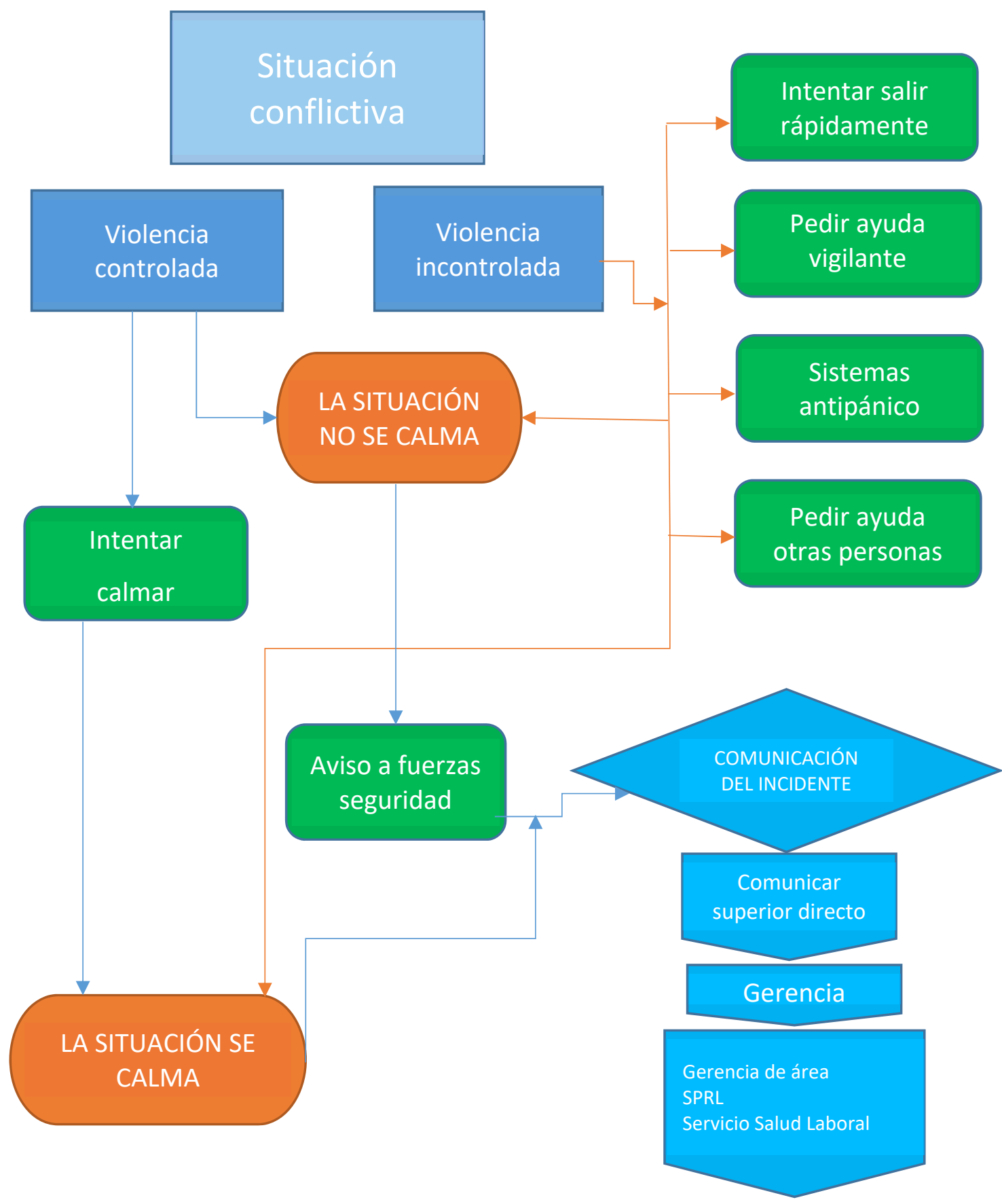

De entre todas esas actuaciones, nos interesa destacar los pasos a seguir cuando, una vez producida la agresión, el trabajador que la ha sufrido lo comunica a su inmediato superior. Recibida la comunicación, éste hará lo siguiente:

1. Facilitar asistencia sanitaria y/o psicológica si es necesaria de modo inmediato.

2. Solicitar el correspondiente parte de lesiones en caso de que éstas se hayan producido. 
3. Comunicar la agresión a la Gerencia que corresponda. La actuación de la Gerencia se describe en el gráfico que se muestra a continuación.

Gráfico 31. Actuaciones de la Gerencia tras serle notificada una agresión.

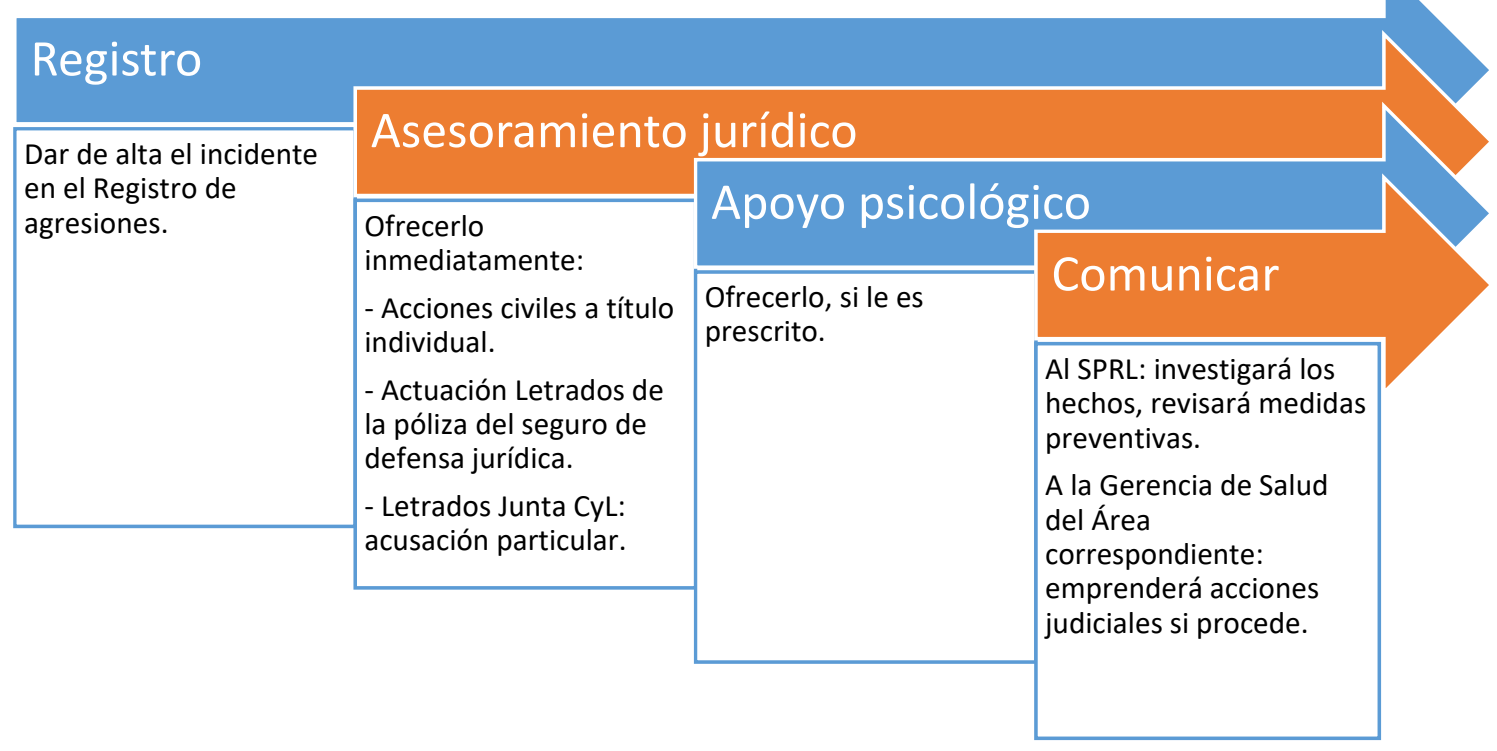

\section{EL ACCIDENTE DE TRABAJO}

Como ya adelantamos en el capítulo correspondiente -al proceder al estudio detallado de esta figura jurídica-, nada obsta a que una agresión por parte de un usuario hacia un profesional de la sanidad sea considerada como accidente de trabajo, siempre y cuando, claro está, se cumplan los requisitos pertinentes ${ }^{372}$.

Debe observarse que no toda agresión será siempre un accidente de trabajo, por faltar alguno de los componentes fundamentales del mismo.

El accidente de trabajo es una institución jurídica que se dirige a la protección del trabajador cuando éste sufre un daño provocado por su actividad laboral. Pero para que una agresión o cualquier otro incidente pueda tener tal calificación, es necesario que se presenten una serie de elementos constitutivos de la propia figura, que valoramos a continuación en conexión con el tema de nuestro estudio.

\footnotetext{
372 El Pacto contra agresiones del SACYL contempla explícitamente la calificación automática de la lesión sufrida como consecuencia de una agresión como accidente de trabajo.
} 
En primer lugar, tiene que haberse producido una lesión o daño, que suponga «cualquier menoscabo» físico o psíquico sobre la salud del trabajador ${ }^{373}$, pero ese menoscabo debe venir originado como consecuencia del trabajo (elemento objetivo).

No obstante, conviene aclarar que tal exigencia no es estricta, puesto que la jurisprudencia acepta el accidente de trabajo en sentido propio (el producido como consecuencia directa del trabajo), pero también en sentido impropio (esto es, cuando el accidente no hubiera tenido lugar de no mediar el trabajo, aunque no haya sido éste su causa directa).

Por ello, se consideran accidentes de trabajo las enfermedades de trabajo (las contraídas por razón del trabajo y que no estén consideradas como enfermedades profesionales). De igual modo, también lo son las enfermedades anteriores agravadas (las que se padecían con anterioridad al suceso y que se han agravado, agudizado o desencadenado por el mismo) y las enfermedades intercurrentes (aquellas que, existiendo una patología previa generada por el accidente, se han complicado o contraído en el medio concreto en que se encontraba el paciente para su curación: infecciones hospitalarias, efectos secundarios no previstos, errores de diagnóstico, etc.).

El elemento subjetivo del accidente de trabajo lo constituye la actividad por cuenta ajena del empleado, esto es, actuar bajo la sujeción a una dirección empresarial.

No es necesario que la relación sea estrictamente laboral. Esto quiere decir que la naturaleza de la relación de trabajo por cuenta ajena puede ser de tipo administrativo, mercantil, etc.

Por esta razón, los profesionales sanitarios, objeto de nuestro estudio, quedan incluidos en el ámbito del accidente de trabajo, ya sea su relación de tipo laboral o estatutaria.

No es óbice que la relación sea a tiempo parcial o eventual, aunque debe estar en vigor en el momento de producirse el accidente. Tampoco se excluiría al facultativo que ejerce su actividad clínica exclusivamente por cuenta propia en su consulta privada (siempre que esté encuadrado en el Régimen de trabajadores autónomos, puesto que éstos también se encuentran incluidos, aunque con ciertos matices). Y, desde luego, quedarían igualmente dentro de su ámbito de protección los empleados del citado facultativo - enfermeras, auxiliares, recepcionistas, etc.-, como trabajadores por cuenta ajena que son.

\footnotetext{
${ }^{373}$ Entre otras, la STS de 27 de octubre de 1992, aclara que comprende «cualquier menoscabo físico o fisiológico que incida en el desarrollo funcional».
} 
Así mismo y, por último, además de los elementos objetivo y subjetivo, es necesario que exista un nexo causal o relación de causalidad entre el evento producido y la actividad laboral (es decir, que el suceso haya acontecido «con ocasión» del trabajo).

Esta expresión («con ocasión») hace que la relación causal sea flexible, permitiéndose que no necesariamente deba ser el trabajo el causante de la lesión, sino que es suficiente con la exposición a riesgos derivados de la actividad laboral (causalidad indirecta).

Pudiera concluirse de este planteamiento que resulta relativamente sencillo establecer el nexo causal correspondiente. No obstante, la situación se complica un poco en caso de enfermedades de trabajo, en que debe acreditarse que la manifestación o agravamiento de la dolencia aconteció precisamente por el accidente producido.

La relación causal debe ser probada, aunque se establece una presunción legal «iuris tantum» por la que se presume que, durante el tiempo y lugar de trabajo, las lesiones sufridas por el trabajador son accidentes de trabajo. Por tanto, se produce una inversión del «onus probandi», puesto que corresponderá probar la falta del vínculo causal entre la actividad laboral y la lesión a quien niegue la existencia del accidente.

Pero para que opere esta presunción legal, las lesiones deberán producirse «durante el tiempo y lugar de trabajo».

Debemos, por tanto, estar a dos criterios: la temporalidad y la ubicación.

\section{¿Cómo se proyectan estos criterios en caso de agresiones a profesionales de la sanidad?}

Ambos concurren en las agresiones contra los profesionales de la salud cuando éstas se producen en el centro de trabajo y durante la realización del mismo (es decir, en consulta, pasillos, salas de espera, mostradores, etc.).

Ha de señalarse que, en este caso, lo importante es la estancia en el centro de trabajo, no la actividad concretamente clínica que se esté realizando. Por ello, una agresión producida en un pasillo cuando el médico se desplaza por las instalaciones o en una sala de espera, cuando la enfermera acude a llamar a los pacientes, se entendería que podría ser constitutiva de accidente de trabajo.

El criterio de que el hecho violento se produzca durante el horario de trabajo es también flexible, comprendiendo igualmente los periodos de descanso regulados dentro de la jornada laboral (imaginemos el caso de un paciente que agrede a un sanitario en la cafetería, durante ese periodo de descanso). 
Pueden plantearse algunos problemas con estos criterios. En primer lugar, en cuanto a la temporalidad, hay casos en que existe accidente de trabajo, aunque el suceso tenga lugar cuando el trabajador no se encuentre estrictamente dentro de su horario laboral. Por ejemplo: en la pausa para comer o el desplazamiento a su domicilio por esta misma causa en el periodo intermedio entre mañana y tarde. Volviendo al caso antes comentado, la agresión se produciría durante la estancia del sanitario en la cafetería, pero esta vez durante la hora de la comida.

En cuanto al requisito de ubicación del trabajador en su centro laboral cuando se produce el suceso causante de la lesión, ostenta varias excepciones específicamente contempladas: son los llamados accidentes «in itinere» y «en misión».

El accidente «in itinere» tiene lugar fuera del lugar habitual de trabajo, pero en el trayecto que media entre éste y el domicilio del trabajador. La lesión se produce cuando el empleado se desplaza hacia y desde el centro laboral a su domicilio habitual con motivo del ejercicio de sus actividades profesionales, por lo que también se denomina accidente «en ruta».

En el entorno de las agresiones al personal sanitario, para ejemplificar un posible accidente de trabajo «in itinere» podríamos recurrir a los casos en que el profesional es agredido en el parking del centro sanitario -ya fuera por incorporarse al trabajo, ya por haber finalizado su jornada laboral y emprender el camino hacia su domicilio. También, si el desplazamiento se realiza a pie, la eventual agresión producida en la vía pública cuando el profesional se dirige o regresa de su trabajo ${ }^{374}$. Precisamente en el enjuiciamiento de un caso de estas características (cuando el trabajador había finalizado su jornada laboral y se encontraba en el exterior del edificio) se produjo la trascendental STS 1030/2007, de 4 de diciembre, que es uno de los hitos en la consideración como atentado de las agresiones a los profesionales de la sanidad.

Respecto al accidente «en misión» ocurre igualmente fuera del centro de trabajo, pero en esta ocasión el empleado se desplaza para realizar tareas relacionadas con su actividad laboral.

Este sería el caso de los médicos y enfermeras de centros de salud que atienden avisos domiciliarios: salen fuera del lugar habitual donde trabajan, pero precisamente para realizar la actividad asistencial que les es propia. Una agresión acaecida en el domicilio del paciente bajo estas circunstancias sería considerada sin lugar a dudas como accidente de trabajo perteneciente a esta modalidad.

Cuestión diferente es la asistencia domiciliaria realizada por los servicios de Emergencias. Ha de tenerse en cuenta que estos profesionales no están trabajando «fuera» del lugar habitual donde

${ }^{374}$ Siempre y cuando, insistimos, la agresión tenga causa en la actividad laboral. Por ejemplo, un paciente que acecha al médico a la salida del centro sanitario para agredirle por entender que le ha producido algún agravio anteriormente. 
realizan sus actividades laborales, dado que su «puesto de trabajo» tiene como nota predominante la itinerancia: el trabajador acude donde está el problema a resolver, no permanece fijo en un lugar determinado dentro de su actividad principal. Por ello, lo acontecido durante una asistencia sanitaria en el domicilio particular del paciente por parte de los servicios de emergencia, no tendría este carácter, sino el de accidente de trabajo general, sin especialidad alguna.

Interesa señalar, llegados a este punto, la irrelevancia de la intervención de terceros ajenos a la organización para que un evento pueda ser considerado como accidente de trabajo. Igualmente improcedente resulta alegar lo impredecible del caso o su inevitabilidad: cuando se produce un daño ocasionado por el trabajo, no importa que éste haya sido casual o imprevisto. Sólo rompería el nexo causal requerido la posibilidad de que la lesión fuera infringida por motivos ajenos al trabajo. Recordaremos estas aseveraciones cuando analicemos el caso del asesinato de Moratalla, en otro apartado de esta Discusión.

En conclusión, la inmensa mayoría de las agresiones contra el personal sanitario, cuando ocurran con ocasión de su trabajo y se haya producido alguna lesión, podrán ser calificadas como accidente de trabajo.

Y esto será así siempre que el profesional afectado trabaje por cuenta ajena (y autónomos con ciertos matices), con independencia de si ejerce en el sector público o privado y de la naturaleza del contrato que le una a la empresa o Administración en la que preste sus servicios (puede ser laboral, administrativa, estatutaria...).

Resulta asimismo, reiterativo e innecesario, la aclaración que realiza el «Pacto contra agresiones» de Castilla y León, que especifica que las agresiones serán consideradas accidente de trabajo, debido a que ni añade nada nuevo, ni la Administración autonómica puede dictar normas de general aplicación de Derecho laboral (por ser competencia exclusiva del Estado) ${ }^{375}$.

\footnotetext{
375 Parece, no obstante, existir una cierta confusión sobre el tema. En 2008, el Diario El País en su versión digital, publicaba la noticia «Osakidetza considerará accidente laboral las agresiones a sus trabajadores» (El País, 2008), en referencia a las declaraciones del Servicio Vasco de Salud (conjuntas con varios sindicatos) en las que se comprometía a asumir la "plena protección y respaldo» a su personal adoptando, entre otras medidas, la consideración de las agresiones como accidente de trabajo. Como hemos podido observar, esto es del todo innecesario, puesto que ya se reputan accidentes laborales todos aquellos sucesos que cumplen con los requisitos que hemos comentado.
} 


\section{RESPONSABILIDAD EN MATERIA DE PREVENCIÓN DE RIESGOS LABORALES}

La responsabilidad en esta materia la ostenta el empleador y queda referida a dos núcleos:

- Cuando se detectan incumplimientos en la prevención de los riesgos laborales antes de que se produzca un accidente de trabajo (o se genere una enfermedad profesional). Llamaremos a estas responsabilidades «preventivas».

- Cuando el accidente de trabajo o la enfermedad profesional ya han acontecido, como consecuencia de los mencionados incumplimientos. Estas responsabilidades las denominaremos «reparadoras del daño».

Varias ramas del ordenamiento jurídico están involucradas en esta cuestión:

- Responsabilidades preventivas: Aquí es donde se despliega la materia de prevención de riesgos laborales en todo su esplendor. Corresponde su enjuiciamiento a la jurisdicción social y contencioso-administrativa.

- Responsabilidades reparadoras del daño: interviene el Derecho de Seguridad Social, Civil y Administrativo (responsabilidad patrimonial de la Administración Pública). De su enjuiciamiento se encargan los órdenes laboral, civil y contencioso-administrativo, respectivamente.

Analizaremos brevemente como operan esos diferentes tipos de responsabilidad y su posible proyección al problema de las agresiones en el ámbito sanitario.

1. Responsabilidad administrativa por incumplimiento de los deberes de prevención.

Está basada en el «ius puniendi» del Estado (que también preside las facultades punitivas que ostenta en el Derecho penal) y se dirige al castigo de las infracciones por incumplimiento del empresario de sus deberes de prevención. Se regula de forma mayoritaria en la LISOS, que contempla una serie de sanciones a este efecto, preferentemente pecuniarias.

Trataremos con más profundidad esta actividad sancionadora de la Administración cuando nos centremos en cómo actúa el Derecho administrativo contra las agresiones al personal sanitario.

Pero no debemos perder de vista que, en este apartado, la responsabilidad es exclusivamente del empresario, que será sancionado en caso de que no haya protegido a sus trabajadores con la diligencia debida de una agresión, por ejemplo. 


\section{Responsabilidad Penal.}

En materia de protección de los derechos de los trabajadores, el Código Penal dedica una serie de artículos que tipifican comportamientos ilícitos relacionados con contratación, derecho a la huelga, etc. En cuanto al tipo penal de omisión del deber protector del empresario de la seguridad de sus trabajadores, se desarrolla en el artículo 316. Se trata de un tipo penal de peligro (en PRL también se denomina «de riesgo»), por lo que para que concurra dicho tipo no es necesario que exista lesión. Si ésta se produce, será un delito de resultado.

Esta responsabilidad opera en los casos de máxima gravedad, en los que la negligencia empresarial ha sido de alta intensidad ${ }^{376}$.

\section{Responsabilidad en materia de Seguridad Social.}

Cuando se produce un daño por causa del incumplimiento del empleador de sus deberes de prevención, surge la necesidad de resarcir al trabajador lesionado y, a la vez, sancionar la conducta indebida del empresario. La figura del recargo de prestaciones cumple con esta función, ya que impone al empleador infractor un incremento del $30 \%$ al $50 \%$ en las prestaciones de la Seguridad Social.

Esta responsabilidad es compatible con cualesquiera otras de todos los órdenes (incluido el Penal).

La STSJ de Andalucía/Granada (Sala de lo Social) 1929/2015, de 8 de octubre ${ }^{377}$ es bastante clarificadora al respecto. Considera el caso de una celadora que sufrió una agresión por parte de un paciente psiquiátrico y que reclama ser resarcida por la Administración (que era su empleadora). La sentencia de instancia avala sus pretensiones, pero el INSS interpone recurso de suplicación (fue condenado (junto con el SAS) al pago de un recargo del $30 \%$ en la prestación por incapacidad permanente total percibida como consecuencia de accidente de trabajo).

En los autos se manifiesta que el paciente acudió al Servicio de Urgencias del hospital en que la celadora trabajaba, y ésta le acompañó a un box hasta que llegara el psiquiatra de guardia.

\footnotetext{
376 Imaginemos el caso hipotético del empresario sanitario que envía un equipo móvil de Emergencias a una zona conflictiva donde sabe que se está produciendo una reyerta multitudinaria y aún no ha acudido la policía. Los empleados se niegan a acudir, por el peligro cierto que supone la intervención sin cobertura policial. El empresario insiste en su orden. Pues bien, si finalmente se produce un daño o lesión, el empleador habrá incurrido en una responsabilidad penal derivada de la omisión de su deber protector (dado que ha puesto en muy grave peligro a sus trabajadores); si el daño no se produce, tampoco el empresario quedaría indemne: sería responsable en cuanto a la infracción de sus deberes de protección, y entrarían en juego las sanciones administrativas.

377 Para un desarrollo más amplio, remitimos al epígrafe «La responsabilidad en materia de Prevención de Riesgos Laborales. Los accidentes de trabajo».
} 
Mientras esperaban en el interior del box, el enfermo la atacó, tirándola al suelo e intentando estrangularla.

El tribunal considera que el protocolo de seguridad que se había implantado era manifiestamente insuficiente para prevenir la agresión y que, en el momento de la producción del mismo, el SAS carecía de PPRL al respecto. Declara por ello que la agresión sufrida tuvo como causa la carencia de medidas de seguridad efectivas, determinando el pago del recargo de prestaciones y confirmando la sentencia de instancia en su totalidad.

4. Responsabilidad civil o patrimonial.

La responsabilidad civil busca el resarcimiento de la víctima del daño, que ha de ser pleno («restitutio ad integrum»), cubriendo el daño emergente, el lucro cesante y el daño moral. Es compatible con todas las demás indemnizaciones, salvo las de Seguridad Social (tratándose de evitar el enriquecimiento injusto). Esta vía de reparación puede ejercitarse de forma acumulada a las acciones penales, pero de las pretensiones indemnizatorias derivadas de responsabilidad por incumplimiento de prevención de riesgos conocerá el orden social (y no el civil).

El responsable es, como en el resto, el empresario por el incumplimiento de sus deberes preventivos. Pero aquí hay que hacer una distinción: si el empleador es la Administración Pública se abre otra vía posible: la responsabilidad patrimonial de la Administración (que veremos con más amplitud posteriormente cuando tratemos la actuación del Derecho administrativo ante las agresiones a los profesionales sanitarios).

Lo que destacaremos aquí a este respecto es que el camino de la responsabilidad patrimonial de la Administración queda expedito para el trabajador en régimen laboral, que puede optar por reclamar ante la jurisdicción contencioso-administrativa o ante la social.

Pero en el caso de que el empleado público preste sus servicios bajo el régimen estatutario o funcionarial, no podrá elegir la jurisdicción social para reclamar la responsabilidad de su empresario (Administración), sino que tendrá que dirigirse obligatoriamente a la contenciosoadministrativa mediante un proceso de reclamación de responsabilidad patrimonial de la Administración (tras la oportuna reclamación en vía administrativa).

En la STSJ de Castilla-La Mancha (Sala de lo Social) 1532/2007, de 18 de octubre, se dirimía un caso de agresión de una paciente psiquiátrica contra una auxiliar de enfermería (con 
contrato laboral: por eso puede acudir ante esta jurisdicción). La interna arrojó varias piezas de vajilla contra la auxiliar, provocándole lesiones que derivaron en una ILT.

El tribunal de instancia consideró que existió negligencia por parte del SESCAM en su deber de prevención de riesgos laborales por las razones siguientes:

- El centro carecía de un PPRL para auxiliares.

- La trabajadora no tenía formación suficiente en prevención del riesgo específico (había hecho un curso en 2003 sobre abordaje de enfermos psiquiátricos) ${ }^{378}$.

- Contra las recomendaciones del servicio de prevención, los utensilios de comida y vajilla eran ordinarios (loza, metal), pudiendo producir cortes si se rompían, siendo además los cubiertos punzantes.

Ante estas evidencias, el tribunal «ad quem» confirma la sentencia condenatoria de instancia ${ }^{379}$.

Como última consideración ha de reflejarse el régimen especial que ostenta la Administración pública en su condición de «empresaria» responsable de la protección de la seguridad de sus trabajadores.

Las sanciones ante un eventual incumplimiento de la Administración de sus deberes de prevención no se rigen por el procedimiento general de tipo laboral ${ }^{380}$, sino por el RD 707/2002 y el RD 67/2010 381 , en el ámbito de la AGE y de aquellas Administraciones que no hayan adoptado un procedimiento propio. Tampoco es de aplicación el procedimiento general sancionador.

La Inspección de Trabajo, a diferencia de lo que ocurre cuando el empresario es privado, no tiene facultades ejecutivas, por lo que, de observarse alguna deficiencia o carencia en las actuaciones

\footnotetext{
${ }^{378}$ Como veremos más adelante, este criterio no fue de aplicación en el caso del asesinato de Moratalla, aunque resulta muy similar.

379 Para un desarrollo más amplio remitimos al epígrafe correspondiente a "La responsabilidad en materia de prevención de riesgos laborales. El accidente de trabajo».

380 Esto es, la LISOS o el RD 928/1998, de 14 de mayo, por el que se aprueba el Reglamento general sobre procedimientos para la imposición de sanciones por infracciones en el orden social y para los expedientes liquidatorios de cuotas de la Seguridad Social.

${ }^{381}$ RD 707/2002, de 19 de julio, por el que se aprueba el Reglamento sobre Procedimiento Administrativo especial de actuación de la Inspección de Trabajo y Seguridad Social y para la imposición de medidas correctoras de incumplimientos en materia de Prevención de Riesgos Laborales en el ámbito de la Administración del Estado, modificado por RD 464/2003, de 25 de abril.

RD 67/2010, de 29 de enero, de adaptación de la Legislación de Prevención de Riesgos Laborales a la Administración General del Estado.
} 
preventivas, debe limitarse a formular meras recomendaciones que la Administración puede o no seguir.

El procedimiento consiste en que la ITSS formula un requerimiento a la Administración que contiene las deficiencias observadas y las actuaciones necesarias para su subsanación. Pero no puede compeler de ninguna manera a su ejecución.

Se observa, por tanto, una diferencia sustancial en el régimen de exigencia de responsabilidades al empresario privado y a la Administración empleadora. 


\section{CONSIDERACIONES SOBRE EL TRATAMIENTO DEL DERECHO ADMINISTRATIVO DE LAS AGRESIONES A LOS PROFESIONALES DE LA SALUD}

\section{LA NORMATIVA SOBRE DERECHOS Y DEBERES DE LOS PACIENTES Y LAS AGRESIONES AL PERSONAL SANITARIO}

La base de la actuación sancionadora de la Administración contra las agresiones a los profesionales sanitarios descansa sobre la delimitación de las conductas que los pacientes y demás usuarios deben o no ejercitar en el transcurso de la asistencia clínica y demás situaciones derivadas de la misma. Esto es, la descripción de los deberes que les son propios y que van acompañados de derechos.

Como veremos, el Derecho administrativo no puede imponer sanción alguna contra una infracción que no esté debidamente tipificada. Y las infracciones, por lógica, deben descansar sobre motivos coherentes que justifiquen la prohibición de una conducta. Esas razones tienen su piedra de toque en los deberes que tienen que cumplir los ciudadanos.

La manifestación de catálogos de derechos y deberes de los pacientes tiene como antecedente remoto las declaraciones de derechos emanados de la Revolución Francesa y, tras otros hitos históricos, el documento que inicia la verdadera tendencia a una implantación general de cartas de derechos y deberes es el Convenio del Consejo de Europa, para la protección de los derechos humanos y la dignidad del ser humano con respecto a las aplicaciones de la Biología y la Medicina (llamado «Convenio de Oviedo»), de 1997.

Ese comienzo no fue más que la culminación de la transformación de la relación médico-paciente, fruto de importantes cambios sociales. Esta profunda modificación afectó a la concepción tradicional, que otorgaba al paciente un papel rotundamente pasivo, de mero receptor obediente de las prescripciones del médico. La clásica relación paternalista ha sido sustituida paulatinamente por la interacción más equilibrada, en la que el paciente ostenta un rol más activo también, que llega incluso a protagonizar de algún modo la relación asistencial.

Estas transformaciones hacen nacer nuevos retos y, desde luego, necesidades de adaptación a las nuevas situaciones. Hay quien ha visto en los cambios en la relación clínica una posible fuente de conflictos, por entender que los pacientes son más exigentes y ven a las instituciones sanitarias como generadoras inagotables de recursos siempre disponibles y a los profesionales como simples facilitadores de servicios que ellos tienen derecho a consumir ${ }^{382}$.

\footnotetext{
382 En cualquier caso, estos posibles problemas podrían tener solución si se informa correctamente a los usuarios sobre sus derechos y deberes. Como hemos visto en otro capítulo de este trabajo, ciertas LPRL prevén el desarrollo
} 
Entendemos que, en realidad, el nuevo modelo de relación no tiene por qué significar la merma en los derechos de ninguna de las partes, puesto que ambas se encuentran al mismo nivel, en una situación de igualdad ${ }^{383}$.

Dejando a un lado estas consideraciones, debemos aclarar que la naturaleza jurídica de la relación sanitaria es de tipo contractual. Esto determina que se generen una serie de derechos y obligaciones para las dos partes. Esos derechos y obligaciones están ligados de modo correlativo: a un derecho le corresponde siempre un deber y viceversa.

Podríamos decir, por consiguiente, que en ese intercambio sinalagmático «quid pro quo» los deberes se generarían en virtud de los derechos de la otra parte de manera recíproca.

Como consecuencia de esta transformación en la relación sanitaria, se fueron dictando una serie de disposiciones legales que sancionaban una serie de catálogos de derechos y deberes de los pacientes.

Algunos autores (Martínez-Jarreta, 2003) (Gascón Santos, 2006), refiriéndose a los primeros elencos de derechos y deberes, hicieron notar una cierta falta de simetría en su reconocimiento: se enumeraba una larga lista de derechos y unos pocos deberes. Esto les llevó a concluir que era necesario que se explicitaran más deberes y con ello equilibrar la situación, porque los deberes de los usuarios eran insuficientes.

En nuestra opinión, esta cuestión no es decisiva en cuanto a las agresiones a los profesionales sanitarios por varias razones:

- Primera: porque, como hemos señalado, la configuración jurídica contractual de la relación clínica hace que los derechos y deberes emanen de forma recíproca y correlativa entre ambas partes.

- Segunda: porque el primer derecho-deber que se genera en esta relación es el respeto mutuo.

- Tercera: porque, como veremos, no es necesario desarrollar un extenso catálogo de deberes para garantizar que los usuarios mantengan la consideración debida hacia el personal sanitario. Basta con unos pocos, pero que contengan la esencia del contenido de la obligación de respeto.

de programas de información a los ciudadanos sobre el funcionamiento y reglas de sus respectivos sistemas sanitarios.

${ }^{383}$ En este aspecto, coincidimos con Blas Orbán (2006). 
La razón de la distinta extensión numérica de los derechos y los deberes puede buscarse en el punto de partida, que era de inferioridad para el paciente, como hemos indicado ya.

Probablemente, en un intento de compensar la anterior situación, en la que el usuario no tenía prácticamente derechos, el legislador detalló una larga lista de ellos.

Las distintas Comunidades Autónomas han elaborado sus propios elencos de derechos y deberes y debe decirse que algunas se han extendido bastante más en materia de obligaciones. Por regla general, los catálogos de deberes son más detallados cuanto más moderna en el tiempo es la normativa en cuestión.

Hemos analizado las disposiciones referidas a este tema de diez autonomías, constatando que coinciden básicamente en los fines y motivos de promulgación de las leyes. Generalmente, suelen centrarse en la promoción de la salud, la salvaguarda de los derechos y deberes en el ámbito de la salud y la protección de la colectividad.

A nivel metodológico, clasificamos los diferentes deberes de los ciudadanos expresados en las distintas normas en los siguientes grupos (con referencia sólo a aquellos que pueden tener relación con las agresiones a los profesionales de la salud):

- Respeto al personal sanitario.

- Respeto a los demás usuarios.

- Respeto a las normas de funcionamiento de los centros.

- Uso adecuado de los recursos sanitarios.

- Buen uso de las instalaciones.

- Deberes de colaboración.

Exponemos a continuación las conclusiones a las que hemos llegado a partir del análisis de cada uno de esos grupos:

El primer apartado es el explícitamente dedicado a la garantía de la debida consideración al personal que trabaja en los centros sanitarios. En los primeros documentos, hasta el año 2010 no aparece, pero posteriormente hace su presencia en la práctica totalidad de las disposiciones estudiadas. Las redacciones en este punto son muy similares, destacando la conexión que algunos de ellas realizan con el segundo grupo: el respeto a los demás usuarios.

En efecto, se entiende que el respeto a los profesionales y al resto de los ciudadanos que acuden a recibir asistencia sanitaria están relacionados. Y esto es así porque la perturbación que suponen las situaciones de violencia afectan al buen funcionamiento de los servicios, además de que 
también pueden repercutir directamente sobre otras personas que se encuentren en las inmediaciones cuando el conflicto se produce.

Algunos PPRL destacan que hay agresiones que tienen su origen en la inobservancia intencionada de las normas del centro. El usuario infractor no acepta la imposición de esas normas y, en su intento de incumplirlas, choca con las admoniciones del personal y reacciona violentamente contra el mismo. Por ello, el deber de respeto en este punto puede ser de cierta trascendencia en materia de agresiones.

El uso adecuado de los recursos sanitarios es también una cuestión en la que inciden los PPRL, por la sensación del usuario de que tiene derecho a disponer de todos los recursos ofrecidos por el sistema de salud y que éstos son inagotables y universales. La negativa del profesional a proporcionar prestaciones demandadas puede ser también una fuente de conflicto generadora de una eventual agresión.

El buen uso de las instalaciones es un deber que aparecía desde siempre en estas disposiciones legales. Esta es la clave de la crítica, antes mencionada, de Martínez-Jarreta (2003) y Gascón Santos (2006): la inclusión de la protección al mobiliario, pero no del personal de los centros. Evidentemente, puede parecer una falta de consideración a los trabajadores, pero también ha de tenerse en cuenta que en los años en que se redactan las primeras disposiciones de derechos y deberes de los pacientes, el asunto de las agresiones al personal sanitario no tenía la consideración de incidencia grave que tiene actualmente. Seguramente esta es la razón por la que se explicitaban obligaciones de respeto a los objetos e instalaciones y no a los trabajadores.

Por último, los deberes de colaboración también tienen conexión con el tema, en el sentido de que hacen hincapié en uno de los motivos por los que se producen las agresiones: las demoras y tiempos de espera prolongados en la atención asistencial. Con el propósito de mejorar esas ratios temporales, se indica que los usuarios tienen la obligación (entre otras) de avisar cuando no puedan acudir a citas, de informar de posibles anomalías en los tiempos de citaciones, de utilizar los sistemas de aplazamiento de citas en caso de necesitar cambiar una y de mantener sus datos de contacto actualizados para recibir correctamente la información relativa a posibles cambios en estos aspectos. 


\section{EL DERECHO ADMINISTRATIVO SANCIONADOR ANTE LA VIOLENCIA CONTRA LOS PROFESIONALES DE LA SALUD}

La Administración tiene encomendada la tutela del interés público y, para ejercerla, debe establecer una serie de limitaciones a las acciones de los sujetos públicos y privados. Para hacer respetar esos límites, es necesario impedir las actuaciones que los incumplan, mediante un sistema sancionador.

El eje del sistema es la infracción, que es la conducta que incumple el mandato. Hay que destacar que la infracción debe estar debidamente tipificada, puesto que de lo contrario sería una mera contravención no sancionable.

Una vez que se ha producido esa infracción, se acompaña de la correspondiente sanción, que deberá igualmente ser concretada legalmente. Han de diferenciarse de la sanción las simples consecuencias desfavorables que pueden derivarse de una contravención o de una infracción, por no tener naturaleza sancionadora ${ }^{384}$.

La capacidad de castigar se bifurca en dos potestades: la punitiva y la sancionadora. El Derecho penal ostenta la primera y el Administrativo sancionador la segunda. Ambas se fundamentan en el «ius puniendi» del Estado.

Pero estas potestades deben tener también límites, en consideración a la garantía de los derechos fundamentales recogidos en los artículos 24, 25 y 26 de la Constitución Española.

Se configura así un sistema garantista de estos derechos, apoyado en una serie de principios similares a los recogidos para el Derecho penal y cuya finalidad es impedir la arbitrariedad.

Los principios del Derecho administrativo sancionador son decisivos en la construcción de todo el sistema y dan las claves de su funcionamiento. Por eso, creemos conveniente incluir a continuación un resumen de su contenido:

1. Principio de Legalidad (art. 25 LRJSP): Para ejercitar la potestad sancionadora dicha potestad ha de ser específicamente atribuida a una Administración pública concreta mediante una Ley formal. Las infracciones y sanciones serán fijadas con la mayor precisión posible y en todo caso debe seguirse el procedimiento correspondiente para imponer una sanción.

\footnotetext{
384 Un ejemplo podría ser la reasignación del agresor a otro centro sanitario o a otro profesional, medida que no tiene naturaleza sancionadora.
} 
2. Principio de irretroactividad (art. 26 LRJSP): Las disposiciones que tipifiquen infracciones y sanciones sólo podrán aplicarse a hechos causantes producidos tras su entrada en vigor y durante su vigencia. Los efectos favorables sí pueden ser retroactivos.

3. Principio de tipicidad (art. 27 LRJSP): Únicamente puede aplicarse una sanción a la infracción específicamente tipificada en una ley. Las dos figuras (infracción y sanción) deben estar debidamente conectadas, de forma que a una infracción corresponde una sanción concreta $^{385}$.

4. Principio de responsabilidad (art. 28 LRJSP): El sujeto debe ser responsable de la comisión de la infracción a título de dolo o culpa. No obstante, cabe la responsabilidad por inobservancia en aquellos casos en que el actor infrinja una norma que tenga el deber específico de conocer; el deber del empresario de prevención genera infracciones por incumplimiento, independientemente de la concurrencia de dolo o culpa ${ }^{386}$.

5. Principio de proporcionalidad ${ }^{387}$ (artículo 29 LRJSP): Determina la adecuación entre la gravedad de la infracción y su sanción correspondiente. En base a este principio, deben establecerse criterios de graduación en las sanciones en función de su gravedad (y por esto también se clasifican en leves, graves, muy graves).

6. Principio de prescripción (art. 30 LRJSP): Tanto las infracciones como las sanciones tienen plazos de prescripción, que pueden fijarse por las propias leyes específicas reguladoras del régimen sancionador de que se trate o remitirse a los establecidos en la LRJSP.

Junto a estos principios, contemplados en la LRJSP y de aplicación concreta al procedimiento administrativo sancionador, deben considerarse también otros cuatro principios generales:

- Principio «Non bis in idem»: Nadie puede ser sancionado más de una vez por la comisión de una infracción ${ }^{388}$. Cabe que se sigan dos procedimientos (administrativo y penal) por una misma causa, pero el administrativo deberá entrar en juego sólo cuando no haya recaído condena en el proceso penal y, en este caso, el administrativo deberá respetar los pronunciamientos sobre la narración fáctica y los hechos probados.

- Principio de presunción de inocencia: Debe contarse con una prueba de cargo válida y suficiente para enervar la presunción de inocencia. La existencia de una duda razonable activa el principio «in dubio pro reo ${ }^{389}$.

\footnotetext{
385 Se prohíbe expresamente la analogía y se permite el desarrollo de la ley mediante normas reglamentarias, pero con limitaciones.

386 Este principio informa también el Derecho penal, con matices muy parecidos, aunque en el caso del Derecho administrativo sancionador, también se incluye en su ámbito de aplicación a las personas jurídicas.

387 Deriva de la interdicción de la arbitrariedad de los poderes públicos.

388 Tampoco puede sancionarse un mismo acto en vía administrativa y penal, siempre que exista una triple identidad del acto causante: de sujeto, hecho y fundamento.

389 La carga de la prueba en el procedimiento administrativo sancionador recae sobre la Administración.
} 
- Garantías procedimentales por aplicación del derecho de defensa: Derechos de defensa y de actividad probatoria, que suponen respectivamente el derecho a ser informado de la acusación y cargos que se imputan, con carácter previo a la imposición de la sanción y la posibilidad de efectuar las alegaciones de descargo que estime procedentes.

- Principios de interdicción del «solve et repete» y de la «reformatio in peius»: No es posible la agravación de la situación del interesado durante el transcurso del procedimiento («reformatio in peius»). En cuanto al «solve et repete» (condicionar la interposición de recurso o reclamación al pago de la sanción o su depósito), debe entenderse prohibido.

Estos fundamentos e ideas clave configuran la actividad sancionadora de la Administración, que se proyecta sobre la actuación sobre los agresores en los casos de violencia contra los profesionales de la salud.

En concreto, diversas Comunidades Autónomas han dictado Leyes que tipifican como infracciones los actos violentos contra su personal sanitario, estableciendo las sanciones aplicables a la comisión de las mismas. Seleccionamos un total de nueve regímenes sancionadores para analizar su contenido y características principales (Extremadura (2001), Madrid (2001), Aragón (2002), Illes Balears (2003), Galicia (2008), Murcia (2009), Castilla-La Mancha (2010), Navarra (2010) y Castilla y León (2010).

Se utilizan dos mecanismos principalmente:

- Promulgar una ley de derechos y deberes, tipificando las infracciones por incumplimiento de los deberes y sus respectivas sanciones.

- Incluir el régimen sancionador dentro de su Ley de ordenación sanitaria (o remitir a la normativa nacional en lo relacionado con este tema, como es el caso de la Comunidad murciana).

Hemos observado una evolución en el desarrollo de estas normativas autonómicas, estableciéndose un punto de inflexión en el año 2010. Podemos fijar tres situaciones:

1. Las normativas de aparición más temprana (Madrid y Extremadura) se refieren básicamente a las «autoridades sanitarias», dejando fuera del régimen sancionador las agresiones a los profesionales de la salud que no ostentan tal condición ${ }^{390}$.

\footnotetext{
390 No debe confundirse la "autoridad sanitaria» con "autoridad», dos instituciones diferentes: la primera, regulada en el Título V de la Ley 33/2011, de 4 de octubre, General de Salud Pública (BOE núm. 240, de 5 de octubre de 2011), ostenta competencias de vigilancia y actuación en materias de salud pública; la segunda, se encuentra contemplada en el artículo 24.1 del CP y el delito de atentado, aplicable a las agresiones que contra la autoridad se cometen, en los artículos 550 y ss. CP.
} 
2. Aragón (2002), Galicia (2008) y Murcia (2009) siguen las pautas anteriores, aunque ya existen referencias indirectas (e interpretables) sobre infracciones contra el personal sanitario.

Cuando hablamos de referencias indirectas, interpretables como conectadas a las agresiones, nos referimos a preceptos en los que se tipifican la obstaculización al disfrute de los servicios por parte de los demás usuarios (porque lógicamente, una perturbación del orden incide en esa cuestión), o el ambiente pacífico necesario para el buen desarrollo de las actividades asistenciales.

En el caso de Aragón, ya se enuncia la falta de respeto al personal como infracción, junto a los tradicionales daños contra las instalaciones, incluyendo también el adecuado uso de los servicios sanitarios (lo que, indirectamente, también afecta al tema que nos ocupa).

3. A partir de 2010 (Castilla-La Mancha, Castilla y León y Navarra) comienza a enunciarse una tipificación más prolija y exhaustiva, con referencias concretas y precisas sobre agresiones a profesionales sanitarios.

Se califican, por ejemplo, como infracciones graves en Castilla-La Mancha «la resistencia, falta de respeto, amenazas, insultos, represalias o cualquier otra forma de presión ejercida contra los profesionales de los centros, servicios y establecimientos sanitarios, los pacientes o sus acompañantes siempre que no sean constitutivas de ilícito penal» y muy graves «la agresión física a profesionales de los centros, servicios y establecimientos sanitarios, a pacientes o a sus acompañantes siempre que no sea constitutiva de ilícito penal».

Es decir, la gravedad se acentúa cuando se trata de una agresión física. Como hemos visto, este criterio es dudoso, habida cuenta de que las consecuencias de las agresiones psicológicas no tienen por qué ser más leves que las producidas por las físicas para la salud de la víctima, sino incluso todo lo contrario.

Con diferentes matices, en cuanto a la graduación de las infracciones y sanciones, se manifiestan el resto de las normas examinadas en este grupo, pero siempre manteniendo una tipificación explícita como infracciones, de las faltas de respeto y demás formas de agresión a los profesionales sanitarios que prestan servicios en sus respectivos ámbitos competenciales. 


\section{EL DEBATE SOBRE LA IDONEIDAD DEL EMPLEO DEL DERECHO ADMINISTRATIVO SANCIONADOR CONTRA LAS AGRESIONES AL PERSONAL SANITARIO. TOMA DE POSICIÓN.}

Como consecuencia de la controversia suscitada con ocasión de las demandas por parte de varios colectivos e instituciones de que se aplicara el tipo de atentado contenido en el Código Penal (cuestión que trataremos más adelante en esta discusión), una parte de la doctrina se inclinó por la defensa de lo inadecuado de emplear el citado tipo penal en el enjuiciamiento de las agresiones contra el personal sanitario.

Al hilo de esta cuestión, algunos autores que estudiaban el tema de las agresiones buscaron una alternativa, entendiendo que el Derecho penal no debía intervenir en estos casos.

En nuestra opinión, no hay que olvidar que el orden penal venía entendiendo de las agresiones a los profesionales de la salud desde siempre, por la vía ordinaria de los delitos contra las personas.

En realidad, el sector de la doctrina del Derecho que se manifestaba en contra de la aplicación del delito de atentado contra estas agresiones, lo hacía por motivos técnico-jurídicos, pero nunca cuestionó la intervención de la jurisdicción penal en la materia a través de otros tipos delictivos.

La alternativa que pareció más conveniente a estos autores, que defendían la no intervención del Derecho penal en la cuestión, fue acudir al Derecho administrativo sancionador.

Marinas-Sanz et al. (2016) pedían el uso de otros recursos distintos al Derecho penal ${ }^{391}$, en

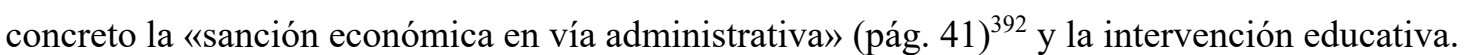

Estos autores se fundamentaban en las afirmaciones de Martínez-Zaporta Aréchaga \& FernándezDelgado Momparler (2008), que criticaban el recurso al delito de atentado por entender que se estaba utilizando el tipo de forma incorrecta.

En realidad, estos últimos no negaban la posibilidad de intervención del Derecho penal, llegando incluso a sugerir la creación de un subtipo agravado por razón del sujeto pasivo en las conductas agresoras o un tipo especial independiente ${ }^{393}$. Lo que discutían era el empleo del delito de atentado concretamente, por entender que podía generar problemas de seguridad jurídica y de vulneración del principio de proporcionalidad.

\footnotetext{
${ }^{391}$ Literalmente: «...es previsible que tal reducción precise de intervención y medidas distintas en ámbitos diversos y distantes a la vía penal» (Marinas-Sanz et al., 2016, p. 41).

392 Lo que significa acudir al Derecho Administrativo sancionador.

393 Posibilidades que también defiende De Juan-Mazuelas (2016).
} 
Es cierto que el Derecho penal se sustenta, entre otros principios, en el de intervención mínima y «ultima ratio», pero ello no significa que deba ser sustituido de forma sistemática por el Derecho administrativo sancionador en el tratamiento de las agresiones al personal sanitario. De JuanMazuelas (2016) observa esta cuestión de forma más matizada, defendiendo que únicamente las conductas más graves deben ser encausadas bajo el tipo penal de atentado.

En esta cuestión parece que los autores que niegan la intervención del Derecho penal se fundamentan sobre el presupuesto de que este orden es más gravoso para el condenado, lo que podría suponer en algunos casos una vulneración del principio de proporcionalidad.

Pues bien, excepción hecha de la pena de prisión (por esencia más grave que cualquier otra) ${ }^{394}$, no cabría hacer una afirmación tan rotunda. Las penas de multa que se aplican en el orden penal son de menor cuantía que en otras jurisdicciones: la contencioso-administrativa en los procesos sancionadores, sin ir más lejos y lo mismo cabe decir de otras sanciones privativas de derechos (Rando Casermeiro, 2010).

Por tanto, entendemos que es un hecho que el Derecho administrativo sancionador no es necesariamente más liviano y, por contra, en su sistema se ven disminuidas notablemente las garantías procesales del orden penal.

En palabras de Rando Casermeiro (2010), «ambas circunstancias deberían ser suficientes para ponernos en guardia ante el peligro de que la potestad sancionadora de la administración acabe convirtiéndose en un recurso cómodo de los poderes públicos, que permita imponer sanciones particularmente graves sin tener que preocuparse por la observancia escrupulosa de garantías y derechos del sancionado» (p. 28).

Debemos además tener en cuenta que, en el caso de los profesionales de la salud, el recurso al Derecho administrativo sancionador significaría dejar fuera de esta protección a quienes ejercen su profesión en la sanidad privada.

Recordemos la multitud de críticas que suscita la aplicación del delito de atentado a las agresiones contra el personal sanitario precisamente por este motivo.

Por todo lo anterior, debemos manifestar que la exclusión del Derecho penal en favor de una intervención exhaustiva del Derecho administrativo sancionador no parece una opción tan clara

\footnotetext{
${ }^{394}$ En general, la jurisprudencia y la FGE consideran las penas privativas de libertad, aunque sean en el grado mínimo de la localización permanente, más onerosas que las pecuniarias.
} 
como manifiestan algunos autores (Martínez-Jarreta, 2011), sino que debe ser meditada con cautela.

García Calvo (2013) señala que la aplicación del régimen sancionador es escasa y aboga por un mayor uso de este sistema ante el incumplimiento de los deberes, por su valor como medio disuasorio. Desconocemos si realmente la aplicación del sistema administrativo de sanciones es escasa, en cuyo caso es probable que resultara aconsejable un mayor empleo.

Entendemos, no obstante, que no debe recurrirse a esta vía como si fuera el paradigma del castigo justo y proporcionado al infractor. Tal vez la actuación más equilibrada sería establecer una distinción entre sucesos en los que interviniera el Derecho penal y los que requirieran de la actuación del administrativo sancionador.

Pero esto resulta muy difícil, toda vez que ambas instancias del «ius puniendi», como hemos señalado en el apartado «El Régimen sancionador administrativo», en la mayoría de las ocasiones pueden conocer del mismo hecho, por encontrarse tipificado penal y también administrativamente (Rando Casermeiro, 2010).

\section{LA ATRIBUCIÓN DE LA CONDICIÓN DE AUTORIDAD A LOS PROFESIONALES DE LA SALUD}

En respuesta al problema de las agresiones contra el personal sanitario, un reducido grupo de Comunidades Autónomas legislaron para conceder a sus empleados la condición de autoridad.

Las razones que expresaron para tomar esta medida se centraban en lograr un aumento del sentimiento de protección de los interesados y dar un reconocimiento a su labor. También se insistía en que lo pretendido era «reforzar su autoridad» y que por ese motivo precisamente se les otorgaba la condición de autoridad.

Encontramos llamativo este razonamiento, porque no basta con utilizar una denominación para que las consecuencias de ostentarla se produzcan, si no lleva aparejadas atribuciones concretas, algo que -como veremos- no ha ocurrido.

La condición de autoridad se acompañó del reconocimiento de una serie de derechos, referidos al respeto debido, protección, apoyo de la Administración y ambiente adecuado de trabajo.

Como puede apreciarse, nada que no estuviera ya incluido en PPRL o en otras disposiciones administrativas. Lógicamente, el incumplimiento de estos derechos puede ser tipificado como infracciones y, por tanto, incluido en el correspondiente régimen administrativo sancionador. 
Pero lo que consideramos verdaderamente importante en este epígrafe es dejar claro cuál es la naturaleza de estas Leyes autonómicas «de autoridad» y cuál su verdadero alcance.

Por más que enfáticamente se proclame la condición de autoridad que otorgan estas disposiciones, no debe olvidarse que las Comunidades Autónomas no ostentan competencias legislativas en el orden penal (competencia exclusiva del Estado).

En consecuencia, estas normas pertenecen al ámbito del Derecho administrativo, y como tales, no proyectan efectos penales de ningún tipo, por lo que no cabe aceptar que esta condición de «autoridad» reconocida se identifique con la figura de autoridad prevista en el art. 24.1 CP. Por lo tanto, estas disposiciones están creando un concepto jurídico nuevo, que no equivale a la «autoridad» contenida en el Código Penal.

Lo anterior nos lleva a analizar el alcance de los efectos que atribuyen a la concesión de esta denominación las Leyes autonómicas estudiadas: presunción de veracidad y «protección reconocida a tal condición por la legislación vigente».

1.- La «presunción de veracidad» se refiere sólo a las manifestaciones escritas del interesado y se garantiza según la «normativa que resulte de aplicación en cada caso», expresión ambigua que puede referirse a cualquier clase de disposición enmarcada en todo tipo de ordenamiento jurídico. Podría significar, por ejemplo, que tras la interposición de una denuncia ante el orden penal, la presunción de veracidad operará según las reglas del citado ordenamiento.

De ser así, entendemos que la posesión de la condición de autoridad para el denunciante sería del todo irrelevante, porque se le aplicarían las reglas específicas de cada procedimiento, sin distinciones respecto al resto de los ciudadanos.

2.- En cuanto a la «protección reconocida por la legislación vigente» cabe decir lo mismo: esta protección es la misma que para el resto de los ciudadanos porque la figura de autoridad concedida por estas CCAA no tiene efectos penales y la legislación vigente no le otorga ninguna protección especial.

En nuestra opinión, la única excepción sería si estas mismas CCAA establecen específicas sanciones administrativas contra la infracción de los derechos que reconocen sus «leyes de autoridad»: en este caso sí tendrían el «plus» de protección que les brindaría el Derecho administrativo sancionador; pero no hemos de olvidar que en la mayoría de los casos las faltas de respeto y consideración ya estaban tipificadas como infracciones en otras normas autonómicas.

Es decir, sería necesario dotar a la nueva figura de «autoridad» de contenido real, porque en estos momentos es un concepto vacío, ya que no despliega efectos propios. 
Por todo lo dicho, hemos de afirmar que, aunque los propósitos de estas Comunidades Autónomas al dictar estas leyes hayan sido encomiables, sus efectos en la práctica no resultan relevantes.

Posiblemente, en su día, lo que movió a estas administraciones fueron razones de gestión política, quizás buscando estimular al Estado para que dictara normas que atribuyeran la condición de autoridad para todo el territorio nacional, incluyendo tal cuestión en la reforma del Código Penal que se encontraba muy próxima.

Pero la citada reforma del Código Penal incluyó a los profesionales de la sanidad y la enseñanza pública en el ámbito de protección del delito de atentado, en atención a su condición de funcionarios (artículo 24.2 CP), y no de autoridad (art. 24.1). Más adelante examinaremos esta cuestión con mayor detalle.

Sin embargo, medios de comunicación y representantes de algunas instituciones siguen insistiendo en afirmar que el Código Penal reconoce la condición de autoridad a los profesionales de la salud pública. Podríamos citar muchísimos ejemplos de esta actitud ${ }^{395}$; pero lo importante es que no se trata de un simple error de terminología, porque se están atribuyendo consecuencias falsas a la comisión de las agresiones, especialmente en el orden penal ${ }^{396}$.

Los profesionales tienen derecho a estar informados de modo veraz, a conocer sus derechos y deberes y a saber de qué forma pueden ejercitarlos. Por ello, queremos manifestarnos en contra de esta cuestión: no se deben generar falsas expectativas, ni proporcionar informaciones inexactas.

Concluimos, en consecuencia, que las «leyes de autoridad» son disposiciones reiterativas que nada aportan a reconocimientos de derechos ya realizados por otras normas, careciendo además de efectos prácticos de importancia. A ello se añade que la utilización del término «autoridad» ha contribuido a aumentar la grave confusión que existe sobre este tema en otros ámbitos.

\footnotetext{
395 Entre las numerosísimas referencias que podrían citarse, destacamos las siguientes a modo de ejemplo: (OMC, 2015), (Noticias sobre sanidad y enfermería. Satse, 2015), ("Sanitarios piden 'tolerancia cero' contra las agresiones que sufren - Local - Diario Córdoba," 2017) (“Los médicos se blindan ante las agresiones de pacientes - Observatorio de Agresiones - COLEGIO DE MÉDICOS DE BIZKAIA,” 2015) (“El 16 de marzo la OMC conmemora el ‘Día Nacional contra las Agresiones en el Ámbito Sanitario' | CGCOM," 2017)

${ }^{396}$ El equívoco llega a tales extremos que el cuerpo de Inspectores de Sanidad de la Comunidad valenciana protestó contra la ley de esta Autonomía que atribuía la condición de autoridad a los sanitarios, cuando a ellos se les consideraba agentes de la autoridad sanitaria. Pedían continuar con su condición de "autoridad sanitaria» porque creían que como agentes de la autoridad sanitaria estarían en un rango inferior a los demás empleados("Los inspectores sanitarios se oponen a la nueva Ley de Salud porque pierden su "autoridad» - Levante-EMV," 2014). Como sabemos, la "autoridad sanitaria» y sus agentes son figuras muy distintas, establecidas por la LGSS, con atribuciones muy importantes en materias de salud pública. De hecho, la Ley 10/2014, de 29 de diciembre, de Salud de la Comunitat Valenciana (contra la que se realizaban las protestas) separa ambos ámbitos, aclarando que la condición de autoridad se otorga «sin perjuicio» de lo establecido en su Título VIII (dedicado a la autoridad sanitaria).
} 


\section{LA RESPONSABILIDAD PATRIMONIAL DE LA ADMINISTRACIÓN}

En el desarrollo de sus actividades, la Administración pública debe responder por los daños que cause, siendo esta responsabilidad de tipo extracontractual y directa. Esto significa que no es necesaria la existencia de vínculo contractual alguno con el perjudicado y que es responsable por los actos de sus agentes.

La responsabilidad patrimonial de la Administración es, así mismo, objetiva: no responde por la concurrencia de culpa o dolo en sus actuaciones, sino a consecuencia del funcionamiento normal o anormal del servicio público.

Debe aclararse que todo lo anterior no supone que la Administración deba responder por todos los daños que se produzcan en el desarrollo de su actividad. No se trata de una responsabilidad universal, sino sujeta a una serie de reglas y requisitos.

Un concepto clave es la lesión, que no posee los mismos caracteres que en el campo del Derecho civil. La lesión ha de ser antijurídica, esto es, productora de un daño que el perjudicado no tenga el deber legal de soportar.

Junto con este requisito central de la antijuridicidad, para que concurra responsabilidad patrimonial de la Administración son necesarias otras condiciones:

- Que los daños no sean producidos por fuerza mayor, debiendo ser predecibles o evitables, excluyéndose la relación de causalidad cuando tengan su origen en caso contrario.

- Que el daño incida sobre bienes y derechos reales, no expectativas.

- Que la lesión sea efectiva, real y económicamente evaluable.

- Que el daño sea individualizado, produciéndose sobre una persona o grupo de personas.

Al igual que ocurre en los demás tipos de responsabilidades que hemos contemplado a lo largo de este estudio, en este caso debe existir un nexo causal que enlace la lesión sufrida con el funcionamiento normal o anormal de la Administración.

Como puede verse, no es el proceder antijurídico de la Administración lo que lo determina (puesto que su funcionamiento puede ser tanto normal como anormal), sino la antijuridicidad del resultado (que el perjudicado no esté obligado legalmente a soportarlo).

Esta relación de causalidad ha de ser directa, inmediata y exclusiva.

$\checkmark$ Directa: la Administración ha de obrar por sí misma (o a través de sus agentes), sin intermediarios.

$\checkmark$ Inmediata: el daño ha debido causarse por una actuación no alejada en el tiempo. 
Exclusiva: no debe darse la intervención de otros actores, la lesión debe producirse precisamente por la acción de la Administración. Por esta razón, se destruye el nexo causal cuando la víctima ha tenido participación a título de culpa y cuando se produce la interferencia de un tercero en la producción de los hechos.

Debe observarse la diferencia con el sistema laboral, en el que la responsabilidad del empresario sólo queda excluida en el caso de que el trabajador haya obrado con dolo o imprudencia temeraria, no bastando la culpa ni la imprudencia leve.

En cuanto al nexo causal, sólo desaparecería si la participación del tercero hubiera sido la única causa de la lesión, de lo contrario cabe la concurrencia de responsabilidades entre el mismo y la Administración.

La aplicación de este sistema a la reclamación de responsabilidad patrimonial por parte de los empleados públicos (y, por tanto, el personal sanitario al servicio de la Administración) requiere de algunas matizaciones. Para ilustrar estas cuestiones, hemos accedido a varios supuestos de reclamaciones interpuestas en vía de responsabilidad patrimonial por empleados sanitarios (cuyo desarrollo analítico se encuentra en el capítulo correspondiente, por lo que remitimos al mismo).

La responsabilidad patrimonial de la Administración es una vía abierta a todos los empleados públicos al margen de la relación jurídica que les ligue con su Administración-empresaria. Es decir, pueden ejercitarla los funcionarios, personal estatutario, personal laboral y, en general, todo aquel que esté a su servicio independientemente de cuál sea la naturaleza de su relación laboral ${ }^{397}$.

No sucede al revés, es decir, cuando se trata de acudir a la jurisdicción social, que queda vedada al personal funcionario y estatutario. Esto tiene su trascendencia porque, como estamos viendo, las reglas de juego del proceso laboral en materia de responsabilidades no exigen los requisitos de la vía de reclamación de la responsabilidad patrimonial de la Administración. No existe, pues, simetría en las posibilidades de reclamación que asisten a todos los empleados públicos.

Por otro lado, y como no podía ser de otro modo, los profesionales que prestan sus servicios en la sanidad privada por cuenta ajena, sí pueden acudir a la vía laboral.

Los empleados públicos han de ser resarcidos de los daños sufridos con ocasión del desempeño de su trabajo en virtud del llamado principio de indemnidad.

\footnotetext{
397 Como ejemplo, puede verse el Dictamen del Consejo Consultivo de Castilla y León 988/2006, de 2 de agosto, en que se estima la reclamación de una auxiliar de enfermería vinculada a la Administración por un contrato laboral de carácter eventual.
} 
Este principio establece que el trabajador público no puede obtener ningún perjuicio que no tenga el deber de soportar legalmente en el desarrollo de su actividad profesional, a menos que en el suceso haya mediado culpa o negligencia por su parte.

Es aquí donde entra en juego la diferencia entre el funcionamiento normal y el funcionamiento anormal de la Administración.

Cuando el daño se ha producido por funcionamiento normal, el daño no es antijurídico (y por tanto tampoco resarcible), porque el empleado ha asumido un riesgo que tiene el deber de soportar $^{398}$

Sólo serán indemnizables a través del instituto de la responsabilidad patrimonial de la Administración los daños causados a sus trabajadores que tengan causa en el funcionamiento anormal de la Administración. Hemos incluido en nuestro trabajo varias resoluciones que entienden de sucesos violentos producidos por pacientes psiquiátricos hacia personal sanitario ${ }^{399}$.

En la inmensa mayoría de las ocasiones, la jurisdicción contencioso-administrativa y los Consejos Consultivos estiman que los profesionales sanitarios que prestan sus servicios en unidades de psiquiatría asumen un riesgo de agresión inherente a su trabajo y que, por tanto, no puede hablarse de funcionamiento anormal de la Administración.

La reparación ha de ser íntegra y completa, pero sólo operará en ausencia de otros regímenes resarcitorios que puedan asistir al reclamante (por ejemplo, daños incluidos en el régimen de indemnizaciones por razón del servicio).

La prueba de la existencia del nexo causal se dirime en el campo de la prevención de riesgos laborales y, más específicamente, si la Administración fue diligente en la implantación y el cumplimiento de las medidas de prevención. En este sentido, hemos encontrado varias resoluciones que inciden en esta cuestión como fundamental, para lo que remitimos al epígrafe «Responsabilidad Patrimonial de las Administraciones Públicas», dentro del capítulo dedicado al Derecho Administrativo y sus actuaciones en materia de agresiones a los profesionales sanitarios.

En nuestra opinión, resulta sustancial que se pruebe que la Administración no obró con la diligencia debida y ello se traduce en la falta de prevención, o prevención insuficiente, en materia de riesgos laborales.

\footnotetext{
${ }^{398}$ Es el caso examinado en el Dictamen 988/2006, de 2 de agosto de 2006, del Consejo Consultivo de Castilla y León, que se basa, entre otros motivos, en este principio, como también lo hace, entre otras resoluciones, el Dictamen 906/2009 de este mismo órgano (ambos dictámenes se tratan en el apartado correspondiente de este estudio). 399 Para el tratamiento especial de los inimputables en el ordenamiento penal, ver Sanz Morán (2017).
} 
Debemos concluir que este es el aspecto central de la cuestión en cuanto a la apreciación de responsabilidad patrimonial de la Administración ante una agresión. 


\section{CONSIDERACIONES SOBRE LA ACTUACIÓN DEL DERECHO PENAL ANTE LAS AGRESIONES AL PERSONAL SANITARIO}

Tradicionalmente, las agresiones a los profesionales sanitarios venían siendo tratadas desde el Derecho penal bajo la órbita de los delitos contra las personas (lesiones, amenazas, injurias, etc.) y la mayoría de las mismas eran calificadas como faltas, siendo bastante infrecuente su reputación como delitos.

A comienzos del siglo XXI algunos tribunales empezaron a calificar estas agresiones como delito de atentado ${ }^{400}$, aunque esta tendencia todavía tenía un largo camino por delante hasta su afianzamiento.

Para aplicar el delito de atentado a estos actos violentos existían una serie de cuestiones técnicojurídicas que impedían su empleo. La base de la crítica se sustentaba en la posible falta de idoneidad de la naturaleza y elementos del tipo para su utilización en el enjuiciamiento de ataques contra el personal sanitario.

Los elementos del delito de atentado eran, en el régimen anterior a la reforma del CP de 2015, los siguientes:

- Elemento objetivo: existencia de acometimiento, empleo de fuerza, intimidación grave y resistencia activa y grave, siendo el bien jurídico protegido el correcto funcionamiento del servicio público. Esta cuarta figura delictiva era de aplicación polémica por parte de los tribunales, por requerir la posesión de algún tipo de autoridad que, salvo excepciones, no detentan los profesionales de la salud.

- Elemento subjetivo: funcionario, autoridad o los agentes de la misma. En este aspecto se generó un debate jurisprudencial y doctrinal en cuanto a si el personal estatutario o laboral podía ser sujeto pasivo del delito de atentado. Finalmente, la discusión se superó, entendiendo que el concepto penal de funcionario (contenido en el artículo 24.2 CP) se extendía a todo el personal que trabajara en la sanidad pública, independientemente del tipo de relación laboral que le ligara a la Administración.

La reforma del CP operada en 2015 modificó la redacción del artículo 550, incluyendo explícitamente en el mismo a los profesionales de la sanidad y la enseñanza públicas como sujetos pasivos del ilícito de atentado.

\footnotetext{
400 Destacamos en cuanto a este tema, la SAP Salamanca (Tribunal del Jurado) 1/2002, de 20 de abril, que enjuició el caso del homicidio de la Dra. Ginel. Para más detalle sobre este asunto, puede verse el trabajo de De Juan-Mazuelas (2016).
} 
Esta inclusión ha suavizado el debate doctrinal existente sobre la cuestión, sin llegar a ponerle fin.

En cambio, sí que aporta uniformidad a la actuación de los órganos jurisdiccionales puesto que, si bien la aplicación de este delito a los supuestos de agresiones cometidas contra los profesionales de la salud era ya una tendencia mayoritaria en los tribunales, aún existía polémica al respecto en recursos de apelación interpuestos ante las AP contra sentencias que condenaron al acusado por la comisión de ese delito (De Juan-Mazuelas, 2016). Es más, incluso después de la entrada en vigor de la reforma, hemos encontrado algún caso en el que la defensa del acusado actúa en ese sentido $^{401}$.

También aclaró definitivamente la exclusión de la posibilidad de incluir en esta protección penal a los trabajadores de la sanidad privada, algo que la propia naturaleza del delito de atentado impedía ya en el CP de 1995, al no estar estos profesionales en posesión de la condición de funcionario requerida por el art. $24.2 \mathrm{CP}{ }^{402}$.

La reforma del Código Penal instituyó además otras novedades de relevancia para los supuestos de agresiones a los profesionales de la salud que pasamos a referir de forma resumida.

Las faltas quedan eliminadas, siendo sustituidas por los denominados «delitos leves» aunque no todas se han mantenido en el ordenamiento penal.

Consideramos de interés señalar, en primer lugar, que se aumentan las cuantías de las multas aplicadas a esas antiguas faltas (ahora denominadas «delitos leves», como acabamos de indicar). En el supuesto de lesiones, también se da ese incremento, pero hay que tener en cuenta que pasan a ser delitos semipúblicos, por lo que el agredido deberá siempre interponer denuncia para posibilitar su persecución.

En nuestra opinión, esta última medida puede influir en el aumento de un fenómeno al que hemos aludido a lo largo de este estudio: la llamada «infradenuncia» o tasa importante de agresiones que se quedan sin denunciar. Creemos que la necesaria denuncia de parte va a determinar que lleguen a los tribunales menos agresiones productoras de lesiones que antes (porque supone una mayor carga de actividad para el interesado y una molestia añadida).

Debemos añadir a todo esto que se elimina la posibilidad de imponer penas de localización permanente a este tipo de infracciones, que constituía una limitación de libertad (aunque lo fuera

\footnotetext{
401 Véase SAP Pontevedra 302/2016, de 23 de mayo.

402 La redacción de este artículo no ha sido modificada por la reforma.
} 
en un mínimo grado) considerada generalmente más gravosa que las penas de carácter pecuniario, como reconoce incluso la $\mathrm{FGE}^{403}$.

Las injurias han sido expulsadas del ordenamiento penal. Siendo estas ofensas tan frecuentes en el ámbito sanitario, habrá que considerar que, aunque las sanciones económicas pueden ser mayores en otros órdenes jurisdiccionales, el poder coercitivo de los mismos es inferior al penal.

Dejando al margen lo relacionado con las antiguas faltas, en los supuestos de agresiones que sean estimados por los tribunales como delitos graves, se reduce el límite inferior de la pena, que es lo que más aplican los órganos jurisdiccionales ordinariamente (De Juan-Mazuelas, 2016).

En cuanto la intimidación grave, se suprime como modalidad autónoma del ilícito de atentado, lo que probablemente limite la tipificación de las agresiones al personal sanitario como delito de atentado y lleve a derivar algunos supuestos como mucho al delito de amenazas. Las penas para las amenazas (aun cuando se consideren delitos y no delitos leves, que posiblemente sea lo más frecuente) son menores en su límite inferior, salvo en casos de especial gravedad.

Todas estas novedades tienen, lógicamente, su influencia en el tratamiento de las agresiones a los profesionales sanitarios desde el Derecho penal.

¿Cómo operan actualmente en la vida real y en el funcionamiento del Derecho penal en cuanto al tema que nos ocupa? ¿Se castigan penalmente las agresiones a los profesionales de la salud con mayor o menor rigor tras la reforma del CP?

Para responder a estas interrogantes, examinamos y analizamos un total de 31 supuestos en los que se produjeron ataques contra profesionales de la salud que llegaron a los tribunales del orden penal, clasificando dichas resoluciones en atención a las penas impuestas.

Esto nos ha permitido llegar a establecer las siguientes consecuencias en cuanto al delito de atentado:

- Se siguen aplicando penas de un año de prisión (lo que parecía ser la tónica predominante con anterioridad a la reforma). En este sentido, la penalidad de estos delitos ni aumentaría ni disminuiría, manteniéndose en el mismo punto.

- Las penas que se imponen con más frecuencia se sitúan por debajo de la media del tramo previsto por la legislación. En lo referido a las condenas a prisión, aunque se aumentó el

\footnotetext{
403 Circular 3/2015 de la Fiscalía General del Estado sobre el régimen transitorio tras la reforma operada por LO 1/2015
} (Fiscalía General del Estado, 2015). 
límite superior a 3 años, la realidad es que se aplica más el límite inferior (6 meses), lo que supone una menor carga punitiva pues el citado límite estaba establecido en 1 año en el CP anterior a la reforma.

- Se aplican penas de más de un año de prisión en aquellos casos en que se aprecia reincidencia, se ha producido una violencia notable o ha estado dirigida contra una pluralidad de personas. No obstante, hay que señalar que, aún en estos supuestos, las penas se mantienen también por debajo de la media del tramo que la legislación penal permite.

Debe observarse además la nueva posibilidad de suspender el cumplimiento de las penas de prisión inferiores a dos años (artículo 80 y ss. CP) $)^{404}$.

Resulta igualmente destacable el funcionamiento del régimen transitorio de la reforma. Durante el mismo, es de aplicación el régimen más beneficioso para los reos de aquellos delitos cuya sentencia no hubiera devenido firme por encontrarse en fase de recurso.

A consecuencia de ello, en el caso de las antiguas faltas ya eliminadas como figuras delictivas, en muchas ocasiones la resolución de instancia se ha revocado en vía de apelación (puesto que el ilícito por el que había sido condenado el agresor ya no existía como tal) ${ }^{405}$, suprimiéndose la multa impuesta y quedando únicamente indemne la responsabilidad civil resultante (y ello en el caso de que el denunciante no hubiera renunciado a la misma).

Por todo lo anterior, a la vista del análisis de la actuación de los tribunales posterior a la entrada en vigor de la LO 1/2015, debemos concluir que, en general, se ha rebajado la punición de las agresiones ya que, en la práctica y en la mayoría de las ocasiones, las penas que se aplican son inferiores a las que se imponían con anterioridad a la reforma ${ }^{406}$.

En relación con esta cuestión, hemos detectado una falta de homogeneidad en cuanto a la aplicación de la reforma con carácter retroactivo, sobre todo en el caso de ilícitos no comprendidos en el delito de atentado. En algunos supuestos no se tiene en cuenta esa retroactividad en tanto que otros los tribunales la aplican incluso de oficio. Esto puede generar inseguridad jurídica, pero también contribuir en alguna medida al problema de la «infradenuncia», sobre todo por los casos en que, al considerarse la retroactividad, se hayan reducido las penas impuestas por la sentencia de instancia.

\footnotetext{
${ }^{404}$ Aunque también ha de tenerse en cuenta que con anterioridad podían sustituirse las penas de prisión inferiores a un año por una multa, posibilidad que ha sido suprimida.

${ }^{405}$ Aunque siga existiendo como delito leve, se trata ya de otra figura delictiva.

${ }^{406}$ Para más detalle, puede verse el Capítulo «El Derecho penal y su tratamiento de las agresiones a los profesionales sanitarios».
} 
Hemos constatado también que, al igual que en otros ámbitos ${ }^{407}$, persiste en los tribunales ${ }^{408}$ la confusión terminológica con la denominación de «autoridad», que abre una gran brecha entre profesionales públicos y privados. La creencia que abona esta confusión es que el personal de la sanidad pública está protegido por el tipo de atentado debido a que ostentan la cualidad de «autoridad», lo cual es falso. Si estos profesionales se encuentran incluidos en el ámbito de aplicación del delito de atentado, como ya sabemos, es debido a su condición de funcionarios públicos (en el sentido penal del artículo $24.2 \mathrm{CP}$ ).

Debemos en este punto realizar una reflexión crítica en torno a la cuestión de la pretendida desigualdad entre sanidad pública y privada, derivada de la no inclusión de los profesionales de la sanidad privada en el delito de atentado.

Si bien es cierto que los profesionales privados se ven excluidos de esta protección penal, no es menos cierto que los funcionarios y estatutarios de la pública también se ven privados del amparo de otras jurisdicciones. $Y$ esto es así porque, como hemos visto, en materia de resarcimiento por daños y perjuicios, tienen vedado el acceso al orden laboral, debiendo obligatoriamente recurrir al sistema de responsabilidad patrimonial de la Administración.

En realidad, el sistema está configurado de forma que tanto el profesional privado como el funcionarial tienen restricciones a la hora de acceder a los distintos recursos jurídicos. Las agresiones al personal privado, por ejemplo, tampoco pueden tener respuesta desde el Derecho administrativo sancionador.

Ello podría llevarnos a afirmar que sólo hay un colectivo que se beneficia de todos los recursos jurídicos disponibles: los empleados públicos que trabajan en régimen laboral.

Este personal laboral puede:

- Ser sujeto pasivo del delito de atentado (en su calidad de funcionario a efectos penales). Esta posibilidad está vedada, como hemos visto para el profesional de la sanidad privada.

- Reclamar en la vía laboral por cuestiones suscitadas por accidente de trabajo y enfermedad profesional, y otras materias relacionadas con PRL (abierto a todos los trabajadores por cuenta ajena, independientemente de la naturaleza de su relación laboral o de si pertenecen al sector público o privado).

\footnotetext{
407 Lo hemos tratado también al analizar los principales supuestos de interés para nuestro tema en el capítulo dedicado al estudio de la acción jurídica administrativa contra las agresiones al personal sanitario.

408 Tanto en las resoluciones utilizadas directamente como en las tomadas a partir de otras fuentes (lo que denominamos «fuentes indirectas»).
} 
- Reclamar en el orden social las indemnizaciones que procedan por responsabilidad del empresario en materia de PRL (posibilidad vedada a los funcionarios y estatutarios, que deben acudir al régimen de responsabilidad patrimonial de la Administración).

- Reclamar ante el orden contencioso-administrativo por responsabilidad patrimonial de la Administración suscitada por la cuestión anterior.

- Acogerse al Régimen sancionador administrativo (esta posibilidad y la anterior están vedadas a los profesionales de la sanidad privada). 


\section{EXPERIENCIA ANTE LAS AGRESIONES Y VALORACIÓN POR LOS PROFESIONALES DE LAS MEDIDAS TOMADAS}

\section{CONSIDERACIONES SOBRE LAS AGRESIONES A PARTIR DE LA EXPERIENCIA DE LOS PROFESIONALES ENCUESTADOS.}

Hemos comprobado a lo largo de nuestro estudio cómo las agresiones a los profesionales sanitarios constituyen un problema cuya importancia no se discute en la actualidad. Los datos oficiales y la doctrina científica reflejan una alta incidencia de comportamientos violentos protagonizados por pacientes y acompañantes, a los que también se da proyección en los medios de comunicación.

También comprobamos cómo desde diferentes instituciones y Administraciones públicas se ha intentado dar respuesta a este fenómeno, calificado por algunos como alarmante (Martínez-Jarreta et al., 2007), y que genera gran preocupación entre los profesionales afectados y alcanza una dimensión social, porque no sólo afecta a la salud de los trabajadores, sino también al resto de los usuarios y a la calidad de los servicios asistenciales.

Los resultados obtenidos en nuestro estudio subrayan en principio esa apreciación. Más de la mitad de los encuestados $(55,4 \%)$ manifestaron haber sufrido algún tipo de agresión a lo largo de su vida profesional. El 5,2\% no sabe si ha sido o no agredido, lo que evidencia una percepción baja del fenómeno por parte de los profesionales, que se relaciona con la minusvaloración de las agresiones verbales y la sensación de que son parte integrante del trabajo.

Estos datos son más elevados que en otros estudios, como el llevado a cabo por el COMB en 2004 (COMB, 2004) entre sus colegiados, que encontró que un tercio de ellos había experimentado alguna vez algún hecho violento. Otros trabajos hallaron incluso porcentajes mayores, de hasta un 64\% (Mayorca Yancán et al., 2013).

Vamos a analizar ahora el alcance de este problema, poniendo en relación los datos provenientes de otros estudios con los resultados obtenidos por medio de nuestra encuesta.

Esto nos llevará a determinar y a valorar de forma comparativa la tipología y frecuencia de las agresiones, de las personas que agreden y del entorno en que se producen las agresiones, cómo reaccionan ante ellas e, incluso, la sensación de soledad o de apoyo que pueden llegar a experimentar.

Como paso previo, hemos de encuadrar a los profesionales que han decidido participar en esta encuesta en las coordenadas de edad, sexo, categoría profesional, tipo de asistencia que realizan 
y su vinculación a la sanidad pública o a la privada, para poder entender mejor sus opiniones y su valoración sobre el conjunto de cuestiones propuestas en este epígrafe.

Por consiguiente, delimitaremos en primer lugar estos parámetros previos para profundizar posteriormente en el análisis de la problemática relacionada con las agresiones propiamente dichas.

\section{CARACTERÍSTICAS DE LOS PROFESIONALES ENCUESTADOS}

\section{$E D A D$}

Los encuestados en nuestro trabajo se encuentran en una franja de edad entre los 35 y los 54 $\operatorname{años}^{409}$. Los que manifestaron haber sido agredidos coinciden con este rango.

Mayorca Yancán et al. (2013) defendieron que se producían más agresiones cuanto más joven era el profesional, lo que parecía indicar que el agresor intentaba no ser violento con las personas de mayor edad. Gutiérrez et al.(2016) afirmaron que en su trabajo las agresiones más frecuentes se habían dado contra personas menores de 25 años. La OMC (Informe del Observatorio de agresiones 2016) reflejó un 30,15\% de agresiones hacia personas comprendidas entre 46 y 55 años y un $27,32 \%$ entre $36-45$ años.

En nuestro estudio, el rango se encuentra en sector de edad de madurez. De ello deducimos, que es precisamente en esa etapa de la vida y del ejercicio de la profesión en la que ya se han acumulado presumiblemente experiencias relacionadas con la violencia.

En cambio, en nuestra opinión, y como señalábamos en la Introducción, los más jóvenes tal vez hayan tenido menos ocasiones de estar en contacto con este problema. En cuanto a los más mayores, pueden haber sufrido o presenciado menos agresiones porque el fenómeno de la violencia del usuario al profesional ha crecido en los últimos años y, como se señalaba en la Introducción, hasta los años 90 del siglo XX resultaba algo anecdótico. Por ello, es posible que las personas con más edad, al haber vivido la mayoría de su carrera profesional en una época en que las agresiones eran mucho menos numerosas, refieran haber experimentado ninguna o escasa violencia.

\footnotetext{
409 Por su parte, Chagoyen Barroso (2016) refiere un rango de edad de 40-61 años, Gutiérrez, Hernández, \& Molina (2016) obtuvieron una edad media de agredido de 42,6 años, Mayorca Yancán et al. (2013) 37,2 años y Villar Doncel \& Aranaz Andrés (2006) 37,2 años.
} 


\section{CATEGORÍA PROFESIONAL}

En lo referente a los grupos profesionales, en nuestro estudio los más afectados fueron los facultativos $(61,3 \%)$ y el personal de enfermería $(60,8 \%)^{410}$.

Son múltiples los estudios que relacionan la enfermería con un riesgo mayor de producción de agresiones. El Consejo Internacional de Enfermeras constataba este hecho ya en 1998, en sus «Directrices para hacer frente a la violencia en el lugar de trabajo» (Consejo Internacional de Enfermería, 1998) ${ }^{411}$. La cuestión se puso también de manifiesto en el «Programa conjunto sobre la violencia laboral en el sector de la salud» publicado en 2002 (OIT/OMS/CIE/ISP, 2002).

Datos provenientes de diversas partes del mundo vienen a confirmar dicha tendencia. En Australia se reportó que el 95\% de las enfermeras habían sido agredidas en 1999 (Oostrom \& Mierlo, 2003). Deeb (2003) desveló que en El Líbano las enfermeras y matronas constituyen los grupos de mayor riesgo. Ferri y col. afirman que la mayor parte de las víctimas de agresiones en el sector sanitario italiano son mujeres pertenecientes a personal de enfermería (Ferri, Silvestri, Artoni, \& Di Lorenzo, 2016). En Inglaterra, el «burn-out» padecido por enfermeras en un alto grado producido por la violencia de todo tipo ejercido contra ellas, hacen que un gran número de las mismas se hayan planteado incluso abandonar su profesión (Estryn-Behar et al., 2008).

En nuestro país también los datos avalan la prevalencia de riesgo del personal de enfermería que, como veremos, parece acumular otro riesgo añadido: el mayor número de agresiones se producen contra mujeres. Siendo el personal de enfermería mayoritariamente femenino, resulta probable que, como decimos, este riesgo se adhiera al anterior.

De-San-Segundo et al. (2016) encontraron un $47,4 \%$ de agresiones en enfermeras y un $29,7 \%$ en TCAE, lo que determina nada menos que un $77,1 \%$ en personal de enfermería. Más elevado es el porcentaje obtenido por Lameiro et al. (2013): 74\% en total, sumados los dos grupos de enfermería. Fernández Martín et al. (2006) también afirman el alto grado de riesgo que tienen los profesionales de enfermería, aunque su investigación se centró únicamente en las UCI. A esta misma consecuencia llegan igualmente Letelier \& Valenzuela (2002).

Las razones por la que este colectivo resulta más afectado se centran en la proximidad con el usuario, señalándose que quien está más en contacto con pacientes o acompañantes, más riesgo tiene de ser agredido (Miret \& Martínez Larrea, 2010).

\footnotetext{
${ }^{410}$ No obstante, estos datos deben verse con cautela, porque en nuestra encuesta fueron estos dos colectivos los que respondieron más mayoritariamente.

411 Esta cuestión fue reafirmada en 1999 (Consejo Internacional de Enfermeras, 1999) y en 2007 (Consejo Internacional de Enfermeras, 2007), entre otras ocasiones.
} 
En este mismo sentido se expresan Fernández Martín et al. (2006), que subrayan que el mayor tiempo de interacción que se da en las UCI entre personal de enfermería y usuarios, determina un alto riesgo de agresiones.

Parece existir un alto consenso en que esa proximidad es la que determina el aumento de riesgo, siendo el profesional «que atiende en primera línea» (Lameiro et al., 2013) quien tiene más posibilidades de ser agredido ${ }^{412}$.

Estos autores aportan una reflexión interesante: lo determinante en realidad no es la pertenencia a un grupo profesional concreto, sino ese condicionante de proximidad.

Y esto nos lleva a valorar los altos índices de violencia que también hemos obtenido en nuestro trabajo, referentes al personal médico. Recordemos que los facultativos obtenían una tasa del $61,6 \%$, más alto que el personal de enfermería $(60,8 \%)$.

Pues bien, parece claro que el factor de la proximidad e interacción mayor con el usuario explicaría estos datos. Tanto las enfermeras y TCAE como los facultativos son quienes más contacto tienen con pacientes y acompañantes, quienes interactúan con ellos en mayor grado y más frecuentemente ${ }^{413}$.

En consecuencia, consideramos que la categoría profesional no es relevante a la hora de producirse agresiones. En cambio, sí lo es el grado de proximidad, interacción e interactuación.

\section{SECTOR DE LA SANIDAD DONDE TRABAJA: PÚBLICA O PRIVADA}

En lo referido a la distinción entre sanidad pública o privada a la hora de sufrir una agresión, parece que los niveles de agresividad son mayores en los centros públicos (Mayorca Yancán et al., 2013), resultados que coinciden con otras investigaciones (Braga et al., 2012)(Steinman, 2003), que relacionan estos datos con contratos precarios o inequidades salariales (Palacios et al., 2003). En su Informe Nacional sobre agresiones de 2016, la OMC mostró un 87\% de violencia sobre el sector público sanitario entre sus colegiados (Organización Médica Colegial, 2016).

\footnotetext{
412 Algunos de nuestros entrevistados no lo entienden así, sino que atribuyen una mayor incidencia sobre el personal de enfermería por ostentar los facultativos un supuesto mayor poder, aunque también expresan que la proximidad es un factor decisivo: «...lo que sucede es que, ante cualquier pequeña contrariedad, el paciente sabe que no puede agredir al médico, que es quien pone las normas. Así que lo paga con el personal que le trata y cuida directamente. Y no tiene ningún problema en expresarlo así. Y nos insulta, intimida o agrede, ya sea de forma verbal o física».

${ }^{413}$ Gascón Santos (2006) defiende que existe una correlación entre la motivación de la agresión y el tipo de profesional agredido: los ataques que se producen contra médicos se producen con la intención de obtener una prestación o servicio, siendo más frecuentes las amenazas.
} 
En nuestro estudio se subraya el predominio de la sanidad pública sobre la privada en cuanto a existencia de agresiones.

Nuestros datos (que fueron estadísticamente significativos), aportaron que había más episodios violentos en la sanidad pública que en la privada $(60,6 \%$ frente a $41,2 \%)$. Los trabajadores que prestaban sus servicios de forma compartida en ambos sectores de actividad, dieron un porcentaje intermedio entre los dos. No obstante, en este último grupo hubo un 11,3\% inseguro sobre si había sufrido o no agresiones.

Insistiendo en este tema, resulta necesario observar que encontramos grupos de encuestados relativamente numerosos que afirman no saber si fueron o no agredidos. Este es un hecho que puede parecer sorprendente, pero ha de tenerse en cuenta que en gran número de agresiones verbales o actos violentos sin contacto físico, la persona receptora puede tener sus dudas porque no tiene conciencia clara de cuál es el límite entre la mala educación y la agresión.

\section{TIPOS DE ASISTENCIA}

En cuanto a las diferencias encontradas entre los diferentes grupos de asistencia sanitaria a que pertenecían los encuestados (Atención Primaria, Atención Especializada, Emergencias, atención psicológico-psiquiátrica y otros), el orden de frecuencia de los grupos que registraron más incidentes violentos fue, de mayor a menor: Emergencias (81,3\%), Atención Especializada (57,7\%) y Atención Primaria (54,6\%).

Estos resultados coinciden en lo referente a Emergencias con los obtenidos por Miret \& Martínez Larrea (2010), que observaron en estas unidades una mayor tasa de agresiones ${ }^{414}$.

Por el contrario, no hemos obtenido resultados concordantes con los hallados en Portugal por Ferrinho et al. (2003), que desvelaron una mayor incidencia de la violencia en centros de salud que en hospitales. Vorderwulbecke, et al. (2015), en Alemania, también obtuvieron altas tasas de agresiones en Atención Primaria, especialmente referidas a episodios de asistencia domiciliaria. La OMC declaró igualmente en 2016 que la Atención Primaria estaba más afectada (55\% de las agresiones a nivel nacional) (Organización Médica Colegial, 2016).

\footnotetext{
${ }^{414}$ También reseñaron altas frecuencias de incidentes violentos en hospitales psiquiátricos, unidades de ancianos y
} centros de rehabilitación de adictos. 


\section{LA EXPERIENCIA DE LOS PROFESIONALES ENCUESTADOS EN MATERIA DE AGRESIONES}

A partir de este momento, vamos a analizar y comparar con los resultados de otros estudios los datos resultantes de nuestra encuesta sobre las agresiones consideradas en sí mismas que se producen en el ámbito de la salud.

Esto nos permitirá extraer conclusiones contrastadas sobre la experiencia que tiene este colectivo sobre las agresiones ya sean propias o vividas por otras personas de su entorno laboral, las actuaciones que han decidido o no tomar cuando los actos violentos ocurren o el grado de apoyo que han percibido.

También podremos establecer una correlación entre actos agresivos y lugares en que ocurren con mayor frecuencia, así como la posibilidad de que adquiera relevancia el binomio sexo de quien agrede y de quien es víctima del ataque.

\section{TIPOS DE AGRESIONES (FÍSICAS Y VERBALES)}

Encontramos un mayor porcentaje de violencia verbal (54,1\%), muy superior a la física $(20,6 \%)$. Esto está en consonancia con el estudio del COMB (COMB, 2004), que reveló una mayor frecuencia de las agresiones verbales y con lo hallado por Gascón Santos (2006), Galián Muñoz, Llor Esteban, \& Ruiz Hernández (2012), Chuliá Fernández (2014) y Chagoyen Barroso (2016), entre otros.

Lameiro et al., (2013), para el período comprendido entre 2005 y 2011,observaron una evolución en las características de las agresiones estudiadas, destacando el aumento de las verbales. No obstante, sus datos globales reflejaron un alto número de agresiones físicas, que explican los autores por la inclusión específica de unidades de psiquiatría y también por la infradeclaración de las agresiones verbales. Castro Corredoira \& Guinarte Cabada (2015) obtuvieron un número mayor de incidentes de tipo físico y lo atribuyeron también a esta última razón.

En nuestro caso, resulta de interés señalar que la mayor parte de los encuestados refiere haber recibido agresiones verbales en más de tres ocasiones (29\%), lo que puede dar idea de una gran incidencia de la producción múltiple de este tipo de agresiones. También puede deberse a una mayor tendencia a valorar negativamente actitudes que no se juzgarían tan relevantes de no haber mediado con anterioridad otra agresión del mismo tipo. Ese pudiera ser, por ejemplo, el caso de las amenazas, que generan un estado anímico de ansiedad y miedo, proclive a hipervalorar situaciones de hipotético peligro. 
Hemos de concluir que en nuestro estudio las agresiones verbales superan a las físicas, siendo igualmente más numerosas las agresiones múltiples en el caso de las verbales $(44,5 \%$ frente a $11 \%)$.

\section{TIPOLOGÍA DEL AGRESOR}

En lo relativo a la tipología del agresor (si se trató de un paciente, de un acompañante del mismo o de un compañero de trabajo), obtuvimos porcentajes similares en los dos primeros casos: $57,6 \%$ y $55,5 \%$, con una ligera mayoría de pacientes agresores, como puede apreciarse.

Coincidimos en estos resultados con los aportados por otras investigaciones ${ }^{415}$, por ejemplo la realizada por De-San-Segundo et al. (2016), donde se recogieron datos parecidos a los nuestros: $56,9 \%$ de pacientes agresores y $45,3 \%$ acompañantes.

En cambio, otros autores encontraron diferencias mayores entre ambos grupos ${ }^{416}$ : Lameiro et al. (2013) un $85 \%$ de casos en que el agresor era un paciente frente a sólo un $15 \%$ en que lo fue el acompañante ${ }^{417}$, Martínez-Jarreta y col. (2007) un 85\% de pacientes agresores. Ortells Abuyé et al. (2013) obtuvo todo lo contrario: un $81 \%$ de acompañantes agresores (aunque esto hay que ponerlo en relación con el hecho de que su estudio se realizara en un servicio de urgencias, donde el nerviosismo y la ansiedad de los familiares puede ser mucho mayor que en otros ámbitos ${ }^{418}$ ). Gutiérrez et al. (2016) observaron que existía una relación entre tipología de agresor y clase de agresión, constatando que los acompañantes ejercen con mayor frecuencia tipos de violencia verbal.

La violencia interna es mucho menos frecuente, pero no por ello deja de estar presente y ser importante en el desarrollo de la actividad profesional. Nuestros datos reflejan un $16,1 \%$ de agresiones procedentes de los compañeros de trabajo o miembros de la propia organización, lo que puede parecer un porcentaje bajo. Pero no debemos olvidar la gravedad del hecho de que sean

\footnotetext{
${ }^{415}$ En este aspecto, los resultados de otras investigaciones resultan muy variados.

${ }^{416}$ Esto puede deberse a la tipología específica del ámbito en que algunos de estos autores desarrollaron su estudio ${ }^{417}$ Esta mayor incidencia se explica, según los propios autores, por la presencia de las unidades de psiquiatría y por infradeclaración de las formas verbales de violencia, como hemos reseñado en el apartado dedicado a la incidencia de las agresiones verbales.

${ }^{418}$ En estos servicios, el familiar muchas veces se ve obligado a permanecer durante mucho tiempo en la sala de espera, sin tener demasiada información sobre qué le está sucediendo al paciente al que acompañaba, que se encuentra en un «box». En algunos Planes de prevención específicos se contempla esta cuestión, por ejemplo, La Rioja (2008) establece que habrá personal sanitario dedicado únicamente a proporcionar información periódica a los familiares en los Servicios de Urgencias, así como garantizar que pueda acompañarse al enfermo cuando así lo aconseje su patología o sea un niño o anciano.
} 
los propios compañeros o directivos los que ejerzan la violencia, con los nefastos y perniciosos efectos que ello provoca en la actividad asistencial ${ }^{419}$.

\section{AGRESIONES Y SEXO DEL/A AGRESOR/A Y DE LA VÍCTIMA}

En lo que se refiere al sexo de la persona agresora, se encontraron más agresiones perpetradas por hombres que por mujeres, en términos absolutos. Los agredidos manifestaron haber sido atacados por un hombre en el 50,4\% de los casos, siendo una mujer la agresora en un 39,9\%.

Estos resultados concuerdan con los obtenidos por otros autores, que incluyeron la variable sexo para determinar un perfil de agresor. Mayorca Yancán et al., (2013) establecieron como perfil: varón de 42 años de promedio que cree que lleva demasiado tiempo esperando a que le atiendan; para Chagoyen Barroso (2016) es un varón entre 31 y 40 años. También De-San-Segundo et al. (2016) concluyeron que los agresores eran mayoritariamente hombres (58,2\%). Este porcentaje es un poco más alto, pero similar al que hemos recogido en nuestro estudio, que refleja que el $50,4 \%$ de las agresiones las cometen hombres.

Lo que puede ser más relevante, según nuestros datos, es observar que las agresiones cometidas por una persona del sexo masculino son más frecuentes, superando las agresiones múltiples (más de una vez) en porcentajes siempre al sexo femenino. Sólo son más numerosos los actos violentos perpetrados por mujeres en el caso de una única agresión (14,8\% hombre-16\% mujer).

Fue significativa estadísticamente la relación que establecimos entre sexo del agresor-sexo del agredido, revelando un porcentaje de $54 \%$ de hombres que atacan a mujeres. A más distancia se encuentran las mujeres que agreden a mujeres $(43,3 \%)$ y los hombres que agreden a hombres (43\%). Sólo un 31,3\% de las mujeres agredieron a un hombre.

Esta situación se correlaciona con lo siguiente: la relación existente entre agresiones producidas y sexo de la víctima, que también fue estadísticamente significativa. Un 59,7\% de mujeres declaró haber sufrido alguna agresión en nuestro estudio (lo cual es muy llamativo, si tenemos en cuenta que supera el porcentaje total de agredidos entre nuestros encuestados, que fue de un 55,4\%, y que hemos considerado un índice de agresiones bastante elevado).

Estos resultados coinciden con los evidenciados en otros estudios, que hallaron porcentajes aún más altos en número de mujeres agredidas: Gutiérrez et al. (2016) hallaron un 75\% de mujeres

\footnotetext{
419 En la última pregunta del cuestionario obtuvimos la siguiente respuesta, relacionada con esta cuestión: «Métodos para evitar el acoso por parte de superiores y jefes de servicio, o al menos poder denunciarlos y tener efectos del tipo que pueda ser un motivo para que esa persona se jubile a la edad que debe y no se le concedan prórrogas».
} 
frente a un 25\% de hombres. También coinciden con esta cuestión Mayorca Yancán et al. (2013), que refieren un $80,3 \%$ de mujeres víctimas de agresión.

Parece haber una diferencia notable entre la posibilidad de sufrir agresiones según el sexo del profesional sanitario, siendo claramente más alto ese riesgo en el caso de ser mujer ${ }^{420}$.

\section{LUGARES DONDE SE PRODUJERON LAS AGRESIONES}

En nuestro estudio obtuvimos un índice de agresiones mayor en consultas (39,3\%), seguidas de hospitalización $(28,5 \%)$, urgencias $(26,9 \%)$ y pasillos $(22 \%)$. Los restantes lugares obtuvieron porcentajes sensiblemente inferiores $(8,2 \%$ mostradores de atención; $4,7 \%$ domicilio del paciente; $3,3 \%$ vía pública; $2,3 \%$ puertas y el resto se agrupó en un conjunto de ubicaciones heterogéneas).

Algunos estudios obtuvieron porcentajes muy altos de agresiones en los servicios de Urgencias. Miret \& Martínez Larrea (2010) destacan que estos servicios son grandes generadores potenciales de estrés, amén de soportar una gran presión asistencial y niveles altos de responsabilidad. Todo ello hace que los profesionales se encuentren sometidos a factores estresores importantes ${ }^{421}$ que pueden dar lugar a situaciones conflictivas. Resulta de especial interés la relación que establece este estudio entre el síndrome de «burn-out» entre los profesionales y la producción de agresiones: el personal sanitario con desgaste profesional genera actitudes reactivas que pueden ser contraproducentes y retroalimentar la situación de agresividad y violencia, algo que observan por las razones señaladas- muy especialmente en los servicios de urgencias.

Otros trabajos encontraron también altos índices de violencia en estos servicios (Gates et al., 2006), (Ray, 2007), (Pawlin, 2008). En nuestro caso, los valores fueron importantes, pero no supusieron la mayoría de los actos agresivos. Tal vez la razón estribe en que los estudios citados se centraron precisamente en los servicios de urgencias, y en el nuestro se haya incluido también otros servicios hospitalarios y extrahospitalarios. No obstante, el COMB (2004) también halló un porcentaje más alto comparando diversos servicios (45\%).

En este sentido, hemos de observar que nuestro mayor porcentaje se obtuvo en consultas y en segundo puesto quedaron los espacios de hospitalización.

De-San-Segundo et al. (2016) hallaron resultados más parecidos a los nuestros, aunque las urgencias siguen encabezando el elenco de ubicaciones: 35,5\% urgencias; 33,9\% en

\footnotetext{
${ }^{420}$ En la siguiente respuesta de nuestro cuestionario puede verse cómo el/la encuestado/a relaciona las agresiones con un cierto grado de misoginia: «Vivimos en una sociedad un tanto ignorante, machista, que minusvalora el trabajo de los profesionales».

421 Señalan también que los profesionales de urgencias «...están sometidos a intensas exigencias por parte de los pacientes y familiares, excesivas horas de trabajo, falta de descanso, situaciones de riesgo y peligrosidad y, por ello, son lugares de especial riesgo para producir desgaste profesional» (Miret \& Martínez Larrea, 2010, p. 199).
} 
hospitalización. En cuanto a las consultas, encontraron un 12,4\%, pero con la salvedad de que dentro de Atención Primaria el porcentaje alcanzaba un 63,9\%.

Lameiro et al. (2013) obtuvieron mayores tasas de agresiones en hospitalización (como en nuestro caso) que en urgencias ${ }^{422}$, aunque en su estudio los valores más altos se daban en las unidades de Psiquiatría (52\%).

Estos resultados pueden relacionarse con la condición común de ambos espacios: ser lugares donde se produce una mayor interacción con el paciente. Como vimos cuando encontramos mayores tasas de agresión hacia médicos y personal de enfermería, este mayor contacto con el usuario es determinante para el riesgo de que se produzcan agresiones. En las consultas, además, pueden darse más situaciones conflictivas, como la expedición de recetas o las certificaciones de bajas laborales ${ }^{423}$.

\section{MEDIDAS TOMADAS POR LA VÍCTIMA TRAS LA AGRESIÓN}

Constituye un aspecto importante conocer qué actuaciones realizó la persona agredida tras recibir la agresión. Por una parte, la mayoría de las investigaciones indica que hay un alto porcentaje de «infranotificación» de los episodios violentos (Fernández Martín et al., 2006), (Ortells Abuyé et al., 2013), lo cual dificulta mucho la comprensión del problema y la toma de medidas eficaces para evitarlo (Montalvo Jääskeläinen \& Pinedo García, 2011) (Marinas-Sanz et al., 2016). Esto evidencia una tendencia de los profesionales sanitarios a no comunicar los hechos y, por tanto, a no reaccionar contra los mismos, evitando que la agresión trascienda.

Partiendo de esas premisas, consideramos que son varias las razones por las que las víctimas no toman medidas ni dan noticia de los actos violentos.

En nuestro cuestionario, se preguntó a aquellas personas que declararon no haber hecho nada tras la agresión sufrida, la razón que les movió a esa inacción.

Encontramos una mayoría de encuestados que manifestaron haber comunicado el suceso a la Dirección o Coordinación de su centro de trabajo (49,3\%), pero sólo un 9,4\% lo denunció a la Policía o Guardia Civil y un exiguo 3,3\% lo comunicó a su Colegio profesional.

\footnotetext{
$42229 \%$ y $14 \%$, respectivamente. Núñez \& Zubillaga, (1999) hallaron igualmente un porcentaje muy similar (aunque algo inferior) al nuestro en agresiones en urgencias generales: un $21,3 \%$.

${ }^{423}$ Un caso de agresión por desacuerdo respecto a una baja laboral puede verse en la SAP Madrid 125/2017, de 24 de febrero. En cuanto a problemas con expedición de recetas, entre otras: SAP Madrid 540/2016, de 18 de julio.
} 
La principal razón por la que el 38\% de los entrevistados afirmaron que no habían tomado medidas fue considerar que lo sucedido no era grave o formaba parte del trabajo (24\%). Este dato coincide con lo evidenciado en otras investigaciones: que existe una tendencia importante a minimizar las agresiones, considerándolas como «gajes del oficio» (Lameiro et al., 2013) (Mayorca Yancán et al., 2013) (Ortells Abuyé et al., 2013). En servicios con pacientes en circunstancias mentales y patológicas especiales, este convencimiento de los profesionales prácticamente se generaliza (Fernández Martín et al., 2006) (Villar Doncel \& Aranaz Andrés, 2006), y se relaciona con empatizar con las situaciones estresantes de los pacientes (Paravic Klinj, Valenzuela Suazo, \& Burgos Moreno, 2004).

\section{APOYO PERCIBIDO POR EL PROFESIONAL AGREDIDO}

Cuando por desgracia no puede prevenirse una agresión y ésta se lleva a efecto, resulta importantísimo actuar sobre la víctima.

Todos los planes de prevención, inciden sobre las acciones a emprender cuando las medidas preventivas han fallado y es necesario apoyar al profesional que ha padecido el incidente violento. Este apoyo ha de ser percibido como real por el interesado, a través de actuaciones concretas. Los diferentes protocolos de actuación contra agresiones especifican los pasos a seguir tras el suceso y suelen incluir la actuación del superior jerárquico, que debe comunicar los hechos a instancias superiores y asesorar en todo lo preciso al trabajador afectado ${ }^{424}$.

Se preguntó a los encuestados que manifestaron haber sufrido alguna agresión hasta qué punto se habían sentido apoyados por tres grupos: Dirección o Coordinación del centro o servicio, compañeros y resto del personal.

En el primer caso (el apoyo percibido por parte de la Dirección o Coordinación del centro o servicio), un 53,7\% manifestaron falta de apoyo en algún grado, frente a un 46,3\% que dijeron haberse sentido apoyados. Pero, con ser alto el porcentaje general de falta de apoyo -más de la mitad-, más llamativo es aún que un 35,3\% manifestaran que no les habían apoyado en absoluto (cifra muy alta, considerando lo extremo de la afirmación).

\footnotetext{
424 Todo esto lo hemos considerado en el epígrafe «Los planes de prevención de agresiones a los profesionales sanitarios» y también en el apartado de esta Discusión dedicado a las "Consideraciones sobre el Derecho laboral ante las agresiones al personal sanitario».
} 
Creemos que estos datos muestran que los profesionales no perciben apoyo por parte de sus superiores que, por otra parte, son los obligados legal y reglamentariamente a prestárselo ${ }^{425}$.

El apoyo por parte de los compañeros alcanzó un 93,6\% que afirmaron haberse sentido apoyados en mayor o menor medida. Como puede observarse, la tendencia se invierte por completo, sobre todo porque el sentimiento de sentirse «completamente apoyado» llegó a un 37,7\%. Es decir, quienes creyeron recibir un apoyo nulo de la Dirección o Coordinación representan un porcentaje muy similar a los que declararon haber recibido un apoyo total por parte de sus compañeros.

El resto del personal ofreció apoyo en algún grado en un $86,4 \%$, lo que le acerca al prestado por los compañeros del agredido. Este porcentaje se encuentra en consonancia también con el 29,3\% que dijo haberse sentido completamente apoyado: también un poco má s bajo que 1 a c i fr a correspondiente en el caso de los compañeros.

Todo ello nos lleva a considerar que los compañeros son los que más apoyan (o al menos el interesado lo percibe así), con porcentajes verdaderamente altos, seguidos del resto del personal con cifras también bastante elevadas. Por el contrario, el apoyo percibido por parte de la Dirección-Coordinación es muy escaso, alcanzando cifras representativas incluso el apoyo nulo.

Esa falta total de apoyo percibido se corresponde casi de forma especular con el sentimiento de apoyo total por parte de los compañeros y, en menor medida pero también, del resto del personal.

Resulta verdaderamente preocupante que los profesionales no se sientan apoyados por sus directivos y superiores, lo que nos lleva a reflexionar sobre si los protocolos de atención posteriores a los episodios violentos son en verdad eficaces o si tan siquiera se cumplen ${ }^{426}$.

Piénsese en que la práctica totalidad de los PPRL establecen con meridiana claridad que es el superior inmediato del sanitario afectado quien debe tomar las riendas de la situación, comunicar el incidente y, sobre todo, prestar el apoyo y ayuda necesarios a la víctima.

La actuación del superior es fundamental: si no se produce o no es adecuada se rompe el hilo de las demás acciones, que devienen ineficaces e incluso inútiles.

\footnotetext{
${ }^{425}$ Algunas de las propuestas recibidas en la última pregunta del cuestionario incidieron en este tema, por ejemplo: «Implicarse la administración y ser ellos los que pongan las denuncias y defiendan a los trabajadores, para ellos son los gerentes y garantes de la salud de los trabajadores».

426 Franco González (2015) llama la atención sobre "el habitual "papel mojado" que suele adornar formalmente la política preventiva de las empresas (sin contenido real o sin voluntad de asunción». Ortells Abuyé et al. (2013) advierten que no basta con diseñar un plan: hay que implantarlo y difundirlo. En este caso, no tenemos información sobre hasta qué punto existe una buena implantación de los planes, pero debemos insistir en la importancia de esta cuestión.
} 
Esto es grave porque, además de constituir una disfunción importante en las acciones que deben emprenderse ante las agresiones, influye directamente en el fenómeno de «infradenuncia»o «infranotificación».

En efecto, no se puede pretender que el profesional se anime a comunicar los hechos violentos cuando percibe que sus superiores no le van a dar apoyo, o al menos, no el suficiente. La OSHA incide en su último informe en la relación entre notificación de los incidentes y el respaldo sentido por los trabajadores por parte de los directivos, resaltando además la gran importancia de este factor en la prevención de la violencia (O.S.H.A. Occupational Safety and Health Administration., 2016).

Por todo ello, creemos que debe ponerse énfasis en cambiar este estado de cosas porque las consecuencias pueden ser muy negativas. En primer lugar, señalan Martínez-Jarreta et al., (2007) que el apoyo percibido actúa como modulador de los efectos psíquicos de las agresiones, por lo que un profesional agredido que no se ha sentido apoyado posiblemente desarrolle cuadros patológicos más intensos (Miret \& Martínez Larrea, 2010) (Gascon et al., 2013), se desanime y genere actitudes reactivas, que repercutirán en el funcionamiento de la organización y probablemente alimente la espiral de las agresiones, aumentando el riesgo de volver a sufrirlas.

Además, como acabamos de señalar, si los profesionales creen que no se les apoya, difícilmente comunicarán las agresiones y el problema de la «infradenuncia» irá en aumento.

En cualquier caso, independientemente de las consecuencias nefastas que ello puede generar, el profesional ha de ser apoyado por sus directivos porque es justo, lógico y porque así se determina en los PPRL y la inacción en este sentido constituye un incumplimiento empresarial del que se derivan (como hemos visto en la primera parte de esta Discusión) una serie de responsabilidades.

\section{PROFESIONALES QUE HAN PRESENCIADO UNA AGRESIÓN}

Preguntamos a nuestros entrevistados sobre este tema, con la intención de medir con más profundidad el volumen de agresiones que puede estarse produciendo en los centros y servicios sanitarios.

En nuestra opinión, el hecho de no haber sufrido agresiones no significa ausencia de violencia: el profesional afortunado que no ha sido víctima de ningún ataque puede, sin embargo, haber sido testigo de esta violencia.

Más de la mitad de los encuestados (57,3\%) declararon haber sido testigos de agresiones al menos una vez. De ese porcentaje total, nada menos que un $60 \%$ dijo que había presenciado en tres o 
más ocasiones, y lo más alarmante de todo es que un $52 \%$ del porcentaje total de testigos de agresión dijo que había visto más de tres agresiones.

Quisimos contrastar estos datos con el sector (sanidad privada, pública o ambas) en que trabajaban nuestros entrevistados para conocer dónde podían darse más episodios violentos. La relación fue estadísticamente significativa y arrojó un $67,9 \%$ de agresiones presenciadas en quienes prestaban sus servicios en ambos sectores, un 65,4\% en la sanidad pública y un 32,1\% en la privada.

Es probable que la cifra más alta proveniente de quienes trabajan en sanidad pública y sanidad privada, se obtenga por una mayor incidencia de agresiones en la parcela pública, que estos encuestados comparten con la privada. En cualquier caso, obtenemos resultados coherentes con otros estudios que hallaron un mayor número de agresiones en la sanidad pública.

La frecuencia de la violencia que refieren nuestros encuestados es verdaderamente alta, lo que nos lleva a pensar en lo elevada que puede ser la infradenuncia. No podemos conocer qué porcentaje de agresiones vistas por otros fueron efectivamente notificadas, pero da la sensación de que, como afirman también la mayoría de los autores (hemos aludido a ello con anterioridad), hay un gran número de agresiones no declaradas.

Por otra parte, parece que la incidencia de agresiones sigue siendo mayor en la sanidad pública y más si, como señalamos en párrafos anteriores, aceptamos que sería posible que un buen número de las presenciadas por el grupo «mixto» lo hayan sido en centros públicos. Aun prescindiendo de esta consideración, el porcentaje es claramente más elevado. 


\section{LA VALORACIÓN DE LOS ENCUESTADOS SOBRE LAS MEDIDAS ADOPTADAS CONTRA LAS AGRESIONES EN LOS DIFERENTES ORDENAMIENTOS JURÍDICOS}

En aras de una mayor claridad expositiva, vamos a seguir en este epígrafe el mismo orden que utilizamos en los capítulos dedicados al tratamiento de cada ordenamiento jurídico de las agresiones al personal sanitario.

\section{A) ACTUACIONES EMPRENDIDAS DESDE EL ORDEN SOCIAL}

En este apartado intentaremos analizar la evaluación que nuestros encuestados realizan en torno a las medidas anteriores y posteriores a la existencia de una agresión adoptadas en los Planes de Prevención

\section{1.- LOS MOTIVOS DE LAS AGRESIONES}

Uno de los aspectos en que más inciden las distintas investigaciones es en la búsqueda de las razones por las que se producen los actos violentos. Y esto es así porque el conocimiento de los motivos debería llevar a la toma de acciones eficaces para la prevención de estos sucesos: si se elimina la causa, se suprimirá el resultado. En nuestra opinión, por consiguiente, como decíamos en el apartado «Consideraciones sobre el Derecho laboral ante las agresiones al personal sanitario», es fundamental encontrar esos motivos que allí denominábamos «motivos-diana».

Como hemos visto en la Introducción, la evolución de la tipología de agresiones parte de un tipo de violencia «tradicional», protagonizada por enfermos psiquiátricos o con alguna modalidad de adicción, a otro modelo en que el agresor es una persona sin estos condicionantes, y está motivada por razones muy distintas.

Los diferentes autores apuntan a una serie de posibles motivos por los que el usuario se vuelve agresivo y ejerce violencia contra el profesional. Miret \& Martínez Larrea (2010) señalan que los pacientes y acompañantes se sienten frustrados y vulnerables, perdiendo el control; esto incidiría en que el profesional con más contacto e interacción con el público es quien presenta más riesgo de sufrir una agresión, como ya hemos observado cuando comentábamos el alto índice de agresiones encontrado entre el personal de enfermería y facultativos.

Por nuestra parte, insistimos en la idea de que conociendo el motivo se podrán tomar medidas más eficaces para erradicar el problema. Por eso, al inquirir de los profesionales encuestados su opinión sobre las medidas que se han ido tomando en los diferentes Planes de Prevención, 
valoramos como más relevante conocer primero a qué atribuyen los propios profesionales el que se produzcan agresiones ${ }^{427}$.

En primer lugar, nos planteamos indagar sobre la posibilidad de que los hechos violentos se entiendan o no como algo evitable o, por el contrario, puedan ser considerados acontecimientos impredecibles.

Mayorca Yancán et al. (2013) observaron que la mayoría de los trabajadores creían que las agresiones no se podían haber prevenido, y añaden que «este dato se podría explicar por la sensación por parte del trabajador, de no tener control sobre el sistema» (p. 254).

Por el contrario, en nuestro caso, la mayoría de los encuestados $(56,9 \%)$ estimaron que sí había existido una razón para que la agresión se produjera, y sólo un $20,9 \%$ creyó que había sido un evento imposible de evitar o prevenir.

La disconformidad con la asistencia recibida se configura, según la OMC, como el principal motivo por el que se producen sucesos violentos. En su «Informe nacional de agresiones 2016», las «discrepancias con la atención médica» alcanzaron un porcentaje del $42,8 \%$, siendo el mayor de los registrados (Organización Médica Colegial, 2016).

Otros autores inciden igualmente en ello: Lameiro et al., (2013) encontró un 8\% de agresiones que tuvieron que ver con la disconformidad con el tratamiento o las terapias; Ortells Abuyé et al. (2013) lo señalaron como una de las razones de más incidencia en su estudio, al igual que Gutiérrez et al. (2016).

La importancia de este motivo, como parece deducirse de dichos estudios, coincide con los datos observados en nuestro trabajo: un $76,6 \%$ de los encuestados entiende que estas discrepancias tuvieron algún tipo de influencia en la producción del incidente.

Algunos estudios indican la mayor incidencia de agresiones, sobre todo de tipo físico (Mayorca Yancán et al., 2013), en las unidades de Psiquiatría (Martínez-Jarreta et al., 2007) (Miret \& Martínez Larrea, 2010). Núñez \& Zubillaga (1999) encontraron un 53,7\% de agresiones en las unidades psiquiátricas de un hospital. Sin embargo, Lameiro et al. (2013) encontraron como motivos de los ataques un 32\% de pacientes con diagnóstico de enfermedad mental y/o contención de los mismos (37\%).

\footnotetext{
${ }^{427}$ En la última pregunta del formulario, y referente a esta cuestión, obtuvimos la siguiente respuesta: «creo que tenemos que entender lo que provoca estas agresiones»
} 
En nuestro estudio, los resultados son similares a los obtenidos por estos últimos autores: Se atribuyó una influencia de las enfermedades psiquiátricas en las agresiones (lo que indicaría que esos actos violentos fueron cometidos por pacientes psiquiátricos) de un $35,5 \%$.

El tiempo de espera prolongado o excesivo es señalado por varios trabajos (Mayorca Yancán et al., 2013) (Moreno Jiménez et al., 2005) (Gutiérrez et al., 2016) (Carrasco Rodríguez, Rubio González, Vílchez Castellano, \& Villalobos Buitrago, 2007) e, incluso, por los PPRL ${ }^{428}$ como una de las razones por las que pueden producirse actos violentos. La OMC, en su «Informe nacional de agresiones 2016» observó un 15\% de agresiones que se cometieron por este motivo.

En nuestro estudio se encontró un porcentaje de 43,7\% de encuestados que atribuían a esta razón la agresión sufrida, frente a un $56,3 \%$ que no creyeron que hubiera sido ese el desencadenante de la violencia, siendo evidentemente este último porcentaje mayoritario.

Por tanto, cabe concluir que nuestros entrevistados no piensan que los tiempos de espera prolongados fueran el principal motivo de la agresión.

Las peticiones insatisfechas (como, por ejemplo, la no concesión o prórroga de una baja laboral, la expedición de recetas, etc.) fueron la razón de las agresiones, según nuestros encuestados, en un $69 \%$. En algunas ocasiones, la violencia ejercida contra un profesional que se niega a dar o prorrogar una baja laboral es tan grave, que termina en los tribunales (por todas: SAP Madrid (sección $6^{\text {a }) ~ 125 / 2017, ~ d e ~} 24$ de febrero).

La falta de comunicación con el agresor o la existencia de fallo en la misma ha sido señalada como posible desencadenante de una agresión (Gutiérrez et al., 2016).

De los datos obtenidos en nuestro estudio no se desprende que ésta sea la causa a la que los encuestados achaquen la agresión: la mayoría piensa que ese no fue el motivo (54,4\%). Esto contrasta con la importancia que parecen darle a la formación en estrategias de comunicación.

Resulta de interés reflexionar sobre la influencia que puede tener el estado anímico del usuario en el surgimiento de un episodio violento. No debemos olvidar que en ciertos espacios sanitarios se generan, por la propia naturaleza del servicio, situaciones de bastante estrés y nerviosismo para los pacientes y sus acompañantes.

${ }^{428}$ Sirvan de ejemplo Región de Murcia (2004), Madrid (2004) o La Rioja (2005), entre otros. 
Ese estado emocional puede constituir un caldo de cultivo generador de comportamientos violentos. Mayorca Yancán et al. (2013) encontraron que la ansiedad (que asocian también a las esperas prolongadas) fue una causa muy importante en las agresiones.

Coincidimos con esta apreciación. En nuestro caso, se subraya también la importancia de este motivo al que los encuestados concedieron una gran relevancia $(81,8 \%)$.

Existen estudios en los que se hace hincapié en la valoración que los pacientes realizan de sus derechos, sin apreciar que también tienen deberes que cumplir (Martínez-Jarreta, 2011) y que este convencimiento, al que contribuyen las declaraciones de derechos numerosos que contrastan con listados de deberes más exiguos (Martínez-Jarreta et al., 2007) daría lugar a un comportamiento exigente en el usuario, que desembocaría en algunos casos en situaciones de violencia.

Por nuestra parte, si atendemos a los datos que hemos obtenido, coincidimos con ese planteamiento: los profesionales encuestados han mostrado conceder importancia también a esta cuestión, con un porcentaje de $76,4 \%{ }^{429}$.

En conclusión, la panorámica de motivos que pueden desencadenar un acto violento es amplia y la valoración de la doctrina respecto a ellos difiere en ocasiones.

En nuestro trabajo, a partir de los datos aportados por los encuestados sobre cuáles son los motivos desencadenantes de agresiones a los que otorgan relevancia, encontramos que la razón principal sería el estrés y nerviosismo del paciente o acompañantes $(81,8 \%)$, seguida de la disconformidad con la asistencia recibida $(76,6 \%)$, la apreciación de ostentar derechos sin deberes correlativos $(76,4 \%)$ y las peticiones insatisfechas $(69 \%)$.

La primera de las causas tendría que ver con las esperas prolongadas con ausencia de información o falta de información sobre diferentes cuestiones, o con las inevitables situaciones de ansiedad provocadas por situaciones sanitarias estresantes ${ }^{430}$. Las demás motivaciones pueden relacionarse

\footnotetext{
${ }^{429}$ Algunas de las respuestas de la última pregunta del cuestionario en este sentido son: «Que los cargos directivospolíticos no prometan un paraíso sanitario a los pacientes, llenos de derechos y sin ninguna restricción, a la vez que asignan a los profesionales sanitarios la labor de poner en práctica esas restricciones y normas. Si hay limitaciones, recortes y deberes de los pacientes, que sean ellos quienes los afronten", "Rectificación del libro "Derechos y deberes del usuario"». "Sólo una página son los deberes y demasiados los derechos».

430 Un entrevistado dijo: «Pienso que los profesionales sanitarios deben informar debidamente al paciente y familiar de lo que ocurre; por ejemplo, el paciente es operado, la operación según el cirujano sale de maravilla, le van a dar de alta el lunes y se muere un domingo; ¿qué es lo que pasa ahí? Yo no voy a poner en duda la eficacia de la operación, no, pero se supone que ese paciente muere por una infección interna, de algún punto de la herida que se infecta...¿ipor qué el cirujano no ve esa infección? ¿no es su competencia? ¿por qué el internista no se ocupa del paciente una vez operado y analiza esa herida?»
} 
con cuestiones referidas a la organización del trabajo, aspecto último en el que coincidimos con Núñez \& Zubillaga (1999).

La falta de comunicación, los tiempos de espera, las enfermedades psiquiátricas y la agresión fortuita ocupan los últimos puestos en la apreciación de los encuestados como posibles razones de los ataques producidos.

Delimitada la cuestión de cómo valoran los profesionales encuestados los «motivos-diana», es decir, qué relevancia tienen para ellos las diferentes posibles causas de surgimiento de agresiones que les habían sido propuestas, pasamos a evaluar su visión sobre las distintas medidas que se han ido tomando a partir de los Planes de Prevención que hemos desarrollado detalladamente en la parte dogmática de este estudio.

En nuestra encuesta habíamos inquirido a los participantes sobre la opinión que les merecían las medidas que parecieron más representativas, de entre las previstas en los Planes de Prevención que hemos analizado en el apartado «Los planes de prevención de agresiones a los profesionales sanitarios», pero con referencia específica -en este caso-al de Castilla y León, que es el ámbito en el que prestan sus servicios los profesionales entrevistados.

En dicho apartado, distinguíamos entre medidas previas y medidas posteriores a la producción de una agresión.

En cuanto a las medidas previas, establecíamos una clasificación de los diferentes medios en físicos y humanos, atendiendo preferentemente al agente que provee la seguridad.

Por lo que se refiere a los medios físicos, las propuestas incluidas en el cuestionario y las opiniones de los encuestados sobre ellas fueron las siguientes:

El «botón antipánico» o botón de alerta, obtuvo una valoración bastante positiva (un $71 \%$ lo consideró en términos de eficacia), contra un $23,9 \%$ que estimó en mayor o menor medida que resultaba ineficaz.

Las salidas alternativas de las consultas tuvieron un porcentaje de eficacia de un $56 \%$, frente a un $30,9 \%$.

Las videocámaras fueron para nuestros encuestados eficaces en un $73 \%$, contra un $21,7 \%$ que, en diferente grado, consideró la medida ineficaz. 
La colocación de carteles, como parte de campañas de sensibilización (aspecto contemplado explícitamente en los documentos de Castilla y León reiteradamente) arrojaron datos de un 60,2\% que lo consideró en un grado mayor o menor como ineficaz, frente a un 37,3\% que sí valoraba la medida.

En cuanto a medios humanos, se les preguntó sobre si los cursos de formación en habilidades de evitación de conflictos, empatía, etc., resultaban de utilidad. Se obtuvo un 72,2\% de valores acumulados que representaban una eficacia en mayor o menor medida, frente a un $24,2 \%$. Por tanto, resulta una medida evaluada positivamente.

La vigilancia de seguridad obtuvo el porcentaje más alto en la valoración positiva de todas las medidas sobre las que fueron consultados: un $84,8 \%$ consideró su eficacia contra sólo un $12,1 \%$.

Del análisis del conjunto de estos porcentajes en torno a las medidas de ambos tipos susceptibles de adoptarse en orden a prevenir las agresiones, se deducen las siguientes valoraciones de nuestros encuestados:

Los profesionales que han respondido al cuestionario valoran mucho más la existencia de medidas de seguridad que suponen una acción directa, como la presencia de vigilantes de seguridad. En cuanto al resto, las videocámaras, seguidas de los dispositivos de alarma obtuvieron buenos resultados. La formación del profesional en técnicas de evitación de conflictos también fue bien valorada. Los resultados más discretos (aunque positivos) se obtuvieron en cuanto a la colocación de carteles informativos y disuasorios y respecto a las salidas alternativas.

En cuanto a las medidas posteriores a la producción de la agresión, nos limitamos a hacer una breve relación que ni siquiera será exhaustiva, puesto que de ellas nos ocuparemos al valorar lo relativo a otros ordenamientos distintos del que ahora nos ocupa.

Nos referimos a la actuación de las diversas instituciones: la carta de rechazo, el teléfono de asistencia jurídica y las medidas sancionatorias, tanto administrativas como penales, entre otras posibles actuaciones.

Únicamente queremos aquí hacer una observación sobre la denominada «carta de rechazo». Se trata de una carta que se dirige al autor del incidente, manifestándole la importancia de los hechos y conminándole a que no repita su actuación, con expresa mención de las consecuencias que pueden derivarse de sus actos. La valoración de nuestros encuestados no fue positiva, como puede verse en los siguientes porcentajes: un $29,8 \%$ creyó que era poco eficaz (el valor más alto de las 
respuestas a la pregunta), un $21,8 \%$ que la consideró completamente ineficaz (lo que, para una afirmación tan extrema, resulta un porcentaje bastante significativo) y un $17,1 \%$ ineficaz. $\mathrm{Si}$ añadimos que un $6,7 \%$ no se pronunció sobre la medida, tendremos que sólo un $24,5 \%$ apoyaba de algún modo esta actuación.

Son datos que consideramos muy relevantes por las razones que aduciremos al hablar de la valoración sobre las medidas de carácter administrativo.

\section{2.- REASIGNACIÓN DEL AGRESOR}

Para finalizar, queremos hacer mención a una medida específica que se propone en algunos Planes de Prevención, como el de Navarra, por ejemplo. Aunque no se contempla en la normativa vigente en la comunidad de Castilla y León, nos pareció de interés y, por tanto, la propusimos también a la valoración de nuestros encuestados.

Esta medida es la posible reasignación del paciente agresor a otro profesional o, incluso, a otro centro sanitario. Se supone que, si existen conflictos entre sanitario y paciente, serán neutralizados con este traslado.

Preguntamos a nuestros encuestados sobre su opinión acerca de esto: un 47,4\% creyó la medida eficaz, frente a un 44,8\% que no lo estimó así. El 7,8\% no la valoró.

Podemos observar cómo ninguno de los grupos llega a la mitad del total de los entrevistados, lo que ofrece una valoración muy tibia tanto en un sentido como en otro (quizás con una ligera inclinación hacia la eficacia de la medida). También parece existir una cierta indecisión, entre pensar si serviría o no para disminuir las agresiones.

Hemos de tener en cuenta que esta medida no deja de ser una traslación del problema de un profesional a otro. En el caso de que el conflicto sea puntual y haya alcanzado cierto grado de personalización, desde luego que cambiar al paciente puede ser útil. Pero cuando no es así, nada garantiza que el mismo paciente no tenga en el futuro otro problema con otro profesional o viceversa: que el profesional no tenga otro problema con otro paciente trasladado desde otro lugar.

Es de suponer que el encuestado, si se ha puesto en el lugar del que tiene el conflicto, tenderá a responder que la medida le parece eficaz; pero si el rol que ha adoptado ante la pregunta es la de quien tiene que recibir a un paciente conflictivo, su respuesta habrá sido negativa. 
Por ello concluimos que la medida resulta controvertida y es valorada por nuestros encuestados de forma ambigua, probablemente por los condicionantes que acabamos de describir ${ }^{431}$.

\section{B) ACTUACIONES EMPRENDIDAS DESDE EL ORDEN ADMINISTRATIVO}

\section{1.- POSIBLES MEDIDAS A ADOPTAR POR LA ADMINISTRACIÓN}

En nuestro formulario, incluimos varias cuestiones en las que se pretendía obtener la opinión de los profesionales encuestados sobre medidas tomadas por la Administración cuando se produce una agresión. Una de las acciones sobre las que se requirió su valoración fue la imposición de sanciones administrativas.

Preguntados sobre la eficacia que podían tener esas medidas, sólo un 2,4\% expresó que era «completamente ineficaz», un 3,2\% que era «ineficaz» y un 11,5\% «poco eficaz». El resto de los entrevistados manifestó que en alguna medida consideraban eficaces las sanciones administrativas, llegando a un porcentaje acumulado de un 79,3\%, lo que indica la alta valoración que obtuvieron estas actuaciones en nuestra encuesta.

A continuación, nos preguntamos si había relación entre esta valoración y el hecho de haber o no sufrido otra agresión y trasladamos esa cuestión a los encuestados.

Las opiniones, tanto de las personas que habían sido víctimas de algún tipo de violencia como de las que no, se inclinaron hacia la eficacia de las sanciones administrativas.

No obstante, pudo observarse una cierta mayoría de agredidos que creía que son «extraordinariamente eficaces» (28,7\% frente a $18,5 \%$ de no agredidos) y sus puntuaciones en los tres ítems de eficacia («eficaz», «muy eficaz» y «extraordinariamente eficaz») son destacadamente más altas $(28,4 \%, 25,9 \%$ y $28,7 \%)$ que en los otros tres ítems $(4 \%, 3,7 \%$ y 9,2\%),

\footnotetext{
${ }^{431}$ Algunas de las respuestas de la última pregunta de la encuesta incidían en esta cuestión: «Que el paciente, si comete agresión, no pueda ser vuelto a citar con ese profesional y note de alguna manera (tener que pedir otra cita con distinto profesional de nuevo, con su consiguiente espera) para que vea que, si no cumple con sus obligaciones, dicho acto tiene consecuencias directas». «Una denuncia pública y que el usuario dejase de poder recibir atención en un centro sanitario». "Tras una agresión física o verbal el paciente no podrá ser atendido en el mismo hospital». "Creo que todas las posibilidades han sido contempladas en este estudio, solo se me ocurre: traslado del profesional a otro centro en caso de agresión para evitar contacto con agresores en la zona de salud donde trabaja».
} 
lo que parece indicar que quien ha padecido ya una agresión cree de forma más indubitada que las sanciones administrativas son eficaces.

En cualquier caso, merecen destacarse los porcentajes que arrojan las respuestas de quienes no saben si sufrieron o no una agresión, que consideran la actuación en un 35,3\% «eficaz» y «muy eficaz» (mismo porcentaje), lo que supone también una valoración relativamente alta.

Podemos deducir de estos resultados, en primer lugar, que el colectivo en general tiene a las sanciones administrativas en cierta consideración, observándose un mayor grado de valoración entre las personas que ya han padecido un acto violento, una evaluación más discreta pero positiva por parte de quienes no la han tenido, en parámetros similares a quienes no saben si lo que les sucedió fue en realidad un acto agresivo. Pero globalmente, repetimos, es una valoración positiva.

Estas fluctuaciones, dentro de la evaluación global, pueden deberse a múltiples razones: desde valorar la medida, pero no confiar en que sea suficiente, hasta la falta de confianza en que realmente se imponga. Por ello, el entrevistado respondería en un sentido de valoración positiva, pero matizando su eficacia: no olvidemos la baja tasa de confianza que manifestaron tener los profesionales en la Administración.

Para completar la visión que de este punto tienen nuestros profesionales, formulamos otras dos cuestiones relacionadas con el mecanismo de actuación del Derecho Administrativo en materia de agresiones.

La primera de estas preguntas iba dirigida hacia la evaluación de una medida que varias CCAA establecen en sus protocolos de actuación (entre ellas Castilla y León) tras la producción de una agresión: la carta de rechazo al agresor, a la que ya hemos aludido ${ }^{432}$.

No es una medida de carácter sancionador, pero sí una acción administrativa reglada, que requiere de la previa autorización del trabajador afectado para su ejecución. Por ello, se preguntaba al encuestado si, en caso de sufrir un incidente violento, autorizaría el envío de esta carta.

Una gran mayoría (el 83,5\%) afirmó que sí prestaría esa autorización, lo que indica que los encuestados están a favor de la medida. El 16,5\% restante expresó motivos diversos para no autorizar esa remisión, siendo quizás el más numeroso la creencia de que la medida no es eficaz ${ }^{433}$.

\footnotetext{
432 En otros PPRL tienen denominaciones diferentes: carta de amonestación (Madrid, 2004) o carta de apercibimiento (Andalucía, 2012).

${ }^{433}$ Otros expresaron que temían empeorar la situación, no conocer la medida o por diversas razones heterogéneas no agrupables.
} 
Aquí nos encontramos con una paradoja: recordemos que la carta de rechazo no era bien valorada por nuestros encuestados en una pregunta anterior. Sin embargo, en esta ocasión, los resultados son más favorables. Interpretamos esta aparente contradicción del siguiente modo: la medida en sí no es bien acogida, pero una vez que se produce la agresión, los encuestados entienden que la Administración debe coger las riendas de la situación y emprender acciones. En este sentido, podemos relacionar esta cuestión con los resultados obtenidos en la que a continuación vamos a reseñar: la apertura de expediente sancionador. Ya adelantamos que será bien valorada, y tiene en común con la carta de rechazo que son actuaciones que deben emprenderse por la Administración y que, como observamos en otros apartados de este estudio, es algo que nuestros encuestados demandan.

La segunda de las cuestiones, planteaba si los encuestados solicitarían la apertura de un expediente sancionador contra el agresor. Un 91,5\% contestaron afirmativamente, lo que sin duda expresa una valoración muy positiva y una actitud activa en este sentido.

Cabría pensar que los encuestados están muy de acuerdo en que se incoe expediente sancionador, porque saben que, a partir de ese momento, todas las actuaciones se efectuarán de oficio, sin recabar de ellos más que las acciones de colaboración imprescindibles. Por ello, resulta posible que, en cuanto que no requiere de más actuaciones posteriores por parte del agredido, los encuestados crean que supone menos molestias y un menor empleo de tiempo.

Por otra parte, es cierto que el agresor tendrá enfrente a la propia Administración, a quien muchas veces se pide que se implique más, y la víctima no tendrá que «dar la cara». Es por estas razones por las que suponemos que para los profesionales resulta una medida atractiva.

En conclusión, recapitulando en cuanto a las medidas de tipo administrativo por las que fueron preguntados, los entrevistados valoraron mayoritariamente de forma positiva el envío de la carta de rechazo al agresor (aunque no habían valorado positivamente la carta como tal) y su evaluación sobre la incoación de expediente sancionador fue también positiva en un porcentaje muy alto.

\section{2.- CONDICION DE AUTORIDAD}

Una de las Comunidades Autónomas que atribuyó a sus profesionales sanitarios la condición de Autoridad fue Castilla y León, lo que permitía realizar una valoración de esa figura jurídica por parte de nuestros encuestados, dado que prestan sus servicios en este espacio territorial.

Se les preguntó por la importancia que atribuían a esta figura, resultando que un 63,3\% consideró que era «muy importante», «importante» o «extraordinariamente importante», frente al 36,9\% 
que no le dio importancia en diferente medida. Más de la mitad de los entrevistados creen, por lo tanto, que esta medida es importante.

Queríamos saber por qué motivos concretos valoraban la figura de este modo, por lo que les pedimos que expresaran si creían ciertas las siguientes cuestiones:

- Si la condición de autoridad promueve un mayor respeto por parte del usuario: el 48,6\% afirmó que así era, contra un 51,4\%.

- Si atribuían a la concesión de la condición de autoridad el hecho de que las agresiones puedan juzgarse como delito de atentado: un 32,3\% creyó que era así, frente un 67,4\% que lo negó. Esta premisa era falsa y buscaba obtener hasta qué punto los profesionales están informados sobre la cuestión y si la errónea creencia de que la condición de autoridad atribuida por Castilla y León (y otras CCAA, como hemos visto) tiene efectos en materia penal.

- Si el hecho de poseer la condición de autoridad otorgaba presunción de veracidad a las declaraciones prestadas por el interesado: un 39,1\% afirmó que sí, frente a un $60,9 \%$ que creyó que esto no es cierto.

- Si el ataque a un profesional investido de la condición de autoridad determina mayores sanciones administrativas al agresor: un $41,3 \%$ no pensó que fuera así, pero un 58,7\% afirmó su veracidad.

En general, a pesar de que la valoración de la figura de la autoridad obtiene resultados positivos, cuando preguntamos sobre qué consecuencias concretas se derivan de la misma, los encuestados no parecen atribuirle grandes efectos. Como mucho, podría decirse que el binomio autoridadmayores sanciones administrativas sí es apreciado por los entrevistados.

El hecho de que la figura jurídica de autoridad no sea de aplicación a las personas que trabajan en la sanidad privada puede suscitar cierta controversia, por cuanto algunos sectores manifiestan (como en la aplicación del delito de atentado), que suscita una situación de desigualdad y cierta discriminación.

Se formuló una pregunta sobre esta cuestión, en la que se ofrecían una serie de afirmaciones que los encuestados debían valorar manifestando su acuerdo o desacuerdo. En concreto, se ofertaron las siguientes:

- La atribución de la condición de autoridad a la sanidad pública y no a la privada no es una cuestión importante, porque en la práctica no suscita diferencias relevantes: el 78\% en mayor o menor medida estuvo de acuerdo con la afirmación. 
- Hubiera sido mejor adoptar otras medidas alternativas que no hubieran excluido a la sanidad privada de su aplicación. En este caso, un 91,3\% se mostraron de acuerdo.

- Dado que la condición de autoridad no puede otorgarse a la sanidad privada y se genera una situación de cierta asimetría, lo procedente sería eliminar la figura: el $86,1 \%$ no fue partidario de que esta acción se llevara a cabo.

- Resulta lógico que la autoridad sólo sea de aplicación en la sanidad pública, porque es en este sector donde se dan más agresiones: el $61,2 \%$ se manifestó en desacuerdo con esta afirmación.

Resumiendo, podemos concluir que la mayor parte de los encuestados piensa que hubiera sido mejor acudir a otras acciones diferentes de la atribución de la condición de autoridad a los profesionales de la sanidad pública. Muchos de ellos creen que, en realidad y a efectos prácticos, la medida no tiene relevancia.

No consideran que la producción de un número mayor de agresiones en la sanidad pública justifique que se emprenda una acción que sólo pueda beneficiar a ese sector, como lo es otorgar la condición de autoridad a sus empleados. Pero la mayoría no cree que deba suprimirse la figura para eliminar la supuesta desigualdad.

En cuanto a la relación de estas respuestas con la pertenencia de los encuestados a la sanidad pública, privada o ambas, obtuvimos lo siguiente:

- Los trabajadores de la sanidad privada se manifestaron más de acuerdo en que la figura de autoridad no ostenta en la práctica demasiada importancia.

- Quienes comparten ambos sectores de actividad fueron más partidarios de que se hubieran tomado otras medidas, seguidos de los profesionales de la sanidad privada y, finalmente, la pública.

- La eliminación de la figura fue más popular entre los trabajadores de la sanidad privada, aunque teniendo en cuenta que los valores de puntuación son bajos en todos los casos.

- La mayor incidencia de agresiones en la sanidad pública como justificante de la concesión de la condición de autoridad sólo a estos profesionales obtuvo más partidarios entre la sanidad pública, aunque seguida de cerca por la sanidad privada.

En conjunto, cabe concluir que la autoridad es bien valorada en general, destacando entre los efectos que le atribuyen los profesionales el hecho de que provoque sanciones más severas en vía administrativa.

En cuanto a la no atribución de la condición a la sanidad privada, muchos de los profesionales estiman que hubiera sido mejor acudir a otras alternativas que no excluyeran al sector, teniendo 
esta opción más seguidores entre aquellos que comparten su trabajo entre ambos sectores de actividad.

Un porcentaje significativo piensa que en realidad tal atribución no tiene importancia a efectos prácticos, por lo que no es relevante que la sanidad privada quede fuera de la medida, cuestión en que estuvieron de acuerdo más profesionales de este sector.

La eliminación de la condición de autoridad con el objeto de que sanidad pública y privada estén en igualdad de conclusiones no contó con muchos partidarios, aunque entre ellos había más profesionales del sector privado.

Por último, menos de la mitad de los encuestados aprobaron la implantación de la figura de autoridad en la sanidad pública, por ser ésta donde más agresiones se producen, siendo los profesionales públicos los que más valoraron dicha justificación, aunque por un pequeño margen con respecto a los pertenecientes a la sanidad privada.

\section{C) ACTUACIONES EMPRENDIDAS DESDE EL DERECHO PENAL}

Las medidas que se adoptan ante las agresiones a los profesionales de la salud desde el Derecho penal ha suscitado bastante expectación desde la entrada en juego del delito de atentado para su encausamiento.

Del mismo modo, las diferentes Administraciones incluyen en sus protocolos de actuación diferentes acciones de asesoramiento, apoyo e impulso a la reacción contra este tipo de violencia, dirigida preferentemente a la intervención del orden penal.

Por estas razones, entendimos que se trataba de un campo en el que, a pesar de sus especificidades técnico-jurídicas, los profesionales sanitarios podrían estar más informados y en mejor posición para opinar y valorar su alcance.

La mayor parte de las preguntas específicamente dirigidas a la actuación desde el ámbito jurídico contra estas agresiones se centró, debido a ello, en la órbita de la actuación penal u otras medidas relacionadas estrechamente con ésta. 
1.- La primera cuestión referida a este campo requirió la opinión de los encuestados sobre intervención de la jurisdicción penal en materia de agresiones al personal sanitario.

El porcentaje acumulado que se alcanzó en quienes concedían algún grado de eficacia a la actuación de esta jurisdicción alcanzó el 83,5\%, lo que nos parece una buena valoración por parte de los entrevistados.

Al indagar en la relación entre estas respuestas y el hecho de haber o no sufrido una agresión con anterioridad, encontramos que las personas ya agredidas mostraban una tendencia mayor a valorar positivamente la actuación de la justicia penal (de hecho, un 40,6\% de este grupo la calificó como «extraordinariamente eficaz»).

2.- También se preguntó sobre una medida que han implantado casi la totalidad de las administraciones autonómicas en sus protocolos de prevención (concretamente dentro de las actuaciones posteriores a realizar cuando se produce una agresión).

Con el ánimo de informar y apoyar al agredido, dentro de las pólizas suscritas con diversas compañías de seguros de asistencia y representación jurídica, se implantan teléfonos de asesoramiento jurídico donde el interesado puede formular sus preguntas y dudas acerca de cuáles son las actuaciones legales que resultaría más ventajoso y adecuado emprender. Esta es una medida que contempla el SACYL, por lo que podíamos preguntar a nuestros encuestados sobre cómo apreciaban su eficacia.

Nuestros resultados arrojaron un $68,4 \%$ de porcentajes de eficacia acumulados, lo que sugiere una buena valoración de la medida.

3.- La intención de denunciar la agresión, en el caso que ésta se produjera, fue otra de las cuestiones sobre las que quisimos incidir. Un 87,5\% afirmó que si era atacado, denunciaría los hechos. Este es a todas luces un porcentaje bastante alto.

Pero también deseábamos investigar sobre cuáles podrían ser las razones de aquellos que manifestaron que no denunciarían: la mayoría de ellos (un 22,4\%) dijo que creía que no serviría para nada hacerlo, un 16,3\% lo consideró un esfuerzo excesivo (posiblemente en comparación con los resultados que esperaban obtener, que considerarían insuficientes).

El resto ofreció porcentajes bastante más bajos, entre las opciones de: que el resto del personal creyera que no sabían manejar las situaciones conflictivas (un $4,6 \%)^{434}$, seguido a bastante

\footnotetext{
${ }^{434}$ Este es uno de los motivos que Martínez-Jarreta (2011) señala como más decisivos para la infradenuncia, pero que en nuestra investigación no se ha evidenciado como tal.
} 
distancia de quienes no denunciarían por considerar la agresión como un riesgo inherente al trabajo $(1,4 \%)$ y, finalmente, un $2,9 \%$ que ofreció otras cuestiones heterogéneas y no agrupables.

Relacionando estas respuestas con la experiencia de una agresión previa, encontramos que un $93,8 \%$ de las personas que han sufrido agresiones estarían dispuestas a denunciar en caso de que se volviera a producir una situación similar, frente a un $82,4 \%$ que también lo haría, pero que no fue agredido previamente.

Debemos, por tanto, aceptar que, al menos en principio, una gran mayoría de los profesionales tienen intención de interponer denuncia si fueran agredidos. Dentro de este grupo de personas dispuestas a denunciar, ganan por una diferencia de aproximadamente un $10 \%$ quienes han sufrido previamente experiencias negativas.

En cuanto a la relación entre la disposición a denunciar y la valoración de las instituciones, encontramos que altas valoraciones de las instituciones se corresponden a su vez con una mayor denuncia. Todas estas relaciones fueron estadísticamente significativas.

4.- Una de las cuestiones del formulario iba dirigida a comparar la opinión que merecía a los encuestados las actuaciones de distintas instituciones. Esta evaluación se verá con más detalle más adelante, por lo que nos referiremos en este momento únicamente a las instituciones relacionadas con la actuación penal: tribunales y fiscales.

La actuación de los tribunales de justicia pareció a nuestros entrevistados eficaz en un 42,1\% (acumulando todos los porcentajes de valoración positiva) y resulta destacable que quienes declinaron valorar su actuación por desconocimiento de en qué consiste representaron un 37,3\%.

En cuanto al Ministerio Fiscal nos encontramos con resultados que abundaban en el mismo sentido: un 36,4\% creyó eficaz su actuación, y un 42,4\% manifestó no saber si era positiva o negativa.

Estos resultados nos llevan a pensar que, a pesar de que nuestros encuestados tienen una idea mayoritariamente positiva de la actuación de estas instituciones, un buen número de ellos no conocen cómo operan o qué hacen concretamente tanto como para atreverse a realizar una valoración.

La cuestión resulta un tanto llamativa en el caso del Ministerio Fiscal. No hay que olvidar que la gran mayoría de Colegios profesionales han suscrito convenios con esta institución y han publicado los objetivos que pretendían conseguir con esta colaboración y, por supuesto, las bondades de esta actuación. 
También es cierto que las acciones que emprende el Ministerio Fiscal quizás sólo resulten visibles para quienes están o han estado inmersos en un proceso, resultando menos llamativas para el resto de las personas, lo que justificaría quizás la falta de información que parece existir.

Entendemos, no obstante, que esto no explica que se manifiesten casi los mismos porcentajes que afirman desconocer las actuaciones de los tribunales. Muchas estadísticas oficiales (incluidas las facilitadas por el observatorio de la $\mathrm{OMC}$ ) ponen de manifiesto porcentajes de casos juzgados y condenados, lo que debería llevar al menos a una cierta perspectiva de la actuación de los tribunales de justicia.

En todo caso, aunque discretamente, la valoración de ambas instituciones es positiva.

5.- Se pidió a los entrevistados que evaluaran una serie de opciones referidas a las medidas que ellos creían que serían más adecuadas para combatir las agresiones.

Uno de los ítems propuestos fueron las penas de prisión. Un 74,8\% fue partidario de enviar a la cárcel a los agresores, frente a un porcentaje acumulado de un $25,2 \%$ de porcentaje acumulado de quienes en algún grado no se mostraron de acuerdo con la medida.

En cuanto a la imposición de penas de multa, se siguió la misma tendencia, pero con valores más altos. Un $83,4 \%$ afirmó su apoyo a su imposición, frente a sólo un 16,6\% que no estuvo de acuerdo, en mayor o menor medida, con esta actuación.

Estos resultados nos inducen a pensar que la valoración de ambos tipos de penas es alta: los entrevistados creen que las penas de prisión y las multas pueden ser eficaces en la lucha contra la violencia contra el personal sanitario por parte de los usuarios ${ }^{435}$.

Pero quisimos profundizar un poco más en la cuestión y ver si existía relación entre estas valoraciones y el hecho de haber sido agredido anteriormente. Aunque sólo se encontró relevancia estadísticamente significativa en el caso de la imposición de multas, obtuvimos lo siguiente:

Entre los ya agredidos, las valoraciones más altas fueron sobre la pena de multa (3,22 sobre 4) y 2,33 respecto a la prisión. Quienes no habían sufrido agresión alguna hasta el momento también valoraron con puntuación alta las multas $(3,02)$ y las penas de prisión $(2,9)$. Aquellos que no sabían si lo que habían experimentado era o no una agresión valoraron igualmente de forma más

\footnotetext{
${ }^{435}$ Algunos de nuestros encuestados se inclinan claramente por la contundencia en las medidas contra el agresor: «El que agrede lo hace a sabiendas. Lo cursos, campañas y demás creo que no sirven para nada. Lo único eficaz es multar y en los casos necesarios, imponer penas judiciales», "El cafre que agrede siempre seguirá siendo un cafre. Hace falta miedo al castigo, pero como la ley siempre protege a los malos...dura lex sed lex».
} 
positiva estas dos cuestiones que el resto de las propuestas: 3,14 en cuanto a las multas y 3,03 la prisión.

A la vista de estos datos, consideramos que la consecuencia más evidente es que nuestros encuestados son firmemente partidarios de estas dos medidas y, sobre todo, de la imposición de multas.

A modo de hipótesis, podríamos apuntar a que posiblemente las penas de privación de libertad parezcan eficaces y contundentes, pero que se entiendan como menos apropiadas para la mayoría de las agresiones que se producen (que, como vimos, son predominantemente verbales).

Por ello, cabe la posibilidad de que, con estas respuestas, lo que los encuestados quieran transmitir es un sentimiento de proporcionalidad entre penas y sanciones. Es decir, desean que los actos sean castigados, pero dentro de sus justos límites. Y como la mayoría de los incidentes que presencian o que han padecido son de tipo verbal, consideran que lo más apropiado para su represión es la imposición de una multa, dejando las penas de prisión para los actos más graves ${ }^{436}$.

6.- La penúltima pregunta de nuestro cuestionario se dirigió a conocer la opinión de nuestros entrevistados sobre tres cuestiones íntimamente relacionadas con el Derecho penal.

La primera fue pedirles su valoración sobre el hecho de que a partir de la última reforma del Código Penal (como ya hemos señalado anteriormente) cuando se producen lesiones sea necesaria la denuncia de parte, esto es, que el ofendido debe necesariamente denunciar por sí mismo para que se inicie el procedimiento penal.

Quienes consideraron de algún modo perjudicial la cuestión rebasaron la mayoría absoluta (un $57,4 \%$ ), pero quienes la consideraron positiva en algún grado llegaron al 42,6\%. Esto nos lleva formular una hipótesis sobre la razón por la que un porcentaje relativamente alto cree que esta nueva situación les resulta beneficiosa en alguna medida: la obligación de denunciar por sí mismo deja en manos del interesado la acción, lo que puede resultar atractivo para aquellos que no tienen demasiada confianza en actuaciones ajenas.

\footnotetext{
${ }^{436}$ Se proponen también, por parte de los entrevistados, medidas sancionadoras alternativas, aunque no por ello menos contundentes en algunas ocasiones: «expulsar al agresor del sistema sanitario público o al menos obligarle al pago (por "morder la mano que le da de comer")», "penalizar al agresor impidiéndole la utilización del sistema sanitario público durante un tiempo como ya marca la ley pero no se aplica. O si lo tuviera que utilizar que abonara el coste», "sanciones de exclusión de la asistencia sanitaria», "retirar la asistencia sanitaria durante un periodo, con aviso de próxima sanción penal», entre otros (para más detalle, puede verse el Anexo II).
} 
El segundo ítem de la pregunta fue si creían que la posibilidad de juzgar al agresor por delito de atentado en los actos violentos cometidos contra los profesionales de la sanidad pública era o no beneficioso.

Un 88,1\% afirmó que le parecía beneficioso (en diferentes grados), frente a sólo un 11,9\% que de algún modo lo consideró perjudicial. Esto parece significar una valoración muy positiva de esta medida, a pesar de que en otras respuestas obtuvimos una cierta tendencia a considerar menos idóneas las penas de prisión que las de multa (y, como hemos visto, en los procesos seguidos por atentado, la condena a prisión no resulta algo poco frecuente).

El tercer punto de la cuestión se centró en cómo valoraban que las injurias leves salieran del orden penal para ser juzgadas desde otras ramas del ordenamiento. Un $60 \%$ lo consideró perjudicial, lo que supone una amplia mayoría.

Debemos destacar que este tipo de ofensas es bastante frecuente en el ámbito sanitario. Por tanto, parece lógico suponer que esta medida tendrá relevancia. En nuestra opinión, la punición de las injurias leves tendrá cambios importantes, referidos a la ausencia de sanciones, quedando el tema reducido a un posible resarcimiento vía indemnización al ofendido.

Todas estas cuestiones parecen ser percibidas por nuestros encuestados con toda claridad.

\section{D) CUESTIONES ANALIZADAS EN DIVERSOS ORDENAMIENTOS: VISIÓN DE CONJUNTO}

Pretendemos ahora englobar las valoraciones aportadas por los encuestados a preguntas con opciones susceptibles de ser clasificadas en apartados o epígrafes diversos dentro de nuestro esquema organizativo, con dos objetivos: en primer lugar, obtener una visión de conjunto que nos permita analizar, con más claridad y comparativamente, cuáles son las actuaciones propuestas desde ópticas diversas a las que los entrevistados otorgan más crédito y eficacia.

Por otra parte, que esta síntesis nos permita realizar una interpretación global de esas evaluaciones a partir de los datos proporcionados por los profesionales encuestados.

\section{1.- VALORACIÓN DE LAS INSTITUCIONES}

Parecía importante que los profesionales valoraran la actuación de las diversas instituciones en defensa de sus derechos relacionados con las eventuales agresiones. Las instituciones que fueron objeto de esta evaluación fueron: Colegios profesionales, SACYL, Administración central, sindicatos, tribunales y Ministerio Fiscal. 
Los Colegios profesionales obtuvieron una valoración positiva global de un $44,7 \%$, aunque hay que tener en cuenta que el porcentaje que no quiso evaluarlos fue del $34,2 \%$ (que posiblemente englobe en gran parte a profesionales no colegiados que, lógicamente, decidieron no valorar una cuestión que les resultaba ajena).

Relacionada esta variable con los distintos colectivos (facultativos, personal de enfermería, psicólogos y otros), se obtuvieron resultados estadísticamente significativos que mostraron unas puntuaciones (puntuación máxima: 4) de 2,93 entre los facultativos (que fueron quienes mejor los valoraron), 2,89 entre los psicólogos, 2,9 el grupo «otros» y 2,51 entre el personal de enfermería, que fue el colectivo que peor valoró la actuación de los Colegios profesionales.

Por lo tanto, podemos concluir que menos de la mitad de los encuestados valoraron positivamente a estas instituciones, pero que este resultado puede tener relación con el porcentaje de personas que no entraron a valorar, por lo que los datos han de interpretarse con cautela. De esta discreta evaluación positiva, quienes más satisfechos se mostraron con la institución fueron los médicos y quienes menos, el personal de enfermería. Considerando que cada Colegio profesional funciona de forma independiente y autónoma, debemos entender que los encuestados responden según su experiencia personal y que diferentes Colegios pueden ser también apreciados en diferente forma.

Los sindicatos fueron valorados positivamente en un $39 \%$, aunque con un $31 \%$ de encuestados que declararon no conocer su actuación. En nuestra opinión, resulta que muchos de los encuestados que no se encuentren sindicados, decidieron no valorar esta cuestión, por entender que no sabían lo suficiente de las posibles acciones sindicales emprendidas en la materia (como apuntamos en el caso de los Colegios profesionales).

Enfocando comparativamente las evaluaciones de las instituciones propuestas, llegamos a lo siguiente: existen porcentajes altos en todos los casos de personas que declaran no conocer las actuaciones de las diferentes instituciones, siendo el caso más llamativo el del Ministerio Fiscal $(42,9 \%)$.

Sería, por tanto, aconsejable que las distintas instituciones u organismos competentes hicieran esfuerzos en orden a difundir la información pertinente y posibilitar que los profesionales supieran qué es lo que hacen realmente en materia de agresiones (en consecuencia, esta mejora de la información redundaría en un mejor conocimiento del personal sanitario de las acciones que se emprenden, los recursos de que disponen y a quién pueden acudir).

La institución más valorada serían los Colegios profesionales (aunque, como hemos dicho, con un porcentaje que no llega a la mitad de los entrevistados), seguida de tribunales, fiscales y sindicatos. Las peor valoradas, por este orden, fueron la Administración central y el SACYL. 
Parece que los profesionales creen que las Administraciones en general y la sanitaria autonómica en particular no son suficientemente eficaces en la lucha contra las agresiones. Esto resulta paradójico si pensamos en que se realizan campañas de sensibilización y que el SACYL proporciona en su portal web información sobre los recursos disponibles y las medidas adoptadas.

Tal vez el profesional sanitario crea que esto no es suficiente y demande actuaciones más inmediatas, o que entienda que no están funcionando como deberían porque percibe que la violencia no decrece. Quizá la difusión de la información sobre las medidas emprendidas no sea correcta o suficiente ${ }^{437}$.

En cualquier caso, la valoración no es buena y debería tomarse como un toque de atención para la evaluación de la situación y la actuación en consecuencia.

\section{2.- GRADO DE CONOCIMIENTO SOBRE DERECHOS Y ACTUACIONES}

Se preguntó a los encuestados sobre si conocían o no los derechos que les asisten ante la producción de una agresión y las actuaciones a seguir tras el suceso.

Los porcentajes que obtuvimos en ambas cuestiones fueron bastante discretos, no alcanzando en ninguno de los dos casos la respuesta positiva de la mitad de los encuestados. Concretamente, un $44,6 \%$ manifestó que conocía sus derechos y un 45,6\% que sabía las actuaciones a emprender.

La conclusión es bastante clara: menos de la mitad de los profesionales encuestados conoce sus derechos y las actuaciones a seguir en caso de producirse una agresión.

Esto contrasta con las manifestaciones públicas de diversas instituciones y de las propias Administraciones en cuanto a la organización de campañas de información entre los profesionales, publicación de las estadísticas del observatorio de la OMC anualmente y las distintas declaraciones que se producen masivamente cada año con motivo del «Día de las agresiones», entre otras ocasiones.

\footnotetext{
437 O tal vez, desde su experiencia personal perciba que, en la práctica, los derechos no se defienden tanto como se anuncia en la teoría. En este sentido, puede verse el siguiente interesante comentario que aportó uno de nuestros encuestados en la última pregunta de la encuesta: "Que las administraciones públicas se impliquen más en proteger los derechos del personal a cargo, no favoreciendo el "el usuario siempre tiene la razón", pues en un número amplio de casos, el propio personal se encuentra desprotegido cuando pone en conocimiento de su superior inmediato cualquier altercado. Imagino que por miedo a no tener una buena estadística de conflictos con familiares y pacientes se tiende muchas veces a mediar en contra del trabajador». Otro/a entrevistado/a pide: "Apoyo claro y explícito de la Gerencia a los profesionales, no aplicando automáticamente el slogan "el cliente siempre tiene la razón"».
} 
Parece claro que todo ello no basta y que los profesionales demandan más formación e información porque, de hecho, manifiestan no poseer la suficiente ${ }^{438}$, como ya hemos adelantado al hablar de la valoración de las instituciones.

Para responder al interrogante de hasta qué punto podría haber diferencias en el conocimiento de derechos y actuaciones según los profesionales trabajaran en la sanidad pública, privada o ambas, cruzamos los resultados, obteniendo en las dos preguntas relaciones estadísticamente significativas.

El sector público cree conocer mejor sus derechos (48,3\%) y las actuaciones disponibles (50,6\%). Quienes participan de ambos sectores manifestaron en un 45,3\% conocer sus derechos y un porcentaje parecido $(43,4 \%)$ las actuaciones a seguir.

Lo más significativo es que un $43,6 \%$ de la sanidad privada afirmó no conocer sus derechos y nada menos que un alarmante $49,1 \%$ no saber qué actuaciones podían emprender ${ }^{439}$.

No cabe sino concluir que los trabajadores de la sanidad privada están mucho peor informados que los otros dos grupos sobre sus derechos y lo que puede hacerse en caso de sufrir una agresión, constatación que nos lleva a sugerir a los empresarios privados la realización de actuaciones urgentes al respecto.

Un profesional que no conoce sus derechos y posibilidades de actuación es un profesional vulnerable y falto de toda posible defensa y capacidad de reacción.

\section{3.- LAS MEDIDAS ADOPTADAS}

La panorámica de la evaluación de una serie de medidas concretas, que hemos visto de forma parcial en distintos epígrafes de esta Discusión, es la siguiente:

- La presencia de vigilantes de seguridad es la más valorada, con un $84,8 \%$ de respuestas que la evaluaban positivamente.

\footnotetext{
${ }^{438}$ De hecho, algunos reflejan cierta confusión en algunos ámbitos, por ejemplo, en el tema de la consideración de Autoridad (cuestión sobre la que -como hemos podido ver- existe un equívoco bastante generalizado): «Hacer campañas para informar a la población de que tenemos consideración de autoridad. Creo que gran parte de la población no está al tanto de ese cambio...y podría ser una buena medida disuasoria». En otras ocasiones, los errores son aún más manifiestos: «Somos muchos los profesionales de la sanidad pública (no sanitarios) que nos exponemos a sufrir una agresión en nuestro puesto de trabajo y no tenemos la consideración de agentes de la autoridad, como por ejemplo, celadores, auxiliares administrativos, vigilantes de seguridad, etc.». En esta respuesta hay que señalar: los celadores son personal sanitario, todos los trabajadores de la sanidad pública tienen el reconocimiento de autoridad (no de agentes de la autoridad) y los vigilantes de seguridad no son empleados públicos. En esta otra respuesta: "Creo que todos los empleados de la sanidad pública deberíamos tener la misma protección ante las agresiones», sólo debe señalarse que eso es efectivamente así, la protección es ya idéntica.

439 Nuestros entrevistados manifiestan: «Realmente hay conceptos legales que en el ámbito de la sanidad privada desconocemos, creo que sería bueno más información de nuestros derechos como profesionales y la forma de actuar ante este tipo de agresiones».
} 
- En segundo lugar, se encuentra el empleo de la justicia penal contra el agresor (83,5\%).

- En tercer lugar, la imposición de sanciones administrativas (79,3\%).

- Las cámaras de seguridad (73\%), los cursos de formación en habilidades de comunicación y manejo de situaciones conflictivas $(72,2 \%)$ y los botones «anti-pánico» (71\%) obtienen porcentajes superiores al $70 \%$ de valoración positiva, y casi lo hace el teléfono de asesoramiento $(68,4 \%)$.

- Porcentajes más discretos arrojan las salidas alternativas de las consultas (56\%) y la reasignación del agresor $(47,2 \%)$.

- Las peor valoradas son: La colocación de carteles disuasorios en los espacios sanitarios (37,3\%), los cursos de autodefensa física (37\%) y la «carta de rechazo» al agresor (24,5\%).

Nuestros profesionales parecen valorar más las medidas directas, tanto de protección como de sanción: vigilancia de seguridad (para que intervenga y evite la agresión) y justicia penal y sanciones administrativas para el castigo del agresor. Debemos concluir que los encuestados prefieren la intervención concreta, tanto en el plano preventivo como con actuaciones posteriores que disuadan de la comisión de futuros actos violentos.

Valoran también, aunque algo menos, la obtención de habilidades que eventualmente les ayude a evitar la agresión por sus propios medios (cursos de formación en manejo de situaciones difíciles) y mecanismos directos para pedir ayuda (los botones «anti-pánico»). Entendemos que la evaluación es positiva porque son acciones que puede emprender el propio interesado y que también son de ejercicio directo e inmediato. Quizá por estos mismos motivos, la valoración positiva alcanza un porcentaje que supera la mitad de las respuestas en el caso de las salidas alternativas de las consultas: la huida es también una acción propia e inmediata que puede salvar la situación.

Como vimos en el análisis concreto de esta cuestión, la evaluación de la reasignación del agresor a otro profesional es bastante tibia y poco clara, por los motivos que también se señalaron y que tienen que ver con la propia ambigüedad de los posibles efectos de la medida.

Lo que está claro es que hay tres cuestiones que nuestros profesionales evalúan de forma muy poco positiva: la colocación de carteles disuasorios, los cursos de autodefensa física y la carta de rechazo al agresor. Estos porcentajes tan bajos, en comparación con los mostrados para las medidas anteriores, reflejan meridianamente una falta de creencia en su eficacia. 


\section{4.- ACTUACIONES QUE GENERAN MÁS EXPECTATIVAS EN ORDEN A LA SOLUCIÓN DEL PROBLEMA DE LAS AGRESIONES.}

Ofrecimos estos cinco enunciados para determinar qué piensan los profesionales que debería hacerse o en qué se debería insistir más para disminuir o eliminar las agresiones:

- Dotar de más medios personales y materiales a la actividad clínica.

- Realizar y difundir campañas educativas dirigidas a los usuarios, en torno a una mejor información sobre recursos disponibles, reglas de funcionamiento de los centros, concienciación de la necesidad del respeto mutuo y mejora de la convivencia, etc ${ }^{440}$.

- Condena a penas de prisión a los agresores.

- Imposición al agresor de penas de multa ${ }^{441}$.

- Mejorar el trato al paciente: generar más empatía, hablarle con respeto y mostrarle consideración.

La jerarquización por orden de valoración positiva fue de mayor a menor: imposición de penas de multa $(83,4 \%)$, mejor trato al paciente $(74,9 \%)$, penas de prisión $(74,8 \%)$, campañas educativas $(71,5 \%)^{442}$, mayor dotación de medios humanos y materiales $(70,7 \%)$.

Todas las medidas son bastante bien valoradas (ninguna tiene una evaluación inferior al 70\%). Aparte de la sin duda mejor valorada (las penas de multa ${ }^{443}$ ), el mejor trato al paciente y las penas de prisión puede decirse que comparten «ex aequo» el segundo puesto ${ }^{444}$.

\footnotetext{
440 Una propuesta interesante es la que hizo uno de nuestros entrevistados, que combinaba aspectos sancionadores y educativos (una especie de educación «especular», en la que el agresor se viera en la situación que padece el sanitario): «Penas de obligatoriedad de prestar servicios a la comunidad en ambientes (como un servicio de urgencias) donde vea reflejada, por parte de otros usuarios, su conducta violenta».

${ }^{441}$ Incluso se proponen medidas sancionadoras nuevas: «Establecer una especie de «Carnet Por Puntos» del paciente. Las agresiones, denuncias y sanciones irían restando puntos. Los médicos podrían saber si un paciente (que muchas veces procede de otro centro o región) es problemático y tendente a la agresión (verbal y/o física) en función de su saldo de puntos. Al perder los puntos debería ser obligatorio hacer algún cursillo de re-educación, control de agresividad, etc...por parte de esta clase de pacientes. Por debajo de un determinado nivel de puntos crítico el Sanitario debería poder ejercer un derecho a veto previo, o poder reclamar la presencia en consulta de personal de seguridad antes de atender a ese paciente, o poder grabar la conversación desde el inicio de la asistencia (previo aviso)".

442 Algunos entrevistados llaman la atención sobre un cierto grado de incivismo social y falta de educación en general: «Creo que el problema de la agresividad no sólo se da en el ámbito sanitario. Por lo que creo que hay que trabajar mucho en la educación de los niños/as donde no sólo deben pedir y exigir sino también tolerar, esperar, y aprender a pedir o quejarse de las cosas que nos pasan de forma adecuada. Así tendremos adultos respetuosos». "En mi opinión todo se deriva del ambiente de agresividad y mala educación que existe en nuestra sociedad. Mientras que, por parte de todos, no se tomen las medidas necesarias para repudiar la zafiedad y el mal tono reinante, y sustituirlo por el respeto mutuo, todas las medidas que se apliquen no dejarán de ser más que un tratamiento puramente sintomático», "es un problema de educación de este país, la gente no tiene respeto por nada ni por nadie».

${ }^{443}$ Cabría preguntarse si existe consciencia de que, a veces, las multas no son finalmente satisfechas debido a situaciones de insolvencia del condenado y que, además, el importe de estas multas no contribuye a resarcir al agredido. Esta reparación opera por los medios de las reclamaciones de responsabilidad civil y patrimonial administrativa.

${ }^{444}$ Esta valoración positiva coincide con lo que ya hemos observado al referirnos a estas actuaciones en los órdenes administrativo y penal.
} 
Las campañas educativas dirigidas al usuario y una mayor dotación de medios humanos y materiales, sin embargo y aunque tengan una valoración muy positiva, no alcanzan los primeros puestos. Resulta algo sorprendente, porque nos parecía predecible que estos fueran los ítems más valorados, dado que se hace tanto hincapié en la importancia de estas cuestiones en los resultados estadísticos oficiales (como hemos visto anteriormente, el énfasis se sitúa en la satisfacción del usuario y, por tanto, en la mejora de los servicios y la implantación de una cultura de convivencia y uso responsable de los medios y recursos),

Sin embargo, aunque los evalúan (insistimos) de forma muy positiva, conceden mayor importancia a darle un mejor trato al paciente. Es muy destacable que muchos profesionales sanitarios manifiestan que existe una cierta deshumanización ${ }^{445}$ y que señalen como una posible solución la empatía, la comprensión y la compasión ${ }^{446}$. Da la sensación de que nuestros profesionales encuestados entienden que de nada sirven campañas institucionales ni cursos generales si falla la relación personal.

También parecen conscientes de que ellos a su vez deben esmerarse en procurar que la relación sea cordial, porque no basta con requerir respeto de la otra parte cuando no se ofrece desde uno mismo. Es cierto que las agresiones son muy numerosas y que debe ponerse coto a esta situación, pero no es menos cierto que en algunas ocasiones el personal sanitario debería poner un granito de arena de respeto y amabilidad para que la otra parte responda de la misma manera.

Como ya hemos reseñado en este estudio, hay muchas clases de agresores y según algunos autores, incluso tienen un perfil cambiante (Lameiro et al., 2013). Es más, algunos trabajos señalan como limitaciones propias la falta de contraste que se produce porque no tenemos acceso a la versión del presunto agresor ${ }^{447}$. Señalábamos en la Introducción que nos hubiera gustado conocer esta perspectiva, pero lógicamente resulta un aspecto que desborda con amplitud el ámbito de nuestro estudio.

Sin intentar desdramatizar, y menos en los casos de gravedad, sí es cierto que deberíamos investigar también en este sentido, porque algunos usuarios pueden sentirse exasperados,

\footnotetext{
445 Uno de nuestros entrevistados propuso: «que haya un mejor trabajo en equipo. En la sanidad pública se ha perdido la humanidad y empatía frente a protocolos y escalas. Debido a las jerarquías profesionales se ha perdido la cooperación y el trabajo en equipo»

${ }^{446}$ Varias muestras de esta actitud se reflejan en las respuestas obtenidas en la última pregunta de la encuesta: "Trabajar la comunicación y el respeto de los profesionales a los pacientes, tratándolos como personas y no como molestias o seres ignorantes. Asumir la posibilidad de error en el diagnóstico y no asumir prepotencia o superioridad", «que el profesional sanitario conozca sus obligaciones, su responsabilidad y que normalmente la persona que le visita está necesitando ayuda».

${ }^{447}$ Otra respuesta incide en este tema: «En la agresión de cualquier tipo, se necesitan dos, un agresor y un agredido. Se debe evitar la escalada, sin dejar de distinguir una emoción violenta producto del mal trato profesional, de un agresor continuo y por cualquier cosa. Es evidente que los agresores necesitan una llamada de atención importante. Y los profesionales otra llamada preguntándose por qué han generado la agresión. 0 no».
} 
abandonados y despreciados en ciertos momentos. Estas personas no serían «agresores natos» y la violencia sería fácilmente reconducible con un trato amable o una información oportuna en el momento adecuado.

La valoración de nuestros encuestados, así, parece polarizarse hacia las medidas sancionadoras y la atención educada al usuario (casi a partes iguales en cuanto a las penas de prisión y el mejor trato al paciente).

Podríamos aventurar una explicación, basándonos en lo que acabamos de señalar: muy posiblemente nuestros entrevistados estén pensando en perfiles diferentes de agresor. El primero es el agresor agresivo, contumaz, reincidente en suscitar conflictos. Pero este tipo de usuario problemático no tiene nada que ver con el que normalmente no plantea problemas, pero que en una situación de estrés o preocupación (fundamentada por el ambiente o la situación clínica) pierde los nervios y estalla ${ }^{448}$.

Siguiendo esta formulación, nuestros encuestados encontrarían soluciones alternativas y diferentes para ambos tipos: la sanción (dependiendo de la gravedad del caso, multas o penas de prisión) o intentar prevenir la agresión del usuario no problemático con una atención más amable y cercana.

Para ahondar más en estas valoraciones, relacionamos las variables con el hecho de que los encuestados hubieran o no sufrido previamente una agresión.

Entre quienes no habían padecido agresiones, encontramos un predominio claro de las penas de multa $(3,02$ sobre 4$)$ y del mejor trato al paciente $(2,97)$, seguidas de las penas de prisión $(2,9)$ prácticamente al mismo nivel que la mayor dotación de medios humanos y materiales $(2,89)$ y campañas educativas $(2,79)$.

Aquellos que tenían una mala experiencia previa agresiva se expresaron de una forma diferente, salvo en las penas de multa, que siguen a la cabeza $(3,22)$. En segundo lugar, se encuentran las penas de prisión $(2,98)$, seguidas de la dotación de más medios materiales y humanos $(2,91)$, mejor trato a los pacientes $(2,87)$ y campañas educativas $(2,79)$.

\footnotetext{
448 Gascón Santos (2006) planteaba la paradoja de que, cuando se reconocen más derechos al paciente y se establecen cauces civilizados para la resolución de conflictos, sea precisamente cuando más agresiones se producen. Creemos que, en este sentido, convendría estudiar si los procedimientos de reclamación son efectivamente operativos y si son así percibidos por el usuario: si el ciudadano piensa que no va a servir de nada tramitar una queja a través del Servicio de Atención al Paciente, probablemente acudirá a actuaciones alternativas cuando esté quejoso ( $y$, en ciertas circunstancias, se producirá una agresión). Alguno de nuestros encuestados apuntó esta posibilidad, sugiriendo: «Cambiar los servicios de atención al paciente, que en vez de resolver problemas, los generan aún más».
} 
La diferencia entre sufrir o no agresiones previas parece determinar una tendencia a la valoración de medidas más directas y claramente sancionadoras o inclinarse por acciones más dirigidas a la prevención. De hecho, en los casos de valoración de mejor atención al paciente y campañas educativas, el índice de evaluación de quienes no han padecido agresiones supera a los que sí las han sufrido.

Debemos reiterar, porque lo creemos muy interesante, que nuestros profesionales se están centrando menos en la eficacia de la organización y la consiguiente satisfacción del usuario ${ }^{449}, \mathrm{y}$ más en una mejor relación entre personas.

Como vimos a lo largo de este trabajo, se ha defendido que el paciente se ha vuelto más exigente, cree que tiene más derechos, busca la eficacia total en la atención sanitaria, etc. Para algunos, se ha vuelto un consumidor exigente de los servicios de salud (Castellano Arroyo, 2011).

Pues bien, con ser ciertamente éstos planteamientos sobre los que reflexionar, nuestros entrevistados dan más importancia al «cara a cara» cercano con el paciente y el acompañante. No debemos olvidar que, hoy en día, las organizaciones sanitarias se han convertido en entramados muy complejos en que puede ser necesaria una cierta humanización ${ }^{450}$. Muchas personas que acuden a recibir asistencia sanitaria se ven abrumados y se sienten vulnerables.

Una mejora en la organización, pero de tipo humanizador, sería en nuestra opinión de utilidad en la prevención de agresiones (en cuanto a los eventuales agresores del «segundo tipo» descrito), y nuestros entrevistados parecen también pensar así. Resultan, desde nuestro punto de vista, especialmente destacables las previsiones de algunos de los planes de prevención estudiados.

Destacamos concretamente lo que dispone el plan de La Rioja (2008) en sus servicios de Urgencias: que ciertos pacientes (niños, ancianos, o cuando su patología o características lo hagan aconsejable) puedan ser acompañados por sus allegados en todo momento y la asignación a un profesional concreto del Servicio de la tarea de informar puntual y periódicamente de la situación clínica en que se encuentre el paciente.

Por supuesto, se trata de un simple ejemplo de una serie de acciones que podrían implementarse. También es imprescindible señalar que constituyen medidas organizativas que es necesario

\footnotetext{
${ }^{449}$ No obstante, ello no significa que no valoren estas cuestiones. En la última pregunta (abierta) en que se pedían sugerencias sobre en qué era necesario realizar un énfasis mayor, obtuvimos respuestas como las siguientes: «más medios materiales y humanos para la atención de los usuarios", "fundamental: más tiempo y recursos personales», «mejorar los recursos del servicio sanitario, agilizar consultas y pruebas complementarias recortando listas de espera, etc. En definitiva, mejorar la calidad del servicio para que el paciente esté satisfecho».

450 Una de las propuestas de nuestros entrevistados fue, en este sentido, la siguiente: «Volver a centrar la asistencia sanitaria en la relación médico-paciente, donde hubiese tiempo para hablar con el paciente, explicar alternativas y ventajas de cada una, permitiendo al paciente implicarse en el tratamiento de su problema patológico y haciéndole partícipe/corresponsable de la evolución del mismo».
} 
evaluar y revisar, conforme a las necesidades de buen funcionamiento del centro. Pero, no obstante, son ideas que pueden resultar productivas en orden a conseguir disminuir el lógico estrés susceptible de generarse ante ciertas situaciones sanitarias.

De otra parte, complementando estas medidas organizativas que puedan ayudar a disminuir o eliminar la sensación de encontrarse en un medio deshumanizado, resulta evidente que el trato personal de cada profesional -como hemos señalado- es absolutamente fundamental para conseguir que el paciente (y sus allegados) se sientan en un medio no hostil y confíen en la pericia y buen hacer del personal sanitario que presta la atención sanitaria.

En definitiva, creemos que -en el caso del ciudadano no habitualmente problemático ${ }^{451}$ - se deberían realizar esfuerzos en conseguir que la actividad sanitaria (curativa y de alivio a la enfermedad) recupere la tonalidad de compasión y empatía que tradicionalmente ha adornado la relación sanitaria.

No debe olvidarse que la profesión sanitaria anida en un noble fin: la ayuda, el cuidado y -cuando es posible- la curación de la enfermedad. Pero, para que tan elevado propósito sea apreciado por el enfermo y sus personas allegadas, debe ser claramente demostrado y percibido por sus destinatarios.

Y esto sólo es posible si se realizan esfuerzos hacia la humanización del sistema sanitario y la propia relación clínica.

\footnotetext{
451 Sin olvidar, como hemos señalado, que existe otro tipo de usuarios, que son conflictivos. En estos casos, lamentablemente, pero en la necesidad innegable de defensa del profesional que eventualmente puede ser receptor de una agresión, deben tomarse medidas preventivas, disuasorias y sancionadoras, como las que hemos señalado a lo largo de este estudio.
} 


\section{UN CASO PRÁCTICO: EL ASESINATO DE MORATALLA.}

En este apartado nos proponemos realizar un análisis en perspectiva sobre el funcionamiento global del sistema jurídico en relación con las agresiones a los profesionales de la salud a través de un acontecimiento que conmocionó a la totalidad del gremio sanitario y la sociedad en general. Esta trascendencia vino dada tanto por el resultado trágico del suceso, como porque parecía evidenciar que la violencia contra los profesionales de la salud estaba alcanzando cotas verdaderamente inconcebibles.

El asesinato de la Dra. Eugenia Moreno, médico residente de último año, que realizaba su actividad profesional en el Centro de Salud de Moratalla (Murcia) fue de tal trascendencia que la OMC celebra anualmente el «Día de las agresiones» en el mes en que ocurrió tan lamentable suceso $^{452}$.

Sin embargo, resulta paradójico el énfasis que se denota en cuanto a no olvidar tan dramático suceso, mientras que, en la práctica la actuación de las instituciones en defensa de los intereses de la finada no sea de tanta efectividad.

De hecho, hemos comprobado como sus causahabientes (viudo, hijo y $\mathrm{madre}$ ) ${ }^{453}$ han visto frustradas en reiteradas ocasiones su pretensión de conseguir que la Administración asuma la responsabilidad patrimonial que por tal violencia consideraban debiera ser devengada.

A los efectos de nuestro trabajo, el caso posee un interés especial, porque los hechos se desarrollaron de tal forma que pueden ofrecer una visión panorámica de cómo funciona en la práctica todo el sistema que se ha construido para abordar las agresiones a los profesionales de la salud.

Por ello, las características del caso nos permitirán examinar desde una óptica práctica y concreta los mecanismos jurídicos que operan en nuestro ordenamiento y las diferentes medidas adoptadas contra las agresiones al personal sanitario, que hemos ido mostrando y analizando a lo largo de nuestro estudio.

\section{A) NARRACIÓN FÁCTICA Y ACTUACIONES PENALES}

El 11 de marzo de 2009, a las 0:20 horas aproximadamente, un hombre se presentó en el Centro de Salud de Moratalla requiriendo asistencia médica. Refirió sentirse fatigado a una celadora que se encontraba en la puerta del centro. Ésta llamó a la Dra. Moreno, quien se encontraba

\footnotetext{
452 «Día Nacional contra las Agresiones a Sanitarios 2017» (2017)

453 Los familiares y herederos tienen la condición de "víctimas indirectas», término que se corresponde con la categoría jurídica clásica de «perjudicados por el delito» y que ha venido a reconocer la LEVD (Vidal Fernández, 2017).
} 
de guardia aquella noche y la doctora le indicó que llamara al enfermero para administrar una nebulización al paciente. La celadora se dirigió a cumplir la indicación recibida. El paciente, dentro de la consulta y a solas con la facultativa, le disparó cuatro veces con un revólver que portaba oculto. El enfermero y un conductor de ambulancia, alertados por los disparos, acudieron en ayuda de la médico: el agresor intentó disparar al enfermero e hirió con otro disparo al conductor de ambulancia. Avisada la Policía Local, se personó en el centro de salud, encontrando al agresor en la puerta con el arma en las manos, que soltó a requerimiento de uno de los agentes.

La Dra. Moreno falleció ese mismo día a causa de los disparos. El conductor de ambulancia quedó herido, pero logró salvar su vida.

Ocurrido el fatal desenlace, el Servicio Murciano de Salud actuó del siguiente modo:

- Incluyó el incidente en el registro informático de agresiones.

- Notificó lo sucedido a la abogada de la compañía con la que tenía suscrita la póliza de defensa jurídica contra agresiones de su personal, con el fin de que se personara en el procedimiento penal subsiguiente.

- Del mismo modo, también se personó el SMS como parte acusadora, nombrando un letrado de los Servicios Jurídicos de la Comunidad Autónoma.

- Tramitó la concesión de las indemnizaciones y ayudas pertinentes por el fallecimiento de la empleada pública.

- Comunicó accidente de trabajo con grado de lesión de fallecimiento.

La Policía Judicial de la Guardia Civil del puesto de Caravaca de la Cruz instruyó atestado, en virtud del cual, la titular del Juzgado de Instrucción $n^{\circ} 1$ de Caravaca de la Cruz ordenó incoar Diligencias Previas por los siguientes delitos:

- Dos delitos de asesinato, uno en grado de tentativa (contra el conductor de ambulancia) y el otro consumado (contra la facultativa).

- Un delito de tenencia ilícita de armas.

- Un delito de amenazas.

El íter judicial no continuó hasta el 27 de octubre de 2009 (siete meses después), en que se dictó Providencia, teniendo por personado y parte al Letrado de la Comunidad Autónoma de Murcia, en nombre y representación del SMS.

Dos meses más tarde (16 de diciembre), se acordó proceder a la tramitación de la causa conforme al Procedimiento Sumario Ordinario. 
La Audiencia Provincial dictó Auto el 22 de febrero de 2010 (dos meses después), confirmando el de conclusión del sumario y acordando abrir juicio oral contra el procesado.

Todos estos hitos procesales quedaron sin efecto porque 14 meses más tarde el procesado murió por causas naturales, cumpliendo prisión preventiva.

Por Auto de 4 de mayo de 2011 se declaró extinta la acción penal por la circunstancia anterior, indicando la subsistencia de la acción civil. El archivo de la causa tuvo lugar por Diligencia de Ordenación de 16 de mayo de 2011.

Ha de llamarse la atención sobre el hecho de que, transcurridos más de dos años desde la producción del hecho delictivo, no se hubiera celebrado la vista correspondiente. Debemos hacer constar que el agresor debería haber sido juzgado mucho antes, a la vista de la gravedad de los cargos. Lo cierto es que su fallecimiento dejó sin sanción penal la muerte de la Dra. Moreno.

Podemos construir, a partir de los hechos narrados, cuál hubiera podido ser el resultado de las acciones penales, si se hubieran completado.

No conocemos cuál habría sido la calificación del Ministerio Fiscal, ni su petición de penas a imponer. Pero sí sabemos que ya las Diligencias Previas se habían incoado por dos delitos de asesinato, otro de tenencia ilícita de armas y otro de amenazas.

Por otra parte, en el año 2011 los Fiscales ya calificaban de forma unánime como delito de atentado las agresiones sufridas por los profesionales sanitarios del sector público y los tribunales resolvían en este sentido de forma mayoritaria (De Juan-Mazuelas, 2016).

Debido a ello, resulta bastante predecible que a los cargos anteriores se hubiera añadido este ilícito penal y el agresor hubiera sido condenado también en base al tipo de atentado.

En este punto, queremos aclarar que nos referimos siempre a lo ocurrido en Moratalla como «asesinato», porque esta es la calificación jurídica correcta y la que mereció en las Diligencias Previas, a pesar de que muchos medios de comunicación e instituciones a veces se refieren al «homicidio» de Moratalla. El asesinato constituye un tipo penal «diferente, autónomo e independiente del homicidio» (Muñoz Conde, 2017), previsto en los artículos 139 y $140 \mathrm{CP}$, y para su calificación como tal se requiere que el acto criminal se lleve a cabo con alevosía, por precio, recompensa o promesa, con ensañamiento o para facilitar la comisión de otro delito o evitar que se descubra. Pues bien, en este caso concurre claramente el requisito de alevosía.

La alevosía se contempla en el artículo $22.1 \mathrm{CP}$, que reza literalmente: «Hay alevosía cuando el culpable comete cualquiera de los delitos contra las personas, empleando en la ejecución medios, 
modos o formas que tiendan directa o especialmente a asegurarla, sin el riesgo que para su persona pudiera proceder de la defensa por parte del ofendido».

Este aseguramiento del resultado concurre en el caso que nos ocupa, por utilizar el agresor un arma de fuego con la que atacó de forma sorpresiva a su víctima. Obviamente, a ésta no le cupo posibilidad alguna de defensa, por lo que hay que concluir que se trató de un ataque alevoso, que acabó con la vida de la médico y, por tanto, de un asesinato.

Pero todas estas actuaciones penales, repetimos, quedaron en el terreno de la hipótesis porque nunca fueron puestas en práctica por falta de agilidad en las actuaciones.

Si seguimos moviéndonos en el terreno de lo hipotético, podemos concluir que, de no haberse calificado el hecho como accidente de trabajo desde un primer momento, ninguna dificultad habrían tenido los causahabientes en que tal cuestión hubiera sido reconocida por el orden social.

Como hemos visto en los epígrafes correspondientes de este estudio, los sucesos tenían todos los requisitos exigibles para ser calificados como accidente de trabajo (y así fueron conceptuados): elemento objetivo, elemento subjetivo, nexo causal, etc.

No obstante, y volviendo a la realidad, en el caso de autos, sólo quedaban para los causahabientes dos caminos posibles para obtener una indemnización por los daños y perjuicios causados por el fallecimiento de la Dra. Moreno.

El primero, indicado por el propio Auto de extinción de la acción penal, era la vía civil, ejercitable contra los herederos del agresor. Pero según lo manifestado por los medios de comunicación, carecía de ellos.

El segundo, el ejercicio de acción de reclamación de responsabilidad patrimonial de la Administración.

\section{B) ACTUACIONES EN VÍA ADMINISTRATIVA PREVIAS AL DICTAMEN DEL CONSEJO JURÍDICO DE LA REGIÓN DE MURCIA}

En esta dirección se embarcaron los causahabientes de la Dra. Moreno: su esposo (en nombre propio y en representación de su hijo menor de edad) y su madre, directos perjudicados por la injusta muerte de la facultativa.

La reclamación estaba sustentada en los siguientes motivos principales:

- La lesión fue antijurídica: la médico no estaba obligada a sacrificarse, ni tampoco a soportar los daños que su fallecimiento produjo a su esposo, madre e hijo (reclamantes), 
ya que no se enfrentaba a un riesgo que fuera inherente a su profesión. Por ello, debe ser reparada hasta su total indemnidad ${ }^{454}$. Desde luego, creemos que hay consenso en que recibir disparos de arma de fuego por parte de un paciente está completamente fuera de los riesgos inherentes a la profesión sanitaria.

- Existió un funcionamiento anormal del servicio público, en el que no participó la víctima a título de dolo, culpa o negligencia ${ }^{455}$.

- La Administración era «conocedora de las cargas de agresividad existentes en las relaciones de ciudadanos y profesionales» y por ello debe desarrollar «actuaciones para analizar, evitar y paliar los perjuicios» ${ }^{456}$.

El daño se cuantifica en 1.444.471,71 euros (recordemos que la lesión debe ser real, efectiva y evaluable).

A modo de reflexión, creemos de interés hacer una recopilación de los aspectos a nuestro juicio más discutibles de los procedimientos que tuvieron $\operatorname{lugar}^{457}$ en relación con este caso.

\section{PERIODO DE INSTRUCCIÓN}

Un punto a reseñar es como se dilata en el tiempo el procedimiento hasta que se dicta propuesta de resolución, por causas ajenas a los demandantes. Incluso se llega a requerir algún informe a todas luces innecesario; es el caso del solicitado a la inspección médica. Hay que recordar que, finalmente, en la propuesta de resolución se declara prescrito el plazo de la acción para reclamar.

En cuanto a lo sustancial, queda claro que la condición de funcionaria fue perjudicial para la víctima, lo que no se compadece con la protección especial que desde la Administración se pretende brindar a estos profesionales al integrarles en el ámbito del delito de atentado por causa del reconocimiento de su condición funcionarial (más aún, después de su inclusión explicita en el art. 550 tras la reforma del ordenamiento penal que entró en vigor el 1 de julio de 2015)

Nos fundamentamos, para efectuar tal afirmación, en que si $\mathrm{D}^{\mathrm{a}}$ Eugenia Moreno no hubiera sido funcionaria (personal estatutario), el procedimiento resarcitorio se hubiera desarrollado en la jurisdicción laboral, con resultado previsiblemente positivo para los intereses de los demandantes. Véase la STSJ de Castilla-La Mancha (Sala de lo Social) 1532/2007, de 18 de octubre, que estimó,

\footnotetext{
${ }^{454}$ El principio de indemnidad, como señalamos anteriormente, supone que el empleado no debe recibir ningún perjuicio que no deba soportar legalmente, debiendo obtener una reparación que restituya dicha indemnidad patrimonial.

${ }^{455}$ Recordemos que, en caso de mediar culpa de la víctima, se destruye el nexo causal.

${ }^{456} \mathrm{Y}$ por tanto, el suceso no era impredecible e inevitable, y depende de la diligencia mostrada por la Administración que subsista o no la relación de causalidad.

457 Para más detalle sobre todas las actuaciones que se siguieron en este caso, remitimos al capítulo "Los procedimientos seguidos en el caso del asesinato de Moratalla».
} 
entre otros fundamentos, que la Administración incumplió sus deberes de prevención por no existir en el centro un PPRL para auxiliares sanitarios y porque la trabajadora no había recibido formación suficiente, no entendiendo como tal un curso en 2003 sobre abordaje de enfermos psiquiátricos (fue una enferma psiquiátrica quien la agredió).

Por otra parte, las incongruencias de las argumentaciones y/o actuación de los órganos de la Administración implicados en el proceso son evidentes. Nos hemos referido anteriormente a la solicitud de un informe a la inspección médica, por parte del órgano instructor. Podemos añadir más actuaciones que consideramos ilustrativas en este aspecto:

\section{En relación con la actuación del SPRL}

Este servicio argumenta que, en el marco de un Plan de Autoprotección elaborado en 2006, se impartieron en el centro de salud de Moratalla cursos de formación sobre emergencias y evacuación, que nada tienen que ver con el tema de seguridad que se sustancia en este caso.

Así mismo, declara no tener constancia de que exista un protocolo formal sobre coordinación con las Fuerzas y Cuerpos de Seguridad del Estado antes de 2009 y sin embargo afirma que sabe de los conocimientos de los profesionales en cuanto a los recursos disponibles ante situaciones conflictivas. A nuestro entender, la existencia de esa coordinación sería uno de esos recursos a los que el SPRL alude. Resulta, cuando menos, paradójico, que el SPRL afirme su certeza en cuanto al conocimiento por parte de los profesionales de un dato que el propio Servicio declara desconocer, como acabamos de constatar.

El Servicio de Prevención de Riesgos manifiesta que en el año 2005 se realizó la evaluación de riesgos del citado centro de salud y la remitió a la Gerencia, que era quien debía cumplimentar el modelo de Planificación de actividades preventivas y de evaluación de riesgos, ignorando las causas por las que no se realizó. Utiliza los mismos argumentos que la Gerencia de Área de Salud IV, por lo que nos referimos a ello a continuación.

\section{2.- La Gerencia de Área IV.}

Este organismo deriva la responsabilidad derivada de que no se haya llevado a efecto tal documento al hecho de que en el año 2005 la gestión de los centros de Atención Primaria estaba centralizada en las Gerencias de Atención Primaria, que era por tanto la encargada de dicha elaboración. Pero hay que reseñar que, en todo caso, aunque la Gerencia a la que ambos órganos aluden ya no exista, la Gerencia de Área IV está en funcionamiento desde 2007. Desde entonces hasta la producción de los hechos (2009) han transcurrido 2 años, tiempo más que suficiente para 
que se hubiera elaborado dicha Planificación de actividades preventivas del Centro de Salud de Moratalla.

No fue así, como se desprende de la petición que efectúa el órgano instructor al SPRL, al solicitar de este servicio que se aclare la causa por la que no se elaboró la «Planificación de actividades Preventivas» de la evaluación inicial de 2005 para ese centro de salud, antes de 2009.

A todo esto se añade que el Plan de Autoprotección elaborado en el año 2006, y de cuya puesta en marcha es responsable, desde el año 2007, el Director Médico de La Gerencia de Área IV, aún está a la espera de los fondos necesarios para su despliegue en 2008.

Todo ello contrasta con la relativa premura (2005) con la que la Comunidad Autónoma de Murcia se interesó en el tema de las agresiones al personal sanitario de su ámbito de competencia.

\section{C) EL DICTAMEN DEL CONSEJO JURÍDICO DE LA REGIÓN DE MURCIA (Dictamen 87/2014 de 31 de marzo).}

\section{La propuesta de resolución}

La propuesta de resolución entiende que no hubo incumplimiento de la legislación de prevención de riesgos y que las medidas que se proponen en el Plan de Agresiones regional son simples mejoras aplicables de forma escalonada.

El concepto de aplicación escalonada parece abarcar, atendiendo a las distintas fechas de que disponemos, un periodo manifiestamente amplio de tiempo. Sin contar con que en 2008, como ya hemos indicado, aún se esperan fondos para su implantación.

Este planteamiento entra en contradicción con el hecho de que está reconociendo, desde que se legisla en 2005 en cuanto al tema que tratamos en esta Comunidad Autónoma, que la situación de violencia en el ámbito sanitario es preocupante ${ }^{458}$.

Resulta aún más paradójico, si se tiene en cuenta que incluso las medidas adoptadas no se ponen en funcionamiento efectivo de forma automática: en el caso que nos ocupa, ni siquiera las medidas efectivamente implantadas (timbres de alarma) estaban activadas en la noche en que se produjeron los luctuosos acontecimientos.

\footnotetext{
458 De hecho, como hemos tenido oportunidad de comprobar en el epígrafe titulado «Los Planes de prevención de agresiones a los profesionales sanitarios», el Servicio de Salud de la Región de Murcia manifestaba en su preámbulo la necesidad de redactar e implantar este Plan de prevención por la incidencia de las agresiones a su personal sanitario, cuestión que llegaba a calificar de «problema emergente».
} 
Por otro parte, la propuesta se mueve en el terreno de las especulaciones y no de la objetividad, por tanto, adolece de subjetivismo. Y es así, porque se fundamenta en hipótesis de lo que podía o no haberse evitado con otras medidas de seguridad. Olvidando, por el contrario, un dato objetivo: el comportamiento cuando menos agresivo que había mostrado esa misma tarde el autor de los hechos.

\section{2.- El análisis del Consejo Jurídico.}

El Consejo deja entrever que reconoce que no se cumplió el PPRL en ese centro de salud, pero pone énfasis en demostrar que el nexo causal está roto por intervención de tercero.

Ciertamente, ese es uno de los requisitos que, como hemos visto, se exige para considerar la responsabilidad patrimonial de la Administración. Esto contrasta con la exigibilidad que se ejerce sobre el empresario, que responde incluso aunque se produzca esta intervención de terceros, lo que abona aún más nuestra anterior afirmación sobre que, en este supuesto, la posesión de la condición funcionarial fue perjudicial para la fallecida.

A la vez, viene a matizar las afirmaciones de los profesionales de la sanidad privada (y de los Colegios Profesionales en ocasiones) en cuanto a la gran diferencia de la protección que se brinda a los profesionales de la sanidad pública respecto al sector privado, en caso de sufrir agresiones. Podría considerarse de ese modo únicamente si se tiene en cuenta el ordenamiento penal en relación con el delito de atentado, aunque tampoco es absoluto que esto sea así después de la reforma de dicho ordenamiento en $2015^{459}$.

En otro orden de cosas, el Consejo entra también en el ámbito de lo subjetivo y de las hipótesis, al valorar lo que podía o no haber ocurrido, de haber tenido el centro de salud otras medidas de seguridad, cuya eficacia parece cuestionar en cuanto a la evitabilidad de lo acontecido. La contradicción es evidente cuando posteriormente se instalan en el centro los mismos sistemas de seguridad que, tanto para el SPRL, como para la propuesta de resolución y para el propio Consejo, como hemos podido comprobar, carecían de eficacia en un suceso violento como el que había ocurrido allí.

Esta tendencia a la subjetividad que acabamos de reseñar por parte del Consejo se comprende menos aún cuando califica de «meras conjeturas carentes de certeza», alguna de las alegaciones de la parte reclamante, concretamente, que una posible falta de formación del personal pudiera

\footnotetext{
459 Nos referimos a los problemas de aplicación que pueden derivarse de la aplicación del art. 554, para lo que remitimos al epígrafe dedicado a la actuación de la Jurisprudencia: «La jurisprudencia penal sobre al personal sanitario tras la reforma del CP de 2015». En este sentido, SAP Madrid 104/2016, de 25 de febrero.
} 
ser la explicación de que, a pesar de la conducta agresiva que manifestó el asesino esa misma tarde, nadie detectara que podría existir peligro en ese comportamiento.

Conviene recordar al respecto, como en una de las testificales se incide precisamente en que el culpable ya había contestado mal a personal sanitario por la tarde. Pero lo que resulta más significativo, es la testifical que afirma que el asesino no llegó «muy» nervioso al centro de salud momentos antes de cometer el asesinato, lo que implica el reconocimiento por parte de la testigo respecto a que sí mostraba el agresor cierto nerviosismo. A pesar de ello, esta trabajadora no activó ningún mecanismo de alarma, lo cual proporciona una base para otorgar credibilidad a la afirmación del letrado de la defensa, que sin embargo el Consejo califica de «meras conjeturas carentes de certeza».

Por otra parte, queremos destacar también algunas de las razones por las que en la valoración del Consejo resulta impredecible lo ocurrido en Moratalla, algo muy importante si se tiene en cuenta que la predecibilidad es otra de las condiciones que se exigen para reconocer que existe responsabilidad patrimonial por parte de la Administración. Por ejemplo, el hecho de que nadie viera que portara armas de fuego; algo lógico, por otra parte, puesto que la llevaba escondida y nadie le practicó un registro previo (lo cual, obviamente, tampoco está previsto, ni hubiera podido realizarse, dado que el centro no contaba con vigilante de seguridad, único profesional habilitado para este tipo de operaciones).

Sin embargo, a nuestro parecer, en cuanto a este punto es más relevante que el Consejo opine que lo ocurrido era impredecible porque nunca antes se había producido un suceso con arma de fuego en la Región. En consecuencia, al hilo de estas afirmaciones, parece deducirse que para el Consejo Jurídico sólo se puede predecir lo que ya ha ocurrido anteriormente.

Esto entra en contradicción con lo que se prevé en los PPRL, en los que la posibilidad de que exista un peligro ya debe hacer poner en marcha los procedimientos para neutralizarlo. Y esas posibilidades, como acabamos de exponer, existían objetivamente, a pesar de las consideraciones en contra de este Consejo.

\section{D) LA SENTENCIA 790/2016, DE 18 DE NOVIEMBRE, DEL TRIBUNAL SUPERIOR DE JUSTICIA DE MURCIA Y ACTUACIONES POSTERIORES.}

Además de incidir en la mayor parte de las aseveraciones hasta ahora expuestas, interesa destacar, los argumentos novedosos que se desprenden de la oposición al recurso formulada por la Administración y la Compañía aseguradora, que se recogen en esta sentencia. 
En primer lugar, parece negar la especificidad de la violencia en el ámbito sanitario, enfatizando como una de sus causas principales el incivismo que muestran los usuarios y, lo que nos parece más relevante, enmarcándola en el ámbito de la violencia en situaciones comunes. Esto último se contradice con el énfasis de la propia administración al insistir en el problema concreto que entraña la violencia contra los trabajadores del sector sanitario, como se pone de manifiesto en los Planes de Prevención, en la normativa existente en relación con el tema y en la especial protección penal que se brinda al colectivo de la sanidad pública por medio de su consideración como posibles sujetos pasivos del delito de atentado (antes incluso de le entrada en vigor de la LO $1 / 2015)$.

Por otra parte, parece como si se estuviera reconociendo la inutilidad de adoptar planes de prevención si las agresiones son impredecibles y, por tanto, inevitables. Lo que, en nuestra opinión, supone cuando menos dudar de la eficacia de las manifestaciones, declaraciones programáticas etc., que se ponen de manifiesto en esas medidas, así como de la necesidad de su existencia.

Con posterioridad, los reclamantes recurren en casación contra la sentencia del TSJ ante el Tribunal Supremo. Por Auto de 6 de febrero de 2017, de la Sala de lo Contencioso-Administrativo del TSJ de la Región de Murcia, se tiene por preparado el recurso de casación contra la citada sentencia y se emplaza a las partes para su comparecencia en el plazo de treinta días ante la Sala de lo Contencioso-Administrativo del Tribunal Supremo.

Esta Sala dicta Providencia con fecha 5 de mayo de 2017, en relación al Recurso de Casación núm: 983/2017, por la que se acuerda su inadmisión a trámite ${ }^{460}$, con imposición de las costas procesales $^{461}$.

Con esto quedaba cerrada cualquier posible actuación ulterior dentro del ordenamiento jurídico español.

\section{E) REFLEXIÓN FINAL}

Como conclusión, únicamente cabe reiterar la paradoja que existe entre la magnitud de los homenajes, que institucionalmente se le ha dado a este trágico suceso (celebración del antedicho

\footnotetext{
460 «...por incumplimiento de las exigencias que el artículo 89.2 de la LJCA impone para el escrito de preparación, conforme al artículo 90.4.b) de la LCA, en especial por falta de fundamentación, con singular referencia al caso, de que concurren alguno o algunos de los supuestos que, con arreglo a los apartados 2 y 3 del artículo 88 del mismo texto legal en los que se pretende fundar el interés casacional objetivo, y en especial de la concurrencia del presupuesto del artículo 88.3.b)...».

461 «...con imposición de las costas procesales a la parte recurrente, para lo que la Sala, conforme al artículo 90.8 de la Ley Jurisdiccional, establece una cantidad máxima de 500 euros por todos los conceptos para cada uno de los recurridos personados».
} 
«Día» así como las reiteradas manifestaciones que en relación con esa agresión continúan dándose incluso a través de la prensa) ${ }^{462}$, y la falta de asistencia a la familia de la víctima por parte de la Administración, en cuanto a la no asunción de la responsabilidad patrimonial.

Sin causahabientes del asesino a quienes poder derivar la responsabilidad civil y sin que la administración se haga cargo de su responsabilidad patrimonial, el delito queda sin resarcimiento por esos conceptos para los allegados de la víctima que tienen que soportar durante años la interposición de recursos, actualizando siempre el dolor por la pérdida del ser querido y sin poder superar el proceso de duelo, teniendo además que soportar una carga pecuniaria. Véase la sentencia del Tribunal de Justicia de Murcia, que les impone las costas del proceso (por más que pudieran ser moderadas), cuando en vía penal, en ocasiones, el tribunal procede a declararlas de oficio.

En definitiva, de poco vale también la protección que se brinda por medio de la posibilidad de aplicar a las agresiones a los profesionales de la sanidad pública la tipificación como delito de atentado y su inclusión explícita en la protección del art. $550 \mathrm{CP}$ con las disposiciones de la LO $1 / 2015$, si la lentitud en el funcionamiento de la maquinaria judicial permite que queden impunes penalmente agresiones como la del asesinato de $\mathrm{D}^{\mathrm{a}}$ Eugenia Moreno. Un acto de tal violencia con resultado de muerte (además de la existencia de otros ilícitos graves), utilización de arma de fuego y existencia de testigos, y que, sin embargo, concluyó con la extinción de la acción penal por la muerte del acusado cumpliendo aún prisión preventiva, dos años después de ocurrir los trágicos sucesos, sin haber sido juzgado $\mathrm{y}$, en consecuencia, sin haber sido siquiera declarado culpable ${ }^{463}$.

De todas estas consideraciones no cabe más que extraer una conclusión final bastante triste: en el caso del asesinato de la Dra. Moreno todos los sistemas fallaron. En primer lugar, la prevención de riesgos laborales (ya sea porque la agresión fuera de verdad inevitable, ya sea porque concurrió negligencia en la implantación y seguimiento de las medidas de seguridad) no fue capaz de suprimir el riesgo. Las medidas de protección implantadas fallaron y las que no se habían instaurado no pudieron, lógicamente, operar. Atendiendo a la sanción del agresor, el proceso penal no llegó a concluir en la imposición de las penas pertinentes. Y, por fin, tampoco se ha procedido a un resarcimiento de daños a los causahabientes de la víctima en cuanto a la responsabilidad patrimonial de la Administración.

\footnotetext{
462 El Colegio de Médicos de Murcia se personó en la causa, como ha sucedido en ocasiones con motivo de agresiones a facultativos por parte de otras organizaciones colegiales.

463 De Juan-Mazuelas (2016) señala este procedimiento como un caso claro de lentitud en el funcionamiento de la maquinaria judicial, que posibilitó que no llegara a cumplirse el natural resultado procesal: la condena del autor del asesinato.
} 
Desde este caso real y práctico, debemos plantearnos la necesidad de establecer mecanismos que impidan que se vuelvan a producir hechos como éste y que, de suceder, al menos funcionen correctamente los mecanismos de sanción y punición pertinentes y, desde luego, se repare el daño en la mayor medida de lo posible a las víctimas o a sus herederos. 
VIII. CONCLUSIONES 
1. Las agresiones al personal sanitario constituyen un problema de entidad significativa. Para erradicarlo, se han tomado medidas encaminadas tanto a la prevención de las agresiones, como al resarcimiento de la víctima o a la sanción del agresor. En nuestra investigación la incidencia de agresiones fue alta, superior a la mitad de los encuestados. La violencia interna, aunque en menor porcentaje, también estuvo presente, lo que reviste importancia por las nefastas consecuencias que conlleva para los trabajadores y el funcionamiento de los servicios, constituyendo una cuestión que igualmente conviene atajar.

2. Las características predominantes de las agresiones externas han sido: mayoría de naturaleza verbal, cometidas por pacientes, con más agresores de sexo masculino. La probabilidad de sufrir una agresión se evidenció mayor para las mujeres. El sector más afectado fue la sanidad pública y la violencia estuvo dirigida sobre todo contra facultativos y personal de Enfermería, siendo las consultas, las áreas de hospitalización y las urgencias, los lugares donde más ataques se produjeron.

3. Los encuestados creen que los motivos de las agresiones están relacionados con el estrés y nerviosismo de los usuarios, la disconformidad con la asistencia recibida, la hiperapreciación de derechos, sin sus correlativos deberes, y por peticiones no satisfechas. Resultaría necesario incidir en la correcta información a los ciudadanos respecto a normas y funcionamiento de los servicios, así como trabajar en cuestiones organizativas para mejorar la calidad de la asistencia y aumentar los niveles de satisfacción del usuario.

4. Se demostró que existe una gran infranotificación e infradenuncia: menos de la mitad de los agredidos manifestaron haber comunicado el incidente. La mayoría de la violencia, por tanto, permanece oculta. La reticencia de las víctimas a notificar la agresión puede deberse a varios motivos, entre los que destacan la minusvaloración de la importancia de la agresión y su consideración como parte del trabajo.

5. El grado de apoyo percibido por parte de la Dirección o Coordinación del centro fue escaso o inexistente cuando se comunicó una agresión. Esto es grave, puesto que se trata de una cuestión normalizada y preceptiva en los PPRL y protocolos de actuación. Sin embargo, no parece ser realmente efectiva, o al menos no es percibida como tal por los interesados. Puede introducir una disfunción importante: el superior del agredido es una pieza fundamental en el despliegue de medidas a tomar tras una agresión y, si este eslabón no funciona, las demás acciones devendrán ineficaces. También puede incrementar el fenómeno de la infranotificación. 
6. Las CCAA han realizado un esfuerzo importante en materia de PRL, estableciendo protocolos de actuación y medidas preventivas específicas ante el problema de las agresiones. Desde la normativa general, está claro que toda agresión puede ser constitutiva de accidente de trabajo, cuando concurran las características propias de esta figura jurídica, lo que ocurre en la mayoría de los casos. Pero es muy necesario que los protocolos de actuación post-agresión se cumplan efectivamente y los profesionales afectados se vean apoyados por quienes, por otra parte, tienen el deber de hacerlo.

7. La mayoría de los profesionales, sobre todo en la sanidad privada, manifiestan que no tienen conocimiento de los derechos que les asisten frente a una agresión, ni tampoco de las actuaciones que pueden emprender. Es necesario insistir, no sólo en la efectiva implantación de las diferentes medidas de prevención y post-agresión, sino también en su correcta difusión, puesto que los trabajadores afirman su desconocimiento de los mismos.

8. Tanto el Estado como las diferentes CCAA, han legislado en materia de derechos y deberes de los pacientes. Ante el incumplimiento de esos deberes puede entrar en funcionamiento el régimen sancionador administrativo para castigar las infracciones con sus correspondientes sanciones. El deber de respeto y consideración a los profesionales sanitarios se encuentra incluido en la mayoría de estas disposiciones (a partir de 2010), derivándose de él y de la propia relación clínica, una serie de obligaciones. Por consiguiente, no resulta necesaria la elaboración de prolijos repertorios de deberes para los usuarios con el fin de evitar agresiones o comportamientos indeseables hacia el personal sanitario.

9. La atribución de la condición de Autoridad a los profesionales de la sanidad pública por algunas CCAA carece en realidad de consecuencias jurídicas. Sólo si esas CCAA establecieran sanciones específicas agravadas para las agresiones cometidas contra un profesional constituido como Autoridad, se observaría un efecto concreto producido por la posesión de esa condición. Ahora bien, creemos que sería una opción reiterativa e innecesaria, ya que en otras disposiciones se les reconoce el derecho al respeto y consideración y su infracción conlleva las correspondientes sanciones. Los encuestados (sobre todo los de la sanidad pública) entendieron que la utilidad de esta medida a efectos prácticos no es relevante pero que no conviene suprimirla, aunque tal vez hubiera sido mejor la adopción de otras medidas. 
10. La valoración de las instituciones, en general, es baja; obteniendo los porcentajes menos favorables el SACYL y la Administración central. Esto representa una contradicción entre la publicidad que se da a las medidas que se adoptan y la percepción del personal sanitario al respecto, lo que puede suponer un toque de atención en orden a trabajar en una mayor efectividad de las actuaciones y que éstas sean más visibles para los interesados. De hecho, una mayoría de los entrevistados manifestaron no conocer cómo actuar ante una agresión.

11. El delito de atentado es de aplicación indiscutible a los profesionales de la sanidad pública desde su inclusión explícita en el art. 550 tras la reforma del CP de 2015. Ahora bien, las penas de aplicación a ese delito han rebajado el límite inferior, que es el que más suele aplicarse. Las amenazas tendrán dificultad para ser tipificadas como delito de atentado, las lesiones consideradas delitos leves precisan denuncia de parte (lo que puede incrementar la infradenuncia) y las injurias leves (muy numerosas) han pasado del orden penal al civil. Por consiguiente, a pesar de esa inclusión, la punición de las conductas agresivas no ha experimentado un incremento, sino más bien lo contrario en la mayoría de los supuestos.

12. Las sanciones administrativas pueden ser una medida eficaz, pero nunca preferente o de aplicación excluyente del Derecho penal. El ordenamiento sancionador administrativo en muchas ocasiones aplica penas pecuniarias más severas y sus garantías procedimentales son menos rigurosas que las del orden penal. Además, del ámbito de estas sanciones administrativas quedarían excluidos los profesionales de la sanidad privada y ya suscita críticas que no estén incluidos en el delito de atentado. Por tanto, debe utilizarse el régimen sancionador administrativo, pero no de manera generalizada, ni como primera opción necesariamente, sino en los casos en que resulte procedente.

13. Existe una falta de igualdad en el acceso a los recursos jurisdiccionales por parte de los trabajadores de los distintos sectores de la sanidad cuando se producen agresiones. No hay una equiparación entre las oportunidades de que disponen los empleados de la sanidad pública, de la privada y, ni tan siquiera, de quienes prestan sus servicios en la Administración pública bajo diferentes figuras contractuales. Se observa que el trabajador que tiene un acceso mayor a todos los recursos que ofrecen los distintos órdenes jurisdiccionales es el empleado público con contrato laboral.

14. Un caso como el asesinato de Moratalla debe hacer reflexionar sobre la eficacia y oportunidad del funcionamiento de nuestro sistema jurídico para garantizar la defensa, 
protección y eventual resarcimiento de la víctima si finalmente la agresión se produce. Se debe agilizar el funcionamiento de la Administración de Justicia y adoptar las medidas necesarias para que estos sucesos, si no han podido evitarse, al menos tengan los efectos reparadores que en justicia deben tener.

15. Los profesionales encuestados reclaman medidas efectivas, directas y contundentes hacia la agresión producida. Parecen otorgar un gran valor a la capacidad de disuasión de las medidas sancionatorias: multas y penas de prisión. Pero también consideran necesario que se produzcan cambios en la actual organización asistencial, que procuren mejores niveles de comunicación y una transformación que potencie la humanización de la relación sanitaria. 
IX. BIBLIOGRAFÍA 
1. Alarcón, M., \& Ruiz de Aldana, J. (2005). La violencia en el medio sanitario. In Actas del Congreso de la Asociación Española de Derecho Sanitario. Madrid.

2. Alcalá Pérez-Flores, R., Jaén Vallejo, M., Martínez Arrieta Vázquez Prado, C., \& Perrino Pérez, Á. (2015). La Reforma del Código Penal. Parte Especial II.

3. Almanzor Elhadad, F. I., \& Martín Galán, Á. M. (2015). Agresiones a profesionales de la salud: La verdadera dimensión del problema. Hygia de Enfermería: Revista Científica Del Colegio, ISSN 1576-3056, No. 88, 2015, Págs. 5-10, (88), 5-10.

4. Anderson, C., \& Parish, M. (2003). Report of workplace violence by hispanic nurses. Journal of Transcultural Nursing, 14, 237-243.

5. Arastey Sahún, L. (2015). Responsabilidades (I): Infracciones y sanciones administrativas. El recargo de prestaciones por falta de medidas de seguridad. In G. García González \& A. Garrigues Giménez (Eds.), Manual de Derecho de la prevención de riesgos laborales [Recurso Electrónico]. Valencia: Tirant lo Blanch.

6. Arenas Viruez, M. (2011). "La repercusión de la culpa de la víctima de un accidente de trabajo." Revista Doctrinal de Aranzadi Social, (21).

7. Arimany-Manso, J., Clos-Masó, D., \& Gómez-Durán, E. L. (2016). Sobre las agresiones a profesionales sanitarios Attacks on health professionals. Aten Primaria, 48(3), 147-148.

8. Atance Martínez, J. C. (1997). Aspectos epidemiológicos del síndrome de burnot en personal sanitario. Revista Española de Salud Pública, 71, 293-303.

9. Benveniste, K., Hibbert, P., \& Runciman, W. (2005). Violence in health care: the contribution of the Australian Patient Safety Foundation to incident monitoring and analysis. 2005;183: 348---51. Title. Med J Aust., (183), 348-351.

10. Bernaldo-de-Quirós, M., Labrador, F. J., Piccini, A. T., Mar Gómez, M., \& Cerdeira, J. C. (2014). Violencia laboral en urgencias extrahospitalarias: una revisión sistemática y líneas de intervención psicológica. Accésit de la XX edición del Premio de Psicología Aplicada "Rafael Burgaleta" 2013. Clínica y Salud, 25(1), 11-18.

11. Bernaldo de Quirós Aragón, M., \& Labrador Encinas, F. J. (2008). Fuentes de estrés laboral en los servicios de urgencia de atención primaria. Atención Primaria, 40(2), 104105.

12. Blas Orbán, C. (2006). El equilibrio en la relación médico-paciente. Barcelona: Bosch Editor.

13. Braga, F., Prats, M., Luna, D., Melamud, A., \& Flichtentrei, D. (2012). Agresiones contra Médicos. Intramed. Retrieved from http://www.intramed.net/userfiles/pdf/36397.pdf

14. Burgos, M., \& Paravic, T. (2003). Percepción de violencia de los pacientes hospitalizados en los servicios de medicina y cirugía de un hospital público. Cienc Enferm 2003; 9: 2942. Ciencia Y Enfermeria, 9, 29-42. 
15. Camerino, D., Estryn-Behar, M., Conway, P. M., van der Heijden, B., \& Hasselhorn, H.M. (2007). Work-related factors and violence among nursing staff in the European Next study: A longitudinal cohort study. International Journal of Nursing Studies, 45, 35-50.

16. Carrasco, D. (2017, March 20). Agredir al médico de una mutua es delito de atentado. Diariomedico.com.

17. Carrasco Rodríguez, P., Rubio González, L., Vílchez Castellano, S., \& Villalobos Buitrago, D. (2007). Estudio de las agresiones recibidas por el personal de enfermería y de las vivencias al respecto en los servicios de urgencias de los hospitales de la comunidad de Madrid en un trimestre. Nure Investigación, 26.

18. Castellano Arroyo, M. (2011). De la relacion médico-enfermo a la relación médicopaciente usuario. Las denuncias y la violencia contra los médicos ¿signos de alarma social? Granada: Universidad de Granada.

19. Castilla La Mancha Sanidad - CSIF pide más medios para evitar agresiones en los centros sanitarios. (2016). Retrieved September 1, 2017, from https://www.csif.es/contenido/castilla-la-mancha/sanidad/223023

20. Castro Corredoira, M., \& Guinarte Cabada, G. (2015). La reforma de los delitos de lesiones (Arts. 147, 152 y 156 CP). In J. L. et. al. González Cussac (Ed.), Comentarios a la reforma del Código Penal de 2015 (1 $1^{\text {a }}$,pp. 487-500). Valencia: Tirant lo Blanc.

21. Cervantes, G., Blanch, J. M., \& Hermoso, D. (2010). violencia ocupacional contra profesionales sanitarios en Cataluña notificada por internet (2007-2009). Retrieved from http://www.archivosdeprevencion.com/view_document.php?tpd=2\&i=1946

22. Chagoyen Barroso, T. (2016). Violencia laboral externa en el ámbito de urgencias generales del Hospital Universitario Virgen del Rocío de Sevilla. Medicina Y Seguridad Del Trabajo, 62(242), 25-48.

23. Chappell, D., \& Di Martino, V. (2006). Violence at Work (3 ${ }^{\text {a }}$ Edition). Geneva: International Labour Office.

24. Chuliá Fernández, F. (2014). Las agresiones a los profesionales sanitarios en un hospital general de la Comunidad de Madrid [Tesis Doctoral]. Universidad Complutense de Madrid. Retrieved from http://eprints.ucm.es/33890/

25. COMB. (2004). Guía para prevenir y gestionar la violencia contra los médicos en el lugar de trabajo. Quaderns de La Bona Praxi., 17, 6.

26. Comisión de recursos humanos del SNS. (2014). Informe del grupo de trabajo de agresiones a profesionales del Sistema Nacional de Salud. Madrid. Retrieved from www.redaccionmedica.com/.../informe_agresiones_profesionales.pdf

27. Condena de seis meses de prisión por insultar e intentar agredir a un médico | Médicos y Pacientes. (2016). Retrieved August 3, 2017, from http://www.medicosypacientes.com/articulo/condena-de-seis-meses-de-prision-por- 
insultar-e-intentar-agredir-un-medico

28. Condena de un año de cárcel a una paciente por agredir, escupir e insultar a una enfermera del Hospital Clínic de Barcelona | iSanidad. (2016). Retrieved September 25, 2017, from http://isanidad.com/66997/condena-de-un-ano-de-carcel-a-una-paciente-poragredir-escupir-e-insultar-a-una-enfermera-del-hospital-clinic-de-barcelona/

29. Condenado por agredir a una doctora para que atendiera «con rapidez» a su yerno. (2016, January 1). ABC Andalucía.

30. Condenado por amenazar a un ATS que le recriminó que fumase en el hospital. (2016). Retrieved September 25, 2017, from http://www.diariodecadiz.es/provincia/Condenadoamenazar-ATS-recrimino-hospital_0_988701761.html

31. Condenado por arrojar dos papeleras contra una doctora en una consulta de Irun . diariovasco.com. (2016). Retrieved September 25, 2017, from http:/www.diariovasco.com/gipuzkoa/201601/03/condenado-arrojar-papeleras-contra20160103134002.html

32. Condenan a seis meses de prisión a un paciente que agredió a una médico en Erandio. Deia, Noticias de Bizkaia. (2015). Retrieved September 25, 2017, from http://www.deia.com/2015/11/04/sociedad/euskadi/condenan-a-seis-meses-de-prision-aun-paciente-que-agredio-a-una-medico-en-erandio

33. Consejería de Sanidad de Castilla-La Mancha. (2017). El Servicio de Salud de Castilla-La Mancha mejora la protección jurídica de sus profesionales frente a las agresiones | Gobierno de Castilla-La Mancha [Nota de prensa]. Retrieved September 20, 2017, from http://www.castillalamancha.es/actualidad/notasdeprensa/el-servicio-de-salud-de-castillala-mancha-mejora-la-protección-jurídica-de-sus-profesionales-frente

34. Consejo Internacional de Enfermeras. (1999). Enfermería y violencia. Boletín Eneromarzo de 1999. Boletín Enero-Marzo.

35. Consejo Internacional de Enfermeras. (2007). Directrices para hacer frente a la violencia en el lugar de trabajo. Ginebra.

36. Consejo Internacional de Enfermería. (1998). Directrices para hacer frente a la violencia en el lugar de trabajo. Ginebra.

37. Cooper, C., \& Swanson, N. (2000). Workplace Violence in the Health Sector. OMS 2000.

38. Corcoy Bidasolo, M., \& Mir Puig, S. (2015). Comentarios al Código penal : reforma LO 1/2015 y LO 2/2015 (2a). Valencia: Tirant lo Blanch.

39. Cuerda Arnau, M. L. (2015). Atentados y resistencia (arts. 550 y ss.). In J. L. et. al. . González Cussac (Ed.), Comentarios a la reforma del Código Penal de 2015 (1ª , pp. 1281-1294). Valencia: Tirant lo Blanch.

40. De-San-Segundo, M., Granizo, J. J., Camacho, I., Martínez-de-Aramayona, M. J., Fernández, M., \& Sánchez-Úriz, M. Á. (2016). [A comparative study of aggression 
towards Primary Care and Hospital Health professionals in a Madrid health area (20092014)]. Semergen. http://doi.org/10.1016/j.semerg.2016.03.017

41. De Juan-Mazuelas, A. I. (2016). La Jurisdicción Penal ante las agresiones al personal sanitario. Estudio jurisprudencial. [Tesis Doctoral]. Universidad de Valladolid.

42. De Juan-Mazuelas, A. I., Sánchez-Benito, C., Martínez-León, C., \& Martínez-León, M. (2017). Agresiones a profesionales sanitarios: tratamiento a partir de la reforma del Código Penal de 2015 de las lesiones y las antiguas faltas. Revista Española de Medicina Legal, [aceptado. http://doi.org/10.1016/j.reml.2017.06.001

43. De Juan-Mazuelas A. I., Sánchez-Benito, M.C., , Martínez-León, C., \& Martínez-León, M. (2017). Las agresiones al personal sanitario. Estado actual de la investigación. Diálisis Y Trasplante, [Aceptado para su publicación el 8 de junio de 2017].

44. De Lorenzo, R. (2015, May 26). 1 de julio de 2015, nuevo Código Penal. Redacción Médica. Retrieved from https://www.redaccionmedica.com/opinion/1-de-julio-de-2015nuevo-codigo-penal-1766

45. Deeb, M. (2003). Workplace Violence in the Health Sector LEBANON Country Case Study, ILO/ICN/WHO/PSI Joint Programme on Workplace Violence in the Health Sector.

46. Desdentado Bonete, A. (1999). Comentario al artículo 115. In J. . (Dir. . Monereo Pérez \& M. Moreno Vida (Eds.), Comentarios a la Ley General de Seguridad Social. Granada: Editorial Comares.

47. Día Nacional contra las Agresiones a Sanitarios 2017. (2017). Retrieved March 16, 2017, from

http://www.lacomarcadepuertollano.com/diario/noticias/2017_03_16/2017_03_16_No_5 6-1.pdf

48. Di Martino, V. (2002). Workplace violence in the health sector-Country case studies: Brazil, Bulgaria, Lebanon, Portugal, South Africa, Thailand, plus an additional Australian study: Synthesis report. Geneva. Retrieved from http://www.who.int/\%0Aviolence_injury_prevention/injury/en/WVsynthesisreport.pdf $\% 0$ A

49. Di Martino, V. (2003). Workplace violence in health sector. Relationship between work stress and workplace violence in the health sector. Geneva.

50. Díaz Fraile, F. (2017). Derecho penal y Derecho administrativo sancionador. Valencia: Tirant lo Blanch.

51. Dorman, P. (2000). The Economics of Safety, Health and Well-being at Work. An Overview. Geneva.

52. El 16 de marzo la OMC conmemora el "Día Nacional contra las Agresiones en el Ámbito Sanitario"| CGCOM. (2017). Retrieved March 16, 2017, from http://www.cgcom.es/noticias/2017/03/17_03_09_tolerancia_cero_ante_las_agresiones 
53. El País. (2008). Osakidetza considerará accidente laboral las agresiones a sus trabajadores | Edición impresa | EL PAÎ́S. Retrieved September 22, 2017, from https://elpais.com/diario/2008/11/19/paisvasco/1227127201_850215.html

54. El riesgo de agresión exige un plan preventivo - Observatorio de Agresiones. (2016). Retrieved September 25, 2017, from https://www.cmb.eus/Canales/Ficha.aspx?IdMenu=8303951e-1552-4f1c-93f1c6ed8a422138\&Cod=c4ce971c-864e-4652-a8ff-86da370c9b8b\&Idioma=es-ES

55. El TSJ obliga al Servicio Vasco de Salud a implantar un plan preventivo de agresiones al personal sanitario | www.comcas.es. (2016). Retrieved September 20, 2017, from https://www.comcas.es/blog/sala-de-prensa-3/post/el-tsj-obliga-al-servicio-vasco-desalud-a-implantar-un-plan-preventivo-de-agresiones-al-personal-sanitario-304

56. Encuesta Nacional de Condiciones de Trabajo. 6 ${ }^{\text {a }}$ EWCS. (2015) (6th ed.). España.

57. Estryn-Behar, M., van der Heijden, B., Camerino, D., Fry, C., Le Nezet, O., Conway, P. M., \& Hasselhorn, H.-M. (2008). Violence risks in nursing--results from the European “NEXT” Study. Occupational Medicine (Oxford, England), 58(2), 107-114. http://doi.org/10.1093/occmed/kqm142

58. Evans, H. (2007). Do patients have duties? Journal of Medical Ethics, (33), 689-694.

59. Faraldo Cabana, P. (2015). Los Delitos Leves [Recurso electrónico] : causas y consecuencias de la desaparición de las faltas / Patricia Faraldo Cabana. Valencia: Tirant lo Blanch.

60. Fernández Aparicio, J. M. (2008). Consideraciones jurídico-penales de las agresiones al personal sanitario (II). Actualidad Del Derecho Sanitario, (150), 451-453. JOUR.

61. Fernández Avilés, J. A. (2005). Concepto de accidente de trabajo. El riesgo objeto de protección jurídica en AA.VV. In J. L. Monereo Pérez, C. Molina Navarrete, \& M. N. Moreno Vida (Eds.), Tratado práctico a la legislación reguladora de los accidentes de trabajo y enfermedades profesionales. Régimen jurídico de la prevención, aseguramiento, gestión y responsabilidad (pp. 71-89). Granada: Editorial Comares.

62. Fernández Avilés, J. A. (2015). La prevención de riesgos laborales y la reparación de accidentes de trabajo y enfermedades profesionales en el sistema español de Seguridad Social. In J. L. Monereo Pérez, C. Molina Navarrete, S. Olarte Encabo, \& J. A. Fernández Avilés (Eds.), Tratado de Prevención de Riesgos Laborales. Teoría y Práctica (pp. 391425). Madrid: Tecnos.

63. Fernández Iglesias, M. (2012). Agresiones a los profesionales de enfermería de los servicios de urgencias de los hospitales públicos de Asturias a partir de su percepción. Retrieved from http://digibuo.uniovi.es/dspace/handle/10651/4279

64. Fernández Martín, M. J., Camacho García, M. G., Olmos Aullón, C., Ruiz García, S., \& Sanjuán Navais, M. (2006). Análisis y registro de las agresiones en UCI. Enfermería 
Intensiva, 17(2), 59-66. http://doi.org/10.1016/S1130-2399(06)73917-7

65. Ferri, P., Silvestri, M., Artoni, C., \& Di Lorenzo, R. (2016). Workplace violence in different settings and among various health professionals in an Italian general hospital: a cross-sectional study. Psychology Research and Behavior Management, (9), 263-275.

66. Ferrinho, P., Antunez, A., A, B., Conceição, C., Fronteira, I., \& Graveiro, I. (2003). Workplace Violence in the Health Sector Portuguese Case Studies. ILO/ICN/WHO/PSI Joint Programme on Workplace Violence in the Health Sector.

67. Ferro Veiga, J. M. (2012). Violencia al personal sanitario: ni una agresión más. Criminología. (Vol. 1). BOOK, Alcalá La Real Jaén: Formación Alcalá.

68. Fiscalía General del Estado. (2015, June 22). Circular 3/2015 de la Fiscalía General del Estado sobre el régimen transitorio tras la reforma operada por LO 1/2015. Fiscal.es, p. 63. Retrieved from https://www.fiscal.es/fiscal/PA_WebApp_SGNTJ_NFIS/descarga/Circular_3_2015_Dere cho_Transitorio_Rev.pdf?idFile=ca1 caeba-5b88-4d97-88ea-d78854b23729

69. Franco González, J. (2015). Seguridad y salud en el trabajo y prevención de riesgos laborales: marco histórico-conceptual y análisis técnico-jurídico. In G. García Gónzalez \& A. Garrigues Giménez (Eds.), Manual de derecho de la prevención de riesgos laborales [Recurso Electrónico]. Valencia: Tirant lo Blanch.

70. Galán Cortés, J. (2011). Responsabilidad civil médica. Navarra: Civitas Thomson-Reuters Cizur Menor.

71. Galián Muñoz, I. (2015). Violencia de los usuarios hacia el personal de enfermería: evaluación del riesgo laboral y análisis de las consecuencias psicológicas [Tesis Doctoral].

72. Galián Muñoz, I., Llor Esteban, B., \& Ruiz Hernández, J. A. (2012). Violencia de los usuarios hacia el personal de enfermería en los hospitales públicos de la Región de Murcia. Revista Española de Salud Pública, ISSN-E 1135-5727, Vol. 86, No. 3, 2012, Págs. 279-291, 86(3), 279-291.

73. García Calvo, T. (2013). Deberes de los usuarios. In J. R. Salcedo Hernández (Ed.), Derecho y Salud. Estudios de Bioderecho. (Comentarios a la Ley 3/2009 de Derechos y Deberes de los Usuarios del Sistema Sanitario de la Región de Murcia) [Recurso Electrónico] (pp. 341-363). Valencia: Tirant lo Blanch.

74. García de Enterría, E. (2005). Responsabilidad patrimonial del Estado legislador en el Derecho español. Madrid: Thomson-Civitas.

75. García Valverde, M. D. (2015). El ámbito de aplicación de la Ley de Riesgos Laborales. In G. García González \& A. Garrigues Giménez (Eds.), Manual de Derecho de la prevención de riesgos laborales. Valencia: Tirant lo Blanch.

76. Gasco, F., Martín, F. J., Rodríguez, A., Cruces Roldán, S., López, I., Varo Baena, R., \& 
Horno, P. (2017). Autodefensa de las agresiones verbales para el personal sanitario. Revista Enfermería Del Trabajo, 7(2), 38-40.

77. Gascon, S., Leiter, M. P., Andres, E., Santed, M. A., Pereira, J. P., Cunha, M. J., ... Martinez-Jarreta, B. (2013). The role of aggressions suffered by healthcare workers as predictors of burnout. Journal of Clinical Nursing, 22(21-22), 3120-3129.

78. Gascón Santos, S. (2006). Análisis médico-legal de la violencia en centros asistenciales: agresiones a profesionales. [Tesis Doctoral]. Universidad de Zaragoza.

79. Gates, D., Ross, C., \& Mc Queen, L. (2006). Violence Against Emergency Department Workers. The Journal of Emergency Medicine, 31(3), 331-337.

80. Generalitat Valenciana. (2009). Decreto 159/2009, de 2 de octubre, del Consell, por el que se establecen las actuaciones de los órganos de la Consellería de Sanidad en prevención y atención de las agresiones de los trabajadores del sector sanitario público de la Generalitat. $D O C V$, (7 de octubre).

81. Gómez-Durán, E. L., Gómez-Alarcón, M., \& Arimany-Manso, J. (2012). Las agresiones a profesionales sanitarios. Revista Española de Medicina Legal, 38(1), 1-2.

82. González Cussac, J. L. (2015). Prefacio. In J. L. et. al. González Cussac (Ed.), Comentarios a la Reforma del Código penal de $2015\left(1^{\mathrm{a}}\right)$. Valencia: Tirant lo Blanc.

83. González García, M. D., \& Martín Ayala, M. (2011). La nueva ley de derechos y deberes en materia de salud de Castilla-La Mancha. In J. Tomillo Urbina, J. Cayón de las Cuevas, \& (Directores) (Eds.), Estudios sobre Derecho de la Salud (pp. 373-394). Pamplona: Thomson Reuters Aranzadi.

84. González Ortega, S., \& Aparicio Tovar, J. (1996). Comentarios a la Ley 31/1995, de prevención de riesgos laborales. Madrid: Trotta.

85. Guerrero Zaplana, J. (2004). Las reclamaciones por la defectuosa asistencia sanitaria. Valladolid: Lex Nova.

86. Gutiérrez, L., Hernández, M. J., \& Molina, L. (2016). Work-related violence among public health professionals (2008-2012). Archivos de Prevención de Riesgos Laborales, 19(3), 166-174.

87. Hoel, H., Sparks, K., \& Cooper, C. (2001). The cost of violence/stress at work and the benefits of a violence/stress-free working environment, Report commissioned by the International Labour Office (ILO). Geneva.

88. Huergo Lora, A. (2007). Las sanciones administrativas ( $1^{\text {a }}$ Edición). Madrid: Iustel.

89. INSHT. (2011). VII Encuesta nacional de condiciones de trabajo. Madrid.

90. Jovell, A., Blendon, R., Fleischfresser, C., Benson, J., Des Roches, C., \& Weldom, J. (2007). Public trust in the Spanish healthcare system. Health Expect, 10, 350-357.

91. Jovell Fernández, A., Navarro Rubio, M., Fernández Maldonado, L., \& Blancafort, S. (2002). Nuevo rol del paciente en el sistema sanitario. Atención Primaria, 38(4), 234- 
237.

92. Lameiro, C., Besteiro, A., Cuevas, A., Pérez Rodríguez, A., Gómez, C., \& Campo Pérez, V. M. del. (2013). Violencia laboral en Instituciones sanitarias Análisis de un perfil cambiante. Revista Enfermería Del Trabajo, ISSN-E 2174-2510, Vol. 3, N. 2, 2013, Págs. 66-74, 3(2), 66-74.

93. Leenen, H. (1987). Patients' Rights in Europe. Health Policy. Health Policy, 8, 33-38.

94. Letelier, P., \& Valenzuela, S. (2002). Violencia: fenómeno relevante de estudio en campos clínicos intrahospitalarios de enfermería. Cienc Enferm 2002; 8: 21-26. Ciencia Y Enfermería, 8, 21-26.

95. Libano Beristain, A. (2017). La perseguibilidad a instancia de parte como proyección de las facultadesde la víctima. In M. de Hoyos Sancho (Ed.), Las víctimas del delito y las últmas reformas procesales. Pamplona: Thomson Reuters Aranzadi.

96. Lo peor es que mi agresor también era mi paciente y tenía la obligación de atenderle. (2015). Retrieved September 1, 2017, from http://www.eldiario.es/norte/euskadi/sanitarios-Osakidetza-sufren-agresiondia_0_437806545.html

97. López Barja de Quiroga, J., Encinar del Pozo, M. Á., Villegas García, M. Á., Martínez Arrieta, A., Climent Durán, C., Águeda Holgueras, C., ... Sabando Seguí, J. (2016). Código Penal con jurisprudencia sistematizada. Valencia: Tirant lo Blanch.

98. López Gandía, J. (2017). Aspectos jurídicos del daño corporal producido por accidente de trabajo o enfermedad profesional. In J. López Gandía \& J. F. Blasco Lahoz (Eds.), Curso de Prevención de Riesgos Laborales $\left(18^{\mathrm{a}}\right)$. Valencia: Tirant lo Blanch.

99. López Gandía, J., \& Blasco Lahoz, J. F. (2017). Curso de Prevención de Riesgos Laborales $\left(18^{\mathrm{a}}\right)$. Valencia: Tirant lo Blanc.

100. Los inspectores sanitarios se oponen a la nueva Ley de Salud porque pierden su «autoridad»- Levante-EMV. (2014). Retrieved September 23, 2017, from http://www.levante-emv.com/comunitat-valenciana/2014/06/11/inspectores-sanitariosoponen-nueva-ley/1123847.html

101. Los médicos se blindan ante las agresiones de pacientes - Observatorio de Agresiones COLEGIO DE MÉDICOS DE BIZKAIA. (2015). Retrieved March 24, 2017, from https://www.cmb.eus/observatorio-de-agresiones-2/los-medicos-se-blindan-anteagresiones-de-pacientes

102. Luque, M. (2014). Marco jurídico, obligaciones principales y responsabilidades en materia de salud laboral. In C. Ruiz Frutos, J. Delclós, E. Ronda, A. M. García, \& F. D. Benavides (Eds.), Salud laboral. Conceptos y técnicas para la prevención de riesgos laborales ( $3^{\mathrm{a}}$, pp. 57-74). Barcelona: Elsevier Masson.

103. Marinas-Sanz, R., Martínez-Jarreta, B., Casalod, Y., \& Bolea, M. (2016). Las agresiones 
a profesionales sanitarios en España: análisis tras la reciente modificación del Código Penal. Medicina Clínica, 147(1), 35-42.

104. Martínez-Jarreta, B. (2003). Los derechos del ciudadano como paciente en el escenario de la sanidad española. Cuadernos de Consumo, (11), 85-92.

105. Martínez-Jarreta, B. (2011). Las agresiones en el ámbito sanitario. In J. Gascón Abellán, M. González Carrasco, \& J. Cantero Martínez (Eds.), Derecho sanitario y Bioética Cuestiones actuales [Libro electrónico]. Valencia: Tirant lo Blanch.

106. Martínez-Jarreta, B., Gascón, S., Ángel Santed, M., \& Goicoechea, J. (2007). Análisis médico-legal de las agresiones a profesionales sanitarios. Aproximación a una realidad silenciosa y a sus consecuencias para la salud. Medicina Clínica, 128(8), 307-310.

107. Martínez-Zaporta Aréchaga, E., \& Fernández-Delgado Momparler, R. (2008). Las agresiones a personal sanitario: propuesta para una reforma penal. Derecho Y Salud, $16(2), 217-234$.

108. Martínez, P. (2011). Seguridad hospitalaria. In F. Bocanegra Morales (Ed.), La seguridad en un hospital. Manual de seguridad. [Recurso Electrónico]. Valencia: Tirant lo Blanc.

109. Martínez Barroso, M. (2002). Las enfermedades del trabajo. (T. lo Blanc, Ed.). Valencia.

110. Martínez León, M., Irurtia Muñiz, M. J., Martínez León, C., Crespo Sierra, M. T., \& Queipo Burón, D. (2011). Estudio de las agresiones a los profesionales sanitarios. Revista Escuela de Medicina Legal REML, (17), 4-11.

111. Martínez León, M., \& Queipo Burón, D. (2010). Aspectos médico-legales de las agresiones al personal sanitario y su consideración como delito de atentado. Revista Sideme. Número Julio-Septiembre, 5.

112. Martínez León, M., Queipo Burón, D., Irurtia Muñiz, M. J., \& Martínez-León, C. (2012). Análisis médico-legal de las agresiones a los profesionales sanitarios en Castilla y León (España). Revista Espanola de Medicina Legal, 38(1), 5-10.

113. Martínez Platel, R. (2015, May 21). Llamar "sinvergüenza" a un médico de la privada sale casi gratis. Redacción Médica. Retrieved from https://www.redaccionmedica.com/secciones/derecho/llamar-sinverg-enza-a-un-medicode-la-privada-sale-casi-gratis-82671

114. Mayorca Yancán, I. A., Lucena García, S., Cortés Martínez, M. E., \& Lucerna Méndez, M. Á. (2013). Violencia contra trabajadores sanitarios en un hospital de Andalucía: ¿Por qué hay agresiones no registradas? Medicina Y Seguridad Del Trabajo, 59(231), 235258. http://doi.org/10.4321/S0465-546X2013000200005

115. McMullan, M. (2006). Patients using the Internet to obtain health information: how this affects the patient-health professional relationship. Patient Educ Couns, 63, 24-28.

116. Medina Alcoz, L. (2007). La teoría de la pérdida de oportunidad. Estudio doctrinal y jurisprudencial de Derecho de daños público y privado. Madrid: Cizur Menor. 
117. Mercader Uguina, J. R. (2017). El trabajador. In A. de la Puebla Pinilla, J. Mercader Uguina, \& F. J. Gómez Abelleira (Eds.), Lecciones de Derecho del Trabajo [Recurso Electrónico] (10 Edició). Valencia: Tirant lo Blanch.

118. Miret, C., \& Martínez Larrea, A. (2010). El profesional en urgencias y emergencias: agresividad y burnout. Anales Del Sistema Sanitario de Navarra, 33, 193-201. Retrieved from

119. Montalvo Jääskeläinen, F., \& Pinedo García, I. (2011). La seguridad de la asistencia sanitaria (y II). La seguridad del personal sanitario. o Sanitario y Medicina Legal del Trabajo. In S. Delgado Bueno (Ed.), Derecho sanitario y Medicina Legal (1 ${ }^{\mathrm{a}}$, pp. 361379). Barcelona: Bosch Editor.

120. Moreno Jiménez, M. A., Vico Ramírez, F., Zerolo Andrey, F. J., López Rodríguez, A., Herrera Serena, P., \& Mateios Salido, M. J. (2005). Análisis de la violencia del paciente en atención primaria. Atención Primaria, 36(3), 152-158.

121. Muñoz Conde, J. A. (2017). Derecho Penal Parte Especial [Recurso electrónico] (21 ${ }^{\mathrm{a}}$ Edició). Valencia: Tirant lo Blanch.

122. Musayón, F., \& Caufield, C. (2007). Workplace violence and drug use in women workers in a Peruvian Barrio. International Nursing Review, 54, 339-345.

123. National Audit Office (NAO). (2003). A Safer Place to Work - Protecting NHS Hospital and Ambulance Staff from Violence and Aggression. London.

124. Navarro Rubio, M., Gabriele Muñiz, G., \& Jovell Fernández, A. (2008). Los derechos del paciente en perspectiva. Aten Primaria, 40(7), 367-369.

125. Nistal Burón, J. (2008). La consideración de las agresiones al personal sanitario como delito de atentado. Criterios jurisprudenciales. Diario La Ley, (7004). JOUR.

126. Noticias Juridicas.com. (2017, August). Se considera accidente de trabajo el sufrido por un médico durante su asistencia a un congreso · Noticias Jurídicas. Noticiasjuridicas.com. Retrieved from http://noticias.juridicas.com/actualidad/jurisprudencia/12236-seconsidera-accidente-de-trabajo-el-sufrido-por-un-medico-durante-su-asistencia-a-uncongreso/

127. Noticias sobre sanidad y enfermería. Satse. (2015). Autoridad pública para el profesional y avances en bioseguridad. Retrieved February 2, 2017, from http://www.satse.es/comunicacion/noticias/autoridad-publica-para-el-profesional-yavances-en-bioseguridad

128. Núñez, M. R., \& Zubillaga, G. (1999). Violencia en el hospital. Medicina Clínica, 113(2), 78. Retrieved from http://www.elsevier.es/es-revista-medicina-clinica-2-articuloviolencia-el-hospital-2882

129. Núñez González, C. (2016). Marco normativo en materia de prevención de riesgos laborales. In C. Núñez González \& F. Estardid Colom (Eds.), Marco normativo y gestión 
de la prevención de riesgos laborales [Recurso electrónico] ( $1^{\text {a }}$ Edición). Valencia: Tirant lo Blanch.

130. Nuñez González, C., \& Estardid Colom, F. (2016). Marco normativo y gestión de la prevención de riesgos laborales [Recurso electrónico] (1 ${ }^{\text {a }}$ Edición). Valencia: Valencia : Tirant lo Blanch.

131. O.S.H.A. Occupational Safety and Health Administration. (2004). Guidelines for Preventing Workplace Violence for Health Care \& Social Service Workers. OSHA. Washington.

132. O.S.H.A. Occupational Safety and Health Administration. (2016). Guidelines for Preventing Workplace Violence for Healthcare and Social Workers. Washington.

133. O'Neill, O. (2002). A Question of Trust: the BBC Reith Lectures 2002. Cambridge: Cambridge University Press.

134. OIT/OMS/CIE/ISP. (2002). Programa conjunto: nueva iniciativa contra La violencia laboral en el sector de la salud (ILO/ICN/WHO/PSI). Directrices marco para afrontar la violencia laboral en el sector salud.

135. Olave Lusarreta, J. (2006). Prólogo. In J. Sánchez-Caro \& F. Abellán (Eds.), Derechos del médico en la relación clínica (pp. XV-XIX). Madrid: Editorial Comares.

136. OMC. (2015). Que las agresiones a sanitarios se consideren delito de atentado contra la autoridad, el mayor logro. Retrieved July 8, 2017, from http://www.medicosypacientes.com/articulo/que-las-agresiones-sanitarios-se-considerendelito-de-atentado-contra-la-autoridad-el-may-0

137. OMC. (2017). Interior se compromete con un protocolo de actuación de la policía y guardia civil contra agresiones a sanitarios. Retrieved July 8, 2017, from http://www.medicosypacientes.com/articulo/interior-se-compromete-con-un-protocolode-actuacion-de-la-policia-y-guardia-civil-contra

138. OMC. Observatorio de Agresiones. (2016). Pte. OMC pide a las Administraciones que afronten las agresiones a sanitarios con transparencia. Retrieved May 6, 2017, from https://www.cgcom.es/noticias/2016/03/16_03_17_presidente_omc_pide_a_administraci ones_afrontar_agresiones_a_sanitarios_con_transparencia

139. Oostrom, J., \& Mierlo, H. (2003). An Evaluation of an Aggression Management Training Program to Cope with Workplace Violence in the Healthcare Sector. Research in Nursing and Health, 2008, 31, 320-328. 8. Research in Nursing and Health, 31, 320-328.

140. Organización Médica Colegial. (2016). Estudio agresiones 2016. Informe nacional. Retrieved August 31, 2017, from https://www.cgcom.es/sites/default/files/estudio_agresiones_2016/\#44

141. Ortega Rodríguez, J. M. (2017, August). Prevención de riesgos laborales en las Administraciones Públicas. Noticiasjuridicas.com. Retrieved from 
http://noticias.juridicas.com/conocimiento/articulos-doctrinales/12237-prevencion-deriesgos-laborales-en-las-administraciones-publicas/

142. Ortells Abuyé, N., Muñoz Belmonte, T., Paguina Marcos, M., \& Morató Lorente, I. (2013). Caracterización de las agresiones producidas al personal sanitario del servicio de urgencias en un hospital comarcal. Enfermería Global: Revista Electrónica Semestral de Enfermería, ISSN-E 1695-6141, Vol. 12, No. 2, 2013, Págs. 196-207, 12(2), 196-207.

143. Osuna Carrillo de Albornoz, E. (2013). Relación sanitaria e información. In R. Pacheco Guevara \& E. Martínez Navarro (Eds.), Derecho y Salud. Estudios de Bioderecho. (Comentarios a la Ley 3/2009 de Derechos y Deberes de los Usuarios del Sistema Sanitario de la Región de Murcia) [Recurso Electrónico]. Valencia: Tirant lo Blanch.

144. Palácios, M., Loureiro dos Santos, M., Barros do Val, M., Medina, M., De Abreu, M., \& Soares Cardoso, J. (2003). Workplace Violence in the Health Sector Country Case StudyBrazil, ILO/ICN/WHO/PSI Joint Programme on Workplace Violence in the Health Sector.

145. Palomeque López, M. C. (1996). El nuevo marco jurídico de la prevención de riesgos laborales. La Ley 31/1995, de 8 de noviembre. Actualidad Laboral, (1), 199-211.

146. Paravic Klinj, T., Valenzuela Suazo, S., \& Burgos Moreno, M. (2004). Violencia percibida por trabajadores de atención primaria. Ciencia Y Enfermería, 2, 53-65.

147. Parejo Alfonso, L. (2016). Lecciones de Derecho Administrativo [Recurso Electrónico] $\left(8^{\mathrm{a}}\right)$. Valencia: Tirant lo Blanch.

148. Pawlin, S. (2008). Reporting violence. Emerg Nurs, 16, 16-21.

149. Pérez Alonso, M. A. (2015). Las distintas formas de accidente de trabajo. In M. A. (Dir. . Pérez Alonso \& V. (Coord. . Cordero Gordillo (Eds.), El accidente de trabajo y la enfermedad profesional [Recurso Electrónico] $\left(1^{\mathrm{a}}\right)$. Valencia: Tirant lo Blanch.

150. Rando Casermeiro, P. (2010). La distinción entre Derecho penal y Derecho administrativo sancionador $\left(1^{\mathrm{a}}\right)$. Valencia: Tirant lo Blanch.

151. Ray, M. (2007). The dark side of the job: Violence in the emergency department. Emerg Nurs, 33, 257-261.

152. Real Academia Española. (2001). Diccionario de la Lengua Española (22 ${ }^{\mathrm{a}}$ Edició). Madrid: Espasa Calpe.

153. Rippon, T. (2000). Agression and violence in health care professions. Journal of Advanced Nursing, 31(2), 452-460.

154. Rivas Vallejo, P. (2015). El empleador y su deber de prevención (I). Fundamento y obligaciones generales. In G. García González \& A. Garrigues Giménez (Eds.), Manual de Derecho de la prevención de riesgos laborales [Recurso Electrónico]. Valencia: Tirant lo Blanch.

155. Ribera Domene, D. , Cartagena De La Peña, / E, Ferrer, / A Reig, Ferri, / M T Romà, 
Sans Quintero, / I, \& Vañó, / A Caruana. (1993). Estrés laboral y salud en profesionales de enfermería. Estudio empírico en la provincia de Alicante. Alicante: Universidad de Alicante.

156. Rodríguez Escanciano, S. (2013). Responsabilidad patrimonial de la Administración en materia laboral. En especial, las lesiones por «mobbing». In T. Quintana López \& T. Casares Marcos (Eds.), La responsabilidad patrimonial de la Administración. Tomo I (pp. 673-762). Valencia: Tirant lo Blanch.

157. Romero Rodenas, M. J. (2017). El accidente de trabajo en la práctica judicial $\left(2^{\mathrm{a}}\right)$. Albacete: Editorial Bomarzo.

158. Rowe, M., \& Sherlock, H. (2005). Stress and verbal abuse in nursing: do Burned out nurses eat their young? Journal of Nursing Management, 13.

159. Sabadell I Bosch, M. M. (2015). Marco normativo de la prevención de riesgos laborales. In Manual de Derecho de la prevención de riesgos laborales [Recurso Electrónico] (1 ${ }^{\mathrm{a}}$ Edición). Valencia: Tirant lo Blanc.

160. Sala Franco, T. (2014). Derecho de la Prevención de Riesgos Laborales [Recurso Electrónico]. Tirant lo Blanch.

161. Sánchez-Benito, C., \& De Juan-Mazuelas, A. I. (2017). Agresiones al personal sanitario: modificaciones sustanciales del delito de atentado a partir de 2015. Medicina Clínica. http://doi.org/https://doi.org/10.1016/j.medcli.2017.04.007

162. Sánchez-Caro, J., \& Abellán, F. (2006). Derechos del médico en la relación clínica. Madrid: Editorial Comares.

163. Sánchez Pérez, J. (2012). La configuración jurídica del accidente de trabajo. Universidad de Granada.

164. Sánchez Pérez, J. (2014). “Ámbito del accidente de trabajo en misión.” Revista de Aranzadi Social, (9).

165. Sanitarios piden "tolerancia cero" contra las agresiones que sufren - Local - Diario Córdoba. (2017). Retrieved March 16, 2017, from http://www.diariocordoba.com/noticias/cordobalocal/sanitarios-piden-tolerancia-ceroagresiones_1131761.html

166. Sanz Morán, Á. J. (2017). El inimputable ante el proceso penal. In M. Hoyos Santos (Ed.), Las víctimas del delito y las últimas reformas procesales. Pamplona: Thomson Reuters Aranzadi.

167. SATSE Madrid reclama al gobierno autonómico la publicación de una normativa que proteja a los sanitarios contra las agresiones. (2016). Retrieved September 1, 2017, from https://www.diariodicen.es/201605/satse-madrid-reclama-al-gobierno-autonomico-lapublicacion-de-una-normativa-que-proteja-a-los-sanitarios-contra-las-agresiones/

168. Sempere Navarro, A. V., Cardenal Carro, M. Y., \& Alzaga Ruiz, I. (2010). Comentarios 
a la Ley de Prevención de Riesgos Laborales. Pamplona: Editorial Aranzadi.

169. Steinman, S. (2003). Workplace Violence in the Health Sector. Country Case Study: South Africa, ILO/ICN/WHO/PSI Joint Programme on Workplace Violence in the Health Sector.

170. Thomasma, D. (1983). Beyond medical paternalism and patient autonomy: A model of physician conscience for the physicianpatient relationship. Ann Internal Medicine, 98, $243-248$.

171. Una madre es condenada por agredir a una pediatra en Cáceres - Observatorio de Agresiones - COLEGIO DE MÉDICOS DE BIZKAIA. (2015). Retrieved August 1, 2017, from https://www.cmb.eus/observatorio-de-agresiones-2/una-madre-es-condenadapor-agredir-a-una-pediatra-en-caceres

172. Una madre es condenada por agredir a una pediatra en Cáceres . hoy.es. (2015). Retrieved August 16, 2017, from http://www.hoy.es/caceres/201509/05/madre-condenada-agredirpediatra-20150905002140-v.html

173. Una sentencia considera un atentado la agresión a un médico fuera del hospital - Alerta Digital. (2016). Retrieved September 25, 2017, from http://www.alertadigital.com/2016/09/25/una-sentencia-considera-un-atentado-laagresion-a-un-medico-fuera-del-hospital/

174. Un paciente que amenazó a su médica no podrá acercarse a ella en 6 meses Observatorio de Agresiones. (2016). Retrieved September 25, 2017, from https:/www.cmb.eus/Canales/Ficha.aspx?IdMenu=8303951e-1552-4f1c-93f1c6ed8a422138\&Cod=1a2400dd-a6e6-430d-a36c-00aff904c0ab\&Idioma=es-ES

175. Urruela Mora, A. (2016). Las agresiones a profesionales sanitarios desde la perspectiva del Derecho sancionatorio. Particular consideración del delito de atentado. Revista Penal, 38(Julio 2016), 322-345.

176. Urruela Mora, A. (2017). La reconfiguración de los tipos penales y el estatuto de la víctima: Particular consideración de la génesis de la reforma penal en materia de atentado (art. $550 \mathrm{CP}$ ) en relación con las agresiones a funcionarios sanitarios. In M. de (coord. . Hoyos Sancho (Ed.), La víctima del delito y las últimas reformas procesales penales (pp. 331-354). Pamplona: Thomson Reuters Aranzadi.

177. Velasco Sánchez, V. (2014). Agresiones a médicos. Una realidad de intensidad creciente y de difusión pendiente.s.

178. Vidal-Martí, C., \& Pérez-Testor, C. (2015). Violencia laboral hacia los profesionales sanitarios en España. Revista Española de Medicina Legal, 41(3), 123-130.

179. Vidal Fernández, B. (2017). La indemnización a las víctimas de delitos y proceso penal. In M. (Coord. . De Hoyos Sancho (Ed.), La víctima del delito y las últimas reformas procesales penales. Pamplona: Thomson Reuters Aranzadi. 
180. Villar Doncel, M., \& Aranaz Andrés, J. M. (2006). Violencia en el medio hospitalario por pacientes con enfermedad mental. Archivos de Prevención de Riesgos Laborales, ISSN 1138-9672, Vol. 9, No. 1, 2006, Págs. 20-27, 9(1), 20-27.

181. Vives Antón, T. S. (2015). La reforma penal de 2015: una valoración genérica. In J. L. et. al. González Cussac (Ed.), Comentarios a la reforma del Código Penal de 2015 (1ª , pp. 29-41). Valencia: Tirant lo Blanc.

182. Vorderwulbecke, F., Feistle, M., Mehring, M., Schneider, A., \& Linde, K. (2015).

Aggression and violence against primary care physicians-a nationwide questionnaire survey. Deutsches Arzteblatt International, 112(10), 159-165. 


\section{ÍNDICES DE TABLAS Y GRÁFICOS}

\section{TABLAS}

Tabla 1. Muestra de Planes de prevención específicos contra las agresiones al personal sanitario en el ámbito autonómico.

Tabla 2. Principales normas autonómicas en materia de deberes de los usuarios de los Sistemas Sanitarios regionales. 146

Tabla 3. Resumen de la normativa sobre agresiones contra el personal sanitario de Castilla y León

Tabla 4. ¿Ha sufrido alguna agresión en su vida profesional?

Tabla 5. Frecuencia de agresiones físicas

Tabla 6. Frecuencia de agresiones verbales

Tabla 7. Agresor paciente

Tabla 8. Agresor familiar o acompañante

Tabla 9. Agresor compañero

Tabla 10. Agresor otro

Tabla 11. Número de ocasiones en que el autor de la agresión fue un hombre.

Tabla 12. Número de ocasiones en las que el autor fue una mujer.

Tabla 13. Motivo de la agresión: sin razón aparente.

Tabla 14. Motivo de la agresión: disconformidad con la atención recibida

Tabla 15. Motivo de la agresión: enfermedad psiquiátrica

Tabla 16. Motivo de la agresión: tiempo de espera prolongado.

Tabla 17. Motivo de la agresión: peticiones insatisfechas 325

Tabla 18. Motivo de la agresión: fallo en la comunicación con el agresor 325

Tabla 19. Motivo de la agresión: alto estrés y nerviosismo del agresor. 326

Tabla 20. Motivo de la agresión: percepción del agresor de tener derechos, pero no deberes . 327

Tabla 21. Apoyo percibido de la Dirección/Coordinación por parte del agredido. 331

Tabla 22. Apoyo percibido de los compañeros por parte del agredido. 331 
Tabla 23. Apoyo percibido del resto del personal por parte del agredido.

Tabla 24. Profesionales que fueron testigos de otra agresión.

Tabla 25. Frecuencia con la que fueron testigos de agresiones

Tabla 26. Posibilidad percibida de sufrir una agresión. 336

Tabla 27. Valoración de cursos de autodefensa física 336

Tabla 28. Valoración de la «carta de rechazo» al agresor. 337

Tabla 29. Valoración de los botones de alerta 338

Tabla 30. Valoración de colocación de carteles disuasorios e informativos. 338

Tabla 31. Valoración de la imposición de sanciones administrativas al agresor. 339

Tabla 32. Valoración de la intervención de la justicia penal contra el agresor. 340

Tabla 33. Valoración del teléfono de asesoramiento jurídico para las víctimas. 342

Tabla 34. Valoración de formación en manejo de situaciones conflictivas. 342

Tabla 35. Valoración reasignación del agresor a otro profesional o centro. 343

Tabla 36. Valoración de salidas alternativas. 344

Tabla 37. Valoración de dotación de personal de seguridad. 344

Tabla 38. Valoración de colocación de videocámaras. 345

Tabla 39. Conocimiento de los encuestados de los derechos que les asisten.

Tabla 40. Conocimiento de los encuestados sobre actuaciones a seguir en caso de agresión... 347

Tabla 41. ¿Denunciaría en caso de agresión?

Tabla 44. Valoración de la figura de «Autoridad».

Tabla 45: La no atribución de la condición de autoridad carece de importancia para el sector privado por carencia de efectos prácticos

Tabla 46. Autoridad: hubiera sido mejor adoptar medidas alternativas que incluyeran a la sanidad privada.

Tabla 47. Autoridad: es mejor eliminar la figura para garantizar una posición de igualdad para la sanidad privada.

Tabla 48. Es lógico que la autoridad se refiera sólo a la sanidad pública, porque registra mayor número de agresiones. 
Tabla 49. Valoración de la actuación de los Colegios Profesionales en materia de agresiones.356

Tabla 50. Valoración de la actuación del SACYL en materia de agresiones. 358

Tabla 51. Valoración de la actuación de la Administración central (estatal) en materia de agresiones.

Tabla 52. Valoración de la actuación de los sindicatos en materia de agresiones. 359

Tabla 53. Valoración de la actuación de los tribunales de justicia en materia de agresiones. .. 360

Tabla 54. Valoración de la actuación del Ministerio Fiscal en materia de agresiones 360

Tabla 55. Dotación de más medios humanos y materiales. 362

Tabla 56. Campañas educativas dirigidas a los usuarios 362

Tabla 57. Condenas de prisión para los agresores. 363

Tabla 58. Imposición de multas a los agresores 363

Tabla 59. Dispensar un mejor trato al paciente. 364

Tabla 60. Valoración de la necesaria denuncia de parte cuando se produce lesión. 365

Tabla 61. Valoración de aplicación del delito de atentado a la sanidad pública. 366

Tabla 62. Valoración de la salida del Derecho penal de injurias y otras antiguas faltas. 366

\section{GRÁFICOS}

Gráfico 1. Edad de los encuestados 313

Gráfico 2. Agresiones por edades. 314

Gráfico 3. Agresiones por categoría profesional. 315

Gráfico 4. Agresiones por sectores de actividad. 315

Gráfico 5. Agresiones por grupos asistencia sanitaria. 316

Gráfico 6. Relación entre sexo del/a agresor/a y sexo de la víctima. 321

Gráfico 7. Relación de las agresiones con el sexo de la víctima. 321

Gráfico 8. Motivos a los que se atribuyen las agresiones 327

Gráfico 9. Lugares en que se ubicaron las agresiones 328

Gráfico 10. Medidas tomadas por la víctima tras la agresión. 329 
Gráfico 11. Razones por las que el agredido no tomó ninguna medida.

Gráfico 12. Grado de apoyo de diferentes sectores percibido por el agredido.

Gráfico 13. Grado de falta de apoyo percibida por el agredido.

Gráfico 14. Profesionales que han sido testigos de agresiones según sector de actividad 335

Gráfico 15. Relación entre valoración de sanciones administrativas y haber sido agredido..... 340

Gráfico 16. Relación entre la valoración de la Justicia penal y haber sido agredido. 341

Gráfico 17. Comparativa de la valoración de las medidas. 346

Gráfico 18. Relación entre sector de actividad y conocimiento de los derechos. 348

Gráfico 19. Relación entre sector de actividad y conocimiento de las actuaciones en caso de agresión. 348

Gráfico 20. Razones por las que no denunciarían una agresión. 350

Gráfico 21. Relación entre la disposición a denunciar y haber sido agredido previamente....... 350

Gráfico 23. Posibles consecuencias que se derivan de la posesión de la condición de autoridad.

Gráfico 24. Relación entre opciones de valoración de la figura de «Autoridad» y sector de actividad.

Gráfico 25. Valoración de los Colegios Profesionales en relación con el grupo profesional. .. 357

Gráfico 26. Panorámica de la valoración de las instituciones en materia de agresiones. 361

Gráfico 27. Relación entre la valoración de las medidas propuestas y haber sufrido una agresión.

Gráfico 28. Estructura-tipo de los Planes de Prevención específicos contra las agresiones al personal sanitario

Gráfico 29. Medidas previas: evitar el riesgo actuando sobre los «motivos-diana».

Gráfico 30. Seguridad: medios humanos y físicos.

Gráfico 31. Protocolo ante agresiones del SACYL

Gráfico 32. Actuaciones de la Gerencia tras serle notificada una agresión. 393 


\section{ÍNDICE DE RESOLUCIONES}

\section{Resoluciones dictadas por tribunales del orden penal}

1.- SAP Santa Cruz de Tenerife (Sección 2a) 315/2015, de 3 de julio.

2.- SAP Madrid (Sección 15a) 509/2015, de 6 de julio.

3.- SAP Cádiz (Sección 4a) 06/2015, de 20 de julio.

4.- SAP Valencia (Sección $3^{\text {a }}$ ) 570/2015, de 27 de julio.

5.- SAP Alicante (Sección 3a) 415/2015, de 31 de julio.

6.- SAP Las Palmas (Sección 2a) 162/2015, de 17 de septiembre.

7.- SAP Ourense (Sección 2a) 326/2015, de 25 de septiembre.

8.- SAP Badajoz (Sección 1a) 70/2015, de 30 de septiembre.

9.- Juzgado de lo Penal n ${ }^{\circ} 10$ de Madrid (Procedimiento Abreviado 209/2013), de 1 de octubre de 2015.

10.- SAP Granada (Sección 2a) 627/2015, de 26 de octubre.

11.- Juzgado de lo Penal no 3 de Bilbao, (Procedimiento Abreviado 210/15), de 26 de noviembre de 2015.

12.- SAP Jaén (Sección 3a) 375/2015, de 10 de diciembre.

13.-AP de Alicante (Sección 2a ${ }^{\mathrm{a}}$ ) 582/2015, de 22 de diciembre.

14.- SAP Madrid (Sección 15ª) 871/2015, de 30 de diciembre.

15.- SAP Cuenca (Sección 1ª) 25/2016, de 16 de febrero.

16.- SAP Málaga (Sección 9a) 120/2016, de 23 de febrero.

17.- SAP Madrid (Sección 29a) 104/2016, de 25 de febrero.

18.- SAP Madrid (Sección 1ª) 115/2016, de 7 de marzo.

19.- SAP Granada (Sección 2a) 158/2016, de 14 de marzo.

20.-SAP Bizkaia (Sección 6a) 90101/2016 (sic), de 16 de marzo.

21.- SAP Sevilla (Sección 7a) 158/2016, de 26 de abril.

22.- SAP Las Palmas (Sección 6a) 175/2016, de 20 de mayo.

23.- SAP Pontevedra (Sección 5a, con sede en Vigo) 302/2016, de 23 de mayo.

24.- SAP Almería (Sección 2a) 272/2016, de 10 de junio.

25.- SAP Murcia (Sección 3a) 417/2016, de 1 de julio.

26.- SAP Madrid (Sección 30a) 540/2016, de 18 de julio.

27.- SAP Les Illes Balears (Sección 1ª) 118/2016, de 25 de julio.

28.- SAP Alicante (Sección 10a) 303/2016, de 29 de julio.

29.- SAP Zaragoza (Sección $3^{\text {a }}$ ) 423/2016, de 9 de septiembre.

30.- Juzgado de lo Penal no 10 de Valencia (Sentencia 243/2016), de 23 de mayo.

31.- SAP Madrid (Sección 16a) 125/2017, de 24 de febrero. 


\section{Resoluciones de los órdenes social y contencioso-administrativo}

1.- Consejo Consultivo de Castilla-La Mancha. Dictamen n ${ }^{\circ}$. 151/2003, de 11 de diciembre.

2.- Tribunal Superior de Justicia de Castilla-La Mancha (Sala de lo Social) Sentencia 1532/2007, de 18 de octubre de 2007.

3.- Juzgado de lo Contencioso-Administrativo ${ }^{\circ} 3$ de Toledo, Sentencia $n^{\circ} 31 / 2012$, de 8 de febrero.

4.- Consejo Consultivo del Principado de Asturias (Dictamen 19/2014, de 6 de febrero).

5.- Juzgado de lo Contencioso-Administrativo $\mathrm{n}^{\circ} 13$ de Barcelona (Procedimiento Abreviado $\mathrm{n}^{\mathrm{o}}$ 37/13), de 7 de abril de 2014.

6.- Tribunal Superior de Justicia de Cataluña, (Sala de lo Contencioso-Administrativo, Sección $4^{a}$ ), Sentencia 923/2015, de 2 de diciembre.

7.- Tribunal Superior de Justicia de Castilla-La Mancha, (Sala de lo ContenciosoAdministrativo, Sección 1ª), Sentencia 48/2015, de 16 de febrero.

8.- Tribunal Superior de Justicia de Aragón, (Sala de lo Contencioso-Administrativo, Sección $\left.3^{\mathrm{a}}\right)$, Sentencia 650/2015, de 9 de septiembre.

9.- Tribunal Superior de Justicia de Andalucía de Granada (Sala de lo Social) Sentencia 1929/2015, de 8 de octubre de 2015.

10.- Tribunal Superior de Justicia del Principado de Asturias, (Oviedo) (Sala de lo ContenciosoAdministrativo, Sección 1ª), Sentencia 138/2016, de 26 de febrero. 


\section{ANEXO I. RESOLUCIONES ESTUDIADAS}

\section{RESOLUCIONES DE LOS TRIBUNALES DEL ORDEN PENAL}

\section{1.- SAP Santa Cruz de Tenerife (Sección 2a) 315/2015, de 3 de julio.}

Dos mujeres protagonizan una agresión mutua en un hospital público, en el transcurso de una discusión. Una de ellas era enfermera del centro sanitario y la otra la hija de una paciente allí ingresada:

«Eva María trabaja como enfermera en el Hospital de Los Dolores, donde está ingresada la madre de Ruth.

Por problemas de días anteriores por, al parecer fallos en el suministro de la medicación y ausencias del personal sanitario, el dia 7 de febrero de 2015 se produjo un enfrentamiento entre la citada enfermera y Ruth, en el curso de la discusión Eva María acusó a Ruth de tener desatendida a su madre, y ésta la llamó maltratadora.

No se formuló al final acusación contra el IASS del Cabildo».

El Juzgado de Instrucción $n^{0} 2$ de San Cristóbal de La Laguna (30/03/2015) condena a ambas, como autoras de una falta del art. $620.2 \mathrm{CP}$, a multa de 10 días a razón de 3 euros diarios.

La enfermera recurre la sentencia solicitando la nulidad de lo actuado porque considera que la agresión verbal hacia su persona podría incardinarse en el ilícito del art. $550 \mathrm{CP}$ (delito de atentado). La AP desestima el motivo de alegación:

«Con carácter previo, debe desestimarse la pretensión de nulidad aducida por la parte apelante, quien alega que los hechos denunciados deberian haberse tramitado como diligencias previas por ser susceptibles de incardinarse en un delito de atentado previsto y penado en el artículo 550 del Código Penal. Así, Mediante Auto de 25 de febrero de 2015 se acordó la incoación de Juicio de Faltas, resolución que ha devenido firme, sin que la parte ahora apelante formulase recurso alguno».

Por otro lado, la Sala tiene en cuenta las disposiciones de la LO 1/2015 en relación con las figuras delictivas que el CP de 1995 tipificaba como "faltas",

«La sentencia recurrida condena a la denunciada como autora de una falta del artículo 620.2 del Código Penal, por entender que profirió expresiones vejatorias hacia la otra denunciantedenunciada.

Este precepto legal ha sido derogado por la Ley Orgánica 1/2015, de reforma del Código Penal, vigente desde el día 1 de julio de 2015 disposición final octava), sin que exista una norma penal 
en el nuevo Código Penal como delito leve análogo, al margen de las conductas más graves que pudieran ser constitutivas de delito».

En consecuencia, procede a absolver a ambas de las respectivas condenas penales que por razón de ellas les había impuesto el juzgador de instancia:

«2 ${ }^{\circ}$.- Al haberse despenalizado la falta tipificada en el artículo 620.2 del Código Penal, procede absolver a las acusadas Ruth y Eva María de dicha imputación».

\section{2.- SAP Madrid (Sección 15ª) 509/2015, de 6 de julio.}

El Juzgado de lo Penal $n^{\circ} 2$ de Getafe (22/04/2015) condenó como autora de un delito de atentado a una mujer que agredió en el octubre del año 2010 a dos enfermeras y a una celadora, en un hospital público. Había sido ingresada allí por ingesta medicamentosa además de otras sustancias. El comportamiento de la acusada fue en todo momento agresivo:

«Ruth se encontraba ingresada, debido a una previa ingesta medicamentosa, en el Hospital Infanta Elena de la localidad de Valdemoro, perteneciente al servicio de sanidad público de la Comunidad de Madrid, cuando, en actitud agresiva, y con ánimo de menoscabar la integridad física del personal sanitario que se encontraba desempeñando sus funciones, comenzó a agredir a varias enfermeras y a una celadora que la atendian.

Así, Bibiana acudió, en calidad de enfermera, y cumpliendo las instrucciones de la médico responsable de la paciente, a colocar las contenciones fisicas a Ruth, momento en el que ésta procedió, con ánimo de menoscabar su integridad física, a arañarle en el brazo y a escupirle.

Una vez lograron colocarle las contenciones Ruth, no obstante, y debido a su complexión delgada, logró zafarse de las mismas, percatándose de ello Joaquina, también enfermera de dicho centro, quien acudió a sujetar a la paciente, momento en el que Ruth, de nuevo en actitud muy violenta, agarró a Joaquina por el pelo le tiró sobre la camilla, golpeándose ésta contra la barandilla, al tiempo que la arañaba».

Al presenciar estas agresiones acude también una celadora que también resultó lesionada. Respecto a esta trabajadora, hay que advertir que la sentencia de instancia se refiere a ella de manera confusa, pues en ocasiones le aplica un nombre propio que corresponde a una persona del género masculino ${ }^{464}$. 464 «Al presenciar dicha agresión diverso personal sanitario acudió en auxilio de Joaquina, entre otros, Luis Antonio,
quien ostentaba el cargo de celadora, a quien durante el forcejeo para reducirla de nuevo Ruth arañó en el brazo». 
El juzgado de instancia condena a la agresora por el delito de atentado a 9 meses de prisión, aplicando una eximente completa y la atenuante de dilaciones indebidas (la causa estuvo paralizada entre 2012 y 2014 sin que ello fuera achacable a la acusada). La considera también responsable de 3 faltas de lesiones; por cada una de ellas le impone una pena de 6 días de localización permanente, además de la obligación de indemnizar a las víctimas en concepto de responsabilidad civil.

La parte condenada interpone recurso de apelación, solicitando la libre absolución o, subsidiariamente, la imposición de una condena a prisión de menor duración (3 meses).

«la recurrente sufría una crisis de agitación y ansiedad y que ello solo le produjo una disminución leve de sus facultades intelectivas y volitivas».

La AP estima parcialmente el recurso, en cuanto a la condena debida al delito de atentado, en aplicación de las disposiciones de la LO 1/2015:

«...la entrada en vigor de la Ley Orgánica 1/2015, de 30 de marzo, introduce una nueva redacción en los arts. 550 y 551 del Código Penal ${ }^{465}$ (...). Esta norma debe ser aplicada retroactivamente, conforme al art. 2.2 del Código Penal y la disposición transitoria tercera de la citada Ley Orgánica, por resultar más beneficiosa para la acusada. La rebaja en un grado de la nueva penalidad del delito de atentado, por la concurrencia de las dos circunstancias atenuantes, nos lleva necesariamente a una duración de la pena de prisión de entre tres y seis meses, dentro de lo cual, siguiendo los mismos criterios que en la sentencia apelada, se estima procedente establecer dicha pena en cuatro meses, lo que nos lleva a la estimación parcial del recurso».

En cuanto a las faltas por las que el juzgador «a quo» condenó también a la recurrente (estando en aquel momento en vigor el CP de 1995), la Sala procede a su absolución respecto a las consecuencias penales que de ellas pudieran derivarse, también por aplicación de las disposiciones contenidas en el nuevo ordenamiento:

«Además, debemos tener en cuenta la disposición transitoria cuarta de la Ley Orgánica 1/2015, según la cual la tramitación de los procesos por falta iniciados antes de la entrada en vigor de dicha Ley por hechos que resultan por ella despenalizados o sometidos al régimen de denuncia previa, y que lleven aparejada una posible responsabilidad civil, continuará hasta su normal terminación, salvo que el legitimado para ello manifestare expresamente no querer ejercitar las

465 El texto que corresponde al paréntesis es el siguiente: "estableciendo una penalidad para el delito de atentado a funcionarios que no tienen la condición de autoridad, cuyo límite mínimo, de seis meses, es inferior al año que fijaba la redacción anterior, vigente en el momento de los hechos». 
acciones civiles que le asistan, en cuyo caso se procederá al archivo de lo actuado, con el visto del Ministerio Fiscal».

En conclusión, en virtud de esta SAP, por lo que se refiere a los ahora denominados delitos leves de lesiones, únicamente subsiste en este supuesto las consecuencias que deriven de la responsabilidad civil:

«En consecuencia, y dado que las lesionadas han mantenido en el juicio sus pretensiones en materia de responsabilidad civil frente a la acusada, procede dejar sin efecto la condena a las penas correspondientes a las tres faltas y mantener exclusivamente los pronunciamientos condenatorios de carácter civil, lo que nos lleva a la estimación parcial del recurso."

\section{3.- SAP Cádiz (Sección 4a ) 06/2015, de 20 de julio.}

Una mujer actúa de forma violenta en un hospital público contra uno de los cirujanos que había intervenido quirúrgicamente a su hijo:

«La acusada Cándida (...) sobre las 22:15 horas del día 10 de agosto de 2009, en el Hospital Puerta del Mar de Cádiz, cuando Don Pelayo, que había realizado la intervención, salió a informar del resultado de la operación del hijo de la acusada a ésta, la misma procedió a increparle llegando a golpearle en el pecho, causándole lesiones consistentes en contusión, que tardaron en curar tres días, sin necesidad de otra asistencia más que la primera».

El Juzgado de lo Penal $n^{\circ} 3$ de dicha ciudad (30/03/2015) estimó que era autora de un delito de atentado y de una falta de lesiones. Por el atentado impone una condena de 6 meses de prisión, aplicando la circunstancia atenuante de dilaciones indebidas. Por la falta de lesiones la condena a multa de 30 días a razón de 6 euros diarios, además de la obligación de indemnizar a la víctima en concepto de responsabilidad civil por los daños que le fueron causados.

La parte condenada interpone recurso de apelación en el que intenta combatir la tipificación de los hechos como atentado alegando, entre otros argumentos, que faltaba el elemento subjetivo del ilícito:

"...que no es la conducta activa (informando) del médico Sr. Pelayo lo que provoca el arrebato de la acusada, sino, antes al contrario, su conducta omisiva negándose a explicarle a la hoy apelante las causas del retraso en la intervención de su hijo y del peligro que dicho médico le decía que corría su vida, aún tras a la intervención; que llevaba horas sin dormir esperando que operaran a su hijo de urgencia sin que nadie le hubiera informado de las causas 
por las que no era operado o del estado en que se encontraba induciéndola a un estado de nerviosismo y angustia que ha sido sobradamente acreditado durante el proceso; que en ningún momento pretendió menoscabar la autoridad del facultativo ni, muchos menos, interferir en el buen funcionamiento del servicio hospitalario, al menos consciente y voluntariamente, lo que excluye su responsabilidad por la comisión del delito de atentado que se le imputa a título doloso».

La AP desestima íntegramente el recurso y confirma la sentencia de instancia en todos sus pronunciamientos.

\section{4.- SAP Valencia (Sección 3 $3^{\text {a) }}$ 570/2015, de 27 de julio.}

Una mujer, en enero de 2015, se comporta de forma violenta en la consulta de una pediatra en un centro médico:

«... sobre las 19 horas del día 19 de enero de 2015 en el centro médico sito en la calle Arabistra Ambrosio Huici de esta ciudad, Fuente de San Luis, donde la denunciante es personal estatutario prestando sus servicios como médico pediatra, recibió en su consulta a la denunciada para el examen de sus hijos menores, al parecer la consulta iba con retraso y varios de los pacientes habian demostrado su descontento, teniendo que salir la denunciante a pedir que estos se callaran para poder continuar con las visitas programadas; una vez cumplido el examen médico de los menores, la denunciada se dirige a Celestina diciéndole "siéntate ahi que seas que te he grabado y esto no va a quedar así, voy a ir a por ti, te vas a enterar, voy a utilizarlo y te vas a enterar", negándose a abandonar la consulta a pesar de las reiteras peticiones en este sentido realizadas por la pediatra».

El Juzgado de Instrucción $n^{\circ} 11$ de Valencia (14/05/2015) la condena como autora de una falta contra el orden público del art. $634 \mathrm{CP}$, imponiéndole multa de 1 mes a razón de 8 euros por día. La acusada recurre la sentencia alegando que, entre otros argumentos, que, como personal estatutario, la víctima no puede estar comprendida en el ámbito de protección del citado artículo. La AP revoca íntegramente la sentencia de instancia aplicando las disposiciones de la LO 1/2015. «No obstante, la entrada en vigor de la Ley Orgánica 1/2015 de 30 de marzo, que modifica la Ley Orgánica 10/1995, de 23 de noviembre, del Código Penal, derogó el artículo 634 del Código Penal, y despenalizó la conducta que castigaba dicho precepto penal, por lo que será obligado aplicar la nueva redacción del Código Penal». 
En consecuencia, procede a la libre absolución de la recurrente como autora de la falta por la que venía acusada.

«TERCERO.- Procede, en consecuencia, ante la despenalización de la conducta castigada en el art. 634 del Código Penal, absolver a la apelante como autora responsable de la falta que se le imputaba».

\section{5.- SAP Alicante (Sección 3a) 415/2015, de 31 de julio.}

Esta sentencia confirma la dictada por el Juzgado de lo Penal n 8 de Alicante (05/03/2015), en la que se condena, por delito de atentado cometido contra funcionario público, a un hombre que atacó a un celador en un centro de salud de dicha ciudad. El acusado estaba molesto porque consideraba que el perjudicado trataba mal a su hermano, razón por la que se produce la agresión: «...se dirigió al mismo diciéndole que si le pasaba algo a su hermano le mataría, llegando a forcejear con dicho celador exhibiéndole un objeto punzante. Finalmente, el hermano del acusado separó a este último del perjudicado, siendo este último quien avisó a la Policía, mientras el acusado intentaba darse a la fuga del lugar, dejando tras de sí al acusado con su ropa dañada. Los agentes acudieron al Centro, acabó hallando al acusado y procedió a la detención del acusado».

Los hechos ocurrieron en agosto de 2014. La condena fue a 16 meses de prisión, así como al pago de una indemnización al acusado por valor de 30 euros, por los daños que le ocasionó en la ropa durante el forcejeo.

El acusado interpone recurso de apelación ante la AP solicita la revocación de esta sentencia, en estos términos:

«...solicita la revocación de la sentencia recurrida y alega en apoyo de su pretensión que el Juez de Instancia ha valorado de manera errónea la prueba practicada.

Concretamente hace hincapié en determinados aspectos que conducirian, según su criterio, a poner en tela de juicio la valoración realizada en la fundamentación jurídica de la sentencia, como son entre otros aspectos la falta de testigos presenciales o el hecho de que el arma presuntamente utilizada no haya sido encontrada».

La AP desestima el recurso rebatiendo los motivos de alegación, argumentando del modo siguiente: 
«Singularmente se valora la declaración del propio celador del centro sanitario y víctima de la intimidación llevada a cabo por el acusado, testigo en el que concurren todos los parámetros que una constante jurisprudencia exige para entender creibles sus manifestaciones.

Asimismo, existe la prueba corroboradora de la anterior que consiste en la testifical de la policía que acudió al lugar de los hechos a requerimiento de los testigos presenciales, y que desde un primer momento ofrecieron explicación al hecho de que el cuchillo no fuera hallado, debiendo además tenerse en cuenta que la detención del acusado se produjo en lugar distinto del edificio».

La Sala confirma íntegramente la sentencia recurrida.

\section{6.- SAP Las Palmas (Sección $2^{\mathrm{a}}$ ) 162/2015, de 17 de septiembre.}

En el servicio de Urgencias de un hospital público, un hombre agrede a un celador y a 2 agentes de la autoridad:

"Ciertamente los hechos que relatan los testigos (porque el acusado dice no recordar nada de lo sucedido en el hospital) apunta a que el mismo se encontraba con sus capacidades mentales alteradas. Primero había sido ingresado en el servicio de urgencias en el área de psiquiatría, segundo fue interceptado por un celador al salir de allí y su reacción fue agredirlo así como a los funcionarios policiales hasta que pudo ser reducido».

El Juzgado de lo Penal $n^{\circ} 2$ de Las Palmas (12/02/2015) le condena como autor de los siguientes ilícitos: Delito de atentado en concurso ideal con falta de lesiones ( 9 meses de prisión y 8 días de localización permanente), delito de resistencia en concurso ideal con delito de lesiones y falta de lesiones (4 y 9 meses de prisión respectivamente por cada uno de los delitos y 8 días de localización permanente por la falta de lesiones). Además, le impone la obligación de indemnizar a las víctimas en concepto de responsabilidad civil.

La parte condenada interpone recurso de apelación ante la AP, alegando principalmente que se había conculcado su derecho a la presunción de inocencia en relación con las pruebas que no admitió la juez de instancia ${ }^{466}$.

La Sala comparte el criterio de la juez «a quo» excepto en lo que atañe a la valoración de las circunstancias psíquicas del acusado a la hora de graduar la intensidad de las penas a imponer:

\footnotetext{
466 "A tal efecto el recurrente comienza alegando que la resolución combatida vulnera su derecho a la presunción de inocencia al no haber sido aceptadas las pruebas presentadas por la defensa que fueron, según afirma, indebidamente inadmitidas por la jueza a quo primero en el auto que resolvió sobre la proposición de prueba y después al inicio de las sesiones del juicio oral lo que, en definitiva, le impidió el legítimo ejercicio del derecho de defensa».
} 
«Lo que no compartimos, sin embargo, con la jueza de instancia es la consecuencia jurídica de esa apreciación y, en concreto, la graduación que se hace de su intensidad y, en consecuencia, de la pena a imponer.

Y lo decimos asi porque si atendemos al informe forense, que habla de grave afectación de capacidades, y si tenemos presente incluso la testifical practicada, comprobaremos que si bien nadie ha podido decir que las capacidades de Eutimio estuviesen anuladas lo que tampoco podemos negar es que, si el mismo fue diagnosticado poco después de los hechos de sufrir un episodio maníaco con síntomas psicóticos por el que debió estar ingresado más de quince días, su alteración, dado que ya padecía un trastorno bipolar, debía estar muy cerca de esa anulación $y$, por tanto de acuerdo con las previsiones del art. $68 \mathrm{del} \mathrm{C.} \mathrm{Penal,} \mathrm{la} \mathrm{pena} \mathrm{correspondiente} \mathrm{a}$ las diversas infracciones cometidas debió rebajarse no en uno sino en dos grados por la entidad y alcance de la alteración».

En consecuencia y atendiendo también a que existe agravante de reincidencia pero que a su vez la LO 1/2015 modifica los tipos "en todo aquello que sea favorable al reo", la Sala revoca parcialmente la sentencia de instancia estableciendo las penas siguientes:

a.-Por el delito de atentado, 2 meses y 15 días: Al ser la condena inferior a 3 meses se sustituye por multa de dos días por cada uno de los días de la condena a prisión (150 días en total), a razón de 6 euros diarios.

«Como quiera, por tanto, que estamos ante una pena inferior a la de tres meses de prisión ${ }^{467}$, la misma deberá ser necesariamente sustituida considerando la Sala que dicha sustitución debe serlo por multa (dado que la pena de trabajos en beneficio de la comunidad no se puede fijar sin consentimiento del penado y la de localización permanente sería más perjudicial por ser privativa de libertad) a razón de dos días multa por cada día de prisión con una cuota diaria de seis euros que se estima razonable en la generalidad de los casos".

b.- Por la falta de lesiones, en concurso ideal con el delito de atentado: multa de 10 días a razón de 6 euros diarios

c.- Por el delito de resistencia: multa de 2 meses y 15 días a razón de 6 euros diarios.

d.- Por el delito de lesiones y la falta en concurso ideal con el delito de resistencia: multa de 1 mes y 15 días para el delito y multa de 10 días para la falta (en ambos casos a razón de 6 euros diarios)

${ }^{467}$ «...de conformidad con las previsiones del art.71». 
La AP confirma la sentencia de instancia en todos los demás pronunciamientos, por lo que desestima otro motivo de alegación del recurso que pretendía derivar su responsabilidad civil al Servicio Canario de Salud, con el siguiente argumento:

"Por último se denuncia igualmente por el recurrente que la jueza a quo ha incurrido en incongruencia omisiva al no pronunciarse sobre su pretensión de que se decretase que la responsabilidad que se fijase a su cargo debía ser asumida por el Servicio Canario de Salud dado que los hechos suceden cuando el acusado está bajo el cuidado de sus empleados y en el centro hospitalario.

En realidad la jueza a quo no se pronuncia sobre el particular porque no habiendo sido llamado a la causa el Servicio Canario de Salud ningún pronunciamiento de condena, en este sentido, podrí llevar a cabo ${ }^{468}$ (...) sin que quepa entrar a analizar, repetimos, la posible responsabilidad civil subsidiaria de la administración cuando no ha sido parte y no se ha podido defender en esta causa."

\section{7.- SAP Ourense (Sección 2a) 326/2015, de 25 de septiembre.}

La AP de Ourense confirma íntegramente la sentencia dictada por el Juzgado de lo Penal $\mathrm{n}^{\mathrm{o}} 2$ (15/05/2015), que condenó a 1 año de prisión por delito de atentado a la agresora de una facultativa en un centro médico. La acusada había acudido allí a consulta puesto que padecía dolor de oídos y la víctima, que no era su médico habitual, procedió a examinarla produciéndose entonces la agresión:

“La acusada, Sonia, (...), acudió al Centro Médico de Verín, alrededor del mediodía del día 23 de abril de 2.013, solicitando ser vista por un doctor puesto que sufría dolor de oídos. Dado que su médico habitual no se encontraba en el centro, fue atendida por Doña Apolonia (personal estatutario fijo del Servicio Galego de Saúde, desde 2006), la cual procedió a examinarla momento que aprovechó la imputada, para con intención de menoscabar la integridad fisica de la doctora, golpearla con la mano en la cara y empujarla, desplazándola un metro hacia el lavabo.

\footnotetext{
${ }^{468}$ El texto de la sentencia que corresponde al paréntesis es el siguiente: « $Y$ no ha sido parte porque las acusaciones, únicas que pueden reclamar responsabilidad civil a terceros, por ser quienes ejercitan las acciones civiles y penales, no han planteado pretensión de condena en este sentido contra dicho organismo público no pudiendo el condenado, cuya responsabilidad civil derivada del delito en nada se ve afectada por el hecho de que puedan existir o no otros que sean responsables subsidiarios, pretender que esa obligación de reparar el daño que, sin duda, le imponen los art. 109, 116 y 118, quede, de alguna forma, eliminada por el hecho de que el delito se cometiera cuando estaba en un centro hospitalario.

Repetimos que son las acusaciones quienes podrían haber obligado a traer a la causa a la administración pero al no hacerlo, al abrirse juicio oral únicamente contra el recurrente, sólo él podía ser condenado o no al abono de una responsabilidad civil que, como se ha dicho, le corresponde conforme a las disposiciones legales...».
} 
Como consecuencia de estos hechos, la doctora sufrió una crisis de ansiedad, que precisó para su sanidad una primera asistencia facultativa sin necesidad de tratamiento médico o quirúrgico, tardando en curar un día durante el cual no estuvo impedida para sus ocupaciones habituales».

Además de la pena que corresponde por el delito de atentado, se la condena por una falta de lesiones a 1 mes de multa a razón de 5 euros diarios.

La acusada interpone recurso de apelación, alegando error en la valoración de la prueba. La Sala desestima el recurso:

«Pues bien, habida cuenta que los hechos enjuiciados se suceden en el curso de la atención médica prestada a la acusada, y que resulta acreditado que ésta golpeó en la cara y empujó a la facultativa, acción en la que - a tenor del exhaustivo análisis de la prueba- no había otra intención sino la de menoscabar la integridad fisica de la víctima, la calificación de los mismos no puede ser otra que la efectuada en sentencia».

La Sala, al desestimar el recurso, confirma íntegramente la sentencia de instancia.

\section{8.- SAP Badajoz (Sección 1 $1^{\text {a }}$ ) 70/2015, de 30 de septiembre.}

El Juzgado de lo Penal no 2 de Badajoz (de 25/05/2015), condenó a 1 año de prisión como autor de un delito de atentado a un hombre que había agredido a un médico, absolviéndole de las faltas de lesiones y amenazas por las que también venía siendo acusado.

En el recurso de apelación interpuesto contra esta sentencia se solicita, que no se consideren los hechos como delito de atentado alegando, entre otros argumentos, que existía relación de subordinación entre el agredido y un enfermero que actuaba como testigo.

La AP desestima esa alegación con la que se pretendía descalificar la prueba testifical:

"Otra cuestión sorprendente es la afirmación que se realiza en el recurso sobre el testigo principal, el enfermero Sr Millán, único testigo que realmente vio los hechos, del que se dice que "debe subordinación al médico". Esto es un auténtico disparate: Primero no existe esa relación de subordinación ciega del enfermero al médico, y segundo, el enfermero, previamente advertido sobre su obligación de decir verdad, únicamente reprodujo lo que ya habia declarado en instrucción. Por cierto, que médico y enfermero casi ni se conocían; pues se trataba de un médico sustituto para un periodo vacacional, que llevaba poco tiempo atendiendo en esa consulta, y era el último día del enfermero en su puesto de trabajo, antes de disfrutar de sus vacaciones estivales». 
También alega el recurso que no se dan todos los elementos objetivos que precisa el ilícito del art. 550, sino, en todo caso, los de la falta tipificada en el art. 639 del CP de 1995.

La Sala afirma que existió delito de atentado porque, en su valoración de los hechos, se dan todos los elementos que integran ese delito siendo además es innegable que hubo agresión física:

«...y lo que no hay que olvidar en ningún momento es que las personas presentes en el momento de la agresión -porque coger del cuello a una persona es agredirla ...».

En el recurso se solicitaba también que se tuviera en cuenta la circunstancia atenuante de dilaciones indebidas, puesto que los hechos habían ocurrido en el año 2010. Hubo un período de cinco años en la tramitación y resolución del proceso, desde la comisión de los hechos.

La Sala realiza un interesante y amplio estudio de lo que suponen las dilaciones indebidas, incluso antes de su entrada en el Código Penal en el año 2010. Analiza los instrumentos legales en los que se apoya, a nivel internacional así como la diferencia entre «dilaciones indebidas» y «plazo razonable».

Finalmente, la AP confirma la resolución de primera instancia, al entender que, si bien es cierto que esas dilaciones existieron y constituyen un atenuante que puede aplicarse para rebajar la pena, en este caso ya fueron tenidas en cuenta por el juzgador «a quo».

«FALLO: Que estimamos parcialmente el recurso de apelación formulado por la representación procesal de Aureliano contra la sentencia del Juzgado de lo Penal $n^{\circ} 2$ de Badajoz de fecha 25 de mayo de 2015 (P.A. $n^{\circ} 203$ /2014), en el único sentido de apreciar como concurrente la circunstancia atenuante de dilaciones indebidas, sin repercusión alguna en la pena a imponer, y confirmamos en todos los demás extremos la sentencia apelada».

En todo momento tiene una importancia decisiva e informe del Ministerio Fiscal, de tal modo que una gran parte de la argumentación de la Sala se elabora en base a ese informe

\section{9.- Juzgado de lo Penal $n^{0} 10$ de Madrid (Procedimiento Abreviado 209/2013), de 1 de octubre de 2015.}

Un hombre lleva a cabo una agresión contra una facultativa en un centro médico, en octubre de 2012:

«El acusado Serafin (...) en el centro médico dependiente de la Comunidad de Madrid, sito en la calle Cabo Machichaco núm. 58 de Madrid, increpó a la doctora D Marta, profirieron contra la misma expresiones tales como "eres una hija de puta, voy a traer a mis amigos y te voy a matar" 
y ello motivado porque se negó a extenderle unas recetas remitiéndole al especialista. En el incidente golpeó algunos muebles dañando una mesa del centro que ha sido tasada en 90 euros. Con anterioridad persona no acreditada modificó con bolígrafo una receta del sistema nacional de salud de la doctora Adoración(... $)^{469}$, con la intención de crear una apariencia , que no respondía a la realidad tachando el nombre del medicamento recetado "alprazolan" y escribiendo encima "tranquimazin" .- Ambos medicamentos tienen el mismo principio activo, siendo el primero el genérico y el segundo una marca.

El acusado tenía levemente afectadas sus facultades mentales».

El Juzgado de lo Penal n ${ }^{\circ} 10$ de Madrid consideró al agresor como autor de un delito de atentado, por el que le condena a 3 meses de prisión, teniendo en cuenta la circunstancia eximente de dilaciones indebidas.

Sin embargo, le absuelve de del delito de falsificación de documento oficial, así como de una falta de daños por las que también venía acusado.

La sentencia fue posteriormente recurrida ante la AP de Madrid ${ }^{470}$.

\section{0.- SAP Granada (Sección 2aa) 627/2015, de 26 de octubre.}

Una anciana de 90 años, en estado terminal, está ingresada en el área de Traumatología de un hospital público. Algunos de sus familiares agreden a una enfermera porque pretendían que se le fuera aplicada la sedación que al parecer le había prescrito ya un médico para aliviar a la enferma de los dolores que estaba padeciendo. Los hechos se producen como se transcribe a continuación: «...el 6 de enero de 2012, encontrándose un familiar de Macarena y su hijo Leovigildo,(...), ingresada en el área de Traumatología del hospital San Cecilio,(...)de Granada y tras avisarles una de las hijas de la enferma de que el médico le iba a prescribir sedación dados los dolores que padecía, acudieron sobre las 1400 horas aproximadamente a dicho centro, procediendo Macarena a dirigirse al Office de la planta, donde se encontraba al ordenador la enfermera María Ángeles, a la que se dirigió diciéndole oye ve y le pones algo a la abuela que se está muriendo y no queremos que sufra", explicándole María Ángeles que era otra compañera la que estaba encargada de dicha enferma y lo estaba preparando, introduciéndose Macarena en el interior del Office dando palmadas continuamente mientras le decía a Maria Ángeles, que te he dicho que te levantes de ahi, so tía floja, y le pongas algo a la abuela", volviendo de nuevo a explicarle que ya otra compañera había ido a buscarle la medicación, contestándole que era una chalada, que no hacía nada, que se estaba todo el día paseando, zorra, no tienes corazón..., cerrando María Ángeles la puerta y regresando de nuevo Macarena con la hija de la enferma

\footnotetext{
469 La receta pertenecía a otra médico diferente de la que había sido víctima de la agresión.

470 Véase SAP Madrid 104/2016, de 25 de febrero.
} 
(Rosana) abriendo la puerta del Office y mientras Rosana solicitaba medicación para su madre, Macarena volvió a increpar a María Ángeles con expresiones similares.

Tras llegar la enfermera encargada con la bomba de profusión al Office se dispuso a preparar la sedación, volviendo de nuevo Macarena dando fuertes golpes y puñetazos en la puerta, advirtiéndole María Ángeles que como continuaran en dicha actitud llamaría a Seguridad, procediendo Macarena a dar con sus dedos varias veces en la espalda de María Ángeles, la que se volvió diciendo a Macarena, ahora sí que voy a llamar a seguridad" dirigiéndose al teléfono, momento en que el hijo de Macarena, Leovigildo, manifestó a María Ángeles, ahora si te vas a enterar" cogiendo a María Ángeles del brazo izquierdo lanzándola contra la pared, llegando el personal de seguridad y posteriormente la Policía.

A consecuencia de los hechos María Ángeles sufrió un menoscabo psíquico con tratamiento en salud mental desde el 23 de enero de 2012 al 24 de febrero de 2012».

El Juzgado de lo Penal $n^{\circ} 4$ de Granada (24/11/2014), tipifica los hechos como constitutivos de delito de atentado a funcionario público además de falta de lesiones. Impone a cada uno de los acusados (Macarena y Leovigildo) las siguientes penas: condena de 14 meses de prisión por el ilícito del $550 \mathrm{CP}$ y multa de 40 días a razón de 4 euros diarios por la falta. Además, deberán indemnizar conjuntamente a la víctima en concepto de responsabilidad civil.

La parte condenada interpone recurso de apelación ante la AP, con una serie de alegaciones en cuanto a los hechos que la Sala resume así:

«...primero, la situación de tristeza, ansiedad y sufrimiento de los acusados que se enteran que su familiar tiene riesgo de muerte horas antes; segundo, el estado de dolor de la paciente ingresada; y tercero, el tiempo transcurrido desde la prescripción de la bomba de perfusión sin que la misma fuera administrada por el personal sanitario».

La AP considera que concurren todos los elementos exigidos por el tipo, para que los hechos sean tipificados como delito de atentado y no como la falta del art. $634 \mathrm{CP}$, como se invocaba en el recurso:

«...se rechaza la aplicación del invocado antiguo art. 634 del C.P. pues la redacción del precepto no incluye a los funcionarios, sólo a la autoridad y sus agentes».

Sin embargo, entiende que hay diferencia entre la actitud de ambos acusados, porque no estima gravedad suficiente en la actitud de Macarena como para que su actuación sea considerada delito de atentado: 
«...los golpecitos en la espalda de la enfermera con un dedo, no pueden integrar el delito de atentado que por su rigurosidad está sometido a una interpretación restrictiva. La acción de "percutir" un dedo sobre la espalda, más bien dirigida a hacer una llamada de atención o a molestar, no puede integrarse en forma alguna en la acción de acometer, emplear fuerza, intimidar o resistirse, conductas todas ellas descritas en el delito de atentado».

Estos hechos se contraponen claramente a los que lleva a cabo el otro acusado, dónde la Sala sí aprecia la existencia de acometimiento y, por consiguiente, delito de atentado:

«...lejos de limitarse a una simple actitud pasiva o solo colaboradora en el comportamiento mal educado y desagradable de su madre, adopta una postura activa y violenta mediante acometimiento fisico, que se realiza con un empellón o lanzamiento contra la pared, para lo cual la coge del brazo».

Atendiendo a todas estas circunstancias y a las modificaciones introducidas por la LO 1/2015, la Sala revoca parcialmente la sentencia de instancia, absolviendo a la acusada del delito de atentado que se le imputaba y rebajando a 6 meses la condena a prisión impuesta por este ilícito a su hijo. Confirma la sentencia recurrida en todos los demás pronunciamientos.

\section{1.- Juzgado de lo Penal $n^{0} 3$ de Bilbao, (Procedimiento Abreviado 210/15), de 26 de noviembre de 2015.}

El Juzgado de lo Penal n 3 de Bilbao tipificó como constitutiva de delito de atentado, la agresión llevada a cabo por una mujer a una enfermera en un hospital público.

Los hechos, que el juzgado considera probados, se produjeron como se transcribe a continuación: «la acusada Hernán (...), sobre las 18:30 horas del día 26 de Septiembre de 2013, encontrándose con su hija de diez meses de edad, en la habitación no 224 del Hospital de Basurto de la localidad de Bilbao, perteneciente a Osakidetza, cogió a su bebé e hizo amago de tirarlo al suelo, interviniendo la enfermera Vicenta, quien logró agarrar a la niña con el brazo izquierdo, momento en que la acusada, con ánimo de menoscabar el legítimo ejercicio de la autoridad de Vicenta, le propinó un golpe en el brazo derecho».

La enfermera reclama, porque además sufrió lesiones a consecuencia de la agresión:

"A consecuencia de éstos hechos, Vicenta sufrió lesiones consistentes en esguince de muñeca que requirieron para su sanidad tratamiento médico consistente en colocación de férula de yeso, 
tardando en curar treinta días durante los cuáles estuvo impedida para sus ocupaciones habituales, sin secuelas».

El juzgador de instancia impone a la acusada, como autora de un delito de atentado contra funcionario público, la pena de prisión de 7 meses y como responsable de un delito de lesiones condena a prisión por 4 meses, además de una indemnización a la víctima por las lesiones causadas $^{471}$.

\section{2.- SAP Jaén (Sección 3a) 375/2015, de 10 de diciembre.}

La AP de Jaén confirma íntegramente la sentencia dictada por el Juzgado de lo Penal n 3 de esa ciudad (21/05/2015), en la que se condenaba al agresor de una médico en un centro de salud como autor de un delito de atentado

Los hechos tuvieron lugar en el mes de marzo de 2011, cuando el usuario, que había sido citado previamente, se mostró descontento porque quería que le atendieran sin esperar su turno. Insultó y amenazó a la médico, forcejeando con ella y golpeándola además con la puerta de la consulta:

«...el acusado Benedicto se personó en el mismo previa cita concertada exigiéndole a la doctora Dña. Juliana que le atendiese, y ante la petición de ésta de que esperarse su turno, el acusado se dirigió a ella diciéndole, "tú eres gilipollas", levantándole la mano y empujando la puerta de la consulta, golpeando con ésta a la Sra. Juliana, produciéndose un forcejeo hasta que finalmente logró cerrar la misma, causándole lesiones consistentes en dolor en la región cervical y hombro izquierdo y crisis de ansiedad, que requirieron primera asistencia médica, tardando en curar 10 días sin impedimento para sus ocupaciones habituales y sanando sin secuelas».

Se le condena por el ilícito del art. 550 a 1 año de prisión, después de aplicarle la atenuante simple de drogadicción.

«En el momento de los hechos el acusado se encontraba bajo los efectos de sustancias psicotrópicas que mermaban levemente sus facultades intelectivas y volitivas».

Por la falta de lesiones se le impone multa de 1 mes a razón de 4 euros diarios, además de la obligación de indemnizar a la víctima.

En el recurso de apelación interpuesto contra la sentencia, la defensa alega la inexistencia de delito de atentado y que, en todo caso, se tenga en cuenta la circunstancia atenuante de dilaciones

${ }^{471}$ Ver SAP Bizkaia 90101/2016 (sic), de 16 de marzo. Documento TOL5736.498. 
indebidas, pero la Sala desestima el motivo al entender que no se paralizó el procedimiento, aunque reconoce que hubiera sido deseable su duración fuera inferior.

«Por lo expuesto, a la vista de las actuaciones practicadas en la presente causa, este Tribunal considera que no concurre la atenuante alegada en esta alzada por la defensa del acusado, pues ni es una dilación extraordinaria ni indebida en la tramitación del procedimiento; tratándose en definitiva de un tiempo de duración del mismo, que si bien sería deseable que fuera inferior, no se encuentra dentro de los parámetros temporales exigidos jurisprudencialmente para que pueda aplicarse la referida atenuante».

La AP desestima el recurso y confirma íntegramente la sentencia de instancia.

\section{3.-AP de Alicante (Sección 2a) 582/2015, de 22 de diciembre.}

Una mujer lleva a cabo una agresión en un hospital público en noviembre del año 2011. La víctima (Esther) era auxiliar de clínica e intentaba explicarle, junto con otra compañera (Matilde), el tratamiento que la Dirección médica le había prescrito. Entonces, «la acusada se enfadó y comenzó a agredir a Esther, propinándole un fuerte empujón». A consecuencia de ello la enfermera Esther:

«...cayó al suelo y sufrió traumatismo en muñeca izquierda con fractura del extremo distal del radio así como traumatismo en el sacro, precisando para su curación de una única asistencia facultativa con tratamiento farmacológico, ortopédico, reposo y rehabilitación, tardando un total de 90 días en recuperarse, todos ellos de carácter impeditivo para sus ocupaciones habituales, no resultando suficientemente acreditado que realmente llegase a recibir sesiones de fisioterapia tras ser atendida por el Médico Forense».

El Juzgado de lo Penal $n^{\circ} 6$ de Alicante (20/10/2015) condenó a la acusada como autora de un delito de atentado en concurso ideal con un delito de lesiones, teniendo en cuenta su estado mental $^{472}$, a las siguientes penas:

«Debo CONDENAR Y CONDENO a Tamara(...), como autor (sic) responsable de un delito de atentado a funcionario público de los arts.550 y 551.1 del Código Penal en concurso ideal con un delito de lesiones del art.147.1 CP, concurriendo la circunstancia eximente incompleta del art.21.1 en relación con el art.20.1 CP, EN RELACIÓN CON EL DELITO DE ATENTADO a la

\footnotetext{
472 «En el momento de los hechos, la acusada sufría un trastorno esquizofrénico bipolar, con trastorno límite e histriónico de la personalidad, y dificultad para el control de impulsos y escasa tolerancia a la frustración, teniendo por ello afectada la voluntad aunque no su capacidad cognitiva».
} 
pena de 6 meses de prisión (...), así como a la medida de internamiento en régimen cerrado en Centro adecuado a su salud mental durante un máximo de 3 años. Por su parte, EN RELACIÓN CON EL DELITO DE LESIONES a la pena de3 meses de prisión (...) así como a la medida de internamiento en régimen cerrado en centró adecuado a su salud mental durante un máximo de 3 años.

Así mismo deberá indemnizar a Esther (...), en concepto de responsabilidad civil por los daños y perjuicios derivados de las lesiones que sufrió (...)».

La acusada interpone recurso de apelación en el que alega, sobre todo, que en el plenario no resultó acreditada la existencia de una agresión que justifique su condena como autora de ambos delitos.

La AP no comparte estas alegaciones y entiende por el contrario que se dan todos los elementos típicos de los ilícitos por los que viene acusada:

"El hecho de que las lesiones pudieran haberse producido al caer el (sic) perjudicada al suelo y no ser consecuencia directa del impacto recibido directamente de la acusada, no afecta a la calificación de los hechos (...). Quien empuja violentamente a otro contempla que pueda caer al suelo y sufrir lesiones consecuencia del segundo impacto, lo que no le impide ejecutar la acción, siendo el resultado previsible imputable a título de dolo (...). El carácter de funcionario público de la agredida artículo $24 \mathrm{CP}$ ) era conocido por la acusada, lo que no le impidió actuar cometiendo un delito de atentado, como correctamente se califica en instancia».

La Sala desestima íntegramente el recurso y confirma la sentencia recurrida en todos sus pronunciamientos.

\section{4.- SAP Madrid (Sección 15a) 871/2015, de 30 de diciembre.}

Una mujer, nacida en Perú y con permiso de residencia en España, estaba ingresada en la planta de Psiquiatría de un hospital público, agrediendo allí en junio del año 2010 a una psiquiatra que la estaba atendiendo:

«...cuando la doctora Fermina, estaba pasando consulta en el hospital Infanta Leonor, (que está en régimen de la Seguridad Social), sito en la calle Gran Vía del Este, 80 de Madrid, en la planta de psiquiatría, y atendiendo a la paciente internada en el mismo, en virtud de auto de 18 de junio de 2009, dictado por el Juzgado de primera Instancia $n^{\circ} 95$ de Madrid, al haber sufrido un episodio autolítico, la acusada, África (...) como no le diera la doctora el alta médica que le requería insistentemente, se abalanzó sobre ella, cuando estaba sentada tras la mesa sita en la 
consulta, cercándola contra las piernas de Fermina, y de un fuerte tirón la cogió de la cinta que llevaba en el cuello con la tarjeta acreditativa médica, consiguiendo que bajara la cabeza del tirón, terminando por romperse, logrando en ese momento zafarse de la acusada solicitando auxilio, apareciendo en vigilantes de seguridad y 2 enfermeras que lograron retenerla y llevarla a una habitación donde la sedaron».

El Juzgado de lo Penal no 22 de Madrid (09/10/2015) ${ }^{473}$ condena a la autora de la agresión como responsable de un delito de atentado, teniendo en cuenta «la circunstancia modificativa de la responsabilidad penal eximente incompleta de enajenación mental», a 5 meses de prisión, así como a «la medida de seguridad con sumisión a tratamiento interno en centro médico hasta que se estabilice la enfermedad por tiempo máximo de 1 año, sin perjuicio de que si mejora se aplique el art. 97, pero en todo caso con control de tratamiento ambulatorio».

La parte condenada interpone ante la AP recurso de apelación ${ }^{474}$ con las peticiones siguientes:

«...solicitó que se absuelva a la acusada del delito de atentado por el que ha sido condenada o subsidiariamente se la condene por la falta del artículo 634 del código penal. Subsidiariamente se acuerde la suspensión de la ejecución de la pena de prisión y la medida de seguridad impuesta. Subsidiariamente, se le sustituya la pena por la de localización permanente, subsidiariamente, por trabajos en beneficio de la comunidad o multa».

La Sala estima el recurso, en lo relativo al error en la valoración pericial de las pruebas médicas ${ }^{475}$ y procede a absolver a la acusada del delito de atentado, aplicando la eximente del artículo 20.1 CP.

En consecuencia, la AP revoca parcialmente la resolución de instancia dictando sentencia en los siguientes términos:

«SE ESTIMA PARCIALMENTE el recurso de apelación formulado por la representación procesal de África, contra la sentencia (...) dictada por el Juzgado de lo Penal $n^{\circ} 22$ de Madrid, que procede revocar parcialmente en el extremo de absolver a la acusada del delito de atentado, por aplicación del eximente de trastorno mental transitorio, y a acordar la medida de seguridad de sumisión a tratamiento externo en Centro médico o establecimiento adecuado al tipo de

\footnotetext{
${ }^{473}$ Sentencia que se aclara posteriormente mediante Auto de fecha 28 de octubre de 2015.

474 "...alegando infracción de la presunción de inocencia y del principio "in dubio pro reo" y error de la valoración de las pruebas».

475 «Debiéndose tener en cuenta la situación psiquiátrica en la que se encontraba la acusada con anterioridad y al tiempo de los hechos, ocurridos el día 21/6/2009».
} 
anomalía o alteración psíquica que padece la acusada por el tiempo que sea preciso, que no podrá exceder de seis meses. Confirmando el resto de la resolución recurrida».

\section{5.- SAP Cuenca (Sección 1ª) 25/2016, de 16 de febrero.}

Un paciente mantiene una actitud violenta contra un enfermero y tres agentes de la Guardia Civil en un centro de salud, en el mes de diciembre de 2012:

«...al percatarse de la presencia de los agentes de la Guardia Civil, que habian sido alertados por el personal sanitario, al encontrarse éste en un gran estado de agitación, se dirigió al agente de la Guardia Civil con TIP NUM001 con expresiones como "hijo de puta, maricón, te voy a arrancar el bigote, no hacéis bien vuestro trabajo" continuó insultando a los agentes presentes y propinando golpes al mobiliario del referido centro de salud. Al no deponer su actitud, y tranquilizarse, los agentes con ayuda del personal sanitario allí presente procedieron a la inmovilización del acusado, momento en que éste le propinó una patada en la rodilla al agente número NUM001, asimismo agresión al agente número NUM002 en un brazo y le propinó otra patada en la rodilla. Igualmente llegó a agredir al agente número NUM003, así como a (...), el cual se encontraba desempeñando sus funciones de enfermero en el centro de salud. Tal era el estado de exaltación y agresividad que presentaba el acusado que se le tuvo que inyectar un calmante por parte de los facultativos del centro».

A consecuencia de estos actos violentos los agentes de la autoridad resultaron con diversas lesiones. El enfermero no llegó a padecer ninguna lesión.

El Juzgado de lo Penal $n^{\circ} 2$ de Cuenca (22/07/2015), consideró estos hechos como constitutivos de delito de atentado, con la concurrencia de eximente incompleta, imponiendo por dicho ilícito la condena a 3 meses de prisión ${ }^{476}$. Además, procede a absolverle de las consecuencias penales de las tres faltas de lesiones de las que también era autor, en aplicación de la Disposición Transitoria cuarta de la LO 1/2015, quedando únicamente cabida para las correspondientes indemnizaciones en concepto de responsabilidad civil.

La AP desestima íntegramente el recurso de apelación que la parte condenada interpuso contra esta sentencia y la confirma en todos sus pronunciamientos.

\footnotetext{
476 "con la inhabilitación especial para el ejercicio del derecho de sufragio pasivo durante el tiempo de la condena y a la libertad vigilada consistente en la obligación de seguir tratamiento médico externo o de someterse a un control médico periódico por un período de 2 años y costas».
} 


\section{6.- SAP Málaga (Sección 9ª 120/2016, de 23 de febrero.}

Un hombre agrede a personal sanitario del Hospital Materno Infantil, donde era ingresado frecuentemente su hijo:

«...nacido con prematuridad, y numerosas patologías crónicas que requieren asistencia ventilatoria continua."

El Juzgado de lo Penal $n^{\circ} 3$ de Málaga (01/07/2015) destaca la constante agresividad que el acusado venía desarrollando contra este personal:

"ha venido provocando numerosos incidentes, manteniendo una actitud beligerante y agresiva contra el colectivo de profesionales de la UCI, y de la Planta $6^{a}$ a los que ha hecho objeto de constantes insultos, amenazas e incluso agresiones, especialmente desde principios del año 2011, habiendo ya sido condenado por la agresión a un enfermero, sometiendo a dicho personal a una tensión constante».

Este colectivo profesional ya había remitido quejas en este sentido a la Dirección del centro, si bien era remiso a interponer denuncias «por temor a represalias», como recoge la resolución de instancia y transcribe en el Primero de los Antecedentes de Hecho la SAP:

«...la situación de terror en que ha de desarrollar su labor asistencial debido a las amenazas y agresiones físicas que sufren, así como el temor a denunciar por miedo a las represalias».

El juzgador «a quo» enfatiza la tensión en que se desarrolla el trabajo en el centro hospitalario, alterándose en consecuencia el funcionamiento de los servicios:

«...sometiendo a dicho personal a una tensión constante, hasta el punto de que han evitado interponer denuncias por miedo a represalias, alterando el normal funcionamiento de la referida Unidad de Cuidados Críticos y Urgencias Pediátricas, por la constante intervención del servicio de seguridad privado de la empresa EULEN para el establecimiento del orden, e incluso con intervención policial».

El agresor era reincidente además en cuanto a la comisión del delito de atentado. Ya había sido condenado por la agresión a un enfermero de este hospital, según se pone de manifiesto en los Hechos Probados de la sentencia del juzgado: 
«El acusado fue condenado en virtud de sentencia firme de fecha 21-2-2011, por delito de atentado, a la pena de 1 año de prisión, cuya ejecución ha sido suspendida por plazo de 2 años, el 26-4-2011».

En virtud de estos hechos, el juez de instancia le condenó a 18 meses de prisión por considerarle autor de un delito de atentado, a multa de 20 días (a razón de 6 euros diarios) por una falta de coacciones del art. $620 \mathrm{CP}$ y a multa de 6 meses a razón de 6 euros diarios por un delito de desórdenes públicos del art. $558 \mathrm{CP}$.

Solicita la defensa la aplicación a su cliente de la atenuante analógica de confesión del artículo 21.7 CP:

«alegando en su favor el reconocimiento de los hechos por parte de su cliente durante el procedimiento, el día de la celebración del Juicio Oral y el total y absoluto arrepentimiento mostrado en todo momento».

La AP desestima ese motivo de apelación, con estos argumentos:

«En el supuesto de autos, se advierte el incumplimiento no sólo del requisito cronológico expuesto, consistente en que la confesión tenga lugar antes de conocer el confesante que el procedimiento se dirige contra él, sino la falta de colaboración del acusado que, en contra de lo manifestado por la defensa, en su declaración sumarial (folio 170), prestada en calidad de detenido en fecha 10.2.12, negó, de forma reiterada, los hechos que se le imputaban, diciendo (sic): "que no son ciertos los hechos que se le imputan" $y$ "que no es cierto que haya agredido ni insultado al personal del hospital", negación que impide la estimación, incluso como analógica, de la atenuante de confesión».

La Sala concluye desestimando íntegramente el recurso a la vez que confirma la sentencia de instancia en todos sus pronunciamientos.

\section{7.- SAP Madrid (Sección 29a) 104/2016, de 25 de febrero.}

Un hombre agrede a una psiquiatra en el centro médico donde ésta trabajaba y al que había acudido el acusado para que le extendiera unas recetas. Los hechos ${ }^{477}$ tuvieron lugar en octubre de 2012:

\footnotetext{
477 Para la transcripción completa de los hechos, véase: SJ Penal № 10 de Madrid de 1 de octubre de 2015.
} 
«El acusado Serafin (...) increpó a la doctora D Marta, profirieron contra la misma expresiones tales como " eres una hija de puta, voy a traer a mis amigos y te voy a matar "y ello motivado porque se negó a extenderle unas recetas remitiéndole al especialista. En el incidente golpeó algunos muebles dañando una mesa del centro que ha sido tasada en 90 euros.

Con anterioridad persona no acreditada modificó con bolígrafo una receta del sistema nacional de salud de la doctora Adoración, con la intención de crear una apariencia, que no respondía a la realidad (...).

El acusado tenía levemente afectadas sus facultades mentales».

El Juzgado de lo Penal $n^{0} 10$ de Madrid (01/10/2015) consideró esta actuación violenta como constitutiva de delito de atentado, por el que condenó al acusado a 3 meses de prisión, aplicando la circunstancia atenuante de dilaciones indebidas. Le absuelve de un delito de falsificación de documento oficial y de una falta de daños por los que venía también imputado.

La parte condenada interpone recurso de apelación contra esta sentencia alegando, entre otros argumentos, que los hechos carecían de la suficiente gravedad como para que fueran tipificados como delito de atentado en opinión del recurrente:

"puesto que la conducta del hoy apelante se limitó a proferir insultos por lo que los hechos sólo pueden ser calificados, a lo sumo, de una falta de injurias, destacándose que en el auto de incoación de abreviados se calificó como delito de amenazas y no de atentado, por todo lo cual lo que procede es la libre absolución ${ }^{478} \gg$.

La AP estima el recurso pero por razones distintas a las que en él se argumentan: entiende que no existe encaje de los hechos en la figura del delito de atentado del artículo 550 tras la reforma operada en 2015, porque en el nuevo ordenamiento la intimidación se vincula a la resistencia y ésta no se produjo.

«El recurrente considera que los hechos carecen de relevancia típica y este tribunal considera que es asi pero por razones distintas a las invocadas en el recurso y que deber ser apreciadas de oficio $^{479}$ (...). En este caso se ha acusado y condenado por un delito de atentado pero la

\footnotetext{
478 La AP estima el recurso y procede a la libre absolución del acusado. Ver SAP Madrid 104/2016, de 25 de febrero. ${ }^{479} \mathrm{El}$ texto suprimido y que corresponde al paréntesis es el siguiente: «En efecto, la intimidación grave ejercida de forma directa y activa sobre autoridad o funcionario público, ha desaparecido del Código Penal como modalidad del atentado de acuerdo con la modificación introducida por la Ley Orgánica 1/2015, dado que la intimidación grave debe estar vinculada a un acto de resistencia grave. Ciertamente el nuevo tipo penal resulta contradictorio porque en el artículo 554 del Código Penal la intimidación grave realizada de modo directo y activo se castiga como atentado cuando se produce contra bomberos, personal sanitario o equipos de socorro con ocasión de un siniestro, calamidad pública o situación de emergencia y cuando se produce contra el personal de seguridad privada que actúe en
} 
intimidación no estuvo vinculada a un acto de resistencia sino que, por el contrario, fue una conducta activa y directa originada porque la doctora se negó a extender la receta que quería el hoy apelante. Por lo tanto, los hechos enjuiciados están despenalizados conforme a la actual regulación penal introducida por la LO 1/2015, que debe ser aplicada de forma retroactiva de conformidad con lo establecido en el artículo 2.2 del Código Penal y en la Disposición Transitoria 1.1 de la LO 1/2015».

La Sala, al estimar el recurso, revoca la sentencia de instancia, procediendo a la libre absolución del acusado:

«Por lo tanto, los hechos enjuiciados están despenalizados conforme a la actual regulación penal introducida por la LO 1/2015, que debe ser aplicada de forma retroactiva de conformidad con lo establecido en el artículo 2.2 del Código Penal y en la Disposición Transitoria 1.1 de la LO 1/2015. En consecuencia y sin necesidad de analizar los restantes motivos del recurso procede su estimación y la libre absolución del denunciado del delito de atentado».

Todo ello, a pesar de apreciar que pueden existir contradicciones en cuanto a algunas de las disposiciones del ordenamiento penal después de la reforma:

«En efecto, la intimidación grave ejercida de forma directa y activa sobre autoridad o funcionario público, ha desaparecido del Código Penal como modalidad del atentado de acuerdo con la modificación introducida por la Ley Orgánica 1/2015, dado que la intimidación grave debe estar vinculada a un acto de resistencia grave. Ciertamente el nuevo tipo penal resulta contradictorio porque en el artículo 554 del Código Penal la intimidación grave realizada de modo directo y activo se castiga como atentado cuando se produce contra bomberos, personal sanitario o equipos de socorro con ocasión de un siniestro, calamidad pública o situación de emergencia y cuando se produce contra el personal de seguridad privada que actúe en cooperación y bajo el mando de las Fuerzas y Cuerpos de Seguridad, pero no cuando se produce frente a autoridades o agentes de la autoridad, puesto que en estos casos la intimidación grave debe estar vinculada a un acto de resistencia (artículo $550 \mathrm{CP}$ ). Por lo tanto, la intimidación mediante amenazas deberá ser castigada a través de los tipos genéricos de amenazas de los artículos 169 a 171 del Código Penal».

cooperación y bajo el mando de las Fuerzas y Cuerpos de Seguridad, pero no cuando se produce frente a autoridades o agentes de la autoridad, puesto que en estos casos la intimidación grave debe estar vinculada a un acto de resistencia ( artículo $550 \mathrm{CP}$ ). Por lo tanto, la intimidación mediante amenazas deberá ser castigada a través de los tipos genéricos de amenazas de los artículos 169 a 171 del Código Penal». 


\section{8.- SAP Madrid (Sección 1ª) 115/2016, de 7 de marzo.}

En el mes de marzo de 2009, un paciente lleva a cabo una agresión contra la psiquiatra que le estaba atendiendo desde tiempo atrás en un centro de salud. Transcribimos a continuación la narración fáctica:

«...el acusado Silvio (...) fue trasladado por el equipo de apoyo socio- comunitario adscrito al Hospital Universitario Puerta de Hierro, al Centro de Salud Mental sito en la avenida de España, $n^{\circ} 7$ de la localidad de Majadahonda, a requerimiento de Doctora Constanza, que ejercía como psiquiatra en dicho centro de salud y venía tratando al acusado desde hacía más de un año, de manera que en un momento en que la doctora le comunicó que iba acordar su traslado forzoso al Hospital Universitario Puerta de Hierro, el acusado se abalanzó sobre la misma y le cogió de la cabeza, golpeándola reiteradamente contra la mesa de la consulta, sin que la Doctora Constanza pudiera impedir la agresión ni minorar sus consecuencias debido a la falta de medidas de seguridad, ni personal ni de ningún otro tipo, en el indicado Centro de Salud, no cesando el acusado en su agresión hasta que intervinieron personas que se encontraban en el exterior del edificio al oír los gritos de auxilio de la doctora (...).

El acusado Silvio tiene reconocido un grado de minusvalía del $65 \%$ y en el momento de la comisión de los hechos padecía una esquizofrenia paranoide que anulaba por completo su entendimiento y juicio crítico, con nula conciencia de su enfermedad».

A consecuencia de la agresión, la víctima sufrió lesiones graves y que entrañaron un largo proceso para su curación:

«....sufrió lesiones consistentes en contusión en la nariz, erosiones en el área interciliar y en la región malar izquierda, contusión en la mano derecha y contractura muscular cervical, lesiones que precisaron para su curación además de la primera asistencia facultativa, tratamiento médico, farmacológico y rehabilitador, tardando en curar 189 días, 168 de los cuales fueron impeditivos para el ejercicio de sus ocupaciones habituales, quedándole como secuelas tres hernias discales (C4-C5, C5-C6 y C7).

Desde el 13 de mayo de 2009 al 2 de julio de 2010 Constanza realizó 63 sesiones de rehabilitación, por las que abonó un total de 2.070 euros.

A partir del día 2 de noviembre de 2010 Constanza continuó realizando sesiones de rehabilitación de mantenimiento con un fisioterapeuta en Sannus Clinic, abonando a razón de 40 euros por sesión, habiendo realizado 83 sesiones más hasta el día 24 de junio de 2015, lo que supone un importe total de 3.320 euros». 
El Juzgado de lo Penal $n^{\circ} 21$ de Madrid (24/07/2015), absuelve al acusado de los delitos de atentado y de lesiones que se le imputaban ${ }^{480}$, aplicando la eximente del artículo 20.1, debiendo indemnizar a la víctima por los daños que le fueron causados.

La parte condenada recurre la sentencia. La AP estima parcialmente el recurso, sustituyendo, como se solicitaba en él, el internamiento en un centro psiquiátrico de media estancia por tratamiento ambulatorio, a la vez que procede a rebajar la cuantía de las cantidades indemnizatorias que habían sido señaladas por el juzgador de instancia.

Hay que reseñar que en el Primero de los Antecedentes de Hecho de la SAP, al relatar cómo transcurrieron los acontecimientos (Hechos Probados), se apunta a la falta de medidas de seguridad del centro de salud donde se produjo la agresión:

«...sin que la Doctora Constanza pudiera impedir la agresión ni minorar sus consecuencias debido a la falta de medidas de seguridad, ni personal ni de ningún otro tipo, en el indicado Centro de Salud».

\section{9.- SAP Granada (Sección $2^{\mathrm{a}}$ ) 158/2016, de 14 de marzo.}

Un hombre lleva a cabo agresiones físicas y verbales contra una enfermera en un hospital público, en junio de 2013. La narración fáctica es como a continuación se transcribe:

«El acusado Melchor (...) se encontraba en el Hospital San Cecilio, sito en la calle Avenida de Madrid de Granada, donde su madre estaba ingresada en la habitación 3309 situada en la planta tercera donde la funcionaria pública Genoveva (...) ejercía sus funciones como enfermera, vestida de uniforme e identificada como tal, atendiendo a los pacientes de cuatro habitaciones. Cuando se encontraba preparando la medicación frente a la habitación 3313, Melchor, que paseaba con su madre por el pasillo, se acercó a aquélla diciéndole qué pasa guapa, continuando la enfermera con su trabajo, si bien, cuando volvieron a coincidir en el pasillo Melchor le dijo a Genoveva esta tarde me comes la polla y que se metieran en un cuarto y luego al encontrarse cerca del office le dijo te vas a enterar cuando salgas, que la iba a esperar fuera y le iba a destrozar la cara, llegando a agarrarle del hombro para acercarla y al zafarse el acusado intentó morderle en la mano.

Tras estos hechos Genoveva llamó al supervisor de guardia, a la policía y a los vigilantes de seguridad que se personaron y acompañaron al acusado Melchor hasta la salida del Hospital».

\footnotetext{
480 «...imponiéndole la medida de seguridad consistente en internamiento para recibir tratamiento médico en un Centro Psiquiátrico de Media Estancia adecuado para el tratamiento de la anomalía psíquica».
} 
La víctima, a consecuencia de estos hechos sufrió problemas de tipo psicológico y emocional:

«...tuvo una reagudización de un cuadro psicológico depresivo precedente que origina, entre otros rasgos, una búsqueda activa de evitación de conflictos y problemas, sufriendo a raíz de los hechos un estado emocional caracterizado por tristeza, indefensión, estado de alerta y disminución de su percepción de control, percepción de amenaza a su integridad física, estando aconsejada intervención psicoterapéutica para el tratamiento de su cuadro emocional».

El Juzgado de lo Penal $n^{\circ} 3$ de Granada (31/03/2015), tipificó esta conducta agresiva como constitutiva de delito de atentado, por el que impuso la condena de 1 año de prisión así como la obligación de indemnizar a la víctima por los daños morales sufridos.

Le absuelve de la falta de maltrato por la que también venía acusado y a la enfermera de los hechos que el acusado la había imputado:

«No ha quedado acreditado que el referido día Genoveva profiriera expresiones de tenor insultante ni que golpeara o empujara a Melchor, ni tampoco que al dia siguiente se refiriera a él con la expresión "este es el padre del hijo de puta ese"».

La parte condenada interpone recurso de apelación contra esta resolución de instancia, en el que, entre otras alegaciones, se intenta neutralizar la prueba testifical que presenta la parte perjudicada, argumentos que la Sala interpreta como insinuaciones de «corporativismo» al ser la testigo compañera de trabajo de la víctima:

«Revisadas sus manifestaciones, al igual que las de la Sra. Silvia, no encuentra la Sala mérito alguno para colegir que faltaran aquéllas deliberadamente a la verdad por mero corporativismo, que viene a ser lo que -en definitiva- se alega en el recurso para neutralizar el valor que a sus testimonios les confirió a tales pruebas el Juzgador a quo».

La Sala deroga parcialmente la sentencia de instancia rebajando la condena por el delito de atentado a 6 meses de prisión y disminuyendo también la cantidad asignada por el juzgador «a quo» en concepto de indemnización ${ }^{481}$.

\footnotetext{
481 «En lo relativo a la responsabilidad civil derivada de las consecuencias de los hechos enjuiciados, considera la Sala que están debidamente objetivadas las secuelas padecidas por la denunciante a raíz de aquéllos mediante la prueba pericial forense practicada en las actuaciones, pero, también, que se aprecian en su historial clínico datos igualmente objetivos acerca de síntomas psíquicos, evidenciados con carácter previo a estos acontecimientos y que podrían asociarse a patologías o causas diferentes de las que pudieran derivarse del delito, lo que nos lleva a modular el importe de la indemnización en porcentaje consistente en el $50 \%$ de lo estipulado, sin otra consideración que el criterio prudencial del Juzgador, en la sentencia apelada».
} 


\section{0.-SAP BizKaia (Sección 6 ${ }^{\mathrm{a}}$ ) 90101/2016 (sic), de 16 de marzo ${ }^{482}$.}

En septiembre de 2013, una enfermera de un hospital público sufre una agresión a manos de la madre de una niña allí ingresada. El Juzgado de lo Penal no 3 de Bilbao (26/11/2015), condenó a la agresora como autora responsable de un delito de atentado y de un delito de lesiones. Por el delito de atentado le impone pena de 7 meses de prisión; por el de lesiones, pena de prisión de 4 meses, con la obligación de indemnizar a la víctima.

Los Hechos Probados que se recogen en esta sentencia del juzgado son los siguientes ${ }^{483}$ :

«La acusada Hernán (...) encontrándose con su hija de diez meses de edad, en (...) del Hospital de Basurto (...), cogió a su bebé e hizo amago de tirarlo al suelo interviniendo la enfermera Vicenta, quien logró agarrar a la niña con el brazo izquierdo, momento en que la acusada, con ánimo de menoscabar el legítimo ejercicio de la autoridad de Vicenta, le propinó un golpe en el brazo derecho».

A consecuencia de lo ocurrido, la enfermera sufrió daños ${ }^{484}$ (por los que reclama).

La parte condenada recurre la sentencia, alegando que el juzgador de instancia no ha valorado correctamente la prueba practicada.

La AP, no admite los hechos declarados probados en la resolución de instancia, que hemos reproducido en párrafos anteriores. Entiende que deben sustituirse por los que se transcriben a continuación

«En su lugar, ha de indicarse que en la tarde del día 26 de septiembre de 2013, la acusada Hernán se encontraba en el Hospital de Basurto custodiando y vigilando a su hija de diez meses de edad que se encontraba internada con una afección respiratoria. En una hora que no ha podido determinarse con exactitud, la enfermera que atendía el turno, la denunciante Vicenta, le indicó que iba a proceder a aplicar al bebé una inhalación, a lo que aquella respondió que antes le quería dar el pecho, a lo que accedió la enfermera. Con posterioridad, por ésta se le colocó a la niña una mascarilla de oxígeno, regresando precipitadamente a la cama por los gritos de la

\footnotetext{
${ }^{482}$ Documento TOL5.736.498

${ }^{483}$ La transcripción completa de los hechos en: SJ Penal no 3 de Bilbao, de 26/11/2015.

484 "A consecuencia de éstos hechos, Vicenta sufrió lesiones consistentes en esguince de muñeca que requirieron para su sanidad tratamiento médico consistente en colocación de férula de yeso, tardando en curar treinta días durante los cuáles estuvo impedida para sus ocupaciones habituales, sin secuelas».
} 
acusada señalando que la niña se estaba ahogando. En ese momento, la enfermera volvió a coger a la niña colocándole unas gafas nasales, momento en el que, al estornudar, expulsó un tapón de mocos, circunstancia que propició un enfrentamiento de la acusada con la enfermera en el que no ha quedado acreditado que aquélla la golpeara causándole un esguince en la muñeca derecha».

La Sala procede luego a analizar la valoración de la prueba efectuada por el juzgador «a quo»:

«En absoluto, a la vista de estos datos, puede darse por acreditada la versión del relato de hechos de la sentencia según la cual "la acusada le propinó un golpe en el brazo derecho", pero, lo que es más importante, en atención a aquéllos no podemos por menos que constatar otra grieta en la fiabilidad de la declaración de la perjudicada, que en todo momento refiere una agresión con golpes de los que se protegía con su mano derecha.

Finalmente, debemos igualmente restar relevancia al otro de los elementos de prueba del que se vale la sentencia para asegurar la corroboración periférica. Se apoya la juzgadora en la declaración de la mencionada Sra. Felicidad, que "si bien reconoció no haber visto la agresión, hizo constar que vio a su compañera agachada frente a la acusada, relato coincidente con el de la denunciante».

Termina concluyendo la Sala que no se ha valorado correctamente la prueba, tal como se alegaba en el recurso:

«En definitiva, la declaración de la denunciante, elemento central de la valoración de la prueba efectuada, no ofrece la seguridad que se señala en la sentencia, tanto por los puntos dudosos que ofrece como por la inexistencia de referencias objetivas externas que la doten de verosimilitud».

En consecuencia, procede a revocar íntegramente la sentencia recurrida, absolviendo libremente a la acusada de todos los cargos que se le habían imputado.

\section{1.- SAP Sevilla (Sección 7a) 158/2016, de 26 de abril.}

Una mujer que acompañaba a su marido a la consulta de un hospital público, se comportó violentamente con una enfermera porque consideró que estaba tratando a otros pacientes antes que a su esposo ${ }^{485}$.

\footnotetext{
${ }^{485}$ Como parece desprenderse de la SAP, no tenía cita con la citada enfermera: «...ese día no tenía cita con la enfermera sino con un médico del Centro».
} 
«La acusada Tarsila, (...), sobre las 13 horas del día 26 de mayo de 2014, acudió a la consulta del Hospital de San Lázaro con su marido, enfermo, que acudía a revisión por una dolencia circulatoria en sus extremidades, y encontrándose en la antesala o sala de espera de diferentes consultas, observó, como la Consulta de la enfermera Cecilia, está una usuaria para entrar, momento, en que con ánimo de quebrantar el ánimo, tranquilidad, desasosiego de dicha enfermera, se introdujo en la Consulta, y dirigiéndose hacia la enfermera cogiéndola por los brazos fuertemente, la zarandea, a la vez que le dice "hija de puta, cabrona, cómo le ocurra algo a mi marido en el pie te voy a matar, y a dejar sin trabajo, se te va a caer el pelo", y si bien, la enfermera, retrocedia, para quitársela, la fue arrinconando, la acusada contra la pared.

Marchándose seguidamente la acusada, encontrando las usuarias que conocía a la enfermera, en un estado de nerviosismo, livida, teniendo que hacer un receso, hasta tanto se recompuso fisica y moralmente para continuar con las consultas».

Por estos hechos, el Juzgado de lo Penal $\mathrm{n}^{\mathrm{o}} 7$ de Sevilla consideró a la agresora como autora responsable de un delito de atentado contra funcionario público, imponiendo una condena de 6 meses de prisión, aunque se suspende su ejecución condicionándolo a que no vuelva a delinquir en el plazo de 2 años a contar desde que la sentencia dictada sea firme.

La acusada interpone recurso de apelación ante la AP, negando que hubiera habido agresión y señalando como testigo a su esposo ${ }^{486}$. La parte perjudicada presenta a su vez prueba testifical en contrario.

La Sala desestima el recurso y confirma íntegramente la sentencia de instancia.

\section{2.- SAP Las Palmas (Sección 6ª) 175/2016, de 20 de mayo.}

Del Segundo de los Fundamentos de Derecho de esta SAP, se deduce que una mujer había llevado a cabo una agresión contra personal sanitario, diciendo textualmente:

«la agresión se produce cuando la denunciada es atendida por personal sanitario».

Por estos hechos, el Juzgado de Instrucción $n^{\circ} 7$ de dicha ciudad (24/02/205) la condenó como autora de una falta de maltrato de obra de artículo $617.2 \mathrm{CP}$. a pena de localización permanente por un período de 4 días.

\footnotetext{
${ }^{486}$ La Sala resta credibilidad al testimonio del esposo que niega los hechos, contra lo que afirma la víctima y otros testigos de cargo: «el marido de la apelante niega los hechos, incluso que su esposa se introdujera en el anterior de la consulta de la enfermera, extremo que quedado (sic) debidamente probado de las manifestaciones de la perjudicada y la primera testigo de cargo».
} 
Se interpone recurso de alegación con una serie de argumentos que valora la Sala de la siguiente manera:

«En el presente caso, procedería el dictado de sentencia absolutoria. Ciertamente, el caso es curioso en cuanto a los hechos pues la agresión se produce cuando la denunciada es atendida por personal sanitario. Sin embargo, del conjunto de alegaciones que plantea el apelante y que encuentran reflejo en el parte médico del 24 de febrero de 2015 que esgrime en su defensa el apelante, se deduce que el día de los hechos hubo ausencia de intencionalidad en la agresión, y esa ausencia de dolo, probada por tales alegaciones y de la documentación aportada por el apelante, nos debe llevar a tal conclusión. Y por ello, entiende este Tribunal que existe una duda sobre la intencionalidad de la agresión, duda que debe llevar a la libre absolución de la denunciada».

En consecuencia, la AP revoca íntegramente la sentencia de instancia y procede a absolver a la acusada de los cargos que se le habían imputado.

\section{3.- SAP Pontevedra (Sección 5a, con sede en Vigo) 302/2016, de 23 de mayo.}

El Juzgado de lo Penal n 1 1 (06/10/2015) de Pontevedra condenó a 1 año de prisión por delito de atentado al agresor de una enfermera en el servicio de Urgencias de un hospital público, a pesar de reconocerse que estaba bajo la influencia del alcohol en el momento de llevar a cabo los hechos que transcurrieron como se transcribe a continuación:

«...sobre las 19:30 horas del día 30 marzo 2014, Mariana, enfermera del servicio de urgencias del hospital público Xeral de Vigo, se encontraba trabajando en este servicio, cuando el acusado Demetrio, (...) a quien asistía en ejercicio de sus funciones, con ánimo de menoscabar su integridad fisica y atentar contra el principio de autoridad, se levantó de la silla de modo sorpresivo y agresivo, empujando fuertemente a Mariana y golpeándola contra la pared, causándole lesiones consistentes en lumbalgia postraumática que requirió primera asistencia facultativa y tardó en curar seis días no impeditivos.- A consecuencia de estos hechos resultó dañado un tensiómetro del Hospital marca Philips cuyo coste de reposición asciende a 1.161.36 euros.- En el momento de los hechos el acusado se encontraba bajo la influencia del alcohol, lo que mermaba su forma de actuar levemente».

Se le condena también como autor de una falta de lesiones del art. $617.1 \mathrm{CP}$ a la pena de 6 días de localización permanente, así como a indemnizar a la perjudicada en concepto de responsabilidad civil y a sufragar el coste de la reposición del tensiómetro al hospital. 
La parte condenada interpone recurso de apelación ante la AP contra esta resolución ${ }^{487}$, sobre todo por entender que no cabe delito de atentado por ser la víctima personal estatutario y no funcionario público en el momento de la comisión de los hechos:

«En concreto se refiere la parte recurrente a la cualidad de funcionario público de la denunciante, pues ésta, enfermera de profesión, es personal estatuario de modo que, siendo de aplicación el art. 550 del CP en su redacción anterior a la reforma -LO 1/2015-, considera que resulta que ésta, dado el concepto de funcionario público recogido en el art. $24 \mathrm{del} \mathrm{CP,} \mathrm{no} \mathrm{puede}$ ser sujeto pasivo de tal delito, por lo que entiende que en la Sentencia se hace una interpretación extensiva de la Ley en perjuicio del reo».

La Sala desestima íntegramente el recurso y confirma la sentencia recurrida en todos sus pronunciamientos.

\section{4.- SAP Almería (Sección 2ª) 272/2016, de 10 de junio.}

En enero de 2013, un paciente, ingresado con su consentimiento en la Unidad de Hospitalización de Salud Mental de un hospital público, agredió a personal sanitario de la planta, causándoles con sus amenazas «temor y desasosiego»:

"«...el acusado acudió al Servicio de Urgencias del Hospital de Poniente, y tras ser valorado por el psiquiatra de guardia, se decidió en consenso con el paciente, el ingreso voluntario en la Unidad de Hospitalización de Salud Mental del centro. Una vez en planta de hospitalización de Salud Mental, sobre las 9:30 horas del día 20 de enero de 2013, el acusado comenzó a mostrar una actitud violenta y desa (sic) ante hacia los enfermeros de planta Don Modesto y Doña Virtudes, profiriéndoles frases tales como "hijos de puta, cabrones, desgraciados, me vais a tocar los huevos, en la calle, me vais a hacer pagar todo, os voy a esperar en la puerta del hospital y os vais a enterar de quién soy yo, causándoles el lógico temor y desasosiego, revolviéndose frente a ellos e intentado agredirles, no consiguiéndolo al ser repelido por aquellos. Ante dicha situación se personó en el lugar la enfermera Doña Francisca quien junto al resto del personal de enfermería proceden a la inmovilización del acusado, quien seguía mostrando una actitud violenta y agresiva hacia el personal sanitario (...)».

\footnotetext{
487 También alega en relación con la responsabilidad civil: «En cuanto a la responsabilidad civil la parte apelante considera que no procede, pues manifiesta que la factura del tensiómetro fue impugnada, y que ninguna prueba se practicó al respecto».

La Sala desestima así mismo ese motivo de alegación: «De acuerdo pues, con lo razonado, no se estima la impugnación con efectos propios, dado su falta de motivación, argumentación y concreción».
} 
A consecuencia de la agresión una de las víctimas, la enfermera Doña Francisca, sufrió diversas lesiones ${ }^{488}$.

El Juzgado de lo Penal $n^{\circ} 3$ de Almería (25/11/2015), le condena como autor responsable de un delito de atentado, un delito leve de lesiones y un delito leve de amenazas.

Por el delito de atentado le impone condena 6 meses de prisión y por los delitos leves multa de 20 días a razón de 6 euros diarios por cada uno de ellos, a lo que se añade una medida de alejamiento a una distancia no inferior a $200 \mathrm{~m}$. durante 2 años respecto a todos los agredidos. Al aplicar las Disposiciones Transitorias $1^{a}$ y $4^{\text {a }}$ de la de la LO 1/2015, declara extinguida la responsabilidad penal debida a la falta de injurias por la que también venía imputado ${ }^{489}$.

El acusado impugna la sentencia de instancia, alegando fundamentalmente error en la valoración de la prueba por indebida aplicación de la eximente prevista en el art. 20.1 CP.

La AP desestima el recurso interpuesto contra dicha sentencia y la confirma en todos sus pronunciamientos.

\section{5.- SAP Murcia (Sección 3ª) 417/2016, de 1 de julio.}

En octubre de 2012, el hijo de una paciente lleva a cabo una agresión contra un médico en un centro de salud, causándole lesiones ${ }^{490}$. El hombre había estado requiriendo reiteradamente los servicios del facultativo para que éste atendiera a su madre, incluso recabando la ayuda de un agente de la autoridad:

"...el acusado, Sabino, (...), se personó en el bar "Los siete hermanos", sito en la Avda. de la Constitución de la localidad de Campos del Río, donde se encontraban almorzando, Pablo Jesús, médico del Centro de Salud de Campos del Río, junto con Martin, administrativo del centro, y José Pablo, ya que había estado anteriormente en el Centro de Salud para que atendieran a su madre y no encontró a nadie. Cuando entró en el bar les preguntó sí es que el centro estaba cerrado y ellos le contestaron que no, que ellos estaban de guardia y que cuando

\footnotetext{
488 "...sufrió lesiones consistentes en contusión en muñeca izquierda con dolor y parestesias requiriendo para su sanidad además de una primera asistencia facultativa inmovilización mediante vendaje elástico y analgésicos, de las que, según el informe del médico forense tardó en curar 25 días, 5 de ellos de incapacidad para la realización de sus ocupaciones habituales».

${ }^{489}$ Las injurias leves han sido expulsadas del ordenamiento penal por la reforma de 2015, excepto en los supuestos previstos en el art.173.4 CP de 2015, en relación con el art. 173.2.

${ }^{490}$ "Como consecuencia de estos hechos Pablo Jesús sufrió lesiones consistentes en contusiones en hombro y codo izquierdo que precisaron para su sanidad de una primera asistencia facultativa, tardando en sanar 7 días no impeditivos y sin que quedaran secuelas».
} 
terminaran de almorzar irían al centro. Que acto seguido el acusado se dirigió a la policía local para dar cuenta de lo ocurrido, personándose un agente en el citado bar, encontrando alli a Pablo Jesús y sus acompañantes, y tras comentarles lo que le habia dicho Sabino, le manifestaron igualmente que estaban almorzando y que ya se dirigían al centro. Que nuevamente se personó el acusado en el bar, y en esta segunda ocasión ya entró alterado y gritando, exigiendo al médico que fuera a atender a su madre, procediendo el médico y el enfermero a pagar la cuenta y a dirigirse al centro, siendo seguidos por Sabino, el cual durante todo el trayecto estuvo increpándoles por su comportamiento.

Al llegar al centro de salud el acusado se abalanzó sobre Pablo Jesús, golpeándole con unos papeles que portaba en la mano y le propinó una patada en el codo».

El Juzgado de lo Penal $n^{0} 5$ de Murcia (15/12/2015), condenó al agresor como autor de un delito de atentado y de un delito leve de lesiones. Por el atentado le condena a 6 meses de prisión y por el delito leve de lesiones le impone multa de 1 mes a razón de 3 euros diarios.

La parte condenada interpone recurso de apelación, alegando fundamentalmente falta de imparcialidad en la juez de instancia:

«En primer lugar denuncia al amparo del art. 790.2, nulidad del juicio por infracción de garantías procesales que causaren la indefensión del recurrente: falta de imparcialidad de la Magistrada al adelantar el fallo condenatorio y realizar funciones de acusación al realizar pregunta incriminatoria que luego traspasa a la sentencia para fundamentar la condena por lesiones. art. 24.1 Constitución Española en relación con el art. 241 LOPJ derecho al Juez imparcial».

La letrada de la defensa niega también que haya atentado, en todo caso, porque el médico se ha excedido en sus funciones. Alega también que no cabe tampoco la estimación penal respecto a las lesiones:

«...denuncia que habiendo quedado destipificada la falta de lesiones, el pronunciamiento de la sentencia debió atender únicamente a la mera responsabilidad civil, la cual fue renunciada por el médico denunciante».

La Sala estima el recurso únicamente en cuanto a la alegación sobre las lesiones ${ }^{491}$ : 491 «El último alegato del recurso debe tener mejor suerte de los anteriores, pues debe prosperar. Al respecto se han
de examinar los efectos producidos en la sentencia que se examina por la entrada en vigor de la LO 1/2015 de 30 de 
«Por dicha razón motivo (sic), aún confirmando la sentencia objeto del presente recurso, debe quedar sin efecto la condena penal por el delito leve de lesiones en el que la Juzgadora de instancia erróneamente reconvirtió la falta de lesiones objeto de acusación (del art 617.1 del Código Penal)».

En consecuencia, procede a revocar parcialmente la sentencia de instancia:

«...dejando sin efecto la condena por el delito leve de lesiones, sin ejecutar el pronunciamiento civil que contiene al haber renunciado el perjudicado ${ }^{492}$, confirmando el resto de pronunciamientos».

\section{6.- SAP Madrid (Sección 30ª) 540/2016, de 18 de julio.}

En febrero de 2013, un médico es agredido en el Centro Integral de Apoyo a la Drogodependencia de Madrid por un por un hombre que no está de acuerdo con la modificación de la dosis del tratamiento de metadona que le estaba prescribiendo:

«...el acusado Daniel (...), acudió al Centro de Apoyo Integral a la Drogodependencia, dependiente del Servicio Madrileño de Salud, sito en la calle Nuestra Señora del Carmen $n^{\circ} 46$ de esta capital, donde fue atendido por el Dr. D. Florian en relación al tratamiento con metadona que recibía dada su condición de drogodependiente y, al no estar de acuerdo con el cambio de dispensación de sus dosis que le prescribió el facultativo, se abalanzó contra el doctor y le propinó un puñetazo en la mandíbula izquierda y, seguidamente se subió a la mesa y le agarro al médico por el cuello y le propinó un segundo puñetazo en la misma zona, causándole contusiones faciales, rama mandibular izquierda y en el cuello, que requirieron primera asistencia y dentro de ella necesitando antiinflamatorios, curando en 15 días con uno de incapacidad».

El Juzgado de lo Penal $n^{\circ} 22$ de Madrid (21/03/2016), condena al agresor como autor de un delito de atentado a 3 meses de prisión (habiéndole aplicado la circunstancia atenuante muy cualificada

marzo que despenaliza algunas faltas, descriminaliza otras, somete al régimen de denuncia previa algunas y el resto las reconvierte en delitos leves.

En efecto, dicha ley ha incorporado al régimen de denuncia previa figuras penales como las lesiones dolosas leves entendiendo por tales las que no precisan tratamiento médico o quirúrgico para su curación- del art. 147.2 CP, y el maltrato de obra fuera del ámbito doméstico del art. $147.3 \mathrm{CP}$, que eran de naturaleza pública en su anterior configuración como faltas (art. $617 \mathrm{CP}$, derogado)».

492 Dice la SAP en el Séptimo de los Fundamentos de Derecho «sin que se deban ejecutar los aspectos civiles de la misma al haber renunciado el perjudicado Pablo Jesús en el acto de la vista según consta claramente en el minuto $50^{\prime} 56^{\prime \prime}$ del vídeo $1^{\prime}{ }^{\prime}$. 
de dilaciones indebidas ${ }^{493}$ ), además de la prohibición de acercarse a la víctima a menos de $500 \mathrm{~m}$. durante un plazo de 3 meses. Le absuelve de la falta de lesiones por las que venía también imputado.

Hay que hacer notar que el perjudicado no había formulado reclamación en concepto de responsabilidad civil.

El acusado interpone recurso de apelación contra la sentencia interesando su absolución o que, alternativamente, le fuera aplicada la atenuante de drogodependencia.

La Sala desestima el recurso y, en cuanto a la aplicación de la citada atenuante, considera lo siguiente:

«No cabe apreciar en Daniel una atenuación de su responsabilidad criminal por drogadicción. Porque no ha sido acreditado por el obligado a ello, el acusado. Así, no cabe duda de la condición de toxicómano del mismo, tampoco de que estaba en tratamiento con metadona y por ello y con la finalidad de que le fuera suministrada su medicación había acudido a la cita con su médico al CAID. Pero en absoluto que en el momento de ejecutar los hechos presentara estado de agitación, nerviosismo, algún tipo de anomalía que hiciera previsible su reacción ante una mera discrepancia con la frecuencia con la que debía acudir a recoger su dosis».

En consecuencia, confirma la sentencia de instancia en todos sus pronunciamientos.

\section{7.- SAP Les Illes Balears (Sección 1ª) 118/2016, de 25 de julio.}

Un hombre agredió gravemente a una enfermera en la Unidad de Psiquiatría de un hospital, teniendo que intervenir otros pacientes, así como compañeros de la afectada e incluso el personal de seguridad. Los hechos se desarrollaron así:

«Y así, durante la tarde del día 7 de julio de 2.012, continuó con su proceder insultante y amenazante, lo cual motivó que la enfermera de guardia Caridad le recriminara su proceder alterando la normal convivencia de todas las personas que se hallaban en dicha Unidad. Por ello, cuando serían sobre las 20'30 horas del meritado día, la citada enfermera mandó a su habitación al acusado, diciéndole que no le daría ningún cigarrillo, aceptando aquel dicha sanción o castigo, si bien cuando pasó junto a una puerta acristalada le dio un fuerte golpe con la finalidad de fracturarla, por lo que la enfermera al ver su proceder se fue detrás de él con la finalidad de avisar a los guardias de seguridad, siendo que el acusado giró sobre sí mismo y se dirigió hacia la Sra. Caridad y le propinó un puñetazo en la cara, que la hizo caer al suelo,

\footnotetext{
${ }^{493}$ El procedimiento estuvo paralizado por causas ajenas al acusado desde octubre de 2013 a septiembre de 2015.
} 
dejándola aturdida, para acto seguido seguir golpeándola, a base de patadas y puñetazos, por diversas partes del cuerpo, la arrastró hasta una zona donde había un sofá, en donde continúo con su acometimiento contra dicha profesional, no cesando en su agresión hasta que fue inmovilizado por otros pacientes y por el personal que allí se hallaba de servicio, siendo que asimismo hizo acto de presencia el servicio de seguridad en cuyo acto le pusieron los grilletes y posteriormente le inmovilizaron en una cama».

El acusado había sido ingresado por orden judicial y desde el primer momento mostró gran agresividad:

«...siendo que desde dicho ingreso no voluntario tuvo en todo momento un comportamiento altivo, insolente, insultante y amenazante hacia los demás internos y hacia los profesionales que trabajan en dicha Área».

A consecuencia de estos actos violentos, la enfermera sufrió lesiones de gravedad y que supusieron un amplio período de tiempo para su curación:

"Como consecuencia de los meritados hechos la Sra. Caridad sufrió lesiones consistentes en cefalea postraumática, cervicalgia, zumbidos en el oído derecho, hematoma en zona mandibular y maxilar superior derecho, fractura pieza dental número 46, contractura muscular

paravertebral cervical, dolor escapular derecho, dolor segunda metacarpófágica en mano derecha, toracalgia, hematomas en ambas rodilla, erosión reactivo, lesión leve del nervio mediano a nivel del codo, dolor neuropático en territorio nervio mediano, las cuales requirieron para su sanidad, además de una primera asistencia facultativa, tratamiento médico quirúrgico, de las cuales tardó en curar 572 días, siendo que dos de los días estuvo hospitalizada, y 570 días estuvo impedida para el desarrollo de sus quehaceres habituales, restándole como secuelas un trastorno neurótico por estrés postraumático, algia postraumática cervical sin compromiso articular, limitación de movilidad en ambos hombros, artrosis postraumática y codo derecho doloroso, gonalgía postraumática inespefica/agravación de artrosis previa, siendo todas dichas secuelas valoradas por el Médico Forense en 14 puntos».

El Juzgado de lo Penal no 1 de Mahón (01/09/2015) condenó al agresor como autor de un delito de atentado en concurso ideal con un delito de lesiones, a 1 año de prisión por cada uno de los ilícitos, además de indemnizar a la víctima en concepto de responsabilidad civil.

A pesar de que el recurso de apelación interpuesto por la representación legal del acusado solicitaba la revocación de la sentencia o subsidiariamente la disminución de la pena por 
aplicación o bien de la circunstancia eximente o bien de la atenuante de anomalía psíquica, la Sala, descarta la existencia de la circunstancia eximente:

«En conclusión, no se aprecia que existe base médica que dictamine que el recurrente, en el momento de los hechos tenía anuladas completamente sus facultades mentales. Ello descarta por completo la aplicación de la eximente solicitada».

Aunque aprecia la atenuante, mantiene los términos de la condena a prisión impuesta por la resolución del juzgador de instancia:

"...la cual revoca únicamente en el sentido de apreciar la circunstancia atenuante análoga de anomalía o alteración psíquica en D. Faustino manteniendo las penas impuestas».

También estima el recurso de apelación que el abogado de la CCAA interpuso en representación de la víctima, solicitando un aumento en la cantidad indemnizatoria, a lo que la Sala accede.

\section{8.- SAP Alicante (Sección 10ª) 303/2016, de 29 d julio.}

Una mujer lleva a cabo una agresión contra una médico del servicio de Urgencias del Hospital Clínico Universitario de dicha ciudad y un médico que intentó ayudar a su compañera. Ambos se encontraban en el mostrador cuando se produjeron los hechos y tuvieron que intervenir agentes de la autoridad. La violencia empleada por la agresora fue mayor en relación con la facultativa porque la acusaba de ser responsable de un aborto que había padecido. Los hechos se desarrollaron del modo siguiente:

«La acusada Fermina, (...), se dirigió al mostrador donde se encontraban los médicos Nicolasa y Gregorio y dirigiéndose a éste último, gritando y de malas maneras, le pidió el informe de urgencias, contestándole Gregorio que eso lo tenía que pedir bajo en atención al paciente y que ellos sólo le podían dar el parte de alta. La acusada se dirigió entonces a Nicolasa y al ver que ésta no le contestaba por las malas formas que estaba empleando, y enfadada porque dicha médico era la que le había atendido en urgencias y la que según ella tenía la culpa de que hubiera abortado, se abalanzó sobre la misma, agarrándola del pelo y tirándola al suelo, propinándole multitud de patadas, manotazos y puñetazos por todo el cuerpo, teniendo que intervenir su compañero Gregorio para separarla. Gregorio, en ese intento de separar a la acusada de Nicolasa, recibió también algún golpe y se cayó al suelo. Finalmente, con ayuda de un familiar de un paciente pudieron poner fin a la agresión, aprovechando Nicolasa para resguardarse en un cuarto del hospital hasta la llegada de los agentes».

Como consecuencia de estos actos violentos, las dos víctimas resultaron con lesiones de distinta consideración. 
El Juzgado de lo Penal $n^{\circ} 1$ de Alicante (03/02/2016) condena a la agresora como autora de delito de atentado a 20 meses de prisión, considerándola responsable de 2 delitos leves de lesiones por los que la impone sendas multas: 2 meses a razón de 6 euros diarios (en el caso de la médico) y 1 mes con la misma cuantía por día (en el caso del facultativo), además de indemnizar a ambos en concepto de responsabilidad civil. En relación con todas las condenas, el juzgador "a quo" cita expresamente que se está ciñendo a lo que establece la reforma del ordenamiento penal que entró en vigor en julio de 2015 (operada por la LO 1/2015 de 30 de marzo).

La parte condenada interpone recurso de apelación, alegando, entre otros argumentos, que consideraba excesiva la pena de prisión impuesta por el delito de atentado. La AP desestima esta alegación:

«Una vez más el recurso pretende hacer estado de la cuestión, y pese a que motivadamente se ha rechazado que el aborto sufrido por la paciente dias antes pudiera tener influencia alguna en su imputabilidad, el recurso insiste en que se valore para la imposición, no de la pena en su mitad inferior, sino en su mínima expresión legal, pese a la brutalidad del ataque. El motivo tampoco puede ser estimado. El juez ha razonado el porqué de la pena impuesta y está perfectamente ajustada a la gravedad del hecho y las circunstancias de la autora».

La Sala insiste en la violencia de los hechos que se imputan a la acusada:

«No es cierto que solo valore la condición de la facultativa, como persona indefensa en su puesto de trabajo, sino que además pondera de manera expresa la brutalidad y gravedad objetiva de la conducta que se refleja no solo del cúmulo de golpes y zonas afectadas del cuerpo de la médico, sino en la existencia de dos facultativos agredidos».

La AP confirma la sentencia de instancia en cuanto hace relación con el delito de atentado pero procede a revocar parcialmente la resolución recurrida, en aplicación de las disposiciones de la LO 1/2015:

«...la interpretación efectuada por el Tribunal Supremo respecto de la Disposición Adicional 4 de la reforma operada por la LO 1/2015 obliga a dejar sin efecto los pronunciamientos penales por los dos delitos leves (antes faltas) de lesiones, ahora sometidos al régimen de previa denuncia». 
En consecuencia, absuelve a la acusada de las consecuencias penales de los delitos leves de lesiones por los que también había sido condenada, quedando a salvo las indemnizaciones en concepto de responsabilidad civil:

«...las faltas antes públicas y ahora delitos leves precisados de denuncia del agraviado, por lo que suprime toda posibilidad de conllevar en los procesos en tramitación condena penal, dejando reducido el objeto del proceso al resarcimiento civil del perjudicado si éste no ha renunciado expresamente al mismo, pues de producirse la renuncia el procedimiento se debe archivar».

\section{9.- SAP Zaragoza (Sección $3^{a}$ ) 423/2016, de 9 de septiembre.}

En marzo de 2016 un paciente, incapacitado civil total y bajo tutela, que estaba ingresado en una residencia pública, agredió de forma verbal a una enfermera que desempeñaba allí su trabajo:

«Ha quedado probado y asi se declara que agredió verbalmente a una enfermera. Domingo lleva ingresado en la Residencia Romareda de Zaragoza desde hace unos dos años, habiendo sido declarado en estado civil de incapacitación total, tanto en el orden personal (gobierno de su persona), como en la espera patrimonial (administración y disposición de sus bienes inter-vivos y mortis causa), estando sometido al régimen de tutela y designando tutor a la Comisión de Tutela y Defensa de Adultos de la DGA.

En este contexto, sobre las 20:00 giras del día 16/03/2016 cuando Ramona, enfermera de dicha Residencia se encontraba trabajando, el denunciado, en actitud agresiva, se dirigió a la misma profiriendo expresiones como "esto lo vas a pagar, no vales una mierda, inútil, asquerosa". Como había firmado una queja en la Dirección de dicho centro dando cuenta del comportamiento de dicho paciente.

Finalmente y a raíz de dicha queja al denunciado lo han trasladado a otra Residencia».

El Juzgado $n^{\circ} 10$ de Zaragoza absuelve al denunciado del delito leve de amenazas por el que venía siendo imputado.

La enfermera perjudicada interpone recurso de apelación alegando fundamentalmente que las injurias debían haberse tipificado como delito, dada su condición de autoridad según una Ley de la CCAA de Aragón y en cuanto a las amenazas, que no fueron de poca entidad sino graves:

«...se alegan como motivos, error en la calificación jurídica de los hechos probados, no siendo ajustada a derecho la sentencia, ya que dichos hechos son constitutivos cuando menos de un delito de injurias tipificado en el artículo $208 p^{\circ} 2$ del Código penal, ya que las mismas se realizan 
dentro del centro laboral, la residencia de mayores "La Romareda", que pertenece a la Diputación General de Aragón, y donde la victima presta sus servicios como enfermera, teniendo la calificación de autoridad pública conforme a lo dispuesto en el artículo 6 de la ley 9/2013 de 28 de noviembre de autoridad de profesionales del sistema sanitario y servicios sociales públicos de Aragón, y en cuanto a la calificación de las amenazas, son graves (...)».

La Sala desestima íntegramente el recurso y confirma la sentencia de instancia en todos sus pronunciamientos. Respecto al motivo de alegación referido a la condición de autoridad de la recurrente, se manifiesta la AP del modo siguiente:

"y aunque los sanitarios sean autoridad por la ley antes mencionada por el recurrente, esto se refiere al delito de atentado, ya que el artículo 550 del código penal, si los incluye, pero en forma alguna nos encontramos con este supuesto".

\section{0.- Juzgado de lo Penal $n^{0} 10$ de Valencia (Sentencia 243/2016), de 23 de mayo.}

Una niña de 11 años muere en diciembre de 2010, a causa de un shock séptico y peritonitis aguda. Los padres responsabilizan del fallecimiento al médico que la había tratado en el centro de atención primaria de Ayora donde éste trabajaba:

«...se le imputaba la posible comisión de un delito de homicidio por imprudencia profesional en relación con la asistencia médica prestada a la niña».

En el mes de noviembre de 2011, padres y médico coinciden por primera vez desde el fallecimiento de la niña en el Juzgado de Primera Instancia e Instrucción n ${ }^{\circ} 4$ de Requena, donde habían ido todos a prestar declaración en el seno de las diligencias previas abiertas ${ }^{494}$ en dicha sede judicial por causa de la denuncia interpuesta por los padres contra el citado facultativo a causa de esa imputación.

Las declaraciones de las dos partes estaban previstas para horas distintas, pero debido a la coincidencia con otros señalamientos del juzgado que tenían carácter preferente, no se llevaron a efecto en el horario previsto por lo que padres y médico coincidieron esperando sus respectivos turnos para declarar.

494 Diligencias previas 1.351/2010. 
Los progenitores, una vez practicada su declaración, esperaron a que saliera el facultativo de efectuar la suya ${ }^{495}$.

"Cuando éste finalizó su declaración y como quiera que el Letrado que asistía en aquel procedimiento al acusado, que había estado presente en la declaración del (...), le dijera que habia dicho toda una sarta de mentiras, siendo aproximadamente las 14:45 horas el acusado, preso de los nervios y en evidente estado de indignación se dirigió hacia el (...), que en esos momentos se disponía a abandonar la sede judicial y, tras abordarlo por detrás y tirarle al suelo un iPad y unos papeles que llevaba, le propinó un empujón que le hizo caer al suelo. Acto seguido, y cuando el (...) trataba de reincorporarse, el acusado visiblemente nervioso y fuera de sí le espetó "esto es el principio de tu fin", dándose media vuelta y abandonando a continuación las dependencias judiciales».

A consecuencia de esa agresión, el facultativo sufrió lesiones de diversa entidad:

«...contusiones en ambos codos y en la cabeza; lesiones para cuya curación únicamente precisó de una primera asistencia facultativa, sin tratamiento médico o quirúrgico posterior, alcanzando la sanidad a los 33 días, ninguno de ellos impeditivo para sus ocupaciones habituales; habiéndole quedado como secuela una pequeña formación nodular a nivel de la región olecraniana en el codo izquierdo que no le provoca molestias ni limitación muscular».

El médico estuvo recibiendo tratamiento psicológico desde el año 2011, a raíz de la agresión ${ }^{496}$. Incluso solicitó y obtuvo el traslado a otro centro en 2012 porque temía sufrir más agresiones:

«Cuando se reincorporó a su actividad laboral ${ }^{497}$ solicitó a la Agencia Valenciana de Salud que se tomaran las medidas oportunas para evitar el riesgo de agresión y garantizar la seguridad en su puesto de trabajo, siendo reasignado a otro destino».

El padre, a su vez, también estaba siendo tratado a causa de los luctuosos sucesos, en la época en que se produjo la agresión:

\footnotetext{
495 Los paréntesis corresponden a espacios en blanco que figuran en la sentencia

496 "...estuvo acudiendo a la unidad de neuropsiquiatría del centro de especialidades de Monteolivete recibiendo tratamiento por un cuadro clínico compatible con diagnóstico de trastorno adaptativo mixto con ansiedad y ánimo depresivo desde el 27 de diciembre de 2011 hasta febrero de 2012, continuando posteriormente en tratamiento psiquiátrico (...)».

497 Había estado de baja laboral por causa de una enfermedad común.
} 
«A raiz del desgraciado fallecimiento de su hija de 11 años de edad y de las circunstancias que rodearon el mismo el acusado fue diagnosticado de un trastorno depresivo mayor, con estrés postraumático, siendo tratado en la época en que sucedieron los hechos en consultas externas de psiquiatría del Hospital General de Almansa, tomando medicación a tales efectos, y acudiendo asimismo a consulta de psicología periódicamente para abordar su trauma y proceso de duelo».

El Juzgado de lo Penal $\mathrm{n}^{\circ} 10$ de Valencia tipificó como delito de atentado la conducta violenta del agresor, considerándole autor también de un delito leve de lesiones.

La condena por delito de atentado fue de 1 mes y 15 días, que se sustituye por multa de 3 meses a razón de 10 euros diarios ${ }^{498}$. El juzgador «a quo» tuvo en cuenta la circunstancia atenuante de dilaciones indebidas y el estado emocional del acusado ${ }^{499}$.

«En dicho contexto, el encuentro del acusado con él en los Juzgados de Requena el día de los hechos supuso un estímulo muy poderoso para el mismo que comprometió seriamente sus capacidades intelectivas y volitivas sin llegar a anularlas».

Por el delito leve de lesiones se le impone multa de 10 días a razón de 10 euros diarios, así como la obligación de indemnizar a la víctima en concepto de responsabilidad civil.

\section{1.- SAP Madrid (Sección 16ª ) 125/2017, de 24/02.}

En junio de 2012, un hombre acude con su hija a una clínica, a que dieran a ésta una baja laboral porque había sido dada de alta el día anterior. El médico examina a la solicitante y comprueba sus circunstancias físicas, después de lo cual no accede a concederle la baja que solicitaba. Entonces, agreden al facultativo y, en el caso del padre, la violencia es física y verbal.

«Apreciando en conciencia la prueba practicada se declara probado que sobre las 9,15 horas del día 26/06/2012, Beatriz y su padre Conrado, antes circunstanciados, acudieron a la Clínica de FREMAP, Mutua de accidentes de Trabajo y Enfermedades Profesionales de la Seguridad Social, sita en la calle Ronda de Valencia núm. 8 de Madrid, a fin de solicitar Beatriz la baja laboral, al haber sido de alta el día anterior, siendo asistidos en su consulta por el facultativo

\footnotetext{
${ }^{498}$ El ordenamiento penal permite esta posibilidad cuando las condenas a prisión sean inferiores a 3 meses.

499 "...por la concurrencia de las circunstancias atenuantes de estado pasional como muy cualificada y de dilaciones indebidas. se considera oportuna la rebaja de la pena en dos grados, siendo procedente conforme a lo prevenido en el art. 70. 1-2" del Código Penal la imposición de la pena mínima prevista de prisión de 1 mes y 15 días".
} 
Felipe, médico asistencial de FREMAP que, tras examinar a Beatriz, a presencia de Conrado, se negó a ello al no considerarlo adecuado a las circunstancias físicas de Beatriz.

Beatriz, con la finalidad de faltar el respeto y la consideración debida, emitió contra Felipe, expresiones tales como "sinvergüenza, hijo de puta, mal nacido, ojalá tengas un cáncer y te mueras de dolor, hijo de puta, llegando a golpear con la muleta que llevaba la mesa de esa consulta médica. Al indicar el médico Felipe, que Beatriz Y Conrado abandonasen su consulta, Conrado con la finalidad de vulnerar el buen funcionamiento de los servicios y funciones públicas, exhibió a Felipe un objeto de ignoradas características que llevaba entre sus ropas diciéndole "estas muerto, voy a ser tu sombra dia y noche hasta que te mate", cogiéndose fuertemente a continuación de su bata, y lanzándole contra una vitrina que habia en el interior de la consulta consiguiendo zafarse Felipe de Conrado y saliendo seguidamente Beatriz Y Conrado de esa consulta».

A consecuencia de esta agresión llevada a cabo por el padre, la víctima sufrió diversas lesiones, por lo que reclama ${ }^{500}$.

El Juzgado de lo Penal n 15 de Madrid (04/11/2016) condena al acusado, como autor de un delito de atentado, a 6 meses de prisión, después de aplicar la circunstancia atenuante de dilaciones indebidas $^{501}$, con la obligación de indemnizar al perjudicado en concepto de responsabilidad civil. En aplicación de las disposiciones de la LO 1/2015, absuelve a los dos de las faltas que también se les imputaban: Respecto a la hija, falta contra el orden público y falta de injurias. En cuanto al padre: falta de lesiones y falta de amenazas.

La AP desestima el recurso de apelación que había sido interpuesto contra esta sentencia y la confirma íntegramente.

\footnotetext{
${ }^{500}$ "A consecuencia de estos hechos, Felipe sufrió contusiones en antebrazo izquierdo, y en región cervical, de las que sanó, tras una única asistencia facultativa, sanando a los diez días, cinco de ellos impeditivos, y sin secuelas. Felipe reclama por estos hechos"

501 «Esta causa ha estado paralizada, por causa no atribuible a Beatriz y a Conrado, entre los días 26/03/20145 al $17 / 06 / 2016 »$.
} 


\section{RESOLUCIONES DE LOS TRIBUNALES DE LO CONTENCIOSO-ADMINISTRATIVO Y DEL ORDEN SOCIAL}

\section{1.- Consejo Consultivo de Castilla-La Mancha. Dictamen $\mathbf{n}^{\circ}$. 151/2003, de 11 de diciembre.}

Una enfermera que había sufrido una agresión por parte de un paciente en un centro hospitalario público, presenta escrito en la Delegación Provincial de la Consejería de Sanidad de Guadalajara, manifestando su intención de reclamar a la Administración por los daños y perjuicios ocasionados por las lesiones causadas en aquella agresión:

"Con fecha 6 de marzo de 2002, $D^{a} X$ presentó en la Delegación Provincial de la Consejería de Sanidad de Guadalajara un escrito en el que expone que el pasado 6 de marzo de 2001 fue agredida en el Hospital $X$, centro donde presta sus servicios como Diplomada Universitaria en Enfermería, y durante su horario de trabajo por $X$, de 13 años, que se encontraba recibiendo asistencia médica. Prosigue con la descripción los hechos acaecidos señalando que "se cruzó con esta persona en un pasillo de la primera planta [...] y sin mediar palabra se abalanzó sobre ella cogiéndola del pelo, arrancándole mechones, zarandeándola brusca y repetidamente y dándole fuertes golpes en todas las partes del cuerpo, principalmente en el pecho [...]"; añade que tales lesiones determinaron su baja médica y que desde entonces viene recibiendo asistencia médica y psiquiátrica. Concluye la interesada manifestando su voluntad de reclamar los daños y perjuicios que le correspondan por los hechos expuestos y al respecto señala que en tiempo y forma concretará su petición una vez que conozca el alcance exacto de los daños y perjuicios que sufre, resultando preciso para ello conocer la resolución que definitivamente dicte el Instituto Nacional de la Seguridad Social en materia de invalidez»

En la fase de instrucción del expediente, se van incorporando diversos informes:

La Inspección Médica de Servicios Sanitarios, que reconoce que efectivamente hubo agresión ${ }^{502}$ aunque alega lo siguiente:

«2.- El que este suceso se considere accidente de trabajo no quiere decir más que el accidente ocurrió en el tiempo en el tiempo y lugar del trabajo».

Posteriormente, el Secretario General del Servicio de Salud de Castilla-La Mancha (10 de septiembre de 2003), formula propuesta de resolución en la que desestimaba la reclamación sobre responsabilidad patrimonial de la Administración, aduciendo:

\footnotetext{
${ }^{502}$ «1.-Si bien la reclamante fue atacada en el Hospital, el niño agresor no se encontraba ingresado, es decir, bajo la responsabilidad y vigilancia hospitalaria, sino que acudía a consultas externas de Otorrinolaringología acompañado de su madre».
} 
«...que la reclamante no ha aportado prueba o indicio alguno que permita mantener que las lesiones que sufre sean consecuencia directa e inexcusable de la agresión producida el 6 de marzo de 2001, y que no resulta posible argumentar la exclusividad de la causa del daño alegado puesto que la reclamante padecía con anterioridad una serie de patologías que le producian el mismo daño por el que reclama».

Por su parte, el Gabinete Jurídico entiende que las consideraciones que se incluyen en esa propuesta de resolución no bastan para considerar la improcedencia de la indemnización que se reclama:

«...al menos en relación con una parte de los daños sufridos por la reclamante, concurren los requisitos originadores de la responsabilidad patrimonial de la Administración» ${ }^{503}$.

En base a todo eso, comienza a argumentar el Consejo Consultivo. Entiende que, en realidad, el argumento final de la reclamante es la responsabilidad objetiva ${ }^{504}$ de la Administración por considerar que el daño que ha sufrido tiene su origen y es consecuencia del trabajo porque lo ha ocasionado un cliente de la empresa, es decir, un paciente del hospital. En este aspecto el Consejo considera lo siguiente:

"Como ya ha puesto de manifiesto este Consejo en anteriores dictámenes, el hecho de que la responsabilidad patrimonial de la Administración haya sido calificada de objetiva no quiere decir que este instituto jurídico se transforme en una obligación universal de resarcimiento a cargo de la Administración pública de todo perjuicio sufrido por los particulares con ocasión de la utilización de un servicio público».

El Consejo entiende que efectivamente las lesiones fueron producidas por la agresión del menor. Una vez admitido esto, estima que «...la cuestión principal que se plantea es la de si concurre relación causal entre el funcionamiento anormal del servicio público sanitario y la citada agresión».

\footnotetext{
${ }^{503}$ Se remite a la doctrina del deber del Centro de proteger a su personal frente a agresiones de los enfermos -citando la Sentencia de la Audiencia Provincial de Vigo de 1 de julio de 2002- "...que viene reconociendo el deber legal del hospital de custodia de su personal para evitar agresiones de los enfermos, con mayor motivo si se trata de enfermos psiquiátricos, declarando la obligación de los centros de adoptar las medidas oportunas en este sentido y su responsabilidad jurídica en caso de que la agresión llegue a producirse».

504 «A tal responsabilidad objetiva se alude igualmente en la propuesta de resolución y en el informe elaborado por el letrado del Gabinete Jurídico».
} 
Considera que no se ha hecho constar que el menor estuviera diagnosticado como "agresivo", aunque la reclamante así lo argumenta ${ }^{505}$. Además, como parece desprenderse del expediente, el menor había acudido al Hospital con su madre no por enfermedad mental sino por una dolencia que correspondía atender al servicio de Ororrinolaringología. Por tanto, entiende el Consejo que el Hospital no estaba obligado a adoptar otras medidas de vigilancia que las constituyen el estándar de asistencia médica ordinaria con respecto a ese paciente.

«En definitiva, entiende este Consejo que los daños sufridos por la interesada son consecuencia única y exclusivamente de la acción del menor, que deambuló sólo por el hospital debido a la falta de una adecuada atención, por parte de la madre, de sus deberes de guarda y tutela del mismo (...)-, sin que se aprecie la concurrencia de elemento alguno de anormalidad en el servicio hospitalario que fuera suficiente para establecer un nexo de causalidad entre la omisión administrativa y la agresión sufrida por la reclamante».

Frente a la opinión del letrado del Gabinete Jurídico en cuanto a que, al menos parte de los daños sufridos por la enfermera le permitan requerir la responsabilidad patrimonial de la Administración ${ }^{506}$, el Consejo entiende lo contrario y que, además el supuesto es distinto del que se sustanció en la STS que el letrado invocaba:

«En el presente caso, ni se trata de un paciente internado, ni es exigible previsión de seguridad alguna para evitar que los usuarios visitantes agredan a otros usuarios o a empleados del servicio».

En consecuencia, dicta resolución en la que desestima la reclamación de responsabilidad patrimonial a la Administración que la enfermera formulaba, por causa de los daños y perjuicios dimanantes de la agresión en su centro de trabajo.

\section{2.- Tribunal Superior de Justicia de Castilla-La Mancha (Sala de lo Social) Sentencia} 1532/2007, de 18 de octubre de 2007.

Una auxiliar sanitaria que presta sus servicios como personal laboral en un hospital público es agredida por un enfermo internado en la Unidad de Salud Mental de dicho centro hospitalario, que se alteró durante la hora de la merienda y atacó al personal sanitario lanzándoles objetos de

\footnotetext{
505 «Por el contrario de los informes incorporados en la fase instructora lo único que se constata es que el agresor es un paciente con retraso mental y autismo infantil (folios 16 y 35) y que se encuentra en tratamiento psiquiátrico (folio 8), $\sin$ que en modo alguno se aluda a su peligrosidad o agresividad y $\sin$ que tales circunstancias quepa necesariamente derivarlas de su enfermedad mental».

506 «...basa tal reconocimiento en el deber legal de custodia de los centros sobre su personal frente a las agresiones de los pacientes, citando a estos efectos la Sentencia de la Audiencia Provincial de Vigo de 1 de julio de2002».
} 
la vajilla. A consecuencia del forcejeo que se produjo la auxiliar cayó al suelo fracturándose una pierna.

La trabajadora interpone demanda ante el Juzgado de lo Social $n^{\circ} 1$ de Talavera, que analiza el caso ampliamente.

Cuando ocurrió la agresión, el Jefe de Servicio de Salud Mental del hospital emitió informe de servicio (27 de septiembre de 2005), en el que se señalaba lo siguiente:

«En la fecha del 14 de agosto de 2003, este Jefe de Servicio no ocupaba dicha plaza, por lo que desconozco si el entonces jefe de servicio comunicó, y a quien comunicó, los acontecimientos de los que se pide información.

La Planta de Psiquiatría (Unidad de Hospitalización Breve), contaba con las medidas preventivas y recursos para reducir a pacientes que se pudieran agitar, aunque en ocasiones estos son insuficientes dependiendo de variables como la intensidad y caracteristicas de la agitación, momento en que se produzca, lugar en que tendrá lugar, actividades que en ese momento se estén realizando con los demás pacientes, etc.

Los trabajadores que realizan su tarea en la Unidad, se les supone unos conocimientos al ser contratados para plazas de Auxiliar de Clínica. Además deben tener conocimiento de la situación de los pacientes a través de las reuniones diarias del equipo asistencia y de las enfermeras responsables.

De los datos obtenidos de la historia de la paciente se deduce que la misma se agitó de una manera inesperada en el transcurso de la merienda, con lanzamiento de elemento de la vajilla y agresión al personal que se enconaba en ese momento realizando la mencionada labor. Previamente la paciente se ha mostrado tranquila hablando con los Auxiliares»

En el informe emitido por la Inspección de Trabajo, con fecha 25 de octubre del mismo año, se decía:

«En relación con su oficio de fecha 19-10-2005, referido a la demanda de reclamación de cantidad por indemnización de daños y perjuicios derivada de accidente de trabajo, se significa que no existe informe de investigación de los hechos referidos al mencionado accidente. Examinados los archivos de la Inspección Provincial de Trabajo y Seguridad Social de Toledo se comprueba la existencia del parte de accidente de trabajo, correspondiente a las lesiones sufridas por la trabajadora Ana María (...). La lesión fue calificada como leve». 
Una compañera de trabajo de la víctima, testigo presencial de los hechos, hizo la siguiente declaración sobre como habían tenido lugar los acontecimientos:

«...la hora del accidente fue las 18'00 horas de la tarde, hora de la merienda, en el comedor con 20 enfermos psiquiátricos, que la vajilla usada ese día era vasos de vidrio, platos de loza y cubertería metálica y que al descontrolarse una de las enfermas psiquiátricas agarró por el pelo a su compañera, la agredió fisicamente, la tiró al suelo y utilizó los elementos de la vajilla contra las restantes auxiliares».

Por su parte, la Mutua Solimat, con quien el hospital tenía cubierto el accidente de trabajo, informa sobre los hechos alegando que la trabajadora a consecuencia de la lesión en la pierna, permaneció con incapacidad temporal derivada de ese accidente de trabajo desde el 24 de agosto de 2003 hasta el 24 de febrero de 2004, causando alta en esa fecha porque la mejoría le permitía realizar el trabajo habitual. Sin embargo, sufrió varias recaídas en su proceso curativo, encadenando una serie de bajas laborales hasta la fecha en que recibió el alta definitiva, en febrero de $2004^{507}$.

Al final del proceso curativo no se le reconocieron ni lesiones permanentes invalidantes, ni grado de invalidez por la Seguridad Social, ni recibió mejora voluntaria por invalidez derivada del Convenio Colectivo de aplicación. Pero su situación familiar había requerido la contratación de una empleada de hogar para que le ayudase en las tareas domésticas ${ }^{508}$.

La Consejería de Sanidad de la JCCLM (4 de noviembre de 2005) informó sobre el Plan de Prevención de Riesgos Laborales, existente en el año 2003. Respecto al Personal Auxiliar del Servicio de Salud Mental el informe precisó lo siguiente:

«Riesgos fisicos de diversa índole por acción directa o circunstancias peligrosas producidas por enfermos mentales». De igual forma que la agrupación n0 2, con el agravamiento que implica el contacto permanente con los internados, tienen sobre sí los riesgos fisicos y tensiones psíquicas que manifiestan. Añadiremos la consideración de que en este colectivo 22 de sus 24 miembros es personal femenino, con lo que en iguales condiciones de riesgo su respuesta puede no hallarse a igual nivel que en el caso del personal masculino. Para el aminoramiento de las situaciones de riesgo se recomienda:

\footnotetext{
507 «La Consejería de Sanidad de la JCCLM, abonó a la demandante en concepto de prestaciones de IT, por el periodo 24-8-03 hasta el 24-2-04 la cantidad total de 7963,10 euros, y el SESCAM abonó por el segundo periodo de IT desde 2-2-05 hasta 24-2-05, la cantidad de 1080,09 euros, lo que hace un total de prestaciones de IT percibido por la actora de 9042,19 euros».

508 "La demandante que es casada y tiene tres niños y su marido trabaja en el campo, se vio obligada a contratar una empleada de hogar $\mathrm{D}$ a Victoria, desde el 25-8-03 al 24-2-04 y desde el 2-2-05 a 24-2-05, excepto sábados, domingos y festivos a tiempo parcial por tres horas diarias para que le auxiliase las tareas domésticas, percibiendo un salario por hora de 7 euros, que por 143 días por tres horas diarias da la cantidad total de 3087 euros, que la demandante abonó a dicha empleada».
} 
a) requisar a los enfermos objetos punzantes, armas blancas, material de fumador, etc.

b) enclavamiento del mobiliario y eliminación de objetos no imprescindibles al alcance de los enfermos.

e) medidas precautorias en evitación de situaciones de aislamiento e indefensión de los operarios a lo largo de toda la jornada de trabajo».

Con base en dicho informe, el 20 de julio de 1988 el Director Provincial de Trabajo y Seguridad Social dicta una Resolución por la que acuerda calificar esos puestos de trabajo como peligrosos.

La Dirección del Centro y la Administración atendiendo a todos estos informes y resoluciones, adoptan diversas medidas al respecto, entre las que destacan:

«a. - La requisa de objetos peligrosos, recogida en el manual de normas de funcionamiento del servicio.

e. - la eliminación de cristales normales en las zonas de riesgo (especialmente unidad de internamiento y urgencias), siendo sustituidos por cristales de seguridad o láminas de plástico, la contratación de vigilantes de seguridad, cuyo número ha aumentado paulatinamente.

g. - Las normas de seguridad han sido objeto continuo de tratamiento tanto en las sesiones de formación en sus diferentes formas:

1.- Cursos formales, reuniones de servicio y contactos personales. En documento adjunto se remite la actividad de formación realizada durante los años 2003 y 2004, según la memoria de actividades del Servicio de Salud Mental (...)».

Precisamente la víctima había sido alumna en el año de 2003 del curso «Abordaje del enfermo psiquiátrico».

El SESCAM aprueba el 5 de diciembre de 2003 (DOCAM 19/12/2013) el Plan General de Prevención de Riesgos Laborales de Castilla-La Mancha.

El Hospital Ntra. Sra. Del Prado en fecha 2 de noviembre de 2005, emitió nota aclaratoria sobre el Plan de Prevención del Servicio de Salud de Castilla la Mancha, en el que señala, entre otras cosas, las medidas que se han implementado atendiendo a lo que se dispone en ese Plan, a partir de octubre de 2004. Destacamos algunas de ellas:

«1.- implementación de diferentes acciones de formación y ayuda al desarrollo de determinadas habilidades de comunicación y resolución de conflictos,

3.- desarrollo de una acción formativa bajo la denominación "Actuación ante pacientes violentos y agresivos",

4.- aislamiento de la zona de recepción de urgencias de salud mental, como medirla preventiva, 
5.- mantenimiento de reunión con las fuerzas de seguridad para que aumenten la frecuencia en las visitas a las instalaciones de la Unidad de Salud Mental,

6.- aumento de la dotación del personal de seguridad en las instalaciones de Salud Mental del I.C.S., contratado por el Hospital Nuestra Señora del Prado,

7.- remodelación de las instalaciones de la Unidad de Salud Mental, como medida para mejorar la seguridad de sus trabajadores».

La demandante interpuso en fecha 22 de febrero de 2005 la preceptiva reclamación administrativa previa frente a los organismos demandados. El SESCAM dictó resolución en fecha 11 de julio del mismo año desestimando la reclamación de la actora previa a la vía laboral y reconducirla a una acción de responsabilidad patrimonial ${ }^{509}$ :

El juzgado de los Social dicta sentencia (10 de noviembre de 2005), en los siguientes términos:

«FALLO: 1.- Que debo desestimar y desestimo la excepción de falta de jurisdicción por razón de la materia alegada por el SESCAM por las razones expuestas en el Fundamento de Derecho $2^{\circ}$ de la presente resolución.

2.- Que debo desestimar y desestimo la excepción de falta de legitimación pasiva alegada por el SESCAM por las razones expuestas en el Fundamento de Derecho $3^{\circ}$ de la presente resolución.

3.- Que estimando en parte la demanda deducida por $D^{a}$. Ana María contra la CONSEJERIA DE SANIDAD DE LA JCCM y el SESCAM en reclamación sobre DAÑOS Y PERJUICIOS CANTIDAD debo condenar y condeno solidariamente a los Organismos demandados a que abonen a la actora la cantidad total de 11.163'30 euros sin intereses legales».

Contra esa sentencia La Consejería de Sanidad y Servicio de Salud de Castilla-La Mancha interpone recurso de Suplicación ante el Tribunal Superior de Justicia (Sala de lo Social) y también la demandante.

El motivo del recurso interpuesto por la Administración era solicitar la nulidad de la sentencia de instancia por infracción del art. 97.2 de la LPL con vulneración del derecho a la tutela judicial efectiva por deficiente motivación de la sentencia.

\footnotetext{
509 "ACUERDA

1.- Denegar la iniciación del procedimiento de reclamación previa a la vía laboral presentado por Da Ana María, por considerar que se trata de un supuesto de responsabilidad patrimonial de la Administración al cual se reconduce en aras a los principios de economía procedimental y de eficacia.

2.- Continuar con la tramitación del procedimiento de responsabilidad patrimonial iniciado por la interesada».
} 
El Tribunal considera probado el relato fáctico, en el sentido siguiente:

«Tanto del relato fáctico de la sentencia como del contenido de los fundamentos jurídicos segundo y cuarto, en los que se recogen declaraciones con valor de hecho probado, se desprende que la trabajadora, a consecuencia de la agresión antes mencionada, sufrió fractura de tibia y peroné derechos, permaneciendo de baja médica un total de 208 días.

Asimismo, se declara probado que el centro de trabajo en cuestión, Unidad de Salud Mental del Hospital Ntra. Señora del Prado, carecía de un plan general o especial de prevención para los auxiliares sanitarios del mismo; que la trabajadora recibió formación de modo insuficiente durante el año 2003 para el abordaje de enfermos psiquiátricos; que el día de la agresión, los enfermos disponían de elementos normales de vajilla (platos de loza, vasos de vidrio y cubertería metálica) que fueron lanzadas y utilizados por la enferma agresora como elementos intimidatorios frente al personal de la Unidad de Salud Mental.

En el apartado relativo a la fundamentación jurídico, se analiza la legislación de prevención de riesgos y doctrina jurisprudencial interpretativa de la obligación empresarial de resarcimiento del daño causado al trabajador por negligencia del empresario en el cumplimiento de su deber de protección».

De todo lo anterior, concluye que la sentencia impugnada está fundamentada adecuadamente, por lo que desestima el recurso interpuesto por la Consejería.

En cuanto al interpuesto por la trabajadora, reclamando se le reconozcan los intereses legales que en la sentencia de instancia no se le han reconocido y un incremento de la indemnización, la Sala se fundamenta en diversa normativa así como en jurisprudencia del TC y del $\mathrm{TS}^{510}$ para estimar

\footnotetext{
510 «...de conformidad con lo prevenido en el art. 39.2 de la Ley Orgánica 9/1982, de 10 de agosto, del Estatuto de Autonomía de Castilla-La Mancha; según tiene establecido las sentencias del Tribunal Supremo de 5 y 6 de noviembre de 1996 , al interpretar el art. 45 del Real Decreto Legislativo 1091/1988, de 23 de septiembre, que aprueba el texto refundido de la Ley General Presupuestaria, de similar contenido al art. 24 de la vigente Ley 47/2003, de 24 de noviembre, precepto que ha de ser tenido en cuenta por remisión del apartado 3 del art. 576 de la LEC .

Conforme a la doctrina del Tribunal Constitucional (Sentencias 69/1996, de 18 de abril y 113/1996, de 25 de junio) y a la doctrina jurisprudencial (Sentencias del Tribunal Supremo de 4 de noviembre de 1997, 2 de julio y 13 de diciembre de 2002), los intereses se devengan a partir de los tres meses desde la sentencia de instancia que contiene el pronunciamiento condenatorio generador de los intereses; puesto que ha de distinguirse entre firmeza y ejecutoriedad de la resolución judicial.

Por otra parte, la doctrina jurisprudencial (Sentencias del Tribunal Supremo de 1 y 10 de febrero de 1999 y 19 de marzo de 2007) señala que la obligación de abonar los intereses de demora procesal nace "ope legis", sin necesidad de petición de parte ni de expresa condena para su exigibilidad, de suerte que tal obligación se integra por imperativo legal en el fallo, de ahí que sea susceptible de recurso de suplicación toda resolución judicial dictada en ejecución de sentencia que desconozca tal extremo».
} 
el primer motivo de recurso ${ }^{511}$, desestimando en cambio la solicitud de aumento en la cuantía indemnizatoria $^{512}$, dictando la siguiente sentencia:

"Que, estimando en parte el recurso de suplicación interpuesto por la representación legal de Doña Ana María; y desestimando el formulado por la representación legal de la Consejería de Sanidad de la Junta de Comunidades de Castilla-La Mancha y SESCAM; contra la Sentencia dictada por el Juzgado de lo Social $n^{\circ} 1$ de Talavera, de fecha 10 de noviembre de 2005 , en los autos número 414/05, sobre Reclamación de Cantidad, siendo recurridos CONSEJERÍA DE SANIDAD, SERVICIO DE SALUD DE CASTILLA-LA MANCHA y Ana María; debemos revocar y revocamos en parte la expresada resolución para establecer que al importe de la condena impuesta en la resolución le será de aplicación las previsiones del art. 576.3 de la LEC en relación con el art. 24 de la Ley 47/2003, de 24 de noviembre.

Se condena en costas a la Junta de Comunidades de Castilla-La Mancha y a que abone al Letrado impugnante de su recurso el importe de sus honorarios, que prudencialmente se establecen en 300 euros».

\section{3.- Juzgado de lo Contencioso-Administrativo $n^{0} 3$ de Toledo, Sentencia $n^{0} 31 / 2012$, de 8 de} febrero.

Un paciente de 80 años de edad agrede a una enfermera que le estaba atendiendo, en la UME de Albacete.

La víctima de la agresión, funcionaria de la Diputación Provincial de dicha ciudad, formula reclamación de responsabilidad patrimonial ante el Servicio de Salud de Castilla-La Mancha SESCAM) por los daños sufridos a consecuencia de esa actuación violenta del enfermo contra ella; fue inadmitida por Resolución de 08/07/2010.

También había reclamado por esos perjuicios ante la Diputación de Albacete; se desestimó por silencio administrativo.

\footnotetext{
511 «En el presente caso, la sentencia de instancia, al establecer condena líquida de dinero a favor de la actora, pero excluyendo la posibilidad de devengo de intereses legales en cualquiera de sus modalidades ("sin que proceda el abono de intereses legales de clase alguna"), infringe lo prevenido en los arts. 576.3 de la LEC y art. 24 de la Ley 47/2003, de 24 de noviembre, en cuanto que los intereses a que tales preceptos legales se refieren lo son por disposición legal y no pueden ser excluidos por la resolución judicial, debiendo estimarse el motivo de recurso en este sentido».

512 «En el presente caso, la fundamentación del motivo de recurso que se examina se debe a meras discrepancias cuantitativas en determinadas partidas indemnizatorias de las consideradas en la sentencia de instancia, que no pueden ser acogidas por la Sala en aplicación de la doctrina jurisprudencial antes indicada, por lo que debe desestimarse el motivo de recurso examinado».
} 
La víctima solicitaba indemnización en estos términos que transcribe la SJ en el Tercero de los Antecedentes de Hecho:

«...solicita una indemnización de $6.061 €$, por los alegados daños y perjuicios sufridos el día 19 de noviembre de 2009 como consecuencia de la agresión de una paciente de la UME (Unidad de Media Distancia Asistencia) en la que la recurrente prestaba sus servicios como auxiliar de enfermería».

La enfermera interpone recurso contencioso-administrativo $\left(n^{\circ}\right.$ 129/11) contra ambas administraciones, acumulando en dicho recurso las impugnaciones de los dos actos administrativos que no habían estimado sus pretensiones.

El Juzgado de lo Contencioso desestima el recurso sin hacer especial declaración en cuanto a las costas procesales:

«...del examen de las actuaciones no puede entenderse que se den los requisitos exigidos por la normativa de aplicación para que se dé la responsabilidad patrimonial de la Administración».

Argumenta el tribunal que, en virtud de la Ley 30/1992, de 26 de noviembre, sólo serán susceptibles de indemnización las lesiones que se produzcan al particular a causa de daños que no tenga el deber jurídico de soportar.

«En el presente caso la recurrente presta sus servicios como funcionaria en el citado centro dedicado a la atención sanitaria y rehabilitadora de personas con enfermedad mental.

Por ello, la actuación de la Administración a la que se refiere la recurrente se encuadraba dentro de la relación especial que vincula a todo empleado público con la Administración de la que forma parte, de naturaleza legal y reglamentaria, en virtud de la cual ostenta frente a aquella los derechos y deberes determinados por su estatuto, por lo que cualquier responsabilidad de la Administración que pueda surgir como consecuencia, salvo los daños que se puedan causar de forma ajena a la condición profesional de empleado público, debe dilucidarse en el estricto ámbito de la relación estatutaria».

Insiste la sentencia en señalar que la jurisprudencia de la Sala Tercera del TS es restrictiva en cuanto a admitir la posibilidad de reclamar responsabilidad patrimonial a la Administración por parte de un empleado público que esté integrado en ella: 
«...realmente sólo admite su prosperabilidad cuando, siendo la lesión antijurídica y concurriendo los presupuestos que se exigen para su existencia, los mecanismos propios de la relación estatutaria no son suficientes por sí para reparar en su integridad el daño producido, es decir, cuando o bien no exista una regulación especifica estatutaria o bien, no obstante la existencia de la misma, se ofrezca como insuficiente a los fines de reparar en su integridad los daños causados».

El juzgador deduce, en consecuencia, que es la existencia de una lesión antijurídica el requisito inicial y esencial a la vez para que pueda prosperar una acción de responsabilidad patrimonial contra la Administración.

«En este sentido la Sala Tercera del Tribunal Supremo ha declarado asimismo -sentencias de 10 de octubre de 1997 y 10 de abril de 2000- que el punto clave para la exigencia de la responsabilidad no está en la condición normal o anormal del actuar administrativo, sino en la lesión antijurídica sufrida por el afectado y que éste no tiene el deber jurídico de soportar, por lo que la antijuridicidad desaparece cuando concurre una causa justificativa que legitime el perjuicio, "un título que imponga al administrado la obligación de soportar la carga" -Sentencia de 3 de enero de 1997- "o algún precepto legal que, imponga al perjudicado el deber de sacrificarse por la sociedad”-Sentencia de 27 de septiembre de 1997«.

Se fundamenta la Sala en un amplio repertorio jurisprudencial, en especial la STSJ de Castilla y León (Sala de lo Contencioso-Administrativo), de 7 de mayo de $2010^{513}$. Para el Juzgado al que está sometido este supuesto, en base a la doctrina del TS, pueden darse dos posibilidades:

«a) En el supuesto de funcionamiento normal, el servidor público ha asumido voluntariamente un riesgo que, de acuerdo con la ley, tiene el deber jurídico de soportar, por lo que el daño no sería antijurídico y la Administración no vendría obligada a indemnizarle por el concepto de responsabilidad patrimonial sino con las prestaciones previstas expresamente en el ordenamiento jurídico aplicable a su relación estatutaria ${ }^{514}$ (...).

b) En el caso de funcionamiento anormal del servicio público, se debe discernir 1) si la deficiencia o anormalidad es consecuencia exclusivamente de la propia actuación del servidor o funcionamiento público, en cuyo caso su misma conducta sería la única causante del daño o perjuicio sufrido, con lo que faltaría el requisito del nexo causal, requerido ${ }^{515}$ (...) para que nazca

\footnotetext{
513 En esta sentencia se hace referencia a diversas SSTS sobre el tema que se sustancia en este supuesto.

514 "siendo éste el criterio mantenido en la Sentencia de esta Sala de 10 de abril de 2000 (recurso de casación $9147 / 95$ (LA LEY 8887/2000), fundamento jurídico tercero B)."

515 "requerido por el apartado 1 del artículo 139 de la mencionada Ley de Régimen Jurídico de las Administraciones Públicas y del Procedimiento Administrativo Común (LA LEY 3279/1992)."
} 
la responsabilidad patrimonial de la Administración, o 2) si la deficiencia o anormalidad del servicio obedece a otros agentes con o sin la concurrencia de la conducta del propio perjudicado. En este último caso -ninguna participación del empleado público perjudicado-, debe ser cabalmente resarcido e indemnizado por la Administración Pública de todos los daños y perjuicios que se le hubiesen irrogado hasta alcanzar su plena indemnidad y obviamente, si hubo concurrencia causal, la indemnización habrá de moderarse en atención a su grado de participación»

Como consecuencia de estos argumentos, en cuanto al deber de soportar el daño por parte de la trabajadora (existencia o no de un daño antijurídico), la Sala estima que el servicio público tuvo un funcionamiento normal, siendo además el paciente un sujeto inimputable. En opinión de la Sala:

«Se dice que la prestación del servicio ha sido normal pues 1) se cumplió en todo momento el protocolo de la Unidad de Psiquiatría, ${ }^{516}$ 2) el paciente estaba tranquilo y calmado, sin que nada hiciese sospechar la súbita agresión, 3) el paciente había sido previamente medicado con Haloperidol y no puede obviarse que tenía 80 años al tiempo de los hechos, y por tanto no tenía la fuerza y peligrosidad de un enfermo joven».

La Sala entiende que la recurrente debe asumir las consecuencias derivadas de la actuación de un enfermo que se encontrase en esas condiciones ${ }^{517}$.

Entiende además que la recurrente no ha probado que la Administración no haya adoptado medidas especiales para evitar ese tipo de agresiones o que las existentes no fueran las apropiadas (frente a lo que la propia Administración sostiene)

Por todas estas razones el recurso fue desestimado.

\section{4.- Consejo Consultivo del Principado de Asturias (Dictamen 19/2014, de 6 de febrero)}

El Presidente del Principado de Asturias solicita informe al Consejo Consultivo en relación con la reclamación por responsabilidad patrimonial dirigida al Servicio de Salud del Principado, por

\footnotetext{
516 Se dice que se cumplió el protocolo de la Unidad de Psiquiatría pues ante pacientes violentos se acuerda la presencia de tres empleados públicos: una celadora, la enfermera y la auxiliar de guardia (v. f. 47 anexo EA), y sólo si se precisa contener a ese paciente se recomienda contar con el mayor número posible de personas, especialmente el personal de seguridad. Nótese que se dice "contener", es decir, cuando ya ha aflorado la violencia. En iguales términos de actuación conforme a protocolo se manifiesta la Inspección Médica.

517 "O dicho en términos jurídicos, existe un título legal -marco jurídico aplicable-y contractual -su contrato de trabajo -en el caso de ser la actora personal laboral- que le impone asumir las consecuencias derivadas de la prestación de un trabajo peligroso, en cuyo seno puede sufrir daños, peligrosidad por la que ya percibe las correspondientes retribuciones, y que además asumió voluntariamente al incorporarse y mantenerse en esa Unidad de Psiquiatría".
} 
los daños y perjuicios que le ocasionó la agresión de una paciente a una enfermera, en un hospital público, por lo que solicita indemnización ${ }^{518}$.

Los hechos ocurrieron el 14 de febrero de 2011:

"...cuando estaba "por la tarde dando las cenas a los pacientes de Psiquiatría", una de las enfermas "sale y entra al comedor levantando una silla y arremetiendo violentamente contra la otra auxiliar", y que al "ir a ayudarla" aquella "me enganchó del pelo, me araña, me golpea y me zarandea hasta que dos pacientes nos ayudan (...), se realiza inmovilización hasta que viene seguridad y se coloca" contención mecánica. Añade que es asistida el mismo día en el Servicio de Urgencias de dicho centro hospitalario, siendo la impresión diagnóstica de "policontusiones y crisis de ansiedad", causando baja "de incapacidad temporal por contingencias profesionales" hasta el "dia 19 de noviembre de 2011", en que se procede al "alta laboral".

Señala que "denunció a la paciente (...) por una falta de lesiones" y que el Juzgado de Instrucción $N^{\circ} 2$ de Oviedo dictó sentencia el 1 de diciembre de 2011 absolviéndola.

Considera que las lesiones sufridas "han sido consecuencia directa de un funcionamiento anormal de las medidas de seguridad" dentro del centro hospitalario, ya que en "la planta de Psiquiatría no se cumplieron", pues, según indica, "tuvo que llamar desde su móvil personal para que accedieran los servicios de seguridad", añadiendo "que dicho comedor está formado por dos auxiliares y dos enfermeras" y que "solo estaban las dos auxiliares y una enfermera"》.

El Inspector de Prestaciones Sanitarias designado para elaborar el preceptivo informe técnico solicita a la Gerencia del área Sanitaria IV informes del Servicio de Psiquiatría ${ }^{519}$, que le es remitido mediante oficio por el Servicio del Área de Reclamaciones del Hospital ${ }^{520}$. Posteriormente, el Jefe del Servicio de Psiquiatría del área IV en el que la Psiquiatra responsable

\footnotetext{
518 "por importe de veintidós mil cuatrocientos euros (22.400 €), que desglosa en los siguientes conceptos: "factor de corrección" -siendo sus ingresos netos por trabajo personal de 27.211,64€ a 54.423,25-, "un 25\%, por las lesiones permanentes, incluidos daños morales", 638,75 €; "indemnización básica por lesiones permanentes, incluidos daños morales", 2.554,98€; "278 días impeditivos", 15.365,06 €, y un "factor de corrección por indemnización por incapacidad temporal (...), un 25\%", 3.841,26€."

519 "que reitera nuevamente los días 19 de octubre y 6 de noviembre de 2012, requiriéndose en este último que se precise "si, dada la patología que presentaba la paciente, era previsible (...) la posibilidad de agresión (...). Si existe protocolo para la prevención de agresiones al personal por parte de los pacientes ingresados en la Unidad y si este fue aplicado en el presente caso».

520 «En dicho informe consta que la reclamante, en el momento de la agresión, "prestaba servicios como auxiliar de enfermería en la Unidad de Hospitalización de Psiquiatría de Agudos" y que existen "dos informes (...) en los que se relata el incidente", remitidos por las dos auxiliares de enfermería, "teniendo constancia de la veracidad del mismo por el resto del personal de la Unidad". Señala, asimismo, que existe "otro documento, de fecha 18 de febrero, emitido por el responsable del Servicio de Prevención de Riesgos (...), que fue enviado" al Servicio de Salud del Principado de Asturias.

Se adjunta al informe el Registro de comunicación interna de agresiones, la cartelera de turnos y el informe del Servicio de Urgencias, de fecha 15 de octubre de 2009, en el que se indica que la reclamante fue atendida tras sufrir una "agresión física" de paciente psiquiátrico».
} 
de la paciente insiste en "la imprevisibilidad del comportamiento violento" de la misma y de "las actuaciones acordes al protocolo vigente en la Unidad de Hospitalización Psiquiátrica" del hospital». Afirma también lo siguiente:

«...dado que está diagnosticada de "trastorno mental orgánico, con síntomas de irritabilidad y desconfianza", no cree que "haya sido posible prever la aparición de síntomas como la agresividad que dicha paciente presentó". Añade que existe "una actuación protocolizada ante las situaciones violentas que puedan ocurrir en la Unidad de Hospitalización Psiquiátrica"; sin embargo, "en situaciones como esta, de inicio brusco, incluso la presencia de todo el personal disponible en un turno concreto puede resultar insuficiente».

En base a estos informes, el Inspector instructor emite un Informe Técnico de Evaluación en la que entiende que debe procederse a desestimar la reclamación ${ }^{521}$ :

«...el personal de la Unidad consiguió inmovilizar a la paciente hasta que llegó el servicio de seguridad", por lo que estima que "no existe relación de causalidad entre el daño alegado y la actuación de la Administración”. Entiende que la reclamación deber ser desestimada».

Cumplidos los trámites reglamentarios (incluida la audiencia a la demandante, que se reafirma en su reclamación), el Coordinador de Responsabilidad Patrimonial y Disciplinaria eleva propuesta de resolución en sentido desestimatorio:

"Argumenta que "la agresión (...) fue totalmente imprevisible e inevitable", que en el "momento en que esta se produjo se separó e inmovilizó inmediatamente a la paciente" y que "la dotación de personal de la Unidad era la adecuada", por lo que "no queda acreditado el necesario nexo causal».

La Presidencia del Principado solicita entonces dictamen al Consejo Consultivo «sobre consulta preceptiva al procedimiento seguido”. El Pleno de este Consejo entiende que no se puede pronunciar sobre el fondo de la consulta solicitada y requiere la realización de nuevos actos de instrucción.

\footnotetext{
${ }^{521}$ Con fecha 1 de febrero de 2013, emite informe una asesoría privada, a instancia de la entidad aseguradora, suscrito por un especialista en Psiquiatría. En él considera, a la vista de la "documentación disponible", que la "Unidad de Internamiento tiene una actuación protocolizada", que la "agresión de la paciente fue impredecible" y que no consta "la existencia de un déficit de personal en la Unidad", dado que "el que había logró separar e inmovilizar a la paciente", puntualizando que la reclamante "sufrió escasos daños físicos: rasguños en ambos antebrazos». Concluye que "...no existe relación de causalidad entre el daño alegado y la actuación de la Administración", por lo que "Ia reclamación debe (...) desestimarse».
} 
De entre los nuevos informes que se emiten ${ }^{522}$, destaca el que remite el Servicio de prevención de Riesgos Laborales:

«... entre las medidas preventivas que "deben tomarse para evitar la repetición del accidente o la disminución del grado de probabilidad" de "la agresión de pacientes a trabajadores", se indica que "existe un pulsador de urgencia que avisa al guarda de seguridad, pero no se recibe confirmación de dicho aviso, ante la duda de que estos no reciban el aviso el personal utiliza un número de teléfono móvil, teniendo que marcar 9 números para dar la alarma (...). En un principio existió una llave maestra, cuando se va estropeando alguna cerradura en vez de repararla (...) cambian el bombín y les dan otra llave nueva, las trabajadoras llevan 5 llaves distintas para abrir las puertas de la Unidad./ Se recomienda el arreglo de la cerradura y que siga sirviendo la misma llave».

La Supervisora del Servicio de Psiquiatría sostiene que se activaron los protocolos y que el personal que se encontraba en la Unidad cuando sucedieron los hechos era el programado en el turno ${ }^{523}$.

En el nuevo trámite de Audiencia que se concede a la acusada, esta modifica al alza la cantidad indemnizatoria, a la vez que insiste en la relación de causalidad entre el daño sufrido y la actuación de la Administración ${ }^{524}$.

Pero la propuesta de resolución del Coordinador de Responsabilidad Patrimonial y Régimen Disciplinario es nuevamente desestimatoria:

"En ella señala que "la agresión de la paciente fue totalmente imprevisible e inevitable”, que en el momento en que se produjo "se puso en marcha el protocolo existente" y que "la dotación de personal de la Unidad era la adecuada", por lo que "no queda acreditado el necesario nexo causal entre el funcionamiento del servicio sanitario público y los daños alegados».

\footnotetext{
522 "En el anexo I del "Registro comunicación interna de agresiones" formulado por la otra auxiliar -compañera de la reclamante- consta que "estando en el comedor dando la cena" una enferma "sale del comedor increpándonos, se vuelve a meter al comedor, coge una silla y se lanza contra mí, intento esquivarla, la bloqueo", añadiendo que al ir en su "ayuda" la otra auxiliar es "agredida fuertemente", y detalla que "gracias a la ayuda del resto de pacientes y de una enfermera (...) y seguridad se puede contener" a la agresora».

523 "2 auxiliares y 2 DUES».

524 "...afirma que "mientras la enfermera da el aviso al guarda de seguridad sin saber si ha sido recibido el personal utiliza un móvil para llamar marcando un número de 9 cifras", añadiendo que "para poder salir no hay una llave maestra sino cinco llaves distintas para abrir las puertas de la Unidad". Por ello, entiende que "existe (...) relación de causalidad entre el daño alegado y la actuación de la Administración"».
} 
En enero de 2014 se solicita nuevamente el dictamen del Consejo Consultivo. Éste comienza refiriéndose al artículo $106.2 \mathrm{CE}^{525}$, art. 139 de la LRJPAC en su apartado $1^{526} \mathrm{y}$ art. 141 de la citada Ley también en su apartado $1^{527}$, en relación con el derecho de los particulares a recibir indemnización por parte de la Administración en ciertos casos. Sin embargo, entiende que esto no supone «...que la Administración tenga el deber de responder, sin más, por todo daño que puedan sufrir los particulares, sino que, para que proceda la responsabilidad patrimonial de la Administración Pública, deberán darse los requisitos que legalmente la caracterizan, analizando las circunstancias concurrentes en cada caso».

Se basa también para fundamentarlo en la jurisprudencia del TS:

«En efecto, en aplicación de la citada normativa legal y atendida la jurisprudencia del Tribunal Supremo, para declarar la responsabilidad patrimonial de la Administración Pública será necesario que, no habiendo transcurrido el plazo de prescripción, concurran, al menos, los siguientes requisitos: a) la efectiva realización de una lesión o daño antijurídico, evaluable económicamente e individualizado en relación con una persona o grupo de personas; b) que la lesión patrimonial sea consecuencia del funcionamiento normal o anormal de los servicios públicos; $y$ c) que no sea producto de fuerza mayor».

En base a todo ello, el Consejo, después de admitir que efectivamente existe producción de daño, pasa a determinar si dicho daño «...es consecuencia del funcionamiento del servicio público y si resulta antijurídico».

A la vista de todas los informes que obran en el expediente en relación con imprevisibilidad del ataque producido, la existencia de medidas de seguridad (a pesar de que algunas fuesen mejorables $^{528}$ ), el cumplimiento de los protocolos y la existencia del personal debido en la Unidad, el Consejo argumenta lo siguiente:

\footnotetext{
525 "Los particulares, en los términos establecidos por la ley, tendrán derecho a ser indemnizados por toda lesión que sufran en cualquiera de sus bienes y derechos, salvo en los casos de fuerza mayor, siempre que la lesión sea consecuencia del funcionamiento de los servicios públicos».

526 "Los particulares tendrán derecho a ser indemnizados por las Administraciones Públicas correspondientes, de toda lesión que sufran en cualquiera de sus bienes y derechos, salvo en los casos de fuerza mayor, siempre que la lesión sea consecuencia del funcionamiento normal o anormal de los servicios públicos". $Y$, en su apartado 2, que "En todo caso, el daño alegado habrá de ser efectivo, evaluable económicamente e individualizado con relación a una persona o grupo de personas».

527 "Sólo serán indemnizables las lesiones producidas al particular provenientes de daños que éste no tenga el deber jurídico de soportar de acuerdo con la Ley. No serán indemnizables los daños que se deriven de hechos o circunstancias que no se hubiesen podido prever o evitar según el estado de los conocimientos de la ciencia o de la técnica existentes en el momento de producción de aquéllos, todo ello sin perjuicio de las prestaciones asistenciales o económicas que las leyes puedan establecer para estos casos».

528 "Teniendo en cuenta lo expuesto, debemos analizar, en primer lugar, el reproche referente al hecho de tener que llamar a un número de 9 cifras desde su móvil para ponerse en contacto con el servicio de seguridad. En el informe de
} 
«Por tanto, entendemos que no resulta probado que un sistema más perfeccionado de aviso al servicio de seguridad o una mayor dotación de personal hubiera evitado el suceso, toda vez que la anticipación no siempre es posible por las especiales características de este tipo de pacientes, y ni siquiera la interesada manifiesta que lo hubiera sido en este supuesto; la operatividad, en todo caso, habría sido posterior al accidente, pero no anterior.

En definitiva, no se ha acreditado un anormal funcionamiento del servicio público, por lo que no cabe establecer una relación de causalidad entre este y el daño que aqui se reclama, que se debió al riesgo de agresión por parte de una paciente ingresada en una unidad de hospitalización de psiquiatría de agudos en la que desempeñaba sus funciones la reclamante; riesgo que es inherente a las caracteristicas de estas unidades y, por ello mismo, inevitable».

Tiene en cuenta, además, que por recomendación del Servicio de Riesgos Laborales, se procedió a cambiar de servicio a la demandante ${ }^{529}$.

En consecuencia, el dictamen que emite el Consejo Consultivo desestima la reclamación de responsabilidad civil por parte de la Administración que solicitaba la recurrente.

\section{5.- Juzgado de lo Contencioso-Administrativo $n^{0} 13$ de Barcelona (Procedimiento Abreviado $n^{0}$ 37/13), de 7 de abril de 2014.}

Contra la resolución del Departamento de Interior de la Generalitat de Cataluña.

Es una demanda que se interpone en ese Juzgado (28 de enero de 2013), contra la citada resolución dictada el 21 de noviembre de 2012. En él se solicitaba que quedara sin efecto la resolución impugnada reconociendo al recurrente el derecho a percibir una indemnización por valor de 17.820 euros.

\footnotetext{
investigación del accidente de trabajo realizado por el Servicio de Prevención de Riesgos Laborales consta que "existe un pulsador de urgencia que avisa al guarda de seguridad" y en el parte de incidencias del servicio de vigilancia se cita el nombre de la enfermera -no el de una de las auxiliares- que "solicita" se personen en la Unidad, lo que contradice lo manifestado por la interesada cuando afirma que "tuvo que llamar desde su móvil personal para que accedieran los servicios de seguridad", aunque dicho sistema -tal y como sugiere el Servicio de Prevención de Riesgos Laboralespodría ser mejorado de manera que el "guarda de seguridad realice una llamada de respuesta confirmando el aviso", lo que evitaría que, "ante la duda" de que no lo reciban, el personal utilice el "teléfono móvil"».

529 "También consta que la recomendación efectuada por el Servicio de Prevención de Riesgos Laborales de que, "a ser posible", se cambiase "de Unidad" a la trabajadora fue atendida y llevada a efecto, pues queda acreditado en el expediente -informe psicológico de 23 de noviembre de 2011- que cuando se reincorpora nuevamente al trabajo el día "20 de agosto" lo hace "en otra área diferente (Cardiología)". De hecho, no se formula reproche alguno en este sentido».
} 
La causa que se sustanciaba eran los daños personales surgidos para el demandante con ocasión del servicio, como miembro de la Policía Autonómica, invocando la aplicación de lo previsto en el art. 180 del reglamento orgánico de policía gubernativa y 28 EBEP, con jurisprudencia de la Sala de lo Contencioso Administrativo del TSJ de Cataluña.

La juez invoca la posición de la sección $4^{\text {a }}$ de la Sala de los Contencioso-Administrativo del TSJ de Cataluña, que entiende «monolítica» y cuyas tesis se recogen, entre otras en la sentencia de 15 de enero de 2013, que reproduce.

En función de lo que se expone en la citada sentencia, la juez procede a estimar íntegramente el recurso interpuesto contra la resolución del Departamento de Interior de la Generalitat.

En consecuencia, condena a la Administración demandada a satisfacer al recurrente la cantidad de 17.820 euros, más los intereses legales que se hubieran devengado desde la interposición de la reclamación administrativa hasta el completo pago del principal, imponiendo además las costas procesales causados a la citada Administración señalando como límite la cantidad de 300 euros.

\section{6.- Tribunal Superior de Justicia de Cataluña, (Sala de lo Contencioso-Administrativo, Sección $4^{\mathrm{a}}$ ), Sentencia 923/2015, de 2 de diciembre.}

Un paciente es apuñalado en un box del Servicio de Urgencias de Traumatología de un hospital público por una mujer que se encontraba en el centro hospitalario por haber sido víctima a su vez de una agresión. La narración fáctica es como a continuación se transcribe:

«Doña. María Luisa el 9 de octubre de 2008, sobre las 6:00h, se encontraba en Urgencias de Traumatología del Hospital del Mar. Había acudido a dicho Hospital para ser asistida por una presunta agresión causada por su pareja sentimental. Una vez asistida de las contusiones que presentaba se sentó sola en la sala de espera de Urgencias a esperar una patrulla de los Mossos d'Esquadra para recibir la denuncia. De súbito, se introdujo en el box $n^{\circ} 3$ donde se encontraban dos pacientes en sendas camillas (uno de ellos el recurrente) y cogiendo de entre los efectos personales de uno de ellos una navaja, arremetió contra el recurrente que se hallaba tumbado y dormido. Y "con la intención de causarle la muerte o, por lo menos, conociendo que podía causársela con una probabilidad rayana en la seguridad" le asestó cuatro puñaladas en el cuello y dos en la pierna derecha para, sin solución de continuidad, dirigirse al otro paciente que estaba en la otra camilla hablando con su madre por el móvil para asestarle una puñalada en la pierna "con la finalidad de lesionar su integridad fisica" ante lo cual éste empezó a gritar y pedir auxilio lo que empujó a Doña. María Luisa a huir, aunque pudo ser interceptada y retenida por un miembro de seguridad del Hospital». 
Enjuiciados los hechos en vía penal, la AP de Barcelona, (SAP n ${ }^{\circ}$ 681/2010, de 25 de octubre), condena a la agresora tanto penal como civilmente; en cuanto a ésta última vía le impone la obligación de indemnizar a la víctima de la agresión en la cantidad de 180.000 euros.

El paciente agredido interpone después recurso ante la jurisdicción contencioso-administrativa, en reclamación de responsabilidad patrimonial por parte de la Administración, dado que los sucesos habían ocurrido en un centro hospitalario público.

El Juzgado de lo Contencioso-Administrativo no 12 de Barcelona (sentencia no 23/2015, de 28 de enero) desestimó la pretensión, basándose además en reiterada jurisprudencia del $\mathrm{TS}^{530}$, por entender que la intervención de un tercero (en este caso, la agresora), había roto el nexo causal:

«...la intervención de tercero rompió el nexo causal (que se asimila a la fuerza mayor) y que es la única causa determinante en la producción del daño».

La parte perjudicada por esta sentencia interpone recurso contra ella ante el TSJ, alegando:

«...que no ha tenido en cuenta que la navaja con la que se causó el daño fue colocada sobre la mesa auxiliar por la enfermera. Tampoco se ha apreciado que Doña. María Luisa no fue debidamente tratada en el Hospital (debió serlo también por el servicio de Urgencias Psiquiátricas). E imputa también unos eventuales fallos de seguridad que, por omisión, propiciaron la agresión.

Del mismo modo, mantiene que la responsabilidad patrimonial es objetiva y que, en este caso, el daño es antijurídico».

La Sala entra a valorar lo que se aduce en el recurso, comenzando por la cuestión de la seguridad. Entiende que no se aprecia infracción del estándar de seguridad exigible y, por tanto, fue suficiente la tutela dispensada por la Administración a los pacientes.

«De hecho, consta en el expediente la declaración de los Vigilantes que actuaron con rapidez consiguiendo alcanzar a Doña. María Luisa -que se dio a la fuga- y reducirla, custodiándola hasta ponerla a disposición de los Mossos de Esquadra (folio 201 y s.s.). En consecuencia, no cabe imputar defecto alguno por las medidas de seguridad adoptadas por la Administración».

\footnotetext{
${ }^{530}$ En el sentido de que «las Administraciones públicas no pueden convertirse en aseguradoras universales».
} 
Se cuestiona también que la agresora no hubiera sido atendida por el Servicio de Urgencias Psiquiátricas, lo que supone, a juicio del apelante, una valoración incorrecta de la sintomatología que ésta presentaba. La Sala, teniendo en cuenta además el contenido de la sentencia en vía penal, entiende que no cabe tampoco ese motivo de alegación ${ }^{531}$ :

«En consecuencia, tampoco la valoración efectuada en el servicio de Urgencias que no derivó a la paciente al servicio de Psiquiatría, se corresponde con un funcionamiento anormal del servicio público por lo que no permite sostener la imputación de responsabilidad de la Administración por esta causa».

Tampoco admite la Sala que pudieran haberse incumplido, por parte del hospital, los protocolos sobre la atención en Urgencias Psiquiátricas, dado que la paciente había ingresado en Urgencias Traumatológicas y no Psiquiátricas; las medidas que se toman en relación con las pertenencias es distinta en ambos casos y en el supuesto que se juzga, la actuación fue la pertinente ${ }^{532}$.

Pasa a examinar el tribunal si hubo infracción de la Guía de recomendaciones de los registros de enfermería de los servicios de urgencias. Entiende que esta Guía es una referencia útil para los profesionales de enfermería pero que cada centro hospitalario (ya sea público o privado) puede aprobar sus propios protocolos ${ }^{533}$.

\footnotetext{
${ }^{531}$ «Es decir, que la patología psiquiátrica le fue diagnosticada con posterioridad y si nada hacía prever su agresiva conducta tampoco era evitable. No cabe pues equiparar la ansiedad que mostraba con unos síntomas claros ausentes de violencia, con los posteriores derivados del brote psicótico que caracteriza el trastorno bipolar».

532 "En relación con las pertenencias, la primera regla es que durante la visita de urgencias la familia guarde los objetos personales. Y si se ingresa en el box se procederá "siempre" a la revisión y retirada de los objetos personales del paciente. Dichos objetos se guardarán debidamente identificados en el armario correspondiente y, en ningún caso, quedarán en el box del paciente (...).

Tales medidas, no eran de aplicación al caso. En primer lugar, porque Doña. María Luisa ingresó en Urgencias Traumatológicas; no Psiquiátricas. En segundo lugar, porque -de haber quedado ingresada en Urgencias Psiquiátricaslas pertenencias que, en su caso, se hubieran puesto a buen recaudo hubieran sido las de Doña. María Luisa, sin que entre las mismas figurara ninguna navaja. En tercer lugar, porque el Sr. Abilio, que era el propietario de la navaja, tampoco estaba ingresado en el Servicio de Urgencias Psiquiátricas, sino en un box del Servicio de Urgencias Traumatológicas.

En definitiva, este protocolo no se aplica en las Urgencias Traumatológicas que es el servicio que atendió a Doña. María Luisa, al Sr. Abilio y al recurrente»

533 «En definitiva, estamos ante una recomendación de mínimos, que parte de una premisa: que los objetos personales sean retirados, lo que aquí no sucedió pues la navaja siguió en posesión del interesado, si bien como se verá más adelante había sido depositada por las enfermeras sobre una mesita del box y a la vista de todo el mundo.

El Hospital del Mar regula el "Circuit d'objectes personals" en los términos que resultan de las actuaciones. Dispone de una caja fuerte para guardar los objetos personales de los pacientes que quedan ingresados. Se trata de un servicio dirigido a los pacientes que permanecen ingresados -en general- dada la especial situación en la que se encuentran; el Centro garantiza la custodia de los objetos personales de dichos pacientes siempre a petición del interesado y siguiendo las formalidades que marca el folio 416 de las actuaciones.

Tal custodia sigue un procedimiento distinto en el servicio de Urgencias porque el ingreso de los pacientes se acuerda por este servicio en cualquier momento (...). No obstante, esta previsión específica exige que sea el propio paciente quien solicite el depósito en la caja (joyas, documentación personal, dineros...). Sin perjuicio de lo que más adelante se dirá, nada se dice sobre "navajas" aunque tampoco contiene una relación cerrada y la omisión no resulta relevante en este caso».
} 
Entra a valorar a continuación el último motivo de alegación planteado en el recurso, relativo a la supuesta imprudencia de las enfermeras al dejar la navaja que utilizó la agresora contra el apelante sobre la mesa del box. La Sala se basa en las pruebas que se practicaron en el procedimiento penal $^{534}$, aunque en ese ámbito quedó imprejuzgado si había habido o no falta de diligencia en el personal sanitario (al dejar sola a la procesada, etc.), dado que esto era irrelevante para las agresiones que allí se juzgaban.

Pero el tribunal de lo contencioso sí considera relevante en el procedimiento que está siguiendo determinar si hubo «algún tipo de participación, a título de imprudencia, en la cadena causal».

La Sala entiende que es relevante que las enfermeras colocaran la navaja sobre la mesa del box y, aunque la conducta de la agresora fue decisiva en la causación del daño, aprecia también un elemento anormal en la actuación del personal del hospital que permitió a la agresora apoderarse del arma y cometer el delito.

«En definitiva, la actuación del personal del hospital contribuyó a la producción del daño aunque a título de simple negligencia, lo que resultará decisivo en el momento de graduar dicha responsabilidad».

En consecuencia, La Sala estima parcialmente el recurso de apelación ante ella impuesto y procede a graduar la responsabilidad para imponer la cantidad indemnizatoria que corresponda ${ }^{535}$ :

\footnotetext{
534 «Hemos dicho que la Audiencia Provincial a la vista de las pruebas practicadas en el proceso penal, declaró probado que Doña. María Luisa "De súbito, se introdujo en el box no 3 donde se encontraban dos pacientes en sendas camillas y cogiendo de entre los efectos personales de uno de ellos una navaja, arremetió contra Fulgencio ... que se hallaba tumbado y dormido y con la intención de causarle la muerte o, por lo menos, conociendo que podía causársela con una probabilidad rayana en la seguridad, le asestó cuatro puñadas en el cuello y dos en la pierna derecha para, sin solución de continuidad, dirigirse hacia Ricardo .... que estaba en la otra camilla hablando con su madre por el móvil y asestarle igualmente una puñalada en la pierna con la finalidad de lesionar su integridad física, ante lo cual éste empezó a gritar y a pedir auxilio lo que empujó a la hoy procesada a emprender la huida, lo que no logró al ser interceptada y retenida por un miembro de la seguridad del Hospital", hechos que vinculan a este Tribunal y a las partes».

535 «Para graduar la responsabilidad hemos de partir de que la conducta de la agresora, Doña María Luis, fue determinante. Y la responsabilidad que se actúa en este proceso no es una responsabilidad subsidiaria, sino por el elemento de anormalidad que se puede imputar al personal de la Administración y que queda limitado a la actuación del personal de enfermería que concurrió a la producción del resultado porque también guarda relación causal con el daño producido (aunque de menor entidad que la participación de la agresora».

También hay que tener presente el principio de indemnidad. Doña. María Luisa ha sido condenada en el proceso penal como civilmente responsable. El recurrente tiene un derecho de crédito frente a ella por la suma de 180.000€, que se corresponde con la valoración de los daños.

En este caso, las lesiones sufridas por el recurrente están debidamente relacionadas en la Sentencia penal que las valora en $180.000 €$ por lo que no es menester reproducirlas. Pero la vinculación de los hechos probados de la Sentencia penal comporta que, siendo el mismo el daño, también ha de ser la misma la valoración en este orden jurisdiccional."
} 
"Ahora bien, la de otra causa en la producción del daño una de ellas es decisiva, como es la actuación de Doña María Luisa, y la otra concurrente, pero de escasa entidad, la actuación de las enfermeras (sobre la que la sentencia penal no entra) nos ha de llevar a limitar la responsabilidad de la Administración.

Valorando las circunstancias concurrentes este Tribunal considera que procede reconocer una indemnización a tanto alzado y condenar a la Administración demandada a indemnizar al recurrente en la suma de $30.000 €$, cantidad a la que se añadirán los intereses legales desde la fecha en que se formuló la reclamación en vía administrativa ${ }^{536}{ }$.

\section{7.- Tribunal Superior de Justicia de Castilla-La Mancha, (Sala de lo Contencioso- Administrativo, Sección 1ª), Sentencia 48/2015, de 16 de febrero.}

En marzo de 2004, una auxiliar de clínica sufre la agresión de un paciente en el centro hospitalario público donde ésta prestaba sus servicios. El paciente estaba ingresado en el servicio de psiquiatría ${ }^{537}$ y la víctima en compañía del ATS de la planta iba a realizar al paciente una radiografía del tórax cuando éste la agarró por la muñeca, sufriendo ella daños al intentar zafarse. La víctima reclamó por responsabilidad civil de la Administración al Servicio de Salud de Castilla la Mancha. El Director Gerente del citado Servicio resuelve desestimar la citada reclamación (septiembre de 2007).

Contra esta resolución, la perjudicada interpone recurso contenciosos-administrativo que el Juzgado de lo Contencioso-Administrativo $\mathrm{n}^{\circ} 1$ de Toledo desestima a su vez ( 29 de enero de 2008, procedimiento ordinario 538/2008), al estimar "que no concurre el requisito de antijuridicidad del daño ya que no existe prueba de que se hubiera producido una anormalidad en el servicio y que esa anormalidad haya contribuido a la producción del daño».

En cuanto al accidente, calificado como laboral (fundamentándose en el informe de Inspección Sanitaria del SESCAM), considera que no hubiera podido ser evitado:

«...ninguna de las medidas de seguridad que venían siendo reclamadas por el personal de la unidad hubiera podido evitar la agresión, lo que implica que la agresión no tiene su causa en la ausencia de dichas medidas de seguridad, pues ni la ausencia de personal de seguridad, ya que se trataba de una actuación asistencial encomendada al personal de enfermería, ni la inexistencia

\footnotetext{
536 "Dicha condena será solidaria para el Consorcio Mar Parc de Salut Mar (hospital del Mar) y el Servei Catalá de la Salut."

537 «Por reagudización de la esquizofrenia paranoide que padecía».
} 
de habitaciones de aislamiento, ni el libre acceso al control de enfermería, ni el hecho de que el único acceso a la planta pudiera estar cerrado, tuvieron».

Entiende «...que las únicas deficiencias alegadas por la recurrente que pudieran tener razonablemente relación con la agresión, son la falta de personal en la unidad psiquiátrica, y la ausencia de formación impartida a la recurrente sobre los riesgos en el desempeño de su trabajo, sin embargo y teniendo en cuenta las circunstancias en que se produjo la agresión, tampoco se puede considerar que hayan tenido relación causal con la agresión» ${ }^{538}$.

La sentencia concluye diciendo que lo único que queda acreditado es la existencia de un accidente laboral sin que pueda acreditarse responsabilidad patrimonial por parte de la Administración:

"...lo único acreditado es que se trata de un accidente laboral que puede producirse en ese tipo de unidades asistenciales, con independencia de que el Hospital, en la fecha de los hechos pudiera adolecer de ciertas deficiencias, pues las mismas no están en el origen de la agresión sufrida por la recurrente, ni consta probado que hayan operado como elementos con incidencia causal en la agresión, por lo que no se puede decretar la responsabilidad patrimonial de la Administración, pues la jurisprudencia exige en estos casos de daños sufridos por un empleado público, que se haya producido una anormalidad en el servicio y que esta anormalidad esté conectada casualmente con el daño producido».

En el recurso de apelación interpuesto ante el TSJ contra esta sentencia, la apelante alega ${ }^{539}$ vulneración de los artículos 106 CE y 139 y 141 de la Ley 30/1992, así como jurisprudencia del TS, argumentando lo siguiente:

«El Tribunal Supremo ha señalado que aún en el supuesto en el que los funcionarios o analógicamente los trabajadores de la Administración, se encuentren cumpliendo las funciones propias de su puesto de trabajo, éstos han de ser indemnizados, en caso de funcionamiento anormal del servicio público, hecho que de forma automática estaría encuadrado en un supuesto

\footnotetext{
538 «...no existiendo prueba de que para la prueba diagnóstica se exigiere protocolariamente el concurso de más personal, siendo que estaban la actora como auxiliar de clínica, el ATS, y el celador, aunque éste no estaba presente, habiendo informado la Inspección que se dieron todas las medidas habituales de control para un paciente con agitación. (...). Respecto la alegada ausencia de formación impartida a la recurrente sobre los riesgos en el desempeño de su trabajo, (...), no se puede poner en relación de causalidad con la agresión, ya que la recurrente lleva años prestando servicios en la unidad de psiquiatría, en la que no es excepcional tener que prestar asistencia a pacientes agitados».

${ }^{539}$ Alega también: «Errónea valoración de la prueba y vulneración del principio de carga de la prueba en un supuesto de responsabilidad objetiva de la Administración. El que alega la ausencia de antijuridicidad debe acreditarlo, y en este caso no se ha acreditado por la Administración demandada la normalidad en el servicio, ni se ha motivado en la sentencia la razón por la que no existe antijuridicidad».
} 
de antijuridicidad, puesto que no tienen el deber de soportar un daño que derive del funcionamiento anormal del servicio público por el hecho de que estén cumpliendo sus funciones».

La Sala entra a valorar los motivos de apelación. En cuanto a la posible vulneración de la normativa a la que se alude en el recurso ${ }^{540}$, el tribunal se fundamenta a su vez en jurisprudencia del $\mathrm{TS}^{541}$ para desestimar el motivo de apelación:

«Pues bien, tal y como señala la sentencia transcrita, para que el daño sea antijurídico, se requiere, tal y como señala la sentencia de instancia no sólo la anormalidad del servicio sino que esa anormalidad haya contribuido a la producción del daño, o como señala el Tribunal Supremo se requiere que ese riesgo profesional conocido, sea interferido o incrementado por un incumplimiento relevante de la Administración, por lo que partiendo de tal conclusión debemos desestimar el primer motivo impugnatorio para entrar a valorar si la sentencia de instancia incurre o no en error en la valoración de la prueba».

Otro motivo de apelación era la errónea valoración de la prueba por parte del juzgador de instancia. La apelante consideraba que la sentencia de instancia no estaba suficientemente motivada en cuanto a declarar la no existencia de antijuridicidad, puesto que en el acto del juicio había quedado probado el mal funcionamiento del hospital, que era conocido por el Servicio de Riesgos laborales sin que se pusiera remedio a la situación ${ }^{542}$. Entiende, además:

\footnotetext{
540 "Añade que la resolución que fue objeto de recurso contencioso-administrativo reconoce que sí podría existir relación de causalidad entre la agresión sufrida y la artrosis postraumática de la mano derecho que presenta la apelante, y que la apelante reclama por las lesiones sufridas por un paciente de psiquiatría cuando prestaba sus servicios en el hospital, pero no reclama por el hecho de haber sido agredida en el desempeño de sus funciones por un paciente, sino por el anormal funcionamiento del servicio público que venía siendo denunciado desde el año 1994. Señala que la resolución del SESCAM declara la improcedencia de la responsabilidad patrimonial de la Administración por ausencia del requisito de la antijuridicidad del daño, cuando el TSJ de Castilla-La Mancha mediante sentencia de 7 de febrero de 2011 , recoge que existe antijuridicidad cuando no se acredita que la funcionara tuviese ninguna participación con el daño producido, al igual que en el presente supuesto, y el Tribunal Supremo, simplemente exige para proceder a la indemnización que se haya producido una anormalidad en el servicio, no que dicha anormalidad contribuya o no a la producción del daño, pues desde que existe un funcionamiento anormal del servicio, ya existe de forma automática responsabilidad de la Administración, por lo que sí ha existido antijuridicidad, dado que la recurrente no tenía el deber jurídico de soportare un daño que tenía su causa en una agresión producida en el hospital, como consecuencia del funcionamiento anormal del mismo, derivado, entre otros del incumplimiento de la normativa de prevención de riesgos laborales, la falta de personal, la falta de medidas de seguridad, y la falta de planes aplicables a un servicio tan especial como el de psiquiatría»

541 «...de fecha 10 de abril de 2012 (LA LEY 46673/2012), recurso 2556/2010».

542 "Señala que en el acto del juicio ha quedado probado el mal funcionamiento del Hospital General Universitario mediante la declaración de los auxiliares de enfermería y enfermeros, así como por las denuncias al jefe de servicio de psiquiatría, sobre falta de medidas de seguridad, escasez de personal, adecuación arquitectónica; la falta de medidas de seguridad desde el año 1994 hasta la agresión, y la falta de personal en el servicio de psiquiatría, pues tal y como han declarado los testigos en la fecha de la agresión, el personal de la planta se encontraba encerrado con los pacientes, y el control de enfermería se encontraba abierto; existían problemas organizativos relevantes, pues no existían protocolos de actuación ante las diferentes situaciones que se planteaban en las actividades diarias de la unidad de psiquiatría, ni definición de las funciones por turno y categoría profesional, o personal mínimo por turno y categoría, tampoco existía personal de seguridad adscrito a la unidad; se ha probado que la falta de personal se ha mantenido hasta el 2008, y que tras la agresión se incorporó al servicio más personal en cada turno; que el Comité de
} 
«...que no ha existido ni se ha practicado prueba alguna encaminada a acreditar que el accidente se hubiera producido en todo caso, aun cuando se hubieran adoptado todas las medidas de seguridad.

Concluye señalando que la sentencia de instancia incurre en contradicción, pues por un lado señala que no existe anormalidad en el servicio y por otro reconoce la existencia de deficiencias».

La Sala desestima estas alegaciones:

«...conforme la jurisprudencia señalada, para que se pueda decretar la responsabilidad patrimonial de la Administración, es necesario que entre la anormalidad del servicio y el daño producido exista en relación causal».

El tribunal hace suyas las argumentaciones contenidas en la sentencia de instancia y desestima el recurso de apelación interpuesto contra ella íntegramente, por entender que no concurre la responsabilidad patrimonial de la Administración que la demandante pretendía al no poder establecerse el necesario nexo causal entre las consecuencias de los hechos ocurridos y un anormal funcionamiento del servicio.

\section{8.- Tribunal Superior de Justicia de Aragón, (Sala de lo Contencioso-Administrativo, Sección $3^{\mathrm{a}}$ ), Sentencia 650/2015, de 9 de septiembre.}

Una auxiliar de enfermería es víctima de una agresión en el hospital público donde trabajaba, por parte de un paciente ingresado en el Servicio de Psiquiatría. Los hechos sucedieron así:

«...el día 1 de agosto de 2011 ingresó en el servicio un paciente psiquiátrico con antecedentes de peligrosidad. El aviso sobre su potencial heteroagresividad fue el máximo previsto para los pacientes del servicio. Para prescribir la inicial medicación a suministrarle se valoró la total oposición que el propio paciente tenía respecto de otros medicamentos, por los efectos secundarios que éstos le producian.

\footnotetext{
Salud Laboral conocía estos problemas con anterioridad a la agresión pero se hizo caso omiso a las denuncias y quejas, siendo que los trabajadores en el momento de la contratación no fueron informados de los riesgos, habiéndose incumplido la normativa vigente de prevención de riesgos; se ha probado también que existía un protocolo de enfermería de contención mecánica en el que el número mínimo de personal sanitario era de cuatro o cinco, entre médicos, personal de enfermería y celadores, no existiendo en el turno de tarde, en el que se produjo la agresión tal personal, ya que sólo existía un enfermero, un auxiliar, y un celador.

Añade que no existe ningún protocolo para realizar pruebas diagnósticas a pacientes sometidos a contención mecánica, y que cuando a un paciente agitado, ya sometido a un proceso de contención mecánica, se le debe hacer una prueba diagnóstica, ha de estar presente la totalidad del personal que se exige en el protocolo de contención incluido el médico, que es el único que debe autorizar la retirada de contención de los cinco puntos. Y que se ha acreditado que desde la contratación, nunca ha habido una información sobre los riesgos, una valoración de los mismos, ni una explicación sobre las consecuencias, y mucho menos se ha impartido un curso a los trabajadores para explicarles cómo deben actuar en ciertas situaciones».
} 
El ingreso continuó hasta el día 8 de agosto de 2011. Tal día el paciente presentó una gran agresividad hacia las 15.00 horas. Ante el escaso efecto de la medicación inicialmente prescrita, le fue cambiada a otra, que era una de las que el paciente no quería que le fuera suministrada. Cuando llegó la hora de la cena, el enfermero de servicio, conocedor de la historia clínica en la que consta la clasificación de peligrosidad del paciente, del episodio de agresividad del mediodía, y del cambio de medicación que tenía lugar, solicitó a la demandante, auxiliar de enfermería, que le diera ella la medicación al enfermo. Afirma la demandante que ningún aviso especial se le dio respecto de la situación del enfermo y su episodio agresivo de las 15.00 horas, y esta afirmación no es desmentida por la contraparte ni por quienes estaban con ella ni, especialmente, por el enfermero que le hizo el encargo de dar el medicamento al paciente. No consta, por otro lado, dato alguno que permita pensar que sí conocía la demandante tales circunstancias.

La demandante dio su medicina al paciente, sin observar medida alguna especial, lo cual es lógico ante su falta de conocimiento tanto de la clasificación de peligrosidad del paciente, como de la agresividad mostrada ese mismo día, como del cambio a un medicamento de los que el enfermo rechazaba frontalmente.

Poco después de haberle sido suministrada la medicación, el paciente se marchó hacia su habitación, donde desde entonces debía permanecer toda la noche. En lugar de permanecer en su habitación, el enfermo salió al pasillo, se acercó sigilosamente hacia la auxiliar de enfermería demandante y le propinó un fuerte golpe en el cuello, de tal ímpetu que dio lugar a que la cabeza le rebotara en la puerta».

La víctima reclama por los daños sufridos ${ }^{543}$ y en resolución dictada por el Consejero de Sanidad, Bienestar Social y familia del Gobierno de Aragón se acuerda inadmitir a trámite la reclamación ${ }^{544}$.

«Resolución de fecha 6 de septiembre de 2013 dictada por el Consejero del Departamento de Sanidad, Bienestar Social y Familia del Gobierno de Aragón que acordó inadmitir a trámite la reclamación de responsabilidad patrimonial presentada por la actora por los daños y perjuicios

\footnotetext{
${ }^{543}$ A nivel cervical síndrome postraumático cervical, síndrome cervico-cefálico o síndrome de Barré Lieou, profusión discal c5-c6 y c6-c7, síndrome miofascial. Además «cabe reseñar que la lesionada se encuentra en tratamiento psiquiátrico con Cymbalta con el Dr. Carlos por un cuadro de ansiedad generalizada por síndrome de adaptación que le ha supuesto primero la propia agresión como también los contratiempos que han surgido con su mutua laboral $M A Z$ con un recurso que tuvo que interponer y que ganó por su $1^{\underline{a}}$ alta laboral en este aspecto valoramos un TRASTORNO DEPRESIVO RECTIVO POR TRASTORNO DE ADAPTACIÓN como secuela». Todo ello por un total de 365 días (234 días impeditivos y 131 no impeditivos).

544 «...por considerar que era órgano manifiestamente incompetente para disponer sobre la cuestión planteada, al no ser la utilizada la vía específica para el resarcimiento de perjuicios sufridos con ocasión del accidente de trabajo acaecido en el hospital San Jorge de Huesca el día 8 de agosto de 2011 por falta de medidas de seguridad».
} 
sufridos con ocasión del accidente de trabajo acaecido en el Hospital San Jorge de Huesca por falta de medidas de seguridad».

Contra dicha resolución, la perjudicada formula recurso contencioso administrativo ${ }^{545}$, al que se opone la administración demandada ${ }^{546}$ interesando subsidiariamente una cantidad indemnizatoria menor que la que se solicitaba por la demandante.

El tribunal entra a analizar la cuestión, comenzando por los motivos de oposición a la demanda, entendiendo que el motivo principal que se alega es que debiera sustanciarse en todo caso en otra jurisdicción.

«Tanto la Resolución impugnada como las codemandadas sostienen como motivo principal de su oposición a la demanda que no es procedente la vía utilizada al amparo de la previsión de los artículos 139 y siguientes de la Ley 30/1992 (LA LEY 3279/1992), ya que entienden que la reclamación se funda en que hubo infracción de las medidas de seguridad propias del puesto de trabajo desempeñado por la actora, por lo que debería accionarse ante la jurisdicción social».

La Sala desestima el motivo ${ }^{547}$ :

"Como ahora la causa de pedir es la propia de la general responsabilidad administrativa es correcto el cauce elegido y, por tanto, incorrecta la resolución administrativa que acordaba que no se podía reclamar por vía de responsabilidad patrimonial por el hecho de haberse producido el accidente cuando se prestaba función pública».

\footnotetext{
${ }^{545}$ «...por considerar que existió responsabilidad de la Administración en la causación del accidente y amparable en la previsión de responsabilidad patrimonial prevista en los artículos 139 de la Ley de Régimen Jurídico 30/1992, de 26 de noviembre».

546 «Por la Administración demandada se considera correcta la resolución impugnada, al igual que por la parte codemandada MAPFRE EMPRESAS S.A., tanto por lo recogido en la propia Resolución como por otras razones relacionadas con su contenido a las que se hará luego referencia. Subsidiariamente, una y otra codemandada. interesan el reconocimiento de una indemnización menor de la que reclama la demandante, cifrada en 40.918,90€». ${ }^{547}$ «Este motivo de oposición se funda en una realidad inexistente, puesto que, como resulta de la reclamación, administrativa y de la demanda, la razón de la reclamación es que el servicio de psiquiatría del Hospital San Jorge, dependiente de la Administración demandada, no funcionó correctamente, pues no le llegó a la demandante aviso de que uno de los pacientes ingresados era de elevada peligrosidad. La reclamación no se da, por tanto, con base en un hipotético incumplimiento de medidas de seguridad laborales. Si la Administración hubiera incumplido tales medidas, lo que no plantea la actora, podrá incurrir en responsabilidad por ello, sumada a la propia del defectuoso funcionamiento de su servicio, que es por lo que ahora se reclama, pero una y otra posibles responsabilidades no son excluyentes entre sí. De modo que la perjudicada por el (está bien) que ella considera defectuoso actuar administrativo puede reclamar por tal razón y, si, además, es funcionaria de la Administración, también podrá hacerlo por su relación especial con la demandada».
} 
En cuanto a los hechos ocurridos ${ }^{548}$, entiende que efectivamente hubo responsabilidad por parte de la Administración:

«Así, el sistema de advertencia falló. Y ello no es en modo imputable a la demandante, sino al déficit del propio sistema, en el que no funcionó la cadena de avisos que debió darse. Lo cual sólo es de responsabilidad del servicio dependiente de la Administración, pues éste fue el que, sin razón explicada alguna, no dio a conocer a todos los que trataran con el paciente su especial peligrosidad derivada del motivo concreto de haberle cambiado la medicación el día 8 de agosto. El defectuoso funcionamiento del servicio fue causa claramente coadyuvante al resultado producido. No cabe entender que estemos ante caso fortuito o que la responsabilidad de lo ocurrido pueda corresponder sólo al enfermo, puesto que se trata de persona que, por sus déficits incapacitantes estaba a cargo del cuidado de la Administración y, por tanto, bajo responsabilidad directa de ésta»

En consecuencia, el tribunal estima el recurso y declara la responsabilidad civil de la Administración que en él se interesaba, anulando la resolución administrativa recurrida.

En cuanto a la indemnización solicitada, procede a minorarla con los siguientes argumentos:

«...con el fin de evitar un enriquecimiento injusto de la demandante, que no procede la indemnización por pérdida de salarios durante 7 meses, puesto que no consta acreditación de que en tal periodo no haya sido abonado salario por el hecho de haber cambiado la ubicación en las listas de funcionarios interinos.

En conclusión, procede reconocer la indemnización por importe de 31.118,90 € que será la cantidad objeto de condena junto con los intereses legales desde la fecha de esta resolución, en que es concretada la suma a abonar».

\footnotetext{
548 "Los hechos narrados evidencian que el sistema previsto para avisar de la especial situación del paciente el día 8 de agosto no funcionó. La auxiliar de enfermería agredida no supo que se encontraba ante un enfermo agresivo, ni que la razón de tal estado era el suministro del medicamento nuevo que ella le iba a proporcionar, ni, en fin, que no se había controlado debidamente que el enfermo permaneciera en su habitación. Es decir, asumió el encargo de proporcionar medicina a un paciente como si de una situación normal se tratara, pues no sabía que la heteroagresividad potencial del enfermo se había hecho real unas horas antes, precisamente por darle la medicina que ella ahora le hacía tomar, y sin conocer tampoco que ninguna medida se había tomado para asegurar que el enfermo especialmente alterado permaneciera en su dormitorio».
} 


\section{9.- Tribunal Superior de Justicia de Andalucía de Granada (Sala de lo Social) Sentencia} 1929/2015, de 8 de octubre.

Una celadora que presta sus servicios en un hospital público (Servicio de Urgencias) sufre una agresión por el ataque de un paciente al que acompañaba para ser valorado por un especialista en Psiquiatría. Los hechos se produjeron como se reproduce a continuación:

«En el trayecto hacia la consulta fue acompañada por un vigilante de seguridad, que después se quedó fuera de la consulta de psiquiatría, mientras la actora permanecía en el interior acompañando a dicho paciente. En ese momento se abalanzó éste sobre la demandante, cogiéndola del cuello fuertemente y tirándola al suelo, donde continuó oprimiéndole el cuello hasta que el vigilante entró en la consulta y la auxilió».

A causa de ese accidente de trabajo, la víctima sufrió múltiples lesiones con secuelas ${ }^{549}$ por las que el Juzgado de lo Social $\mathrm{n}^{\circ} 7$ de Granada le reconoció una incapacidad permanente total. La sentencia fue dictada el 26 de junio de 2008 y devino firme el 12 de septiembre del citado año.

El 1 de abril de 2005, había entrado en vigor el Plan de Prevención y agresión al personal del Sistema Sanitario de Salud Público de Andalucía, que establecía:

"Ante una situación de agresión en la que el profesional perciba un posible riesgo, el primer paso es solicitar ayuda del vigilante de seguridad, en el caso de que el Centro o Servicio cuente con este personal. De no ser así, el profesional solicitará la presencia de un/a compañero/a u otra persona cercana que le ayude a acabar con la situación de violencia y que al tiempo pueda servir como testigo de los hechos En caso de que la situación de violencia/agresión persista, se pasará al siguiente punto. Paso 2: Alertar a Fuerzas y Cuerpos de Seguridad: Como se ha indicado anteriormente, en el caso de que a pesar de los intentos de disuadir al agresor, I; situación de violencia/agresión persista, se pasará a telefonear a las Fuerzas y Cuerpos de Seguridad, bien sea la Policía Autonómica, local, nacional o Guarda Civil, y se les solicitará que se personen en el centro o servicio o lugar donde se encuentre en el ejercicio de su profesión se desarrollen los hechos para acabar con la situación».

Por otra parte, en el año 2008 se estableció una Guía para la admisión, circulación e información de pacientes en el área de urgencias, en la que se preveía que a los pacientes remitidos para psiquiatría por servicios extrahospitalarios se les asignara un box, en tanto acudía el psiquiatra

\footnotetext{
549 «Como consecuencia de dicha agresión, la trabajadora sufrió múltiples lesiones, las cuales han derivado en el siguiente cuadro clínico residual cervícalgia crónica por hernia dtscal C5-C6, prolusiones cervicales postagresión trastorno adaptativo mixto con síntomas emocionales mixtos, entre otras patologías»
} 
que estuviese de guardia, donde estaría acompañado por su familia y, en caso de no tenerla, por un celador y el servicio de seguridad.

A la fecha en que se produjo el accidente, el hospital de referencia carecía de protocolo de actuación en casos de acompañamiento de enfermos psiquiátrico.

El Juzgado de lo Contencioso administrativo $\mathrm{n}^{\mathrm{o}} 14$ de Sevilla por sentencia de fecha 6-7-2012, estimó parcialmente la demanda interpuesta por la trabajadora, procediendo a anular la resolución dictada por el SAS (15 de febrero de 2010), y condenando a dicha Administración a pagar a la reclamante una indemnización ${ }^{550}$ en concepto de daños y perjuicios derivados por el accidente laboral.

La trabajadora solicita el recargo de las prestaciones en fecha 26 de julio de 2012. La Inspección de Trabajo y Seguridad Social (20 de marzo de 2013) propone al INSS la imposición de un recargo a la empresa de un 30\%, dictando el INSS resolución en 8 de julio de ese mismo año, en denegación de la imposición de dicho recargo basándose en el informe del EVI (11 de junio de 2013) que consideró que el hospital donde ocurrieron los hechos actuó conforme al protocolo existente habiendo sido ya resarcida la trabajadora por indemnización del SAS.

La celadora interpone reclamación en vía administrativa contra esa resolución (18 de septiembre de 2013) que la entidad gestora desestima al no apreciar falta de medidas de seguridad e higiene en el trabajo.

La trabajadora presenta demanda ante el Juzgado de lo Social $n^{\circ} 7$ de Granada, que dicta sentencia (13 de febrero de 2015), estimando la demanda interpuesta por la recurrente. En consecuencia, deja sin efecto la resolución de la entidad gestora y declara el derecho de la actora a percibir un recargo del $30 \%$ de la prestación por incapacidad permanente total que en su día le fue reconocida, imponiendo la obligación del pago al SAS.

El Instituto Nacional de la Seguridad Social interpone recurso de Suplicación (nº 1192/15) contra dicha sentencia ante el Tribunal Superior de Justicia de Andalucía.

Alega el recurrente, entre otros motivos, que se revisen los hechos probados de la sentencia, en especial el $3^{\circ}$, para que se le dé una redacción alternativa ${ }^{551}$, y el hecho probado $5^{\circ}$, cuya redacción se solicita rectificar en los términos que siguen:

\footnotetext{
550 La cantidad fijada fue la cantidad de 21.603 .12 euros, más intereses.

551 «Como consecuencia de dicha agresión, la trabajadora fue atendida por el Servicio de urgencias (folio 97 vuelto) presentando dolor en el cuello e intraescapular emitiéndose como díagnóstico de presunción de esguince cervical. La exploración clínica posterior según informa el servicio de neurocirugía el 1 de febrero de 2005 descarta la existencia de signos medulares o radiculares, no procedinedo tratamiento quirúrgico sino rehabilitador y sintomático (folio 95
} 
«En el año 2004, y con sucesivas prórrogas hasta el año 2006 estando vigente el contrato de Servicio de Vigilancia y Seguridad del Complejo Hospitalario Torrecárdenas con la empresa Black Star SL (C.A. 2002/0122). Como parte integrante de dicho contrato se incluye en el Pliego de Prescripciones Técnicas del Servicio de vigilancia y Seguridad, en cuyo apartado 5, referido a la "funciones" a desempeñar los vigilantes de seguridad, se indica expresamente: Disponibilidad inmediata ante posibles incidentes en razón de la actividad asistencia de carácter psiquiátrico (folio 255). En fecha 1 de abril de 2005...».

La Sala desestima estas peticiones argumentando:

«En base a la anterior doctrina, respecto del hecho probado tercero no se accede a su modificación ya que viene a decir lo mismo que lo que figura recogido en el hecho probado se de la sentencia no modificando como consecuencia o alterando la argumentación derivada de tal hecho probado. En consecuencia, no procede dicha modificación que se pretende. Respecto del hecho probado quinto tampoco procede su modificación ya que no se ha discutido que no exista vigilancia, sino que no hay protocolo que garantice la seguridad de los empleados, con lo cual la modificación por adición que se interesa resulta innecesaria».

El recurrente solicitaba se reconociera que no existió responsabilidad por su parte en el accidente laboral acaecido y, en consecuencia, quedar sin efecto el recargo de prestaciones que la había sido impuesto.

La Sala reconoce que con posterioridad al accidente entró en vigor el plan de Prevención (1 de abril de 2005) en relación con los servicios de urgencias y los pacientes derivados de psiquiatría, completado en 2008.

Pero falla a favor de la empleada, en los siguientes términos:

«Dicho lo anterior y teniendo en cuenta que existe prueba que determina que en el momento y día del accidente, no existía Plan de Prevención, y que además el "Protocolo" existente en el momento del accidente era notablemente insuficiente como lo pone de manifiesto el hecho mismo de cómo ocurrió éste, cuando las medidas de protección colectiva son insuficientes pone de manifiesto precisamente esa relación de causalidad precisa y necesaria para determinar el recargo de prestaciones cuando precisamente el accidente ocurrió por la inexistencia de las mismas según se detalla en el hecho probado quinto.

anverso). Dichas lesiones ha derivado en el siguiente cuadro clínico residual: cervicalgia crónica por hernia discal C5C6, protusiones discales postagresión, trastorno adaptativo mixto con síntomas emocionales mixtos, díagnóstico actual distimian. 
Luego en consecuencia, se producen todos y cada uno de los requisitos señalados al efecto para la aplicación de la responsabilidad de la demandada empleadora en el recargo de las prestaciones señaladas al efecto con además apoyo legal y fáctico quedando así acreditada la relación de causalidad entre la infracción imputable a la misma y el daño producido, debiéndose en consecuencia confirmar el recargo de $30 \%$ impuesto en la sentencia que se recurre».

Procede por tanto a desestimar el recurso de suplicación interpuesto por el Instituto Nacional de la Seguridad Social contra la sentencia del Juzgado de lo Social, confirmando los términos de la sentencia recurrida.

\section{0.-Tribunal Superior de Justicia del Principado de Asturias, (Oviedo) (Sala de lo Contencioso-Administrativo, Sección $1^{\text {a }}$ ), Sentencia 138/2016, de 26 de febrero.}

En octubre de 2011, una auxiliar de enfermería de un hospital público sufre la agresión de un paciente de avanzada edad allí ingresado, aquejado de demencia degenerativa. Los hechos ocurrieron como se describen a continuación:

«...encontrándose la recurrente en su puesto de trabajo como auxiliar de enfermería en la planta de Medicina Interna del Hospital Universitario Central de Asturias, mientras tomaba la temperatura a un paciente anciano con deterioro cognoscitivo y episodios de desorientación y agresividad, le propino dos patadas en la cara y en la muñeca izquierda, causándole traumatismo en muñeca izquierda. Existía orden de contención medica del paciente cuando tuviera tales crisis, por su estado de agitación en la tarde del día de los hechos no fue levantado de la cama y se le habian sujetado los brazos y el abdomen.

Resulta acreditado que el paciente de edad avanzada con demencia degenerativa, debido a los trastornos de su enfermedad tenia prescrito medidas de inmovilización con contención mecánica total cuando la precisara, medidas que habian sido adoptadas en otras ocasiones. Estamos por ello ante un enfermo problemático por su alteración psíquica con episodios de desorientación y agresividad que precisaba atención y cuidados especiales por el personal sanitario mediante un seguimiento y control de su estado. Comprobada la agitación del paciente en horas previas a la agresión se optó por las medidas de precaución y contención señaladas en lugar de la medida cuestionada a falta de conducta violenta o de riesgo de se produjera como en ocasiones precedentes, situación de la fue informada la recurrente en el cambio de turno para que la tuviera en cuenta tomando las precauciones debidas en el contacto con el citado paciente». 
La enfermera interpone recurso contencioso-administrativo contra la desestimación presunta y la resolución de la Consejería de Sanidad del Principado de Asturias, que había desestimado la reclamación de responsabilidad civil ${ }^{552}$ por los daños sufridos a causa de la agresión.

La víctima de la agresión entiende que los daños y perjuicios tanto físicos como morales que se le han causado se deben a que el paciente no había sido objeto de la contención total prescrita, entendiendo que de ello deriva responsabilidad civil de parte de la Administración «...que derivan del mal funcionamiento del servicio médico, al valorar erróneamente que un paciente pautado con medidas de contención mecánica, no las necesitaba en el momento de la agresión a esta parte».

La parte demandada se opone considerando que fue correcta la actuación y que no puse da el presupuesto de necesaria causalidad para que pueda estimarse la responsabilidad civil de la Administración ${ }^{553}$ :

«La agresión se produjo de manera abrupta e impredecible, siendo el riesgo de agresión inherente para los cuidadores de esta clase de enfermos al responder a reacciones imprevistas a actos normales. Estamos pues ante un desenlace fatal y fortuito de la prestación de un servicio público que excluye la responsabilidad de la Administración en relación al funcionamiento del servicio».

El tribunal entra a valorar los hechos y entiende que de lo acontecido se desprende que no era predecible la actuación violenta ni que existiera deficiente actuación en el personal sanitario del turno precedente al de la demandante ${ }^{554}$ :

«En este sentido los informes médicos realizados a propuesta de las partes codemandadas señalan que la contención mecánica total de un paciente debe ser puntual y retirarse cuando el paciente este estable, la agitación por sí misma no es indicación de sujeción mecánica, el paciente

\footnotetext{
552 Por valor de 83.919,21 euros más los intereses legales correspondientes desde la fecha de la reclamación en vía administrativa.

553 «...que un paciente tenga prescritas órdenes de contención no implica que tenga que aplicarse las mismas en todo momento, sino que se trata de medidas puntuales que deben ser usadas para resolver una crisis del paciente, el hecho de que el paciente este agitado no parece ser causa suficiente para su aplicación como lo evidencia que estuviera en este estado toda la tarde y ello no implico agresión a otros trabajadores».

554 "Y ello es así a falta de prueba que la enfermedad del paciente conllevara siempre una conducta violenta para que se hubiera podido prever certeramente con anterioridad mediante la aplicación de las medidas de inmovilización absoluta, pues el factor de riesgo expuesto no se había exteriorizado en actos violentos en horas previas pese a su estado de agitación, por lo que únicamente requería su seguimiento por el personal sanitario para evaluar el riesgo potencial de actuaciones agresivas, toda vez que la etiología de los estos trastornos con manifestaciones de crisis, precedidas en algunos casos de estados de agitación, suele ser multifactorial dependiendo de circunstancias endógenas y exógenas, lo que hubiera requerido la aportación de un dictamen médico legal certero y claro que hubiera acreditado que en estos casos era preciso la contención total del enfermo y sí la agitación previa era causa suficiente para la aplicación de medidas de contención total».
} 
estuvo agitado toda la tarde y ello no implico agresión a otros profesionales sanitarios que lo atendieron, siendo esta medida el último recurso para contener un paciente cuando constituya un peligro contra los demás o contra sí mismo. Se trata de una medida excepcional no habitual en un ingreso hospitalario».

A tenor de estos argumentos, el tribunal no aprecia un defectuoso o negligente funcionamiento del servicio y, en consecuencia, considera que no existe la necesaria relación de causalidad que se exige para que prospere la reclamación de responsabilidad patrimonial a la Administración.

En consecuencia, procede a desestimar el recurso contencioso-administrativo interpuesto por la demandante contra la resolución de la Consejería de Sanidad. 


\section{ANEXO II. PROPUESTAS DE LOS ENCUESTADOS: RESPUESTAS A LA PREGUNTA № 30 DEL CUESTIONARIO.}

La última pregunta del formulario invitaba a los encuestados a formular sus propias propuestas e indicar cuáles serían, a su juicio, las medidas más efectivas a implantar para solucionar el problema de las agresiones al personal sanitario.

En este Anexo se agrupan las diversas respuestas en un total de 10 grupos:

1. Medidas organizativas y de mejora de las condiciones laborales.

2. Medidas concretas de protección al trabajador.

3. Educación ciudadana, información y participación del usuario.

4. Formación del personal sanitario.

5. Campañas institucionales.

6. Multas económicas.

7. Penas de cárcel.

8. Otras consecuencias.

9. No sabe.

10. No contesta.

A continuación reproducimos de forma literal las respuestas que hemos considerado más representativas.

Dentro del grupo 1 se incluyen todas aquellas medidas organizativas propuestas que implican la acción de la Administración, empresas o instituciones. Muchos entrevistados, entre otras propuestas, demandan un mayor compromiso por parte de sus organizaciones y de la Administración, sugieren mejoras en los procesos y cambios organizativos en distintos niveles (para mejorar la calidad del servicio) así como una mayor «humanización» del trabajo sanitario y reclaman más medios materiales y humanos. En concreto:

- En unidades de psiquiatría habría que fortalecer las plantillas con personal especializado en neutralizar los comportamientos agresivos sobre todo en unidades de agudos. Más ayuda de la administración. En el resto de los servicios también personal para ayudar a los profesionales que han sufrido agresión tanto física como psíquica.

- Mayor asignación presupuestaria para la sanidad pública.

- Que las administraciones públicas se impliquen más en proteger los derechos del personal a cargo, no favoreciendo el "el usuario siempre tiene la razón", pues en un numero amplio de casos, el propio personal se encuentra desprotegido cuando pone en conocimiento de su superior inmediato cualquier altercado. Imagino que por miedo a no tener una buena estadística de conflictos con familiares y pacientes se tiende muchas veces a mediar en contra del trabajador. 
- Más personal y más tiempo para la atención a los pacientes/clientes. Menos listas de espera. Más espacios para la información a los pacientes y para los familiares.

- Que haya un mejor trabajo en equipo. En la sanidad pública se ha perdido la humanidad y empatía frente a protocolos y escalas. Debido a las jerarquías profesionales se ha perdido la cooperación y trabajo en equipo.

- Que el personal sanitario esté satisfecho de su puesto, conozca sus obligaciones, su responsabilidad...

- Me parece muy importante la mejora de la atención por parte de los profesionales (menos presión asistencial, mejorar el entorno físico de los hospitales).

- Hay veces que el propio sistema de atención (administrativa. citaciones, lista de espera etc.) genera por si mismo conductas violentas.

- ...no sé si me he explicado bien, pero pienso que en sanidad hay mucho protocolo, y mucho miedo de los profesionales a ser denunciados, y creo que este protocolo no deja ejercer la profesión sanitaria de un modo eficaz.....

- Adecuación de los criterios de ingreso y/o atención

- Cuidar a los profesionales para que no estén saturados, quemados o irritados.

- Dotar de mayor autoridad y prestigio al personal sanitario.

- Mejorar los recursos del servicio sanitario, agilizar consultas y pruebas complementarias recortando listas de espera, etc. En definitiva mejorar la calidad del servicio para que el paciente este satisfecho.

- Sobre todo, creo que si hubiera más personal, tanto en el ámbito público como en el privado, podríamos controlar un poco más ciertas actitudes. Hablo desde mi trato con personas demenciadas y con patología psiquiátrica.

- Mejor trato del sanitario por parte de la Administración.

- Dotar a las instituciones de mejores medios materiales y humanos para mejorar la atención de los pacientes

- Mayor personal cualificado.

- Implicarse la administración y ser ellos los que pongan la denuncias y defiendan a los trabajadores, para ellos son los gerentes y garantes de la salud de los trabajadores

- Menos tensión y más amabilidad, para eso la carga de trabajo tiene que ser justa.

- Volver a centrar la asistencia sanitaria en la relación médico-paciente, donde hubiese tiempo para hablar con el paciente, explicar alternativas y ventajas de cada una permitiendo al paciente implicarse en el tratamiento de su problema patológico y haciéndole partícipe / corresponsable de la evolución del mismo.

- Estar más respaldado por las instituciones y colegios profesionales.

- Y despolitizar los organismos públicos. 
- Menos burocracia a la hora de denunciar la agresión y mayor grado de empatía por parte de los servicios correspondientes de la consejería.

- Que los cargos directivos-políticos no prometan un paraíso sanitario a los pacientes, lleno de derechos y sin ninguna restricción, a la vez que asignan a los profesionales sanitarios la labor de poner en práctica esas restricciones y normas. Si hay limitaciones, recortes, y deberes de los pacientes, que sean ellos quienes los afronten.

- Apoyo claro y explícito de la Gerencia a los profesionales, no aplicando sistemáticamente el slogan «el cliente siempre tiene la razón».

- Rectificación en el libro «Derechos y Deberes del Usuario». Sólo una página son los Deberes, y demasiadas los Derechos.

- Cambiar los servicios de atención al paciente que en vez de resolver problemas los generan aún más.

- Mejorar las listas de espera contratando personal sanitario y evitando que desde citaciones masifiquen las consultas sin ningún criterio y sin autorización médica.

El grupo 2 agrupa las sugerencias centradas en medidas concretas de protección al trabajador, siendo éstas muy heterogéneas.

- Que ante situaciones potenciales de agresión, como en la atención a personas que anteriormente hayan sido agresoras o que presenten alteraciones de conducta, siempre estén al menos dos personas para atenderla.

- Advertir de que las sesiones son grabadas.

- Videovigilancia en zonas comunes. Personal de seguridad. Sistemas de alarma. Medidas especiales en recintos con pacientes con patología psiquiátrica.

- Tener un busca.

- Es esencial que se establezca una tasa de pago en urgencias (2-5€) como en Portugal!!!!! y la mayoría de países de la Unión Europea!!!!!!.

- Que ningún médico pase consulta sólo, ya que la mera presencia de otra persona puede disuadir de la agresión.

- Métodos para evitar el acoso por parte de superiores y jefes de servicio, o al menos poder denunciarlo y tener efectos del tipo que pueda ser un motivo para que esa persona se jubile a la edad que debe y no se le concedan prorrogas.

- Mayor seguridad en los hospitales, control de acceso a los familiares y acompañantes de los pacientes.

- Creo además necesaria la presencia de personal de seguridad, en los centros sanitarios como elemento disuasorio.

- Aumentar los vigilantes en los centros de salud y que haya forma de poder llamarlos rápidamente si fuera necesario. 
- Botones de pánico en todas las consultas de los centros de salud.

- Posibilidad de pedir ayuda cuando ves venir la agresión.

El grupo 3 aúna las propuestas dirigidas a trabajar en la educación y concienciación del usuario, así como fomentar mayor información, participación y comprensión del sistema por parte del mismo.

- Más educación cívica en los centros educativos. Los estudiantes son los futuros usuarios, que protestarán y agredirán, de la Sanidad.

- Más educación en valores en las escuelas y en los hogares. Inculcar el respeto hacia los demás.

- Trabajar el respeto a la autoridad en general. Respeto y educación en todo momento Mejorar la educación en valores.

- Pienso que los profesionales sanitarios deben informar debidamente al paciente y familiar de lo que ocurre; por ej. un paciente es operado, la operación según el cirujano sale de maravilla, le van a dar el alta un lunes y se muere un domingo; ¿qué es lo que pasa ahí? yo no voy a poner en duda la eficacia de la operación, no, pero se supone que ese paciente muere por una infección interna, de algún punto de la herida que se infecta...¿por qué el cirujano no ve esa infección? no es su competencia?? por qué el internista no se ocupa del paciente una vez operado, y analiza esa herida...

- No estaría de más información disuasoria por ejemplo en las salas de espera, advertencias e información sobre los castigos, en general en cualquier servicio sanitario.

- No se me ocurren otras medidas. Creo que el problema de la agresividad no sólo se da en el ámbito sanitario. Por lo que creo que hay que trabajar mucho en la educación de los niños/as donde no sólo deben pedir y exigir sino también tolerar, esperar, y aprender a pedir o quejarse de las cosas que nos pasan de forma adecuada. Así tendremos adultos respetuosos.

- Incluir asignaturas como «educación para la ciudadanía»o «Habilidades SocialesInteligencia Emocional». en el sistema educativo desde edades muy tempranas.

- Que haya más información. Consecuencias más claras legales, económicas y/ o judiciales de dichas agresiones. Mayor cultura de respeto y tolerancia social y profesional en general...psicoeducación en medios escolares familiares y sociales.

- Formación y trabajo conjunto entre profesionales de diferentes ámbitos sanitarios, centros y familiares.

- La instauración educativa del Respeto como valor reduciría el uso de la violencia en general, así como de los diferentes subtipos en particular 
- Simplemente dar mayor información generalizada, charlas, coloquios y una educación ante este problema desde la infancia a través del centro escolar hasta la Universidad e incluso el puesto de trabajo que se desempeñe.

- Mayor respeto mutuo pero eso va en las personas

- También creo que se debería educar más en conductas sociales y psicológicas tanto a los profesionales de la salud, como a pacientes y familiares, en función de sus posibilidades.

- Inculcar educación y respeto mutuos (de los derechos y obligaciones que todos tenemos) desde la infancia.

- La educación y el respeto. Vivimos en una sociedad un tanto ignorante, machista, que minusvalora el trabajo de los profesionales. La mejor manera de atajarlo es la educación y el respeto desde que somos pequeños.

- Educación al ciudadano desde niños. Los profesionales sanitarios ayudamos, no somos enemigos.

- Cambiar la cultura...

- INFORMACIÓN: Si los pacientes que agreden al personal sin motivos coherentes (que son la mayoría) supieran que se exponen a multas económicas o incluso a penas de cárcel, lo harían mucho menos.

- Es un problema de educación en este país. La gente no tiene respeto por nada ni por nadie. Avisar de alguna manera (con carteles o campañas) de si se falta el respeto a un miembro sanitario sea de igual nivel que a un policía (a nadie normal se le ocurre insultar a un policía) porque ello suponga sanción administrativa e incluso penal.

- La educación a los niños y adolescentes en el colegio que explique las limitaciones que en un momento dado puede tener la medicina y el respeto a los profesionales.

- Lo principal son las campañas de educación y respeto al trabajo del otro y fomentar las conductas de educación y respeto entre las personas, que se está perdiendo dando la sensación de que se puede decir lo que se quiera y se tiene derecho a todo.

- Mayor educación sanitaria y uso de recursos sanitarios por la población como una asignatura, conocer deberes porque derechos parece que se conocen bien.

- En mi opinión todo se deriva del ambiente de agresividad y de mala educación que existe en nuestra sociedad. Mientras que, por parte de todos, no se tomen las medidas necesarias para repudiar la zafiedad y el mal tono reinante y sustituirlo por el respeto mutuo, todas las medidas que se apliquen no dejarán de ser más que un tratamiento puramente sintomático.

- Informar a los familiares y pacientes sobre el tiempo de espera previsto para ser atendido en Urgencias.

- Informar de causa de retraso en la atención sanitaria. 
- Informar sobre errores cometidos y medidas tomadas para que no vuelvan a cometerse. Solicitar su colaboración para mejorar el sistema.

- Mejorar la información sobre derechos y medios de actuación al personal sanitario que no recibimos formación al respecto.

La formación de los propios profesionales es el denominador común de las propuestas agrupadas en el apartado 4. Incluye también trabajar en la actitud del profesional en su trato con el paciente y comprende diferentes facetas de formación, en concreto:

- Mayor educación en el trato hacia los usuarios etc...

- Trabajar la comunicación y el respeto de los profesionales a los pacientes, tratándolos como personas y no como molestias o seres ignorantes. Asumir la posibilidad de error en los diagnosticos y no asumir prepotencia y superioridad. Que las figuras de autoridad traten a las personas con respeto en todo momento.

- Mejorar el manejo de la comunicación interpersonal y el autocontrol.

- El profesional sanitario debería contar con más formación en el área de la comunicación.

- Trato de respeto impecable a 1@s pacientes por parte de 1@s profesionales. Habilidades asertivas en el personal.

- Que los trabajadores se formen mejor en cuanto al trato con el paciente.

- Que el profesional sanitario conozca sus obligaciones, su responsabilidad y que normalmente la persona que le visita está necesitando ayuda.

- Formación al personal sanitario, es lo principal. El trato al paciente es fundamental. Aprender habilidades sociales. Como responde ante la ira. Aprender manejo de las quejas...Es más fácil cambiar nuestra conducta que la de aquellos que no quieren cambiar. Buenas prácticas modifican condiciones laborales.

- Formación en manejo de clientes difíciles.

- No se puede generalizar. En servicios de psiquiatría y psicología es diferente al resto de servicios sanitarios. Las agresiones existen a veces por la propia naturaleza de las patologías psiquiátricas siendo muy difícil preverlo a veces. La prevención es difícil, pero sí que se puede dar algún tipo de formación específica a los profesionales para detectar signos y saber actuar verbalmente o pedir ayuda a tiempo.

- Favorecer el diálogo, la escucha, mejorar la preparación de los profesionales en la escucha de los pacientes.

- Trabajar con los profesionales inteligencia emocional y habilidades sociales porque en muchos casos su grado de empatía es nulo.

- Preparar al personal sanitario en cuanto a promover calma y tranquilidad ante momentos violentos. 
- En la agresión de cualquier tipo, se necesitan dos, un agresor y un agredido. Se debe evitar la escalada, sin dejar de distinguir una emoción violenta producto del mal trato profesional, de un agresor continuo y por cualquier cosa. Es evidente que los agresores necesitan una llamada de atención importante. Y los profesionales otra llamada preguntándose por que han generado la agresión. $\mathrm{O}$ no.

- Realmente hay conceptos legales que en el ámbito de la sanidad privada desconocemos, creo que sería bueno más información de nuestros derechos como profesionales y la forma de actuar ante este tipo de agresiones.

- Los sanitarios debemos actuar como verdaderos profesionales y me refiero a todos los trabajadores que tenemos contacto con pacientes y acompañantes, muchas veces hacemos comentarios en el ámbito laboral que llegan a los pacientes/acompañantes que generan inseguridad y falta de respeto hacia los propios sanitarios.

- No permitir las actitudes del personal sanitario tanto Enfermeras como médicos y auxiliares con exceso de confianza con los pacientes y familias, pues al colocarse en un plano de igualdad algunos enfermos y familiares se consideran con derechos mal entendidos.

- El personal sanitario tiene que ser amable, cordial, comprensivo y distante. Mayor ejemplaridad, etc.

- Enseñar desde las facultades técnicas para evitar conflictos y su manejo así como derechos de los profesionales sanitarios al respecto de agresiones.

El 5 es el grupo que recopila las sugerencias en torno a la realización de campañas de concienciación, de información acerca de la realidad de las agresiones y sus consecuencias y de mejora de la imagen del sistema ante los usuarios.

- Campañas en tv que conciencien a los pacientes de que los sanitarios intentamos pero no garantizamos éxito.

- Campañas informativas en los medios de comunicación desde el punto de vista de valorar positivamente la gran suerte que tenemos con la Sanidad Pública y Privada en este País.

- Dar más publicidad a los deberes y no solo a los derechos de los usuarios Valoración del servicio sanitario que poseemos

- Informar a la población (campañas) de que podrían cometer un delito si agreden a personal sanitario (nadie en su sano juicio agredería a un policía o un guardia civil que creo en este caso tendría la misma consideración de autoridad). Campañas más agresivas que mejoren la imagen del personal sanitario sobre todo en el sector público...en este existe la idea de que «para eso pago» y me da derecho a «usar» al personal sanitario como un objeto al que se puede maltratar. 
- Hacer campañas para informar a la población de que tenemos consideración de autoridad. Creo que gran parte de la población no está al tanto de ese cambio... y podría ser una buena medida disuasoria.

Los grupos 6, 7 y 8 se refieren a la imposición de medidas post-agresión que supongan consecuencias para el agresor, en orden a disuadirle de cometer nuevas agresiones. El número 11 está relacionado con este grupo porque se destaca la necesidad de que las consecuencias sean efectivas, que se apliquen de verdad al agresor, en evitación de la impunidad de su conducta.

- Aumento de penas de agresión verbal. (6)

- Sanciones pecuniarias o que pagaran la prestación. (6)

- Penas mayores a los agresores. (6)

- El cafre que agrede siempre seguirá siendo un cafre. Hace falta miedo al castigo, pero como la ley siempre protege a los malos.... «dura lex sed lex». (7)

- A corto plazo medidas punitivas severas, tanto para agregó es a sanitarios como maestros (7)

Si los pacientes que agreden al personal sin motivos coherentes (que son la mayoría) supieran que se exponen a multas económicas o incluso a penas de cárcel, lo harían mucho menos.

- (es decir, valora que estas medidas tienen un efecto disuasorio).

- Avisar de alguna manera (con carteles o campañas) de si se falta el respeto a un miembro sanitario sea de igual nivel que a un policía (a nadie normal se le ocurre insultar a un policía) porque ello suponga sanción administrativa e incluso penal.

- Muchas multas y cobradas a través de Hacienda.

- El que agrede, lo hace a sabiendas. Los cursos, campañas y demás creo que no sirven para nada. Lo único eficaz es multar y en los casos necesarios, imponer penas judiciales.

- Penas de prisión para los agresores. (7)

- Sanciones económicas en casos concretos de abusos de los servicios sanitarios. (6)

El grupo 8 está caracterizado por una gran variedad de medidas propuestas. En concreto, lo que sugieren los encuestados es lo siguiente:

- Prohibición de entrar a los centros sociosanitarios.

- Acto de mediación que facilite el pedir disculpas por parte del agresor.

- Penas de obligatoriedad de prestar servicios a la comunidad en ambientes (como un servicio de urgencias) donde vea reflejada, por parte de otros usuarios, su conducta violenta.

- Que el paciente, si comete agresión, no pueda ser vuelto a citar con ese profesional y note de alguna manera (tener que pedir otra cita con distinto profesional de nuevo, con su 
consiguiente espera) para que vea que si no cumple con sus obligaciones, dicho acto tiene consecuencias directas.

- NO hay que ser nada tolerante con estas actitudes y actuar con la máxima contundencia y castigos que sirvan de ejemplo disuasorio para el resto de los pacientes.

- Establecer una especie de «Carnet Por Puntos» del paciente. Las agresiones, denuncias y sanciones irían restando puntos. Los médicos podrían saber si un paciente (que muchas veces procede de otro centro o región) es problemático y tendente a la agresión (verbal y/o física) en función de su saldo de puntos. Al perder los puntos debería ser obligatorio hacer algún cursillo de re-educación, control de agresividad, etc... por parte de esta clase de pacientes. Por debajo de un determinado nivel de puntos crítico el Sanitario debería poder ejercer un derecho a veto previo, o poder reclamar la presencia en consulta de personal de seguridad antes de atender a ese paciente, o poder grabar la conversación desde el inicio de la asistencia (previo aviso).

- Tras una agresión física o verbal el paciente no podrá ser atendido en el mismo hospital.

- Sanciones de prestaciones para casos concretos de abusos.

- Entre las sanciones podrían estar las de expulsar al agresor del sistema sanitario público o al menos obligarle al pago (por "morder la mano que le da de comer").

El grupo 9 conforma el conjunto de sugerencias encaminadas a facilitar la denuncia o notificación del incidente, hecho crucial, debido al fenómeno conocido como «infradenuncia»o «infraregistro», que obstaculiza el conocimiento de la situación real respecto a las agresiones y, por tanto, también la adecuada toma de medidas que puedan atajar el problema. También se incluyen algunos casos de clara confusión terminológica o necesidad de mejor información.

- Hoja de Registro de la incidencia en el Servicio de Rehabilitación que pase directamente a la Dirección del centro DESDE EL PROPIO TRABAJADOR, sin ser filtrado por el Supervisor.

- Una denuncia pública y que el usuario dejase de poder recibir atención en un centro sanitario

- Denunciar cuando el profesional se sienta intimidado/agradado (sic). En cuanto a los pacientes hay que ser estrictos y no tolerar ninguna falta de respeto a nuestra profesión, a nuestro trabajo y a nuestras personas.

- Concienciar a las profesionales en la tolerancia cero ante la agresión.

- Más que sobre medidas recalcar que profesionales de riesgo somos los de atención pública y también privada.

- Creo que tenemos que entender lo que provoca estas agresiones....

- Somos muchos los profesionales de la sanidad pública (no sanitarios) que nos exponemos a sufrir una agresión en nuestro puesto de trabajo y no tenemos la consideración de 
agentes de la autoridad como por ejemplo, celadores, auxiliares administrativos, vigilantes de seguridad....Etc.

- Creo que todos los empleados de la sanidad pública deberíamos tener la misma protección ante las agresiones. 